Tesis doctoral

Universidad de Valladolid

Departamento de Pedagogía

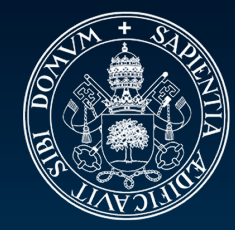

\title{
Análisis de portales para compartir contenido digital en la formación del profesorado.
}

Una propuesta conceptual de diseño

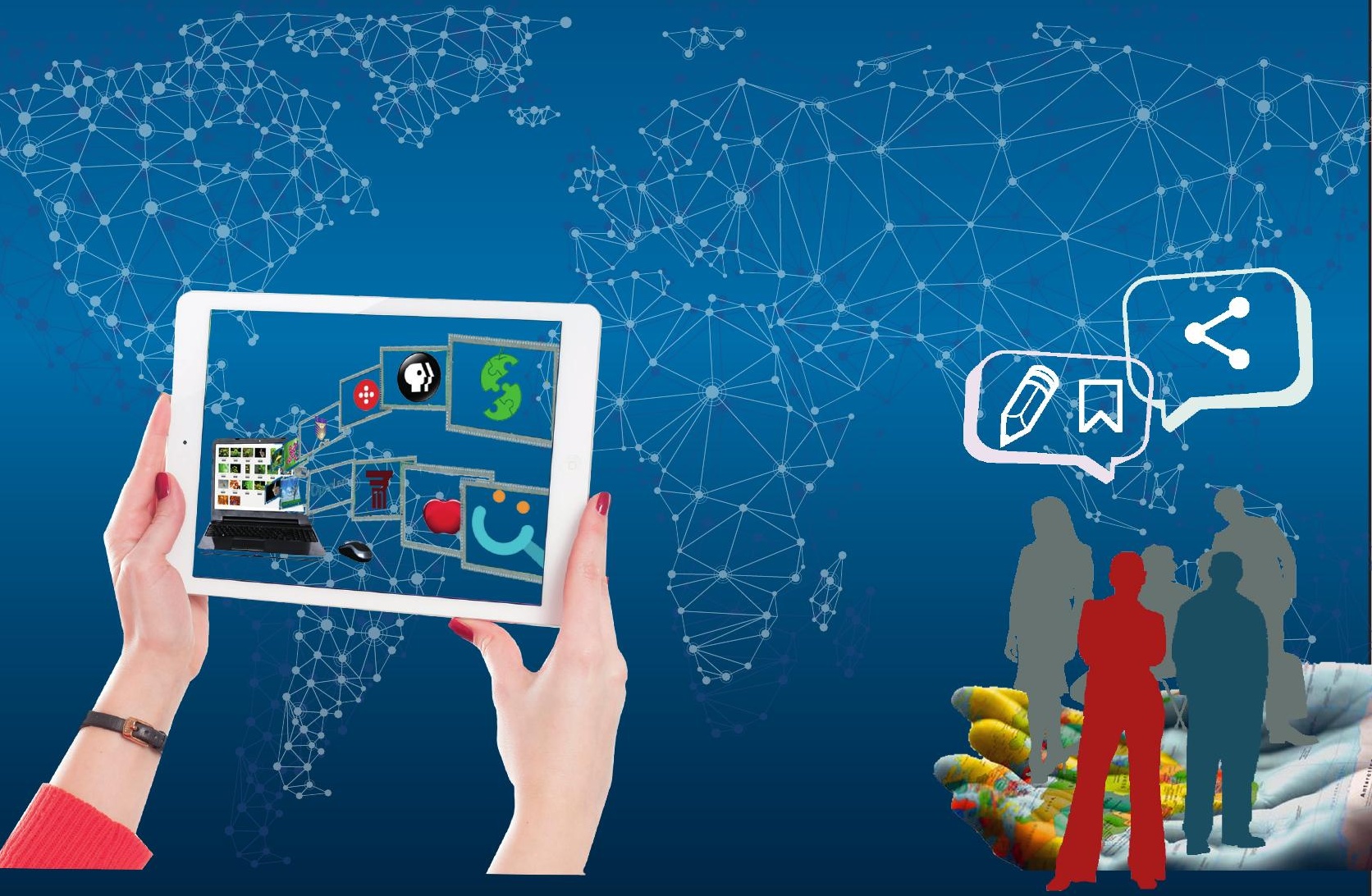

Autora: Beatriz Carramolino

Director: Dr. Bartolomé Rubia Avi 
Portada: collage elaborado a partir de imágenes de dominio público extraídas de pixabay.com y reeditadas.

Imagen de fondo "Global network mess": MaxBorovkov

(bigstockphoto.com). Id. 85856486.

Se incluyen logotipos de algunos de los portales analizados. 


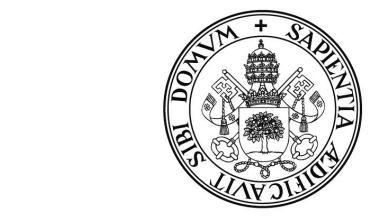

Universidad deValladolid

FACULTAD DE EDUCACIÓN Y TRABAJO SOCIAL

DEPARTAMENTO DE PEDAGOGÍA

TESIS DOCTORAL:

\section{ANÁLISIS DE PORTALES DE CONTENIDO DIGITAL EDUCATIVO EN LA FORMACIÓN DEL PROFESORADO Propuesta conceptual de diseño}

Presentada por Beatriz Carramolino Arranz para optar al grado de doctora por la Universidad de Valladolid

Dirigida por: Dr. D. Bartolomé Rubia Avi 



\section{Índice de contenidos}

Español

INTRODUCCIÓN

1. Objetivos y contribuciones 2

2. Metodología 3

3. Estructura del documento 5

CAPÍTULO 1

LOS CONTENIDOS DIGITALES EN EL CAMPO DE LA FORMACIÓN DEL PROFESORADO 9

1. Fundamentación Teórica 9

2. Lecciones aprendidas de otros estudios $\quad 74$

CAPÍTULO 2

MARCo TeÓrico Metodológico 83

$\begin{array}{ll}\text { 1. Introducción } & 83\end{array}$

2. Aproximación filosófica y metodológica 88

3. Método de investigación de Share.TEC: estudio de caso 104

4. Método de investigación de los Portales educativos 112

$\begin{array}{ll}\text { CAPÍTULO } 3 & 117\end{array}$

$\begin{array}{ll}\text { EL PROCESO DE INVESTIGACIÓN } & 117\end{array}$

$\begin{array}{ll}\text { 1. Introducción } & 118\end{array}$

2. Objeto de estudio 119

3. Objetivos de la investigación 120

4. Preguntas de investigación 121

5. Estudio 1: Estudio de caso Share.TEC 124

6. Estudio 2: Sistemas para compartir contenidos digitales 197

CAPÍTULO $4 \quad 209$

ANÁLISIS E INTERPRETACIÓN: ESTUDIO 1

1. Introducción 209

2. Análisis e interpretación del estudio de caso Share.TEC 210

CAPÍTULO 5

ANÁLISIS E INTERPRETACIÓN: ESTUDIO 2

1. Construcción de la herramienta de análisis 361

2. Comparación de los portales seleccionados 374

3. Conclusiones del Estudio $2 \quad 418$

4. Estrategias interesantes pedagógicas, sociales y técnicas adoptadas por los portales analizados 
CONCLUSIONES, PROPUESTA Y TRABAJO FUTURO

1. Introducción 427

2. Conclusiones 428

3. Limitaciones de la tesis 455

4. Líneas de Trabajo futuro 457

$\begin{array}{ll}\text { ABSTRACT } & 463\end{array}$

INTRODUCTION $\quad 465$

1. Objectives and Contributions 466

2. Methodology 466

3. Structure of the document 468

4. General outline 470

CONCLUSIONS, PROPOSAL AND FUTURE WORK

1. Introduction 473

2. Conclusions 474

3. Research limitations $\quad 500$

4. Future work directions 501

REFERENCIAS / REFERENCES 507 


\section{INDEX OF CONTENTS}

Spanish

\section{INTRODUCTION}

1. Objectives and contributions

2. Methodology 3

3. Structure of the document 5

CHAPTER 1

DIGITAL CONTENTS IN TEACHER EDUCATION

1. Theoretical framework 9

2. Lessons learnt from other researches 74

CHAPTER 2

THEORETICAL FRAMEWORK OF THE METHODOLOGY

1. Introduction 83

2. Philosofical and methodological assumptions 88

3. Share.TEC research method: case study 104

4. Research methods for the Educational web portals research 112

CAPÍTULO $3 \quad 117$

THE RESEARCH PROCESS

1. Introduction 118

2. Object of study 119

3. Research objectives 120

4. Research questions 121

5. Study 1: Share.TEC Case Study 124

6. Study 2: Systems for sharing digital content 197

CHAPTER $4 \quad 209$

ANALYSIS AND INTERPRETATION: STUDY 1

1. Introduction 209

2. Data analysis and interpretation 210

CHAPTER 5

ANÁLISIS E INTERPRETACIÓN: ESTUDIO 2

1. Construction of the evaluation model for educational portals 361

2. Qualitative comparative analysis 374

3. Conclusions 419

4. Interesting educational, social and technological strategies from educational portals 423

CHAPTER 6

CONCLUSIONS, PROPOSAL AND FUTURE WORK 429

1. Introduction 429 
2. Conclusions 430

3. Research limitations 457

4. Future work research lines $\quad 459$

\section{English}

$\begin{array}{ll}\text { ABSTRACT } & 463\end{array}$

INTRODUCTION 465

1. Objectives and Contributions 466

2. Methodology 466

3. Structure of the document 468

4. General outline 470

CONCLUSIONS, PROPOSAL AND FUTURE WORK 473

1. Introduction 473

2. Conclusions 474

3. Research limitations $\quad 500$

4. Future work directions $\quad 501$

$\begin{array}{ll}\text { REFERENCES } & 507\end{array}$ 


\section{Índice de Tablas}

Tabla 1 Las generaciones del aprendizaje online. Elaboración propia partiendo de Dos Reis, 2011 (2011), Moravec (2008a, pp. 256-266, 2013); Cobo Romaní y Moravec (2011); y Hayes (2006) 15 Tabla 2 Diferentes clasificaciones de repositorios educativos

Tabla 3 Características que ha de integrar un LOR según futuros profesores: categorías emergidas tras el análisis documental de las respuestas a un cuestionario (Adaptación de la Tabla 1 de Yalcinalp \&

Emiroglu, 2012, pp. 479-480)

Tabla 4 Autores y foco de orientación de la definición de métodos mixtos. Adaptación y traducción de Creswell \& Plano Clark (2010, p. 2)

Tabla 5 Miembros del Consorcio del Proyecto Share.TEC 127

Tabla 6 Declaraciones temáticas y preguntas informativas del Estudio de Caso Share.TEC $\quad 137$

Tabla 7 *Metadatos obligatorios y Metadatos Opcionales de los Objetos Digitales a Incluir en

Share.TEC 149

Tabla 8 Métodos de análisis de datos por cada fuente de datos 190

Tabla 9 Información de los participantes de las pruebas y explicación de su nomenclatura $\quad 211$

Tabla 10 Nomenclatura de las evidencias cualitativas del estudio de caso Share.TEC 214

Tabla 11 Prueba [09]. Respuestas cuantitativas '"Evaluación de la Calidad de los metadatos": Media

$(\mu)$ y Desviación Típica $(\sigma) \quad 225$

Tabla 12 Prueba [33] Puntúa el portal del 1 al 5 como recurso para acceder a los contenidos digitales

para la formación del profesorado $\quad 240$

Tabla 13 [Google Analytics]. Estadísticas sobre las sesiones abiertas en el portal Share.TEC por países (sólo los 10 con mayor número de sesiones).

Tabla 14 [Google Analytics]. Estadísticas sobre las sesiones abiertas en el portal en la fase del proyecto vs. en la fase posterior al proyecto 250

Tabla 15 Prueba [20]. Idioma de preferencia de búsqueda de contenidos digitales. 254

Tabla 16 Prueba [44]. Idiomas que utilizan para realizar búsquedas de contenidos digitales para la

formación del profesorado. $\quad 254$

Tabla 17 Prueba [35]. Opinión de los informantes sobre la información relevante para entender la calidad de los recursos y para seleccionar recursos 258

Tabla 18 Prueba [20]. Fiabilidad de la escala frecuencia de uso del tipo educativo de contenido digital.

Alfa de Cronbach.

Tabla 19 Prueba [20]. Frecuencia de acceso a contenido digital tipo: Quiz-test. Diferencias entre roles

Tabla 20 Prueba [20]. Frecuencia de acceso a contenido digital tipo: lista de preguntas frecuentes.

Diferencias entre roles $\quad 262$

Tabla 21 Prueba [20] Frecuencia de acceso a contenido digital tipo: Figura. Diferencias entre roles 263

Tabla 22 Prueba [20]. Frecuencia de acceso a contenido digital tipo: Enunciado de problema.

Diferencias entre roles 263

Tabla 23 Prueba [20]. Frecuencia de acceso a contenido digital tipo: Cuestionario. Diferencias entre roles 
Tabla 24 Prueba [20]. Frecuencia de acceso a contenido digital tipo: Presentación de diapositivas.

Diferencias entre roles

Tabla 25 Prueba [20]. Fiabilidad escala tipos de aprendizaje. Alfa de Cronbach 265

Tabla 26 Prueba [35] Chi cuadrado con diferencias estadísticamente significativas entre roles. 269

Tabla 27 Prueba [20] Contenidos digitales de mayor interés para los informantes tras realizar

búsquedas (pregunta 1) 275

Tabla 28 Prueba [20] Rol * Tipo de material más interesante entre artículo/capítulo, ejercicios resueltos y unidades didácticas/programaciones $\quad 275$

Tabla 29 Prueba [33] Tabla de contingencia. Frecuencia de utilización de los repositorios de contenidos digitales y motivo de su utilización. (preguntas 13,14 y 8 ) 279

Tabla 30 Prueba [44]. Frecuencia de uso de contenido digital por rol 281

Tabla 31 Prueba [33] Comparten recursos en su comunidad vs. usan recursos creados por otros 282

Tabla 32 Prueba [44] Frecuencia de compartición de contenido digital por rol 283

Tabla 33 Prueba [44]. Comparación entre utilización vs. compartición de contenido digital 284 Tabla 34 [20] Tabla de contingencia: frecuencia de uso de herramientas Web para compartir archivos * Rol 285

Tabla 35 Prueba [33] p.1.) 5.) 8.) Tabla de contingencia ¿Compartes recursos educativos en línea? (Comunidad de intercambio?) * ¿Compartirías tus recursos digitales en Share.TEC? ¿Por qué? * Rol

Tabla 36 [44] Compartición de contenidos digitales en Share.TEC: afirmaciones con las que los usuarios están de acuerdo

Tabla 37 Diferencia de uso y compartición en las pruebas [20], [33] y [44] entre formadores de profesores vs. la media del conjunto de roles de cada prueba

Tabla 38 Prueba [44]: Respuestas de los informantes sobre la facilidad de búsqueda de contenidos digitales en Share.TEC

Tabla 39 Prueba 44. Valoración general de los apartados Acceder, Usar y Ofrecer 306

Tabla 40 [33] Opinión de los informantes sobre la función "Grupos" vs. el conjunto del portal Share.TEC como herramientas para la creación/remodelación de sus materiales

Tabla 41 Opinión general de los usuarios sobre la interfaz de Share.TEC en los apartados Ofrecer, Acceder y Usar del Portal. ¿Mejoraría la forma de visualizar las funcionalidades?

Tabla 42 [21] Adjetivos positivos y negativos concordados por los jueces sobre "Apariencia", "Eficiencia", "Usabilidad" y "Utilidad" seleccionados por los 69 usuarios de diferentes países

Tabla 43 Cariz positivo y negativo de los adjetivos seleccionables concordados por los jueces

Tabla 44 Selección de adjetivos descriptivos de Share.TEC de la prueba [44]. Los 19 informantes podían elegir cualquiera de los adjetivos del listado 320

Tabla 45 Prueba [20] Redes sociales a las que pertenecen los informantes 332

Tabla 46 [35] Chi-cuadrado entre roles sobre: "Conocimiento de Comunidad de Práctica"; "Conocen y han pertenecido" y "Es miembro de comunidad práctica" 336

Tabla 47 Tabla de contingencia: conocen lo que es una comunidad de práctica vs. es miembro de una comunidad de práctica por Rol.

337

Tabla 48 Prueba [35]. Información relevante para la elección de un recurso por roles: "Abstract" 341 Tabla 49 [35] Opinión de los informantes sobre los elementos decisivos para seleccionar un recurso. Elementos sin diferencias significativas entre roles (tras la aplicación de un Chi-2). 
Tabla 50 Prueba [20] Frecuencia de pago de recursos diferenciada por roles

Tabla 51 Comparación de las categorías para la evaluación de los repositorios extraídas de las fuentes de la literatura y propuesta de nuestro modelo.

Tabla 52 Categorías de análisis de portales de contenidos digitales para formadores de profesores 373

Tabla 53 Derechos de acceso y coste de contenidos digitales: : tabla comparativa 376

Tabla 54 Ontología, metadatos y coste de lo portales: tabla comparativa 377

Tabla 55 Administración, financiación y gestión del contenido 398

Tabla 56 Aspectos Educativos de los portales: Niveles, temáticas y destinatarios. 401

Tabla 57 Aspectos educativos de los contenidos 1. Gratuidad y Formato del contenido digital 403

Tabla 58 Aspectos Educativos de los contenidos 2: Formato técnico, calidad y reconocimientos 404

Tabla 59 Contenidos, miembros y comunidades de los portales analizados. 406

Tabla 60 Tipos de búsqueda y funcionalidades existentes en los portales analizados en el "Estudio 2"

Tabla 61 Funcionalidades Técnicas extraídas del análisis del "Estudio 2" 441

Tabla 62 Funcionalidades sociales extraídas del análisis del "Estudio 2" 442

Tabla 63 Funcionalidades de Contenido Digital extraídas del análisis del "Estudio 2" 442

Tabla 64 Funcionalidades de personalización extraídas del análisis del "Estudio 2" 443

Tabla 65 Funcionalidades de Accesibilidad extraídas del análisis del "Estudio 2" 443

Tabla 66 Funcionalidades de sostenibilidad extraídas del análisis del "Estudio 2" 443

Tabla 67 Dimensiones y Elementos que definen la calidad de los contenidos digitales en un portal educativo $\quad 451$

Table 68 Types of search and existing functionalities from "Study 2" analysed portals. 484

Table 69 Technical Features from portals analysed in "Study 2". 487

Table 70 Social features from portals analysed in "Study 2" 487

Table 71 Features of Digital Content from portals analysed in "Study 2" 487

Table 72 Personalization features from portals analysed in "Study 2" 488

Table 73 Accessibility features from portals analysed in "Study 2" 488

Table 74 Sustainability features from portals analysed in "Study 2" 489 


\section{Índice de llustraciones}

Ilustración 1 Principales hitos de la formación del profesorado en el Contexto Europeo. Elaboración Propia 25 llustración 2 Paradigmas Educativos y TICs en Educación Superior. Elaboración Propia 43 llustración 3 Un marco para la investigación: interconexión entre filosofía, diseños y métodos de investigación. Adaptación y Traducción de Creswell (2014, p. 5) 86 llustración 4 Los tres grandes paradigmas y subtipos de métodos mixtos. Adaptación de Johnson et al. (2007, p. 124) 92 llustración 5 Esquema de investigación de la tesis doctoral 103 llustración 6 Estructura conceptual. Adaptación de Stake (2005, p.446) 110 llustración 7 Metodología de investigación de la tesis doctoral 123 llustración 8 Elementos estructurales del Estudio de Caso Share.TEC 135 llustración 9 Representación de las capas de la ontología de Share.TEC. Elaboración Propia, basada en el Share.TEC Cosortium, $2008 \quad 145$ llustración 10 Captura de pantalla de la ontología desde el software Portergé. 146 Ilustración 11 Técnicas de recogida de datos aplicadas a los profesores en el Estudio de Caso Share.TEC 155 llustración 12 Folleto de Divulgación del Portal Share.TEC en español 157 llustración 13 Análisis DAFO para la creación del plan de sostenibilidad elaborado en Share.TEC. En verde, los aspectos de origen externos; en azul, los de origen interno. 159 Ilustración 14 Red Social NING: Share.TEC Recursos, creada por el grupo UVa como estrategia de diseminación del proyecto. $\quad 161$ llustración 15 Interfaz de la página principal del Portal Share.TEC en español. 164 llustración 16 Captura de Pantalla del Apartado Acceder del portal Share.TEC 165 llustración 17 Muestra de la visualización de los metadatos de un contenido digital en la sección $\begin{array}{ll}\text { Acceder de Share.TEC. } & 167\end{array}$ llustración 18 Página principal de la sección Usar de Share.TEC 168 llustración 19 Capturas de Pantalla del apartado Usar. A la izquierda, su función de Grupos; a la derecha, visualizamos el aspecto de uno de los grupos del sistema. 169 llustración 20 Sección Ofrecer del Portal Share.TEC 170 llustración 21 Captura de pantalla de la prueba de selección de adjetivos, traducida al español 178 llustración 22 Captura de pantalla del cuestionario sobre el Impacto del Portal Share.TEC, en español, realizado en limesurvey. $\quad 180$ llustración 23 Captura de pantalla de la Red Social NING (realizada en Mayo de 2011). 182 llustración 24 Captura de pantalla de las visitas al portal Share.TEC, datos recogidos automáticamente por Google Analytics. 183 llustración 25 Fases de investigación multimétodo del caso de estudio Share.TEC enmarcadas en su contexto. llustración 26 Fases y técnicas de recogida de datos del estudio de caso Share.TEC enmarcadas en su contexto. 
Ilustración 27 Metodología de la investigación del estudio de portales para compartir contenido digital

Ilustración 28 Ejemplo de visualización de la interfaz que aparece en Share.TEC tras la búsqueda y selección de un recurso. Idioma del recurso vs. idioma de los metadatos. 223 llustración 29 Interfaz de búsqueda simple en Share.TEC 302 llustración 30 Interfaz de búsqueda avanzada 303 Ilustración 31 [21] Nube de adjetivos por frecuencia de selección por parte de los usuarios. Imagen creada con Tagxedo.

\section{Índice de Cuadros}

Cuadro 1 Esquema general de la tesis

Cuadro 2 Traducción de los "Worldviews" o cosmovisiones (Creswell, 2014, p. 36), 85

Cuadro 3 Preguntas cuantitativas de la prueba 09 "Evaluación de la Calidad de los metadatos". 225

Cuadro 4 Esquema-resumen de la tesis $\quad 429$

Figure 5 General framework of the dissertation $\quad 471$

\section{Índice de Gráficos}

Gráfico 1 Estado actual de los Ecosistemas maduros de OER. Reelaboración a partir de The Boston Consulting (2013, p. 3) 54

Gráfico 2 Proporción de Organizaciones de Repositorios por Continente. $\quad 70$

Gráfico 3 Número de registros de metadatos incorporados por los diferentes miembros del consorcio $\begin{array}{ll}\text { Share.TEC. } & 128\end{array}$

Gráfico 4 Evolución de la calidad de los metadatos en Share.TEC. 228

Gráfico 5 Tipología pedagógica y cantidad de metadatos catalogados referentes a contenidos educativos alojados en Share.TEC. $\quad 229$

Gráfico 6 Formato técnico de los contenidos educativos descritos en Share.TEC. 231

Gráfico 7 Sesiones de Share.TEC durante el proyecto (17/12/2010 - 01/07/2015) 245

Gráfico 8 Porcentaje de sesiones en Share.TEC, por fases del proyecto y países. Datos de Google Analytics. 249

Gráfico 9 Google Analytics desde 17/12/2010 (lanzamiento del portal) hasta 01/12/2015 (fecha final de recogida de datos para esta tesis). 251

Gráfico 10 Número de registro de metadatos de contenidos digitales aportados por cada colección (miembros del consorcio, otros proveedores y usuarios) 252

Gráfico 11 [35] Porcentaje de informantes de cada área que utiliza cada tipo de herramienta para buscar contenidos digitales. $\quad 267$ Gráfico 12 Prueba [20] Frecuencia de uso de los diferentes tipos educativos de contenido digital y desviación típica 
Gráfico 13 [44] Compartición y utilización del contenido digital diferenciada por roles 285

Gráfico 14 [44] Herramientas que utilizan los informantes para compartir contenidos digitales 294

Gráfico 15 Prueba [44]. Valoración de los informantes sobre los diferentes filtros que ofrece Share.TEC

305

Gráfico 16 Prueba [44]. Opinión sobre la Utilidad, Facilidad de Uso e Interfaz de las Funcionalidades del apartado Usar de Share.TEC

Gráfico 17 Adjetivos de Share.TEC seleccionados por más del 10\% de los 67 informantes (debían elegir 6 de un listado de 118)

Gráfico 18 Tipos de permisos de modificación de metadatos de los portales analizados (Elaboración propia)

Gráfico 19 Perfil de las funcionalidades de los portales analizados

Gráfico 20 Contenidos totales vs. contenidos para la formación del profesorado 


\section{Agradecimientos}

El desarrollo del Doctorado y la actividad como investigadora y profesora en la Universidad de Valladolid ha supuesto para mí una etapa personal y profesional muy enriquecedora.

En ella he podido vivenciar diversos encuentros y desencuentros, alegrías y tristezas, éxitos y lecciones aprendidas, momentos de motivación y desmotivación, etc. Ante todo, ha sido un proceso de maduración y aprendizaje constante que ha influido en mi devenir personal y profesional de forma muy positiva. Esta sensación ha sido posible gracias a todas y cada una de las personas que de una manera $u$ otra han formado parte de mi vida durante los últimos años. Por ello, me gustaría dedicar unas breves líneas para expresarlas mi agradecimiento, y pedir disculpas de antemano a todas esas personas que no quedarán explícitamente aquí reflejadas, pero que también forman parte de mí.

En primer lugar, quería mostrar mi agradecimiento a Bartolomé Rubia Avi. Eres el principal responsable mi introducción y permanencia en el mundo de la investigación. Gracias por ofrecerme la posibilidad de colaborar con el grupo de investigación GSIC-EMIC desde que era estudiante de magisterio, y haber sido mi tutor de las diferentes becas de investigación de las que he podido disfrutar a lo largo de estos años, hasta la actual dirección de esta tesis doctoral.

Sara (Villagrá), te agradezco muchísimo el acompañamiento que me has proporcionado durante la última etapa de esta tesis. Tu implicación profunda como revisora de este trabajo ha supuesto el impulso motivador que me ha permitido que el proceso haya sido mucho más enérgico, confiado y agradable. Personas como tú son un diamante muy poco frecuente en nuestras instituciones universitarias, por la implicación, esfuerzo, honestidad, tiempo y responsabilidad que impregnas en cada acción. Tengo la gran suerte de tenerte como compañera y amiga. 
Un evento significativo en el desarrollo de esta tesis fue la estancia doctoral que realicé gracias a la financiación proporcionada por la Universidad de Valladolid en la Open University de Reino Unido. Quiero dar las gracias a mis tutores de esta estancia, Patrick McAndrew y Yishay Mor. Asimismo, quiero mostrar mi gratitud a los "Spanish invaders": José Antonio, Gema, Eloy y Mariano", porque hicisteis mucho más divertida, interesante y enriquecedora la estancia. Todas estas personas, provenientes de diversas áreas pero vinculadas en gran medida a la temática de esta tesis, me proporcionaron valiosas visiones y orientaciones que me hicieron repensar, redefinir, complementar y revitalizar este trabajo.

Querido José Juan Barba, compañero y amigo, fui una de las personas privilegiadas que tuve la suerte de conocerte. Me brindaste muchas dosis de humildad, bondad, humor y generosidad. Te echaré de menos; aún hoy me resulta muy duro escribir estas líneas pensando en tu injusta y temprana pérdida. Un abrazo muy grande allá donde estés.

Gracias a todos los componentes del grupo GSIC-EMIC (Nesi, Iván, Sara G., Guille, Yannis, Asen, Edu, Miguel, Alejandra, Edu, etc.), por proporcionarme la oportunidad de crecer profesionalmente. Gracias Henar, por confiar y pensar siempre en mí. Gracias Benito por cedernos un poquito de tu sabiduría e introducirnos con paciencia en el mundo "Quanti-Hard". También quiero agradecer a todas las personas con las que vivencié experiencias y aprendizajes en CETIE y ACOGE, con quienes tuve la suerte de colaborar codo a codo y desarrollar con ilusión proyectos educativos con la pretensión de mejorar la situación cultural y social de colectivos desfavorecidos. De cada uno de los componentes de estos grupos de investigación me llevo muy buenas experiencias y momentos, me habéis enseñado mucho y ha sido un placer encontraros en el camino.

Gracias a: la Universidad de Valladolid, la Junta de Castilla y León, el Ministerio de Educación, Ciencia y Deporte de España y el Fondo Social de la Unión Europea, por permitirme disfrutar de becas y contratos de investigación que han proporcionado las ayudas económicas que me han posibilitado formarme como investigadora y docente en la Universidad de Valladolid.

Gracias a mis amigos (Patri, Elena Marina, Antonio, Silvia, Eva, Ester, Rubén, etc.), por preocuparos por el desarrollo de este trabajo (a veces con demasiada 
frecuencia (:) y por darme ánimos y entenderme durante el proceso. Vosotros, sin importar los años ni la distancia, sois uno de los pilares de mi felicidad, pues me proporcionáis grandes dosis de energía y alegría.

Gracias a mi familia por su amor, comprensión, paciencia y apoyo incondicional. Sin ellos, nada sería posible.

Gracias a ti, Gonzalo, por apoyarme, por regalarme momentos tremendamente divertidos, por ser un constante estímulo intelectual, por ser una gran persona, por ser paciente y comprensivo y por la felicidad que me proporcionas. Soy muy afortunada por poder construir una vida contigo.

"Las huellas de quienes caminaron juntos

nunca se borran"

(Proverbio africano) 

A mi familia

Croyez ceux qui cherchent la vérité, doutez de ceux qui la trouvent; doutez de tout, mais ne doutez pas de vous-même.

André Gide (1952) 



\section{Introducción}

Actualmente detectamos escasos espacios especializados para la compartición de contenido digital y experiencias educativas en el ámbito de la formación del profesorado (Carramolino Arranz \& Rubia Avi, 2013; Earp, Sarti, \& Bocconi, 2011; EdReNe, 2010). En la red encontramos un gran número de recursos destinados a este campo, pero habitualmente se encuentran dispersos en múltiples servicios y, por tanto, resulta difícil su localización cuando se demandan recursos con determinadas características pedagógicas. Adicionalmente, existen pocas tendencias de compartición y reutilización de contenido digital entre los profesores, debido a la consideración contextual de la educación. Desde las políticas educativas y programas de financiación internacionales, europeos y nacionales (CORDIS, 2009; European Commission, 2005, 2008a, 2010b, 2011a; Red.es, 2012) se han propuesto programas y proyectos que han favorecido la generación de espacios web que han tratado de solventar estos problemas (véanse los apartados Problema y Marco teórico del Cuadro 1).

En cambio, existen numerosos portales educativos muy valiosos que permiten tanto la compartición de contenido digital como conocimiento entre sus usuarios, y algunos de ellos integran servicios multidisciplinares y multinivel (e integran servicios para la formación del profesorado). Además, día a día somos testigos de los avances tecnológicos que permiten una mayor personalización de los servicios y una mejora de la calidad de las herramientas que permiten compartir contenidos y generar redes profesionales.

Un intento de solventar esta situación es el portal Share.TEC (Sharing Digital Resources in the Teacher Education Community) (Share.TEC Consortium, 2008a), que nació como fruto de un proyecto formado por un consorcio europeo, financiado por el programa eContentplus (European Commission, 2008a) del $7^{\circ}$ Programa Marco de la Unión Europea. Uno de los equipos participantes en este proyecto fue la Unidad de Investigación Consolidada de Castilla y León GSIC-EMIC (Grupo de Sistemas Inteligentes e Informáticos - Educación, Medios, Informática y Cultura). Gracias a mi pertenencia a este grupo de investigación, pude participar activamente 
en el desarrollo de los aspectos pedagógicos y sociales del proyecto, durante la construcción y evaluación del portal con usuarios finales. Por este motivo, surgió mi interés por ahondar en la temática con el objetivo de mejorar los servicios existentes. Esta tesis profundiza en el devenir del proceso de elaboración del portal y en la valiosa información que aportaron sus informantes en la fase previa a la elaboración del portal, la fase de lanzamiento del portal, y la fase posterior a la finalización del proyecto, analizando la experiencia para dar respuesta a las preguntas de investigación y objetivos que nos plateamos. Asimismo, se evalúa un conjunto de portales educativos, con el objetivo de detectar buenas prácticas educativas, sociales y tecnológicas de éstos. Mediante la integración de las evidencias de ambos estudios pretendemos alcanzar el fin último de esta tesis, proporcionar una propuesta de recomendaciones conceptuales de diseño de portales web para la compartición de contenido digital y experiencias educativas en el ámbito de la formación del profesorado.

\section{Objetivos y contribuciones}

Ante este marco, proponemos cinco objetivos que fundamentan esta tesis doctoral, consistentes en (véase apartado Objetivos del Cuadro 1): A) la identificación de las necesidades pedagógicas, tecnológicas y sociales de los formadores de profesores ante los sistemas para compartir contenido digital y experiencias educativas; B) el conocimiento de las formas de uso, compartición y reutilización de contenido digital de estos; $\mathrm{C}$ ) el diseño de un modelo de evaluación de portales educativos basado en otros modelos existentes; D) la detección de buenas prácticas existentes en portales para la compartición de contenido digital; y E) la propuesta de recomendaciones a tener en cuenta en el diseño de portales educativos online para la formación del profesorado que permitan la compartición de contenido digital y conocimiento.

Para abordar estos objetivos de la tesis, llevamos a cabo dos estudios. En el primero de ellos, analizamos las contribuciones y limitaciones del portal estudiado, ahondando en las opiniones que manifestaron los usuarios en las distintas pruebas de su evaluación. Asimismo, investigamos los hábitos y necesidades de uso en torno a los contenidos digitales y portales educativos de los formadores de profesores y otros profesionales de la educación. Para enriquecer esta información y poder realizar nuestra propuesta, analizamos otros portales educativos, abstrayendo las buenas prácticas que integran y dan respuesta a las necesidades detectadas en el estudio previo. 
Tras la realización de la investigación, los objetivos alcanzados se traducen en las principales contribuciones de la tesis: 1) Definición de necesidades pedagógicas, tecnológicas y sociales de los formadores de profesores y otros profesionales de la educación sobre el uso de portales para compartir contenidos digitales educativos y experiencias; 2) Generación de un modelo de evaluación de portales educativos de contenido digital; 3) Detección de buenas prácticas de portales educativos y 4) Propuesta teórica para la creación/remodelación de portales educativos para la formación del profesorado (ver Cuadro 1).

\section{Metodología}

Nuestra metodología se enmarca desde una cosmovisión pragmática (Creswell, 2014) de la investigación, siguiendo principios epistemológicos y ontológicos interpretativos, en la que hemos utilizado técnicas cualitativas y cuantitativas de investigación. El paraguas metodológico que abarca el conjunto de los estudios de esta tesis doctoral es la metodología de investigación multimétodo (Brewer \& Hunter, 2006; Hunter \& Brewer, 2003; Morse, 2003), que hemos identificado como la más adecuada para dar respuesta a nuestras preguntas de investigación:

1) ¿Qué necesidades pedagógicas, tecnológicas y sociales demandan los usuarios potenciales de portales para compartir contenidos digitales en el ámbito de la formación del profesorado?

2) ¿Qué características ha de tener el sistema para compartir contenido que pueda dar respuesta a las necesidades de los formadores del profesorado?

Para poder iluminar estas preguntas hemos analizado e interpretado dos realidades que convergen en la realización de una propuesta de recomendaciones pedagógicas, tecnológicas y sociales para la generación de portales educativos que permitan la compartición de contenido digital y de experiencias y conocimiento:

1) El caso de estudio instrumental del portal Share.TEC.

2) El análisis descriptivo y comparativo de portales para la compartición de contenido digital educativo.

Además de los objetivos generales, planteamos unos objetivos específicos a alcanzar con el estudio de cada una de las realidades y unas preguntas de investigación para cada uno de ellos (explicitadas en el capítulo 3 de esta tesis).

Para la recogida y análisis de datos de la primera realidad hemos empleado una metodología multimétodo (aplicando técnicas cualitativas y cuantitativas llevadas a 
cabo de manera independiente e integradas en la interpretación de los datos), a través del método de investigación de estudio instrumental de caso. Utilizamos diferentes técnicas de recogida de datos cualitativas (cuestionarios, Focus Group, Think Aloud Protocol, etc.) y cuantitativas (encuestas, recogida automática de datos mediante Google Analytics) y llevamos a cabo diversas pruebas en tres fases: I) fase de diseño del portal; II) Fase de creación del portal y III) fase de evaluación del portal y de las pruebas acontecidas en las fases anteriores. Para el análisis de los datos de naturaleza cualitativa se ha seguido un proceso de reducción anticipada de los datos (Miles, Huberman, \& Saldaña, 2014; Miles \& Huberman, 1984); para los cuantitativos hemos aplicado diversos test estadísticos y estadísticos descriptivos en función de las características de los datos. Tras el análisis e interpretación de los datos, recopilamos en el capítulo 4 de esta tesis las conclusiones de este estudio, aplicando técnicas de fiabilidad y validez (en el tratamiento de los datos cuantitativos) y de confiabilidad y credibilidad (en el caso de los cualitativos, a través de la triangulación severa de los datos (Denzin, 1970). Extraemos una serie de conclusiones sobre los aspectos pedagógicos, tecnológicos, sociales, económicos y de personalización de los portales educativos online para compartir contenido digital y experiencias, basándonos en las opiniones de los informantes (de alcance nacional y europeo) (alcanzando en este estudio los objetivos A y B de la investigación) (véase el apartado Objetivos del Cuadro 1).

En el estudio de los portales educativos hemos aplicado la metodología interpretativa de análisis exploratorio cualitativo y el análisis comparativo. Hemos diseñado un modelo de análisis de portales educativos basándonos en fuentes relevantes de la literatura existente y en las categorías de análisis emergidas en la reducción anticipada de datos del caso de estudio de Share.TEC (logrando el objetivo C). Tras un análisis exploratorio de las categorías del modelo creado, abstraemos las características que comparten y en las que divergen los portales, así como las buenas prácticas que los definen (atendiendo a características pedagógicas, tecnológicas, sociales, de personalización y modelo de negocio) (consiguiendo el objetivo D) (véanse los apartados Objetivos y Contribuciones del Cuadro 1).

Para finalizar el estudio de esta tesis doctoral, extraemos unas conclusiones generales de la combinación de las dos realidades estudiadas, atendiendo al contexto en el que se sitúa esta investigación. A través de los datos apreciamos que existen pocas diferencias entre las necesidades de los formadores de profesores y otros profesionales de la educación sobre las características pedagógicas, tecnológicas y sociales que han de poseer los portales para compartir contenido 
digital en la formación. Comprobamos, como hacen otros estudios (Clements, Pawlowski, \& Manouselis, 2015; Clements \& Pawlowski, 2012; Lund \& HojsholtPoulsen, 2010) e instituciones relevantes educativas (UNESCO, 2011), la gran relevancia de la existencia de una comunidad de práctica como garante del éxito de portales educativos. Identificamos la necesidad de potenciar la cultura de generar y compartir contenido educativo desde los planes de formación del profesorado. Asimismo enfatizamos la necesidad de diseñar servicios acordes a las necesidades de la comunidad a la que va dirigida el portal. Para finalizar, realizamos una propuesta (teórica) sobre las recomendaciones pedagógicas, tecnológicas y sociales a tener en cuenta a la hora de diseñar estos portales para satisfacer las necesidades detectadas de los usuarios finales, convergiendo las interpretaciones y conclusiones de las dos realidades estudiadas (de acuerdo con lo explicitado en el objetivo E de esta investigación).

\section{Estructura del documento}

La memoria de tesis se estructura en los siguientes capítulos:

En el capítulo 1 sintetizamos los principales apoyos teóricos que constituyen el marco teórico de esta tesis doctoral. Comenzamos el capítulo analizando los cambios que se han producido en la sociedad actual como fruto de la evolución e integración de las TIC en la sociedad y en la educación. Analizamos los diferentes paradigmas educativos y la interrelación entre estos y el uso de las TIC, perspectivas que tienen reflejo en la organización y filosofía de los diferentes portales educativos. Incluimos una breve descripción de la evolución de los contenidos digitales (entre los que destacamos los recursos educativos abiertos) y reflexionamos sobre los aspectos que potencian y limitan su reutilización. Posteriormente introducimos los sistemas para compartir contenido digital en el ámbito de la formación del profesorado, las tipologías de sistemas, la forma de organizar el contenido en ellos y los aspectos sociales de los portales educativos. Para finalizar, integramos algunas lecciones aprendidas en experiencias de investigación previas sobre sistemas para compartir contenidos educativos en el ámbito educativo.

El capítulo 2 recopila el marco teórico-metodológico desde el que fundamentamos este trabajo. Describimos las diferentes cosmovisiones que guían la investigación en ciencias sociales y justificamos la utilización de una cosmovisión pragmática describiendo cómo la hemos aplicado a nivel axiológico, ontológico, epistemológico y metodológico. Justificamos el por qué de la elección de la 
Introducción

metodología multimétodo dentro de este marco, recopilando las ventajas y desventajas de su utilización y detallamos las racionalidades que guían nuestro trabajo, enfatizando el carácter interpretativo que hemos adoptado para diseñar y analizar los dos estudios que componen esta tesis doctoral. Para finalizar, describimos los métodos de investigación que hemos seguido para cada estudio, así como las técnicas de recogida y análisis de datos que nos han permitido extraer las conclusiones que guían la propuesta de esta tesis.

En el capítulo 3 describimos en detalle cómo hemos diseñado la investigación, cuáles son los objetivos que la guían y las preguntas que iluminamos con la realización de los dos estudios. Tras abordar estos aspectos generales, nos centramos en cada uno de los estudios. En primer lugar describimos en profundidad los procesos de investigación desarrollados durante el estudio instrumental de caso "Share.TEC", comenzando por una contextualización del origen, objetivos, desarrollo y resultados del proyecto europeo y el portal. Explicamos cómo se ha llevado a cabo el estudio de caso siguiendo la estructura conceptual de Stake (2005). Profundizaremos en las tres fases de esta investigación multimétodo: diseño del portal, creación del portal y evaluación del portal, y describimos cada prueba realizada: técnicas utilizadas, método de selección y características de los informantes y métodos de recogida y análisis de datos. Posteriormente, detallamos cómo hemos llevado a cabo el análisis descriptivo y comparativo de los portales para la compartición de contenido digital educativo, de acuerdo al modelo de evaluación generado (partiendo de la revisión de fuentes de la literatura y del esquema de análisis emergido en el estudio de caso Share.TEC). Finalmente explicamos cómo hemos abordado el análisis individual y comparativo de los portales.

En el capítulo 4 integramos el análisis e interpretación de los datos del estudio de caso Share.TEC. Estructuramos el capítulo partiendo de declaraciones temáticas y preguntas informativas que emanan de los issues del estudio de caso de acuerdo a las declaraciones temáticas previamente identificadas. Integramos desde una cosmovisión pragmática y una metodología multimétodo los análisis cualitativos y cuantitativos de las diferentes pruebas realizadas en el contexto del estudio de Share.TEC, dando sentido a la información obtenida mediante diversas estrategias de triangulación. Concluimos el capítulo dando respuesta a las preguntas informativas y declaraciones temáticas, iluminando los issues planteados.

En el Capítulo 5 recogemos el análisis e interpretación de los datos del estudio descriptivo y comparativo de los portales para compartir contenido digital en el ámbito de la formación del profesorado. En primer lugar describimos cómo hemos 
realizado el análisis de las fuentes de la literatura y los elementos que hemos abstraído de cada una de ellas para generar nuestro modelo de evaluación de portales educativos. Posteriormente, reflejamos el análisis comparativo de los aspectos tecnológicos, pedagógicos y sociales de los portales por cada categoría del modelo de evaluación realizado tras el análisis individual de cada portal. Finalizamos el capítulo con la extracción de unas conclusiones y destacamos características interesantes y novedosas de los portales analizados.

En el último capítulo de esta tesis, capítulo 6, se integran las conclusiones emanadas de los dos estudios y la propuesta conceptual de recomendaciones para el diseño de portales educativos (atendiendo a aspectos pedagógicos, tecnológicos y sociales). De este modo, se proporciona respuesta a las preguntas de investigación que rigen esta tesis doctoral. Asimismo, se recopilan las principales limitaciones detectadas en el presente trabajo. Finalmente, definimos tres líneas de trabajo futuro, entre las que proponemos la generación de un mock-up del portal basado en las características identificadas, que será construido por un equipo interdisciplinar mediante una metodología mixta de investigación, utilizando para el diseño del portal el método de "diseño centrado en usuarios".

En el siguiente Cuadro 1 presentamos el esquema general de la tesis al que hemos hecho referencia en los diferentes apartados del presente capítulo. 
Cuadro 1 Esquema general de la tesis

\section{Problema}

Escasez de portales para compartir y crear de contenido digital y experiencias específicos para la formación del profesorado y basados en sus necesidades

Dispersión del contenido digital educativo

Escasa tendencia a la reutilización del contenido digital

Portal Share.TEC: aproximación con poca repercusión en la comunidad de formación del profesorado europea

\section{Marco teórico}

Sociedad y educación 2.0 hacia sociedad y educación 3.0

Repercusión de nuevos modelos pedagógicos en portales educativos de contenido digital

Formación del profesorado escasa en la creación y compartición de contenidos educativos

Rápida evolución de las TIC: portales educativos.

Dispersión de contenidos digitales y OER.

Interés por la compilación de contenido digital de entidades internacionales.

Tendencias hacia la estandarización de sistemas para facilitar la recuperación y reutilización

Modelos educativos de metadatos

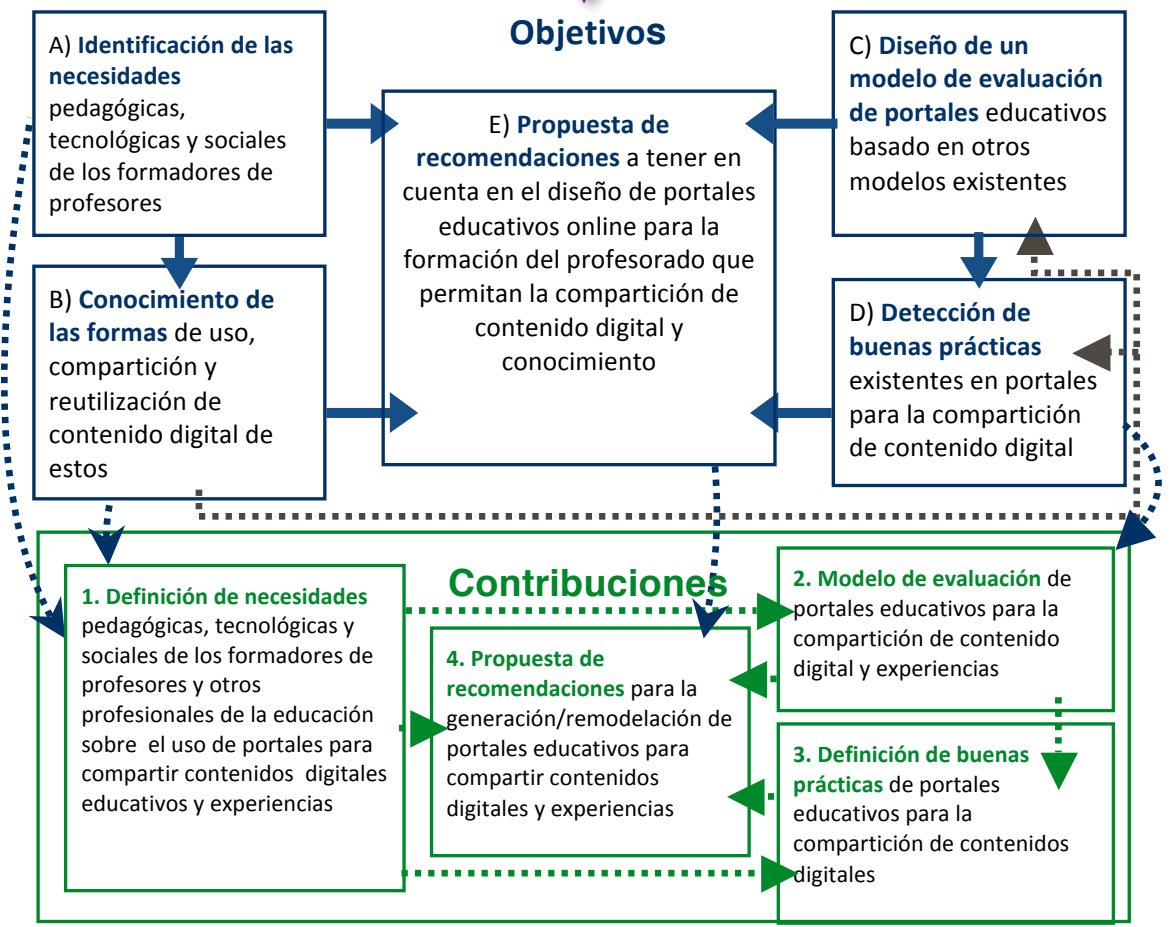




\section{Capítulo 1}

\section{Los contenidos digitales en el campo de la formación del profesorado}

Este capítulo incorpora los apoyos teóricos y contextuales en los que se enmarca nuestra investigación. Estructuramos el capítulo en dos bloques. En primer lugar, reflejamos aquellos aspectos políticos y educativos que determinan la configuración de los portales educativos para la compartición de contenido digital en el ámbito de la formación del profesorado, especialmente en Europa. En la segunda parte del capítulo, reflejamos los resultados obtenidos por otras investigaciones relacionadas.

\section{Fundamentación Teórica}

\subsection{Cambios influenciados por la evolución y adopción social de las TIC}

En las últimas décadas hemos presenciado un vertiginoso crecimiento y desarrollo de las Tecnologías de la Información y la Comunicación (TIC), así como de las infraestructuras que las sustentan y sus aplicaciones a los diferentes sectores de la sociedad (INE, 2008). Hemos sido testigos de cómo las TIC ha impulsado de forma activa transformaciones sociales, culturales, económicas, políticas, educativas, etc.

Hoy en día, en la mayoría de los hogares de Europa se dispone de acceso a Internet, teléfonos móviles, ordenadores, y otro tipo dispositivos tecnológicos que favorecen la accesibilidad y ubicuidad de la comunicación a través de la red. El informe del servicio de estadísticas europeas. Eurostat, de 2014, muestra que el uso 
de Internet por la población de los países europeos sigue una tendencia de crecimiento, a pesar de la brecha digital que sigue existiendo, pues existen países que pronto alcanzarán el nivel de saturación de uso de Internet (tales como Dinamarca, Luxemburgo y Holanda) y otros que no la alcanzan (como Rumanía, Bulgaria, Grecia, Italia y Portugal). El objetivo de la Agenda Digital Europea para 2015 es que al menos el $75 \%$ de la población europea utilice internet de forma regular (Eurostat, 2014). A nivel mundial, apreciamos un crecimiento del uso de internet de un 753\% desde el año 2000 hasta el 2015, siendo la población de Norte América la más conectada a Internet (86.9\%), y la que menor crecimiento ha experimentado durante estos últimos 15 años; seguida de Oceanía (72,1\%), Europa (70.4\%), América del sur (52,4\%), y por los territorios donde menos de la mitad de la población tiene acceso a Internet: Oriente Medio (48,1\%), Asia $(34,8 \%)$, y África $(27,5 \%)$. Sorprende ver que los países con menos utilización de Internet, son los que más crecimiento porcentual han experimentado durante estos últimos 15 años, mientras que aquellos pioneros en el uso de Internet, experimentan un incremento de uso mucho menor (Miniwatts Marketing Group, 2015). Estas estadísticas son alentadoras para los países menos desarrollados, pues cada vez más población ubicada en estos países tiene mayor acceso a la información, lo que puede posibilitar en estos contextos la apertura a transformaciones políticas, económicas, culturales y sociales en los próximos años.

Sorprende ver como en esta era digital en la que integramos las TICs en nuestra vida diaria, encontramos aún una incapacidad por parte de la educación europea y los sistemas de formación a la hora de incorporarlas en las prácticas educativas (European Commission, 2005). Es habitual que la tecnología avance de forma muy rápida, más de lo que la sociedad es capaz de adoptar, y así se refleja en el ámbito que nos atañe en este trabajo, la Educación, y más concretamente la utilización de sistemas para compartir contenidos digitales en el ámbito de la formación del profesorado. Vivimos en una sociedad globalizada caracterizada por la coexistencia multicultural, la información digital y la importancia de la conectividad social, a pesar de que en la mayoría de las escuelas (Gutiérrez Martín \& Tyner, 2012) y centros de formación del profesorado, no se prepara a los estudiantes para los requerimientos que demanda esta sociedad. 
La globalización y la crisis económica están generando presión en los programas educativos a nivel mundial, demandando nuevas aproximaciones de enseñanza-aprendizaje. La nueva sociedad requiere de ciudadanos dotados de nuevas habilidades, que les formen como personas con flexibilidad y capacidad de adaptación al cambio. En la actualidad, muchas escuelas y universidades se centran aún en el desarrollo de prácticas de enseñanza que fomentan la adquisición de habilidades cognitivas tradicionales, enseñando hechos limitados y resolviendo problemas de forma mecánica. En cambio, algunos de los requerimientos formativos para adaptarse a las nuevas demandas sociales están constituidas por la necesidad de enseñar a "aprender a aprender" y "aprender haciendo" (Brown, 2012). Es necesario reinventar la educación, tanto en relación a las prácticas pedagógicas como a la utilización de forma efectiva de las TIC. Las prácticas educativas actuales no cubrirán las necesidades de la globalización si la reforma continúa demandando estandarización y comportamientos convergentes (Zhao, 2009; en Hathaway \& Jaquith, 2014, p. 29). Algunos autores consideran que la clave para transformar la educación descansa en la valoración de los diferentes tipos de inteligencia, la consideración de la creatividad como motor fundamental del cambio, y el cultivo de relaciones creativas entre las disciplinas y entre la educación, la economía y la sociedad (Robinson, 2011). Las TIC son el motor para el crecimiento de la productividad y el cambio social, por lo que los currículos educativos (de todos los niveles) han de reconfeccionarse teniendo en cuenta las investigaciones educativas y las demandas sociales, integrando de forma efectiva las TIC (Brown, 2012).

Los "Millenials", también conocidos como "Generación del Milenio" o "Generación Y" (términos que discutiremos en el apartado 1.5), son el grupo de jóvenes generaciones que utilizan con gran frecuencia la tecnología, que están familiarizados con los medios digitales y están siempre conectados, hechos que, antes 0 después, puede que se reflejen en la organización de los diferentes aspectos de la sociedad, como en la educación. Las escuelas juegan un rol crucial en el desarrollo de las competencias y habilidades digitales, por lo que los docentes y las instituciones deben adaptarse a los nuevos retos que plantea esta generación, para dar respuesta a sus necesidades, expectativas y comportamientos (OECD, 2012). Esta generación requerirá de más flexibilidad de espacios y tiempos a nivel educativo y laboral, y necesitará desarrollar las habilidades necesarias para el aprendizaje permanente, dada la celeridad con la que evoluciona y seguirá evolucionando el conocimiento y las tecnologías. En este contexto, los contenidos digitales juegan un rol crucial, como materiales que les permitirán estar actualizados frente a los cambios sociales. 
Brun \& Hinostroza (2014), recogen que los contextos institucionales cuentan con los medios necesarios para la integración de las tecnologías en la formación inicial de los maestros, gracias a las políticas existentes en esta materia, la disponibilidad y el acceso de recursos TIC, y la disponibilidad y calidad del apoyo pedagógico y tecnológico. En cambio, las investigaciones revelan que, en el ámbito de la formación del profesorado, se proporciona formación desde una perspectiva más tecnocéntrica que didáctica, lo que dificulta la adquisición de competencias para integrar las TIC en sus prácticas pedagógicas. Este hecho se refleja en las escuelas, donde los profesores noveles las utilizan TIC de forma personal, para su planificación docente, pero las utilizan menos que los profesores con más experiencia laboral para guiar a sus alumnos en el proceso de aprendizaje, es decir, existen dificultades para la transferencia tecnológica a las prácticas pedagógicas (Brun \& Hinostroza, 2014; Centre for Educational Research and Innovation, 2008).

\subsection{De la sociedad 1.0 a la sociedad 3.0}

La era de la información o sociedad postindustrial (Bell, 1974), se caracteriza por los procesos interrelacionados de la informacionalización, globalización, interconexión, construcción de identidad, y crisis del patriarcado y del Estado-Nación (Castells, 2005, p. 26)

Hoy en día, debido a los efectos de la globalización y al impacto de las TIC, han surgido nuevas formas de intervenir, producir y consumir en todos los ámbitos de la sociedad, lo que ha generado el surgimiento de nuevas formas de gestionar las empresas (públicas y privadas), una nueva cultura, nuevas formas de organizar y participar en la política y la administración, etc.) (Castells, 2005; Vilaseca i Requena \& Torrent i Sellens, 2005).

Las redes se están convirtiendo en el "sistema nervioso" de nuestra sociedad (Castells, 2010; Melucci, 1997; Van Dijk, 2012, p. 2). Vivimos en una sociedad conectada ${ }^{1}$ con vistas a alcanzar la sociedad del conocimiento ${ }^{2}$. Estamos en vías de

1 En 1981, Stein Bråten utiliza por primera vez el término Sociedad Conectada; término retomado posteriormente por Jan van Dijk, en 1991, y difundido masivamente gracias a la adopción del término en la trilogía de "La era de la Información", concretamente en su primera volumen, "La sociedad Red"1, de 1996 (Molinaro \& Wolfgang Sarlet, 2014).

${ }^{2}$ Aún hoy existe confusión y controversia entre los términos sociedad de la información y sociedad del conocimiento. En este trabajo, siguiendo la diferenciación que establece la UNESCO (2005) entre ambos conceptos, trabajamos con la idea de "sociedad del 
alcanzar esta última, pero aún queda un largo camino hasta lograr una educación para todos a lo largo de toda la vida, una generalización de los trabajos de I+D en todos los países del mundo, una regulación de la circulación mundial de competencias y un fomento de la solidaridad digital (Vilaseca i Requena \& Torrent i Sellens, 2005).

La UNESCO recoge los tres pilares fundamentales en los que las diferentes naciones deberían trabajar para alcanzar la sociedad del conocimiento (UNESCO, 2005, pp. 207-209):

- Mejorar la valorización de los conocimientos existentes para luchar contra la brecha cognitiva, [...] evaluando las competencias [...] y explotando los puntos fuertes disponibles en educación, investigación científica y desarrollo tecnológico.

- Adoptar un enfoque más participativo de acceso al conocimiento. Las sociedades solo lograrán ser sociedades del conocimiento cuando el mayor numero de individuos que las componen sean generadores de conocimientos, y no meros consumidores de lo que ya está disponible.

- Integrar de forma más efectiva las políticas del conocimiento.

Con el objetivo de que los diferentes países logren solidificar estos pilares, proponen una serie de recomendaciones, entre las que destacamos aquellas relacionadas con el presente trabajo (UNESCO, 2005, pp. 210-212):

- Invertir más en una educación de calidad para todos, a fin de garantizar la igualdad de oportunidades

- Multiplicar los lugares de acceso comunitario a las tecnologías de la información y comunicación

- Alentar el acceso universal al conocimiento mediante el incremento de los contenidos disponibles, a través de los principales lugares del saber: centros docentes de enseñanza superior, centros de investigación, museos o

conocimiento", como concepto prospectivo y complejo que involucra las transformaciones sociales, culturales, económicas y políticas que se están llevando a cabo y han de seguir realizándose para alcanzar este concepto ideal. El término sociedad de la información enfatiza los progresos tecnológicos. En cambio, el concepto de sociedades del conocimiento comprende dimensiones sociales, éticas y políticas mucho más vastas (UNESCO, 2005, p. 17). La información es efectivamente un instrumento del conocimiento, pero no es el conocimiento en sí (2005, p. 19). Castells habla de "sociedad red", como concepto intermediario entre estas dos concepciones (Castells, 1996). 
bibliotecas, que deberían producir y difundir conocimientos de manera efectiva.

- Crear redes e infraestructuras ("colaboratorios") de colaboración científica, accesibles a los investigadores de distintos países y regiones

- Dar prioridad a la diversidad lingüística, utilizando lenguajes comunes en el ciberespacio, pero preservando la lengua propia de la cultura a la que pertenece el individuo. Será necesario apoyar la creación de contenidos digitales multilingües, especialmente en el ámbito pedagógico.

- Avanzar hacia una certificación de los conocimientos de internet

Según Siemens \& Conole (2011), las nuevas tecnologías que influyen en el modo en el que la información se genera y comparte, y en cómo la gente conecta y socializa, son muy susceptibles de ser adoptadas en la educación. Así como la idea de un libro necesitaba de la existencia de la biblioteca, o el currículo estructurado por áreas de conocimiento necesitaba de clases, la idea de internet (distribuido, social y en red), influye sobre la educación, enseñanza y aprendizaje. Los docentes han explorado por varias décadas el rol de Internet como herramienta de investigación y aprendizaje. Estos autores recogen que finales de los años 90 comenzaron los primeros servicios de redes sociales y herramientas de publicación de contenido, lo que permitía a cualquier usuario publicar contenido y mantener conversaciones en línea. Desde ese momento, el número de servicios, de usuarios y de actividad en línea, han incrementado en vasta medida (redes sociales, comercio electrónico, herramientas de videoconferencia, de trabajo colaborativo, servicios de ocio para ver/compartir vídeos, podcasts, música, imágenes, mapas personalizados con servicios de geolocalización, etc.). En 2004, el conectivismo se presenta como una nueva teoría de aprendizaje que aborda el aprendizaje en entornos complejos, sociales y conectados. Desde ese momento, han proliferado numerosos artículos, MOOCs ${ }^{3}$, Cursos Online Abiertos, conferencias, etc., que han explorado la aplicación del conectivismo a la educación (Siemens \& Conole, 2011).

En este contexto, se justifica la necesidad de la construcción o aglutinación de portales que permitan el acceso global a contenidos digitales en todos los ámbitos del conocimiento, pero por supuesto, aquellos relacionados con uno de los pilares fundamentales de las sociedades, la educación, en todas sus niveles. La habilidad de capturar conocimiento, de forma que pueda ser analizado, reutilizado y compartido con otros, desarrollando de este modo una espiral de nueva generación

${ }^{3}$ MOOCs, siglas en inglés de Massive Open Online Courses - Cursos Masivos Abiertos en línea. 
de conocimiento, es, tal vez, la promesa más poderosa que la tecnología de la información puede proporcionar (Hodgins, 2002, p. 79).

Durante los últimos años hemos oído en numerosas ocasiones en los diferentes medios de comunicación los conceptos de sociedad 1.0, 2.0 y 3.0. En la siguiente tabla recogemos las principales características de cada uno de estos conceptos siguiendo a los siguientes autores:

Tabla 1 Las generaciones del aprendizaje online. Elaboración propia partiendo de Dos Reis, 2011 (2011), Moravec (2008a, pp. 256-266, 2013); Cobo Romaní y Moravec (2011); y Hayes (2006)

\begin{tabular}{|c|c|c|c|}
\hline Sociedad & 1.0 & 2.0 & 3.0 \\
\hline $\begin{array}{l}\text { Características } \\
\text { básicas: }\end{array}$ & $\begin{array}{l}\text { Era industrial y era de la } \\
\text { información. Sociedad } \\
\text { jerárquica. }\end{array}$ & $\begin{array}{l}\text { Sociedad basada en el } \\
\text { conocimiento, guiada } \\
\text { por la globalización y el } \\
\text { crecimiento de las } \\
\text { tecnologías en red. } \\
\text { Sociedad democrática. }\end{array}$ & $\begin{array}{l}\text { Cambio social y tecno- } \\
\text { lógico acelerados; } \\
\text { continua la globaliza- } \\
\text { ción y democratización } \\
\text { del conocimiento y de } \\
\text { las relaciones; la inno- } \\
\text { vación es alimentada } \\
\text { por los "knowmads"4. } \\
\text { Sociedad auto-organi- } \\
\text { zada. Empoderamiento } \\
\text { de los individuos }\end{array}$ \\
\hline $\begin{array}{l}\text { Centro de } \\
\text { interés }\end{array}$ & Información & $\begin{array}{l}\text { Conocimiento: interpre- } \\
\text { tación de la información } \\
\text { y generación de } \\
\text { significado }\end{array}$ & $\begin{array}{l}\text { Incremento sustancial } \\
\text { de la información } \\
\text { disponible, y decreci- } \\
\text { miento exponencial de } \\
\text { la vida del conoci- } \\
\text { miento útil. }\end{array}$ \\
\hline $\begin{array}{l}\text { Descripción } \\
\text { de la } \\
\text { tecnología }\end{array}$ & $\begin{array}{l}\text { Aprendizaje mixto: con- } \\
\text { tenidos educativos mul- } \\
\text { timedia para ser usados } \\
\text { de forma presencial o a } \\
\text { distancia. Evaluación } \\
\text { formativa mediante } \\
\text { tutorías online; aprendi- } \\
\text { zaje a distancia; tutorías } \\
\text { online. }\end{array}$ & $\begin{array}{l}\text { Tecnologías de código } \\
\text { abierto engranadas en } \\
\text { plataformas, más que } \\
\text { en una aplicación. }\end{array}$ & $\begin{array}{l}\text { Introducción de las } \\
\text { tecnologías de web } \\
\text { semántica e introduc- } \\
\text { ción de hipervínculos a } \\
\text { texto, voz o imagen, } \\
\text { linked data, etc. }\end{array}$ \\
\hline
\end{tabular}

4 El término inglés "knowmad" hace referencia a trabajadores nómadas del conocimiento, personas creativas, imaginativas e innovadoras, capaces de trabajar con casi cualquier persona, en cualquier momento y en cualquier lugar. Desaparecen los espacios convencionales de trabajo (Moravec, 2008b, 2013). 


\begin{tabular}{ll}
\hline Sociedad & $\mathbf{1 . 0}$ \\
\hline Relaciones & $\begin{array}{l}\text { Individuales, orientadas a } \\
\text { la tarea, simples, orga- } \\
\text { nizadas. }\end{array}$ \\
& \\
$\begin{array}{l}\text { Tecnología } \\
\text { Herramientas } \\
\text { para la } \\
\text { distribución de } \\
\text { contenido }\end{array}$ & $\begin{array}{l}\text { Documentos o vídeos } \\
\text { (Primeras versiones web) }\end{array}$ \\
\hline
\end{tabular}

Modos para la Contenido distribuido a distribución del través de tecnologías contenido (Eb- asíncronas (comunicación ner, 2007) unidireccional, del poseedor del conocimiento al estudiante). Modelo de arriba a abajo de distribución del contenido.

\section{Educación}

Rol de la educación

\section{0}

3.0

Orientadas a un fin, globalizadas, comunitarias, complejas, caóticas intencionalmente, flexibles, hiperconectadas, sociedad con poder.

Web 2.0: wikis, blogs, Tecnologías en tiempo chats, juegos, podcasts, real, Web colaborativa, compartición de publica-entornos virtuales ciones personales, por- multiusuario, crecitales $2 \mathrm{D}$, redes sociales, miento de portales 3D, etc. Algo de control sobre datos $y$ participación. representaciones con avatares, perfiles interoperables, reuniones en línea, webcasts ${ }^{5}$, etc. Análisis automáticos y en tiempo real de Big data.

Contenido interactivo (comunicación

síncrona).

Modelo de abajo a arriba de distribución del contenido (son los usuarios/estudiantes quienes se comunican y generan conocimiento $o$ reutilizan /reelaboran el existente).

Genera estudiantes que Las personas son más Pensamiento y acciones harían un buen trabajo en valoradas por su conoci- creativas generadas por parámetros y relaciones muy definidas miento personal, que todos los miembros de convencional. La educa- la sociedad.

ción debe desarrollar

nuestros talentos para

${ }^{5}$ Retransmisión de eventos en directo a través de la web apoyados por el uso de diferentes tecnologías (vídeos, chats, herramientas sociales, etc.) 


\begin{tabular}{|c|c|c|c|}
\hline Sociedad & 1.0 & 2.0 & 3.0 \\
\hline & & $\begin{array}{l}\text { ser competentes en un } \\
\text { mercado globalizado } \\
\text { que demanda nuevas } \\
\text { relaciones. }\end{array}$ & \\
\hline Pedagogía & $\begin{array}{l}\text { Prevalencia de instruc- } \\
\text { cionismo (diseño de } \\
\text { objetos de aprendizaje), } \\
\text { socioconstructivismo } \\
\text { (revisión de pares; e-mail, } \\
\text { foro, chat); cognitivismo } \\
\text { (consumo de tecnología). } \\
\text { El profesor aloja el saber y } \\
\text { lo transmite al estudiante. }\end{array}$ & $\begin{array}{l}\text { Favorece el } \\
\text { conectivismo } \\
\text { (colaboración distri- } \\
\text { buida), } \\
\text { sociocognitivismo y el } \\
\text { compromiso sociocul- } \\
\text { tural. Aprendizaje explí- } \\
\text { cito transferido de per- } \\
\text { sona a persona, y tácito, } \\
\text { aprendiendo mediante } \\
\text { la acción, hasta } \\
\text { conformar significados } \\
\text { construidos } \\
\text { individualmente. }\end{array}$ & $\begin{array}{l}\text { Aún no se ha logrado } \\
\text { este modelo, la tecno- } \\
\text { logía aún debe avanzar } \\
\text { algo más. El estudiante } \\
\text { aprende del profesor, } \\
\text { de otros estudiantes, de } \\
\text { la sociedad, enseña al } \\
\text { profesor (co-cons- } \\
\text { tructivismo) }\end{array}$ \\
\hline
\end{tabular}

En la sociedad 1.0, podemos dividir dos etapas, la previa a la revolución industrial, donde los niños aprenden en casa y están involucrados en los procesos económicos y productivos, aprenden haciendo mediante trabajos, y actividades económicas. En una segunda etapa, desde la revolución industrial hasta el siglo XX, se produce una industrialización de la educación, en la que se prepara a los estudiantes para trabajo industrial o burocrático, a través de la memorización y repetición. Adquiere notoria importancia la medida de los resultados. El aprendizaje tiene lugar en las escuelas, y existe un uso limitado de la tecnología. El aprendizaje sigue una aproximación top-down, es decir, el profesor es el "virtuoso" del conocimiento y se lo transmite a los estudiantes.

La sociedad 2.0 aparece asociada a la emergencia de la sociedad del conocimiento, que tiene lugar en el siglo XX (Drucker, 1969, 1985; en Cobo Romaní \& Moravec, 2011, p. 50). Los cambios tecnológicos son el motor que ha impulsado los cambios sociales que estamos viviendo en la actualidad. Los individuos participan en interacciones sociales, compartiendo su conocimiento en sistemas cada vez más complejos donde la tecnología cobra más y más presencia en todos los ámbitos sociales. En la segunda mitad del siglo XX comienza a cobrar importancia la gestión del conocimiento, con el fin de ordenar el caos y la ambigüedad generada en los sistemas organizativos, debido a la disposición de más información y a la democratización de la misma (favorecida por espacios virtuales 
donde cualquier individuo puede producir y consumir información, tales como las redes sociales). Los avances en las TIC facilitan la creación de significados socialmente construidos.

La sociedad hacia la que caminamos, la 3.0, se caracteriza por el cambio social y tecnológico acelerados; la constante globalización y redistribución vertical del conocimiento y las relaciones; y la sociedad en la que los "knowmads" alimentan la innovación. En esta sociedad, el significado es socialmente construido y contextualmente reinventado. Esta sociedad está interconectada constantemente y en tiempo real, cualquier persona tiene la capacidad de compartir y aprender nueva información. El caos y la ambigüedad son parte necesaria de la sociedad, y han de aprenderse las estrategias para ser capaz de discernir la información veraz y válida para cada individuo. El aprendizaje evoluciona constantemente y de forma rápida, a medida que evoluciona el conocimiento. No sólo se aprende en las escuelas, si no que se aprende en cualquier lugar y de cualquier persona 0 material, y los estudiantes son agentes activos, ellos también pueden enseñar y compartir en cualquier lugar sus conocimientos. En el modelo de sociedad que perfila el auge de la Web 3.0, las tecnologías usan integran eficazmente en la educación (a diferencia de la educación 2.0, donde las tecnologías se emplean, a veces, sin tener claro cuál es el objetivo de su aplicación).

\subsection{La formación del profesorado en la actualidad}

La formación del profesorado en el contexto europeo, ha sido un ámbito de preocupación común desde el lanzamiento de la Estrategia de Lisboa en el año 2000 (Parlamento Europeo, 2009). Recogemos a continuación los principales hitos que han tenido lugar desde la publicación de este documento:

En la Estrategia de Lisboa (Consejo Europeo de Lisboa, 2000) se recoge que "Ios sistemas educativos y de formación deben permitir a todos los ciudadanos europeos participar en la nueva sociedad del conocimiento", y por ello se define como objetivo importante "mejorar la calidad de los sistemas de educación y formación” (Coba Arango, 2011, p. 32).

En 2002, tiene lugar el "Consejo de Barcelona", donde se acuerdan los objetivos específicos para mejorar los sistemas de educación y formación de los estados miembros" de la Unión Europea, incluyendo la mejora de la formación de profesores y formadores (Coba Arango, 2011, p. 33). 
En 2004, el "Informe conjunto del Consejo y de la Comisión sobre los avances hacia los objetivos de Lisboa en los ámbitos de la educación y la formación" pide "que se desarrollen principios europeos comunes respecto a las competencias y cualificaciones necesarias para profesores y formadores (Coba Arango, 2011, p. 33).

En la Comunicación de la Comisión al Consejo y al Parlamento Europeo, sobre la Eficiencia y la equidad en los sistemas europeos de Educación y Formación de 2006, se acuerda que "la educación y la formación son factores clave para desarrollar el potencial de competitividad a largo plazo de la UE, así como para la cohesión social", por lo que debían realizarse más reformas para lograr sistemas educativos de gran calidad, eficientes, y equitativos (Coba Arango, 2011, p. 33).

En diciembre de 2006, el Parlamento Europeo y el Consejo aprobaron la "Recomendación sobre las Competencias Clave para el Aprendizaje permanente ${ }^{6 "}$. Este consejo implicó que se realizaran cambios sustanciales en los centros educativos (programación, metodología, evaluación, materiales, organización de los centros escolares, etc.), y hace responsable de la adopción de este nuevo modelo a los profesores (Coba Arango, 2011).

En 2006, La Ley Orgánica 2/2006 de 3 de mayo de Educación establece una formación inicial del profesorado más alineada con las prácticas y tendencias de los paises referentes de la UE (Coba Arango, 2011, p. 34).

En 2007, la Comisión Europea emite un comunicado "Mejorar la calidad de la formación del profesorado", en el que incorporan la idea de llevar a cabo programas de máster y doctorado, y transformar la diplomatura de magisterio al título de Grado, con el fin de impartir la cantidad y calidad necesaria de formación docente y promover la profesionalización de la docencia. Asimismo, consideran que debe haber una mayor transversalidad y coordinación entre los formadores de profesores, los profesores en activo, el mundo laboral y otros organismos, para garantizar que los futuros profesores aprendan buenas prácticas en el aula y adaptadas a su momento actual. Afirman que la calidad de la enseñanza es un factor fundamental para alcanzar los objetivos de Lisboa en materia de cohesión social, crecimiento y competitividad económica (European Commission, 2007), permitiendo a los profesores formar a ciudadanos competentes a nivel personal y profesional.

6 En este trabajo utilizaremos los términos "Aprendizaje Permanente" y "Aprendizaje a lo largo de la vida" de forma sinónima, pues son dos formas sinónimas de traducir el término original "Lifelong Learning". 
Durante este mismo año, 2007 se publica la Ley Orgánica 4/2007, de 12 de abril, por la que se modifica la Ley Orgánica 6/2001, de 21 de diciembre, de Universidades (BOE, 2007), de aplicación nacional. Establece para la Educación Superior la importancia de la formación continua y la transferencia y transversalidad del conocimiento para dar respuesta a los nuevos retos que plantee la sociedad, y refleja sus principios en la siguiente frase:

La Ley apuesta decididamente por la armonización de los sistemas educativos superiores en el marco del espacio europeo de educación superior y asume la necesidad de una profunda reforma en la estructura y organización de las enseñanzas, basada en tres ciclos: Grado, Máster y Doctorado. Se da así respuesta al deseo de la comunidad universitaria de asentar los principios de un espacio común, basado en la movilidad, el reconocimiento de titulaciones y la formación a lo largo de la vida. El nuevo modelo de enseñanzas aporta una manera diferente de entender la universidad y sus relaciones con la sociedad. Se trata de ofrecer una formación de calidad que atienda a los retos y desafíos del conocimiento y dé respuesta a las necesidades de la sociedad. (BOE, 2007, p. 16241).

En 2010, los estados comunitarios y otros países no comunitarios, en total hoy, 49 países, hicieron realidad el un Espacio Europeo de Educación Superior, cuyo proceso comenzó en 1998 con la Declaración de la Sorbona, y en 1999, con la declaración de Bolonia (por lo que al proceso de creación del Espacio Europeo de Educación Superior, también se le dota el nombre de "Proceso de Bolonia") (European Higher Education Area, 2012a). La adopción de este espacio instaura en España los grados de Maestro de Educación Infantil y Maestro de Educación Primaria (con sus respectivas menciones), así como el Máster de Educación Secundaria para el profesorado de Educación Secundaria Obligatoria (ESO) y Postsecundaria Obligatoria. Curiosamente, la adopción de estos nuevos planes conlleva una mayor libertad a la hora de generar los planes de estudio (evaluados por el organismo acreditativo ANECA).

En el Comunicado de Bucarest (European Higher Education Area, 2012b), la Comisión Europea reitera su compromiso para promover el aprendizaje centrado en el estudiante en la Educación Superior, caracterizado por métodos innovadores de enseñanza, involucrando a los estudiantes como participantes activos de su propio aprendizaje.

En 2013, el grupo de trabajo temático de "Desarrollo Profesional Docente" de la Unión Europea, conformado por expertos de 26 países europeos y organizaciones, genera dos informes: 1) Apoyar al desarrollo de la competencia docente para 
mejores resultados de aprendizaje; y 2) Apoyando a los formadores de profesores para mejorar los resultados de aprendizaje.

Además de las políticas europeas, La UNESCO${ }^{7}$, como organización que promueve el desarrollo mundial de la educación a nivel internacional, recientemente ha lanzado varias políticas y programas que promueven la renovación de la formación del profesorado, entre las que destacamos las siguientes:

A) Estrategia educativa 2014-2021, actualmente en vigor, que tiene como objetivo promover programas para profesores y formadores de profesores, a través de estrategias y modalidades de formación mixta: virtual y presencial, tratando de formar a los profesores para adaptarse al nuevas formas de enseñanza centrada en el alumno, abordando temas que fomenten el desarrollo sostenible educativo y la calidad de la educación (UNESCO, 2014a).

B) Otro de los temas de prioridad actual para la UNESCO es la construcción de sociedades del conocimiento, pues consideran que la compartición de conocimiento e información, particularmente a través de las TIC, tiene el poder de transformar las economías y las sociedades (UNESCO, 2013).

C) La UNESCO lanza en 2008 el Marco de Competencias TIC para profesores, y en 2011 desarrolla una nueva versión (UNESCO, 2011) (gracias al apoyo de varias empresas ${ }^{8}$ ). Su objetivo era generar un marco basado en las investigaciones y demandas actuales de la sociedad, para ayudar a los países a desarrollar políticas y estándares nacionales que capaciten a los profesores a enseñar con TIC. De este modo se pretende promover que los estudiantes trabajen de forma colaborativa, sean capaces de solucionar problemas y pensar y actuar de forma creativa, posibilitando, según la UNESCO, la adquisición de competencias que les permitan adaptarse eficazmente las demandas sociales de cada momento. Para lograr estos objetivos, el programa establece que los profesores deben formarse en tres aproximaciones:

- alfabetización digital

- profundización del conocimiento y aplicación de este a los contextos reales

- y creación del conocimiento

A través de seis aspectos del trabajo de un profesor:

7 UNESCO es la Organización de las Naciones Unidas para la Educación, Ciencia, Cultura, Comunicación e Información (United Nations for Educational, Scientific and Cultural Organization)

${ }^{8}$ CISCO, INTEL, ITSE y Microsoft 
- entender las TICs en educación

- currículum y evaluación

- pedagogía

- TIC

- organización y administración, y desarrollo profesional del profesorado.

Los profesores deben ser capaces de seleccionar e integrar con sentido pedagógico en el currículo y en su práctica docente herramientas 2.0 y tecnologías. La integración debe realizarse en las diversas actividades que conllevan la labor docente: búsqueda y diseño de actividades y materiales, programaciones didácticas, evaluación y seguimiento, planificación, formación continua, establecimiento de colaboración con otros profesionales, etc., tratando de garantizar el acceso y la adaptación de la enseñanza a las necesidades de cada alumno.

Se pretende que los profesores sean vistos como aprendices modelo y productores del conocimiento, involucrados constantemente en la experimentación e innovación en colaboración con sus compañeros de trabajo y expertos, para producir nuevo conocimiento sobre el aprendizaje y la práctica docente. Los dispositivos conectados, recursos electrónicos y entornos virtuales, se utilizan para crear y apoyar a esta comunidad para producir conocimiento y colaboración en línea en cualquier momento y lugar.(p.13)

En relación al trabajo de esta tesis doctoral, este marco referencial destaca la importancia de la generación y participación por parte de los profesores en redes profesionales, y la utilización y generación de contenidos digitales para potenciar el aprendizaje y el desarrollo profesional, promoviendo:

- la generación de comunidades de práctica presenciales y virtuales, y la participación en entornos virtuales y de construcción del conocimiento, tanto por parte de los profesores, como por parte de los alumnos (p. 39);

- la utilización de recursos TIC para participar en comunidades profesionales y compartir y discutir buenas prácticas en la enseñanza (p. 39);

- que los profesores sean capaces de encontrar y compartir recursos para apoyar sus actividades y su propio desarrollo profesional, y desarrollar habilidades de gestión de conocimiento para analizar y discutir con otros profesionales la calidad de los recursos digitales, describiendo, discutiendo y demostrando ejemplos de sus prácticas a este respecto (p. 33);

- Identificar los recursos TIC apropiados y las habilidades necesarias para utilizar estos recursos (p. 46); 
- evaluar y seleccionar recursos educativos TIC adaptándolos a las necesidades de cada uno de sus alumnos, investigando cómo otros profesores comparten recursos digitales o herramientas en escenarios particulares (p. 47);

- ayudar a los estudiantes a ver que los recursos digitales son valiosos en todos los aspectos de su vida, no únicamente en la educación, para obtener información y extender conocimiento;

- utilizar los ordenadores y contenidos digitales dentro de las clases, para apoyar y fortalecer las interacciones sociales entre los alumnos (p.31).

También consideramos relevante tener en cuenta el Marco para el Desarrollo y Comprensión (European Commission, 2013a) de una de las competencias clave y transversal para el Aprendizaje Permanente de la Unión Europea (European Parliament \& Council of the European Union, 2006), la Competencia Digital en los ciudadanos europeos. En este informe se recopilan 21 competencias que han de desarrollarse para alcanzar la competencia digital, recogidas en 5 áreas (European Commission, 2013a, p. 13):

- Información: identificar, localizar, almacenar, organizar y analizar información digital, juzgando su relevancia y propósito.

- Comunicación: en entornos digitales, compartir recursos mediante herramientas online, establecer unión con otros y colaborar mediante las herramientas digitales, interactuar con y participar en comunidades y redes, y tener una concienciación intercultural.

- Creación de Contenido: los ciudadanos deben ser capaces de desarrollar contenido, integrar y reelaborar conocimiento y contenido existente, programar y generar artefactos de forma creativa y saber interpretar y aplicar las diferentes licencias de derecho de los recursos.

- Seguridad: acceder de forma segura a Internet y preservar su identidad y sus datos.

- Resolución de problemas: identificar necesidades digitales y recursos, decidir qué herramientas digitales utilizar en función de las necesidades, actualizar sus competencias y las de otros, etc.

Para lograr los objetivos que plantea la UNESCO (2011) y la Comisión Europea (2013a), estas ideas han de plasmarse en los programas de la formación del profesorado de las diferentes naciones, de modo que la educación pueda adaptarse a las demandas sociales y a la formación de sus futuros ciudadanos. La convergencia de la globalización, la emergencia de la sociedad del conocimiento y 
el cambio acelerado de nuestra sociedad actual, "contribuyen a lo que podría ser llamado un nuevo paradigma de producción del conocimiento en Educación Superior (Moravec, 2008a, p. 123).

En el tema que nos atañe en esta tesis doctoral, muchos profesores requieren de más formación en el uso de repositorios de objetos de aprendizaje y en las herramientas para la reutilización, para fomentar las habilidades TIC que les permitan la reutilización de OER en su práctica diaria (Clements \& Pawlowski, 2012; Santos-Hermosa, 2014). Comprenderemos, más adelante, en el apartado 1.6 C), la importancia de los OER en la educación, y por qué es necesario incluir estos aspectos en los planes de la formación del profesorado. Sintetizamos la siguiente llustración 1 las medidas que hemos recogido en este apartado: 
llustración 1 Principales hitos de la formación del profesorado en el Contexto Europeo. Elaboración Propia

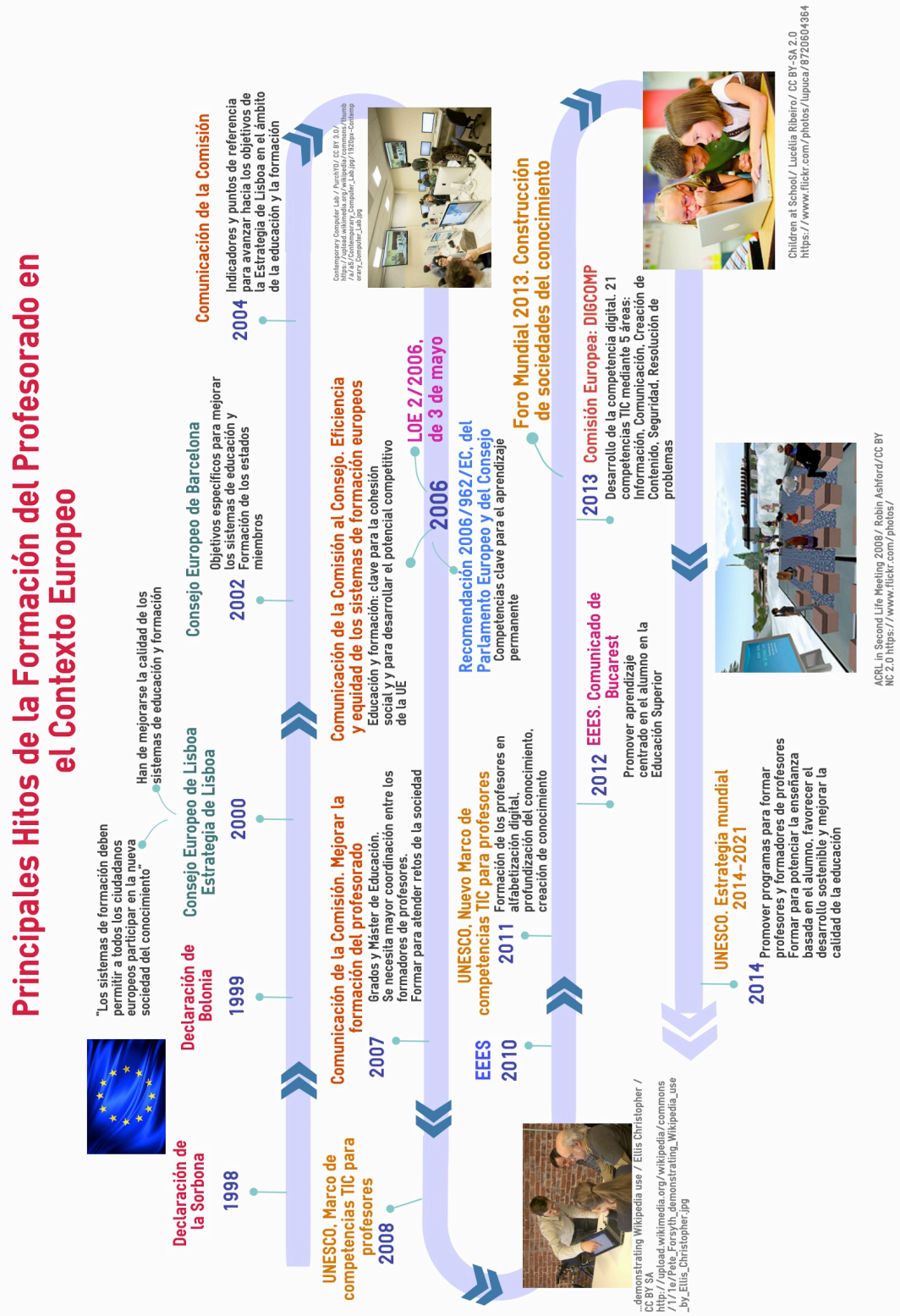




\subsection{Políticas potenciadoras del desarrollo de las TIC en Europa}

Desde el contexto político-social han sido amplias y variadas las iniciativas internacionales y locales creadas a través de iniciativas legislativas, programas y proyectos, para favorecer el crecimiento socioeconómico de nuestras sociedades. Debido a que esta tesis se enmarca en un contexto Europeo, principalmente, nos centraremos en las políticas europeas y nacionales que han fomentado el desarrollo de la compartición de contenidos digitales en el ámbito educativo.

La estrategia de Lisboa (2000-2010) fue el programa de desarrollo de la Unión Europea que intentó solventar la ecuación que se establece entre crecimiento económico, competitividad y empleo, por un lado, y sostenibilidad social y del entorno, por otro. Se basaba en la presunción de que los modelos económicos de la Unión Europea necesitaban cambiar para ser competitivos en la economía global, pues desde los años 70 habían permanecido rezagados con respecto a otros países, como Estados Unidos, presentando problemas relacionados con la productividad y la innovación (Alesina \& Giavazzi, 2008).

El conocimiento es el eje vertebrador que respalda todos los aspectos reflejados en la estrategia (European Commission, 2013c). No es objeto de la presente disertación analizar la consecución 0 no de los objetivos que perseguía esta estrategia, objetivamente marchitados por la "recensión" económica sufrida en gran parte de los países europeos, sino que nos centraremos en los principios que reflejaba y en el impulso político y de financiación económica que han repercutido de manera positiva en la difusión del conocimiento. La estrategia constó de dos fases (Parlamento Europeo, 2009).

- En la primera (2000-2005) se pretendía preparar el paso a una economía y una sociedad basadas en el conocimiento mediante la mejora de las políticas relativas a la sociedad de la información y de I + D [...]; modernizar el modelo social europeo [...]; y mantener las sólidas perspectivas económicas y las expectativas favorables de crecimiento [...] (Consejo Europeo de Lisboa, 2000, p. 4).

- En una segunda fase (2005-2010), propiciada por la necesidad de impulsar los objetivos que no se estaban cumpliendo en la primera, se propone centrar la nueva estrategia, entre otros aspectos, en el apoyo al conocimiento y la innovación y en la supresión de los obstáculos a la libre circulación en el sector del transporte y movilidad laboral y académica (Comisión Europea, 2005). 
Con el objetivo de potenciar los objetivos planteados en la estrategia de Lisboa, y en los albores de la crisis financiera europea, la Comisión Europea decide poner en marcha un nuevo plan sucesor, la Estrategia 2020 (European Commission, 2013b). La Estrategia 2020 (European Commission, 2010b), pretende potenciar el crecimiento de Europa de una forma más sostenible, inteligente e inclusiva. La Unión Europea se propone 5 objetivos, entre los que destacamos los tres que atañen a esta tesis doctoral:

- reducir las tasas de desempleo, incrementar la inversión en innovación;

- reducir las tasas de abandono temprano en la enseñanza obligatoria e incrementar el número de graduados universitarios a un $40 \%$;

- luchar contra la exclusión social (European Commission, 2015a, 2015b).

Estos objetivos aparecen interconectados y desglosados en siete "acciones emblemáticas". En nuestro caso, nos interesa la de la "creación de una Agenda Digital europea". Su objetivo principal consiste en explotar el potencial de las TIC para promover la innovación, el crecimiento económico y el progreso, tratando de lograr un único mercado digital de calidad. Para lograrlo, se necesitan tomar una serie de acciones:

- mejorar la interoperabilidad de los dispositivos, aplicaciones, repositorios de datos, servicios y redes;

- revisar las políticas de establecimiento de estándares, y promover las reglas de derechos de autor apropiadas;

- Proporcionar el acceso a Internet para todos y un servicio más rápido, independientemente de sus características personales o condiciones sociales.

- Invertir en la investigación e Innovación;

- Promover la alfabetización, las habilidades y la inclusión digital.

En el programa Horizon 2020, la Comisión Europea llama al reto de reinventar el ecosistema de la educación y empoderar a los profesores en la era digital (European Commission, 2013d), por lo que proponen la creación y utilización de plataformas de libre acceso y gratuitas para la colaboración (para el ámbito educativo, pero también para promover desarrollo de la ciencia en general por parte de los ciudadanos), ya que son espacios que sirven de puente de unión entre la ciencia, la tecnología, la innovación y la sociedad (European Commission, 2014, p. 5).

En síntesis, vislumbramos a través de las diferentes políticas europeas el interés por la mejora de la competitividad de los países europeos en el ámbito global, donde la educación y la integración de las tecnologías y servicios existentes juegan un rol 
crucial. En relación a nuestra tesis doctoral, consideramos que estas políticas europeas sustentan la necesidad de construir servicios que potencien el acceso y la compartición de contenidos de calidad y construcción de conocimiento e intercambio de experiencias en portales Web en el ámbito de la formación del profesorado. Este tipo de portales no sólo permiten la comunicación y enriquecimiento entre personas de diferentes contextos culturales, si no que tienen el potencial de fomentar la calidad de la educación y la innovación a nivel europeo.

\subsection{Implicaciones educativas de los avances en TIC}

En el último siglo se han realizado muchos esfuerzos para reinventar el arte de la educación, pero en consonancia con los avances tecnológicos de nuestra sociedad actual, la educación debe repensarse. Muchos profesores son acusados de utilizar las tecnologías sin atender a si estas prácticas son pedagógicamente efectivas y sin tener en cuenta las evidencias y pensamientos pedagógicos tradicionales. El papiro, la tiza, la imprenta, los proyectores, los juguetes educativos, la televisión, e incuso las tecnologías básicas para la escritura, fueron innovaciones una vez. Hoy en día disponemos de ordenadores conectados a la red, tecnologías WiFi, y dispositivos móviles, entre otros. Ninguno de estos avances ha cambiado la capacidad de las personas para aprender, pero sí se han transformado profundamente la forma de comunicar las ideas y las prácticas y lo que significa ser una persona capaz o experta (Beetham \& Sharpe, 2013).

Algunos estudios han designado ciertos nombres a las jóvenes generaciones, tratando de reflejar sus características en relación con las tecnologías digitales. Así, encontramos nombres como Generación N o Generación en Red, definida así por Tapscott (1998), Generación D (digital) o Nativos Digitales, término acuñado por Prensky (2001), Generación Y (nacidos entre 1979 y 1994) (Hewlett, Sherbin, \& Sumberg, 2009) equivalente a lo que posteriormente Howe y Strauss (2000) definieron como Millenials (aquellos nacidos entre 1982 y 2005), y la más reciente, denominadas popularmente Generación Z o iGen (aquellos nacidos desde los años 2004 hasta la actualidad). Estos estudios consideran que todas las generaciones comparten una característica, y es la de ser competentes digitalmente. En cambio, existe una amplia discusión en torno a esta aseveración, encontramos resultados discordantes entre estudios (sobre la capacidad innata o no para usar tecnología en función del año de nacimiento, diferenciación de perfiles, evidencias contrarias, factores influyentes, etc.), como recogen Cabra-Torres \& Marciales-Vivas (2009) y Bautista Pérez, Escofet Roig, Forés Miravalles, López Costa, \& Marimon Martí (2013). Asimismo, existen diversos estudios que contradicen el aserto e incluyen 
matizaciones de otros factores que influyen en el nivel de competencia digital (Margaryan, Littlejohn, \& Vojt, 2011; Rodrígues, 2014; Rodríguez Rosell, Berlanga Fernández, \& Sedeño Valdellós, 2013). El hecho de nacer rodeados de tecnología no es un factor único para aplicar el término "competente digital", pues han de considerarse los aspectos culturales, personales, sociales, formativos, etc., de los individuos y colectivos que modelan esta competencia (Margaryan \& Littlejohn, 2008; Rodrígues, 2014). Por ejemplo, varios estudios comparten la idea de que los jóvenes presentan dificultades a la hora de seleccionar información relevante en la Web (Cabra-Torres \& Marciales-Vivas, 2009; Rodrígues, 2014), que constituye una de las competencias básicas de la competencia digital (European Commission, 2013a).

En cambio, como hemos recogido en el apartado 1.4, las demandas sociales y las orientaciones de las diferentes políticas internacionales y europeas, demandan que las TIC se integren de forma natural en la educación de las nuevas generaciones. Muchos de los profesores de las escuelas o de los centros de formación del profesorado pertenecen a generaciones más antiguas, a las que Prensky denomina "Inmigrantes Digitales" (Prensky, 2001), y que han tenido que adaptarse al uso de las TIC, ya que están ampliamente extendidas en todos los ámbitos de la sociedad, pero, por lo general, presentan mayores dificultades para adaptarse a ellas que las generaciones que las han adoptado de forma temprana. Por ello, resulta de vital importancia que el profesorado se actualice a través de formación continua en las nuevas demandas conceptuales y sociales que requiere la sociedad en la que vivimos inmersos.

Según Selwyn (2014, pp. 197-199) las repercusiones de internet en la educación y el aprendizaje pueden considerarse desde cuatro ángulos diferentes:

- Reduce las limitaciones físicas, espaciales, temporales, geográficas, y sin impedimentos sociales o materiales, que permiten a los sujetos tener oportunidades de aprendizaje y a medios educativos de alta calidad, favoreciendo la democratización del aprendizaje.

- Posibilita un aprendizaje socioconstructivo, permitiendo aprender con otros y acceder a fuentes de conocimiento teórico y práctico fuera de su entorno inmediato.

- Cambia la relación de los individuos con el conocimiento gracias a la conectividad que posibilita internet, surgiendo nuevas corrientes epistemológicas, tales como el "conectivismo" o la inteligencia distribuida. De este modo, los individuos pueden acceder a las fuentes de información especializada cuándo y como necesiten. 
- Profundiza en la individualización del aprendizaje, permitiendo personalizar sus experiencias de conocimiento atendiendo a sus características y necesidades personales, sin necesidad de amoldarse a las normas y expectativas de un sistema educativo.

En nuestros días estamos siendo testigos de cómo la disrupción digital en educación comienza a desbancar los modelos institucionalizados y tradicionales de educación de los siglos XIX y XX, y comienza a barajarse la idea de la implantación de modelos de educación desinstitucionalizada en los próximos años (Selwyn, 2014). Este tipo de desinstitucionalización podemos verla en las tendencias de lanzamiento de cursos online, MOOCs y plataformas que proveen recursos digitales de calidad, donde cualquier individuo puede formarse a través de un ordenador conectado en la red en cualquier área o concepto de su interés.

En el ámbito europeo, a pesar de estos avances tecnológicos y su adopción en todos los ámbitos de la sociedad, a nivel educativo, las TICs "no se aprovechan plenamente en los sistemas de educación y formación". "Un 63\% de los niños de 9 años de edad, no estudian en un centro adecuadamente equipado desde el punto de vista digital" y sólo entre un $20-25 \%$ "de los alumnos, tienen profesores que fomentan estas tecnologías" (Comisión Europea, 2013, p. 2). En la Educación superior, a pesar del potencial de las TICs, las utilizan como herramientas para su desarrollo profesional y para la preparación de las clases, más que para fomentar la adquisición de aprendizajes entre el alumnado (Jimoyiannis \& Komis, 2007; Mahdizadeh, Biemans, \& Mulder, 2008; Pynoo et al., 2012).

Masson y Udas (2009, pp. 258-259) establecen que el cambio educativo de la adquisición del aprendizaje a través de la red de forma pasiva y asíncrona a una forma centrada en la interacción, co-creación y relaciones sociales, ha llevado a los educadores a pensar más allá de los sistemas de gestión de contenido (CMS), comenzando a considerar nuevas herramientas y técnicas que mejoren las nuevas aproximaciones y liberen la creatividad. Los ejemplos más comunes integran tecnologías que contienen:

- Herramientas de autoría: blogs, wikis, foros de discusión (e.g., WordPress, pbWiki, JForum).

- Herramientas de comunicación: Mensajería instantánea, aplicaciones de telefonía, microblogging (e.g., G-talk, Hangout, Skype, Twitter).

- Repositorios: colección de archivos, compartición de contenido, distribución (EduTube, iTunesU).

- Herramientas de redes sociales (e.g., Facebook, Flick'r, Instagram). 
- Entornos virtuales (e.g., Croquet, SecondLife, SimCity, etc.).

La existencia de espacios en la red donde cualquier persona puede crear contenidos: páginas web, blogs, podcasts, wikis, servicios de vídeos, de fotografías, etc., está promoviendo la democratización de la creación y el consumo de la información (Beetham \& Sharpe, 2013).

Aún hoy es frecuente utilizar TICs enfocadas en el almacenamiento y la recuperación de información, pero los nuevos avances tecnológicos están llevándonos hacia un nuevo desarrollo epistemológico de la inteligencia artificial, que será capaz de generar conocimiento personalizado y contextualizado (Moravec, 2008a, p. 131).

\subsubsection{Principales paradigmas pedagógicos y su influencia en las TIC}

El término pedagogía hace referencia a estrategias de enseñanza. En otras ocasiones, el término pedagogía se utiliza para hacer referencia al proceso de aprendizaje desde la perspectiva de la enseñanza. Las teorías del aprendizaje, por otro lado, no son descripciones de la enseñanza, ni proporcionan un conjunto de instrucciones para su utilización en clase, sino que han de considerarse como aproximaciones filosóficas que permiten y facilitan el aprendizaje (McHaney, 2011). Las tres corrientes epistemológicas que se han aplicado de forma más extendida en la educación, y en la que podríamos englobar las diversas teorías del aprendizaje son: el conductismo, cognitivismo y constructivismo. Hoy en día, una cuarta teoría, el conectivismo, está ganando gran atención y está siendo cada vez más aceptada por la comunidad científica internacional (a pesar de que no todos la aceptan como un cuarto paradigma, si no que lo consideran una extensión del constructivismo). Esta teoría considera el aprendizaje dentro del contexto de la era digital (Siemens, 2010).

Las corrientes pedagógicas tienen influencia en la concepción de todos los elementos que contiene el hecho educativo: diseño de currículos y programas académicos, formas de enseñar al alumno, interacción con su entorno, evaluación y seguimiento, diseño de actividades, etc., y por tanto, influyen directamente en el diseño de los contenidos digitales educativos y espacios que los contienen. A continuación, recogemos las características generales que definen cada corriente educativa, y posteriormente, sus implicaciones en la digitalización de la educación: 


\section{A) Principales corrientes pedagógicas}

\section{Conductismo}

El conductismo o perspectiva asociacionista, cuyos máximos representantes teóricos son Watson ${ }^{9}$, Pavlov $^{10}$, Skinner ${ }^{11}$ y Thorndike ${ }^{12}$, tiene gran influencia en la educación superior, y varias pedagogías están enraizadas en esta influencia. La epistemología conductista considera que la verdad existe fuera de la mente humana, o de forma independiente a lo que un individuo crea o no, por lo que han de diseñarse métodos para alcanzar el conocimiento (Bates, 2015).

Skinner mostró las aplicaciones de su teoría en el desarrollo de máquinas de enseñar y para explicar la aplicación del lenguaje (Bartolomé-Pina \& Stefens, 2015, p. 95). A los conductistas les preocupan las conductas observables y medibles, que comporten cambios. Por ejemplo, los exámenes son la fuente principal de medida para los conductistas. Algunas teorías cercanas al conductismo son la instrucción directa 0 instructivismo, que representan la forma de pensar actual en la educación superior (Kim\&Alexrod, 2005). En la teoría instructivista, el aprendizaje no lo posee el alumno, si no que otro (normalmente, una persona), ha de enseñárselo. Es un aprendizaje centrado en el profesor, y se basa en los modelos que facilitan la transferencia de información del experto al novato. Los estudiantes los aprenden memorizando, repitiendo acciones, etc., pero este tipo de adquisición del conocimiento presenta limitaciones a la hora de aplicar los contenidos, relacionarlos, sintetizarlos, etc.

\section{Cognitivismo}

El cognitivismo surge como respuesta al conductismo. Sus principales representantes son Piaget ${ }^{13}$ (1964) (psicología genética), Ausubel14 $(1960,1977)$

9 Condicionamiento instrumental: se puede conseguir la asociación de una respuesta emocional a un estímulo neutral (Watson, 1913)

10 Condicionamiento clásico: las conductas son innatas e internas, y se modifican por la asociación de estímulo-respuesta (Pavlov, 1927)

11 condicionamiento operante: las conductas se cambian por el refuerzo externo ante la respuesta de un estímulo (Skinner, 1963, 2003)

12 conexionismo: el sujeto selecciona las mejores respuestas para los estímulos externos y las aprende

13 Piaget introduce diferentes etapas del aprendizaje de los niños atendiendo a las capacidades de pensamiento que tienen en cada una de ellas. Considera que los 
(aprendizaje significativo), Bruner (1977) ${ }^{15}$ (aprendizaje por descubrimiento) y Vygotsky $^{16}$ (1962) (su concepto de zona de desarrollo próximo). Bode, en 1929, sugiere que el conductismo es una simplificación del aprendizaje, y está extremadamente basada en el comportamiento, considerando que es una realidad mucho más compleja que involucra aspectos internos del individuo que dan como resultado cambios cognitivos (McHaney, 2011). Los cognitivistas consideran que las funciones psicológicas básicas: atención, percepción, memoria, y los procesos de metacognición, son los responsables de que el sujeto aprenda, incorporando la información que percibe mediante los diferentes canales, seleccionando la información relevante y reintegrándola con los conocimientos previos. El aprendiz es un sujeto activo y el responsable principal del aprendizaje, que aprende gracias a la guía de los "adultos" (profesores), quienes les dotan de los recursos apropiados para que puedan tener experiencias de aprendizaje. Las teorías más aceptadas del cognitivismo se basan en la taxonomía de Bloom (1956), que sugiere que existen diferentes niveles de adquisición de conocimientos: recordar, entender, aplicar, analizar y evaluar, y la reciente incorporación de un nivel más, crear nuevo conocimiento, propuesto por Anderson y Kratwhwol, (2000) (en Bates, 2015, pp. 4748).

\section{Constructivismo}

El constructivismo lleva al cognitivismo a un siguiente nivel, haciendo aún más énfasis en el individuo. Sus representantes son los teóricos del cognitivismo que evolucionan sus teorías, dotando de más importancia al rol del alumno en su

estudiantes incorporan conocimientos a sus esquemas previos a medida que integran nueva información.

14 Ausubel introduce la idea de aprendizaje significativo como oposición al aprendizaje memorístico. Considera que el estudiante aprende siendo expuesto a conceptos relevantes que el profesor selecciona, y el alumno integra con sus conocimientos ya adquiridos. Este autor critica el aprendizaje por descubrimiento.

${ }^{15}$ Bruner, precursor del constructivismo, a igual que Vygotsky, considera la interacción social juega un rol crucial en la adquisición del lenguaje y del conocimiento. El profesor proporciona los mecanismos e información necesaria, sin organizar, para que los alumnos, de forma activa, construyan su aprendizaje a través del descubrimiento.

${ }^{16}$ El concepto de zona de desarrollo próximo hace referencia al potencial de aprendizaje actual, teniendo en cuenta lo que el alumno puede hacer sin ayuda, su nivel de desarrollo actual, y lo que el alumno puede llegar a hacer a través de la guía y proporción de las experiencias adecuadas. 
aprendizaje a través de su interacción con el entorno (Vygotsky, Bruner, Piaget, Ausubel). Esta corriente considera el aprendizaje como la construcción de procesos en los que el aprendiz activamente construye nuevas ideas y comprensión conceptual basada en aprendizaje previo y las experiencias actuales. El aprendizaje tiene lugar mientras que los discentes reflexionan sobre las experiencias que adquieren en el mundo real. Dentro de este paradigma, los constructivistas sociales, que retoman las ideas escritas en los años 30 del siglo XX por Lev Vygotsky, consideran que el aprendizaje es construido mediante la interacción social entre individuos, a través del diálogo y la participación en actividades sociales, a partir de las fuentes existentes en su entorno; el aprendizaje es situado, está sujeto a su contexto sociocultural y es donde adquiere relevancia para el aprendiz. Esta perspectiva del aprendizaje se centra en que el aprendizaje está distribuido socialmente. Existen numerosas formas de manifestaciones constructivistas del aprendizaje: activo, autodirigido, experiencial, prácticas reflexivas, por descubrimiento, construcción del conocimiento, y aprendizaje-servicio. El factor común de estos tipos de aprendizaje es que el alumno experimenta para aprender, y que el rol del profesor es el de ser guía facilitador del aprendizaje (McHaney, 2011). El socioconstructivismo constituye un paradigma holístico, pues además de la interacción social, el conocimiento depende de las actitudes, emociones, valores y acciones (Beck \& Kosnik, 2006, p. 13). Esta teoría evoluciona hacia el construccionismo, teoría del aprendizaje creada por Saymour Papert' ${ }^{17}$ (1990), que considera que la construcción del aprendizaje es más efectiva cuando se crean artefactos o productos tangibles que se pueden compartir de forma pública.

\section{El conectivismo}

El conectivismo es una teoría reciente propuesta por George Siemens en 2004 (Cormier, 2008; Downes, 2009; Siemens, 2013), y criticada por muchos pedagogos (aún hoy no hay consenso sobre si este es un paradigma educativo nuevo o es una aplicación del constructivismo). Siemens sugiere que el aprendizaje, además de ser

17 Papert trabaja con Piaget, y adopta su concepción de que el aprendizaje es socialmente construido, pero en su teoría construccionista incorpora el valor de generar un producto visible para otros. Papert elabora esta teoría para comprender las formas en las que la tecnología entra en la sociedad (1990). El germen de su teoría es la participación en proyectos educativos donde los niños construían su aprendizaje elaborando artefactos usando tecnología (e.g., modelando una serpiente en un ordenador, utilizando conceptos físicos y matemáticos).(Papert \& Harel, 1991; Papert, 1990). 
responsabilidad del sujeto (como ocurre en la corriente constructivista social), tiene lugar a nivel social, donde el sujeto es un elemento clave.

Esta teoría se basa en características importantes derivadas de sus observaciones de la era digital. En primer lugar, dado que la información es abundante y evoluciona rápido, para aprender es importante la rápida evaluación y la habilidad para reconocer y sintetizar conexiones o patrones. En segundo lugar, cuando la información es escasa, es necesario recurrir a formas de aprendizaje más tradicionales. En el entorno de conocimiento abundante, la tecnología y las conexiones facilitan el aprendizaje. El aprendizaje se convierte en compartido, en la experiencia de la comunidad (McHaney, 2011).

La reciente emergencia de teorías del aprendizaje basadas en contextos en red, como la "heutagogia" y el "conectivismo", nos ayudan a entender que el aprendizaje consiste en establecer conexiones con ideas, hechos, personas y comunidades. Obviamente, la Red destaca en permitir a los usuarios encontrar y utilizar estas conexiones (T. Anderson, 2008, p. 49)

Siemens considera que los medios de comunicación, el lenguaje, la tecnología y los símbolos, son dispositivos que permiten al ser humano externalizar los conocimientos explícitos y tácitos para potenciar la construcción conjunta de conocimientos. Siemens (2006) propone varios principios del conectivismo, de los que abstraemos sus implicaciones educativas:

- El aprendizaje y el conocimiento descansan en la diversidad de opiniones

- El aprendizaje es un proceso de conectar nodos especializados o fuentes de información

- El aprendizaje puede residir en dispositivos no humanos.

- La capacidad de saber más, es más crítica que lo que se sabe actualmente.

- Generar y mantener conexiones es necesario para facilitar el aprendizaje continuo

- La habilidad de ver las conexiones entre campos, ideas y conceptos, es una habilidad principal.

- La actualización del conocimiento es la pretensión de todas las actividades de aprendizaje

- La toma de decisiones es un proceso de aprendizaje. Elegir qué aprender y el significado de la información que se recibe, se perfila mediante las lentes de una realidad cambiante

Una de las materializaciones de esta teoría tuvo lugar en uno de los primeros MOOC (Curso Online Abierto Masivo), creado por Stephen Downes y George 
Siemens en 2008 en la Universidad de Manitoba (Canadá), donde los usuarios comenzaron a establecer conexiones y aprendizaje en diferentes espacios, de forma espontánea:

El éxito de nuestro primer curso - CCK08 - no estaba previsto. Nos dimos cuenta rápidamente de que el curso cobraba vida por sí mismo, a medida que los participantes creaban áreas de encuentro de Second Life, Google Groups para discutir ciertas áreas temáticas, grupos de estudio para personas de localizaciones similares, grupos de Facebook, y demás (McAuley, Stewart, Siemens, Cormier, \& Creative Commons, 2010).

\section{B) Los principales paradigmas educativos y evolución de su adopción gracias al desarrollo de las TIC}

Según Becta, 2007; Carmichael, 2007; Department for Education and Skills, 2005; Underwood et al., 2010; Watson, Cox, \& Johnson, 1993 (en Loveless, 2011), el contexto social, económico y político de las TIC ha influido en las estrategias y recursos destinados a la educación, desde la provisión de equipamiento TIC en las escuelas, y el diseño de las escuelas del futuro, hasta la promoción de la investigación en tecnologías para la mejora del aprendizaje; además, ha repercutido en la continuidad del desarrollo profesional de los docentes. Kress y Pachler (2007) consideran que las tecnologías digitales y los medios de comunicación han configurado no sólo los contextos sociales y culturales, si no también las aproximaciones y los entornos para el aprendizaje (en Loveless, 2011, p. 305). De este modo, creemos conveniente perfilar cómo el desarrollo tecnológico ha influenciado en las prácticas y modelos educativos desde la aparición de los primeros ordenadores:

En la era de los ordenadores, el modelo conductista era el máximo referente desde los años 60-70 hasta mediados de los 80 , donde los programas informáticos utilizados con más frecuencia eran los de repetición y práctica, que potenciaban aprendizajes mecánicos y repetitivos (Benito, 2009; Trillo Miravalles, 2011). Desde finales de los 80 hasta inicios de los 90 , el cognitivismo (que sirve de modelo para la creación de inteligencia artificial) comienza a influir a nivel tecnológico mediante la enseñanza asistida por ordenador ${ }^{18}$ creando software y hardware para cursos de

18 El término EAO (Enseñanza Asistida por Ordenador, en inglés: Computer Assisted Instruction), comienza a utilizarse en los años 60 en Estados Unidos, partiendo de los métodos de enseñanza programada propuestos por Skinner, pero no es hasta los años 80 90 cuando tiene una repercusión real más extendida en los centros educativos. 
formación que permitieran la capacidad del usuario para dialogar, intermediar o ejercer un cierto control sobre el ordenador (Bartolomé-Pina \& Stefens, 2015; Trillo Miravalles, 2011, p. 2). Los cognitivistas consideran que los procesos mentales básicos pueden replicarse en máquinas. Esta concepción de mente como una máquina, les lleva a diversos desarrollos de enseñanza apoyada por tecnología, como: sistemas de tutoría inteligente, inteligencia artificial, objetivos de aprendizaje predeterminados (a través del análisis y desarrollo de diferentes tipos de actividades cognitivas), aprendizaje basado en problemas y diseño instruccional (Bates, 2015, p. 49).

La aparición de Internet a principios de los años 90 y su expansión y crecimiento de usuarios durante esa década, promueve la aparición de las primeras redes, la información comienza a democratizarse (Benito, 2009), y ya no sólo los profesores y las universidades son fuente de saber. En esta época encontramos las primeras experiencias de comunidades de práctica online (Lave \& Wenger, 1991), aprendizaje colaborativo apoyado por ordenador (Koschmann, 1996), redes de construcción del conocimiento (Scardamalia \& Bereiter, 1993), clases virtuales (Hiltz, 1994) y redes de aprendizaje (Harasim et al.1995) (en Harasim, 2006, p. 84). Las TIC potencian el compromiso activo del alumno, su participación, interacción, retroalimentación y conexión con el entorno real. Las TICs evolucionan enormemente en esta década, pero sus aplicaciones formativas tienen poca repercusión en la educación (Benito, 2009). A finales de los 80 y principios de los 90, existían dos tendencias educativas (Mayes \& de Freitas, 2013):

- una tendencia de utilizar prácticas basadas en tecnología que replicaban los modelos instructivistas del aprendizaje (centraban la importancia de la investigación en los métodos para que los profesores pudieran transmitir información y contenidos mediante tecnología de forma eficiente a los alumnos),

- mientras que la línea de la comunidad investigadora se centraba en la importancia del aprendizaje basado en tareas y el contexto social. Desde el desarrollo de la web, estas dos tendencias han convergido en la comunicación como clave que permite la construcción (Mayes \& de Freitas, 2013, p. 22).

De acuerdo con lo comentado anteriormente, autores como Bates (2015, p. 44), hacen alusión a la vigencia de modelos tradicionales de enseñanza en contextos de educación superior, en los que las clases magistrales y los libros de texto son la principal fuente de transmisión del conocimiento, y el rol del profesor es el de 
secuenciar los contenidos y actividades de aprendizaje, preparar la evaluación y controlar qué y cómo aprenden los estudiantes.

A finales de los años 90 el aprendizaje se flexibiliza, se utiliza material multimedia interactivo (disquetes, CD-ROM), aparecen aplicaciones de comunicación por Internet (Benito, 2009; J M Duart \& Sangrá, 2000). Es la fase de la enseñanza virtual, comienzan a expandirse los campus virtuales que permiten la gestión de material educativo, facilitan las interacciones síncronas y asíncronas entre alumnos y estudiantes y comienzan a construirse escenarios de enseñanza virtuales (especialmente en Educación Superior) (Benito, 2009). Los entornos virtuales educativos aportan flexibilidad e interactividad; tienen el potencial de permitir la vinculación a una verdadera comunidad de estudiantes mediante foros, tableros de anuncios, actividades, etc.; y permiten acceder a materiales de estudio, fondos de recursos, material hipervinculado, etc. (J M Duart \& Sangrá, 2000).

Los avances tecnológicos de esta época favorecen el comienzo de la difusión del aprendizaje electrónico a través de los medios digitales (e-learning) ${ }^{19}$. El elearning puede definirse como el uso de Internet para acceder a recursos de aprendizaje, interactuar con contenidos y otros estudiantes, con el fin de obtener apoyo en el proceso de aprendizaje para adquirir conocimiento, construir significado individual y crecer a través de la experiencia de aprendizaje" (Ferran \& Minguillón, 2011, p. vii). El e-learning ofrece dinamismo, flexibilidad y un mayor abanico de opciones relativas al aprendizaje, atendiendo a los espacios (físicos y tecnológicos) y al tiempo (síncrono o asíncrono), así como a la personalización y adaptación de las experiencias de aprendizaje a las peculiaridades, necesidades y preferencias de cada individuo, tan importantes para la sociedad actual. El e-learning ha promovido la creación de entornos de aprendizaje inteligentes que posibilitan la adopción de métodos de enseñanza y asesoramiento personalizados, que no eran viables en el pasado, permitiendo una enseñanza centrada en el estudiante (Collis \& Moonen, 2011; Isaías, Spector, Ifenthaler, \& Sampson, 2015).

En 2002, con la aparición de la Web 2.0., y la presencia del constructivismo como modelo imperante en los contextos educativos, comienzan a tener mayor repercusión educativa las tecnologías. Los constructivistas piensan que el cerebro

19 El término e-learning fue creado por Aldo Morri en 1997 en su artículo "A bright future for distance learning: One Touch/Hughes alliance promotes interactive 'e-learning' service", a pesar de que se atribuye a Jay Cross, quien lo utiliza en 1998 (Big Dog Little Dog \& Knowledge Jump, 2010). 
humano tiene mucha más plasticidad, adaptabilidad y complejidad que los ordenadores, y que poseen características únicas: emoción, motivación, voluntad, etc., por lo que han de desarrollarse tecnologías que propicien el aprendizaje reflexivo de forma humana, más que tratar de adaptar el cerebro humano a las restricciones que imponen los software conductistas (Bates, 2015, p. 53). Internet permite la interacción social de los estudiantes en contextos virtuales, se extiende el uso y la generación de herramientas de comunicación y dispositivos para su acceso, cada vez hay más usuarios conectados a Internet. Los recursos digitales comienzan a proliferar, en gran medida, debido a que los usuarios ya no son sólo consumidores de la información, si no que las herramientas TIC permiten la generación de contenidos y conocimientos (Benito, 2009).

Podemos considerar que actualmente el constructivismo es el paradigma más vigente en educación, tanto en los espacios físicos como en los virtuales. Algunos de los métodos pedagógicos que emplea el constructivismo son la reflexión, seminarios, foros de discusión, trabajo en grupos pequeños, y proyectos, etc., que se ven favorecidos por el aprendizaje colaborativo apoyado en ordenador y las comunidades de práctica online (Bates, 2015). El aprendizaje se concibe como un proceso social y, especialmente, en el ámbito de la cultura digital, las comunidades de usuarios conforman una nueva ecología de aprendizaje caracterizada por una alta motivación hacia la participación y la colaboración (Valverde Berrocoso, Fernández Sánchez, \& Garrido Arroyo, 2015, p. 5). Cada vez se da más importancia al aprendizaje centrado en cada individuo, mediado por la guía del profesor, y a la interacción social con sus iguales a través del desarrollo de trabajos y proyectos colaborativos y cooperativos desde las diferentes materias de la Educación Superior. La proliferación de portales educativos y materiales para el aprendizaje para las diferentes áreas de Educación Superior, y por tanto, para la formación del profesorado, es un hecho que aún hoy sigue en expansión. Las herramientas tecnológicas de estos portales permiten que el aprendizaje pueda ser socialmente situado, de formas que nunca antes fueron posibles. [...] Internet proporciona a cada curso de cada institución su potencial de alcance global (Mayes \& de Freitas, 2013, p. 28).

En los últimos 10-15 años, la tecnología ha influenciado enormemente en las actividades principales de enseñanza de todos los niveles educativos, y estamos asistiendo a un momento en el que las tecnologías están pasando de ser utilizadas colateralmente a ser la base de la formación, como puede apreciarse en iniciativas en expansión como: 
- Aprendizaje completamente online (fully e-learning): cursos en los que se proporciona formación a los estudiantes gracias al apoyo de las TIC, y se reconoce su participación mediante créditos. Las inscripciones en cursos online han crecido un $15-20 \%$ al año durante los últimos 15 años en Norteamérica, mientras que las inscripciones a cursos presenciales en los campus, crecen un 2-3\% anualmente (Bates, 2015, p. 31).

- Blended Learning (Aprendizaje híbrido y mixto, combinación de aprendizaje online y presencial): consiste un aprendizaje en el que se emplea la asistencia presencial y las plataformas tecnológicas (por ejemplo, sistemas de gestión del aprendizaje). Hoy en día, un ejemplo, famoso y en auge, de aprendizaje híbrido podemos apreciarlo con las "Flipped classrooms 20", donde los estudiantes revisan los materiales de aprendizaje de contenidos en casa (para lo que los profesores crean o seleccionan material y los alojan en plataformas 0 medios digitales), y se aprovechan las horas de presencialidad para la interacción con otros compañeros trabajando y practicando los conceptos aprendidos (este tipo de prácticas potencian el aprendizaje desde la visión socioconstructivista.

- Aprendizaje de libre acceso (Open learning): durante los últimos 10 años, numerosas iniciativas han potenciado este tipo de aprendizaje, como los libros de texto de libre acceso (open textbooks) o los recursos educativos de libre acceso (OER) (Bates, 2015, p. 32), que pueden modificarse y adaptarse para su reutilización en otros contextos diferentes para los que fueron diseñados, traducirse a varios idiomas, etc.

- MOOCs: Cursos Online Masivos de libre acceso, ofrecidos por muchas universidades a nivel mundial. En 2008 se crea el primer MOOC como tal, y a partir de entonces se ha producido una fuerte expansión e interés por la comunidad investigadora y educativa hacia ellos. Estos cursos, al ser masivos, generalmente presentan retos para realizar una evaluación y seguimiento de los alumnos, por lo que en numerosas ocasiones utilizan estrategias cognitivistas, conectivistas y constructivistas como peer-review; y en otras ocasiones emplean estrategias más conductistas (como comprobar

20 La Red de Flipped Learning ("aprendizaje volteado") definen el término "flipped learning" como una aproximación pedagógica en el que la instrucción directa se desplaza desde el espacio de aprendizaje grupal al espacio individual de aprendizaje, y el espacio grupal se transforma en un entorno de aprendizaje dinámico, interactivo, donde el educador guía al estudiante a medida que aplican conceptos y se involucra de forma creativa en la asignatura (FLN, 2014) 
la adquisición de los conceptos mediante test que proveen de forma automática e inmediata una revisión) ${ }^{21}$. Gracias a la expansión de iniciativas como los MOOCs, SPOCs (Cursos Online Privados Pequeños), OCW (OpenCourseWare), etc. se están haciendo más conocidos ganando confianza por parte de los estudiantes; además, las universidades, prevén un cambio en los modelos de sostenibilidad económica futura de estas instituciones, por lo que la preocupación por adaptarse a las nuevas demandas sociales se está viendo reflejada en la oferta cada vez más fuerte de este tipo de formación.

El progreso tecnológico garantiza a los estudiantes la posibilidad de perseguir sus objetivos de aprendizaje de forma independiente y proactiva. Los servicios basados en web semántica y el desarrollo ontológico, son un primer medio para mejorar las herramientas educativas, mejorar la gestión del aprendizaje y generar objetos de aprendizaje reutilizables. Las tecnologías sociales continúan promoviendo y apoyando los OER, la edición y compartición de contenido digital, especialmente en su forma de comunidades de aprendizaje (Isaías et al., 2015).

En definitiva, el rol de las tecnologías en el diseño de entornos de aprendizaje, y de entornos de acceso, creación y compartición de contenidos y de conocimiento, se ha visto potenciado por el reconocimiento de la comunidad científica de los beneficios y la necesidad de las teorías constructivistas, socioconstructivistas y las más recientes, las conectivistas, aplicando sus principios para dar respuesta a las demandas de la sociedad actual. Este tipo de teorías educativas promueven el aprendizaje activo, la construcción y mejora del conocimiento, la interacción social, el debate, la reflexión, etc., a través de la colaboración de comunidades en entornos virtuales que pueden alcanzar, incluso, una extensión global. Hemos de destacar el

21 El grupo de investigación GSIC-EMIC, actualmente está participando en el proyecto RESET (Reformulando EcoSistemas Escalables educaTivos), financiado por la Dirección General de Investigación Científica del Ministerio de Economía y Competitividad de España. El proyecto pretende reformular los MOOCs y SPOCs (Cursos online Pequeños Privados), tratando de dar respuesta a las limitaciones que presentan en cuanto a los actores implicados en los cursos, las pedagogías que se utilizan, y los contextos en los que se da el aprendizaje. De este modo, el proyecto pretende desarrollar experiencias pilotos en contextos de educación formal y no formal, utilizando pedagogías activas, teniendo en cuenta la evaluación basada en competencias, fomentando la individualización de la enseñanza y orquestando aproximaciones de flipped-classroom en contextos de "blendedlearning" (Delgado Kloos, 2014). 
rol de las comunidades de usuarios en el aprendizaje como proceso social, especialmente en el ámbito de la cultura digital.

En la siguiente llustración 2 representamos de forma cronológica la adopción de las tecnologías educativas y los paradigmas educativos imperantes durante los últimos 45 años. 
Ilustración 2 Paradigmas Educativos y TICs en Educación Superior. Elaboración Propia

\section{Paradigmas educativos y TICs en Educación Superior}
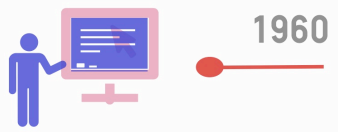

En la era de los ordenadores el modelo CONDUCTISTA era el máximo

referente El cognitivismo sirve de modelo para la creación y perfeccionamiento de la inteligencia artificial.

Aparición de Internet

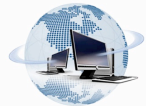

Aparición de las primeras redes

En Educación Superior, sigue imperando el modelo conductista:

- Profesor transmisor

- Medir resultados

En investigación se potencia el modelo Cognitivista

\section{Finales 90s}

Enseñanza virtual

$$
\text { Aparición Web } 2.0
$$

2002

EI CONSTRUCTIVISMO es el modelo imperante en los modelos educativos

\section{Doble rol de usuarios: productores y consumidores, prolifera el número de recursos en la Red}
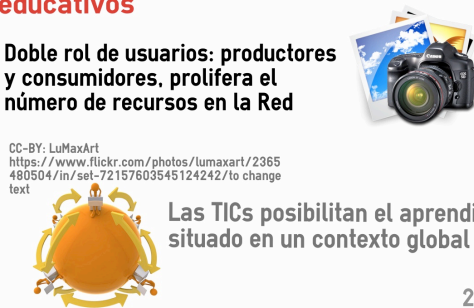

$$
\text { Las TICs posibilitan el aprendizaje }
$$
situado en un contexto global

Conectivismo, ¿Nuevo paradigma educativo? $\begin{array}{ll}\begin{array}{l}\text { Aprendizaje mecánico y } \\ \text { repetitivo }\end{array} & \begin{array}{l}\text { Programas de repetición y } \\ \text { práctica }\end{array}\end{array}$
1985 El COGNITIVISMO comienza a influir a nivel tecnológico
Programas que permiten interacción activa del usuario

Aprendizaje basado en problemas

Diseño instruccional

Objetivos de aprendizaje predeterminados

Flexibilización e Interactividad del Aprendizaje

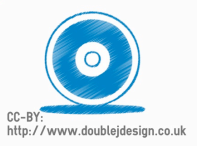

Mayor repercusión educativa de las TIC

Interacción Social de Estudiantes en contextos virtuales

Uso de CSCL y Comunidades de

práctica para apoyar el

aprendizaje individual en el

contexto social

Importancia del

Aprendizaje Social:

reflexión. seminarios.

trabajo en pequeños

grupos, proyectos

Aprendizaje completamente online

Aprendizaje Híbrido y mixto

Open Learning

MOOC y Cursos online

El aprendizaje es responsabilidad del sujeto

y tiene lugar a nivel social, donde el sujeto es

un elemento clave
Software y Hardware para cursos de formación

ฮั Enseñanza asistida por ordenador

$\frac{\pi}{6}$ Sistemas de tutoría inteligente

Cursos universitarios online

Comunidades de práctica online

峞 CSCL

Redes de construcción del conocimiento

Uso de material multimedia interactivo

Aplicaciones de comunicaciones por Internet

Portales virtuales

Herramientas para la Comunicación síncrona y asincrona con estudiantes y profesores

Incremento de usuarios conectados a Internet

Extensión del uso y generación de herramientas de comunicación y dispositivos

Proliferación de Portales educativos

Proliferación de sistemas de Gestión del Aprendizaje: PLEs, LMS, VLE MUVE, etc.

La comunidad OER sigue en expansiónCreative Commons

Proliferación de redes sociales y comunidades online

Knowmads 


\subsection{El contenido digital educativo}

El contenido digital hace referencia a cualquier pieza de información disponible en la red, que puede ser descargada o distribuida en medios electrónicos, tales como un artículo, una canción de Spotify, un e-book, etc. Hoy en día cualquier usuario de internet tiene el potencial de ser creador de contenido digital (ya sean tweets, posts de blogs, comentarios en foros, vídeos, e-books, actualizaciones de estado en Facebook, etc.) (Mullan, 2011).

Para que los contenidos digitales puedan ser reutilizados por otros usuarios, tras su creación, éstos deben ser descritos, almacenados y ser fácilmente accesibles por diversos usuarios. Este proceso puede realizarse de forma manual, automática (gracias a software que etiquetan los datos si están basados en estándares conocidos) o mediante una combinación de ambos procedimientos (incorporando de forma automática las descripciones básicas de metadatos que siguen esquemas estandarizados y enriqueciendo estos en base a estructuras más complejas y adaptadas a la comunidad concreta que utilice el contenido digital) (Bates, 2011). El material puede ser ofrecido de forma gratuita o mediante licencias que involucran algún tipo de pago. Hoy en día la organización "Creative Commons" proporciona diferentes tipos de licencias para proteger la propiedad intelectual y el uso del material de acceso libre, proporcionando alternativas al "Copyright" (Mullan, 2011).

En muchas ocasiones las comunidades de formadores profesores actúan como consumidores de contenidos digitales y no tanto como productores de los mismos. Para incentivar la creación de contenido digital, las instituciones deben ofrecer a los individuos que contribuyen algún tipo de refuerzo, no necesariamente económico: reconocimiento profesional de sus contribuciones, formación gratuita para desarrollar materiales digitales de aprendizaje, asistencia técnica y educativa, financiación para investigación o reducción de la carga docente. Otra posible estrategia para incentivar la creación y compartición de material educativo, podría ser la consideración del historial de uso de sus recursos para promocionar en su posición docente (Bates, 2011).

Para asegurar la calidad del contenido, las instituciones y portales que ofrecen material educativo deben proporcionar mecanismos de evaluación del material, tales como considerar la autoría y reputación de los autores, la puntuación media del 
recurso, las evaluaciones cualitativas de otros usuarios (tal y como apreciamos en MERLOT ${ }^{22}$ ), etc. (Bates, 2011).

\subsubsection{Evolución de los contenidos digitales educativos}

La idea de compartir contenidos educativos digitales es casi tan antigua como la propia informática. Ya en los años 60 , los investigadores comenzaron a describir cómo "las unidades de aprendizaje podían hacerse más compactas y combinarse, como las partes estandarizadas del Mecano (juego de construcción) en una gran variedad de programas personalizados para cada alumno (Gibbons et al., 2002; en D. A. Wiley, 2008, p. 346). Ted Nelson, en los años 60, acuña el término hipertexto, creando un vocabulario y un catálogo de conceptos y aproximaciones cercanas a lo que conocemos hoy en día como objetos de aprendizaje (Hodgins, 2002). Fue la primera vez que se contempló la reutilización de unidades de información, y que fue retomada en los años 90 , con la aparición de internet.

Le sucede el término "objetos de aprendizaje", acuñado por Hodgins en 1994 (D. A. Wiley, 2002). Hodgins (2002), escribe un artículo visionario sobre el futuro de los objetos de aprendizaje, asegurando que son los elementos fundamentales de un nuevo modelo conceptual para la creación y distribución del contenido. Los objetos de aprendizaje son materiales que están descritos por metadatos que proporcionan información sobre las propiedades básicas y el uso del recurso. Hodgins manifiesta la importancia de trabajar en la estandarización universal de los metadatos de objetos de aprendizaje para cada área, con el fin de favorecer la creación de sistemas tecnológicos avanzados que aprendan y permitan la personalización de la enseñanza congregando objetos de aprendizaje en unidades mayores, adaptadas a las necesidades y preferencias de cada individuo.

Otra tendencia que comienza a vislumbrarse desde 1998, gracias a que David Wiley comienza a hablar sobre "contenidos abiertos" (open content), es la del movimiento de los OER. Wiley crea este término en el contexto educativo, a pesar de que se extiende rápido a los usuarios de internet. Empieza a entenderse que el

22 MERLOT (Multimedia Educational Resource for Learning and Online Teaching - en español, Recurso educativo multimedia para la enseñanza y el aprendizaje online): http://www.merlot.org es un portal que integra materiales de diversas áreas de la educación superior. Es creado en 1997, mediante un programa de "California State University System", en colaboración con instituciones educativas, sociedades profesionales y empresas (California State University, 2012). 
open source/open software puede aplicarse al campo de los contenidos. En 2001, Larry Lessig y otros fundan Creative Commons, contribuyendo al mundo de los OER mediante el incremento de la credibilidad de las licencias abiertas para la comunidad de "contenidos abiertos". En ese mismo año, 2001, el MIT anuncia la iniciativa OpenCourseWare (publicando todos los cursos del MIT en Internet mediante libre acceso), constituyendo un ejemplo de compromiso con el movimiento OER a nivel institucional, promoviendo la creación de proyectos similares y presentando la "marca" MIT al movimiento. En 2002, la UNESCO celebra un fórum compuesto de algunas de las personas que deseaban desarrollar juntos un recurso educativo disponible para toda la humanidad, a lo que llamaron "OER" (D. A. Wiley, 2006).

\section{A) Concepto de Contenido digital}

Morais, Miranda y Alves (2014) recopilan definiciones de contenido digital de varios autores, de los que abstraemos que: los contenidos digitales educativos son entidades 0 artefactos digitales diseñados con una intencionalidad educativa (para apoyar el proceso de enseñanza/aprendizaje, ayudar a los agentes que intervienen en la educación, etc.). Estos se pueden presentar en diferentes formatos técnicos (vídeo digital, audio digital, software multimedia, sitios web, sistemas de gestión del aprendizaje, programas de simulación, discusiones online, bases de datos en línea, etc.). Los contenidos digitales, al igual que los objetos de aprendizaje, se describen con metadatos para facilitar su recuperación y reutilización en otros contextos.

El concepto de contenido digital educativo es mucho más amplio de lo que era hace años, e incluye todos los recursos que utilizan los estudiantes y profesores en un entorno virtual, ya sean objetos de aprendizaje, micromundos, unidades didácticas, vídeos, artículos, recursos educativos abiertos (OER), etc. A continuación profundizaremos en los dos conceptos más frecuentes a la hora de hablar de contenidos digitales en la actualidad.

\section{B) Objetos de Aprendizaje (Learning Objects -LO)}

Quizá la forma más común de contenido digital educativo sean los llamados objetos de aprendizaje, de los que existen varias definiciones, así como varias expresiones que hacen referencia al mismo concepto:

- IEEE define objeto de aprendizaje como una entidad, digital o no digital, que puede ser utilizada para el aprendizaje, la educación o la formación (IEEE, 2002 b, p. 3).

- En 2002, Wiley definió por primera vez objeto de aprendizaje como un recurso digital que puede ser reutilizado para mediar el aprendizaje; y recurso 
educativo abierto como un objeto de aprendizaje que puede ser utilizado, reutilizado, adaptado y compartido de forma gratuita (2008, p. 345).

- Mason y Rennie (2006, pp. 71-73) describen los objetos de Aprendizaje (LOs) u objetos de aprendizaje reutilizables (RLOs) como pequeñas unidades de aprendizaje. Presentan una serie de características que denotan que son una nueva forma de pensar en relación al aprendizaje: son independientes, pueden ser estudiados de manera individual y no suelen hacer referencia a otros objetos de aprendizaje; son reutilizables en múltiples contextos diferentes, además pueden ser incorporados en cursos completos y combinados con contenido tradicional; por último, otra característica que define su idiosincrasia radica en que tienen asociados metadatos 0 metaetiquetas con información descriptiva sobre los objetos de aprendizaje, de modo que puedan ser buscados en repositorios de objetos de aprendizaje.

A pesar de las múltiples definiciones existentes de objeto de aprendizaje, todas ellas concuerdan que:

- están disponibles en formato digital,

- se describen mediante metadatos, de acuerdo a estándares,

están destinados a ser reutilizables, desmenuzando los recursos en pequeñas unidades que puedan ser reutilizadas de forma individual (Minguillón, Sicilia, \& Lamb, 2011, p. 31).

Este tipo de contenidos educativos pueden ser de pago o gratuitos, y estar construidos bajo cualquier tipo de licencia (ya sea copyright, Creative Commons, etc.), a diferencia del siguiente tipo de contenidos que presentamos a continuación, que sólo admiten licencias de libre uso.

\section{C) EI movimiento OER (Open Educational Resources)}

Hoy en día el movimiento más popular dentro del campo de los contenidos digitales es el de los Recursos Educativos de libre acceso, a los que denominaremos OER en este documento. Una definición consensuada y propuesta por UNESCO los define de la siguiente manera:

Los recursos educativos de libre acceso son materiales de enseñanza, aprendizaje o investigación que se encuentran en el dominio público o que han sido publicados con una licencia de propiedad intelectual que permite su utilización, adaptación y distribución gratuitas (UNESCO, 2014b). 
Capítulo 1. Los contenidos digitales en el campo de la formación del profesorado

La OECD complementa esta definición describiendo qué puede ser un OER, desde pequeños recursos aislados de aprendizaje hasta módulos de contenido 0 cursos completos:

- contenido de aprendizaje: cursos completos, lecciones de cursos, módulos de contenido, objetos de aprendizaje, colecciones y revistas científicas

- herramientas: software para fomentar el uso, reúso y distribución de contenido digital [...].

- recursos de implementación: licencias de propiedad intelectual para promover la publicación abierta de material, principios de diseño de buenas prácticas y localización del contenido (Hylén, 2006, p. 2).

\section{C.1 Origen y evolución de los OER}

Una de las instituciones impulsoras de este movimiento fue el MIT (Massachussetts Institute of Technology), que en 2001 pone a disposición pública en Internet casi todos sus cursos (Open Courseware ${ }^{23}$ ), creando el precedente para que otras instituciones siguieran la iniciativa. El término OER se crea en 2002, cuando la UNESCO se reúne para evaluar el impacto de los Open Courseware en la educación Superior en el primer foro mundial sobre recursos educativos de libre acceso (Mello \& Caine, 2012). En este momento sugirieron definir los OER como: la provisión de objetos educativos de libre acceso, mediante las tecnologías de la información y la comunicación, para la consulta, utilización y adaptación por parte de una comunidad de usuarios para propósitos no comerciales (UNESCO, 2002b). Como estrategia para la potenciación de este movimiento, la UNESCO creó un espacio wiki para generar discusión y colaboración en torno a los OER, que posteriormente trasladó a un portal donde gestionaba, a la vez, otras comunidades (International Council for Open and Distance Education, 2011).

23 Open Courseware hace referencia a generar la mayor parte de los cursos accesibles de forma gratuita, a través de la Web e Internet. El "Courseware" puede incluir: material para exposiciones, referencias y lecturas, simulaciones, experimentos y demostraciones, todo ello disponible para ser utilizado 0 adaptado por facultades 0 individuos de cualquier parte del mundo (para adecuarlo a los contextos culturales y pedagógicos), sin costes y para su uso no comercial (UNESCO, 2002a, 2002b). No existe una traducción precisa en español de "Courseware", pero podríamos decir que es un juego de palabras entre la combinación "course", "software"; e incluso, podríamos pensar en el término "warehouse" (almacén), por lo que courseware, en español, podríamos entenderlo como "almacén de cursos basados en TIC". 
El interés por los OER seguía ganando importancia y redefinición, y cada vez más profesionales e instituciones estaban interesados en este movimiento. En 20102011, un conjunto de instituciones ${ }^{24}$ conforman un consorcio desarrollando el proyecto OPAL (Open Educational Quality - Calidad de la Educación Abierta y de Libre Acceso) (OPAL, 2011). En la primera reunión de proyecto de OPAL determinan la intención de extender el término OER más allá del acceso a los recursos, gestando el término "Open Educational Practices" -OEP- (prácticas educativas abiertas). Este equipo define las OEP como prácticas que apoyan el uso, reúso y producción de OER de alta calidad mediante políticas institucionales, promueven modelos pedagógicos innovadores y respetan y empoderan a los estudiantes como coproductores en su camino de aprendizaje a lo largo de la vida. La implementación de las prácticas educativas abiertas requiere que el conjunto de elementos que relacionados con los $\mathrm{OER}^{25}$ tomen las medidas necesarias para ser llevadas a cabo de forma efectiva. Este consorcio refina su definición en un informe de 2011, donde acuerdan que:

Las Prácticas Educativas Abiertas constituyen el rango de prácticas en torno a la creación, uso y gestión de los Recursos Educativos Abiertos, con la intención de mejorar la calidad y la innovación educativa (OPAL, 2011, p. 4).

Atendiendo a estas concepciones y a la importancia que el movimiento OER ha ganado durante los últimos quince-veinte $\operatorname{años}^{26}$ (si tenemos en cuenta los precedentes de OER), hemos presenciado un creciente incremento del número de portales educativos que ofrecen servicios tecnológicos para la compartición, reutilización y utilización de contenidos digitales y OER.

24 UNESCO, The Open University de Reino Unido, ICDE, UNESCO, the Open University de Reino Unido, coordinados por la universidad de Duisburg-Essen, Germany

25 Los elementos que interaccionan en relación a los objetos educativos abiertos son: los diseñadores de políticas, gestores y administradores de las organizaciones y profesionales de la educación y estudiantes

${ }^{26}$ En http://oermap.org/home/1900-2/ puede accederse a un mapa mundial que recoge las principales iniciativas y proyectos en torno a los OER en el mundo, creado por el Institute of Educational Technology de la Open University de Reino Unido, en colaboración con Hewlett Foundation.

En http://www.sparc.arl.org/resource/list-oer-projects-policies puede accederse a un listado de proyectos y políticas de OER de Canadá y Estados Unidos. 


\section{C.2 Ventajas y retos de los OER}

Los OER manifiestan ciertas ventajas pedagógicas -por ejemplo, apoyan el aprendizaje colaborativo en las comunidades en las que se utilizan (Dimitriadis, McAndrew, Conole, \& Makriyannis, 2009) -y sociales - democratizan el acceso a la educación - que han captado el interés de instituciones internacionales tales como el Instituto de Tecnologías de la Información en Educación de la UNESCO27, la Open University de Reino Unido (mediante iniciativas como OER Hub ${ }^{28}$ y Tessa ${ }^{29}$ ), el programa de OERs del centro JISC ${ }^{30}$ y ONGs (e.g., William \& Flora Hewlett Foundation ${ }^{31}$ y University of the People ${ }^{32}$ ) que han fomentado la proliferación de proyectos y plataformas..

Existen grandes expectativas sobre el movimiento OER, debido, en parte a: a) el éxito del movimiento de software libre y abierto y a la consideración del potencial de éxito que podría tener una práctica similar aplicada a la reutilización de contenidos educativos; b) la consideración de que la reutilización de contenidos podía reducir los costes y c) el impacto y percepción de éxito de iniciativas de OER llevadas a cabo por organizaciones prestigiosas como OpenCourseWare (de MIT) y Open Learn (de La Open University de Reino Unido (Dimitriadis et al., 2009, p. 200):

La expansión de los OER ha sido promovida gracias a las evidencias de investigación que reportan los beneficios que repercuten en la educación gracias a la utilización de estos recursos, entre los que podemos destacar que:

- Posibilitan acceder a los mejores posibles recursos (Hylén, 2006, p. 6) de universidades de gran calidad (e.g., Open Yale Courses, JHSPH OpenCourseWare, MIT OpenCourseWare).

- Permiten disponer materiales y oportunidades de aprendizaje más abiertos y flexibles (Hylén, Damme, Dirk, Mulder, \& D’Antoni, 2012; Hylén, 2006).

- Proporcionan acceso gratuito cursos y recursos globales de gran calidad tanto a instituciones educativas, servicios de contenido, y usuarios finales como:

\footnotetext{
27 http://iite.unesco.org/

$28 \mathrm{http}: / /$ oerhub.net/

${ }^{29} \mathrm{http}: / /$ www.tessafrica.net/

$30 \mathrm{https://www.jisc.ac.uk/rd/projects/open-education}$

31 http://www.hewlett.org/programs/education/open-educational-resources

32 http://www.uopeople.edu/
} 
profesores, estudiantes, y aquellos que realizan aprendizaje a lo largo de la vida (Hylén, 2006; Mello \& Caine, 2012; OLCOS, 2007, p. 20), lo que fomenta la reducción de los costes y la democratización de la educación (Hylén et al., 2012; Yuan, MacNeill, \& Kraan, 2008).

- Los profesores y otras organizaciones pueden traducir el material a su propia lengua, y volver a publicarlo para favorecer que otras personas lo reutilicen, adapten, recombinen y sigan mejorándolos (Hylén et al., 2012; Mello \& Caine, 2012; OLCOS, 2007).

- Se incrementa la eficiencia y calidad de los recursos de aprendizaje (Hylén et al., 2012; Yuan et al., 2008) gracias a las comunidades que trabajan con ellos (OLCOS, 2007)

- Mejora la reputación de las universidades, así como la del profesor 0 investigador y por tanto la capacidad de atraer estudiantes (Hylén et al., 2012; Yuan et al., 2008).

- Fomentan el aprendizaje activo e individual (Hylén et al., 2012, p. 12) a lo largo de la vida, y la inclusión social, proporcionando material de libre acceso para todos (OLCOS, 2007).

En cambio, hoy en día, existe poca reutilización de los OER (Bates, 2015) debido a diferentes barreras que han de superarse:

- Algunos estudios educativos argumentan que el contenido, donde mejor se aprende, es en su contexto (aprendizaje situado), cuando el alumno es activo y sobre todo cuando el estudiante puede construir conocimiento dotando de significado sus experiencias. Los OER tienen un carácter acontextual, por lo que se hace necesario incorporar el feedback de un profesor y el feedback de la interacción con otros compañeros o referencias (Bates, 2015)

- Existe poca claridad ante los diferentes tipos de copyright y permisos que ofrecen las diversas licencias Creative Commons, así como el concepto de Open (que no tenga coste, no significa que no tenga restricciones), lo que puede provocar problemas de infracción de licencias, o evitar su compartición (I. De Vries, 2013; Downes, 2007)

- Sigue estando vigente el síndrome del "not invented here"(Bryant, 2009). Los profesores consideran que si un contenido no ha sido directamente creado para su contexto, no es útil.

- Muchos profesores de universidad consideran que es una pérdida de prestigio para ellos o para sus instituciones la reutilización de contenido digital creado por otros, incluso, su readaptación (Hampson 2013, en Bates, 2015, p. 346). 
- Los profesores de universidad no saben qué hacer con los OER, y no todo el mundo confía en ellos (Green, 2013).

- No es fácil recuperar OER, pues la asignación de metadatos apropiados a estos constituye aún un reto, a pesar de que la utilización de software y herramientas 2.0 pueden ayudar a fomentar su localización (JISC, 2015).

Santos Hermosa (2014) detecta algunos factores que pueden promover la compartición y reutilización de contenidos digitales en el ámbito de la formación tales como la calidad (precisión, actualidad, puntuaciones positivas recibidas y comentarios), el tipo de copyright (existe mayor reutilización cuando los contenidos se encuentran bajo licencias abiertas), la granularidad del material (se utilizan más cuando pueden utilizarse de forma independiente -como objetos de aprendizaje); la disponibilidad (accesibilidad y facilidad de descarga); y los aspectos económicos (sin costes asociados).

Son claros los beneficios que los OER aportan a la educación, pero para progresar en su adopción, han de tomarse medidas de apoyo formativas e informativas, técnicas, etc., con el objetivo de hacer comprender a los profesores, instituciones, órganos de gestión, y demás entidades relacionadas con los OER los beneficios de su utilización y publicación, así como la interrelación con otras instituciones y comunidades de práctica (JISC, 2015). Asimismo, se necesita la colaboración y apoyo de comunidades de defensores de cambios en las políticas y organizaciones educativas, desde las que han de proporcionarse incentivos para facilitar y extender su adopción. En este sentido, algunas de las medidas que propone The William and Flora Hewlett Foundation (2013) a nivel político son:

- Políticas que favorezcan la aplicación de licencias abiertas al contenido desarrollado con fondos públicos, para favorecer que los editores y desarrolladores de los currículums tengan incentivos para crear, distribuir y revisar OER.

- Favorecer el uso de OER más que el de libros de texto que cambian cada cierto tiempo (especialmente en las áreas de Educación primaria y Secundaria).

- Fomentar políticas que integren los OER en el desarrollo profesional y los programas de formación del profesorado; esta medida podría promoverse con inventivos para los profesores de escuelas de Primaria y Secundaria que participen en entrenamiento en OERs 0 en comunidades de práctica de esta temática; además, la inclusión de OER en los programas de formación del profesorado podría promover mejores ratios de uso de los OER en las clases. 
También la UNESCO (2012), en su Declaración de OER de París, recopila una serie de medidas para fomentar el impulso y adopción de los OER a nivel global. Esta es una declaración muy importante para la consecución del cambio de paradigma de los contenidos digitales a los OER, ya que hace un llamamiento a los gobiernos mundiales para fomentar políticas que obliguen a otorgar licencias gratuitas a todos los contenidos generados con fondos públicos.

Actualmente, se siguen realizando estudios de la situación de los OER en el mundo, apoyados por la financiación de entidades diversas: Unión Europea, Commonwealth of Learning, Banco mundial, MIT, JISC, Shuttleword Fundation, HEFCE ${ }^{33}$, OECD, William and Flora Hewlett Foundation, Andrew W. Mellon Foundation, etc.

Es un movimiento que continúa en expansión, con la pretensión no sólo de desarrollar sistemas tecnológicos que favorecen el acceso a cualquier persona a contenidos de acceso libre de alta calidad, si no, su aplicación pedagógica en los contextos educativos. Uno de los estudios recientes encargado por The Williams and Flora Hewlett Foundation a la empresa "The Boston Consulting" (2013) pretende evaluar el estado actual del ecosistema de los Recursos Educativos abiertos en EEUU, y las medidas que han de adoptarse para la adopción plena en los contextos educativos. El estudio proporciona los pasos que deben darse para la proliferación de ecosistemas ${ }^{34}$ maduros de OER.

33 Entre 2009 y 2012, la HEFCE (Higher Education Funding Council for England - Consejo de Financiación de la Educación Superior de Inglaterra) invierte en el programa UK OER Programme para promover el uso y compartición de contenidos digitales de aprendizaje y proporcionar un beneficio reputacional a la Educación Superior de Reino Unido mediante la promoción de OER de calidad a nivel mundial (JISC, 2014)

${ }^{34}$ El término "Ecosistema" aplicado a los entornos educativos de contenidos digitales está comenzando a ganar importancia. El término es importado de su aplicación durante los últimos años al ámbito empresarial. A igual que la acepción biológica del término, comienza a utilizarse para hacer referencia a entornos digitales de aprendizaje en los que todos los elementos que lo componen interaccionan y son interdependientes y necesarios: comunidad y su interacción y producción de contenido y conocimiento, intercambio de experiencias, etc.; los contenidos digitales que genera y su modificación y mejora constante, favorecidos por la tendencia hacia la creación de OER que están potenciando los gobiernos e instituciones; la plataforma y herramientas tecnológicas y el acceso a Internet, para lograr el acceso a información de alta calidad y la comunicación global. 
Gráfico 1 Estado actual de los Ecosistemas maduros de OER. Reelaboración a partir de The Boston Consulting $(2013$, p. 3)

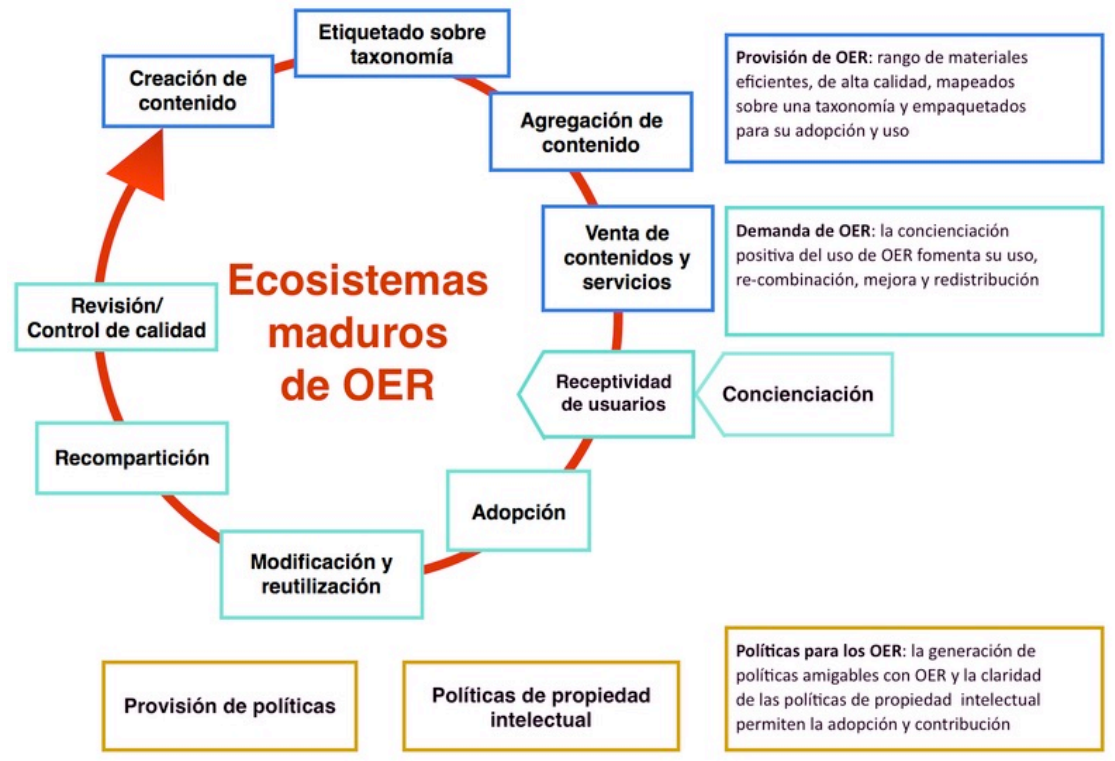

En el Gráfico 1 se representa el ecosistema de los $\mathrm{OER}^{35}$, que requiere de la provisión y creación de contenidos de alta calidad etiquetados en base a taxonomías educativas específicas para cada temática/nivel, de sistemas y servicios para agregar contenido y/o comprar o acceder a contenido digital. Es necesario concienciar a los profesores, formadores de profesores, instituciones, editoriales, etc., de los beneficios de los OER. De esta forma, se puede promover la adopción de OER, su modificación para adecuarlos a las características de su contexto específico de aplicación, y de nuevo, la compartición de este nuevo material adaptado. Es importante informar de los beneficios de compartir recursos y/o experiencias de uso, como acciones que potencian la calidad de los recursos compartidos y estimulan la práctica docente. La maduración de estos ecosistemas

35 The Williams and Flora Hewlett Foundation encarga la elaboración de un informe a la empresa "The Boston Consulting" para evaluar el estado actual del ecosistema de los Recursos Educativos abiertos en EEUU, y las medidas que han de adoptarse para la adopción plena en los contextos educativos. 
será facilitada si las instituciones responsables de la creación de políticas educativas tienen en cuenta las medidas planteadas previamente.

En este marco, se justifica como necesaria la realización de nuestra investigación, pues aún han de desarrollarse los entornos óptimos que faciliten la creación, compartición y reutilización de contenidos digitales, y especialmente, OER en cada contexto educativo.

\section{C.3 Reutilización de los REA y contenidos digitales}

La reutilización de los contenidos digitales es muy importante, entre otros motivos (además de los recogidos en el apartado C.1), porque evita la duplicidad de esfuerzos en la generación de materiales educativos (Alemu, Stevens, \& Ross, 2012; C. Wiley, 2014). Según Mason \& Rennie (2006), el e-learning ha fomentado el incremento de materiales digitales pedagógicos, y para que estos sean de gran calidad, se necesita un amplio número de usuarios que accedan al contenido para que los costes sean justificables. Para potenciar la reutilización de los contenidos digitales y de los OER, concretamente, algunos autores como Santos-Hermosa (Santos-Hermosa, 2014) Clements y Pawlowski (2012, p. 12) recomiendan reforzar la concienciación sobre la reutilización y la calidad de los OER en las comunidades de usuarios. Para ello, plantean que es necesaria más formación y formación en el uso de repositorios de objetos de aprendizaje y herramientas específicas de reutilización de OER, de forma que los docentes sean capaces de integrar estas prácticas en su día a día.

A nivel nacional e internacional, se han desarrollado numerosas iniciativas que han fomentado la generación de repositorios de objetos de aprendizaje para los diferentes niveles y áreas educativas. Con estos, se pretende que los diferentes usuarios/promotores (editores, profesores, personal de apoyo, compañías comerciales e incluso estudiantes) puedan contribuir con objetos de aprendizaje que puedan ser accesibles y recombinables para adaptarse a diferentes niveles y modelos educativos. Ejemplos de este tipo de repositorios son CLOE, MERLOT, CAREO, Edutella, The Learning Object Frederation, etc. (Mason \& Rennie, 2006, p. 72).

En este sentido, uno de los principios fundamentales del movimiento OER es la generación de material educativo gratuito, etiquetado con metadatos basados en estándares (para favorecer su recuperación), y con licencia abierta, de modo que los recursos puedan ser combinados, modificados o reutilizados, incluso para otros propósitos diferentes a los que fueron diseñados (OLCOS, 2007). 
Para que los usuarios sean capaces de reutilizar los contenidos digitales, estos requieren que sean organizados de forma intuitiva, utilizando diferentes aproximaciones para poder encontrarlos, como por ejemplo, su descripción técnica básica: palabras clave, materia/tema, nivel educativo, tipo educativo de recurso, tipo técnico de recurso, etc. Con el objetivo de facilitar que los profesores comprendan los usos y valoren maneras posibles de reutilización de un contenido. A su vez, los metadatos deberían incluir ciertos aspectos educativos contextuales más allá de la mera descripción bibliográfica: objetivos de aprendizaje, audiencia a la que está destinado el material, requerimientos de software, fecha de creación, porcentaje de contenido que es específico para un contexto determinado, etc. (Cervone, 2012, p. 15).

Hoy en día existen ciertas formas estandarizadas y no estandarizadas de etiquetar los materiales, que permiten tanto la recuperación de los contenidos digitales como la interoperabilidad entre diferentes portales (es decir, los sistemas comparten lenguajes a la hora de comprender la descripción de los metadatos, por lo que se facilita la recuperación automática de los contenidos, y por tanto, la federación entre diferentes portales y sistemas).

Cervone (2012, p. 15) sugiere que la expansión de materiales de libre acceso compartidos en formatos estandarizados, puede promover la reutilización de contenido digital:

Para facilitar la reutilización, los materiales de los repositorios deberían estar libres de restricciones de copyright, o registrados bajo licencias de Creative Commons. De esta forma, se minimizarían muchos de los aspectos relacionados con la reutilización y recombinación de los objetos de aprendizaje. Además, para hacer la reutilización del contenido digital más simple, los objetos se deberían compartir en formatos estandarizados y universalmente aceptados, como Open Document Format [...] o HTML5 [...]

Es necesario que entendamos, para la comprensión posterior de los capítulos 3 y 4 de esta tesis doctoral, cuáles son los sistemas para clasificar los contenidos digitales:

\section{Ontologías y Web semántica}

Según Gruber (1993), en el campo de la informática, una ontología es una especificación explícita de una conceptualización. Esto significa que elaboramos de forma detallada y organizada las relaciones de los elementos que componen una realidad. 
El término ontología está prestado de la filosofía, donde una ontología es una explicación sistemática de la Existencia. Para sistemas basados en conocimiento, lo que "existe" es exactamente lo que se puede representar (Gruber, 1993, p. 92). Por otra parte, para Pérez Hernández (2002), una ontología es un entendimiento común y compartido de un dominio, que puede comunicarse entre científicos y sistemas computacionales. Weigand (1997, p. 138) ofrece una definición más concreta de ontología: una base de datos que describe los conceptos en el mundo o en algún dominio, algunas de sus propiedades, y cómo se interrelacionan estos conceptos.

De forma simplificada podemos describir las ontologías como sistemas de organización de una realidad concreta, donde se detallan los elementos descriptibles que las componen y las relaciones e influencias que se dan entre ellos. En nuestro caso, desde el proyecto Share.TEC, tratamos de realizar una ontología del "universo ${ }^{36 "}$ de "Los contenidos digitales en la Formación del Profesorado" en Europa, de forma que pudiéramos explicar los elementos que componen esta realidad y las relaciones que se dan entre ellos. Para ello, tratamos de concretar los tipos pedagógicos y técnicos de contenido; las áreas y niveles de formación en las que pueden utilizarse; las diferentes personas involucradas en las diferentes fases del ciclo de vida del contenido educativo; etc.

El hecho de disponer de metainformación didáctica y pedagógica repercute, en cierta medida, sobre la correcta utilización de los objetos de aprendizaje, puesto que aporta información adicional a los recursos, favoreciendo la correcta reutilización de los mismos (AENOR, 2009). Si conocemos el contexto y características en las que se ha utilizado un objeto de aprendizaje determinado, podremos conocer si éste es útil para nuestro contexto o necesitamos adaptar en cierta medida sus características para su correcta utilización.

La Web Semántica es un conjunto de herramientas que permiten acceder a las ontologías (Pirnay-Dummer, 2012, p. 2507). Esta tecnología, a pesar de estar en sus primeras etapas de desarrollo, junto con el uso de las ontologías, están ganando aceptación y popularidad para facilitar la catalogación, búsqueda y compartición de los contenidos digitales entre educadores y estudiantes (Yalcinalp \& Emiroglu, 2012).

36 Wenger denomina "Universo del Discurso" al conjunto de objetos que pueden ser representados en un dominio de conocimiento (Wenger, 1998, p. 92) 


\section{Metadatos}

Siguiendo a Doulamis et al. (2008), los metadatos de contenidos educativos digitales no son suficientes para proporcionar interoperabilidad entre los diferentes sistemas para compartir contenido digital ni para apoyar una compartición sencilla del contenido. Las diferentes instituciones, escuelas, universidades y organizaciones educativas, utilizan diferentes estructuras de metadatos (vocabularios) para describir objetos educativos similares. Este hecho se da con más intensidad en los países europeos, donde no hay tanta homogeneización como en el sistema educativo de Estados Unidos. Según Doulamis, por este motivo, en Europa se necesitan estrategias comunes de enriquecimiento de contenidos, herramientas software de repositorio que permitan a los usuarios: etiquetar contenido con estructuras comunes de metadatos; codificar estos contenidos utilizando el estándar ${ }^{37}$ para facilitar la interoperabilidad e intercambio; buscar, recuperar y explorar contenido de interés; y generar nuevo contenido a través de herramientas de autoría reutilizando los contenidos existentes.

El sentido principal de los repositorios que incorporan contenidos con metadatos educativos es el de aportar un valor añadido a los motores de búsqueda generales (e.g., Google, Bing). Los metadatos, a pesar de tener cierta estructura, están basados en descripciones de lenguaje natural, por lo que no son fácilmente interpretables por los sistemas semánticos automáticos. Para que esto ocurra, se necesitan ontologías que expliquen las relaciones entre los conceptos. Los repositorios semánticos aún están en su fase inicial y han de seguir desarrollándose para facilitar la recuperación automática de contenidos con descripciones pedagógicas, tal y como se puede extraer de las siguientes reflexiones de Minguillón et al (2011, p. 38):

37 IEEE LOM (Learning Object Metadata Model of the Institute of Electrical and Electronics Engineers - Modelo de Metadatos de Objetos de Aprendizaje del Instituto de Ingenieros de Electricidad y Electrónica). Es un modelo de datos estándar utilizado para describir objetos educativos y contenidos digitales similares. Este vocabulario fue creado en 2002 por la organización IEEE, con la pretensión de promover la adquisición y reutilización de contenidos digitales educativos, así como favorecer que los diferentes sistemas de gestión de contenido educativo puedan comunicarse entre ellos e incorporar de forma sencilla (a veces automática) contenidos etiquetados bajo este modelo (favorecer la interoperabilidad). El estándar puede encontrarse en https://standards.ieee.org/findstds/standard/1484.12.12002.html, y en su modelo de datos incluye descripciones técnicas y básicas, así como ciertos campos pedagógicos 
La completa integración de los repositorios en el proceso de aprendizaje no será posible hasta que el conjunto de entornos virtuales de aprendizaje sea conducido por las ontologías, estableciendo la apropiada relación entre recursos, servicios y usuarios. Los LOR, como parte sofisticada de los entornos virtuales de aprendizaje, necesitan dotar a los estudiantes de mejor apoyo para la búsqueda de actividades, el almacenamiento, etiquetado, votación y evaluación de los recursos de aprendizaje.

En el capítulo 3 de esta tesis doctoral, ampliaremos la descripción del concepto metadatos, mencionaremos diferentes estándares y explicaremos cómo se elaboró el esquema de metadatos que se construyó para el proyecto Share.TEC.

\section{Folksonomías o Etiquetado Social}

Según recoge Seel $(2012$, p. 3124) en la Enciclopedia de Ciencias del Aprendizaje, etiquetado social y folksonomías son términos sinónimos, que se definen de la siguiente manera:

Una etiqueta es una palabra clave asignada a una pieza de información. Por lo tanto, etiquetar es la actividad de asignar etiquetas. Etiquetado social significa realizar esta acción online y de forma colectiva, es decir, generalmente dentro de un grupo abierto de usuarios de internet, para compartir contenido digital. Al etiquetado social también se le conoce como folksonomía. El término folksonomía enfatiza que son la mayoría de los usuarios [...] y no los expertos quienes elaboran sus propias taxonomías.

Zervás y Sampson (2014, p. 293), recogen que los beneficios del etiquetado social de los recursos educativos pueden resumirse en dos:

- Los metadatos de los contenidos digitales educativos pueden ampliarse con las etiquetas que aportan sus usuarios. Esto puede ofrecer a) una forma personalizada de búsqueda (Cho, Yeh, Cheng, \& Chang, 2011; Vuorikari, Poldoja \& Koper, 2010, en Zervas \& Sampson, 2014, p. 293) y b) un mecanismo para capturar el valor contextual educativo de los recursos, que puede ser diferente al de sus creadores (Dahl \& Vosen, 2008, en Zervas \& Sampson, 2014, p. 293).

- Los vocabularios estructurados formalmente por los creadores de recursos educativos pueden expandirse con nuevos términos que reflejan los vocabularios que utilizan las comunidades de usuarios, lo que puede ofrecer formas alternativas de clasificar y recuperar recursos educativos basados en folksonomías (Trant, 2009a en Zervas \& Sampson, 2014, p. 293). 
El título de los recursos y la información que llevan asociada (metadatos) son muy importantes para encontrar un recurso determinado o no; muchas veces los usos de los contenidos digitales diseñados por técnicos o expertos académicos no son comprensibles para los usuarios potenciales (Warwick, 2012), por lo que el etiquetado social puede reflejar con vocabularios de la comunidad potencial una descripción más completa y certera de los usos de los recursos.

\subsubsection{Sistemas para compartir contenidos educativos digitales}

Vivimos en una era de sobreinformación donde el problema no es encontrar contenidos, sino organizarlos y seleccionar los más apropiados en función de los objetivos de aprendizaje que pretendamos conseguir (Minguillón et al., 2011). La evolución vertiginosa de las TIC y de sus aplicaciones didácticas, genera una gran complejidad a la hora de ordenar la realidad. Cada día surgen nuevas formas y denominaciones de la recombinación de espacios que alojan contenido (VLEs ${ }^{38}$, $\mathrm{LMS}^{39}, \mathrm{MUVES}^{40}$, PLEs, etc.). La esencia de estos sistemas es interactuar con las plataformas para adquirir aprendizaje gracias a las herramientas que integran, que permiten, entre otros, la comunicación síncrona y asíncrona con profesores y alumnos, la asignación y evaluación de tareas, la gestión de su aprendizaje, etc. En esta tesis doctoral, nosotros nos centraremos exclusivamente en los portales educativos que permiten la recuperación, compartición y reutilización de contenido en el ámbito de la formación del profesorado.

\section{A) Los portales educativos en el ámbito de la formación del profesorado}

En la red encontramos diversidad de sistemas e iniciativas para la compartición y gestión de contenido digital educativo: comunidades de práctica online educativas (e.g. EducaNetwork ${ }^{41}$ ), portales educativos de contenidos digitales (e.g.

38 VLE- Virtual Learing Environment (Entorno virtual de aprendizaje).

39 LMS- Learning Management System (Sistema de Gestión del Aprendizaje).

40 Los MUVEs (Multi-User Virtual Environments for Education) son "juegos educativos" de plataforma en comunidad en los que, a través del aprendizaje por indagación y la comprensión conceptual, los estudiantes adquieren y comparten conocimientos y competencias. Según Ketehult, Dede, Clarke y Nelson (2006, en Research Center for implementing Teachnology in Education: Multimedia Technologies, 2007) la utilización de los MUVEs proporciona en los estudiantes mejor comprensión del contenido científico.

${ }^{41} \mathrm{http}: / /$ educanetwork.org/ red que permite generar grupos de aprendizaje y compartir e intercambiar documentos 
Tiching.com ${ }^{42}$ ), herramientas de software social (e.g. Twitter, Facebook), plataformas virtuales de aprendizaje, espacios Web, cursos que ofrecen contenido gratuito online (MOOCs, Open Courses), libros de textos gratuitos, etc. En ocasiones, este tipo de sistemas pueden integrar contenido desorganizado, sin descripciones de los datos que los contienen, lo que hace difícil la recuperación organizada del material (e.g. Grupos de Facebook); aunque en otras ocasiones, aparecen categorizados e incluso contienen descripciones educativas de los contenidos basadas en aplicaciones de estándares como IEEE LOM (e.g. el portal Connexions ${ }^{43}$ ), en ontologías (Digital Content Portal ${ }^{44}$ ) y en folksonomías (Twitter). Los portales pueden integrar contenido gratuito y de libre acceso (OERs), contenidos de pago (editoriales educativas), o incluso, una mezcla de ambos tipos de contenido. Los servicios de libre acceso están favoreciendo la disponibilidad pública de material de calidad, democratizando el acceso al contenido, lo que repercutirá positivamente en el desarrollo de las sociedades que pueden acceder a ellos en un futuro.

Area Moreira (2003, p. 32) define los web educativos como espacios o páginas en la WWW que ofrecen información, recursos o materiales relacionados con el campo o ámbito de la educación. En este campo semántico podríamos incluir cualquier tipo de web institucional educativa, páginas de profesores, páginas de recursos y actividades para estudiantes y profesores, bitácoras educativas, wikis educativas, etc. Moreira establece dos tipos de sitios web, atendiendo a la finalidad y naturaleza - didáctica o informativa- de los espacios. En los espacios informativos (web de recursos y bases de datos educativas), encontramos recursos sin criterios pedagógicos asociados a los mismos, mientras que en los espacios formativos 0 didácticos, los contenidos están asociados a una finalidad didáctica, para un determinado tipo de contexto educativo, y con el objetivo de adquirir aprendizajes y desarrollar unas determinadas competencias o habilidades con su aplicación (material didáctico web). Habitualmente encontramos espacios mixtos, que integran las dos finalidades, y que se orientan más hacia una u otra finalidad.

42 http://www.tiching.com/ red social para profesores, estudiantes y padres, que permite acceder a contenidos digitales, organizarlos y acceder a experiencias con otros profesores/estudiantes. Disponible en 19 países de habla española.

${ }^{43} \mathrm{https}: / / \mathrm{cnx}$.org/ Portal educativo que permite acceder, usar y compartir contenido digital ${ }^{44} \mathrm{http}$ ://digitalcontent.sdcoe.net/ Un portal creado por la oficina de educación del condado de San Diego y permite acceder a diversos servicios de suscripción para profesores y estudiantes. 
Bedriñana Ascarza (2005, p. 83) define los portales educativos como espacios web que ofrecen múltiples servicios a los miembros de la comunidad educativa (profesores, alumnos, gestores de centros y familias), tales como información, instrumentos para la búsqueda de datos, recursos didácticos, herramientas para la comunicación interpersonal, formación, asesoramiento, entretenimiento, etc. Según este autor, los portales educativos ofrecen una serie de ventajas:

- Proporcionan información diversa a los usuarios implicados en la educación (padres, educadores, estudiantes, etc.).

- Proporcionan recursos didácticos descargables o utilizables online.

- Contribuyen a la formación del profesorado, ofreciendo información, materiales, y cursos que fomentan el desarrollo profesional.

- Ofertan asesoramiento educativo y legal a los profesores.

- Ofrece canales de comunicación y proporciona instrumentos para la misma entre los diferentes agentes de la educación (foros, chat, videoconferencias, comentarios, etc.).

Los portales educativos son espacios web en los que no sólo pueden encontrarse recursos de forma organizada, si no que además ofrecen otro tipo de servicios que dan cobertura a comunidades de práctica en las propias plataformas, y ofrecen otro tipo de herramientas e información. Algunas plataformas educativas ofrecen gestión escolar y módulos de aprendizaje, mientras que otras se centran exclusivamente en la proporción de contenido.

No existe una definición consensuada de portal Web, pero Kaur y Baba (2006) ofrecen una aproximación basada en varios autores, recopilando las características comunes de las definiciones. Establecen que un portal web es un servicio que ofrece información indexada (se puede buscar) y personalizable en la web, y que actúa como centro de comunicación para sus usuarios. Estos espacios servicios personales y de contenido para apoyar a la comunidad a la que da cobertura. Butcher (2002, p. 32) define tres tipos de portales educativos:

- Portales de redes sociales (networking portals): portales web que proporcionan a varios individuos (educadores, estudiantes, gestores y administradores) un punto central desde el que accede a varias herramientas educativas y facilidades (online y offline).

- Portales organizativos, construidos por una organización, cuyo objetivo es distribuir contenido digital 
- Portales basados en recursos, portales que proporcionan acceso a recursos educativos online, que contienen facilidades de búsqueda, links a otras organizaciones o instituciones relevantes y servicios de subscripción.

El autor, matiza que estas tipologías no son exclusivas, si no que en muchos casos, un mismo portal puede integrar los tres tipos de portales.

En este trabajo, consideramos los portales o plataformas educativas como espacios Web que integran funcionalidades técnicas, pedagógicas y sociales, que permiten el acceso y compartición de contenido digital etiquetado educativamente, y que permiten la colaboración e intercambio de contenidos y conocimiento de forma síncrona y asíncrona entre los diferentes agentes del proceso educativo.

Consideramos que la gestión del contenido es un elemento muy relevante de los portales o plataformas, puesto que es determinante para la calidad de acceso y visibilidad de los materiales, y por tanto, para la mayor o menor aceptación del servicio por una comunidad de usuarios. Por este motivo, consideramos que debemos comprender qué son, para qué sirven y qué ventajas aportan.

\section{B) Organización del contenido de los portales educativos}

Durante los últimos 40-45 años, han existido diferentes formas de organizar el contenido educativo en los espacios Web, entre las que destacamos las más relevantes:

En 1971, Illich introduce el concepto "webs de aprendizaje", como espacios donde los usuarios jugaban un rol importante para transformar la creación y compartición de conocimiento, actuando como profesores o estudiantes en función de las circunstancias.

A pesar de que en 1990 ya existían repositorios de contenidos digitales, es a partir de 2002 cuando los sistemas de gestión del contenido -CMS ${ }^{45}$ - comienzan a establecerse en el panorama técnico, pues empiezan a verse las oportunidades que Internet puede aportar a los diferentes ámbitos de la sociedad (empresas, servicios públicos, educación, etc.) (Pérez Montoro, 2011).

45 Los sistemas de gestión de contenido (CMS) son soluciones software que pretenden organizar los materiales educativos para facilitar la recuperación y reutilización de los materiales que alojan o referencian. 
En el ámbito educativo, los "Learning Object Repositories"46 (LOR) son un tipo de CMS para la educación. Los CMS, permiten añadir metadatos a los contenidos, proporcionar feedback sobre los contenidos, crear contenidos, mantenerlos, registrar la actividad de publicación, etc. Los LOR, además de estas características, incorporan información más específica, están orientados educativamente y presentan una serie de características que los hace valiosos para los contextos de aprendizaje:

- proporcionan descripciones de metadatos específicas, relevantes para contextos educativos (por ejemplo, los basados en el esquema IEEE LOM), evitando la obtención de contenidos no deseados.

- Proporcionan mecanismos de búsqueda y exploración más efectivos, basados en metadatos educativos.

- Los recursos están formados por objetos de aprendizaje, por lo que pueden ser reutilizados de forma simple (Minguillón et al., 2011).

- Proporcionan recursos apropiados para ser utilizados directamente en sistemas de gestión de aprendizaje (LMS).

Los repositorios de objetos de aprendizaje son una especialización de las bibliotecas digitales, y se han convertido en un elemento común de las instituciones educativas, permitiendo tanto a los profesores como a los estudiantes construir comunidades de aprendizaje en torno a temáticas de su materia o campo de interés (Ferran \& Minguillón, 2011).

Abadal (2012, p. 23) define repositorio como un sitio web que recoge, preserva y difunde la producción académica de una institución (o de una disciplina científica), permitiendo el acceso a los objetos digitales que contiene y a sus metadatos. Los repositorios son colecciones de objetos digitales que alojan el contenido, tanto si han sido creados en él como si provienen de otros espacios; poseen una arquitectura que gestiona contenido y metadatos; ofrecen un mínimo de servicios: de acceso, búsqueda, control de acceso, etc.; y son sostenibles, confiables, y están bien gestionados (Heery \& Anderson, 2005). Además de los repositorios encontramos otro tipo de servicios, los referatorios (que contienen las descripciones de metadatos de contenidos alojados en otros portales).

Otro autor relevante, McGreal (en Zervas \& Sampson, 2014), define en 2004 los Repositorios de Objetos de aprendizaje como sistemas que permiten a los

${ }^{46}$ Repositorios de objetos de aprendizaje 
usuarios localizar, evaluar y gestionar objetos de aprendizaje mediante el uso de metadatos tanto técnicos como pedagógicos. Posteriormente, con la popularización y extensión de los OER, McGreal (2010) define los repositorios de Recursos Educativos Abiertos como bases de datos digitales que albergan contenido de aprendizaje, aplicaciones y herramientas, tales como videos, grabaciones de audio, aplicaciones multimedia y herramientas de redes sociales.

Una característica común de este tipo de repositorios es que pueden ser definidos como "centrados en el contenido". Organizan los materiales para un nivel, una materia concreta, etc., pero no dan orientaciones sobre aspectos pedagógicos metodológicos relativos a los recursos o a la metodología educativa en general (Blas, Fiore, Mainetti, Vergallo, \& Paolini, 2014, p. 2).

De esta manera, fruto de lo comentado anteriormente, entendemos que los recursos electrónicos para la formación del profesorado deberían incluir: definiciones de educación a distancia y de TICs para la educación, enlaces a documentación de políticas, revistas educativas en línea, libros y periódicos online, recursos educativos y materiales de enseñanza para todos los niveles educativos, actividades para la formación del profesorado y workshops, asociaciones de profesores de diferentes partes del mundo y sus actividades principales.

Los MUVEs (Multi-User Virtual Environments for Education) son "juegos educativos" de plataforma en comunidad en los que, a través del aprendizaje por indagación y la comprensión conceptual, los estudiantes adquieren y comparten conocimientos y competencias.

Existen diferentes clasificaciones de los tipos de repositorios educativos, en función de los aspectos en los que se centra la atención. Recogemos algunas de las principales clasificaciones de la literatura y sus autores en la siguiente Tabla 2.

Como vemos, estas categorías hacen referencia a diferentes criterios de clasificación, atendiendo al público al que están destinados, las temáticas que abordan, si integran los contenidos digitales o sólo metadatos referentes a contenidos alojados en otros portales, etc. Veamos a qué se refieren las tipologías de repositorios integrados en la tabla, y algunos ejemplos de cada tipo de repositorio:

- Repositorios de disciplinas o temáticas específicas: e.g., TELearn ${ }^{47}$, un portal multidisciplinar y multilingüístico de contenidos abiertos de tecnologías para la

47 http://www.telearn.org 
mejora del aprendizaje, generado por la Red de Excelencia Europea Kaleidoscope ${ }^{48}$ (proyecto financiado por la Comisión Europea dentro de su Sexto Programa Marco).

Tabla 2 Diferentes clasificaciones de repositorios educativos

\begin{tabular}{|c|c|c|c|c|c|c|}
\hline Repositorios: & 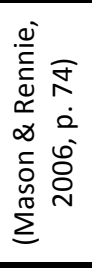 & 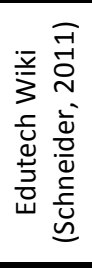 & 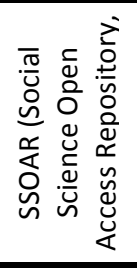 & 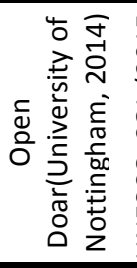 & 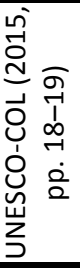 & 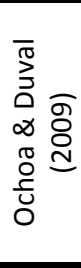 \\
\hline de temáticas específicas & $x$ & & $x$ & $\mathrm{x}$ & $x$ & \\
\hline de software & $x$ & & & & & \\
\hline para estudiantes & $\mathrm{x}$ & & & & & \\
\hline generales de aprendizaje & $\mathrm{x}$ & $\mathrm{x}$ & & & & \\
\hline de diseño de patrones & & $x$ & & & & \\
\hline $\begin{array}{l}\text { Meta-repositorios - } \\
\text { colaboratorios }\end{array}$ & & $\mathrm{x}$ & & & $x$ & \\
\hline $\begin{array}{l}\text { asociados con un entorno } \\
\text { virtual de aprendizaje }\end{array}$ & & $\mathrm{x}$ & & & & \\
\hline institucionales ${ }^{49}$ & & & $x$ & $x$ & $\mathrm{x}$ & $x$ \\
\hline gubernamentales & & & & & $x$ & \\
\hline de objetos de aprendizaje & & & & & & $\mathrm{x}$ \\
\hline Open Courseware & & & & & & $x$ \\
\hline Referatorios & & & & & & $x$ \\
\hline LMS & & & & & & $X$ \\
\hline
\end{tabular}

- Repositorios de software: e.g., DOOR ${ }^{50}$ (digital Open Object Repository), una pieza de software abierto y gratuito para generar repositorios de objetos de

48 http://www.noe-kaleidoscope.org/pub/

${ }^{49}$ Repositorios institucionales: Por ejemplo, el repositorio institucional de la Universidad de Valladolid es accesible a través de http://uvadoc.uva.es/, y pueden encontrarse objetos de aprendizaje, tesis doctorales y otros documentos de producción científica del personal de la Universidad de Valladolid, documentos institucionales, etc.

$50 \mathrm{http}: / /$ door.elearninglab.org 
aprendizaje que pueden integrarse con Moodle; o Edutools ${ }^{51}$ :, que proporciona revisiones de software de repositorios de objetos educativos.

- Repositorios para estudiantes: e.g., Connexions ${ }^{52}$;, integra materiales para las áreas de educación básica obligatoria y post obligatoria, así como materiales para el desarrollo profesional docente. Permite a los docentes gestionar actividades y enviárselas a los estudiantes desde el portal.

- Repositorios generales de aprendizaje: e.g., MERLOT53: integra materiales de diversas áreas de la educación superior.

- Repositorios de diseño de patrones: E-LEN ${ }^{54}$ es un repositorio de Diseño de Patrones para e-learning que nace a raíz de un proyecto europeo.

- Meta-repositorios: espacios que constituyen un directorio de repositorios, e.g.: OER Commons ${ }^{55}$, que además de ser una biblioteca dinámica que recopila recursos educativos abiertos provee de una red para la comunicación de los educadores. Otros ejemplos son REBIUN (Red de Bibliotecas Universitarias de España) ofrece un directorio de repositorios institucionales universitarios de España ${ }^{56}$. Otros dos grandes referentes para alojar este tipo de repositorios, entre otros, son OPEN DOAR ${ }^{57}$ y ROAR ${ }^{58}$.

- Repositorios asociados con un entorno virtual de aprendizaje: e.g., LAMS (Learning Activity Management System, en español, Sistema de Gestión de Actividades de Aprendizaje ${ }^{59}$ ) es una herramienta de diseño que permite crear, distribuir y realizar el seguimiento de actividades de aprendizaje, e integrar las actividades que se desarrollan en él con otros entornos virtuales de aprendizaje (e.g., con Moodle). LAMS contiene un repositorio Central60 donde la comunidad comparte sus diseños de aprendizaje, actividades, etc., y pueden ser reutilizadas por otros profesores.

\footnotetext{
51 http://www.edutools.info/

$52 \mathrm{http}: / / \mathrm{cnx}$.rice.edu

$53 \mathrm{https}: / /$ www.merlot.org/merlot/index.htm

$54 \mathrm{http}: / /$ www2.tisip.no/E-LEN/patterns_info.php

$55 \mathrm{https}: / /$ www.oercommons.org/,

56http://www.rebiun.org/repositorios/Paginas/Directorio-de-Repositorios-Institucionales-

REBIUN.aspx

${ }^{57} \mathrm{http}: / /$ opendoar.org

$58 \mathrm{http}: / /$ roar.eprints.org

$59 \mathrm{https}: / /$ www.lamsfoundation.org/

$60 \mathrm{https}: / /$ www.lamsfoundation.org/
} 
- Repositorios institucionales: Por ejemplo, el repositorio institucional de la Universidad de Valladolid 61 , donde pueden encontrarse objetos de aprendizaje, tesis doctorales y otros documentos de producción cientíica del personal de la Universidad de Valladolid, documentos institucionales, etc. OpenLearn (The Open University, 2014), también puede constituir un ejemplo de este tipo de repositorios.

En la red encontramos directorios que compilan repositorios existentes de Acceso Abierto, como Open Doar (University of Nottingham, 2014), Registry of Open Access Repositories (Southampton, 2011), Open Access Directory (Open Access, 2015), etc., en los que pueden encontrarse ejemplos de cada uno de los diferentes tipos de repositorios que acabamos de diferenciar.

En este trabajo adoptamos la clasificación de OpenDoar (University of Nottingham, 2014), donde se generan una clasificación que tiene en cuenta la intencionalidad y ámbito de influencia del repositorio, estableciendo cuatro tipologías. Nos decantamos por esta clasificación porque además de incluir las dos categorías más frecuentes entre los distintos autores que hemos recogido en la Tabla 2: "repositorios institucionales" y "repositorios temáticos", consideramos que todos los tipos descritos con anterioridad tienen cabida en alguna de estas cuatro clasificaciones:

- Repositorios institucionales: de organizaciones que compilan el contenido que producen y lo hacen accesible al público. Existe una tendencia cada vez mayor por parte de las Universidades a crear este tipo de repositorios, fomentando el acceso libre al conocimiento que generan.

- Repositorios temáticos: que integran contenido digital de materias específicas. Este tipo de repositorios son los que nos interesan en el trabajo de esta tesis doctoral, puesto que analizaremos un portal temático de contenidos digitales para diferentes ámbitos de la formación del profesorado y diversos portales de contenido digital educativo.

- Repositorios gubernamentales: que recopilan contenidos seleccionados por las organizaciones internacionales, nacionales, regionales o locales de las instituciones que los gestionan.

- Colaboratorios: espacios que se encargan de conectar diferentes repositorios y ofrecen acceso al contenido de todos ellos desde un único espacio, como por ejemplo, el reciente portal CORE (Knowledge Management Institute, 2015) .

61 http://uvadoc.uva.es/ 
A su vez, la clasificación de McGreal (2010, pp. 2-3) es compatible con cada uno de estos tipos, pues centra la atención en el criterio de si albergan o no en el contenido digital, o únicamente los metadatos descriptivos:

- Repositorios de Portales de OER: o referatorios que integran metadatos y enlaces a contenidos digitales alojados en otros repositorios o portales (e.g., Merlot)

- Repositorios de contenidos OER: que almacenan el contenido en un mismo servidor (e.g., MIT OCW)

- Híbridos: Repositorios de contenido y portales: son una combinación de los dos anteriores (e.g., ARIADNE; COL OER repository).

Según Open Doar, el número actual de repositorios educativos de acceso abierto registrados por esta institución es de 177 (University of Nottingham, 2014). La distribución de este tipo de repositorios por amplias zonas geográficas está distribuida de la siguiente manera, tal y como refleja el Gráfico 2.

La mayor cantidad de organizaciones que ofrecen repositorios la encontramos en Europa, seguida por Asia, Norteamérica, Sudamérica, y África.

Hoy en día existe una tendencia a hablar de Repositorios de Recursos Educativos Abiertos, debido a la difusión del movimiento de los OER, y a que un objetivo clave de las iniciativas de los OER es apoyar los procesos de organización, clasificación y almacenamiento de los contenidos educativos y sus metadatos en repositorios de objetos de aprendizaje (Lane \& McAndrew, 2010; McGreal, 2004, en Zervas \& Sampson, 2014, p. 292). 
Gráfico 2 Proporción de Organizaciones de Repositorios por Continente.

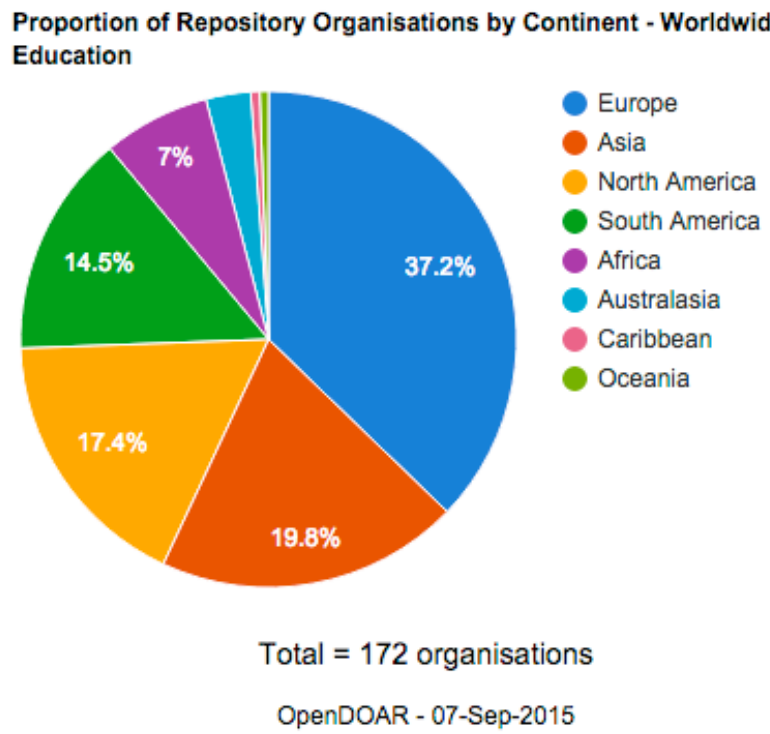

En Europa existe una preocupación por congregar los recursos educativos abiertos, y existe una tendencia hacia la unificación de servicios. A raíz de la adopción de la filosofía del Espacio Europeo de Educación Superior, el proceso de aprendizaje ha incrementado su complejidad. El foco de atención de la educación ya no está en los contenidos, si no en las actividades y en la adquisición de competencias individuales a través de estas. Los entornos virtuales de aprendizaje pueden utilizarse para apoyar mejor las necesidades propuestas por el EEES: personalización, modelo centrado en el alumno, proceso de aprendizaje activo y participativo, actividades basadas en competencias (más que en contenidos), etc. Por este motivo, instituciones internacionales, como la Comisión Europea, se han propuesto congregar los contenidos y servicios existentes en sistemas unificados:

En base a la experiencia inicial del portal de e-learning y al fortalecimiento de la implicación de los interesados, la comisión lanzará con financiación de Erasmust, un espacio para Recursos Educativos Abiertos producidos en Europa, federando las plataformas existentes con sistemas de búsqueda avanzados que permitan a los usuarios encontrar el contenido apropiado (European Commission, 2013c, p. 8) 


\section{C) Aspectos sociales de los portales educativos}

Desde las teoría de la "zona de desarrollo próximo" de Vygotsky, diversos investigadores y teóricos han indagado sobre la importancia de la comunidad y la interacción social como parte del proceso de aprendizaje. Así, encontramos la "teoría cognitiva social" de Miller y Dollar, la "teoría del aprendizaje social" de Bandura, quienes resaltan que el aprendizaje ocurre mediante la observación en entornos sociales. Posteriormente, los antropólogos sociales Lave y Wenger, en 1991 trabajan la idea del aprendizaje como actividad social, e introducen el concepto de las "comunidades de práctica". Más adelante, con la aparición de Internet y la evolución de los modelos de aprendizaje distribuido, Downes y Siemens establecen la "teoría conectivista" del aprendizaje, que vimos con anterioridad (ver apartado 1.5.1). Por último, el "aprendizaje conectado", propuesto por Siemens, aparece como teoría pedagógica de los procesos de aprendizaje en red, y se centra en estudiar cómo los sistemas pueden mejorar ese aprendizaje (Reynolds, 2015).

En relación al tema que nos atañe, los portales educativos para la compartición de contenido digital, diferentes estudios de la literatura demuestran que un elemento clave y vital para su éxito es la existencia de una comunidad de usuarios en torno a ellos (i.e., Clements et al., 2015; Minguillón et al., 2011, p. 35; Tosato, Carramolino Arranz, \& Rubia Avi, 2014).

Una comunidad práctica es un grupo de personas que comparten una preocupación o interés por algo que hacen, y aprenden cómo hacerlo mejor a través de su interacción habitual (Wenger, 1998). En estas comunidades se comparten experiencias individuales, se genera nuevo conocimiento y se resuelven problemas mediante la interacción de los miembros de la comunidad (Brown \& Duguid, 1991, 1998, 2001; Wenger, 1998; en Zhang \& Watts, 2008, p. 55). Según Zhang y Watts (2008), la mayoría de estudios de la literatura atribuye el éxito de las comunidades de práctica a la posibilidad de manejar el conocimiento en la relación "cara a cara" y las relaciones cercanas potenciadas por la interacción social. Según estos autores, la generación de comunidades prácticas online cobra sentido a medida que las organizaciones se expanden geográficamente e incrementan las demandas de incluir a miembros ubicados en zonas lejanas. En cualquier caso, los estudios sobre el uso colaborativo de información en los entornos virtuales sugieren que tanto las comunidades online como las comunidades cara a cara, comparten muchas similitudes (Hersberg, Murray, \& Rioux, 2007, p. 135). Algunos estudios demuestran que las comunidades que mezclan la presencialidad con la no presencialidad, son 
más beneficiosas que las comunidades de práctica exclusivamente online para el desarrollo profesional de los docentes (Matzat, 2013).

Segú Cheung, Lee \& Lee (2013), varios autores (Baker-Eveleth, Sarker, \& Eveleth, 2005; Brown \& Duguid, 2001; Wasko \& Teigland, 2004; Wenger, 1998) consideran que las comunidades prácticas online proveen de espacios útiles para acceder, intercambiar y crear contenido, tanto en los límites de la propia institución como fuera de ellas. De este modo, el conocimiento se vuelve más colaborativo e integrado (Cho, Cheng and Chung, 2007).

Las comunidades no emergen por sí solas, si no que necesitan ser impulsadas mediante estrategias de motivación para captar el compromiso de los usuarios, para que logren desarrollar un sentimiento de identidad y compartan prácticas. Una cosa es crear el entorno técnico de la comunidad, que permite a los miembros comunicarse, y otra, ver a una comunidad emerger por sí sola entre miembros conectados; de hecho, pocos estudios han demostrado que esto sea posible (Erickson, 1997; Johnes, 1997; en Zhang \& Watts, 2008, p. 56). A pesar de la gran cantidad de comunidades online existentes, los estudios demuestran que muy pocas son capaces de mantener a los miembros y motivarles para que contribuyan con sus conocimientos en ellas (Butler, 2001; Wasko \& Faraj, 2005) (Chou, 2010, p. 829). De hecho, según Chen, 2007 y Fang \& Chiu, 2010 (en Cheung et al., 2013, p. 1358), el valor de una comunidad de práctica depende en gran medida de la continuidad de la participación de sus miembros.

Las comunidades virtuales exitosas se construyen teniendo en cuenta factores relacionados con la pertenencia, la influencia, la integración y satisfacción de las necesidades, y la conexión emocional compartida (Hersberg et al., 2007, p. 145). Una vez asentadas esas bases, las redes sociales evolucionan desarrollando diferentes vinculaciones con los miembros que las conforman, a través de dos componentes esenciales para el mantenimiento de las redes sociales: la comunicación y la compartición de información.

Existen ciertos factores que estimulan a las personas a participar en comunidades online y compartir su conocimiento. Cheung et al, (2013, p. 1359), y Liang et al (2008) realizan una clasificación de factores en torno a tres dimensiones, según:

- cognición individual: hace referencia a los beneficios percibidos, tanto extrínsecos (estatus, reciprocidad y reputación) como intrínsecos (diversión e interacción social con otros miembros de la comunidad); y al compromiso (apego psicológico a una comunidad) (Cho et al., 2010; Hew \& Hara,2007), 
siendo este un potente factor motivacional para la participación en la comunidad (Wasko \& Faraj, 2005) (Cheung et al., 2013, p. 1359). Asimismo, en las comunidades de práctica online, la identidad (el establecimiento de su propia reputación y el reconocimiento de los otros) juega un rol crucial en la percepción de autovalía y reconocimiento (Chou, 2010).

- interacción interpersonal: que contempla factores como la interacción social efectiva (Chou, 2010; Clements et al., 2015) y confianza que se genera entre los miembros, y la centralidad que favorece la red social (Chai et al., 2011; Usoro, Sharratt, Tsui, \& Shekhar, 2007) (Cheung et al., 2013, p. 1359).

- esfuerzos organizativos: contemplan los apoyos que reciben de la organización para usar la red social, y las formas en las que les compensan por ello (Davenport \& Prusak, 1998; van Knippenberg \& Sleebos, 2006), ya sean refuerzos económicos, de reducción de otras tareas, o de reconocimiento social (Cheung et al., 2013, p. 1359).

Hew y Hara (Hew \& Hara, 2007), realizan un estudio en el que detectan los factores que potencian la compartición de conocimiento en un grupo online de profesores ${ }^{62}$ : el espíritu colectivista (el interés por mejorar su propio campo de conocimiento); el sentido de reciprocidad (comparten y ayudan porque alguien lo hizo con ellos); por beneficio personal (ya sea mejorar su reputación profesional, ganar apoyo emocional o una mayor comprensión de la materia discutida); altruismo (motivado por la empatía, o el simple hecho querer beneficiar a otros); un entorno respetuoso; y participar en una red en la que los individuos tienen interés por ampliar conocimiento.

- Los repositorios o portales de objetos de aprendizaje requieren de funcionalidades sociales, no solo para facilitar la comunicación sobre cómo se utilizan los recursos y cómo se pueden aplicar a varios contextos, si no para construir redes de confianza (Cervone, 2012, p. 15). Muchos portales y espacios web de contenidos contienen aplicaciones de Software Social. El Software Social es un conjunto de aplicaciones diseñadas para ayudar en la comunicación (síncrona o asíncrona), la creación personalizada de contenidos y el intercambio de información entre usuarios, de modo que esta comunicación e intercambio genera la creación espontánea de redes sociales o comunidades (Pérez Montoro, 2011, p. 7). Entre las herramientas sociales

62 Hemos excluido uno de los factores que detectan "Tecnología", porque lo consideramos muy dependiente de los elementos contextuales del estudio (realizado en una lista de correo). 
existentes, podemos mencionar: e-mail, listas de correo, RSS, (sistemas de sindicación del contenido), wikis, blogs, microblogging (e.g., Twitter), herramientas de curación de contenido (filtrado manual de contenido, e.g., Scoop it); marcadores sociales etiquetados con folksonomías (e.g., Pearltrees), Second Life; etc. Algunas herramientas sociales, además del email, listas de correo, mensajería instantánea o grupos de noticias, son los sistemas de sindicación de contenido (RSS), wikis, y marcadores sociales etiquetados con folksonomías (Pérez Montoro, 2011).

Para algunos autores las redes son tan importantes que consideran que constituyen en sí mismas el conocimiento. De este modo Downes (2012, p.361) sugiere que el conocimiento es la red, se encuentra en las conexiones que se establecen entre las personas; y en este contexto, el aprendizaje consiste en desarrollar y saber aplicar de forma transversal esas conexiones.

Clements, Pawloswski y Manouselis (2015), realizan una revisión de la literatura de los repositorios de recursos educativos abiertos con el objetivo de analizar cómo se gestiona la calidad de los repositorios, donde concluyen la importancia de la comunidad:

La tendencia futura de los repositorios no sólo se orientará hacia la facilitación de las interacciones colaborativas entre los usuarios, como predecían Chatti, Jarke, \& Frosch-Wilke, 2007, si no a hacerlo mediante instrumentos específicos que aseguren la calidad. [...]. Los instrumentos de colaboración por sí solos no pueden asegurar la calidad, si no hay comunidades que las respalden.

\section{Lecciones aprendidas de otros estudios}

En este apartado recogemos las aportaciones realizadas por otros autores a través de la publicación de sus investigaciones relacionadas con la compartición en portales web de contenido digital educativo.

\section{1. ¿Qué estimula a los profesores para usar las TIC y contenidos digitales en sus prácticas pedagógicas?}

Kreijns, Van Acker, Vermeulen y Buuren realizaron un estudio para conocer qué estimula a los profesores para integrar TICs en sus prácticas pedagógicas y el uso de los materiales digitales en educación en el contexto de la Iniciativa del ministerio 
holandés de Educación, Cultura y Ciencia: Wikiwijs ${ }^{63}$. Los autores analizaron la influencia de tres variables proximales ${ }^{64}$ en las variables distales.

Estos autores definieron que las variables proximales que favorecen (o dificultan) el uso de los contenidos digitales de aprendizaje por parte del profesorado eran: a) la actitud hacia el uso de los contenidos digitales (dependiendo de la "simpatía" o "antipatía" hacia las consecuencias o resultados de usar contenidos digitales; b) la norma subjetiva hacia el uso de contenidos digitales (creencias personales de lo que los demás esperan, en este caso, que utilice contenidos digitales - podríamos definirlo como percepción de la presión social); c) y la autoeficacia (percepción de la capacidad de utilizar contenidos digitales con sentido pedagógico en clase).

Las variables distales que influencian el uso o no de los contenidos digitales están organizados a tres niveles: a) a micronivel o nivel individual: variables demográficas; personalidad; variables motivacionales; demandas de trabajo, control y apoyo; síndrome del profesor quemado; utilidad y usabilidad; y otras variables de diferencia individual: uso previo de contenidos digitales, y percepción de habilidades y conocimiento de contenidos digitales educativos; $b$ ) a mesonivel, o nivel de escuela o institución, encontramos: liderazgo para la transformación de la institución; influencia social: apoyo social, norma descriptiva (uso de los contenidos por parte de sus compañeros); y políticas y visión de la institución; y por último, c) a nivel local/regional y nacional de las instituciones, los elementos que intervienen son: las políticas; variables regulatorias y variables organizativas (Kreijns, Van Acker, Vermeulen, \& Van Buuren, 2013, p. 219). Estos autores analizan dos variables distales del micronivel: uso previo de contenidos digitales y percepción de autoeficacia; y una del meso nivel: norma descriptiva (Kreijns et al., 2013, p. 220).

$Y$ concluyen que las variables proximales (actitud hacia el uso de materiales digitales de aprendizaje, presión social de su uso y autoeficacia) son consecuencia de las variables distales, influyendo en la intención de utilizar contenidos digitales. El estudio demuestra que cuanta mayor percepción de autoeficacia tiene un profesor

63 Wikiwijs es una plataforma de contenidos digitales para la Educación Primaria, Secundaria y Educación Superior, promovida por el ministerio holandés de Educación, Ciencia y Cultural http://www.wikiwijsleermiddelenplein.nl/start/.

64 Los autores utilizan el Modelo Integrador de la Predicción del Conocimiento (IMBP Integrative Model of Behaviour Prediction), donde las variables proximales influyen en los procesos cognitivos de autorregulación con respecto al comportamiento deseado; en este estudio, estas variables influyen directamente en la intención de usar contenidos digitales. 
utilizando contenidos digitales, sienten menor presión de sus compañeros por utilizarlos (tienen cierta seguridad). Otros estudios, siguiendo las Teoría Cognitiva Social para explicar por qué se utilizan o no las TIC, también hacen énfasis en la importancia de la autoeficacia para la aceptación, implementación y uso de tecnología; las personas con mayor con mejor percepción de autoeficacia tienden a esforzarse más y ser más persistentes para aceptar, implementar y utilizar las tecnologías (Cheung et al., 2013).

\subsection{Los contenidos digitales en las áreas de humanidades y Educación}

Hasta hace poco tiempo, era poco habitual estudiar a los usuarios de contenido digital en las áreas de humanidades, se presumía que no tenían conocimientos técnicos para opinar o que no estarían preocupados por estas temáticas, por tanto, los desarrolladores eran quienes decidían qué recursos utilizar y cómo construir los portales para estos usuarios. De acuerdo con Warwick (2012), estudiantes de humanidades tienen necesidades diferentes de información (tanto en línea como no en línea) que los científicos más puros, y son una población difícil para la que diseñar contenidos y espacios digitales. En muchas ocasiones, la prueba de los usuarios (tanto en proyectos académicos como en industria), se deja para las partes finales de los proyectos (cuando el recurso ya ha sido construido y el prototipo se está probando). Este procedimiento puede funcionar si a los usuarios les gusta lo que se ha construido para ellos, pero si no, puede que no haya suficiente financiación, tiempo o voluntad de los desarrolladores para realizar las modificaciones que sugieren los usuarios (Warwick, 2012, p. 4). Este hecho es extensible a los repositorios pensados para la Educación superior, pues tradicionalmente, los repositorios no satisfacen las necesidades de los profesores, ya que se requiere un diseño diferente para la generación de repositorios de objetos de aprendizaje frente a los repositorios generales (Cervone, 2012, p. 14). Para conseguir un portal exitoso se necesita la implicación de los desarrolladores y usuarios potenciales en todas las fases de su construcción, desde su detección de necesidades, diseño, construcción, evaluación y procesos continuos de adaptación y mejora (Cervone, 2012; Davis, 2007; Toikkanen, Purma, \& Leinonen, 2010; Warwick, 2012)

Los estudiantes pueden perder rápidamente la motivación por utilizar contenidos digitales cuando: están alojados en interfaces confusas, tienen problemas con la navegación o la búsqueda, necesitan descargar datos y utilizarlos con otra aplicación, el contenido está incompleto, poco desarrollado o tiene poca calidad. En 
cualquier caso, cuando los estudiantes están motivados y confían que encontrarán un recurso de buena calidad en un portal, persisten y aprenden a utilizar incluso interfaces complejas, a pesar de que el número de usuarios persistentes parece ser bastante pequeño (Warwick, 2012, p. 8).

La clave del éxito de los portales educativos Web descansa en la competencia de los educadores para acceder y usar la tecnología del portal, y en la calidad y presentación de los recursos, que los educadores han de considerar útiles en su práctica diaria (Di Paola, 2007).

\subsection{Características que los formadores de profesores piensan que son más importantes en los repositorios de objetos de aprendizaje}

Existen estudios que ya han proporcionado líneas sobre qué necesitan los profesores para compartir contenidos digitales en portales educativos, como el realizado por Yalcinalp y Emiroglu (2012). Estos autores publican un estudio para fomentar el uso eficiente de los repositorios de contenidos de aprendizaje, y en este caso de centran en las visiones de 75 futuros profesores de Educación Primaria, seleccionados aleatoriamente entre los asistentes a una asignatura. Respondieron a preguntas abiertas a un cuestionario analizando los 17 repositorios abiertos de LOR, portales que habían investigado durante la asignatura, y abstrajeron de las respuestas de los estudiantes las características que eran relevantes para ellos en los repositorios. Categorizan la información obtenida de acuerdo a tres aspectos principales: 
Tabla 3 Características que ha de integrar un LOR según futuros profesores: categorías emergidas tras el análisis documental de las respuestas a un cuestionario (Adaptación de la Tabla 1 de Yalcinalp \& Emiroglu, 2012, pp. 479-480)

\begin{tabular}{|c|c|}
\hline $\begin{array}{l}\text { Categorías } \\
\text { principales }\end{array}$ & Subcategorías y hallazgos \\
\hline $\begin{array}{l}\text { Uso GENERAL, } \\
\text { dividido en } \\
\text { subcategorías }\end{array}$ & $\begin{array}{l}\text { Accesibilidad: } \\
\text { - } \quad \text { el repositorio debe ser fácilmente accesible } \\
\text { - } \quad \text { gratuito } \\
\text { - } \quad \text { y tener nombres atractivos } \\
\text { Confiabilidad: } \\
\text { - } \quad \text { deben mostrar información correcta y fiable } \\
\text { - } \quad \text { deben actualizarse } \\
\text { - } \quad \text { ha de poder visualizarse el número de miembros del portal. } \\
\text { Seguridad: } \\
\text { - } \quad \text { deben tener mecanismos de seguridad. } \\
\text { - } \quad \text { Para } 22 \text { de } 75 \text { usuarios, la membresía debe ser un criterio; en } \\
\quad \text { cambio, para } 21 \text { de } 75, \text { no debe serlo. } \\
\text { Usabilidad: } \\
\text { - } \quad \text { el idioma de los repositorios debe ser el de la lengua materna } \\
\quad \text { (importante para } 55 \text { de } 75 \text { ); } \\
\text { - deben mostrar estadísticas de miembros, uso de los contenidos, } \\
\text { - } \quad \text { las propiedades visuales deben ser acordes a la edad de los } \\
\quad \text { usuarios; } \\
\text { - } \quad \text { deben haber opciones para añadir material al repositorio; } \\
\text { - } \quad \text { el contenido del repositorio debe ser reflejado claramente en la } \\
\text { página principal; } \\
\text { - debe existir interconexión entre los objetos del repositorio; } \\
\text { - } \quad \text { debe proporcionar opciones de audio para ciegos. } \\
\text { Interconexión: } \\
\text { - } \quad \text { el repositorio debe ser capaz de llevarte a otros LOR relacionados. } \\
-\quad \text { Debe existir interacción entre los miembros del repositorios }\end{array}$ \\
\hline BÚSQUEDA & $\begin{array}{l}\text { - } \quad \text { las opciones de búsqueda han de incluir sujeto, nivel y título } \\
\text { - } \quad \text { las clasificaciones de los LO han de basarse en niveles educativos } \\
\text { - } \quad \text { han de ofrecerse detalles de búsqueda avanzada en las opciones } \\
\text { - } \quad \text { un requerimiento de los LOR es una buena clasificación de los } \\
\text { - } \quad \text { temas de cada área. } \\
\text { - Ha de poder buscarse mediante búsqueda avanzada }\end{array}$ \\
\hline
\end{tabular}


Lecciones aprendidas de otros estudios. Estrategias que deben adoptar los sistemas de

\begin{tabular}{|c|c|}
\hline $\begin{array}{l}\text { Categorías } \\
\text { principales }\end{array}$ & Subcategorías y hallazgos \\
\hline $\begin{array}{l}\text { CONTENIDOS } \\
\text { DIGITALES }\end{array}$ & $\begin{array}{ll}\text { - } & \text { deben poder compartirse } \\
\text { - } & \text { ser flexibles } \\
\text { - } & \text { poder verse el nombre del creador del contenido } \\
\text { - } & \text { el repositorio ha de evaluar cada LO } \\
\text { - } & \text { debe existir una previsualización de los LO } \\
\text { - } & \text { el repositorio debe incluir tantos LO como sea posible, de mi área } \\
\text { - } & \text { debe haber más de } 1 \text { LO por área } \\
\text { - } & \text { ha de proporcionarse el tiempo que conlleva la aplicación de cada } \\
\text { - } \quad \text { las imágenes y animaciones usadas han de ser acordes al nivel para } \\
\text { - } \quad \text { debe animarse a los estudiantes a que contribuyan con sus LO } \\
\text { - } \quad \text { ha de proporcionarse una lista de referencias, cuando estas hayan } \\
\text { sido utilizadas para generar el LO } \\
\text { deben ser inclusivos }\end{array}$ \\
\hline
\end{tabular}

Es decir, los autores organizan las características que han de integrar los LOR en las categorías: a) uso general: obteniendo que los recursos deben ser accesibles y usables, confiables, y estar interconectados con otros espacios; b) búsquedas: sobre las que los estudiantes opinaron que debían ser de calidad y estar bien organizadas; y c) los contenidos digitales: que debían contemplar de forma eficaz los aspectos descriptivos básicos y la información relativa a su uso.

Como veremos, a pesar de que este estudio fue realizado con futuros formadores de educación primaria, y nosotros nos hemos centrado, principalmente, en formadores de profesorado, abstrajeron necesidades similares a las que mostraremos en el estudio que hemos realizado y del que presentaremos los principales resultados de su análisis en los capítulos 4 y 6 de esta tesis doctoral.

\subsection{Estrategias que deben adoptar los sistemas de compartición de contenido digital educativo}

La red de repositorios EdReNe, financiada por la comisión europea a través de un proyecto (ECP-2006-EDU-42002) del programa eContentPlus, realiza una recopilación y análisis de los repositorios educativos europeos. Ofrecen recomendaciones relativas a las estrategias que deben adoptar los repositorios y otros sistemas para compartir contenido digital, la forma de involucrar a usuarios en 
su participación, derechos de uso y estándares e interoperabilidad (Lund \& HojsholtPoulsen, 2010).

Estrategias relativas a los repositorios (2010, pp. 4-9):

- Conocer las necesidades de las comunidades de práctica existentes para potenciar su apoyo.

- Aprovechar los estándares abiertos utilizados con frecuencia para permitir la expansión de alianzas, la adaptabilidad futura y la innovación.

- Interaccionar con todas las partes interesadas desde el principio del proceso de planificación y basar su desarrollo en las necesidades de los usuarios.

- Apoyar las licencias abiertas para aumentar el impacto de la financiación y maximizar las posibilidades de reutilización.

- Reconocer que la integración con herramientas y servicios existentes beneficiarán en gran medida la adopción y utilización de recursos digitales para el aprendizaje.

- Construir cuidadosamente un modelo de negocio sostenible, basado en las amplias evidencias existentes

Estrategias para involucrar a los usuarios (Lund \& Hojsholt-Poulsen, 2010, pp. 10-17). Estos autores consideran que para que se consiga la participación de un mayor número de usuarios, debe existir facilidad y simplicidad en el portal que se utilice, en las formas de invitar amigos al portal y de favorecer la participación de todos los miembros.

- Analizar el comportamiento de los usuarios en el portal para apoyar su desarrollo

- Facilidad de invitar a amigos al portal

- Hacer sencilla la participación de todos los miembros.

- Hacer un portal simple, utilizable por usuarios de diferentes niveles de habilidad y procedencias.

- Planificar la creación de una comunidad fuerte a largo plazo, reutilizando las comunidades que ya existen. Los primeros años de lanzamiento de una comunidad son los más importantes para garantizar el éxito.

- Es esencial la presencia de un gestor de la Red hábil y dedicado a ella, que motive a los usuarios para participar en la comunidad de práctica.

- Construir confianza, reputación y crear marca, de forma que los usuarios se sientan seguros como parte de la comunidad.

- Es necesario describir por qué quieres una comunidad en línea y hacérselo saber a los usuarios. 
- Incentivar la actividad de los usuarios empleando diferentes estrategias: comunicación, feedback, badges, reconocimiento en la red, etc. Es importante reforzar a todo tipo de usuarios (ya sean productores o consumidores de contenidos o conocimiento).

- Mantener la moderación a niveles mínimos, dejando que sean los usuarios los que autogestionen la red (interviniendo cuando es necesario).

- Hacer la comunidad la parte central de tu Página Web, nunca esconderla.

- Motivar y facilitar los encuentros en tiempo real entre los usuarios, haciendo que los usuarios se sientan realmente conectados. Las comunidades de usuarios funcionan mejor cuando pueden encontrarse en escenarios reales.

En cuanto a las estrategias que indican para abordar los derechos de uso, destacamos las siguientes de entre las 10 medidas que proponen, por su vinculación con los temas que abordamos en esta tesis doctoral (2010, pp. 18-22):

- Explicitar con claridad los derechos de uso cuando se aportan o se accede a los recursos.

- Motivar a las instituciones para que compartan y produzcan contenido abierto

- Nuevos modelos de negocio deben ser tenidos en cuenta, incluso aquellos que mezclan contenido comercial y no comercial para favorecer la sostenibilidad del portal.

- Los propietarios de los repositorios deben formar sobre el uso de licencias de Creative Commons.

- Recomendar a los estudiantes y alumnos publicar con licencias de Createive Commons su contenido.

Sobre las estrategias de estándares e interoperabilidad (Lund \& HojsholtPoulsen, 2010, pp. 22-26):

- Presentar información clara y fácil de entender relativa a los derechos de uso

- Apoyar el desarrollo de "compartir como una cultura", proporcionando mecanismos de contribución y reutilización sencillos.

- Facilitar el acceso a contenido de calidad, utilizando herramientas 2.0 como puntuación, número de descargas, etc., y dotar de metadatos de calidad a los recursos.

- Facilitar la integración de otros servicios con el portal.

- Las especificaciones de metadatos deben ser construidas por grupos de usuarios y expertos, adaptándolos a las necesidades de la comunidad.

- Minimizar el número de repositorios a los que accede un usuario, federando repositorios existentes, y accediendo a su contenido desde un solo portal. 
Estas estrategias están estrechamente relacionadas con el trabajo desarrollado en esta tesis doctoral, ya que apoyamos su importancia basándonos en el estudio de las necesidades de los usuarios, recopiladas durante el proyecto Share.TEC mediante diferentes estrategias de recogida de datos, como podemos ver en el capítulo 4 de este trabajo, y en el análisis de los portales educativos, recogidos en el capítulo 5 . Además, se proponen otras recomendaciones más específicas para el contexto de los portales educativos para la formación del profesorado.

En relación a las estrategias para asegurar la calidad de contenidos los repositorios Clements et al. (2015), realizan un análisis de la literatura sobre esta temática y extraen la idea de que se necesitan modelos mixtos: revisión de expertos y revisión de la comunidad. La revisión de expertos es fundamental hasta que una comunidad de usuarios fuerte utiliza el repositorio (para asegurar que el portal se puebla de recursos de calidad y los usuarios confían en el repositorio). En ese punto los usuarios generan confianza en los instrumentos colaborativos de control de calidad generados por los usuarios (tales como revisión de pares, comentarios, etiquetado social, favoritos, suscripciones, rankings, etc.). 


\title{
Capítulo 2
}

\section{Marco Teórico Metodológico}

\begin{abstract}
El propósito de este capítulo es analizar los principales apoyos teóricos desde los que afrontamos la presente tesis doctoral. Para ello establecemos la fundamentación teórico-metodológica estableciendo los fundamentos filosóficos y metodológicos que guían esta tesis doctoral. Nos apoyaremos para ello en la visión pragmática de la investigación, desde la que definimos las dimensiones axiológica, ontológica, epistemológica y ontológica de esta cosmovisión. Justificamos la utilización de la investigación multimétodo como dimensión metodológica desde la que diseñamos y analizamos dos realidades, utilizando para la primera el método de investigación de estudio de caso, y un estudio descriptivo y comparativo para la segunda.
\end{abstract}

\section{Introducción}

El marco teórico metodológico de esta tesis doctoral parte de la aproximación filosófica pragmática (Creswell, 2014) de la investigación. La pretensión de este proceso es la de profundizar en el conocimiento de los sistemas para compartir contenido digital en el ámbito de la formación del profesorado y proporcionar guías para mejorar la creación de este tipo de portales o para mejorar los existentes. Para ello, conjugamos la interrelación entre aspectos complejos a los que damos respuesta desde una investigación multimétodo que nos permite explorar de forma más profunda y completa la realidad estudiada. En este capítulo vamos a profundizar en los principios axiológicos, epistemológicos, ontológicos y metodológicos que han guiado este trabajo.

Crotty (1998) propone que a la hora de diseñar un estudio es necesario realizar un esfuerzo considerable para responder a cuatro preguntas: 
- ¿Qué métodos proponemos utilizar? (técnicas o procedimientos utilizados para recopilar y analizar datos relacionados con algunas preguntas de investigación o hipótesis)

- ¿Qué metodología determina nuestra elección y uso de métodos? (La estrategia, plan de acción, proceso o diseño que subyace a la elección de utilizar métodos particulares y vínculo de la elección y utilización de los métodos para el propósito deseado).

- ¿Qué perspectiva teórica subyace a la metodología elegida? (La postura filosófica que sigue la metodología y por tanto, proporciona un contexto para el proceso y una base para su lógica y criterios).

- ¿Qué metodología informa de esta perspectiva teórica? (Epistemología: la teoría del conocimiento intrínseca en la perspectiva teórica y por tanto en la metodología).

Creswell $(2003,2014$, p. 5) conceptualiza el modelo de Crotty para dar respuesta a las tres preguntas principales de un diseño de investigación: las asunciones filosóficas de ver el mundo y aproximarse a la comprensión de la realidad (paradigmas), los diseños de investigación que se vinculan a ella y los métodos 0 procedimientos específicos de investigación que se emplean para trasladar esta visión teórica al estudio de la realidad en la práctica.

Otros autores (Guba \& Lincoln, 2005) plantean cuatro dimensiones que han de considerarse para definir la visión de la que parte el investigador: dimensión axiológica (naturaleza de los principios éticos que guían la investigación), dimensión ontológica (naturaleza de la realidad que nos rodea), dimensión epistemológica (naturaleza del conocimiento) y dimensión metodológica (formas de acceder al conocimiento). En función de la perspectiva que se adopte para cada una de estas dimensiones diferenciamos cuatro formas de entender el mundo (aproximaciones filosóficas): post-positivista, constructivista, transformadora y pragmática (Creswell, 2003, 2014). En el Cuadro 2 se sintetizan los elementos principales que caracterizan cada cosmovisión.

Las asunciones post-positivistas (o tradicionalmente conocidas como el método científico) mantienen una visión determinista del mundo sugiriendo que las causas determinan los efectos o resultados. Tratan de reducir el problema a hipótesis a validar mediante la observación y medida de la realidad objetiva (Creswell, 2014, p. 36). 
Cuadro 2 Traducción de los "Worldviews" o cosmovisiones (Creswell, 2014, p. 36),

\begin{tabular}{ll}
\hline Post-positivismo & Constructivismo \\
\hline Determinación & Comprensión \\
Reduccionismo & Significados de múltiples participantes \\
Observación y medida empírica & Construcción histórico social \\
Verificación de la teoría & Teoría de la generación \\
\hline Crítico/transformador & Pragmatismo \\
\hline Político & Consecuencias de acciones \\
Orientado hacia el empoderamiento y la & Centrado en el problema \\
justicia & Plural \\
Colaborativo & Orientado a la práctica del mundo real \\
Orientado al cambio & \\
\hline
\end{tabular}

Los constructivistas o constructivistas sociales creen que los individuos buscan la comprensión del mundo en el que viven y trabajan, desarrollando juicios subjetivos de sus vivencias. El objetivo de la investigación consiste en hacer converger tanto como sea posible las diferentes formas de concebir la realidad de cada participante involucrado en la situación estudiada, construyendo significado. Estos significados subjetivos son negociados de forma social e histórica (Creswell, 2014, p. 37).

La cosmovisión crítica/transformadora surge como respuesta al positivismo, dado que estas teorías imponían leyes y teorías que no daban respuesta a las necesidades de los individuos socialmente marginados 0 a los aspectos relacionados con el poder y la justicia social, la discriminación ni la opresión. Esta visión del mundo parte de que se requieren leyes y cambios políticos para luchar contra la opresión. Desde esta perspectiva se plantea la investigación de forma colaborativa, haciendo formar parte del proceso de investigación en todas sus fases a los propios interesados con el objetivo de mejorar su realidad (Creswell, 2014, p. 38).

Por último, la cosmovisión pragmática de la que partimos en esta tesis doctoral, derivada de los trabajos de Peirce, James, Mead y Dewey (Cherryholmes, 1992); así como de Murphy (1990), Patton (1990) y Rorty (1990) (en Creswell, 2014, p. 39). Los pragmatistas tienen en cuenta las acciones, situaciones y consecuencias más que los antecedentes. Tratan de buscar soluciones que funcionen a problemas. Combinan los métodos que consideran más adecuados para dar respuesta al problema de investigación. Esta visión del mundo se utiliza comúnmente en los métodos mixtos, pues desde ella, los investigadores tienen libertad para elegir los 
métodos, técnicas y procedimientos de investigación que mejor se ajustan a sus necesidades y propósitos. Los investigadores que siguen esta corriente tienen una visión post-positivista del mundo, considerando que la investigación tiene lugar en determinados contextos histórico, político, social y otros. El objetivo de realizar la indagación es el de cambiar la realidad (Creswell, 2014, pp. 39-40)

En la llustración 3 recogemos la interconexión entre las aproximaciones filosóficas, los métodos y los diseños de investigación, en relación a las tres aproximaciones para el estudio de una realidad: cualitativa, cuantitativa y métodos mixtos/ multimétodo.

Ilustración 3 Un marco para la investigación: interconexión entre filosofía, diseños y métodos de investigación. Adaptación y Traducción de Creswell (2014, p. 5)

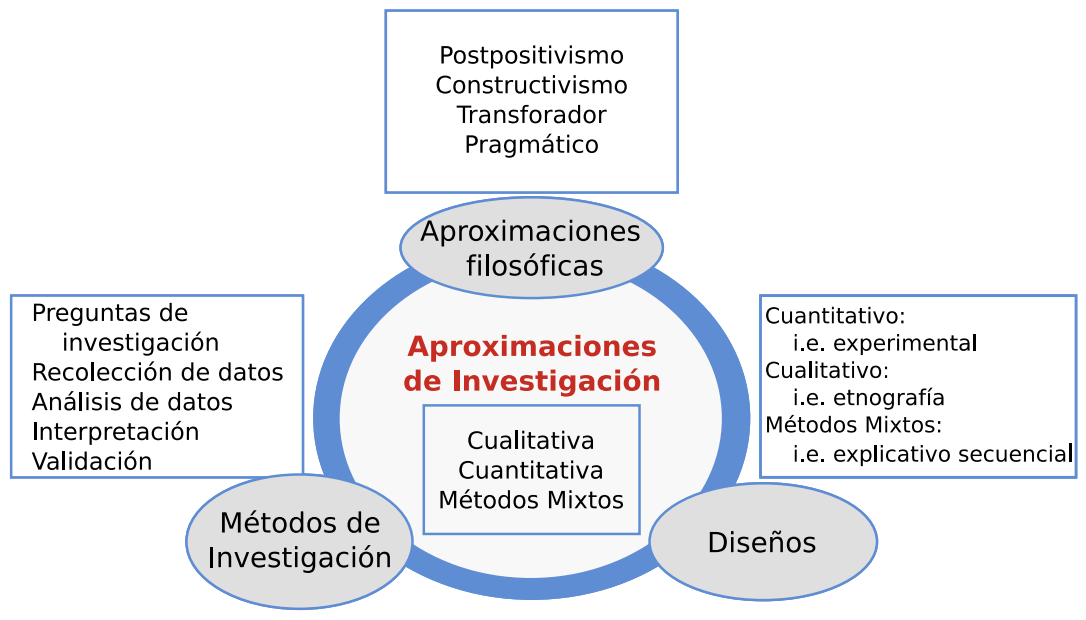

Existen tres aproximaciones para estudiar una realidad: cualitativa, cuantitativa y métodos mixtos (o multimétodo). Las dos primeras, no deberían ser vistas como rígidas, como categorías diferentes ni polos opuestos o dicotomías. En su lugar, deberían representar diferentes fines de un continuum (Newman \& Benz, 1998). Los métodos mixtos residen en el medio de estas dos corrientes (Cook \& Reichardt, 1979). A mediados del s. XX, comienza a tomar más protagonismo la corriente cualitativa, casi olvidada por los científicos en el periodo anterior, como fruto del 
incremento de su uso en el mundo de las ciencias sociales. A partir de los años 70 del siglo XX es cuando comienzan a plantearse los métodos mixtos (Cook \& Reichardt, 1979) como congregación de las dos corrientes. Desde entonces se ha producido un crecimiento del interés explícito en los métodos mixtos de investigación (Brannen, 1992; Bryman, 1998; Creswell, 2003; Tashakkori \& Teddlie, 2003; en Alasuutari, 2010, p. 139; Cook \& Reichardt, 1979), hecho que se refleja en la cantidad de workshops, seminarios y publicaciones crecientes en torno a esta temática (Brannen, 2005, p. 4; Verd \& López, 2008, p. 13) .

La investigación con métodos mixtos es una aproximación que integra los dos tipos de datos, y que utiliza distintos diseños que pueden involucrar asunciones filosóficas y marcos teóricos. La principal asunción de los métodos mixtos 0 multimétodo, es que la mezcla de las aproximaciones cualitativa y cuantitativa provee de un entendimiento más completo de la investigación que la utilización de una sola de ellas (Creswell, 2014).

Las diversas teorías de métodos mixtos focalizan su atención en varios elementos: métodos, procesos de investigación, corrientes filosóficas y diseños de investigación. Estas diferentes posturas son resumidas en la siguiente tabla:

Tabla 4 Autores y foco de orientación de la definición de métodos mixtos. Adaptación y traducción de Creswell \& Plano Clark (2010, p. 2)

\begin{tabular}{|c|c|}
\hline \multicolumn{2}{|c|}{ Autores y foco de orientación de la definición de métodos mixtos } \\
\hline Autor y año & Enfoque de la definición \\
\hline Greene, Caracelli \& Graham, 1989 & $\begin{array}{l}\text { Métodos } \\
\text { Filosofía }\end{array}$ \\
\hline Tashakkori \& Teddlie (1997) & Metodología \\
\hline Johnson, Onwuegbuzie \& Turner (2007) & $\begin{array}{l}\text { Investigación cualitativa y cuantitativa } \\
\text { Propósito }\end{array}$ \\
\hline Journal of Mixed Methods Research (JMMR) & $\begin{array}{l}\text { Investigación cualitativa y cuantitativa } \\
\text { Métodos }\end{array}$ \\
\hline Greene (2007) & $\begin{array}{l}\text { Múltiples formas de ver, escuchar y dotar } \\
\text { de sentido al mundo social }\end{array}$ \\
\hline Creswell \& Plano Clark (2007) & $\begin{array}{l}\text { Métodos } \\
\text { Filosofía }\end{array}$ \\
\hline Creswell \& Plano Clark (2010) & $\begin{array}{l}\text { Métodos } \\
\text { Filosofía } \\
\text { Diseño de investigación }\end{array}$ \\
\hline
\end{tabular}

Existe una amplia variedad de concepciones sobre cómo se utilizan las técnicas cualitativas y cuantitativas dentro delos métodos mixtos, cómo se triangulan los 
datos y cómo se denominan. Entre las diversas formas de denominarlos encontramos las siguientes:

Investigación Mixta (Thomas, 2003); investigación integrativa (Johnson y Onwuegbuzie, 2004), investigación multimétodo (e.g., Hunter y Brewer, 2003; Morse, 2003), métodos múltiples (Smith, en prensa), estudios triangulados (cf. Swandelowski, 2003), análisis etnográfico residual (Fry, Chantavanich y Chan Tavanich, 1998) y métodos mixtos (Johnson y Christensen, 2004). (en Johnson, Onwuegbuzie, \& Turner, 2007, p. 118)

El término métodos mixtos es actualmente el más popular para hacer referencia a estos métodos (Johnson et al., 2007). Por su carácter reciente, la teorización sobre los métodos mixtos está en proceso de definición, existiendo múltiples concepciones y discusiones sobre los aspectos que los configuran, tal y como recogeremos a lo largo de este capítulo.

A continuación reflejamos las asunciones filosóficas y metodológicas que han guiado la realización de esta tesis doctoral, donde hemos llevado a cabo un estudio multimétodo desde una "cosmovisión pragmática" (Creswell, 2014) de la investigación.

\section{Aproximación filosófica y metodológica}

\subsubsection{Nuestra visión paradigmática}

Algunos autores localizan cuatro perspectivas paradigmáticas fundamentales en el campo de las ciencias sociales (Creswell, 2014): post-positivismo, constructivismo, cosmovisión transformadora y, cosmovisión pragmática. Guba \& Lincoln describen las dimensiones ontológicas, epistemológicas y metodológicas desde las que parte cada cosmovisión ("worldview") (Guba \& Lincoln, 1994). Mertens (2010) considera relevante incorporar a estas la dimensión ética 0 axiológica. Esta tesis doctoral parte eminentemente de una cosmovisión práctica (pragmática). Esta visión paradigmática considera oportuno utilizar los métodos y técnicas que sean más adecuados en cada investigación para aproximarse al estudio de la realidad (ya sean de carácter cualitativo y/o cuantitativo), con el objetivo de dar una respuesta adecuada a los objetivos y preguntas planteados (Hernández Sampieri, Fernández-Collado, \& Baptista Lucio, 2010). Siguiendo a Mertens (Mertens, 2010, pp. 35-39), veamos a continuación cómo hemos abordado 
desde el paradigma práctico cada una de las cuatro dimensiones de la investigación.

\section{A) Dimensión axiológica:}

Parte de la investigación de esta tesis doctoral está enmarcada en un proyecto europeo en el que se solicitaba permiso a los informantes para utilizar de forma protegida los datos que proporcionaran tanto para mejorar el portal Share.TEC como para utilizarlos con propósitos investigativos, a igual que las pruebas que se realizaron posteriormente (obteniendo consentimiento por parte de los participantes). A nivel axiológico los investigadores tienen en cuenta y respetan la ética de la investigación propia de la disciplina desde que se aborda la realidad estudiada, y consideran que "todo lo que merece ser valorado depende de sus consecuencias" (Mertens, 2010, p. 37). Los informantes del estudio eran pertenecientes a diversos países, pero cercanos a los diferentes equipos del consorcio, facilitando el acceso al campo y sinceridad en sus contribuciones. En el caso de los portales para compartir contenido digital no hemos trabajado con informantes.

\section{B) Dimensión Ontológica:}

En el caso del estudio de Share.TEC, tratamos de comprender la dualidad del hecho investigado (existencia de una realidad única que cada sujeto interpreta) a través de la extracción de opiniones generalizadas dentro de los informantes, atendiendo a las opiniones individuales de cada sujeto (exploradas con detalle y tenidas en cuenta a la hora de analizar e interpretar los datos). En el caso de los portales, analizamos e interpretamos la realidad desde nuestro punto de vista y desde un método de evaluación de portales educativos generado a partir de otros trabajos.

\section{C) Dimensión epistemológica:}

Hemos partido de diferentes racionalidades para recoger datos, analizarlos e interpretarlos, en función del tipo de información que deseábamos obtener. Por ello, veremos cómo en esta tesis se integran y analizan datos desde una visión postpositivista (reflejada en las pruebas que integran encuestas a los informantes, y en el análisis estadístico de determinados datos de la investigación); y desde una visión constructivista y transformadora: pues el fin último de esta tesis es mejorar los sistemas actuales para la compartición de contenido digital en el ámbito de la formación del profesorado, por lo que escuchamos las voces de los sujetos a los 
que van dirigidos estos servicios. En cualquier caso, la dimensión epistemológica de esta tesis doctoral pretende conocer a fondo y dar sentido a las realidades estudiadas desde un enfoque eminentemente interpretativo.

\section{D) Dimensión metodológica}

Hemos realizado una investigación multimétodo que integra métodos cualitativos y cuantitativos de indagación, con el objetivo de dar respuesta a las preguntas generales que guían la investigación a través de la integración de lo aprehendido en dos estudios: un estudio de caso instrumental fundamentado en la investigación multimétodo, donde integramos métodos cualitativos y cuantitativos para la recogida y análisis de información desde la cosmovisión pragmática, y un estudio descriptivo y comparativo cualitativo.

Desde esta perspectiva pragmática, la forma en la que concebimos el conocimiento y la realidad en nuestro trabajo, parte de diversas perspectivas epistemológicas, complementarias y enriquecedoras entre sí: la perspectiva fenomenológica definida por Husserl y Heidegger (Echarri \& Iturriaga, 1997; San Martín, 2008), la hermenéutica de Gadamer y Parada (1998), y la perspectiva constructivista:

La fenomenología estudia la experiencia consciente vivida desde el punto de vista subjetivo de la persona que la experiencia (Echarri \& Iturriaga, 1997; San Martín, 2008).

La hermenéutica se centra en la interpretación y la comprensión de procesos y fenómenos con sentido. El conocimiento se construye percibiendo relaciones entre los fenómenos y sus contextos. El conocimiento se concibe con un proceso continuo donde la interpretación y el conocimiento se renuevan; a este proceso de formación de conocimiento se le llama el círculo hermenéutico (Universidad de Jyväskylän Koppa, 2011b).

El enfoque constructivista pretende comprender los fenómenos y formar a quienes participan en ellos, de forma que su actuación sea más rica, efectiva y eficaz (Pérez Gómez, 1992, p. 121); la consideración del contexto en este enfoque es esencial, pues las realidades adquieren significado en función de su contexto específico. Según este paradigma, en el mundo no existe el conocimiento a priori, si no que son los científicos quienes construyen conocimiento y verdad a partir de las personas que estudian (quienes producen diversas verdades y conocimiento mediante sus acciones). Los fenómenos del mundo son vistos como construcciones sociales y culturales (Universidad de Jyväskylän Koppa, 2011a). 
De este modo consideramos el conocimiento como el resultado de la vivencia y participación en el objeto de estudio y como resultado de la interpretación de los hechos analizados.

Ruíz Bolívar recoge los fundamentos de esta visión paradigmática, donde se aboga por la interpretación subjetiva y la particularidad de las situaciones y actores que conforman una realidad:

Desde este paradigma interpretativo, la naturaleza ontológica de la realidad social es compleja, dinámica, singular, determinada históricamente, por lo que debe ser estudiada de manera holística y sistémica, desde una perspectiva fenomenológica y hermenéutica. Se asume la producción de conocimiento a partir del mundo interior de los actores sociales, donde el sujeto y objeto no son separables, puesto que forman parte del fenómeno estudiado; se revindica la subjetividad como fuente de conocimiento; la investigación enfatiza la comprensión e interpretación de la realidad y se aboca al estudio de casos (2008, p. 15).

Como podemos apreciar en la literatura, siempre ha existido una tensión incómoda entre los investigadores "cualitativos" y los "cuantitativos". Los cuantitativos, con tendencia a la generalización estadística, consideran que los cualitativos se centran demasiado en un contexto muy específico, de forma que sus muestras no son representativas, ni sus resultados reproducibles; los cuantitativos, a su vez, creen que los cuantitativos realizan una investigación sobre-simplificada, descontextualizada, reduccionista en términos de generalización e incapaz de capturar los significados que los actores tienen adjuntos a sus vidas y circunstancias (Brannen, 2005, p. 7). Este tipo de tensiones surgen porque unos y otros parten de diferentes asunciones paradigmáticas y filosóficas, que ha llevado a lo que los investigadores que abordan estas diferencias llaman "la guerra de los paradigmas" (i.e., Gage, 1989; Hammersley, 1992; Abbas Tashakkori \& Teddlie, 1998).

Las diferentes concepciones acerca de los enfoques mixtos (Hernández Sampieri, Fernández-Collado, \& Baptista Lucio, 2006) se ubican en un continuum entre métodos cualitativos y métodos cuantitativos y mixtos. En la llustración 4 podemos ver los tres paradigmas que consideran Johnson et al. (2007), entre los que existen diferentes tendencias con las que cada investigador se identifica. En nuestro caso, más allá de entrar en debate de la existencia o no de un tercer paradigma (los métodos mixtos o multimétodo), utilizamos este gráfico para identificar dónde nos ubicamos para desarrollar la presente investigación (puesto que los propósitos de la misma nos han llevado a partir desde éste). Esta tesis se centra en la interpretación de los datos recogidos a través de las diversas fuentes, 
técnicas e informantes, donde hemos recopilado información de corte cualitativo y cuantitativo, y analizado cada tipo de información acorde a sus métodos.

Ilustración 4 Los tres grandes paradigmas y subtipos de métodos mixtos. Adaptación de Johnson et al.

(2007, p. 124)

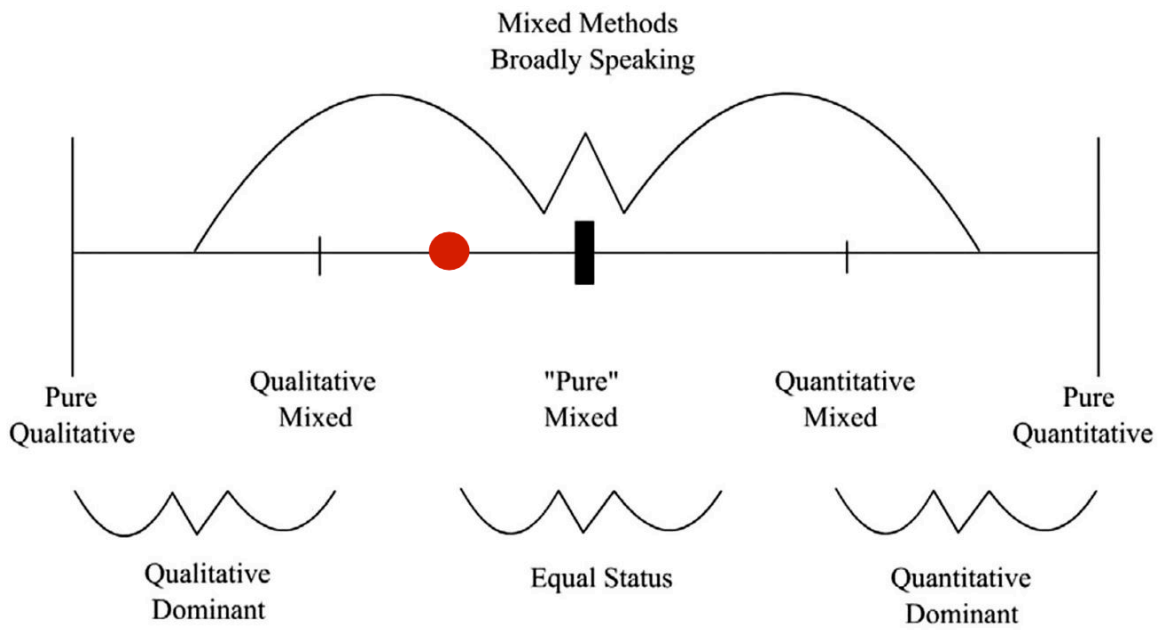

La filosofía que hemos seguido en nuestra investigación concuerda con las ideas que manifiestan Nelson, Treichler \& Grossberg en las siguientes líneas, donde manifiestan que la investigación cualitativa pretende aproximarse a la realidad de forma naturalista con propósitos interpretativos, a través de múltiples métodos y enfoques, ya que consideramos que lo transcendente es la fuente de los datos y cómo unos datos informan a otros:

La investigación cualitativa es interdisciplinar, transdisciplinar y algunas veces contradisciplinaria. Tiene impacto en las humanidades y las ciencias sociales. La investigación cualitativa es muchas cosas a la vez. Es multiparadigmática en su enfoque. Quienes la llevan a cabo son sensibles al valor de la aproximación multimétodo. Están comprometidos a la perspectiva naturalística y a la comprensión interpretativa de la experiencia humana. Al mismo tiempo el campo [...] se configura por múltiples posiciones éticas y políticas ${ }^{65}$. $(1992$, p. 4)

65 Traducción personal del texto original 
Estos autores consideran que la investigación cualitativa adopta dos tensiones simultáneamente, por un lado, trata de dar su visión interpretativa, amplia, crítica; y por otro, trata de definir las concepciones positivistas, humanísticas y concepciones naturalísticas de la experiencia humana, así como su análisis. Además, creen que estas tensiones pueden contemplarse en una misma investigación, integrando ambas tensiones.

\subsubsection{Selección de "investigación multimétodo".}

Existen diversas definiciones de investigación con métodos mixtos. Johnson et al (2007), realizaron un estudio preguntando a través de un e-mail a los líderes de esta temática cuál era su concepción actual sobre los mismos, recibiendo un total de 19 respuestas. Para 15 de los 19 autores, lo que se mezcla en los métodos mixtos es la investigación cualitativa y la investigación cuantitativa. Entre ellos existen diferencias sobre dónde o cuándo han de mezclarse, cuál ha de ser la amplitud de los métodos mixtos (combinación de métodos, combinación de métodos en cada etapa de investigación, etc.), por qué se mezclan los métodos (7 autores concuerdan en que se usan para ampliar, y 5 autores para corroborar datos, etc.). Para concluir su análisis, realizan una definición consensuada de las diferentes visiones de los métodos mixtos:

La investigación con métodos mixtos es un tipo de investigación en la que un investigador o un equipo de investigadores combina elementos de aproximaciones de investigación cualitativas y cuantitativas (por ejemplo, uso de puntos de vista cualitativos y cuantitativos, colección de datos, análisis, técnicas de inferencia) con el propósito de ampliar y profundizar en la comprensión y corroboración (2007, p. 113).

Esta definición se refiere a los métodos de investiga como un tipo de investigación.

La distinción entre multimétodo y método mixto es confusa y variada en la literatura. En nuestro caso hemos considerado la utilización de una estrategia multimétodo como metodología de investigación, puesto que a través de la revisión bibliográfica hemos encontrado matices que inferimos que le otorgan un carácter diferente y que se ajustan en mejor medida al diseño de los métodos de esta tesis doctoral. De este modo, las distinciones que encuentran algunos autores entre métodos mixtos y multimétodo son las siguientes (Johnson et al., 2007, p. 119):

- Pat Bazeley: distingue entre investigación con métodos mixtos y multimétodo, a pesar de que utiliza el término métodos mixtos cuando se refiere a el método 
genérico. Los métodos mixtos involucran el uso de más de una aproximación o método de diseño, y recolección y análisis de datos, con la integración de diferentes aproximaciones o métodos durante el programa de estudio, y no únicamente en su punto final (interpretación de los datos). En cambio, la investigación multimétodo se da cuando se utilizan diferentes aproximaciones o métodos, en paralelo o secuencialmente, pero no se integran hasta que se realizan las inferencias de la investigación.

En esta tesis doctoral, como veremos en el siguiente capítulo, la mayoría de los datos, tanto del estudio de caso de Share.TEC (cualitativos y cuantitativos) como la integración de los dos estudios (Share.TEC y Portales), han sido integrados en la última fase (en la fase de interpretación de los datos).

- Al Hunter: Define la investigación multimétodo como la práctica de emplear diferentes tipos [...] de métodos de recolección de datos en el mismo estudio o programa de evaluación (Hunter \& Brewer, 2003, p. 577), de modo que se superan las limitaciones de la utilización de un solo tipo. Considera que la única novedad del multimétodo es la síntesis planificada y sistemática de los diferentes estilos de investigación (ya que los métodos que se utilizan para hacer investigación multimétodo son los ya conocidos y utilizados) (Brewer \& Hunter, 1989, p. 11).

Otros autores, definen los diseños con múltiples métodos como la investigación en la que más de un método o más de un paradigma es utilizado (Teddlie \& Tashakkori, 2003, p. 11). Estos autores proponen una distinción de tres categorías para hacer referencia a los métodos múltiples: A) Diseños Multimétodo: cuando más de un método es utilizado, pero se restringe dentro de una forma de ver el mundo (E.g., QUAN/QUAN; QUAL/QUAL)66, existiendo estudios multimétodo Cuantitativos y Estudios multimétodo Cualitativos. En cambio, hablan de B) Diseños de métodos mixtos (cuando utilizan procedimientos de recolección de datos o métodos de investigación cualitativos y cuantitativo s), y distinguen entre: 1) Investigación de métodos mixtos (ocurre en la etapa de métodos de un estudio); 2) modelo de investigación mixto (puede ocurrir en varias etapas de un estudio) ${ }^{67}$.

${ }^{66}$ Como vemos, estos autores generan una clasificación que choca con la teorización de otras autoras, como Betzley y Morse (a quienes tomamos como referencia para elegir el multimétodo como metodología de investigación en esta tesis doctoral).

${ }^{67}$ Tashakkori \& Teddlie (2003) reconocen la inconsistencia conceptual de la investigación multimétodo y de métodos mixtos en la literatura, y retan a otros autores a proponer nuevas redefiniciones de su tipología. 
Morse (2003:190) define la investigación con métodos multimétodo como aquella que utiliza de dos o más métodos de investigación, cada uno de ellos llevado a cabo de forma completa y rigurosa dentro de un mismo proyecto (entendiendo éste como una investigación que se centra en una pregunta). Los resultados son posteriormente triangulados para formar un todo; en cambio habla de investigación con métodos mixtos como la incorporación de diversas estrategias cualitativas y cuantitativas en un único proyecto, que pueden tener tanto una conducción teórica cuantitativa como cuantitativa. Las estrategias secundarias son incorporadas al método principal para dar luz a los datos obtenidos con este. Para esta autora, la diferencia principal entre el diseño de investigación multimétodo y el diseño mixto es que en el multimétodo todos los proyectos son completos en si mismos.

En esta tesis doctoral hemos empleado métodos cualitativos y cuantitativos de investigación, que han sido analizados de forma independiente (es decir, utilizando técnicas de análisis cualitativo para los datos cualitativos, y técnicas de análisis cuantitativas para los datos cuantitativos). Los datos han sido combinados en la integración e interpretación de los datos, tratando de triangular los resultados mediante diferentes estrategias (que veremos más adelante en este capítulo).

Siguiendo a esta autora, Morse (2003), los tres principios fundamentales del multimétodo son:

- Principio 1: identificar la orientación teórica del proyecto de investigación, si es inductiva (descubrimiento) o deductiva (comprobación).

En nuestra investigación, la orientación ha sido eminentemente inductiva, partiendo de los datos recopilados a través del estudio de caso de Share.TEC y del análisis de los portales; aunque en el caso de Share.TEC, se han aplicado pruebas cuantitativas ${ }^{68}$ que han seguido planteamientos deductivos (análisis de las encuestas mediante procedimientos estadísticos que han demandado el planteamiento de hipótesis).

- Principio 2: desarrollar concienciación manifiesta del predominio de la inducción o deducción en cada momento. Existen dos tipos de diseños multimétodo, simultáneo y secuencial.

${ }^{68}$ Las encuestas no fueron validadas, pues tenían el propósito de recopilar información para mejorar el portal Share.TEC y conocer las necesidades de sus futuros usuarios; incluimos estas técnicas como deductivas, puesto que parte de los datos cuantitativos obtenidos los hemos analizado siguiendo procedimientos estadísticos (en los casos aplicables). 
Hemos aplicado eminentemente diseños multimétodo, aunque como veremos en el próximo capítulo, también hemos aplicado pruebas simultáneas (cuestionarios que integraban datos cualitativos y cuantitativos; pruebas simultáneas, y diseños que dependían en parte unos de otros, como puede apreciarse en los cuadros explicativos de la metodología de investigación que recogemos en el capítulo 3).

- Principio 3: respetar la integridad metodológica de cada uno de los métodos (tal como hicimos en nuestra investigación, como hemos comentado en el Principio 1).

Morse (2003) propone ocho combinaciones diseño multimétodo, a partir de la combinación del enfoque (cualitativo o cuantitativo) y del diseño (simultáneo 0 secuencial): Cuatro Simultáneos (CUAL+cual; CUAN+cuan; CUAL+cuan; CUAN+cual) y cuatro secuenciales (CUALcual; CUCUANCuan; CUALquan; CUANcual). Los proyectos de investigación pueden estar formados por diseños complejos conformados por combinaciones de los diseños anteriores, tal y como puede apreciarse en nuestra investigación. En el capítulo 3 de esta tesis, reflejamos en el cuadro de metodología de Share.TEC el tipo de combinaciones cualitativas y cuantitativas que hemos utilizado; en el análisis exploratorio y comparativo de los portales para la compartición de contenido digital, hemos realizado un estudio plenamente cualitativo.

Hunter y Brewer (Hunter \& Brewer, 2003, p. 578) consideran que la aproximación multimétodo es una estrategia para superar las debilidades y limitaciones de cada método combinando deliberadamente diferentes tipos de métodos en la misma investigación.

\subsubsection{Ventajas y desventajas de la investigación multimétodo}

Siguiendo a Brannen (2005), la investigación con métodos mixtos o multimétodo presenta una serie de ventajas :

-1) constituyen una oportunidad para la mejora de habilidades de investigación, profundizando en el conocimiento y aplicación de métodos cuantitativos y cualitativos;

-2) en relación al punto anterior, constituyen una oportunidad para el aprendizaje a lo largo de la vida gracias a la formación y experiencia en ellos;

-3) permite superar los límites teóricos de una disciplina aislada, centrándose en los aspectos prácticos de la investigación social, aprovechando los beneficios de la unión de diferentes aproximaciones metodológicas; 
-4) el marco político fomenta la investigación práctica para satisfacer las necesidades de los usuarios y las partes interesadas;

-5) el crecimiento de la aproximación orientada estratégicamente y de forma práctica para alcanzar las necesidades de los usuarios ha supuesto un énfasis en la diseminación, donde importan tanto los aspectos verbales como numéricos a la hora de comunicar las evidencias;

-6) las oportunidades para los métodos mixtos crecen a medida que se amplían las investigaciones transnacionales en el contexto de crecimiento de financiación de la Unión Europea

Otros autores recogen las siguientes ventajas que proporcionan la combinación de métodos:

- proporciona la oportunidad de desarrollar una visión más completa, profunda y amplia (Fielding \& Fielding, 1986; Jick, 1983).

- permite la corroboración de los resultados utilizando diferentes métodos (Brewer \& Hunter, 1989; Greene, Caracelli, \& Graham, 1989; Rossman \& Wilson, 1994).

- complementan los resultados (Greene et al., 1989; Rossman \& Wilson, 1994).

- Expanden los resultados (Greene et al., 1989; Rossman \& Wilson, 1994).

- Proporcionan una oportunidad para investigar posibles contradicciones entre un tipo de datos y otros (Greene et al., 1989; Rossman \& Wilson, 1994).

Brannen (2005), también recoge las limitaciones que surgen con este tipo de investigación:

-1) es posible que los investigadores de una disciplina particular puedan adquirir una falta de identidad segura en la disciplina;

-2) las aproximaciones teóricas de este tipo de investigaciones se vuelven más eclécticas, de modo que los investigadores que no tienen un amplio bagaje teórico antes de realizar una investigación importen teorías de diversas tradiciones a la hora de apoyar sus evidencias, por lo que es necesario indicar cuál es la postura desde la que parte el investigar al principio del proyecto;

-3) los investigadores tienen menos capacidad de definir sus propias preguntas de investigación y de seguir sus ideas cuando las políticas obligan a realizar estudios con métodos mixtos;

-4) la presentación de datos cualitativos junto a los cuantitativos en un mismo espacio puede ser poco manejable, incómodo; 
-5) en las investigaciones transnacionales en las que se presentan ambos tipos de datos conjuntamente, es necesario no caer en la generalización sin realizar un análisis preciso de cómo se han interpretado los datos.

Por tanto, los métodos mixtos ofrecen tanto oportunidades como riesgos, y permiten acercarnos a las preguntas de investigación de forma creativa en cuanto al rango de métodos que podemos utilizar (Brannen, 2005, p. 6). A pesar de las limitaciones que deriva la utilización de la investigación multimétodo, desde una racionalidad pragmática (que explicaremos en el apartado 2.1.4, consideramos oportuna su utilización, como medio para conocer la realidad a la que nos aproximamos en esta investigación, las necesidades que tienen los profesores y formadores de profesores en torno a las peculiaridades pedagógicas, tecnológicas y sociales de los sistemas para compartir contenido digital. Consideramos que la investigación multimétodo -a través del estudio de caso (donde empleamos múltiples métodos de diseño y recogida de análisis) y a través del análisis exploratorio y comparativo de los portales-, nos ayuda a reconstruir la realidad y aportar una visión más compleja de lo ocurrido, y nos permite proporcionar mayor credibilidad y fiabilidad a nuestro estudio mediante la triangulación de métodos, técnicas y datos cualitativos y cuantitativos provenientes de diversas fuentes.

\subsubsection{Racionalidades que guían la elección de métodos mixtos o multimétodo}

Un error que muchos investigadores han ido acarreando a lo largo de los años es el de asumir que lo cuantitativo forma parte del mundo positivista y lo cualitativo del interpretativista, puesto que lo cualitativo puede ser tanto realista como constructivista, dependiendo de cómo se recolecte y cómo sea interpretado por el investigador. La distinción entre investigación cualitativa e investigación cuantitativa estriba en el tipo de conocimiento que se pretende, entre ofrecer explicaciones (cuantitativa) e investigar para impulsar la comprensión (cualitativa) (Stake, 1995, p. 42). La Según Guba y Lincoln (1994) tanto los métodos cualitativos como cuantitativos pueden emplearse con cualquier paradigma de investigación; además, dentro de cada paradigma, las estrategias mixtas pueden cobrar sentido perfectamente (Guba \& Lincoln, 2005; Schwandt, 2000, 2006; Stake, 1995). Actualmente existe una discusión abierta sobre la consideración o no de los métodos mixtos como el tercer paradigma de investigación. Nosotros no entraremos en esta compleja discusión que involucra profundas discusiones epistemológicas y ontológicas, dado que no es objeto de esta tesis doctoral. 
Los investigadores parten de una posición basada en las asunciones y las racionalidades que sostiene. Las diferencias entre las asunciones son un aspecto muy relevante en los métodos mixtos, porque es mucho más difícil mezclar aproximaciones que se orientan al conocimiento focal contingente, con aproximaciones que se orientan al conocimiento general, abstracto. Los puristas, nunca deberían considerar hacerlo. (Alexander, Thomas, Cronin, Fielding, \& MoranEllis, 2008, pp. 137-138).

Como recoge Brannen (2005), a nivel epistemológico los positivistas buscan causalidad y predictibilidad, utilizan test de hipótesis. Los interpretacionistas argumentan que la realidad social únicamente puede producir significado históricamente contingente. Buscan entendimiento y explicación, cuentan historias. La mayoría de los investigadores cuantitativos se ubican a sí mismos en tradición positivista, pero algunos también buscan evidencias cualitativas para apoyar sus investigaciones. Los más puristas rechazan los datos que estudian muestras pequeñas, porque estos no son generalizables. Asimismo, la mayoría de los cualitativos se asocian a la tradición interpretativa. Los más puristas también rechazan estudios cualitativos que intentan ser investigaciones cuantitativas para teorizar las causas y producir resultados generalizables. Según diversos autores, estas visiones son extremas, puristas, caricaturizadas, por lo que muchos investigadores adoptan una visión mucho más intermedia, buscando el valor de la variedad de investigaciones; por ejemplo, muchas encuestas, que podrían considerarse datos cuantitativos, no son conducidas sobre la base de asunciones positivistas (Brannen, 2005, p. 7).

Siguiendo a Alexander et al. (2008), en los métodos mixtos, muchos investigadores se basan en una racionalidad pragmática (i.e., Bryman, 1988; House, 1994; Onwuegbuzie \& Teddlie, 2003; Patton, 2008; Abbas Tashakkori \& Teddlie, 1998), centrándose en las aportaciones positivas que produce la integración de los métodos cualitativos y cuantitativos en la práctica investigadora, sin entrar en discusiones paradigmáticas. Otros investigadores adoptan una aproximación dialéctica, que llama a buscar las sinergias beneficiosas de la integración de ambos paradigmas (Maxwell \& Loomis, 2003; Rocco et al., 2003)69. Aquí, la visión es que el investigador que explícitamente mezcla paradigmas se dirige hacia un entendimiento más completo del mundo social. La mezcla de métodos permite comprender la complejidad de los fenómenos sociales, que contemplan aspectos

${ }^{69}$ Rocco et al. (Rocco et al., 2003, p. 598) recopilan en una tabla estudios realizados por varios autores, y la racionalidad desde la que parten. 
interpretativitos y positivistas (Greene \& Caracelli, 1997). En esta tesis doctoral, utilizamos métodos cualitativos y cuantitativos, principalmente partiendo de una "cosmovisión pragmática" (Creswell, 2014; Mertens, 2010).

En términos prácticos, los investigadores deben saber qué tipo de conocimiento quieren generar con su investigación y qué niveles de explicación esperan, para lo que tendrán que elegir la integración de métodos cualitativos, cuantitativos o ambos tipos. Muchas investigaciones, como la desarrollada en esta tesis doctoral, son llevadas a cabo por asunciones pragmáticas, y suelen integrar elementos interpretativistas y positivistas en función de la utilidad de cada una de ellas para alcanzar los objetivos de la investigación, influyendo incluso en las preguntas que planteamos y la forma en la que enmarcamos la investigación. Los autores justifican esta integración razonando que de este modo se aporta una visión más completa a través del estudio de la complejidad desde perspectivas múltiples. Algunas de las ventajas de la investigación de métodos mixtos puede que no emerjan hasta el final del proceso de investigación. De hecho, la generación de nuevas perspectivas es vista como una de las posibles ventajas de su uso (Brannen, 2005).

El investigador que parte de la racionalidad paradigmática se centra en las asunciones filosóficas que guían la investigación y en los ideales sobre los que han de construirse. Esta visión contrasta con los investigadores que se basan en la racionalidad práctica, quienes están dispuestos a relajar las concepciones teóricometodológicas y se centran en poder afrontar la investigación social mediante el enriquecimiento de diferentes perspectivas. Por tanto, una racionalidad pragmática abrazará más fácilmente una combinación de métodos, si las preguntas de investigación y los aspectos prácticos del contexto lo sugieren (Brannen, 2005, p. 10). Esta tesis doctoral que parte del paradigma práctico, da un gran peso a la interpretación de los datos (pues consideramos que el valor cualitativo de las opiniones de los informantes es esencial para dar respuesta a las preguntas de investigación planteadas), sin olvidar las evidencias positivistas que brindan los datos.

\subsubsection{Combinación de métodos y triangulación}

Lo que tradicionalmente se ha llamado triangulación en ciencias sociales ha sido cómo diferentes análisis de datos llegan a la misma conclusión; cómo diferentes datos se comprueban, se validan o se corroboran entre ellos (Denzin, 1970). Los datos recogidos a partir de diferentes métodos no pueden ser añadidos sin más 
para producir una verdad redonda o unitaria, si no que han de combinarse de alguna de las siguientes formas (Denzin, 1970):

- 1) Corroboración, o utilizar diversas fuentes para reforzar los datos obtenidos mediante una sola.

-2) Elaboración o expansión: usar un tipo de análisis de datos añade comprensión a la ganada por otro.

-3) Iniciación: obtención de nuevas hipótesis mediante un método, que pueden ser exploradas mediante otros.

-4) Complementación: cada análisis de datos mejora el otro; se yuxtapone el análisis de datos de un método con el del otro para crear una visión más global, se da una relación simbiótica.

-5) Explicitación de contradicciones: existen conflictos entre los datos cualitativos y cuantitativos.

Siguiendo a Branen (2005), existen dos contextos en los que se combinan los métodos durante el proceso de investigación:

- En la fase de diseño de investigación, donde el tipo de preguntas de investigación determinan el método atendiendo a las bases epistemológicas 0 al propósito particular de la misma.

- En la justificación de los datos que se han obtenido, donde los diferentes tipos de verdad y validez vendrán marcados por las decisiones relativas a los métodos y asunciones que los han provocado.

Como veremos en los próximos capítulos de nuestra investigación, hemos utilizado estrategias de complementación, corroboración y expansión en ambos contextos.

Según (Denzin, 1970) la triangulación consiste en la combinación de dos o más teorías, fuentes de datos, métodos de investigación, en el estudio de un fenómeno singular. Existen diferentes estrategias de triangulación:

- Triangulación de datos: observamos si el fenómeno o caso sigue siendo el mismo en otros momentos, en otros espacios o circunstancias. Al confrontar los datos se comprueba si existe concordancia o discrepancia entre estos.

- Triangulación de investigadores: hacemos que otros investigadores observen la misma escena o el mismo fenómeno.

- Triangulación teórica: interpretaciones de más de dos personas con diferentes perspectivas de la realidad sobre un mismo fenómeno. 
- Triangulación de métodos: se comprueba la complementariedad entre métodos, existiendo triangulación inter-métodos (combina métodos cualitativo y cuantitativos) y la combinación intra-métodos (combina diferentes tipos de análisis de datos)

- Triangulación múltiple: se combinan dos o más alternativas de la triangulación

Veremos en los capítulos de análisis e interpretación de los datos de esta tesis (capítulos 4 y 5) cómo hemos utilizado todas estas estrategias para dotar de fiabilidad a los datos e interpretaciones realizadas.

En la llustración 5 representamos de forma simple la metodología de investigación que sustenta esta tesis doctoral, y que ampliamos y explicamos de forma más completa en el capítulo 3 de este trabajo, en la ilustración "Metodología de investigación de la tesis". Incorporamos esta representación simplificada con el objetivo de comprender cómo se vincula la filosofía de la que partimos y la metodología, métodos y técnicas que recogemos en el marco teórico metodológico. De este modo, una vez asentadas las bases de nuestros puntos de partida filosóficos y paradigmáticos que nos han llevado a la elección de la investigación multimétodo como metodología de investigación, veamos con más detalle los métodos de investigación que nos han facilitado la comprensión de las realidades estudiadas para dar respuesta a los objetivos y preguntas de investigación de esta tesis ${ }^{70}$ : el estudio de caso, y los métodos exploratorio y comparativo.

En la ilustración podemos ver, en verde, los métodos de investigación seguidos en cada estudio, en morado, los métodos de recogida de datos, y los tipos de técnicas utilizadas (en cuanto a su calidad de cuantitativas o cualitativas o ambas), y en naranja, los métodos de análisis de datos.

70 Los objetivos de la tesis doctoral y las preguntas de investigación, tanto de la investigación como de cada uno de los dos estudios, están recogidos en el capítulo 3, El Proceso de Investigación. 
Ilustración 5 Esquema de investigación de la tesis doctoral

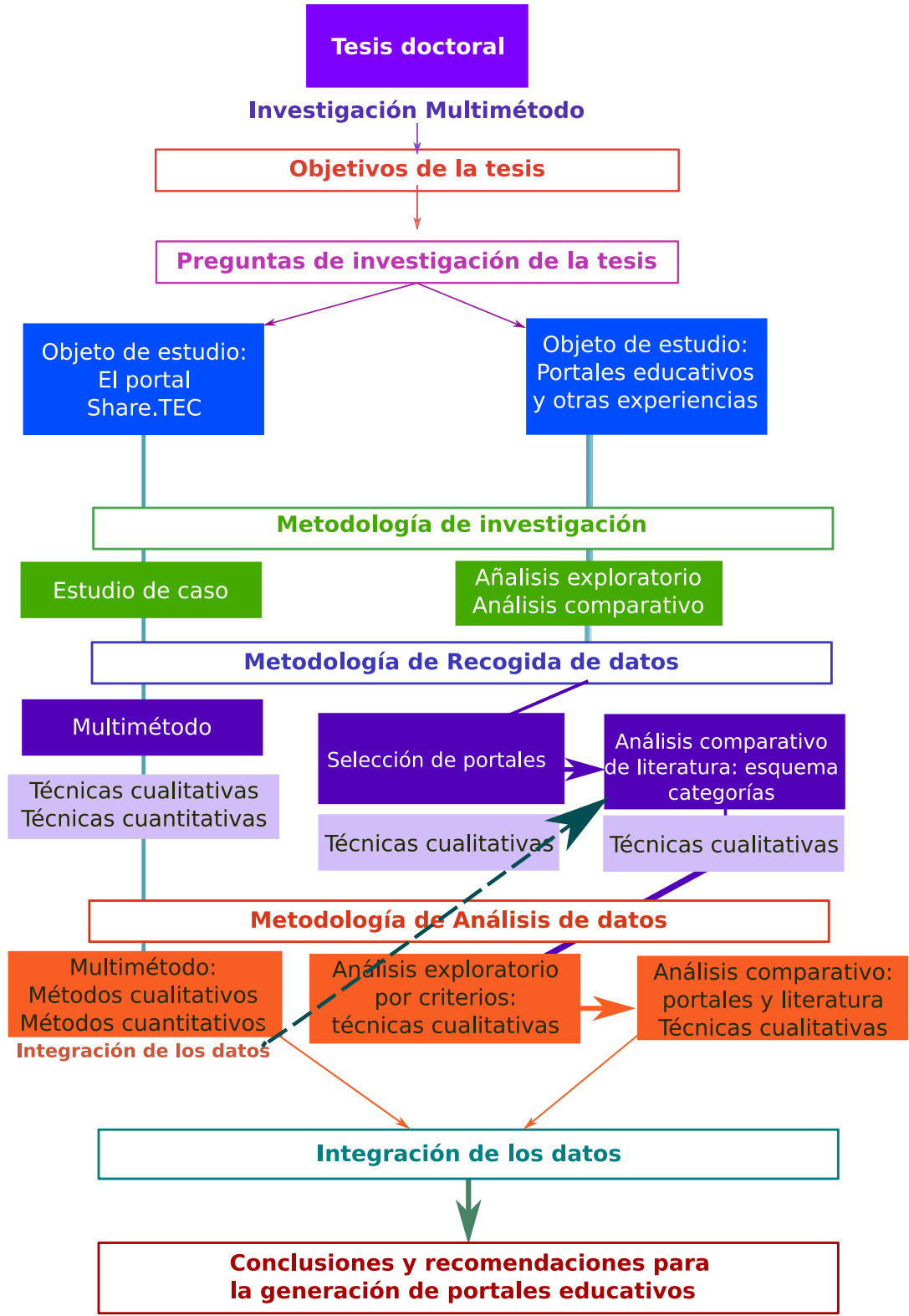




\section{Método de investigación de Share.TEC: estudio de caso}

En investigación educativa el uso de la aproximación del estudio de caso no sólo genera conocimiento y comprensión, además configura un estándar para buenas prácticas de enseñanza a través de dos medios principalmente: el desarrollo y la implementación de políticas, y la adquisición de experiencia a través de la exposición a un fenómeno particular (Timmons \& Cairns, 2010).

El estudio de casos es uno de los principales medios que utilizan los investigadores para hacer investigación en ciencias sociales (G. Thomas, 2011, p. 511). Su utilización como método de investigación en educación tiene lugar en los años 1970s y 1980s en Reino Unido y Estados Unidos, como reacción ante la fuerte inclinación de los investigadores educativos hasta el momento hacia las metodologías positivistas (Hamilton \& Corbet-Whittier, 2013, p. 5).

No existen un consenso en cuanto a las características básicas de los estudios de caso en parte, porque esta metodología no se utiliza sólo en ciencias sociales. De este modo, su comprensión oscila en un amplio rango, desde una herramienta especifica, en una perspectiva positivista, hasta una estrategia pedagógica en educación y procesos de aprendizaje social (Blatter, 2008, p. 68).

Encontramos diversas definiciones y teorizaciones sobre el estudio de caso en la literatura. Veamos las concepciones de algunos de los autores más relevantes de estudio de caso en educación:

En los años 80, el trabajo de Yin (1983) (en Hamilton \& Corbet-Whittier, 2013, p. 6 ) era uno de los pocos libros de estudio de caso disponibles en esa década. Su experiencia era cuantitativa, y plantea el estudio de caso como método general (desde una perspectiva científica general, no sólo centrada en educación), de forma que se adaptara a un modelo de investigación cuantitativo. Yin se centra en su teorización del estudio de caso en la replicabilidad de los datos y la generalización de los resultados (Yin, 2009). Yin caracteriza tres tipos de estudio de caso: exploratorio (recolección de datos y búsqueda de patrones en ellos), descriptivo (genera posibles explicaciones teóricas para enmarcar el estudio y preguntas de investigación para centrarlo) y explicativo (lleva a un paso más los dos anteriores, tratando de explicar el cómo o el por qué del objeto estudiado) (Hamilton \& CorbetWhittier, 2013). En la cuarta edición de su libro "Investigación con Estudio de casos", plantea una definición operativa de estudio de caso con dos caras:

1. Un estudio de caso es una investigación empírica, que: 
- investiga un fenómeno contemporáneo en profundidad dentro de su contexto real, específicamente cuando

- los límites entre el fenómeno y el contexto no son claros.

2. La investigación de estudio de caso:

- lidia con una situación técnicamente distintiva en la que habrá muchas más variables de interés que puntos de referencia, y por lo tanto

- depende de múltiples fuentes de evidencia, y sus datos que necesitan converger en una moda de triangulación, y

- se beneficia del desarrollo previo de proposiciones teóricas para guiar la recolección de datos y el análisis (Yin, 2009, p. 18).

Sarah Merriam (1998, pp. 29-39) describe tres tipos de estudio: particular, descriptivo y heurístico, que pueden adoptar diferentes diseños: etnográfico, histórico, psicológico y sociológico. Además, describe tres estudios de casos basados en la intención de tu investigación: descriptivos, interpretativos 0 evaluativos. ${ }^{71}$

Robert Stake (1995) no caracteriza el estudio de caso como un método, si no como un objeto de elección en relación a la particularidad a ser estudiada ${ }^{72}$. Para Stake el estudio de caso es una herramienta que nos permite comprender la particularidad y complejidad de un caso concreto (Stake, 1995, p. xi) que tiene un interés muy especial, tratando de entender su actividad ligada a las circunstancias importantes que lo rodean (condicionantes politicos, históricos, sociales y especialmente personales) (Stake, 1995, p. 17). El estudio de caso es definido por el interés en casos particulares, no por los métodos de investigación utilizados (Stake, 1998, p. 86).

El estudio de caso no es una opción metodológica, sino una elección sobre el objeto a estudiar, que como forma de investigación se define por su interés en casos particulares, y no por los métodos de investigación usados [...]. El estudio de caso es tanto el proceso de indagación acerca del caso como el producto de nuestra investigación (Stake, 1994).

71 Esta autora cambia su concepción inicial de estudio de caso planteada por primera vez en 1988 diez años después, modificando el foco de su definición centrada en el caso más que en el objetivo de la investigación, coincidiendo con los planteamientos de Smith (1978) y Stake (1995) (en Hamilton \& Corbet-Whittier, 2013, p. 6).

72 Yin (2009) considera insuficiente considerar el "caso" (tal y como hace Stake) como el criterio definitorio estudio de caso como método de investigación. 
Para este autor, el asunto principal del estudio de caso es la particularización (Stake, 1995), a diferencia de Yin, que se decanta más por la generalización (Yin, 2009).

Swanborn (2010) sugiere que cada autor elabora su propia definición incorporando matices diferenciadores de las demás, y recopila los puntos comunes que comparten la mayoría de definiciones. De este modo, establece que un estudio de caso es un fenómeno social; llevado a cabo dentro de los límites de un sistema social (el caso) o varios (los casos); en su contexto natural; recopilando información del fenómeno durante un cierto periodo de tiempo (durante su transcurso o posteriormente $\left.{ }^{73}\right)$; en el que el investigador se centra en trazar el proceso de eventos, opiniones de los participantes, percepciones, recursos, decisiones, etc.; donde el investigador explora los datos guiándose por una pregunta de investigación inicial que va reformulando a medida que realiza la investigación; utilizando diversas fuentes de datos (documentos, participantes, observaciones, etc.), en los que opcionalmente el investigador invita a los actores involucrados a confirmar las conclusiones de su estudio.

Según Timmon y Cairns (2010), las metodología de estudio de caso es flexible, pues permite estudiar fenómenos de diversa complejidad y frecuencia, y permite descubrir aspectos que podrían no haberse tenido en cuenta a la hora de plantear la investigación. Además, permiten capturar los diferentes elementos que contribuye a definir las peculiaridades del fenómeno bajo estudio (Timmons \& Cairns, 2010, p. 99).

A la hora de generalizar los resultados pueden presentarse retos mediante la utilización de esta metodología de investigación, dado que la situación observada es relevante en su contexto específico para un fenómeno particular (Timmons \& Cairns, 2010 , p. 100). Cuando se selecciona un caso, es probable que la muestra de un solo caso o de unos pocos sea una buena representación de otros. De cualquier modo, el objetivo primordial del estudio de casos no es la comprensión de otros (Stake, 2007, p. 17), es comprender en profundidad el caso seleccionado, tratando de estudiar la particularidad más que la generalidad del objeto de estudio (Stake, 2006, 2007, p. 20).

73 Por ejemplo, uno de los autores más conocidos del estudio de caso, Yin, no concibe que los estudios de caso puedan realizarse a posteriori, recabando información del desarrollo de la realidad. 
Para llevar a cabo el estudio de caso nos hemos guiado por la concepción de estudio de caso propuesta por Stake (Stake, 1995, 2005, 2010), principalmente por los siguientes motivos:

- El potencial de esta herramienta para aprender de forma significativa sobre los aspectos abordados durante el desarrollo del proyecto Share.TEC. Stake sugiere que a la hora de elegir un caso nos decantemos por aquellos que percibamos que podemos maximizar lo que podemos aprender (Stake, 1995, 2005).

- La visión interpretativista y hermenéutica de este autor sobre el estudio de caso, dotando de importancia a la particularidad del estudio, más que a la generalidad.

- La familiaridad con la metodología de estudio de caso de este autor ${ }^{74}$

Según Erickson (1986), la característica principal de la investigación la indagación cualitativa es la prioridad que se otorga a la interpretación (Stake, 1995, 2010). El investigador cualitativo tiene la función de interpretar los datos basándose en las evidencias y extraer conclusiones a partir de generalizaciones (Stake, 1995). La interpretación del investigador se verá influenciada por su background 0 experiencia personal, así como por el estudio e interpretaciones de otros investigadores (2007).

En una investigación de este tipo no nos interesa generar una hipótesis ni declaraciones objetivas, puesto que reducen en gran medida el interés por la situación y la circunstancia; en cambio, utilizaremos temas (issues).

El término issue puede traducirse al español como "preocupación temática", y constituye la pregunta a la que ha de darse respuesta a través de las declaraciones temáticas y preguntas informativas del estudio de caso.

La palabra issue sugiere que nos enfrentamos a una situación problemática [...]. A veces se habla de temas controvertidos. Algunos problemas son el foco de nuestro estudio. Los temas no son simples y claros, sino que tienen una intrincada relación con contextos políticos, sociales, históricos y sobre todo personales. [...]

74 Tal y como Ruíz Requies (2009) recoge en su tesis doctoral, diversos miembros del grupo de investigación reconocido por la Universidad de Valladolid GSIC-EMIC (Grupo de Sistemas Inteligentes y Cooperativos - Educación, Medios, Informática y Cultura) han utilizado esta estructura conceptual para definir el diseño de sus casos de estudio: Jorrín (2006); Hernández (2007); Ruíz, Jorrín y Villagrá (2007); Rubia, Anguita, Jorrín y Ruíz (2007), Arribas (2008). 
Las preguntas temáticas o las afirmaciones temáticas constituyen una valiosa estructura conceptual para la organización de un estudio de caso (Stake, 1995, pp. 26-27).

Stake define tres tipos de estudios de caso, y considera que la elección de un tipo u otro determinará los métodos que se usaran en el estudio:

En el estudio de caso intrínseco el interés del investigador radica en conocer "el caso", este es el elemento principal del estudio (Stake, 1995). Este tipo es el diseño clásico de caso único, donde el investigador trata de describir en profundidad la particularidad del caso para conocerlo. Con estos casos se pretende conocer el caso como una entidad holística, así como su propio funcionamiento (Johnson \& Christensen, 2004).

En el estudio de caso instrumental "el issue" es el elemento principal (Stake, 1995). Estamos interesados en conocer el issue y estudiamos el problema a partir de un caso particular. Es decir, lo usamos como instrumento para dar luz al issue. Las conclusiones de este tipo de estudios tienden a extraer conclusiones del estudio que van más allá de los límites de la investigación (en oposición al estudio de caso intrínseco) (Johnson \& Christensen, 2004).

El estudio de caso colectivo (Stake, 1995) ${ }^{75}$, al que posteriormente llama estudio de caso múltiple (Stake, 2006), se utiliza cuando consideramos que a partir del análisis de varios casos de estudio instrumentales se puede ganar mucha mayor comprensión sobre el "quintain" 76(Johnson \& Christensen, 2004; Stake, 1995, 2006)

Para realizar el diseño del caso utilizaremos como estructura conceptual la propuesta por Stake $(1995,2005)^{77}$, representada en la llustración 6, aunque realizaremos modificaciones, como veremos en el capítulo 3. Jorrín Abellán (2006)

75 Yin denomina diseños de caso múltiple a este tipo de estudios (Yin, 2009).

${ }^{76}$ Stake genera el término "quintain" (pronunciado kwin'ton, según el autor) para referirse al objeto o fenómeno a ser estudiado de forma colectiva. Elabora este término para dotarle de un carácter genérico, más allá de palabras como programa o fenómeno que no conllevan de forma implícita este sentido (Stake, 2005)

77 La estructura conceptual que utilizaremos (ver llustración 6) se basa en la utilizada por Stake (2005). Esta figura es similar a la que Jorrín (2006) adapta en su tesis doctoral a partir del desarrollo realizado por en un curso de doctorado "Case Study Research Methods" en la Universidad de Illinois (Urbana-Champaign), dirigido por Stake. Ruíz Requies (2009) también emplea una adaptación de esta figura. 
establece seis pasos a seguir para diseñar el caso, siguiendo los fundamentos que refleja Stake (1995):

a) Selección del caso y descripción de sus características: tras la definición y limitación del estudio de caso, analizamos las principales características que lo componen, reflejadas en la estructura circular central de la llustración 6 : las funciones del caso, actividades particulares donde se recaba información, y lugares en los que tienen lugar estas.

b) Marco general del caso: hace referencia al contexto en el que se enmarca la investigación. Los casos a estudiar son una entidad compleja que se ubica en diversos contextos (Stake, 2005) históricos, culturales, geográficos, conceptuales, etc.

c) Delimitación del Issue y Propuesta de Tópicos de investigación: que nos permitirán desglosar en temáticas el issue (o pregunta a la que queremos dar luz con nuestra investigación).

d) Preguntas informativas, que nos permitirán aclarar con preguntas más concretas los tópicos en los que se desglosa el issue, y que constituirán la estructura del informe de análisis e interpretación de los datos de esta investigación.

Antes de comenzar el trabajo de campo, los investigadores plantean preguntas de investigación para guiar su trabajo, pero al utilizar el estudio de caso la investigación adopta direcciones inesperadas, y las preguntas informativas, tópicos e issue/s se irán redefiniendo a medida que avanza la investigación (Stake, 1995).

e) Selección de Técnicas, Documentos y Participantes, reflejados en la parte inferior del círculo central de la llustración 6). Definiremos cuáles son las técnicas cualitativas y cuantitativas (en nuestro caso) más apropiadas para recabar información de los participantes y de los diferentes documentos y pruebas que están vinculados con el caso; todos estos elementos nos permitirán dar luz al issue planteado.

En nuestro estudio de caso hemos utilizado técnicas multimétodo para la recogida y el análisis de los datos: cualitativas, cuantitativas y mixtas, que nos han permitido obtener datos de los actores y fuente principales del 
estudio (formadores de profesores y otros profesionales de la educación, participantes del proyecto Share.TEC, documentación del proyecto, etc.) y que nos han permitido acercarnos a la comprensión del estudio de caso Share.TEC.

En el capítulo 3 detallamos de forma contextualizada en el estudio de caso Share.TEC cada uno de estos pasos.

Ilustración 6 Estructura conceptual. Adaptación de Stake (2005, p.446)

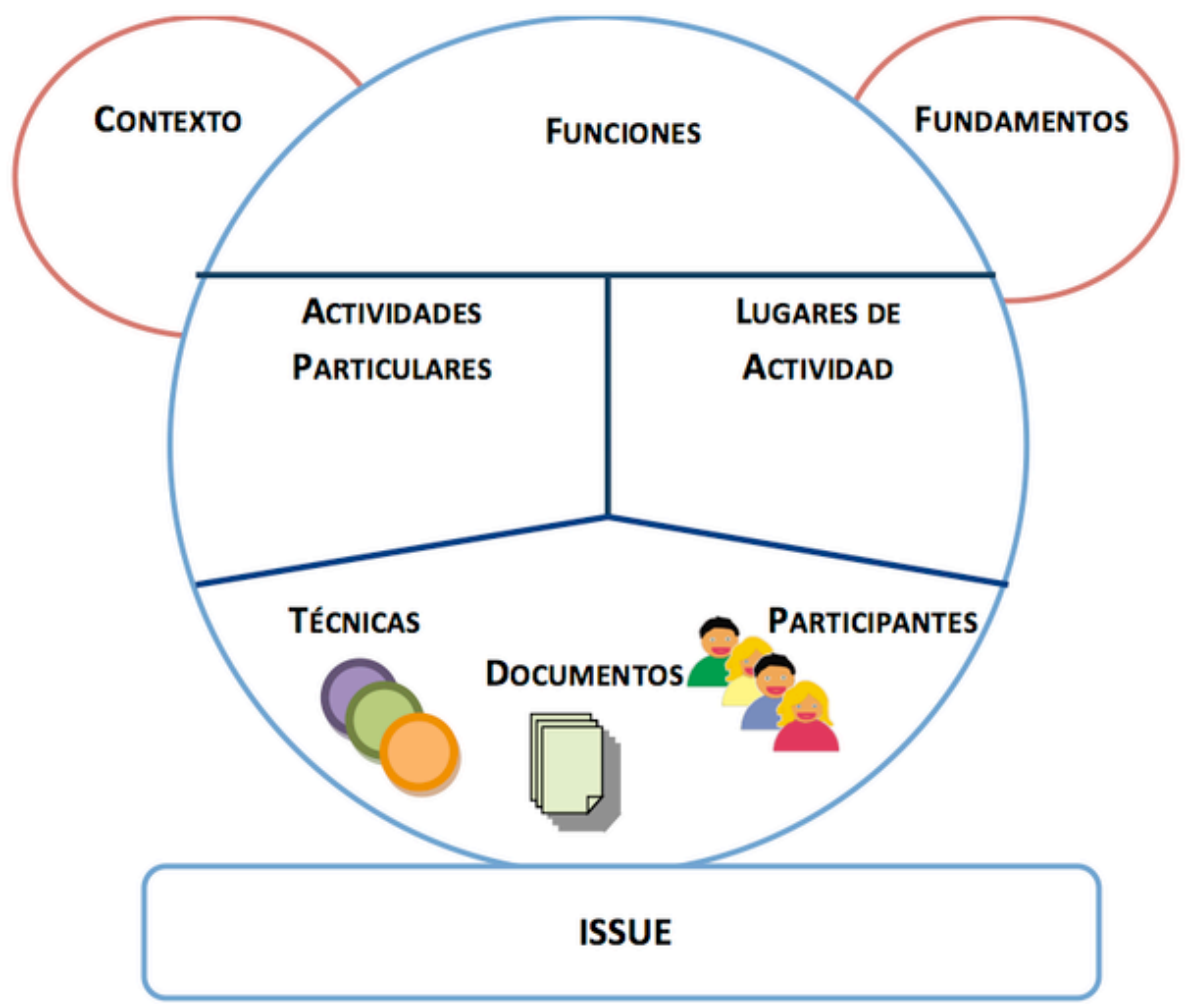

Declaraciones Temáticas

Preguntas Informativas 
Ventajas y desventajas de la utilización de estudio de caso.

La realización de estudios de caso en la investigación educativa plantea ventajas y también algunas limitaciones con las que debemos contar y paliar en la medida de lo posible (Álvarez Álvarez \& San Fabian Maroto, 2012, pp. 3-4):

1. Permite descubrir hechos o procesos que si se utilizasen otros métodos probablemente se pasarían por alto, arrojando luz sobre cuestiones sutiles (Walker 1983, pp. 42-59; Arnal et al. 1994, p. 209; Stake 1995, pp.48-49).

2. Ayuda a desvelar significados profundos y desconocidos, así como orientar la toma de decisiones en relación a problemáticas educativas (Bell 2002, pp.22-23; Heras Montoya 1997, pp. 121-124; Pérez Serrano 1994, pp. 99-102).

3. Es valioso para informar de realidades educativas complejas, invisibilizadas por la cotidianeidad, para entender procesos internos y descubrir dilemas y contradicciones, ayudando a reflexionar sobre las prácticas.

4. Aporta concreción, intensidad y detalle respecto al tema de estudio, al explorar lo más profundo de una experiencia.

5. Es posible emplear una diversa gama de técnicas en la recogida y análisis de datos, tanto cuantitativos como cualitativos (Pérez Serrano 1994, pp. 99102; Rodríguez Gómez y otros 1996, pp. 91-92; Cebreiro López y Fernández Morante 2004, pp. 667).

6. Permite, y requiere, la triangulación de la información recogida para evitar el sesgo del investigador (Arnal y otros 1994, p. 209; Pérez Serrano 1994, pp. 99-102; Cebreiro López y Fernández Morante 2004, pp. 667; Stake 1995, pp. 48-49).

7. Se considera un método muy adecuado para investigadores individuales y a pequeña escala.

Las principales limitaciones del estudio de caso hacen referencia a:

a) la difícil generalización de los resultados de la investigación

b) la subjetividad del investigador podría ser considerada una limitación, aunque en realidad se utiliza para interpretar la realidad partiendo de la intersubjetividad de los participantes y fuentes.

c) la posibilidad de alterar el modo de vida de los sujetos estudiados, al permanecer en el campo durante un tiempo. 
Flyvbjerg (2006) desmitifica los cinco malentendidos sobre el estudio de caso, ya recogidos en la literatura por otros autores como Campbell (2006, p. 221):

-1. El conocimiento general, teórico (independiente de contexto) es más valioso que el conocimiento concreto, práctico (dependiente del contexto). Ante este "malentendido", Flyvbjerg opina que en el estudio de asuntos humanos no pueden encontrarse teorías predictivas. Por este motivo considera más válido el conocimiento dependiente del contexto en estos casos que la búsqueda de teorías predictivas y universales.

-2. Uno no puede generalizar sobre la base de un caso individual; de este modo, el estudio de caso no puede contribuir al desarrollo científico. Para el autor, la "fuerza del ejemplo" se encuentra infravalorada, mientras que la generalización como fuente de desarrollo científico está sobreestimada.

- 3. El estudio de caso es más útil para la generación de hipótesis; es decir, en la primera etapa de un proceso de investigación, donde otros métodos se adaptan mejor para la comprobación de hipótesis y la construcción de teorías. Ante este malentendido puede decirse que el estudio de caso es útil tanto para generar como para contrastar hipótesis, pero no se limita únicamente a estas actividades

- 4. El estudio de caso contiene medios para la verificación, es decir, una tendencia a confirmar las nociones preconcebidas. Para Flyvbjerg, en el EC estos sesgos no son mayores que en otros métodos de investigación, es más, la experiencia indica que el estudio de caso contiene más sesgos hacia la falsificación de nociones preconcebidas que hacia la verificación

-5. Frecuentemente es difícil resumir y desarrollar proposiciones generales y teorías sobre la base de estudios específicos. El autor recoge que los problemas para resumir los estudios de caso se deben con más frecuencia a las propiedades de la realidad estudiada que al caso como un método de investigación. Considera que los buenos estudios no deberían ser resumidos y generalizados, sino leídos como narrativas en su totalidad.

\section{Método de investigación de los Portales educativos}

La evaluación de los portales educativos para la formación del profesorado se ha realizado íntegramente desde el paradigma cualitativo de la investigación, siguiendo una aproximación filosófica pragmática (puesto que hemos seleccionado diseñado nuestro estudio con propósitos prácticos, tratando de dar respuesta a los objetivos y preguntas de investigación del estudio). 
A través de la revisión de la literatura, explorando la metodología llevada a cabo por estudios similares (entre los que destacamos Luna et al., 2004; Martínez Méndez, Martínez Méndez, \& López Carreño, 2012 y aquellos mendionados en el capítulo 5 de la presente tesis doctoral), hemos configurado la estructura metodológica que hemos seguido para la evaluación de los portales (detallada en el capítulo 3 de esta tesis). En síntesis, los pasos del método que hemos diseñado han consistido de las siguientes partes:

- Determinación de un listado de categorías de análisis, configurado a partir de la revisión de la literatura y de la combinación con el esquema de categorías emergido durante el análisis del estudio de caso de Share.TEC (mediante la comparación de los criterios para analizar los portales) (ver capítulo 3 y capítulo 5).

- Selección de los portales mediante muestra de juicio, a través de la búsqueda de determinadas palabras clave en Google (ver capítulo 5).

- Recogida de información mediante el análisis individual de los portales, utilizando el método descriptivo, a través de la observación directa e interacción con los portales, partiendo de las categorías de análisis predefinidas.

- Comparación descriptiva del análisis de los portales, a través del cotejo de las características similares o distintivas entre los diferentes portales.

Según Hine (2004) Internet es un artefacto cultural, y ha de profundizarse en la adaptación de las técnicas de investigación cualitativas tradicionales en los entornos online. La peculiaridad de nuestro estudio es que la observación no ha sido llevada a cabo en un contexto físico natural, si no que el objeto de estudio han sido los portales online para compartir contenido digital en el ámbito de la formación del profesorado. Es decir, podemos denominar e-observación u observación online a la técnica que hemos utilizado.

Siguiendo los planteamientos de Bartolomé $(1984)^{78}$, el método observacional es una técnica perteneciente al método descriptivo. La observación es un proceso sistemático mediante el que el investigador recopila de forma autónoma información

78 Existen diversos autores que consideran que si la observación cumple una serie de criterios puede ser considerada un método de investigación (Seltiz, 1976; Anguera 1998, Colas, 1992) (Medina \& Delgado, 1999). No es objeto de esta tesis ahondar en esta discusión, pero contemplamos la observación como estrategia de recogida de datos, y como técnica del método descriptivo que empleamos. 
relacionada con algún problema o tópico. Esta técnica cualitativa de recogida de datos está influenciada por las percepciones (objetivos, preconcepciones, marco de referencia, instrumento de recogida de datos, etc.) y las interpretaciones de la persona que observa (Rodríguez Gómez, Gil Flores, \& García Jiménez, 1999). Partimos de la tradición fenomenológica hermenéutica para la realización de este estudio (ya definida al principio de este capítulo).

Para realizar la observación hemos elaborado nuestro propio sistema de categorías de análisis, definido a partir del análisis de estudios de la literatura (como veremos en el capítulo 3 y 5 de esta tesis), relacionados con las categorías que integran los portales para compartir contenidos digitales en el ámbito de la formación del profesorado, principalmente, y teniendo en cuenta el sistema de categorías de análisis que emergió tras el análisis de Share.TEC. Rodríguez Gómez et al. conciben un sistema de categorías como una construcción conceptual en la que se operativizan las conductas a observar (Rodríguez Gómez et al., 1999). En nuestro caso no hemos operativizado conductas, si no criterios de análisis de los portales educativos, siguiendo una serie de reglas generales descritas por estos autores:

a) las categorías deben estar definidas con precisión y claridad; para ello, en el capítulo 3 definimos a qué nos referimos con cada una de las categorías de análisis de nuestro estudio.

b) deben ser mutuamente excluyentes y mantener una relación lógica, como queda reflejado en la descripción de las categorías, no existen conceptos solapados, y además estos aparecen organizados en subcategorías homogéneas.

c) debe tener un carácter exhaustivo, por lo que hemos planteado un modelo integral a partir de la comparación de diferentes estudios de la literatura, en el que tenemos en cuenta la mayoría de las características de los diferentes estudios.

Una vez realizada la recogida de datos y el análisis individual de cada uno de los diferentes portales (a través de la descripción de las características principales observadas (en base a las categorías prefijadas) a través a la interacción con los portales seleccionados, procedimos a la fase de análisis de las principales diferencias y similitudes de los diferentes portales mediante la estrategia de la comparación (Lijphart, 1971; Sartori, 1984). Para ello, en el capítulo 5 abstraemos 
las principales propiedades de los portales (Fideli, 1998; Lijphart, 1971), atendiendo a las categorías que hemos predefinido en nuestro estudio.

Gracias a la participación en la creación y evaluación con los usuarios del portal Share.TEC, la abstracción de las características relevantes de los diferentes portales constituía un campo conocido para la investigadora de esta tesis. 



\section{Capítulo 3}

\section{El proceso de investigación}

El propósito de este capítulo es sintetizar el proceso de investigación llevado a cabo en la presente tesis doctoral. Introducimos el capítulo reflejando los objetivos de la tesis y su objeto de estudio. Posteriormente nos centramos en cada una de las dos realidades en las que hemos profundizado. En primer lugar, recogemos los aspectos relativos al estudio de caso instrumental del portal Share.TEC. Enmarcamos la realidad en su contexto y describimos sus elementos estructurales. Para ello, motivamos la elección del caso, y definimos el issue, las cinco declaraciones temáticas y las preguntas informativas en las que nos apoyamos para analizar esta realidad. Explicitamos con detalle el origen y el proceso de creación del proyecto Share.TEC, que genera como producto el portal que constituye el objeto de estudio del primer caso. Concluimos esta sección detallando las fases de recogida y análisis de datos llevadas a cabo mediante la metodología multimétodo, y las técnicas e instrumentos empleados. La última parte de este capítulo contempla el proceso de investigación de la segunda realidad estudiada, los portales para la compartición de contenido digital educativo. En ella definimos los objetivos particulares del estudio ubicándolos en el contexto de la tesis. Explicamos el proceso de selección de la muestra atendiendo a los criterios que demarcamos basándonos en nuestro juicio. Seguidamente, explicamos cómo hemos construido el modelo de evaluación de portales a partir de fuentes de la literatura y de la estructura de análisis del estudio de caso Share.TEC. Por último, concretamos la metodología cualitativa utilizada para el análisis individual y el análisis comparativo de los portales. 


\section{Introducción}

El presente capítulo conforma, junto con la justificación teórica del capítulo 1 y la teórico-metodológica del capítulo 2, la base sobre la que se fundamenta el trabajo realizado durante los últimos cinco años.

Esta tesis doctoral se cimenta en dos preguntas de investigación a las que damos respuesta a través una investigación multimétodo. En ella integramos dos estudios independientes con un vínculo común, que constituye nuestro objeto de análisis, ya que son sistemas de compartición de contenido digital en el ámbito de la formación, y en concreto, de la formación del profesorado.

Para ello, hemos indagado en estas realidades centrándonos especialmente en variables pedagógicas, tecnológicas y sociales. Somos conscientes de que en el modelo explicativo subyacente a estos escenarios intervienen muchos más aspectos, ya que son objetos complejos, en constante proceso de evolución y en los que influyen variables contextuales, históricas, económicas, políticas y personales, además de las que hemos contemplado.

En el estudio 1: "Estudio de Caso instrumental de Share.TEC", introducimos la sección contextualizando la realidad analizada, justificamos la selección y tipología del caso y, posteriormente, reflejamos sus elementos estructurales: issue, declaraciones temáticas, preguntas informativas, contexto y fundamentos. Hacemos especial hincapié en la descripción profusa del contexto en el que se enmarca el caso, pues consideramos que es relevante comprender cómo se gestó el portal Share.TEC para poder entender el análisis y la interpretación de los datos detallados en el capítulo 4 de esta tesis. Continuamos describiendo el proceso establecido para la recogida y análisis de datos mediante la metodología multimétodo: narrando las técnicas e instrumentos cualitativos y cuantitativos empleados en las tres fases de este estudio: inicial, intermedia y final. Por último, reseñamos las características de los informantes, pertenecientes a diversos contextos culturales y profesionales, y las herramientas en las que nos hemos apoyado en las distintas fases.

Iniciamos la sección del estudio 2: "Portales para compartir contenido digital educativo" describiendo los objetivos de esta investigación, su vinculación con los objetivos de la tesis y los motivos que nos condujeron a su selección. En siguiente lugar, describimos el procedimiento de selección de la muestra de portales educativos, elaborado mediante muestra de juicio, atendiendo a una serie de criterios que predefinimos. Finalizamos el capítulo precisando cómo se construyó el 
modelo de análisis de los portales educativos, y cómo se emprendió el análisis individual y comparativo de los datos.

\section{Objeto de estudio}

Como ya mencionamos en el capítulo 1 de la presente tesis doctoral, la justificación de su necesidad y de su aportación vienen dadas por varios factores, entre los que destacan: la carencia de sistemas para la compartición de contenidos digitales en el ámbito de la formación del profesorado, las reticencias de los formadores de profesores para compartir contenidos digitales con otros formadores a nivel amplio, la diversidad y multiplicidad de sistemas aparentemente desorganizados que existen para compartir y la rápida evolución tecnológica que favorece el desarrollo caótico de todos ellos.

De este modo delimitaremos nuestra investigación a partir del análisis y convergencia del estudio de dos realidades, partiendo de una visión pragmática de la investigación, mediante una metodología multimétodo y con un cariz ontológico y epistemológico principalmente interpretativo:

- Por un lado, nos planteamos (i) analizar de forma profusa el proceso completo de diseño, construcción y puesta en marcha del portal para la compartición de contenidos digitales de la comunidad educativa de formadores de profesores, Share.TEC (que será explicado en el apartado 1 del presente capítulo);

- Por otro lado, (ii) analizar una selección de portales de contenidos digitales existentes en la red, extrayendo de ellos las buenas prácticas y aspectos que pueden mejorarse de los mismos (referentes a la compartición de contenidos del ámbito de la formación del profesorado).

Somos conscientes de la complejidad intrínseca del estudio de esta realidad, dado que sería inabarcable realizar un estudio completo en una tesis doctoral. Asimismo, la temática investigada está en constante evolución, fundamentalmente marcada por el desarrollo vertiginoso de la tecnología.

El objeto de estudio de Share.TEC (i) es de suma relevancia, puesto supone un importante ejercicio conceptual pionero en el campo de la formación del profesorado. Entre sus logros, podemos destacar los siguientes: 
- Diseño y creación de un portal para federar contenido digital de la formación del profesorado disperso en la red.

- Creación de un sistema ontológico de la formación del profesorado.

- Generación de un portal multilingüe de contenidos digitales a nivel europeo.

Debido a la complejidad de la realidad, consideramos que la utilización de un estudio de caso como metodología de investigación, constituye la más apropiada para comprender el primer problema abordado por esta investigación y dar luz a los issues de nuestra investigación, planteados más adelante. Esta metodología nos va a permitir conocer en profundidad cómo se construyó el portal, cómo se generó la toma de decisiones que afectaron al resultado final del mismo y principalmente, nos ha permitido detectar necesidades y preferencias de los usuarios finales de portales de contenidos digitales dirigidos al ámbito de la formación del profesorado.

En el segundo estudio (ii) realizamos un análisis cualitativo exploratorio y comparativo de un conjunto de portales que incluyen contenidos digitales para la formación del profesorado. Explicamos la razón de la inclusión de este estudio en el apartado 6.2.1. Analizamos con un modelo, creado a partir de la revisión de la literatura sobre los portales para la compartición de contenido digital, los portales seleccionados a partir de una muestra de juicio, y abstraemos las características más adecuadas que han de contemplar este tipo de portales.

\section{Objetivos de la investigación}

La propuesta de los principales objetivos de la investigación, que son abordados desde los dos estudios, y que convergen en el capítulo de análisis e interpretación de los datos y conclusiones son:

A. Identificar las necesidades pedagógicas, tecnológicas y sociales de los formadores, y en especial de los formadores de profesores, respecto al contenido digital de diversos contextos europeos.

B. Estudiar las formas de uso, compartición y reutilización de contenido digital de formadores y formadores de profesores de diversos contextos europeos.

C. Analizar portales de contenido digital en el contexto de la formación del profesorado.

D. Explorar y analizar otro tipo de sistemas en los que se produce un intercambio de recursos y conocimiento, y aprehender de ellos las características útiles para los formadores de profesores.

E. Extraer recomendaciones teóricas para generar una propuesta conceptual de diseño y remodelación de portales para la compartición de contenido digital, 
apoyadas en las necesidades de nuestros informantes y en las buenas prácticas de otros portales educativos.

Es decir, consideramos necesario profundizar en esta temática con el objetivo de analizar realidades existentes, conocer las necesidades de los formadores de profesores y proponer soluciones para: conseguir que los sistemas existentes mejoren; y para que los aún no creados tengan en consideración las lecciones aprendidas en otras experiencias, así como las necesidades y preferencias de sus usuarios finales.

\section{Preguntas de investigación}

En esta investigación hemos explorado la realidad de portales para la compartición de contenidos digitales desde diferentes estudios, con el objetivo de comprender desde diferentes prismas la realidad. Los estudios descritos en los apartados 1 y 1 del presente capítulo convergen en las preguntas de investigación de esta tesis doctoral:

1) ¿Qué necesidades pedagógicas, tecnológicas y sociales demandan los usuarios potenciales de portales para compartir contenidos digitales en el ámbito de la formación del profesorado?

2) ¿Qué características ha de tener un sistema para compartir contenido que pueda dar respuesta a las necesidades de los formadores del profesorado?

Cada una de nuestras realidades, mencionadas previamente, ha sido analizada siguiendo un método diferente de investigación, todas ellas bajo el prisma interpretativista.

- En primer lugar, la construcción del portal Share.TEC fue analizada a partir del método de estudio de caso, desde una perspectiva multimétodo para la recogida y análisis de datos (integrando técnicas cualitativas y cuantitativas).

- Desde el análisis de lo acontecido en el portal emergieron categorías (émicas), que nos sirvieron, junto con aquellas extraídas en la literatura (éticas), como guía para la evaluación del segundo objeto de estudio de nuestra investigación, los portales de contenido digital para la formación. Nos aproximamos a la comprensión de la realidad mediante una investigación exploratoria cualitativa para la recogida de datos y de un análisis exploratorio y comparativo cualitativo para el análisis e integración de los datos. 
Para comprender la estructuración de la investigación, veamos la siguiente Ilustración 7 , en la que se refleja de forma sintética la metodología de investigación seguida.

Para construir esta investigación, como hemos explicado en el capítulo 2, se ha utilizado una metodología multimétodo. Nos planteamos un conjunto de objetivos que concretamos en dos preguntas de investigación, a la que damos respuesta a través de dos realidades, por un lado, el Portal Share.TEC, y por otro lado, otros sistemas para la compartición de contenido digital en la formación del profesorado: (ii) portales para compartir contenido digital. En la ilustración podemos ver, en verde, la metodología de investigación y tipo de investigación seguida en cada estudio, en morado, la metodología de recogida de datos, y los tipos de técnicas utilizadas (en cuanto a su calidad de cuantitativas 0 cualitativas 0 ambas), y en naranja, la metodología de análisis de datos. Hemos estudiado cada una de las realidades íntegramente de forma independiente, aunque el estudio de caso Share.TEC ha influenciado en el estudio de las realidad (ii), como veremos más adelante. En el capítulo 4 y 5 , detallaremos el análisis e integración de los datos de cada realidad de forma individual, y de forma conjunta en el capítulo 6, en el apartado de "integración de los datos y recomendaciones para la creación de portales de contenido digital para la formación del profesorado".

Una vez introducidos los objetos de estudio de nuestra investigación, y comprendida cuál es la relación que los une, veamos con detalle las características de cada uno de ellos y la metodología de investigación que hemos empleado para comprender cada objeto de estudio. 
llustración 7 Metodología de investigación de la tesis doctoral

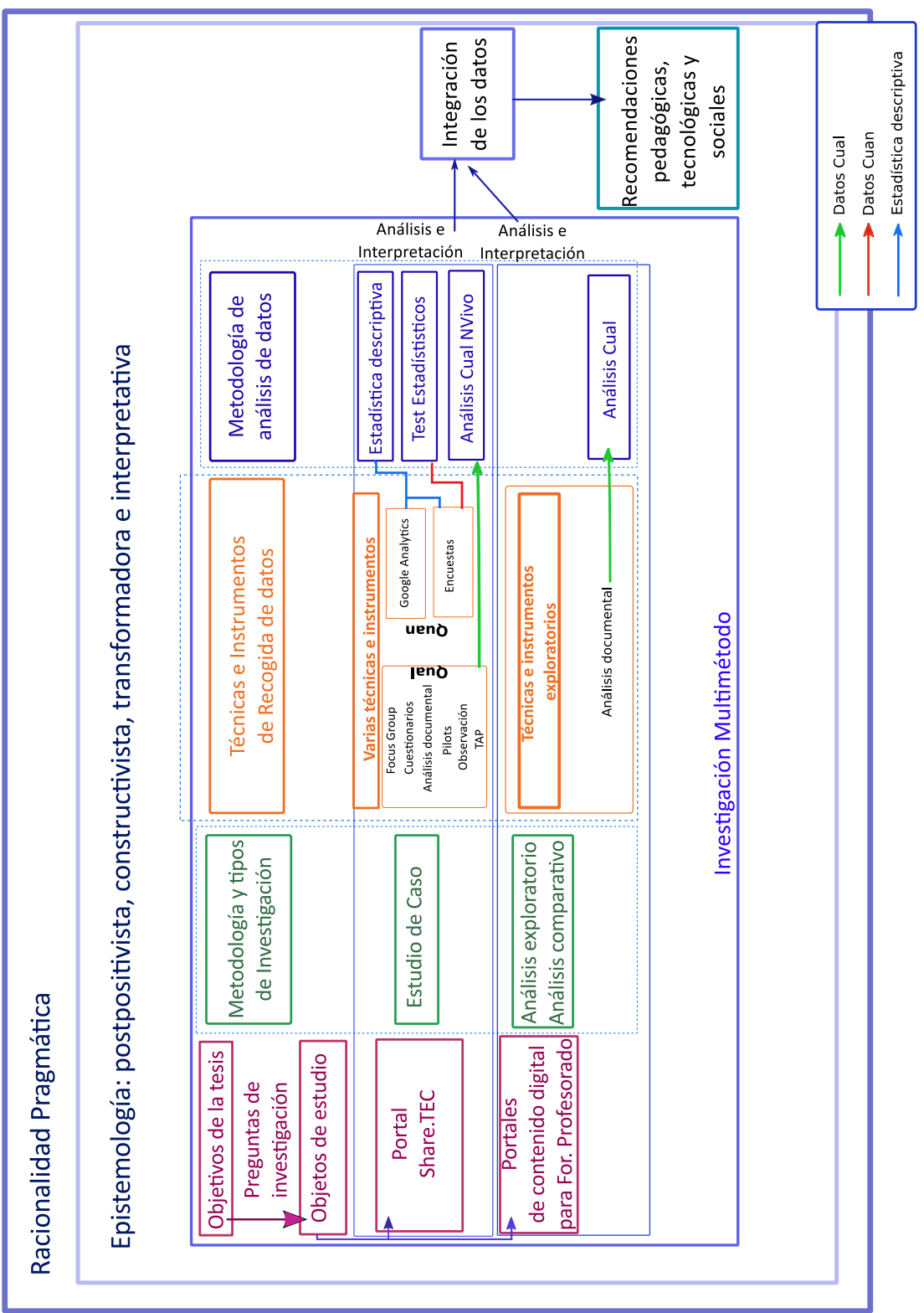




\section{Estudio 1: Estudio de caso Share.TEC}

Durante los últimos años, diversas políticas nacionales e internacionales se han preocupado por la promoción de servicios tecnológicos que permitieran reducir la dispersión del contenido en la red, potenciando programas y proyectos para todas las áreas de conocimiento que trataran de solventar el problema promoviendo un desarrollo de servicios para fomentar la transición de la sociedad de la información a la sociedad del conocimiento (Castells, 2010; Meier, 2012; Tuomi, 2004):

En la última década hemos presenciado cómo la Comisión Europea ha puesto en marcha diversos programas que abordan la promoción de los mismos. En 2001 se lanzó el programa comunitario eContent (20012004)(CORDIS, 2009) de estímulo al desarrollo y al uso de contenidos digitales europeos en las redes mundiales y de fomento de la diversidad lingüística en la sociedad de la información (Unión Europea, 2007). Al finalizarse este programa, se puso en marcha eContentplus (2005-2008), que ha financiado medidas para hacer el contenido digital en Europa más accesible, usable y reutilizable (European Commission, 2008b) por parte de diferentes ámbitos territoriales, nacionales, etc. Este programa ha dado cobertura a tres líneas de contenido digital: Contenido Geográfico, Librerías Digitales (contenido cultural y científico escolar) y Contenido Educativo. Posteriormente se puso en marcha el Programa de Apoyo de las Tecnologías de la Información y la Comunicación (ICT PSP, 2007-2013), que persigue estimular el desarrollo inteligente y el crecimiento inclusivo a través de la rápida adopción y el mejor uso de tecnologías digitales innovadoras y contenidos por parte de los ciudadanos, gobiernos y empresarios. (Carramolino Arranz \& Rubia Avi, 2013, p. 292)

Share.TEC es un proyecto trianual (2008-2011), financiado por el programa eContent Plus (European Commission, 2008b), perteneciente al $7^{\circ}$ Programa Marco de la Unión Europea (adoptado por Decisión del Consejo 2005/456/CE). Este programa pretendía incrementar las posibilidades de acceso, utilización y explotación de los contenidos digitales en Europa, facilitando la creación y difusión de información a nivel comunitario (European Commission, 2008b; Unión Europea, 2005). Los objetivos del programa trataban de dar cobertura a tres líneas de actuación. La primera de ellas, era facilitar el acceso y aprovechamiento de los contenidos digitales a nivel comunitario. La segunda línea consistía en facilitar la mejora de la calidad y fomentar las buenas prácticas de contenidos digitales entre los diferentes tipos de usuario. Por último, perseguía reforzar la cooperación y sensibilización entre los agentes interesados en los contenidos digitales. En este 
marco surgió Share.TEC, a través de una propuesta de proyecto del grupo de investigación italiano "Instituto per le Technologie Didattiche - ITD (Instituto de la Tecnología didáctica) $)^{79}$, miembro del Consejo Italiano Nacional de Investigación.

El proyecto solicitado aspiraba a la creación de un portal federado para compartir, acceder y reutilizar contenidos digitales específicos para el ámbito de la formación del profesorado, atendiendo a las necesidades concretas de estos usuarios. El planteamiento emerge a partir del análisis de la realidad, detectando un número muy bajo de portales de contenidos digitales específicos para la formación del profesorado. Muchas personas relacionadas con el campo de la formación del profesorado crean recursos, pero en el campo educativo existe un síndrome conocido como "not invented here" (no inventado aquí) (Bryant, 2009) que hace referencia a la reticencia de los profesores de utilizar contenidos digitales diseñados para otros contextos educativos (Rodríguez Illera, Escofet Roig, \& Azzato, 2005, p. 4). Además, los portales existentes hasta ese momento carecían de descripciones contextuales y pedagógicas de los contenidos digitales, sumado a la existencia de un gran número de ellos, pero muy dispersos en la red.

Adicionalmente, el trabajo se fundamenta, principalmente en los siguientes aspectos (Carramolino Arranz \& Rubia Avi, 2009, 2013; Share.TEC Consortium, 2008b):

- La inexistencia de redes federadas de recursos destinados a cubrir las necesidades de los formadores de profesores.

- La carencia de una operabilidad semántica, lingüística y cultural de los contenidos digitales para este ámbito, y de especificaciones de metadatos descripciones pedagógicas.

- La ausencia de interoperabilidad entre los sistemas que integran contenidos digitales para este ámbito.

- La escasa personalización que permiten los sistemas existentes

Por tanto, los objetivos del proyecto que tienen relación con nuestra investigación, de entre los planteados en el proyecto Share.TEC, son los siguientes:

79 Los estudios elaborados por este instituto se centran en diferentes temas tecnológicos y educativos, de los cuales, por su vinculación con el presente caso de estudio, destacamos dos: la integración de las TIC en diferentes entornos educativos, y el estudio de la innovación tecnológica como un recurso de aprendizaje (ITD/CNR, 2004). 
- Crear un portal altamente visible y funcional con servicios intermediarios (brokerage), que facilitaran el acceso personalizado a una importante cantidad de contenidos federados.

- Interconectar las bases de datos de recursos para la formación del profesorado, permitiendo el enriquecimiento continuo y la diversificación del servicio.

- Incorporar recursos de diferente tipo que permitieran el autoaprendizaje, el aprendizaje guiado y el aprendizaje colaborativo.

- Permitir que quienes recuperaran los contenidos digitales se formaran una imagen clara de las características pedagógicas de los mismos, lo que preveíamos que fomentaría la reutilización de los recursos en contextos reales.

- Crear una ontología específica para la formación del profesorado, diseñada para capturar una semántica que contemplara varios sistemas educativos y culturales a nivel europeo.

(Carramolino Arranz \& Rubia Avi, 2013, p. 292)

Share.TEC, como proyecto de Desarrollo e Innovación, perseguía convertirse en un punto de referencia para el acceso y compartición de contenidos digitales en el ámbito de la formación del profesorado, que fuera sostenible en el tiempo.

Atendiendo a las líneas del programa y a los objetivos del proyecto, ITD contactó con un equipo de expertos de áreas tecnológicas, pedagógicas y comerciales Tabla 5) para llevar a cabo el proyecto, que da su inicio en julio de 2008, tras ser concedido.

El consorcio estuvo formado por 7 miembros, 6 de ellos, grupos/centros de investigación pertenecientes a instituciones nacionales o universidades públicas, y un miembro comercial (La editorial CLUEB). En cuanto a la procedencia, encontramos representantes de 4 países europeos diferentes: 1 grupo de Bulgaria, España, Holanda, Suecia e Irlanda, y 3 grupos de Italia. 
Tabla 5 Miembros del Consorcio del Proyecto Share.TEC

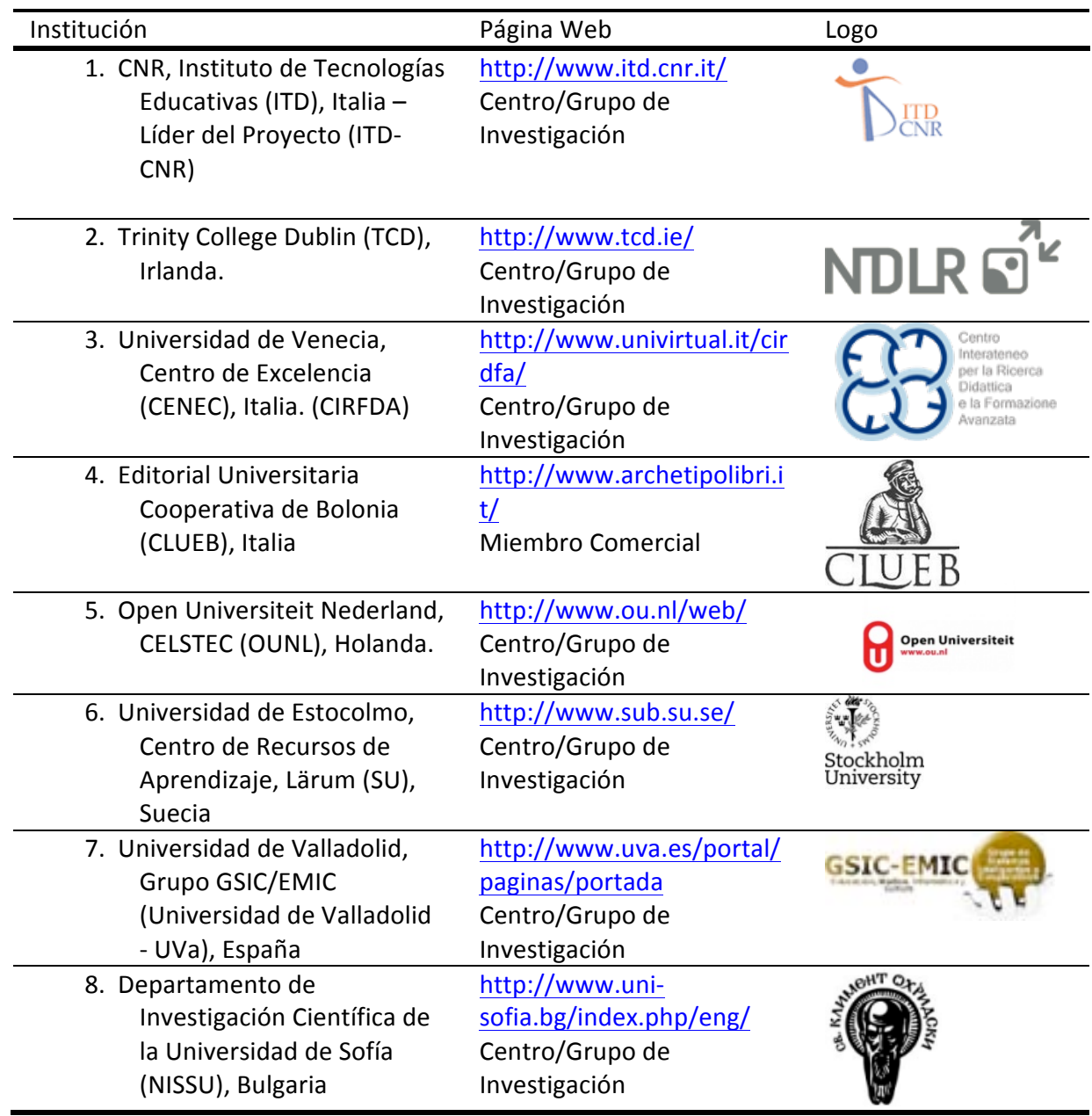

El miembro comercial, CLUEB, fue una editorial italiana que vendía contenido digital para la formación del profesorado, asentada en Bolonia. El equipo ITD-CNR, se encargó de proponer, organizar y liderar, de forma general, el proyecto Share.TEC. Los miembros que desarrollaron la plataforma tecnológica fueron principalmente OUNL, UVa y NISSU. Todos los miembros aportaron contenidos digitales al proyecto, especialmente NISSU, CLUEB y TCD (Gráfico 3) y colaboraron tanto en las tareas técnicas, como pedagógicas y sociales asociadas a este, en mayor o menor medida. CENEC, con sede en Venecia, se encargó de gestionar las 
tareas relacionadas con el contacto y evaluación del portal por parte de los usuarios. El equipo encargado de gestionar las tareas de diseminación del proyecto fue, eminentemente, SU.

La diversidad de los equipos favoreció el enriquecimiento cultural y el resultado del proyecto, pero a la vez, la complejidad a la hora de consensuar acuerdos y generar los diferentes componentes del Portal educativo. La mayoría de los objetivos del proyecto lograron alcanzarse gracias al esfuerzo de cada uno de los socios del proyecto.

Gráfico 3 Número de registros de metadatos incorporados por los diferentes miembros del consorcio Share.TEC.

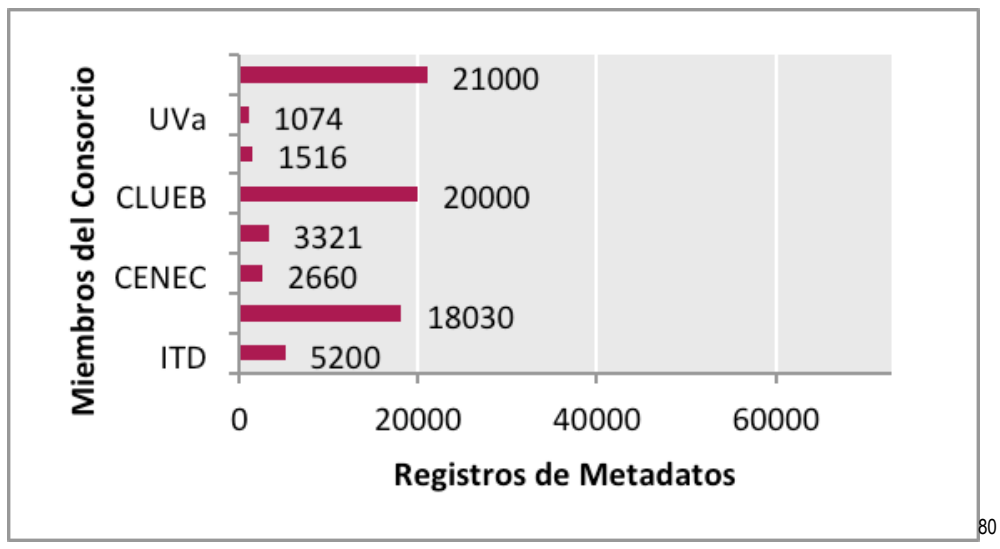

De este modo, analizaremos a partir del método de investigación de estudio de caso los componentes contextuales, factores influyentes y desarrollo investigativo que han tenido lugar a partir de la creación del portal Share.TEC. Nos centraremos en los aspectos pedagógicos, sociales y tecnológicos que han configurado el portal, desde una perspectiva especialmente educativa, a través de la cual trataremos de conocer las necesidades que demandan los diferentes roles relacionados con la formación del profesorado en torno a este tipo de servicios (formadores de profesores, proveedores de contenido, editores, profesores en proceso de formación, etc.). El fin último de este estudio de caso pretende generar una propuesta conceptual de las necesidades que manifiestan estos roles, de modo que

${ }^{80} \mathrm{En}$ el Gráfico 3 representamos los diferentes miembros del consorcio (ver Tabla 5) y el número de registros de metadatos con los que contribuyeron en el portal Share.TEC. 
trabajos futuros relacionados con la creación de servicios de contenido digital para la formación del profesorado puedan tenerlas en cuenta a la hora de generarlos.

Este apartado se centra, en primer lugar, en ubicar el estudio de caso Share.TEC en el marco de la investigación completa de la presente tesis doctoral; continuamos con una descripción del proyecto Share.TEC (sus características, participantes, y servicio generado); posteriormente, describimos la tipología de estudio de caso ${ }^{81}$ (instrumental), los motivos por los que se ha seleccionado el caso, su estructura conceptual y los componentes de esta. Finalmente, describimos cómo hemos llevado a cabo un estudio multimétodo para la recogida y el análisis de los datos, y las técnicas e instrumentos de investigación y roles de los informantes del estudio.

Continuando la línea descrita en el apartado 2 de este capítulo, en el que concretábamos el objeto de estudio de la investigación completa, mencionábamos el estudio de caso Share.TEC como el análisis de una realidad que pudimos conocer de forma directa, siendo actores participantes en el desarrollo de la misma. Share.TEC constituye la concreción de la ideación y realización de un portal para compartir contenido digital en el ámbito de la formación del profesorado a nivel europeo, una experiencia desde la que hemos podido interactuar con profesorado real y generar una plataforma pensada específicamente para este contexto. A través de la participación en el proyecto, consideramos conocer en profundidad los aspectos relacionados con las necesidades de los formadores de profesores respecto al contenido digital para su desarrollo profesional y labor docente. Consideramos que este estudio es el eje principal de nuestra investigación y aquel en el que centraremos nuestros esfuerzos, aunque ampliaremos las lecciones aprendidas y las necesidades de los formadores a través del análisis de otras realidades, mencionadas en el apartado 3 de este capítulo, para alcanzar los objetivos de la tesis.

${ }^{81}$ Existen diversas tipologías de estudio de caso en función de cada autor. Atendiendo a la clasificación realizada por Helen Simons, el nuestro es un "estudio de caso evaluativo" (2011, pp. 43-44). Las otras dos categorías definidas por esta autora son: "estudio de caso dirigido por la teoría o generado por la teoría" y "estudio de caso etnográfico" 


\subsection{EI Grupo GSIC-EMIC}

Esta tesis doctoral tiene su germen en la pertenencia de la autora a uno de los miembros del consorcio Share.TEC, el grupo de investigación GSIC-EMIC (Grupo de Sistemas Inteligentes y Cooperativos - Educación, Medios, Informática y Cultura) ${ }^{82}$. Este equipo de investigación, cuyo origen se remonta a 1994, está formado por más de 20 personas provenientes de diversas áreas: Ingeniería en Telecomunicaciones, Ingeniería Informática, Ciencias de la Educación, Pedagogía, Psicopedagogía, etc. Como todo grupo social, a lo largo de sus 20 años, ha ido evolucionando y definiendo su perfil e intereses en función de diversos aspectos, tales como el perfil e intereses de las personas que ha ido componiendo el mismo y los avances tecnológicos y educativos que han ido aflorando en estos años.

Los puntos de convergencia de este grupo de personas tan heterogéneas son de carácter simbiótico: mejorar la educación a partir del desarrollo de tecnologías orientadas a su servicio, y a su vez, realizar avances tecnológicos partiendo del campo educativo. En la diversidad del grupo se encuentra la riqueza y la experiencia valiosa de poder intercambiar ideas y realizar producciones conjuntas, a partir del afrontamiento de los problemas desde las distintas "gafas" que aporta cada componente. Los principales campos de trabajo del grupo son: (1) Los Sistemas Inteligentes, que incluyen redes neuronales y sistemas neuro-difusos, con especial interés en los modelos derivados de la Teoría de Resonancia Adaptativa (ART) y (2) Los Sistemas Cooperativos, es decir en CSCW83 (Computer Supported Cooperative Work) con especial énfasis en $\mathrm{CSCL}^{84}$ (Computer Supported Collaborative Learning) (GSIC-EMIC, 2010). Durante su trayectoria, el grupo ha participado en múltiples proyectos de investigación regionales, nacionales, e internacionales, estableciendo redes con equipos de notable importancia en el contexto internacional.

El grupo líder del proyecto Share.TEC, ITD, tenía buena relación y experiencia de colaboración previa con el líder del grupo GSIC-EMIC, Ioannis Dimitriadis, y con algunos de sus componentes, por lo que conocían el tipo de trabajo que desarrollaba el grupo, especialmente en cuanto al CSCL y CSCW. Algunas de las líneas de investigación del GSIC-EMIC estaban centradas en investigar y desarrollar

${ }^{82}$ Página Web del Grupo de Investigación reconocido por la Universidad de Valladolid GSICEMIC http://www.gsic.uva.es

${ }^{83}$ Trabajo Colaborativo apoyado por ordenador

${ }^{84}$ Aprendizaje Colaborativo apoyado por ordenador 
diferentes tipos de soluciones tecnológicas y modelos para mejorar el aprendizaje gracias al apoyo de la tecnología (tales como el proyecto mosaicLearning ${ }^{85}$, Grid and Peer-to-Peer Middleware for Cooperative Learning Environments ${ }^{86}$, BibliotecasHíbridas: Sistemas y servicios avanzados para acceder a sitios de información virtual y física ${ }^{87}$, etc).

El equipo de trabajo de GSIC que participamos en Share.TEC, lo conformamos 7 personas: 4 ingenieros de telecomunicaciones, una ingeniera informática, un pedagogo y una psicopedagoga, por lo que constituíamos un equipo capaz de abordar las diferentes tareas de los paquetes de trabajo del proyecto Share.TEC, tal y como desarrollamos más adelante.

\subsection{Descripción de los elementos del caso}

Tras esta visión general de Share.TEC, en la que hemos realizado un recorrido sobre el trabajo desarrollado, sus partes fundamentales y hemos presentado las funcionalidades que presenta Share.TEC, ahondamos en los elementos que definen el estudio de caso Share.TEC. Para ello, en primer lugar, mostramos una visión holística del caso, y nos servimos de una representación gráfica de los elementos estructurales que lo componen. Posteriormente, especificamos cada uno de estos elementos, de modo que el lector pueda comprender el caso globalmente.

\subsubsection{Tipología y selección del caso: estudio instrumental de} casos

Abordamos nuestra investigación a partir de la metodología de estudio de caso de tipo instrumental (Stake, 2007), puesto que el caso Share.TEC constituye un pretexto para acercarnos al fenómeno de la compartición de contenido digital en el ámbito de la formación del profesorado. De este modo a partir de esta realidad conoceremos mejor otras realidades análogas de generación de portales educativos para compartir contenido digital en nuestro ámbito de interés.

85 Mosaic Learning: Aprendizaje electrónico móvil, de código abierto, basado en estándares, seguro, contextual, personalizado y colaborativo https://www.gsic.uva.es/proyectos.php?lang=es\&pld_p=7

86 Software intermediario de computación grid y red entre pares para entornos de aprendizaje cooperativos https://www.gsic.uva.es/proyectos.php?lang=es\&pld_p=1.

${ }^{87}$ https://www.gsic.uva.es/proyectos.php?lang=es\&pld_p=8 
A la hora de escoger un estudio de caso [..], en [...] ocasiones, nos encontraremos con una cuestión que se debe investigar, una situación paradójica, una necesidad de comprensión general, y consideramos que podemos entender la cuestión mediante el análisis de un caso particular. [...]. La finalidad de este estudio de casos es comprender otra cosa. Podemos llamar a esta investigación estudio instrumental de casos.(1995, pp. 16-17)

De acuerdo con el extracto del libro de Stake, consideramos esta metodología como la más oportuna para nuestro estudio de caso por diversas razones, entre las que señalaremos las que consideramos más relevantes. En primer lugar, Share.TEC constituye un ejemplo específico de creación de un portal educativo para el ámbito concreto de la formación del profesorado, siendo este tipo de portales tan especializados relativamente escasos. Además, ejemplifica un intento de unificación conceptual y lingüística a nivel pedagógico entre diferentes países europeos. Por último, el portal Share.TEC lo construimos entre diferentes entidades europeas que conformamos un equipo multidisciplinar, contando con especialistas de diversas áreas: pedagogía, psicología, economía, marketing, ingeniería de telecomunicaciones, ingeniería informática, etc., hecho que nos permitió conocer de manera global las necesidades que requiere a nivel pedagógico, tecnológico, económico y social la creación de este tipo de portales o servicios. De este modo, consideramos que el estudio en profundidad de la realidad de Share.TEC como ejemplo de portal educativo multicultural para la formación del profesorado, puede ser interés para la comunidad científica en orden a generar o mejorar este tipo de portales o servicios que contemplen contenidos digitales destinados a este ámbito.

\subsubsection{Elementos estructurales del caso de Estudio}

\section{A) Selección del caso}

En 2011, consideramos oportuno seleccionar la temática de generación de portales educativos para la formación del profesorado como objeto de estudio de la tesis doctoral, a partir del estudio instrumental de caso Share.TEC, que sería cumplimentado con el estudio de otros portales y realidades de compartición de contenido en el ámbito de la formación del profesorado. Los motivos principales hacían referencia a:

- la importancia que, como formadores de profesores, consideramos que emanaba la temática, puesto que la existencia de servicios de contenidos digitales especializados para este campo es limitada, y apreciamos su 
necesidad y demanda a partir de las diferentes pruebas que realizamos con usuarios;

- la facilidad de acceso al contexto y la existencia de datos relevantes para nuestra investigación, que recopilamos a lo largo del proyecto y tras su finalización;

- el conocimiento de la compleja realidad adquirido durante los tres años de participación activa en el Share.TEC.

- Consideramos que los datos que se obtuvieron en el proyecto no fueron explotados de manera suficiente para concretar las necesidades que requerían estos usuarios, y además, concebíamos esta experiencia como una excelente oportunidad para analizar los aciertos y errores que se manifestaron en la realización del portal, con el objetivo de aprovechar las lecciones aprendidas para trabajos futuros.

- Y por último, la necesidad de mejorar estos servicios para dar respuesta a las necesidades de la sociedad actual, que queda reflejada en diferentes normativas e informes europeos (European Commission, 2007, p. e.g., 2010b, 2013c, 2014).

\section{Marco general del caso:}

La imagen que utilizaremos para representar los elementos que componen el caso se basa en los trabajos de Robert Stake (2005) y en la adaptación realizada por Jorrín Abellán (2006, p. 103). Hemos elegido esta representación porque consideramos que es una forma sencilla, clara y multimodal de mostrar los elementos que componen el caso, de modo que facilite la comprensión del caso y el análisis a través de sus componentes (Jorrín Abellán, 2006).

En el círculo central de la llustración 8 observamos tres zonas diferenciables a primera vista: por una parte, un círculo central, recoge los aspectos relativos a la recogida y análisis de datos; por otra, dos rectángulos superiores externos al círculo, que simbolizan los contextos y fundamentos que lo configuran y contribuyen a su idiosincrasia. Por último, en la zona inferior podemos ver la estructura conceptual que define el proceso de investigación (declaraciones temáticas y preguntas informativas), y que puede consultarse en detalle en la Tabla 6. Por último, el último componente estructural reflejado en la llustración 14 hace referencia a la selección de Técnicas, Documentos y Participantes, en la que nos centramos en el siguiente apartado. 


\section{B) Estructura conceptual}

En la zona inferior de la llustración 8 encontramos dos rectángulos que recogen las bases en las que se sustenta el caso, el issue, 5 declaraciones temáticas y las preguntas informativas en las que estas se desglosan.

Los elementos mencionados constituyen los componentes estructurales y conceptuales de nuestro estudio de caso, que abordaremos en profundidad para dar respuesta al issue, una vez se haya realizado la integración y análisis de los datos recopilados.

\section{Issue}

Empleando la orientación del estudio de caso de Stake (2007), planteamos el siguiente issue que nos permitirá comprender en profundidad la singularidad y complejidad del caso en su contexto:

¿Cómo se relacionan los servicios que ofrece Share.TEC a nivel pedagógico, tecnológico y social para atender las necesidades requeridas por los usuarios potenciales de los sistemas de acceso y compartición contenido digital en el ámbito de la formación del profesorado?

Este tema controvertido nos guiará hacia el conocimiento de qué necesidades manifiestan los formadores de profesores a la hora de acceder y compartir contenidos digitales en el ámbito de la formación del profesorado. Partiendo de la realidad concreta de Share.TEC, podremos extraer unas conclusiones genéricas que nos guiarán en el propósito último de esta tesis doctoral, que es generar unas recomendaciones acerca de los requisitos y características que deben contemplar los sistemas para compartir contenidos digitales para la formación del profesorado.

\section{Aserto}

Teniendo en cuenta el issue formulado, explicitamos el aserto de investigación que ha de ser iluminado por los resultados que obtengamos en el proceso:

Aserto: "Consideramos que los servicios que ofrece Share.TEC a nivel tecnológico, pedagógico y social se adaptan a las necesidades requeridas por los formadores de profesores cuando acceden y publican en portales web contenido digital y experiencias educativas en el ámbito de la formación del profesorado". 


\section{Ilustración 8 Elementos estructurales del Estudio de Caso Share.TEC}

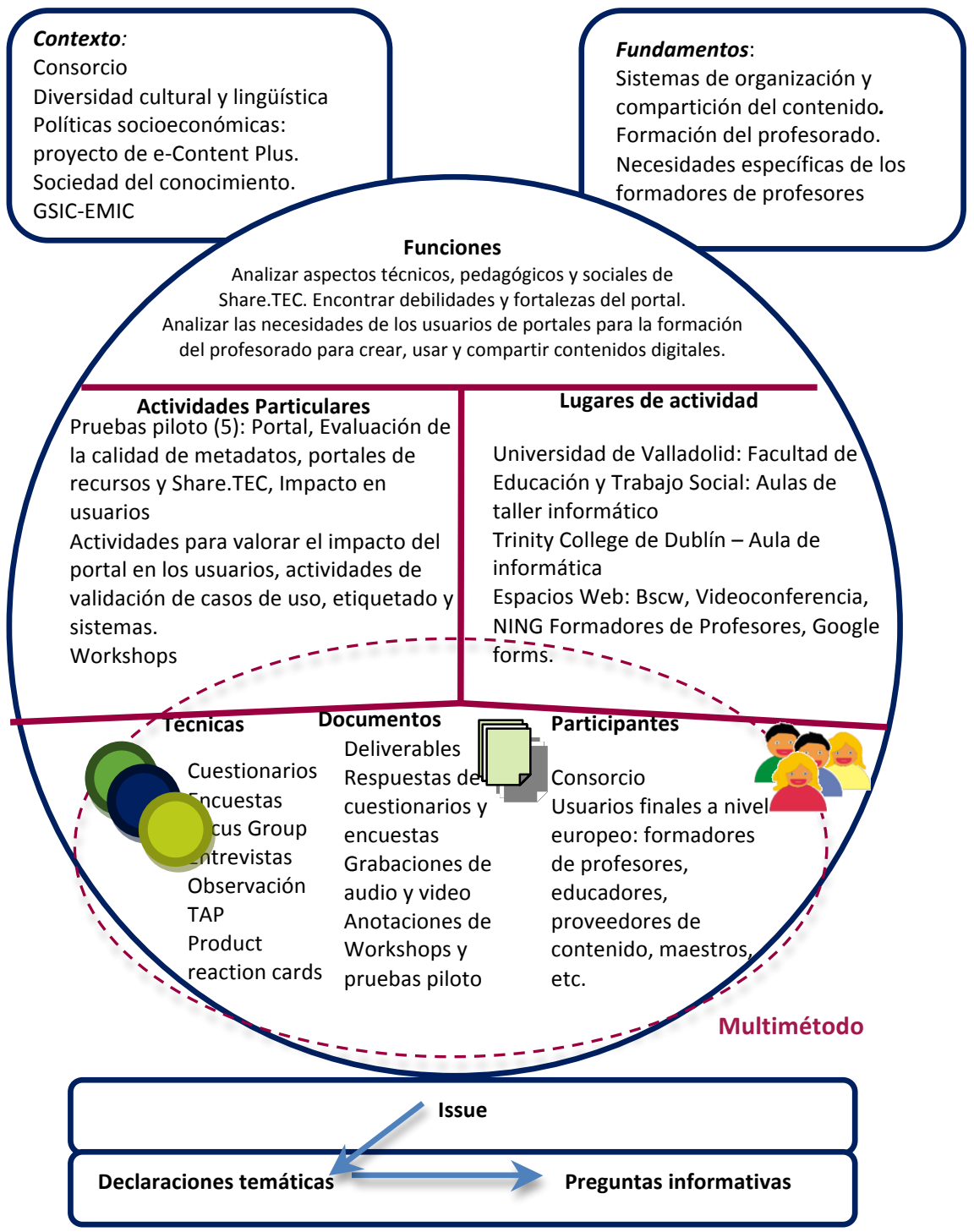




\section{C) Declaraciones temáticas y preguntas informativas}

Las declaraciones temáticas facilitan al investigador describir el conjunto de aspectos que influyen y concretan el issue. A su vez, estas declaraciones temáticas se desglosan en preguntas más particulares, llamadas preguntas informativas, que permitirán iluminar los temas y el issue planteados. Las preguntas informativas son preguntas concretas que nos permiten indagar sobre los aspectos que componen una declaración temática.

En un diseño de investigación cualitativa los temas emergen y se van redefiniendo a medida que avanza la investigación. Inicialmente el investigador plantea categorías y preguntas "éticas", basadas en lo que conoce sobre la temática, desde su perspectiva, antes de tener en cuenta las voces de los implicados en la investigación; a medida que avanza en el caso, emanan temas desde las perspectivas de los informantes en la investigación o desde el análisis de los datos, lo que se conoce como temas "émicos" (Stake, 2007). El investigador crea una lista de preguntas flexible, redefine progresivamente los temas, y valora las oportunidades de aprender lo imprevisto ${ }^{88}$ (Stake, 1995, 2010). Tras varios procesos de redefinición de las declaraciones temáticas, preguntas informativas y el esquema de categorías a partir de varios procesos de análisis, nuestro caso de estudio se compone de las siguientes declaraciones temáticas y preguntas informativas (véase Tabla 6).

Por último, el último componente estructural reflejado en la llustración 8 hace referencia a la selección de Técnicas, Documentos y Participantes, en la que nos centramos en el siguiente apartado.

${ }^{88}$ Este proceso es denominado por Stake: "Progressive focussing", que traducimos como "focalización progresiva". Stake se refiere a éste como el proceso donde los significados, la recogida de datos, los issues planteados y los resultados previsibles, van evolucionando y cambiando a lo largo del estudio. 
Tabla 6 Declaraciones temáticas y preguntas informativas del Estudio de Caso Share.TEC

\section{DECLARACIONES TEMÁTICAS Y PREGUNTAS INFORMATIVAS}

\section{ASPECTOS PEDAGÓGICOS}

¿Qué modelo pedagógico subyace a Share.TEC?

¿Es compartida la ontología subyacente a Share.TEC por los formadores de profesores y otros profesionales de la educación?

¿El etiquetado de metadatos de los contenidos digitales en Share.TEC es adecuado según los Formadores de profesores y otros Formadores?

¿Los contenidos que ofrece Share.TEC son útiles para los Formadores de profesores y otros Formadores?

¿Es la multiculturalidad un aspecto demandado y útil en este tipo de sistemas para los formadores de profesores?

¿Qué ventajas pedagógicas aporta Share.TEC frente a otro tipo de sistemas?

¿Cómo ha sido utilizado el portal Share.TEC?

$¿$ ¿s necesaria la existencia de un sistema similar a Share.TEC para compartir y reutilizar contenido digital educativo y experiencias?

¿Qué hábitos de uso y compartición de contenidos digitales presentan los formadores que usaron Share.TEC?

\section{ASPECTOS TÉCNICOS DEL SISTEMA SHARE.TEC}

¿Qué opinan los formadores de profesores del servicio de búsqueda ofrecido por Share.TEC? ¿Qué funcionalidades demandan los formadores de profesores para este tipo de sistemas y qué opinan de las ofrecidas en Share.TEC?

¿Es apropiada la interfaz de Share.TEC?

¿Constituye Share.TEC un sistema usable y accesible?

\section{ASPECTOS SOCIALES}

¿Qué piensan los Formadores de profesores sobre compartir contenidos digitales para la formación del profesorado?

¿Qué utilidades sociales oferta Share.TEC y cómo han sido utilizadas?

¿En qué redes profesionales participan los usuarios de Share.TEC y qué ofrecen éstas en oposición a Share.TEC?

\section{ASPECTOS PERSONALES}

¿Las funcionalidades de personalización ofrecidas por Share.TEC son adecuadas para los usuarios?

¿Qué factores motivacionales favorecen/limitan la participación de una persona en Share.TEC?

\section{ASPECTOS ECONÓMICOS}

¿Qué hábitos de compra manifiestan los formadores que utilizaron Share.TEC? ¿Qué tipo de contenidos digitales son más comprados por los formadores y dónde los adquieren? 


\section{D) Contexto y fundamentos}

En el apartado de "Contexto" se representan los elementos que rodean al caso que más influencia han tenido en el devenir del estudio de caso de Share.TEC. Hemos de enmarcar el estudio en el momento sociocultural actual en el que nos encontramos, donde determinadas políticas de la unión europea tratan de dar soluciones a las demandas de la sociedad del conocimiento relativas a todos los ámbitos productivos de la sociedad, entre ellos, los que hacen referencia a la educación y la optimización de los recursos digitales que se producen en determinados contextos, como ya hemos descrito en profundidad en el capítulo 1 de esta tesis. En este contexto, hemos de tener en cuenta las circunstancias que rodean a los diferentes miembros del consorcio de Share.TEC, así como su interrelación y trabajo colaborativo para lograr la creación de este portal, así como comprender la conexión entre esta tesis doctoral y la existencia del grupo GSICEMIC.

Definimos Share.TEC (European Commission, 2011b) (ECP-2007-EDU-427015) como un proyecto europeo de Desarrollo e Innovación cuyo resultado final constituye la creación de un portal para compartir contenido digital en el ámbito de la formación del profesorado a nivel europeo. Una de las principales contribuciones del proyecto fue la de generar un sistema de contenidos digitales etiquetados en varios idiomas con metadatos técnicos y pedagógicos (en base a un modelo creado por los miembros del proyecto basado en el estándar LOM $^{89}$ que principalmente han añadido las descripciones pedagógicas).

El proyecto estaba estructurado en 7 paquetes de trabajo (WP'0):

- WP1- Gestión del proyecto

- WP2- Ontología y modelo de metadatos

- WP3- Interoperabilidad

- WP4-Usabilidad

- WP5-Plataformas y Servicios Integrados

- WP6- Asesoramiento y Evaluación; y WP7- Concienciación, Diseminación y sostenibilidad

89 LOM, siglas en ingles de Learning Object Model (en español, Modelo de Objetos de Aprendizaje). Este concepto aparece definido en el Capítulo 1 de esta tesis doctoral (IEEELOM).

90 Paquete de trabajo, en inglés, Work Packages (WP) 
A continuación presentamos los diferentes paquetes de trabajo que constituyen el proyecto, para entender cómo y con qué temporalización se crearon las diferentes partes del portal, y qué aspectos lo conformaron.

WP1 "Gestión del proyecto, reuniones de trabajo y evolución general en el tiempo"

ITD se encargó de la Gestión del Proyecto (WP1) (Share.TEC Consortium, 2008b, p. 4). Los miembros se coordinaron mediante videoconferencias, intercambio de correos, reuniones presenciales de trabajo, workshops, etc. El principal medio para la compartición, discusión de puntos concretos mediante foro y gestión de documentos, fue un BSCW (plataforma privada de gestión de contenidos e información).

A lo largo del proyecto tuvieron lugar 5 workshops grupales en los que participaron expertos y profesores que proporcionaron su experiencia y feedback para mejorar el portal.

En 2008, en el encuentro inicial en Génova (Italia) y en la conferencia WWC en Milán ${ }^{91}$, se fraguó la idea de crear Share.TEC como un portal sostenible, pensando que tras su finalización seguiría en funcionamiento activo gracias a la incorporación al portal de diversas editoriales de contenido digital (Share.TEC kickoff apuntes, 2008); la plataforma se perfila como un portal federado de metadatos, adaptado al usuario, que integraría herramientas para crear una comunidad de formadores de profesores, y que estaría basado en estándares, así como en especificaciones técnicas y ontológicas, teniendo en cuenta una dimensión multicultural, multinacional y multilingüística (Anexo 1, Anexo 2 y Anexo 3).

En febrero de 2009 se organizó una reunión de trabajo en la Isla de San Sérvolo, Venecia (Italia), donde se explicita la dificultad de alcanzar los ambiciosos objetivos de Share.TEC en un tiempo tan breve (tres años), por lo que los miembros del consorcio fuimos conscientes de que tendríamos que priorizar objetivos para cumplir con las exigencias de la evaluación de la Unión Europea. En este momento se abordaron los temas relacionados con la ontología y Modelo Multicultural de Metadatos que se trataban de construir para el proyecto. Ya en esta fase inicial del proyecto, los miembros nos dimos cuenta de la necesidad de diseñar en el poco tiempo disponible un producto útil, sencillo y valioso para los usuarios finales, pues era la forma de conseguir involucrar a comunidades reales de profesorado en el sistema (Anexo 4).

91 http://www. fipip.org/wcc2008/site/congress.php.html 
En Julio de 2009 se celebró un encuentro en Dublín, al que atendimos los miembros del consorcio y expertos del área tecnológica, económica y pedagógica. Los usuarios probaron la versión inicial a través de una prueba piloto generada por el consorcio y aportaron su valioso feedback (Anexos 5, Anexo 6, Anexo 7 y Anexo 8)

En noviembre de 2009, la sede de la reunión de trabajo se fijó en Bolonia. La evaluadora del proyecto, Claire Belise ${ }^{92}$, evaluó positivamente el primer año del proyecto, habiendo conseguido muchos de los objetivos planteados, aunque sugirió una serie de recomendaciones para fortalecer los puntos débiles del proyecto hasta ese momento. El consorcio anticipó serias dificultades para superar los objetivos de las fases siguientes, pues el portal contaba con diversas dificultades técnicas que impedían que se pudiera involucrar masivamente a comunidades de usuarios por temor a que los usuarios no desearan utilizar con posterioridad el portal; de este modo, se optó por trabajar con pequeñas comunidades locales, cercanas a cada uno de los países del consorcio. En este momento seguía sin estar claramente consensuado cómo se iba a tratar la multiculturalidad (Anexo 9).

En Junio de 2010, de nuevo en Bolonia (Italia), se celebró una reunión de los miembros del consorcio en la que, de nuevo, salió a la luz la preocupación por la multiculturalidad, puesto que el portal, hasta este momento, sólo había conseguido ser multilingüe. Un asesor experto del proyecto aportó posibles soluciones para fomentar la sostenibilidad del portal (por ejemplo, incrementar sustancialmente el número de recursos, mejorar las funcionalidades e interfaz existentes, y tener en cuenta las tendencias de la educación, para dar cobertura a las necesidades previsibles (Anexo 10 y Anexo 11).

En 2011, tuvo lugar la última reunión de trabajo, en Bruselas, en la que se pusieron en común los aspectos pendientes para superar la evaluación final del proyecto, y se tomaron las medidas prácticas para cubrir los objetivos del proyecto.

${ }^{2}$ Claire Belise es una Psicóloga Social, Doctora en Psicología por la Universidad de Lyon y experta en investigación. Su perfil abarca las áreas tecnológicas, pedagógicas y sociales relativas a los portales de contenidos digitales. Entre sus temas de investigación destacamos el estudio de las nuevas formas de presentación de la información; las modificaciones y transformaciones en las prácticas de investigación de la información y su reproducción en medios digitales; la investigación sobre la integración de las TIC en la educación abierta y a distancia; estudio de la navegación dentro de los documentos hipermedia y en la red. 


\section{WP2 "Construcción de la Ontología y Modelo de Metadatos y del Portal"}

Este paquete de trabajo estuvo liderado por ITD y TCD, orientado a la creación de las estructuras semánticas que permitieran la organización del contenido (Share.TEC Consortium, 2008b, p. 26).

\section{Construcción de TEO - "Teacher Education Ontology"}

Los formadores de profesores que buscan contenidos a nivel europeo se encuentran con repositorios con grandes barreras lingüisticas y culturales para ellos, muchas veces basados en modelos de metadatos poco familiares (Alvino, Bocconi, Boytchev, Earp, \& Sarti, 2009; Alvino, Bocconi, \& Sarti, 2008; Earp, 2008; Lavagnino, Bocconi, Earp, \& Sarti, 2010; Share.TEC Consortium, 2008b). Como solución a este problema se propuso desde el proyecto la creación colaborativa de una ontología para la formación del profesorado de diferentes nacionalidades y contextos educativos, así como referencias internacionales. Esta ontología proporcionó la base de dos componentes clave interrelacionados: el Modelo Común de Metadatos (CMM) y un perfil de aplicación ad hoc basado en LOM (Learning Object Model) como modelo de referencia para el Modelo Multicultural de Metadatos (MMM), vía mediante la que se pueden generar instancias culturales y lingüísticas específicas del modelo de referencia. La pertinencia de crear esta ontología radicaba en la posibilidad de definir de manera colaborativa entre los diferentes equipos del consorcio aquellos conceptos que son relevantes en un dominio, así como las relaciones que vinculan esos conceptos. Además, proporcionaba un vocabulario no ambiguo y consistente para identificar esos conceptos. Las ontologías, aunque proveen restricciones semánticas entre conceptos, permiten aumentar el nivel de reutilización de los contenidos (Share.TEC Consortium, 2008b). El valor añadido de Share.TEC residía en la elaboración de un perfil de aplicación de LOM al que se incorporan metadatos específicos para el ámbito de la Formación del Profesorado en Europa.

Pero, ¿cómo se construye?. Dado que el portal necesitaba una base lógica de organización de conceptos, es decir, una descripción del mundo de la formación del profesorado, fue necesario definir una ontología que satisficiera sus necesidades. Existían diversos modelos genéricos de la descripción de metadatos en el campo de la educación tales como la Iniciativa de Metadatos de Dublin Core ${ }^{93}$ - DCMI; Modelo de Objetos de Aprendizaje- IEEE LOM; y ADL SCORM ${ }^{94}$ (AENOR, 2009; IEEE,

${ }^{93}$ Dublin Core Metadata Initiative

${ }_{94}$ SCORM Shareable Content Object Referente Model 
2002a; Share.TEC Consortium, 2008b), pero ninguna que se ajustara a los requerimientos específicos de este campo, y que fuera ajustable a la idiosincrasia cultural de diversos contextos internacionales.

El consorcio configura la ontología a partir de una mezcla de modelos que fueron adoptados y adaptados específicamente para describir el mundo de la formación del profesorado en Europa (Dorn, Naz, \& Pichlmair, 2007; Paquette, Léonard, de la Teja, \& Dessaint, 2002; Wiley, 2002) (Anexo 12).

Modelo de Metadatos

Los estándares de metadatos, e.g., IEEE LOM, tienen una capacidad limitada para ofrecer una visión completa y ajustada al mundo de la educación. Para solventar este problema se venían desarrollado dos tipos de soluciones contempladas en diversos estudios, tales como definir metadatos pedagógicos basados en el análisis de los usuarios potenciales, o definir perfiles de aplicación de acuerdo con la orientación y objetivos de comunidades de usuarios específicos. Estos estudios muestran la complejidad de generar un modelo de metadatos pedagógicos apropiado para ser utilizado de manera satisfactoria por una variedad de comunidades de usuarios.

El equipo líder del proyecto, ITD, había colaborado previamente con otro grupo de investigación italiano, IMATI, para generar un modelo que combinara las dos soluciones aplicadas al problema, contemplando la generalidad y la flexibilidad, para que fuera compartido entre diferentes comunidades, pero, a la vez fuera adaptable a la especificidad de cada una de ellas (Alvino, Forcheri, lerardi, \& Sarti, 2008; Alvino, 2008).

Los autores crearon un modelo extensible para metadatos pedagógicos, IMATIITD, que incluía un conjunto de descripciones como marco común para capturar las características de los Objetos de Aprendizaje; y para cada comunidad y cada descriptor, un vocabulario de posibles valores que representara la concepción de esa comunidad específica. Este modelo integraba descripciones de los estándares de metadatos internacionales con otras nuevas, con el objetivo de identificar el contexto de uso, las características educativas, la estructura y la aproximación al aprendizaje del recurso.

Para crear el modelo realizaron un ciclo iterativo de evaluación de la propuesta por diversas comunidades de formadores, desarrollando un modelo de metadatos pedagógicos extensible al que denominaron POEM (Pedagogy Oriented Educational Metadata - Metadatos Educativos Orientados Pedagógicamente). Este modelo fue 
validado por 89 profesores en proceso de formación para el nivel de Bachillerato, a través de un cuestionario que contestaron tras una fase de entrenamiento en el modelo para su validación(Alvino, Forcheri, lerardi, \& Sarti, 2009).

El proceso de construcción de la ontología y modelo de metadatos en Share.TEC parte de POEM, dado que su configuración se adecuaba en gran medida al contexto de la formación del profesorado. ITD, como creador, lo reconfiguró para ajustarlo al contexto de Share.TEC, y ofreció una nueva propuesta a los miembros del consorcio para su evaluación. Cada equipo de Share.TEC se encargó de proponer la modificación de aspectos de este modelo para adecuarlo a la estructura educativa de su país. En nuestro caso (UVa) esta tarea requirió de la realización de unos cuadros comparativos entre la parte de la ontología que definía la estructura de los niveles educativos y los estudios correspondientes a cada uno de ellos, así como las áreas de conocimiento, competencias, etc., con la documentación que definía en aquel momento la estructura general del sistema educativo español (titulaciones por área de conocimiento y por nivel) $)^{95}$.

Este proceso se equiparó con relativa sencillez, aunque en algunos casos encontramos dificultades debido a la diferente ordenación entre la ontología general propuesta y los niveles educativos de España, así como los títulos de Formación Profesional que se presentaban, pues algunos no existían en España y otros eran concebidos de forma diferente (por ejemplo, en un mismo ciclo se abordaban estudios desglosados en dos ciclos; o lo que en un país era un ciclo, en otro era una diplomatura) (Ministerio de Educación y Ciencia, 2007a; Ministerio de Educación y Ciencia, 2007b; Ministerio de Educación y Ciencia, 2007c; Ministerio de Educación y Ciencia, 2007d; Ministerio de Educación, Cultura y Deporte, n.d.).

A través de un foro interno, alojado en la plataforma de trabajo cooperativo (BSCW) del consorcio, comentamos las sugerencias de modificación y adaptación de la ontología a nuestro contexto, e ITD se encargó de generar la versión definitiva de la ontología: TEO v.2.0 (generando un documento que fue revisado de nuevo por los diferentes socios y finalmente matizado). Cada socio creó la traducción de los

${ }^{95}$ Podemos ver un ejemplo de cómo realizamos el cotejo de la relación entre las categorías establecidas en la Ontología de Share.TEC referentes a "competencias", y las competencias que se proponían los nuevos planes de estudio de la Universidad de Valladolid en el Plan de Formación de Maestros de Educación Primaria. Maestros de Educación Primaria en los Anexos de esta tesis doctoral, en la carpeta de "Anexos no indexados en la memoria de la tesis": "Relación entre competencias.xls". 
campos educativos adaptándolos a la idiosincrasia de su contexto, construyendo entre los diferentes socios el MMM (Modelo Multicultural de Metadatos).

La interfaz del sistema también aparecía traducida en diversos idiomas. Los usuarios registrados en Share.TEC se asociaron con perfiles basados en una ontología, teniendo acceso así a conceptos clave y relaciones lingüísticas y culturalmente vinculadas.

Como podemos observar en la llustración 9, la ontología está formada por dos capas jerárquicas. La primera de ellas (ver rectángulo grande de la parte superior de la figura) constituye el nivel común superior de referencia de la ontología, en este caso, la ontología genérica de la formación del profesorado en Europa; el segundo rectángulo grande situado en la parte inferior de la ilustración representa las instanciaciones de contextos específicos de la ontología para la formación del profesorado (adaptados al idioma y características particulares de la organización educativa de cada contexto). Así, cada ontología específica (contextual) es una instancia de la ontología general, y permite la incorporación progresiva de nuevas especificaciones en otros idiomas o lenguas. La ontología de Share.TEC tiene 9 subcategorías principales; cada una de ellas, a su vez, desglosa sus propios conceptos jerárquicos. Para que una ontología sea tal, ha de contemplar las relaciones entre sus componentes y la descripción de los mismos. 
llustración 9 Representación de las capas de la ontología de Share.TEC. Elaboración Propia, basada en el Share.TEC Cosortium, 2008

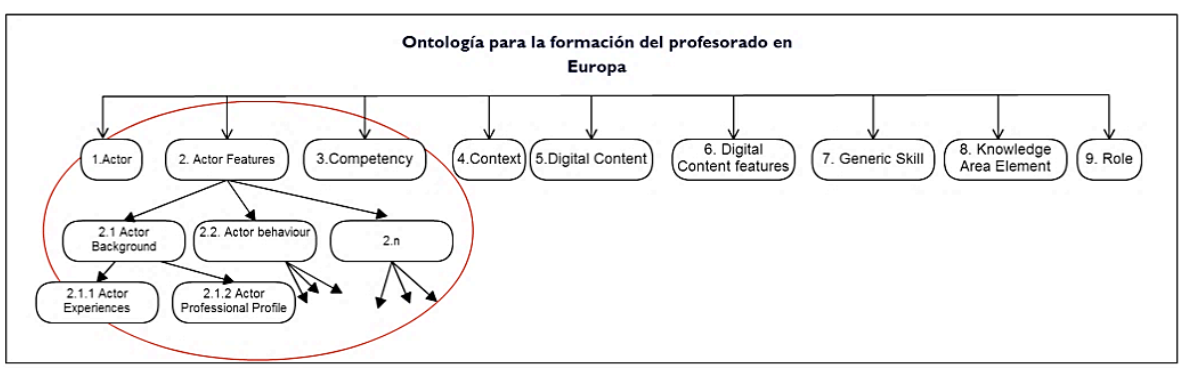

Instanciaciones de contextos específicos de la

ontología para la formación del profesorado

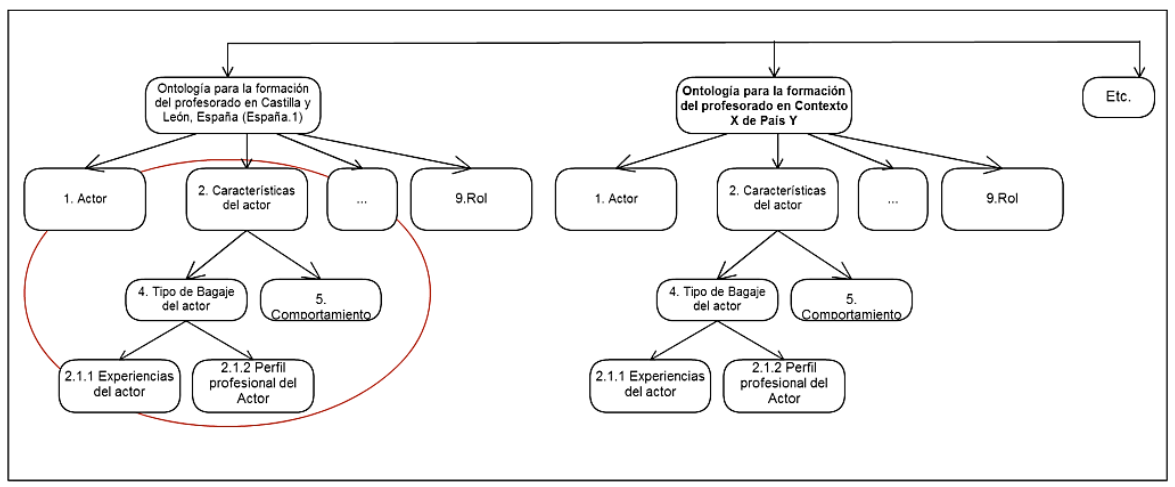

El modelo CMM y el MMM siguen el mismo proceso jerárquico explicado en la llustración 9, siendo el CMM el nivel superior de referencia (representado en el cuadro superior) y el MMM el nivel de especificación cultural y lingüística de cada país o contexto (representado en el cuadro inferior).

La interfaz del sistema también aparece traducida en diversos idiomas. Los usuarios registrados en Share.TEC se asocian con perfiles basados en una ontología, teniendo de este modo acceso a conceptos clave, y a las relaciones lingüística y culturalmente vinculadas.

Veamos un ejemplo para comprender cómo está estructurada la ontología de Share.TEC en la llustración 10. Como podemos observar, la ontología tiene 9 elementos principales que parten de la etiqueta "thing", en este caso, equivalente a ontología para la Formación del Profesorado (Actor, Características del Actor, Competencia, Contexto, Contenido Digital, Características del Contenido Digital, Habilidades Generales, Elemento de área de conocimiento y Rol). Cada uno de los 
campos tiene sus propias relaciones de dependencia e independencia con otros campos. Como ejemplo, hemos desglosado el campo "Características del Actor" (Actor features), y podemos apreciar las interrelaciones mediante las flechas.

Ilustración 10 Captura de pantalla de la ontología desde el software Portergé.
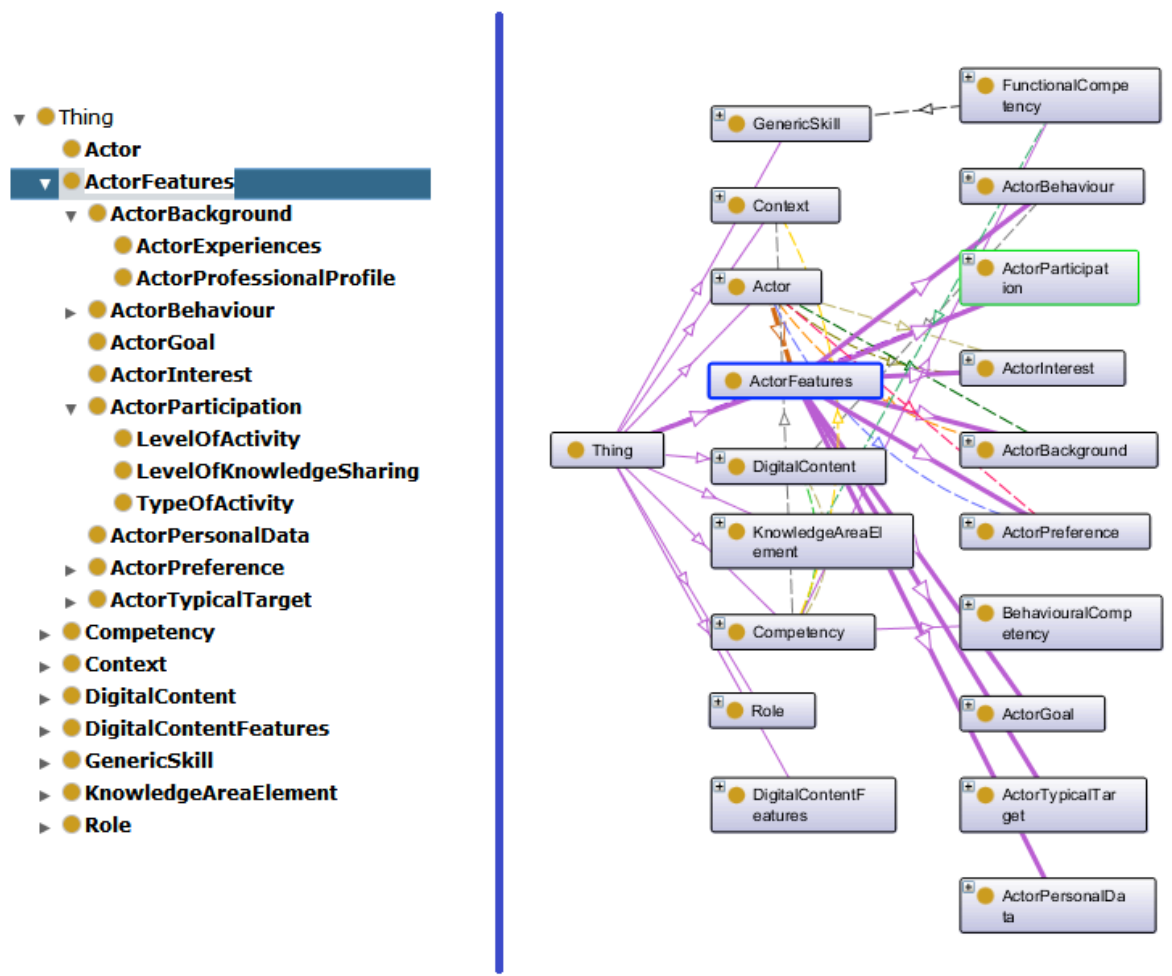

\section{WP3 "Interoperabilidad"}

Los servicios de contenidos digitales para la formación del profesorado raras veces adoptaban soluciones que permitieran la intercomunicación con otras especificaciones de metadatos. En este caso se decidió realizar un perfil de aplicación de LOM, al que se añadieron campos pedagógicos de metadatos. Además el sistema permitió integrar registros de metadatos etiquetados en estándares como SCORM (Bohl, Scheuhase, Sengler, \& Winand, 2002; Rustici Software, 2012) o DublinCore (Dublin Core Metadata Initiative, 2010).

La gestión de interoperabilidad del proyecto fue liderada por la editorial CLUEB. Este paquete de trabajo comprendió la tarea de permitir la interoperabilidad 
semántica, lingüística y cultural, así como de activar el proceso de migración de los metadatos de las bases de datos de los socios y de proveedores externos hacia el repositorio de metadatos Share.TEC (Share.TEC Consortium, 2008b).

Modelo Multicultural de Metadatos

Tras la realización de las versiones finales de la ontología (TEO v.2.0) y del modelo común de metadatos (CMMv2), se requirió de la unificación de los dos sistemas de representación para generar un único modelo que se integrara en la plataforma Share.TEC. Se construyó un modelo compatible e interoperable con modelos de metadatos utilizados en otros proyectos del programa eContentplus, e.g., MACE ${ }^{96}$ y MELT ${ }^{97}$.

En el documento CMM-TEO (Anexo 13), se presenta la realización de la integración de ambos, convergiendo los elementos de TEO que son relevantes para describir objetos de aprendizaje y proporcionado un mapeado entre los elementos de TEO v2.0 y los campos de CMM 2.0.

El CMM es un perfil de aplicación de LOM. Es un contrato entre los proveedores de metadatos y el Sistema Share.TEC. Este contrato recoge la sintaxis y semántica de las instancias de metadatos que se intercambian entre los repositorios de los proveedores de metadatos y el portal, pero muchos de estos campos nunca se presentan al usuario final en la interfaz de usuario del sistema. El objetivo era poder recuperar automáticamente metadatos alojados en otros repositorios, que incluyeran descripciones de las recogidas en TEO-CMM (llustración 10).

El CMMv2 permite describir características de contenidos digitales sobre la base de conceptos y relaciones representadas en TEOv2.0 (Taxonomía de contenido digital; Características de LOM del contenido digital; Características pedagógicas del contenido digital; Propiedades del objeto y tipo de datos; y otras taxonomías educativas generadas en el proyecto) (Anexo 13).

Tras esta integración se realizaron diversas extensiones multiculturales del CMM. Cada grupo participante en el proyecto aportó la traducción de su lengua y su adaptación cultural del CMM genérico. La realización de este trabajo dio lugar al Modelo Multicultural de Metadatos -MMM-).

${ }^{96}$ MACE - Metadata for Architectural Contents in Europe - Metadatos para Contenidos de Arquitectura en Europa http://www.fit.fraunhofer.de/en/fb/cscw/projects/mace.html

${ }_{97}$ MELT (Metadata Ecology for Learning and Teaching) - Ecología de Metadatos para la Enseñanza y el Aprendizaje http://info.melt-project.eu/ww/en/pub/melt_project/welcome.htm 
La tarea de inclusión o población de metadatos en el repositorio comenzó una vez concluida la estructura ontológica y de metadatos del sistema. Inicialmente los miembros del proyecto se comprometieron a poblar el repositorio con contenidos digitales pertenecientes a repositorios de terceros, con los que se establecieron contratos de permiso para su inclusión en Share.TEC. Dependiendo del repositorio origen, los metadatos se presentaban en diferentes formatos (tanto estandarizados: Dublin Core o LOM, como no estandarizados), y requerían una adaptación para incorporar los campos de Share.TEC relativos a la información pedagógica que se había creado e integrado en el CMM (puesto que era uno de los valores añadidos de este proyecto). Cada miembro del consorcio aportó un número diferente de recursos, en función del peso designado a esta tarea para cada uno de ellos y el compromiso que adoptó cada equipo. Como veíamos en el Gráfico 3, el portal pretendía incluir 72.801 registros de metadatos alojados en diversos portales educativos.

Para la recuperación automática o introducción manual de metadatos fue necesaria la generación de dos herramientas tecnológicas que facilitaran la expansión de los metadatos originales, creando dos soluciones accesibles para el usuario: RICK ${ }^{98}$ (Rodríguez Triana, 2011), un software que permite al usuario incorporar metadatos de sus contenidos digitales, e incluso exportarlos directamente al repositorio general de Share.TEC; y MMF (Metadata Migration Facility99), una herramienta que permite incorporar al repositorio general de Share.TEC datos etiquetados con esquemas de metadatos en LOM o Dublin Core, y los traduce al formato CMM (Rodríguez-Triana, Vega-Gorgojo, Asensio-Pérez, Martínez-Monés, \& Dimitriadis, 2009), de modo que fueran comprensibles para el portal Share.TEC.

Las herramientas descritas recogían la TEO integrada con MMM, y determinaban campos obligatorios para cumplimentar la información de un recurso, así como los opcionales, tal y como vemos en la siguiente tabla: *Metadatos obligatorios y Metadatos Opcionales de los Objetos Digitales a incluir en Share.TEC

98 Resource Integration Companion Kit - Kit de guiado para la integración de recursos https://www.gsic.uva.es/RICK/

${ }_{99}$ MMF (Metadata Migration Facility - Utilidad para la Migración de Metadatos), que permite agregar metadatos de recursos alojados en otros servicios. 
Tabla $7{ }^{*}$ Metadatos obligatorios y Metadatos Opcionales de los Objetos Digitales a Incluir en Share.TEC

\begin{tabular}{|ll|}
\hline Campo & Contenidos del campo \\
& $\begin{array}{l}* \text { identificación del recurso (URL; ISBN; etc.), Título, Descripción, } \\
\text { *Idioma, Palabras clave (en varios idiomas) }\end{array}$ \\
\hline *Ciclo de vida & $\begin{array}{l}{ }^{*} \text { Colaboradores: autor, editorial, editor, proveedor de contenidos, } \\
\text { desconocido }\end{array}$ \\
\hline *Meta-metadatos & $\begin{array}{l}\text { *Identificación, *Colaboradores: personas o entidades involucradas } \\
\text { en la identificación del recurso e Idioma }\end{array}$ \\
\hline *Técnica & *Ubicación del recurso; Formato técnico del recurso (Tipo y subtipo) \\
\hline *Derechos & Coste, *Derechos de autor, *Descripción de la Licencia \\
\hline Clasificaciones & $\begin{array}{l}\text { Disciplina, Nivel Educativo, Nivel de habilidad que se trabaja con el } \\
\text { recurso }\end{array}$ \\
\hline $\begin{array}{l}\text { Descripción } \\
\text { pedagógica }\end{array}$ & $\begin{array}{l}\text { Modo de empleo (presencialidad o no); tipo de interactividad, tipo de } \\
\text { contenido digital } \\
\text { Si es del tipo estructurado pedagógicamente: características de la } \\
\text { estructuración: tipo (guiado, basado en problemas, mixto); estrategia } \\
\text { didáctica de aprendizaje; Nivel de colaboración (individual, grupos } \\
\text { pequeños, clase completa) } \\
\text { Si es del tipo no estructurado pedagógicamente, tipo de contenido } \\
\text { pedagógico. }\end{array}$ \\
\hline
\end{tabular}

Etiquetado de metadatos

El etiquetado de metadatos fue una de las tareas que causó discrepancias entre los miembros del consorcio, pues había socios que se habían comprometido a incluir en el sistema Share.TEC un gran número de recursos, y no todos los grupos partían de metadatos etiquetados en DC o LOM, por lo que deberían etiquetar manualmente muchos metadatos

Algunos equipos (e.g., TCD ${ }^{100}$ y UVA), contrataron a personas para etiquetar manualmente los metadatos, proporcionando las descripciones pedagógicas del CMM. Desde UVa, se contrató a una persona licenciada en psicopedagogía y con conocimientos acreditados de inglés para el etiquetado de los metadatos. Inicialmente nos comprometimos a aportar más de 1000 metadatos referentes a

100 TCD se comprometió inicialmente a proporcionar un elevado número de contenidos digitales (18.000), por lo que tuvieron que contratar a varias personas encargadas de realizar el etiquetado manual de los metadatos. El etiquetado manual de metadatos es una tarea que conlleva tiempo y es costosa (económicamente), pero reporta beneficios y valor añadido a los portales educativos. 
contenidos digitales para la formación del profesorado. Las bases de datos escogidas antes de comenzar el proyecto fueron: Biblioteca Semántica de WebQuests, Enciclopedia Virtual de Tecnología Educativa, Webquests producidas por los alumnos de magisterio de la asignatura de TICs Aplicadas a la Educación de la Universidad de Valladolid ${ }^{101}$ y la Revista Comunicar ${ }^{102}$. A medida que el consorcio iba tomando decisiones en torno al tipo de contenido que debería ser incluido por los miembros del consorcio, fuimos modificando la elección de nuestros recursos. Para ello elaboramos una tabla (Anexo 14) en la que establecíamos la comparación entre los diferentes repositorios de los que podríamos obtener contenido, atendiendo a criterios de calidad y variedad del contenido, disponibilidad y estabilidad de las páginas web que alojaban el contenido, disponibilidad o no de metadatos, robustez del repositorio, número de recursos prometidos, número de recursos reales y derechos de autor del contenido. Finalmente el grupo UVa aportó recursos de la Biblioteca Semántica de WebQuest del Centro de Formación e Innovación Educativa de Valladolid103 (CFIE2), la Revista Comunicar, la base de datos de Dialnet ${ }^{104}$ y la revista RIFOP ${ }^{105}$ (Revista Internacional de Formación del Profesorado).

Esta tarea presentó ciertas dificultades pedagógicas a la hora de etiquetar los datos educativos de los recursos, dado que un mismo material puede ser utilizado en diferentes contextos en función de los objetivos de aprendizaje que se pretendan con su uso (puede servir para formar a profesores de diferentes niveles educativos, se pueden trabajar diferentes habilidades y competencias con ellos, y puede usarse en entornos educativos presenciales, semipresenciales 0 a distancia, especialmente cuando los materiales son artículos de investigación y son recursos no estructurados de forma pedagógica).

Para comprobar la calidad del etiquetado que se estaba realizando, desde el grupo UVa, desarrollamos una prueba de evaluación de la calidad de los metadatos de forma presencial (Anexo 32). Con las aportaciones realizadas por los miembros que realizaron la evaluación de los metadatos, tratamos de mejorar las descripciones realizando revisiones del idioma, así como del contenido (por ejemplo, revisando de forma completa las WebQuest y aportando de nuevo descripciones

\footnotetext{
101 http://www.gsic.uva.es/TIC/

$102 \mathrm{http}: / /$ www.revistacomunicar.com/

$103 \mathrm{http}: / /$ cfievalladolid2.net/webquest/common/index.php

$104 \mathrm{http}: / /$ dialnet.unirioja.es/

105 http://www.aufop.com/aufop/home/
} 
apropiadas de las mismas para los campos pedagógicos del Modelo Común de Metadatos). En el apartado de Análisis e Interpretación de los datos de la presente tesis doctoral hablaremos con mayor profundidad de este proceso de evaluación.

El repositorio, creado y gestionado por NIS-SU, fue generado en una plataforma de repositorio de código abierto denominada "Fedora"106.

Calidad de los metadatos

En una reunión del proyecto, los miembros del proyecto consensuaron la utilización de una clasificación para definir la calidad de los metadatos. La clasificación constó de un rango de cinco categorías en función de los campos del CMM que incluyó (recordemos que nos referimos al Modelo Común de Metadatos definido por los miembros de Share.TEC en base al estándar LOM). Estas categorías fueron las siguientes:

- Incompleto: algunos elementos obligatorios del CMM no han sido descritos.

- Baja calidad: sólo han sido completados los elementos obligatorios del CMM.

- Calidad de bronce: contempla los datos obligatorios del CMM, y define un campo extra del CMM (los elementos extra de la ontología están formados por Palabras clave, Área de conocimiento y Formato del contenido digital).

- Calidad de plata: contempla los datos obligatorios y define dos elementos extra del CMM.

- Calidad de oro: contempla los datos obligatorios y define tres elementos extra del CMM.

Para comprobar la adecuada incorporación de metadatos en el repositorio, así como para satisfacer uno de los comentarios de la evaluadora del proyecto (Claire Belise) relativos a la necesidad de especificar qué era "calidad" de metadatos, se desarrolló una herramienta que analizaba los campos que habían sido completados de cada registro de un recurso, el "analizador de metadatos" (creado por TCD). Esta herramienta recopilaba los registros de metadatos incorporados en Share.TEC y realizaba un análisis estadístico cuantitativo de cada metadato, cotejando con el CMM los campos que incluía cada uno de ellos (elementos de las descripciones de las categorías: General, Ciclo de vida, Meta-metadatos, Aspectos Técnicos, Derechos y Clasificación pedagógica). Conocer la calidad de los metadatos constituía un hecho esencial para poder satisfacer las necesidades de los usuarios potenciales del sistema (Earp et al., 2011)

106 http://www.fedora-commons.org/ 
Durante los tres últimos meses del proyecto se llevaron a cabo tres análisis de la calidad de los metadatos (dos en marzo de 2011 y otro en junio de 2011). Estos resultaron ser muy relevantes, dado que tras un primer test, se detectó que el número de metadatos referente a los contenidos digitales era escaso atendiendo al compromiso inicial contemplado en el Technical Annex (Share.TEC consorcio, 2008), y la calidad de los mismos era susceptible de ser mejorada. En el plazo de tres meses el número registros de metadatos incrementó sustancialmente. Además, se mejoraron las descripciones de los registros de metadatos previamente incorporados para cumplir con los requisitos necesarios para la evaluación positiva del proyecto por parte de la Comisión Europea (ver Gráfico 4 del capítulo 4). La evaluación del número de registros y de datos del portal fue realmente útil para que los miembros del consorcio Share.TEC consiguieran federarse con más repositorios de contenidos digitales y mejoraran sus técnicas para cumplimentar los datos del portal Share.TEC (bien a través de la herramienta RICK o bien a través de repositorios con datos en los formatos compatibles con Share.TEC - DublinCore y LOM). El número de metadatos que estaban incorporados en el sistema tras finalizar los plazos del proyecto fue de 49263, aunque los metadatos comprometidos inicialmente fueron 72801. En cualquier caso, tras negociaciones posteriores con otros proveedores de metadatos, el portal cuenta actualmente con 71626 registros de metadatos de contenidos digitales.

En cuanto a la variedad del contenido, en el documento Technical Annex se recogía que la mayoría de lo metadatos harían referencias a libros, seguidos por tutoriales, unidades didácticas y programaciones. Los metadatos de la plataforma Share.TEC recogen la variedad inicialmente planteada y presentan la distribución contemplada en el Gráfico 5 del capítulo 4. En el Gráfico 6 del capítulo 4 se visualiza el formato técnico de los contenidos digitales (sólo el de 43929 recursos, pues el resto carece de este campo descriptivo).

Además, el tipo de contenido pedagógico o formato del recurso no siempre ha sido etiquetado de manera correcta en los casos en los que el etiquetado ha sido manual o partiendo de metadatos incorrectos, tal y como hemos podido observar a la hora de explorar el sistema, y como hemos detectado en diferentes pruebas con usuarios finales del portal, aspecto que será discutido en el capítulo 4 de esta tesis.

\section{WP4 "Usabilidad"}

La gestión de este paquete de trabajo fue liderada por UVa. Comprende el trabajo enfocado a generar un entorno efectivo sensible al perfil profesional y 
cultural del usuario, permitiéndole mejorar la usabilidad con el uso del portal (Share.TEC Consortium, 2008b, p. 26).

Las tareas principales consistieron en proporcionar elementos de un sistema adaptado a los perfiles de usuario individuales, a través del desarrollo de un prototipo del sistema y de una interfaz de usuario multilingüística, así como un recomendador de recursos en base a las búsquedas realizadas por el usuario.

La interfaz del sistema fue inicialmente diseñada y propuesta por NIS-SU, y evaluada por diferentes miembros del consorcio. Posteriormente se recogieron sugerencias realizadas por usuarios finales mediante diferentes pruebas del portal y sus correspondientes encuestas y/o cuestionarios; también los miembros del consorcio realizamos diversas sugerencias de mejora. Se fueron haciendo pequeñas modificaciones a medida que avanzó el proyecto, pero todas ellas sobre la base del prototipo inicial del sistema. Como se abordará en el próximo capítulo (4), el hecho de partir de un diseño realizado sin tomar en cuenta al usuario de manera inicial, generó numerosos problemas a posteriori, dado que la arquitectura del sistema era compleja y requería mucho esfuerzo realizar grandes modificaciones.

\section{WP5 "Plataformas y Servicios Integrados"}

El paquete de trabajo fue liderado por NIS-SU y hace referencia a la configuración de la plataforma basada en Web que proporciona los medios de acceso a contenido para los usuarios finales

(Share.TEC Consortium, 2008b, p. 26).

Este paquete de trabajo centraba sus esfuerzos en establecer una arquitectura distribuida que permitiera dar un acceso unificado a los recursos de proveedores externos. Este paquete de trabajo tiene una importancia especial, pues constituye el esqueleto sobre el que se organiza el sistema Share.TEC y además aborda los aspectos relacionados con la inclusión de metadatos de contenido de otros repositorios. Está íntimamente relacionado con los paquetes de trabajo 2, 3, 4 y 6 .

Entre las principales tareas que integraba esta parte del proyecto, destacamos la creación de servicios para búsqueda y el desarrollo del prototipo del sistema. Al igual que en el WP4, esta tarea requirió del feedback de los usuarios y de los propios miembros del consorcio, quienes propusieron desde su desarrollo hasta el final del proyecto mejoras para el sistema (ver ejemplo en Anexo 15, Anexo 16, Anexo 17 y Anexo 18).

Del mismo modo que en el paquete de trabajo recién descrito anteriormente, fue complicada la modificación de la arquitectura del sistema y de las funcionalidades 
que se ofrecían. Uno de los servicios que fue más complejo y costoso de mejorar fue el de la búsqueda del sistema (que mejoró sustancialmente desde el inicio del desarrollo hasta la finalización del proyecto).

\section{WP6 "Asesoramiento y Evaluación"}

Este WP fue liderado por CENEC, y trataba de evaluar la efectividad del trabajo, tanto para probar el sistema Share.TEC como para evaluar la validez de los resultados. Cada socio llevó a cabo test locales del sistema y de sus componentes, de acuerdo con un protocolo definido. Otro objetivo de este paquete era que los usuarios finales evaluaran las características y funcionalidades del sistema (Share.TEC Consortium, 2008b). Se pretendía mejorar la calidad del sistema Share.TEC a través de la evaluación del mismo por parte de los usuarios finales, con el objetivo de hacer el contenido de la formación del profesorado a nivel europeo más accesible, reutilizable y explotable.

A lo largo del proyecto se desarrollaron diversas pruebas en cada uno de los contextos de los miembros del consorcio, así como pruebas generales en Workshops comunes. En la llustración 11 pueden observarse las principales pruebas elaboradas por el consorcio de Share.TEC, en el que hemos hecho énfasis en las pruebas con usuarios que desarrollamos desde UVa (en color verde las comunes, y en morado las propias de UVa), así como aquellas en las que solicitamos más información a los usuarios en previsión del desarrollo de la presente tesis doctoral (resaltadas en color amarillo). Las pruebas aquí recogidas serán explicadas en mayor profundidad en el apartado 5.2.4 de este documento.

Otra de las subtareas en las que se desglosa este WP hace referencia al cumplimiento en el envío de informes de cada tarea/paquete de trabajo en las fechas prefijadas al inicio del proyecto. El retraso en el desarrollo de las diferentes partes del sistema y la inclusión de contenidos en el mismo fue común, por lo que muchos entregables (deliverables) tuvieron que ser aplazados para poder desarrollar un trabajo de buena calidad. 
Ilustración 11 Técnicas de recogida de datos aplicadas a los profesores en el Estudio de Caso Share.TEC
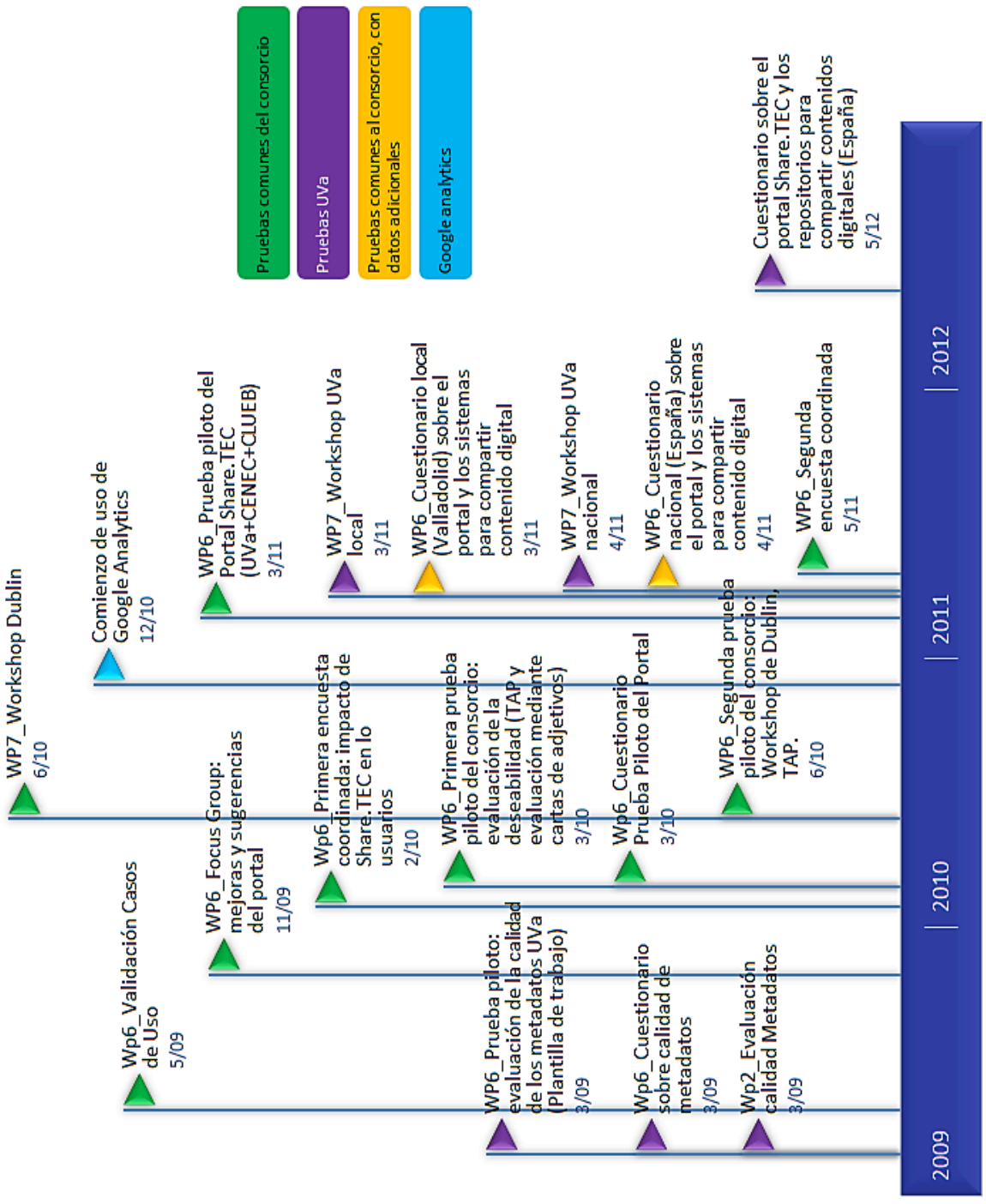


\section{WP7 "Concienciación, Diseminación y sostenibilidad"}

Este paquete de trabajo, liderado por SU (equipo sueco de la Universidad de Estocolmo), evoluciona a lo largo de la vida del proyecto para apoyar los contactos con el entorno, las comunidades de formadores de profesores, las actividades de formación a los usuarios finales, las actividades de diseminación, etc. (Share.TEC Consortium, 2008b). Los objetivos principales que se plantearon fueron dos: a) Establecer una nueva actitud hacia la compartición y reutilización de recursos en el contexto europeo favoreciendo la multiculturalidad, contribuyendo de esta forma a los objetivos de la Agenda de Lisboa; b) Contribuir a la aproximación entre el mercado actual de contenidos digitales y el mundo de los contenidos abiertos para los formadores de profesores.

Para lograr el primero de los objetivos citados se requería de la actualización constante de la página Web del proyecto, donde debían reflejarse los logros, resultados y progreso del proyecto. En ella pueden encontrarse informes finales, presentaciones, artículos de investigación, vídeos y un listado de los eventos que tuvieron lugar en relación al proyecto. Esta página fue utilizada para publicitar el proyecto y ubicar los contenidos más relevantes relativos al mismo. El contenido que se ofertó de forma pública fue limitado (puesto que la mayoría de los informes y trabajo interno era compartido de forma privada en el espacio BSCW del proyecto) y puede accederse a él desde http://www.share-tec.eul.

Las actividades de diseminación, fruto de este paquete de trabajo, fueron el elemento más útil para dar a conocer el proyecto. Se realizaron diversas acciones que tuvieron lugar en cada uno de los países de los miembros del consorcio, realizando cada equipo, a su vez, varias actividades de difusión: pruebas con usuarios locales de cada contexto, diseminación en congresos y conferencias, redes sociales online, redes de formadores de profesores nacidas del proyecto 0 ya existentes, etc. Los eventos más relevantes pueden verse en http://www.sharetec.eu/content/events-and-meetings. A través de las actividades, se pretendía: a) incrementar la visibilidad del proyecto, sus objetivos y concienciar del potencial de una red europea de contenidos digitales para la formación del profesorado; b) asegurar una expansión sostenible y coordinada del proyecto; c) activar una red de comunidades de formadores de profesores a nivel europeo, como medio de diseminación, sostenibilidad y propagación de innovación educativa; d) involucrar a usuarios finales para recoger las necesidades de los usuarios y su grado de satisfacción (Anexo 19). 
La estrategia metodológica llevada a cabo para realizar las actividades de diseminación consistió, en términos generales, en la aplicación de las siguientes acciones:

a) Se utilizaron diversos formatos, tanto materiales de comunicación (folletos informativos traducidos a los diferentes idiomas de los miembros del consorcio -ver Ilustración 12-, pancartas presentes en eventos) como transmisión de información cara a cara, sesiones de formación en el uso de la plataforma y workshops sobre el proyecto. Asimismo, la página web del proyecto sirvió como medio de publicitación del mismo, y se utilizó una imagen corporativa del proyecto coherente en todas las actividades de difusión del proyecto (logotipo, plantillas para informes y presentaciones, etc.).

Ilustración 12 Folleto de Divulgación del Portal Share.TEC en español

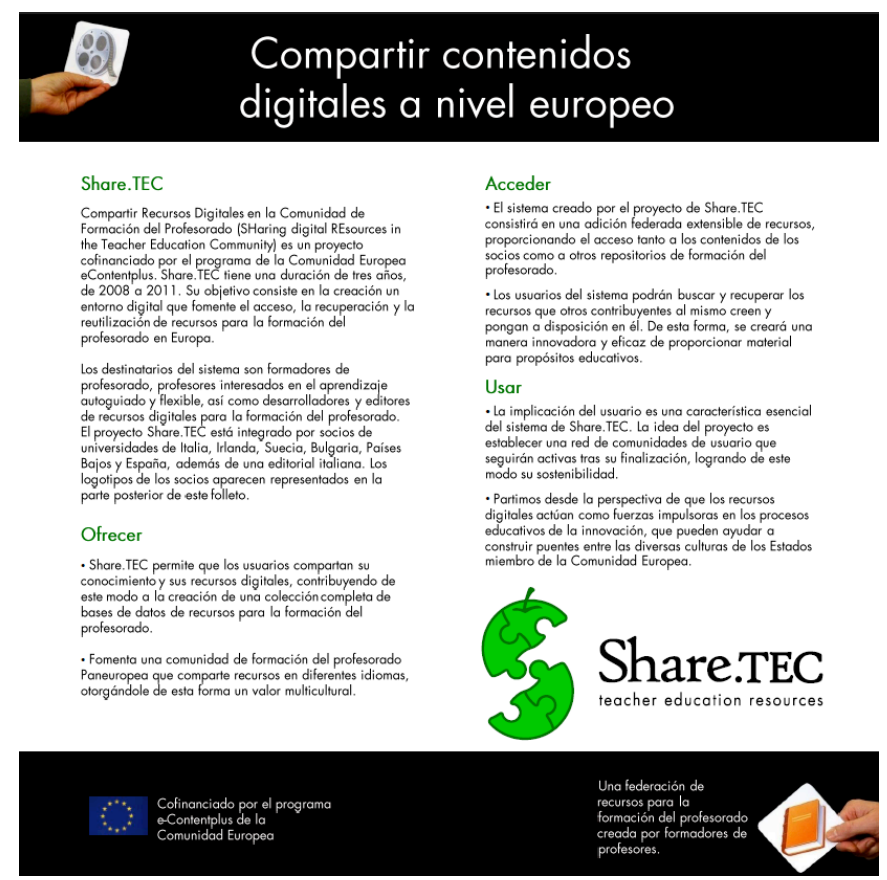

b) La fórmula AIDA -Atención/Interés/ Deseo/ Acción- (Gharibi, Danesh, \& Shahrodi, 2012, 2015), tomada del ámbito del marketing y la publicidad, que persigue progresivamente, a través de estos cuatro pasos, involucrar a los clientes en la utilización de un producto. Esta técnica se inició con la concienciación de los usuarios con los que los miembros del consorcio establecimos contacto. Se les hizo 
ver la importancia de la utilización de los contenidos digitales en éste ámbito y se generó la consiguiente captación de interés a través de campañas de información mediante la Web del proyecto y la celebración de los diversos eventos y workshops mencionados, creando la expectación de un producto que ofrece unos beneficios que no ofertan otros. Posteriormente se trató de trasladar a los contactos el interés del portal Share.TEC como herramienta útil para el desarrollo profesional de los formadores de profesores. Finalmente, se esperaba que los usuarios, una vez comprendidas las ventajas y el potencial del proyecto, contribuyeran en el sistema tanto utilizando los servicios sociales como generando nuevo contenido digital y utilizando los disponibles en el portal (en el siguiente capítulo explicaremos cómo este último paso nunca llegó a desarrollarse de forma óptima, y de las limitaciones encontradas de acuerdo con este punto).

c) El análisis mediante DAFO (llustración 13) es un método de estudio de la situación de un proyecto para analizar las Debilidades, Amenazas, Fortalezas y Oportunidades mediante una matriz, que se utilizó para construir una base estable para el plan de difusión. Una de las fortalezas fundamentales internas del proyecto radicó en la cooperación y colaboración de los miembros del consorcio y sus socios, quienes contribuyeron en el proyecto con ideas y trabajo basado en sus respectivos contextos. Una de las debilidades internas del proyecto fue la dificultad de operar entre diferentes culturas y formatos, teniendo en cuenta las divergencias entre conceptos y percepciones. Una de las oportunidades externas de Share.TEC hace referencia a la inexistencia de un sistema específico como éste para compartir y acceder a contenidos digitales de formación del profesorado. La principal amenaza de origen externo que se preveía en Share.TEC era la posibilidad de que el sistema no fuera utilizado por usuarios, lo que comprometería seriamente la sostenibilidad y calidad del proyecto; en el capítulo 5 explicaremos cómo esta amenaza se hizo realidad, a pesar de que el sistema sigue existiendo aunque no de la forma inicialmente esperada (Anexo 19). 
llustración 13 Análisis DAFO para la creación del plan de sostenibilidad elaborado en Share.TEC. En verde, los aspectos de origen externos; en azul, los de origen interno.

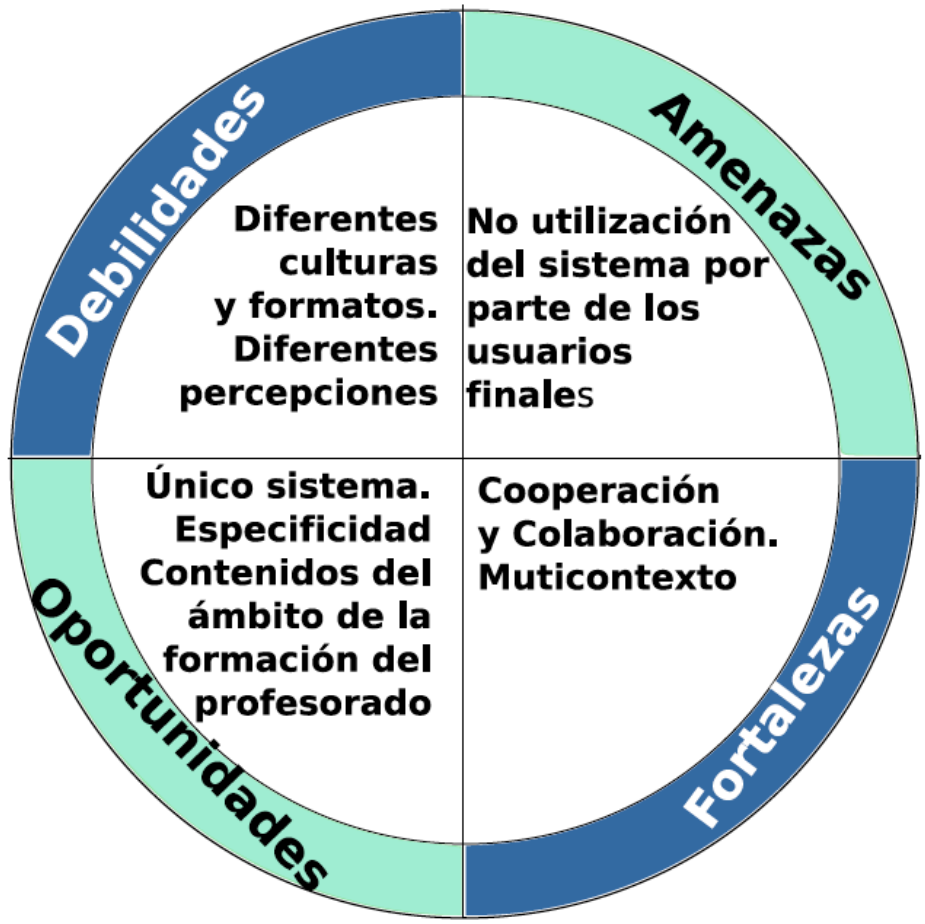

c) Las actividades se centraron en la participación de los miembros del consorcio en reuniones y conferencias, enfocadas en conseguir la involucración de redes y comunidades de usuarios. Estas sirvieron tanto para la difusión del proyecto como para el conocimiento de la opinión de los usuarios finales en diferentes contextos. El enfoque del proyecto pretendía captar usuarios de diferentes perfiles para generar una red de comunidades de usuarios finales: formadores de profesores, 0 formadores de profesores en proceso de formación, universidades e instituciones académicas para la formación del profesorado, administraciones ministeriales y coordinadores involucrados en tecnología educativa, editores educativos, desarrolladores de contenido, directores de centros educativos, representantes de redes temáticas, el público y medios en general. Inicialmente se partió de la necesidad de establecer contacto tanto con redes, proyectos y portales similares (KAL, PROLEARN, IFIP, TNTEE, EdReNe, European Schoolnet, Stellar and the European Association of TeLearc) (Anexo 19), como con los contactos profesionales 
directos de cada miembro del consorcio. Para captar a estos usuarios se utilizaron diversas estrategias: herramientas sociales (tales como Facebook ${ }^{107}$, que alcanzó 48 usuarios; Twitter, mediante hastags para diversas exhibiciones y pruebas piloto, e.g., \#sharetec); el contacto y activación de redes existentes de formadores de profesores (mediante listas de correo y páginas web de universidades, portales educativos, etc.; en el caso del equipo UVa utilizamos listas de correo de personas del ámbito de la tecnología educativa, puesto que era nuestro objetivo principal, y creamos una red NING ${ }^{108}$ para trabajar con ellos (ver llustración 14). Inicialmente se pensó en la posibilidad de crear una Wiki, un blog, boletines de noticias del desarrollo del proyecto, y discusiones con herramientas sociales en la propia web del proyecto. Lamentablemente estas acciones no fueron llevadas a cabo (ver Anexo 20).

En los registros de Google Analytics configurados para el portal Share.TEC se demuestra los usuarios sí que accedieron al portal (como veremos en el capítulo 4), pero la recuperación de los contenidos era limitada y la actividad social apenas existente.

Uno de los aspectos más preocupantes y polémicos del proyecto, puesto que había posturas divergentes entre los miembros del consorcio, fue el diseño del Plan de Sostenibilidad. Según el documento de descripción inicial del trabajo de Share.TEC (Technical Annex, p.28) debía elaborarse para el mes 12 del proyecto. Existían diferentes tipos de equipos, la mayoría de ellos, grupos de investigación universitarios o centros nacionales tecnológicos, y un equipo comercial (una editorial que, entre otros fines, estaba interesada en la participación en el proyecto para fomentar la venta de sus materiales educativos digitales). Debido a las diferencias de intereses y opiniones, y a dificultades en su elaboración, finalmente fue publicado en el mes 27 (Septiembre de 2010) por CLUEB.

El plan de sostenibilidad tenía como objetivo incrementar el interés y crecimiento de los contenidos digitales de Share.TEC más allá de la vida del proyecto, así como comunicar de forma efectiva los resultados del proyecto (Anexo 21). Debía asegurar que todos los metadatos de contenidos digitales que se encuentran en el repositorio central de Share.TEC fueran accesibles una vez finalizado el proyecto, para garantizar la supervivencia del sistema. Para ello era necesario seguir explorando,

$107 \mathrm{https}: / / w w w . f a c e b o o k . c o m / p a g e s / S h a r e T E C / 223569527660438$

$108 \mathrm{http}: / /$ sharetec-recursos.ning.com/ - actualmente no disponible, ya que era una red de pago- 
revisando e implementando diversos factores esenciales (las necesidades de los usuarios e inversores, la relevancia del contenido digital y la usabilidad y facilidad de uso del portal y servicios de Share.TEC) (Anexo 22).

Ilustración 14 Red Social NING: Share.TEC Recursos, creada por el grupo UVa como estrategia de diseminación del proyecto.

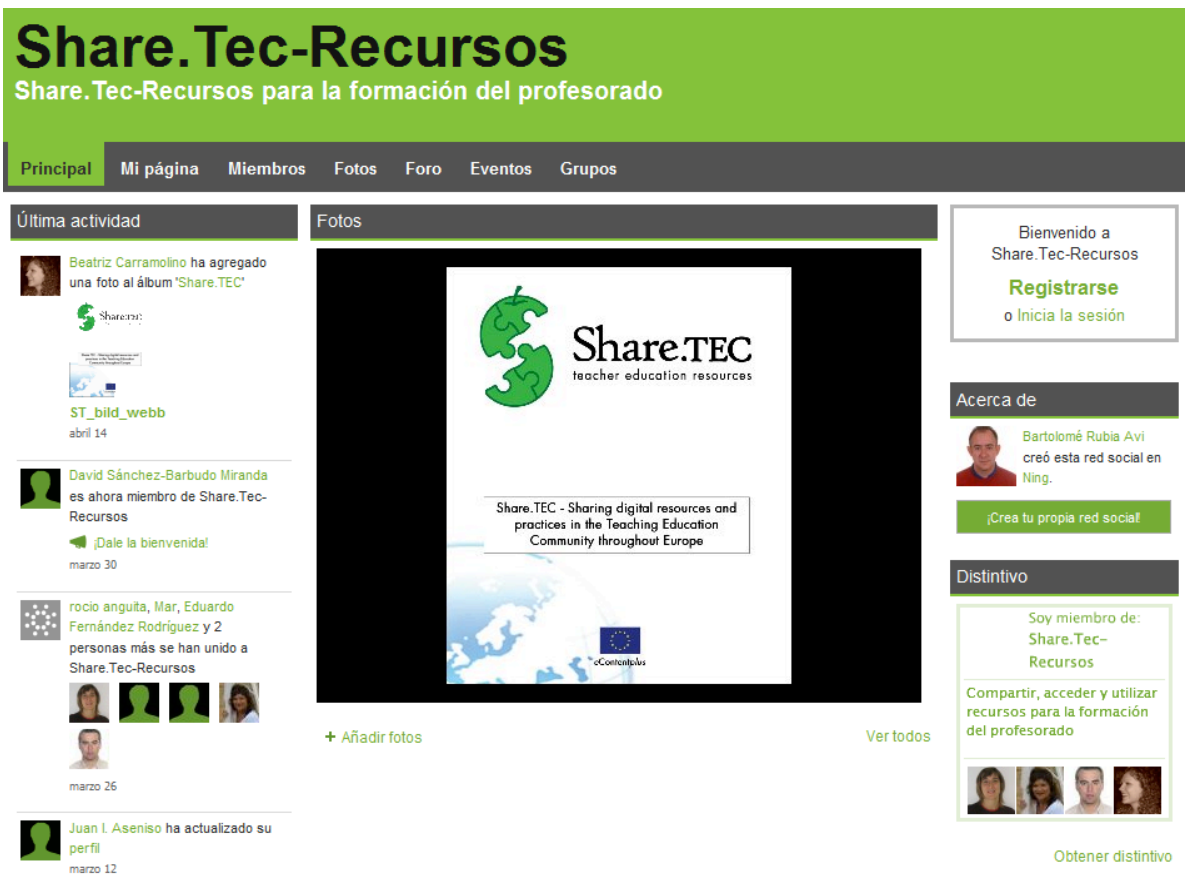

A la hora de identificar y definir los aspectos clave y retos de una estrategia de sostenibilidad realista para Share.TEC, se tuvieron en cuenta las conclusiones extraídas en estudios de caso sobre la sostenibilidad de proyectos patrocinados por fundaciones de Reino Unido, como JISC (Joint Information Systems Committee) y NEH (National Endowment for the Humanities), y de Estados Unidos, NSF (National Science Foundation), tomándolos como referencia de líderes de iniciativas digitales para gestionar sus negocios (Anexo 22). Los objetivos principales del plan de sostenibilidad que se definieron fueron: a) Estimular la compartición, reutilización y publicación de recursos para la formación del profesorado en Europa, y b) Maximizar y enriquecer el uso de recursos educativos para la formación del profesorado (Anexo 22, p.10). 
Como estrategia para la difusión y sostenibilidad, se definieron tres niveles de usuarios del campo de la formación del profesorado: 1) Redes profesionales: regionales, nacionales e internacionales; 2) Nivel organizativo y curricular y 3) Grupos de trabajo de profesores. La participación en seminarios, encuentros y workshops durante los dos primeros años del proyecto fue sustancial para identificar inversores potenciales, especialmente organizaciones, otros proyectos europeos y asociaciones cuyos miembros son formadores de profesores interesados en Share.TEC (Anexo 22). Cada socio debía responsabilizarse de potenciar el conocimiento y difusión del proyecto en sus contextos locales. Para ello, se diseñaron acciones como estrategias de sostenibilidad, tanto a corto plazo como a largo plazo (tras la finalización del proyecto (Anexo 22), entre las que se incluía la gestión del sistema tras la terminación del proyecto. El plan inicial, siguiendo el Diseño de Sostenibilidad creado por CLUEB, era que el portal fuera sostenido por este equipo tras la finalización del proyecto, pero finalmente se decidió que fuera NIS-SU quien se encargara de esta función (puesto que disponía de los medios y personal técnico adecuado para ello).

Durante el desarrollo del sistema se tuvieron en cuenta dos direcciones, aparentemente divergentes, tratando de generar una sostenibilidad más completa que si se hubiera contemplado únicamente una de ellas: una visión orientada al contenido (cantidad y calidad de los recursos), y una visión orientada al usuario (centrada en la construcción de un entorno constructivista, enriquecido con servicios y herramientas que fomentan la colaboración entre usuarios y recursos). El mercado objetivo de Share.TEC lo constituian: consumidores de contenido (formadores de profesores, profesores, organizaciones de formación del profesorado) y creadores de contenido (editoriales educativas, desarrolladores de contenido o autores, profesores).

Los aspectos clave que afectarian a la sostenibilidad del sistema fueron recogidos en el plan de sostenibilidad (Anexo 22): la arquitectura del sistema y la usabilidad. En cuanto a la arquitectura del sistema, debía ser capaz de llevar a cabo las siguientes funciones cruciales para la sostenibilidad ${ }^{109}$ (Anexo 23 y Anexo 22).

109 Las funciones que fueron definidas para promover la sostenibilidad fueron: soportar pagos seguros, gestionar varios tipos de suscripciones, gestionar a los usuarios no suscritos, gestionar los grupos de discusión, gestionar las comunidades virtuales, gestionar las direcciones de email, un registro completo de las acciones de los usuarios, integrar continuamente y actualizar metadatos en un formato que no sea OAl-PMH, permitir a los usuarios enriquecer registros de metadatos, permitir en los campos de metadatos los 
Algunos miembros del proyecto no estaban de acuerdo con la posibilidad de incluir solamente metadatos etiquetados en LOM, DC o CMM, y con utilizar únicamente OAI-PMH (Open Archive Initiative - Protocol for Metadata Harvesting), como fue el caso de CLUEB, puesto que incluyeron una gran cantidad (20.000) de metadatos etiquetados en su propio esquema, y no existía posibilidad de integración directa de sus metadatos en Share.TEC mediante MMF (Anexo 23). En cualquier caso tuvieron que adaptarse a la idiosincrasia del sistema.

Asimismo, se generaron estrategias de desarrollo de contenido de Share.TEC. Durante el proceso de población de metadatos, había que llegar siempre a un equilibrio entre calidad y cantidad de contenido digital. Al no existir inicialmente herramientas para determinar la calidad de los contenidos (posteriormente, en los últimos meses, TCD generó el "Analizador de metadatos"), los socios deberían responsabilizarse de la cantidad del contenido que incorporaban. Un aspecto que dotaba de valor adicional frente al resto de servicios de contenido digital para formadores de profesores, era la existencia de las etiquetas pedagógicas de los contenidos digitales del sistema. Únicamente aparecen etiquetados con este contenido metadatos aportados por los miembros del sistema, puesto que es una categoría de metadatos no estandarizada, creada por los socios de Share.TEC. Los metadatos que incorporen nuevos usuarios/entidades, si se hace de forma automática, no contemplarán estas categorías. Por ello, era relevante que la búsqueda simple del sistema no buscara por etiquetas, si no por texto completo (Anexo 22).

\section{¿Qué producto genera el Proyecto Share.TEC?}

Atendiendo a los objetivos que perseguía el consorcio, se generó un Portal Educativo multi-idioma (inglés, italiano, holandés, búlgaro, sueco y español, coincidiendo con los idiomas de los miembros del consorcio), que presenta una interfaz simple en la que pueden realizarse tres acciones dicotomizadas: "Acceder", "Usar" y "Ofrecer" contenido digital. Es importante que comprendamos qué permite hacer el portal y cuáles son las funcionalidades que contiene, puesto que es fundamental para entender las opiniones de los usuarios sobre estas, y las necesidades que demandan. Veamos de manera pormenorizada las acciones que pueden desarrollarse desde cada sección:

formatos: libro, parte de libro y artículo; y permitir al administrador del sistema gestionar y operar en el sistema. 


\section{a. Acceder}

En el apartado acceder, pueden realizarse búsquedas avanzadas (mediante palabras clave, restricciones, filtrados y presencia de determinadas etiquetas) y simples (mediante palabras clave), en las que se recupera contenido digital en varios idiomas. Una vez realizada la consulta, el portal nos muestra los resultados que ha encontrado en base a los metadatos de los que dispone. Veamos un ejemplo de búsqueda para comprender mejor su estructura.

llustración 15 Interfaz de la página principal del Portal Share.TEC en español.

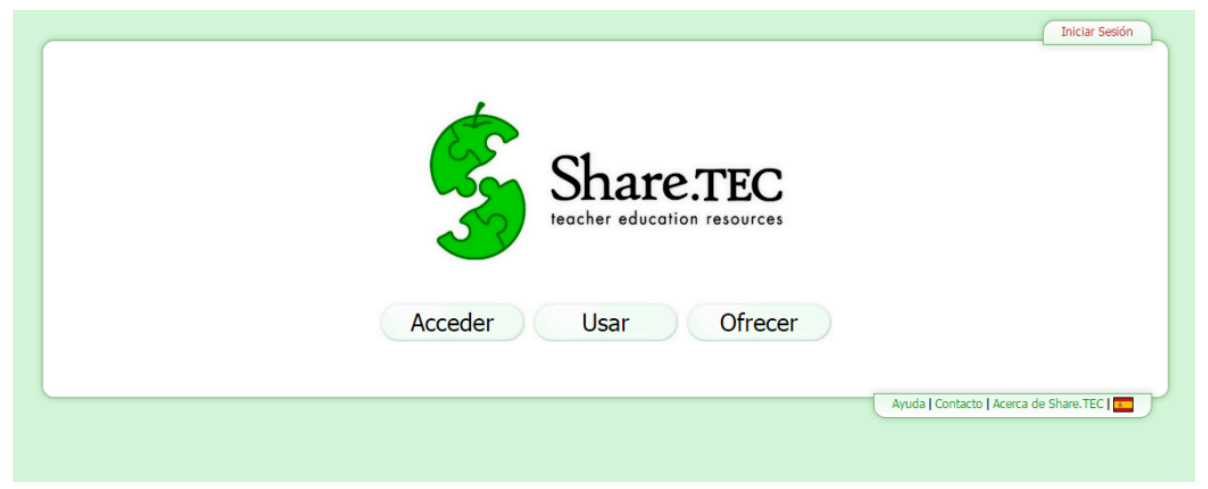

Cuando entramos en acceder, realizamos una búsqueda simple del término "pedagogía", y el programa nos devuelve 126 registros de metadatos que han sido etiquetados con esta palabra. Podemos filtrar nuestra búsqueda mediante diferentes campos, ordenar los resultados en función a varios criterios, filtrar por colección (conjunto de recursos de un mismo banco), por idioma (original del recurso en sí), por formato técnico, por tipo de institución educativa al que está destinado, por coste y por tipo pedagógico de material (véase llustración 16). 
Ilustración 16 Captura de Pantalla del Apartado Acceder del portal Share.TEC

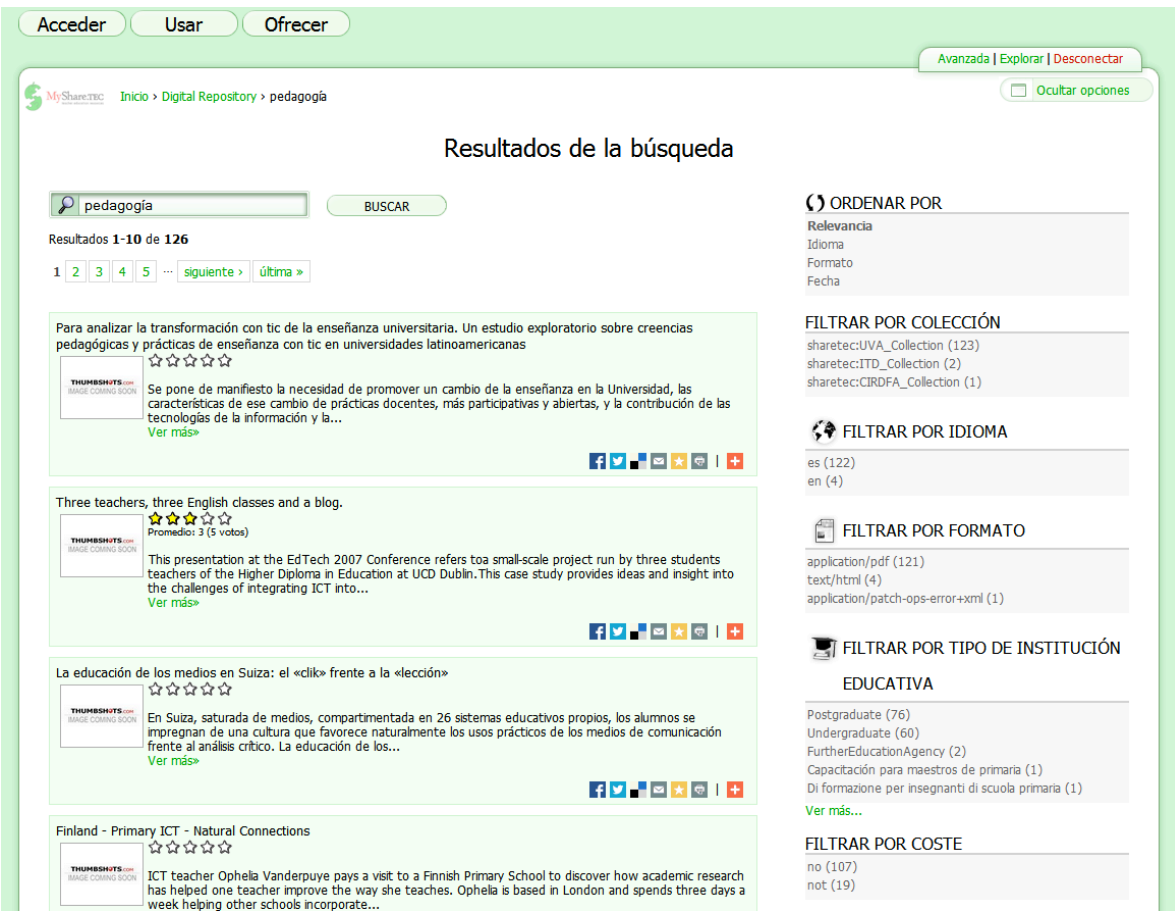

Vemos que hemos buscado el término pedagogía y nos aparecen resultados en inglés. Esto es debido a que los metadatos de algunos recursos están catalogados en varios idiomas, por lo que si buscamos en español un término, y los metadatos de un recurso inglés han sido etiquetados en español, además de en inglés, este recurso de otro idioma aparecería en nuestro listado de recursos. Este hecho, como veremos posteriormente en el análisis e interpretación de los datos, ha resultado polémico para los formadores.

Si realizamos una búsqueda con muchos filtros, es posible que no encontremos todos los resultados que existen y que tienen estas características, pues no todos los contenidos están etiquetados con todos los campos de metadatos (como veíamos en el

Al realizar esta búsqueda, los resultados de contenidos digitales basados en esas palabras clave aparecen en un listado que integra título, puntuación y número de votos, resumen, compartición en redes sociales y una previsualización gráfica 
(aunque no aparece para la gran mayoría de los recursos). Si hacemos clic en "ver más" en uno de los resultados, accedemos al registro de metadatos completo de cada recurso, tal y como podemos apreciar en la llustración 17. En este apartado aparecen los campos de metadatos: creador, título, localización del recurso, idioma, palabras clave, área de conocimiento, habilidades de aprendizaje que trabaja, tipología pedagógica del recurso, descripción, derechos de acceso, información sobre su coste (si es que lo tiene), y formato técnico (su extensión de formato). Puede verse en la ilustración, que se permite compartir el recurso en redes sociales, ver los comentarios (y comentar), ver la puntuación del recurso, guardarlo en mis favoritos, así como observar las estadísticas relacionadas con el registro y la sugerencia de recursos similares (por etiquetado). Además, vemos diferentes banderas que aluden a los idiomas en los que encontramos las descripciones del recurso, que se generan automáticamente cuando los conceptos están mapeados en TEO-CMM, o cuando se introducen manualmente las correspondencias entre unos y otros conceptos (aunque el sistema no aprende automáticamente). Como vemos, Share.TEC no integra el contenido, si no que apunta a un enlace web externo (lo que puede causar problemas en la sostenibilidad del recurso, ya que puede cambiar su localización o desaparecer). 
llustración 17 Muestra de la visualización de los metadatos de un contenido digital en la sección Acceder de Share.TEC.

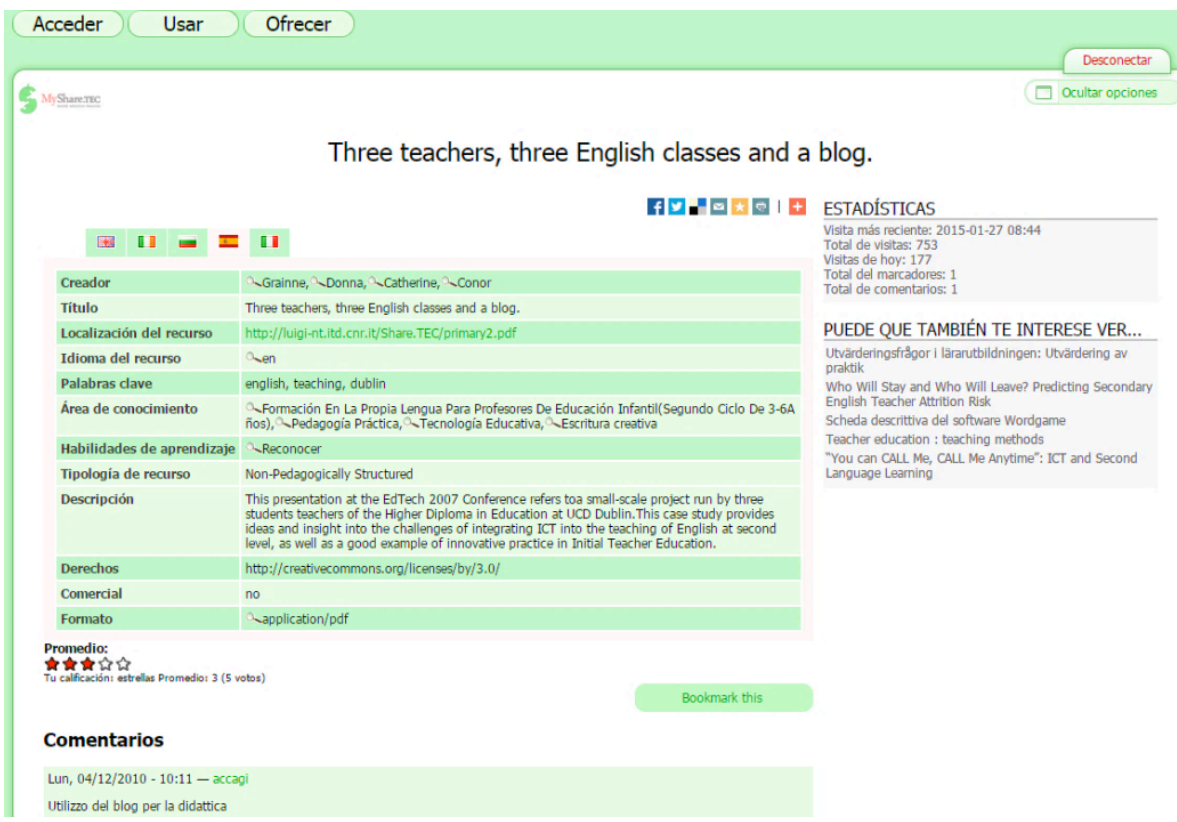

b. Usar

Contiene las funcionalidades sociales del sistema: permite crear comunidades de usuarios, ver la votación de los recursos realizada por otros usuarios, acceder a los recursos más recientes o mejor puntuados (Carramolino Arranz \& Rubia Avi, 2013, p. 295).

Cuando accedemos a esta sección (ver llustración 18), lo primero que vemos es una introducción en la que se recoge el número de recursos que integra Share.TEC y las colecciones. En esta sección se enlazan las funcionalidades de buscar, explorar y anotar recursos existentes. 
Ilustración 18 Página principal de la sección Usar de Share.TEC

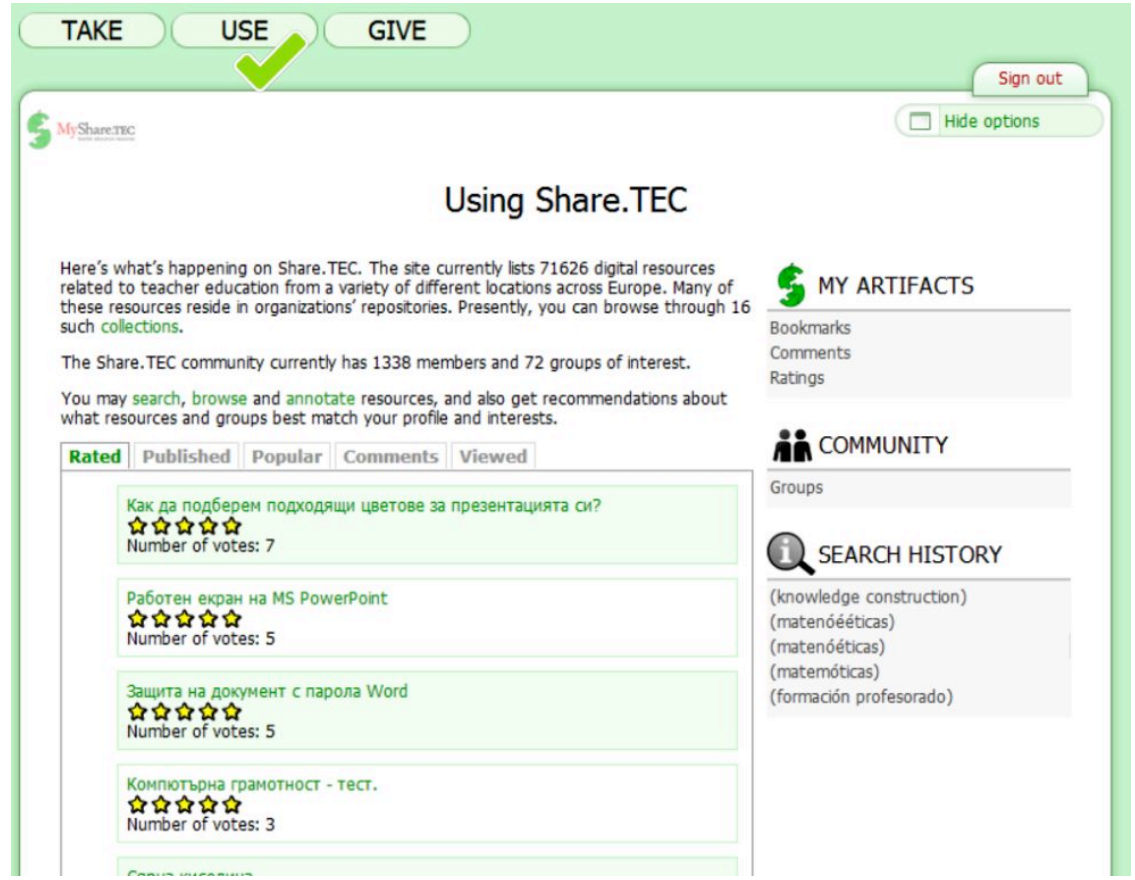

Además, vemos los listados con los 5 últimos recursos puntuados, publicados, populares, comentados 0 vistos. No es casualidad que los recursos que aparecen en estas opciones aparezcan en búlgaro (pues fue el miembro búlgaro NIS-SU quien se encargó de mantener el portal tras la finalización del proyecto). Esto es así, incluso cuando en nuestro perfil hemos definido la preferencia de idioma, por lo que no nos permite personalizar los idiomas en los que queremos que aparezca la información. Veremos en el capítulo 4 los inconvenientes de este hecho.

Si exploramos un poco esta sección, podemos acceder a "mis artefactos", donde aparecerán los recursos que hemos marcado como favoritos, hemos comentado y puntuado. También accedemos a "comunidad". Por último, podemos ver "historial de búsqueda", donde nos recuerda las 5 últimas búsquedas por palabra clave que hemos realizado.

Entrando en la sección "comunidad" (véase llustración 19), se muestra un listado de los grupos existentes en el sistema, visualizando el nombre, descripción, número 
de integrantes, y un link para unirse. Además, aparecen recogidos los grupos en los que ya estamos inscritos, donde se comentan temas de forma asíncrona mediante foro, y donde visualizamos la imagen de perfil de los participantes. Haciendo clic sobre la imagen de cada participante tenemos acceso a su: nombre, apellido, idioma de trabajo, rol, área de interés, último acceso, última actividad y fecha desde la que es miembro (no aparece información de contacto). También podemos ver los miembros conectados y los usuarios no registrados activos (aunque es un número irreal, suelen aparecer invitados conectados, pero en realidad son sistemas que acceden automáticamente al portal), pues podemos comprobarlo en las estadísticas de Google Analytics.

Ilustración 19 Capturas de Pantalla del apartado Usar. A la izquierda, su función de Grupos; a la derecha, visualizamos el aspecto de uno de los grupos del sistema.
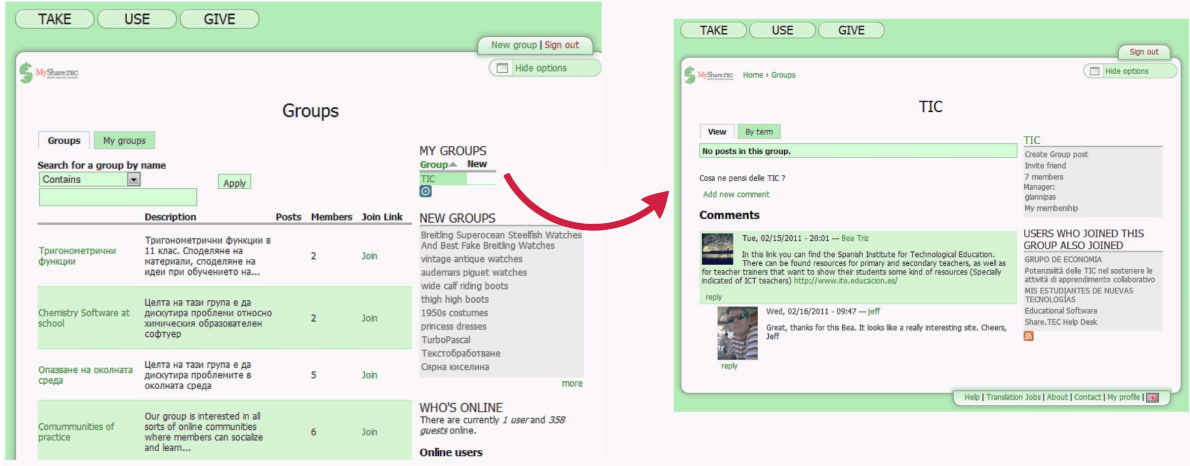

\section{c. Ofrecer}

Por último, la sección "Ofrecer" (ver llustración 20) permite a los usuarios contribuir con sus propios recursos en el sistema con las herramientas, RICK o MMF (Carramolino Arranz \& Rubia Avi, 2013, p. 295)

Apreciamos tres funciones principales: anotar, subir recurso, 0 introducir metadatos; y de nuevo, tres funciones que veíamos en "Usar" (comunidad, mis artefactos e historial de búsqueda) y los recursos recientemente visitados por el usuario.

En la sección anotar, vuelve a aparecer lo que visualizamos en la página principal de la sección usar. En la sección cargar recurso aparecen los metadatos obligatorios y opcionales (que vimos en la Tabla 7 en formato de formulario. Cuando subimos un recurso, no aparece directamente publicado, si no que ha de ser 
revisado por uno de los miembros de NIS-SU para permitir que sea visible para cualquier usuario).

En la sección Metadatos, aparecen los recursos que hemos subido a lo largo del tiempo, y podemos volver a editar los metadatos que introducimos. No podemos cambiar los metadatos de recursos subidos por otras personas, sólo podemos comentarlos.

Ilustración 20 Sección Ofrecer del Portal Share.TEC

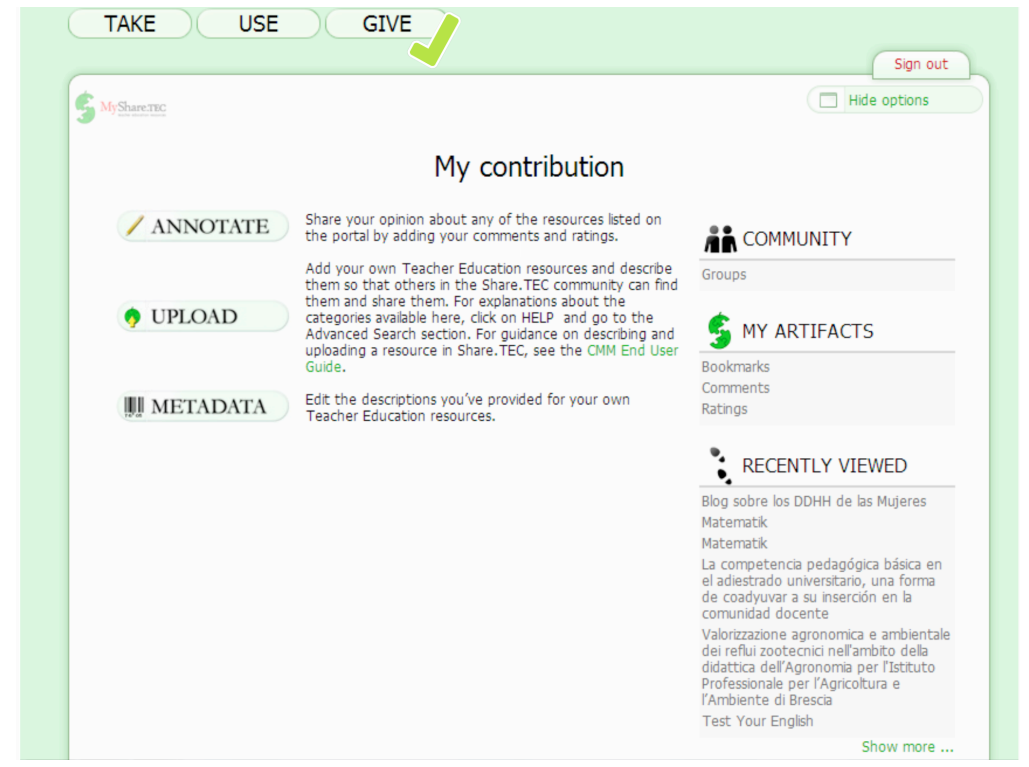

Los fundamentos que sustentan el presente trabajo y la existencia del portal Share.TEC, estrechamente relacionados con los aspectos definidos en el "Contexto" (apartado D) de este capítulo), son aquellos que hacen referencia a la necesidad de generar soluciones técnicas, sociales y pedagógicas para organizar el contenido disperso en la red, en nuestro caso, aquel referente a la formación del profesorado. Uno de los principios fundamentales que consideramos que da fuerza a este trabajo es el de considerar las necesidades que demandan los formadores de profesoras y profesores en proceso de formación, ya que sólo a través de la comprensión de estas podemos ofrecer soluciones útiles, flexibles (para adaptarse a la evolución tecnológica, pedagógica y social) y sostenibles en el tiempo. 


\subsubsection{Recogida y análisis de datos: Aproximación multimétodo}

En el círculo central de la llustración 8 se encuentran los aspectos relativos a la metodología e investigación puestos en práctica. En la parte superior encontramos las "funciones" que perseguimos con el estudio de caso Share.TEC, en orden a poder iluminar el issue generado. Las funciones de nuestro caso de estudio son tres:

- Analizar aspectos pedagógicos, técnicos y sociales que caracterizan al portal Share.TEC.

- Encontrar debilidades y fortalezas presentes en el portal, en orden a poder abstraer características deseables en los portales de contenido digital para la formación del profesorado, desde la perspectiva de nuestros informantes.

- Analizar las necesidades de acceso, creación y compartición de contenidos digitales para la formación del profesorado de los informantes de nuestro estudio.

Bajo esta, en la zona central, hallamos las "actividades particulares y lugares de actividad", que constituyen aquellas acciones de diseminación y de evaluación que se desempeñaron durante y tras la finalización del proyecto, en las que pudimos recopilar información de usuarios finales, así como los lugares en los que tuvieron lugar estas actividades. En la parte inferior se contemplan las "técnicas de investigación" que utilizamos: cuestionarios, encuestas, entrevistas, observaciones, Think Aloud Protocol y Focus Group, etc. También podemos ver los "documentos" utilizados para la investigación (anotaciones de workshops y pruebas piloto, documentos que generamos para su desarrollo, entregables del proyecto, registros de "Google Analytics" del portal Share.TEC, etc. Por último, se recogen los "informantes" que tuvieron influencia en el caso de estudio Share.TEC, que configuraron el devenir del proyecto, y proporcionaron información útil para comprender el caso.

En la parte inferior del círculo de la llustración 8 también apreciamos una elipse punteada que recoge los aspectos de la zona inferior del cuadro, representando el "método" de recogida y análisis de datos que se ha utilizado, multimétodo. 


\section{A) Aproximación Multimétodo para la recogida de datos}

Como mencionamos en el marco teórico-metodológico de esta tesis (capítulo 2), nuestro caso de estudio utiliza una aproximación multimétodo en las fases de diseño, recogida y análisis de los datos. A lo largo del estudio de caso de Share.TEC, utilizamos diferentes tipos de fuentes, técnicas y estrategias de recogida de datos, obteniendo información tanto cualitativa como cuantitativa. El objetivo de incluir técnicas y datos cualitativos y cuantitativos tiene como fin realizar la triangulación de los datos atendiendo dos combinaciones: expansión (añadir comprensión a los datos analizados con cada técnica) y complementación (yuxtaposición de los datos para la obtención de una visión más global) (Brannen, 2005).

\section{A.1 Fases del método}

Una de las peculiaridades de esta investigación es que utiliza como objeto de estudio datos obtenidos durante la generación de un portal educativo perteneciente a un proyecto europeo. De esta manera, hemos creído conveniente comentar cómo se enmarca nuestra investigación en este proyecto de Desarrollo e Innovación.

Durante el periodo activo del proyecto (2008-2011), se realizaron diferentes pruebas con los usuarios con el objetivo de conocer las necesidades de los formadores de profesores relativas a los portales para compartir contenido digital en su área, así como evaluaciones del propio portal Share.TEC durante su proceso de creación. Asimismo, como parte de esta investigación exclusivamente, basándonos en nuestros objetivos, tras finalizar el proyecto, nos interesamos en ahondar en las necesidades y opiniones de usuarios finales sobre el portal generado y sobre otros portales de este tipo. Atendiendo a estas circunstancias, nuestra investigación consta de tres fases:

- Fase 1 - Inicial, que incluye dos subfases:

- Fase 1.1 Diseño del portal

- Fase 1.2 Prueba del portal

- Fase 2- Intermedia

- Fase 3: Final

Fase 1: Inicial

Esta fase se corresponde con la duración del proyecto Share.TEC. 
- Fase 1.1. Diseño del portal

En esta fase se generó el diseño del portal y sus primeras versiones. En ella se recogieron aportaciones de informantes a través de diversas pruebas que permitieron refinarlo antes de su lanzamiento. En ella se sentaron las bases conceptuales y de la arquitectura tecnológica del proyecto Share.TEC, generando el CMM y MMM, hasta llegar al lanzamiento del primer prototipo del portal. Con el objetivo de conocer la opinión de usuarios potenciales, en diversos contextos culturales realizamos las primeras pruebas. En esta primera subfase, incorporamos al caso de estudio tres pruebas (que serán descritas en más detalle en el apartado 5.2 .4 de fuentes y técnicas de recogida de datos): 1) las pruebas de evaluación del etiquetado de los recursos que incorporaría nuestro grupo (metadatos) que fueron realizadas por formadores de profesores de la UVa; 2) Un cuestionario de validación de los casos de uso del posible portal Share.TEC, que sirvió para redefinir las acciones que debería realizar el portal (prueba que se realizó en diversos contextos, pero sólo disponemos de los datos de UVa); y 3) Un focus group en el que participaron diversos formadores de profesores de la UVa, para ofrecer su opinión sobre el portal Share.TEC y sobre el primer prototipo de la plataforma que fue diseñada. Las pruebas fueron analizadas en función de los objetivos perseguidos por el proyecto y la interpretación de los resultados obtenidos enviadas a los responsables del consorcio encargados de realizar cada informe. Por ello, en la llustración 25 junto al nombre de cada fase, incluimos el texto: "Análisis preliminar de los datos", que se hizo con unos fines diferentes a los que nos planteamos en esta investigación, que fueron analizados de una forma más rudimentaria que la utilizada para la presente tesis, que será explicada posteriormente.

\section{- Fase 1.2: Prueba del portal}

En esta etapa las bases ontológicas y la arquitectura del proyecto se encontraban completamente definidas y el primer prototipo de la plataforma para la compartición de contenidos digitales para la formación del profesorado, recién lanzado. En esta subfase los informantes de los diferentes países del consorcio realizaron evaluaciones del portal, con el objetivo de adaptarse mejor a sus necesidades y mejorar el prototipo lanzado. Se creó la interfaz de usuario del portal con una función multiidioma (contemplando los idiomas de los miembros del consorcio), encontrando traducciones de los esquemas de metadatos e interfaz gráfica del portal. Las primeras pruebas llevadas a cabo fueron: una encuesta 
coordinada entre varios equipos del consorcio, un cuestionario sobre la prueba piloto del portal, un TAP (Think Aloud Protocol ${ }^{110}$ ) (Solomon, 1995) de la prueba del portal y una evaluación mediante la selección de 6 de entre más de 100 adjetivos calificativos del sistema por usuarios de todos los países del consorcio.

A medida que el portal era evaluado y refinado, los miembros del consorcio iban poblando el repositorio central de Share.TEC con los metadatos de contenidos digitales prometidos por cada equipo en el Technical Annex del proyecto. De este modo se generó un cuestionario sobre el portal Share.TEC y de nuevo, una segunda encuesta coordinada por varios miembros del consorcio. Con los datos obtenidos en las diferentes pruebas de evaluación de los usuarios, así como atendiendo a las recomendaciones que la evaluadora externa del proyecto realizó, se lanzó la versión final. Todos estos datos fueron analizados y enviados a los responsables del consorcio de cada prueba, al igual que en la subfase anterior.

\section{Fase 2: Intermedia}

En esta etapa realizamos un cuestionario, basada en pruebas anteriores, con informantes españoles [44] con el fin de conocer su opinión sobre el portal tras los cambios que fueron incorporados en el portal tras la finalización del proyecto Share.TEC, así como con el de complementar los datos que recogimos en la Fase 1.

En esta etapa se analizan todos los datos recogidos en la Fase I y Fase II atendiendo a los objetivos y preguntas de investigación de esta tesis, y a los issues, preguntas informativas y declaraciones temáticas planteadas en el estudio de caso de Share.TEC.

\section{Fase 3: Final}

Por último, este ciclo se corresponde con la integración de los datos y la generación del presente informe de investigación. En el capítulo 4 se recopila la integración y el análisis de los datos del estudio instrumental de caso de Share.TEC.

110 El método Think Aloud es una estrategia de investigación utilizada en investigación psicológica y educativa. La técnica consiste en solicitar a una persona o grupo de personas que resuelva un problema o tarea, mientras se le pide que verbalice todas aquellos pensamientos que le emergen a medida que va avanzando en ello. Esta estrategia cognitivista permite acceder, en cierta medida, a los pensamientos de los sujetos. 


\subsubsection{Fuentes y técnicas de recogida de datos}

La información obtenida a través de las visiones y experiencias de los informantes descritos en el apartado anterior, junto con los documentos recopilados a lo largo del desarrollo del proyecto y los datos automáticos recogidos por Google Analytics constituyen las fuentes de información de esta investigación. En este apartado presentamos las diferentes pruebas que se llevaron a cabo durante el desarrollo del proyecto Share.TEC y tras su finalización, y las enmarcamos en cada una de las fases de la metodología multimétodo de esta investigación. En cada cuadro, en el apartado "fecha", se incluye un número entre paréntesis (correspondiente al mes en el que se realizaron las pruebas), y que corresponde a la etiqueta identificadora de cada prueba (como veremos en el capítulo 4 de esta tesis). Las fuentes y técnicas aparecen sintetizadas en la llustración 8 (estructura conceptual del caso). Adicionalmente, en la llustración 25 podemos ver estas pruebas y técnicas (reflejando si proporcionan datos cualitativos o cuantitativos) enmarcadas de forma visual en cada fase de investigación y ubicadas en una línea temporal. Además, puede observarse la relación temporal entre los hitos relevantes del proyecto Share.TEC y la aplicación de estas pruebas y técnicas.

\section{A) Recogida de datos en Fase 1.1 Diseño del portal}

\section{VALIDACIÓN DE CASOS DE USO}

Definición y Objetivo:

Prueba que consistió en la presentación de casos de uso posibles del portal Share.TEC (realizados por NIS-SU con el feedback del resto de miembros del consorcio, y traducidos a español) a usuarios potenciales del portal, tratando de conocer si el sistema daría respuesta a sus necesidades, tratando de descubrir si podrían existir más casos de uso.

Feedback aportado: detección de los casos de uso posibles del Portal Share.TEC.

Fecha: 12 de Mayo de 2009 (11)

Informantes: Formador de profesores de Didáctica y Organización Escolar; Profesora de Didáctica de las Matemáticas.

Número de informantes: 2

Técnicas de recogida de datos:

Aplicación de cuestionario con preguntas cerradas y abiertas (sólo respondieron a preguntas cerradas cuantitativas). 


\section{TEST de Evaluación de la calidad de los Metadatos}

Definición y Objetivo:

Test realizado con el objetivo de identificar si los metadatos, que una persona contratada por UVa estaba generando desde cero, tenían una calidad adecuada, sin errores de contenido ni ortográficos o gramaticales, y sin errores de traducción del abstract y título al inglés.

Se pedía a los evaluadores que dieran su opinión sobre la calidad de cada campo de metadatos (10 preguntas cuantitativas y 4 cualitativas). Se les explica la estructura ontológica de Share.TEC y se les entrega un resumen en español de la misma. Se presentaron los metadatos en la herramienta RICK. Los evaluadores completaron sus respuestas en una plantilla Excel que se les entregó; donde posteriormente fueron analizados los datos.

Esta prueba permitió detectar errores del etiquetado de metadatos generado por una persona contratada para tal fin y reconducción del etiquetado de los recursos de UVa, evaluación del sistema de metadatos.

Fecha: 3 de Junio de 2009 (12)

Informantes: Formadores de profesores y expertos en lenguaje técnico. 3 profesores de tecnología educativa, 1 ingeniero de telecomunicaciones con conocimientos pedagógicos, 1 profesora de didáctica de la música.

Número de informantes: 5

Técnicas de recogida de datos:

Entrega de un cuestionario de evaluación de 5 registros de metadatos relativos a contenidos digitales. Selección al azar de un registro de metadatos completo (de entre los creados hasta esa fecha) de cada fuente de datos comprometida por UVa: Rifop; Dialnet; Biblioteca Semántica de WebQuests y Comunicar, en total, cinco (de este último se evaluaron dos recursos).

\section{FoCUS GROUP UVA}

Definición y Objetivo:

Focus Group realizado con el objetivo de conocer cuál era la opinión de usuarios potenciales del portal sobre el servicio Share.TEC, así como sus hábitos de uso y compartición de contenidos digitales. La investigadora de la presente tesis moderó la intervención de los informantes en torno a los tópicos de interés de la prueba.

El informe aportó información sobre los hábitos generales en torno al uso, compartición y reúso de los contenidos digitales para la formación del profesorado, de forma que los responsables de la construcción del portal pudieron reorientar las funcionalidades del mismo para adaptarla a las necesidades de los usuarios.

Fecha: 11 de noviembre de 2009 [17] Grupo objetivo: 6 Formadores de profesores del área de Didáctica y Organización Escolar, 1 Profesor de Didáctica de la Educación Física; 1 Profesor de Telecomunicaciones.

Número de informantes: 8 


\section{Focus GROUP UVA}

Técnicas de recogida de datos:

Focus Group

Grabación de audio de la prueba (para su posterior transcripción)

\section{Primera Encuesta coordinada}

Definición y Objetivo:

Encuesta generada para conocer qué tipo de contenidos digitales utilizan los usuarios potenciales del portal, así como las técnicas pedagógicas que emplean en su labor docente.

Fecha: Febrero de 2010 (20)

Informantes

Formadores de profesores, Profesores, Editores y otros profesionales educativos.

Número de informantes: 67 (NIS Su - 27; UVa - 26; CLUEB 28)

Para captar a la muestra de informantes se utilizaron listas de e-mail, contactos de los

miembros del consorcio, comunicación cara a cara.

Técnicas de recogida de datos:

Aplicación de una encuesta creada con Google Forms. Envío automático de las respuestas.

\section{B) Recogida de datos en fase 1.2: Prueba del portal}

\section{PILOt del PORTAL Share.TEC}

\section{Definición y Objetivo:}

Evaluación del portal a partir de una plantilla de tareas que los usuarios debían completar.

Fecha: 30 de marzo de 2010 [21]

La opinión de los usuarios sobre los adjetivos que mejor describen al sistema sirvió para mejorar la usabilidad del mismo.

Número de informantes:

6 formadores de profesores de Pedagogía y 1 de Didáctica de la música de la Universidad de Valladolid.

Roles adicionales: 3 observadores, aplicando registrando las verbalizaciones de los usuarios. Técnicas de recogida de datos:

- TAP - Think Aloud Protocol y registro de las verbalizaciones por 3 observadores en sus libretas.

- Grabación de audio de la sesión. Grabación de fragmentos de vídeo.

- Cuestionario realizado tras finalizar la prueba. CENEC, SU y UVa también recogen respuestas en el cuestionario elaborado entre estos equipos. En total, 30 respuestas CUAN y CUAL relativas al tipo de búsquedas que realizan los usuarios y su opinión sobre las que pueden realizar con Share.TEC, principalmente

- Cuestionario del kit de deseabilidad (descrito a continuación) 


\section{Pilot del PORTAL Share.TEC}

llustración 21 Captura de pantalla de la prueba de selección de adjetivos, traducida al español

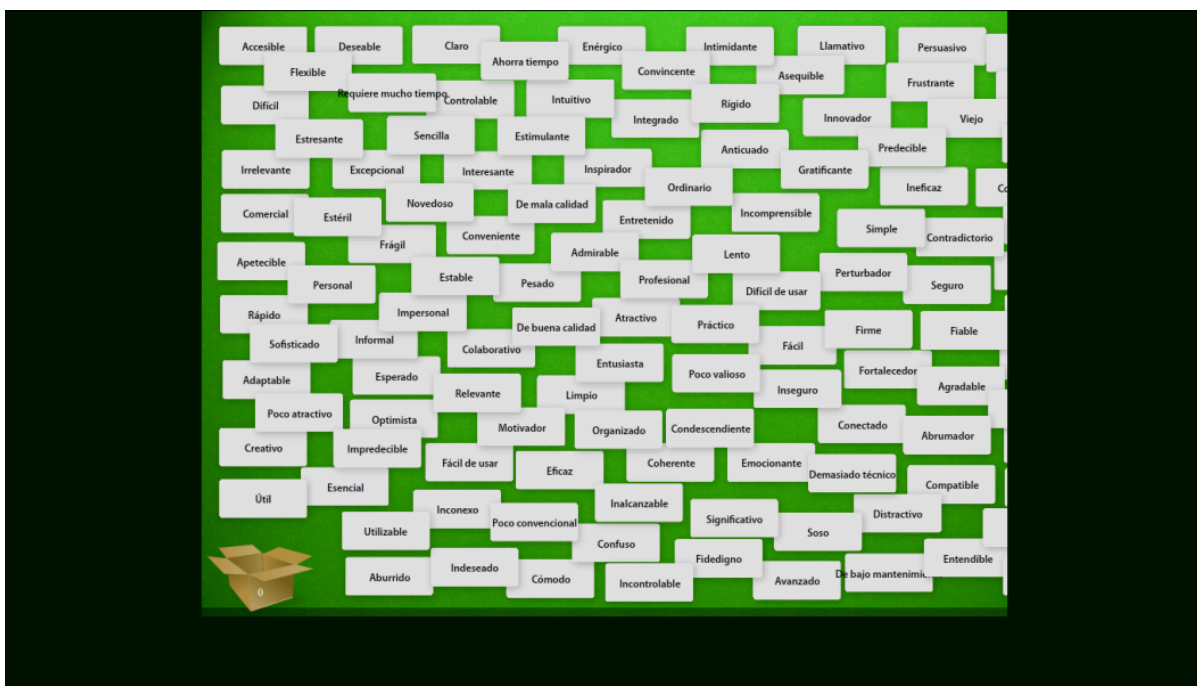

Kit de deseabilidad

Prueba que consiste en una descripción mediante adjetivos del portal, por parte de usuarios finales. Esta prueba fue diseñada por OUNL y aplicada por los miembros de los diferentes equipos del consorcio en sus contextos locales.

Fecha: 30 de marzo de 2010

Prueba local:

Número de informantes: 7

Prueba internacional:

Grupo objetivo: Formadores de profesores de Número de Informantes: 67

Tecnología educativa (5) y Didáctica y

Organización Escolar (2)

Grupo objetivo: Formadores de profesores y profesores de educación básica y secundaria.

Método de captación de usuarios: contacto directo cara a cara con los evaluadores, Método de captación de usuarios: cada grupo se encargó por diferentes medios pertenecientes a la Universidad de Valladolid. (presenciales y virtuales) de contactar con personas de su círculo de contactos. 


\section{PILOT DEL PORTAL SHARE.TEC}

Técnicas de recogida de datos:

Product reaction cards: Aplicación de un método desarrollado por Benedek and Miner (2002), para evaluar la usabilidad de servicios de e-learning. Este método pretende medir el grado de satisfacción de los usuarios con el portal Share.TEC. OUNL desarrolló una adaptación del método con otros colaboradores en un proyecto sobre la virtualización en una aplicación Web a partir del método de Benedek y Miner. El método, denominado Product Reaction Cards (Tarjetas de Reacción de un producto), está compuesto por un conjunto de 118 adjetivos, (60\% positivos y $40 \%$ negativos o neutrales) entre las que los usuarios han de elegir. En la adaptación realizada de esta prueba, el usuario tenía que elegir 6 adjetivos que, a su juicio, describían mejor el portal. Además, el usuario tuvo que escribir y motivar las razones de su selección.

\section{WORKSHOP NACIONAL SHARE.TEC.}

PRUEBAS PILOTO SOBRE EL IMPACTO DEL PORTAL PARA LOS USUARIOS

Definición y Objetivo:

Prueba elaborada por CENEC y UVa, que pretendía recoger evidencias de acuerdo al impacto del portal en los usuarios potenciales del sistema.

Desde UVa se crearon grupos ad hoc en la red social NING (actualmente inexistente). Se realizaron presentaciones técnicas y pedagógicas sobre el proyecto y el portal a los asistentes a los workshops.

La realización de estas pruebas piloto favorecieron la creación de nuevos usuarios que aportaron diversos recursos al portal Share. TEC. A su vez, los informantes aportaron información valiosa para mejorar los aspectos técnicos, pedagógicos y sociales del portal.

Fecha Piloto 1, nacional: $\quad$ Fecha Piloto 2, local:

07 de abril de 2011 [33] 30 de marzo de 2011 [33]

Informantes:

Número de informantes Piloto 1:

Número de informantes Piloto 2: 


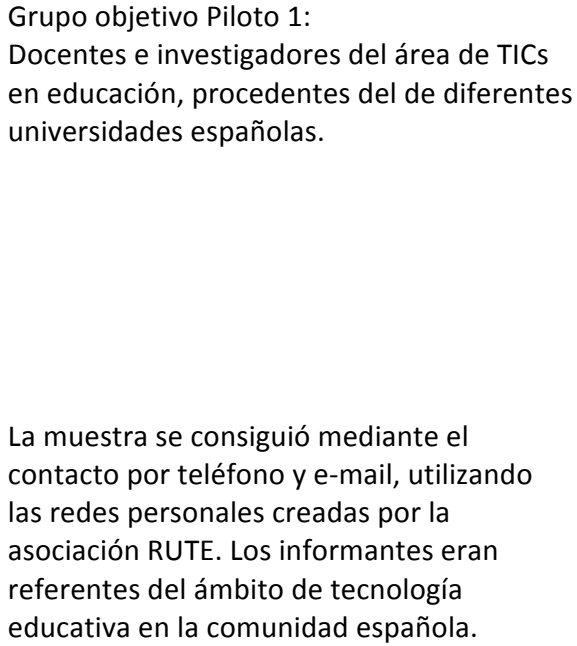

La muestra se consiguió mediante el contacto por teléfono y e-mail, utilizando las redes personales creadas por la asociación RUTE. Los informantes eran referentes del ámbito de tecnología educativa en la comunidad española.

Grupo Objetivo Piloto 2:

Profesores de Tecnología Educativa, Profesores de lengua extranjera, Formadores de Profesores de Educación Secundaria, Formadores de empleo, Formadores de profesores de educación artística en Educación Primaria e Infantil. Todos ellos formadores de profesores de la Universidad de Valladolid y de otras instituciones educativas y formativas.

Método de captación de usuarios: Contacto con personas e instituciones que queríamos que estuvieran representadas mediante el la comunicación cara a cara con profesores dela UVa, correo electrónico y teléfono con otros servicios educativos

Técnicas de recogida de datos:

- Distribución de hoja de tareas para recoger evidencias sobre las funcionalidades de Share.TEC (algunos informantes aportaron notas escritas en ellas, que se recopilaron en formato digital).

- Aplicación de un cuestionario sobre el portal Share.TEC y hábitos de búsqueda y compartición de contenidos digitales, durante el workshop (26 respuestas al cuestionario de UVa; 6 respuestas CENEC; 6 Suecia; 1 Holanda).

- Observación de usuarios mientras realizaban las tareas y recopilación de las ideas que aportaron verbalmente.

Ilustración 22 Captura de pantalla del cuestionario sobre el Impacto del Portal Share.TEC, en español, realizado en limesurvey.

Encuesta sobre el impacto del portal Share.TEC en el trabajo profesional de los usuarios

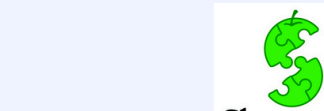

Share.TEC

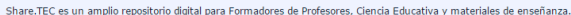

El objetivo de esta encuesta es recopilar feedthark sobre el uso del portal Share. TEC

Hav zag arequnras en osa oncuerta.

Nota sobre la privacidad

Eita cneustes os anovima.

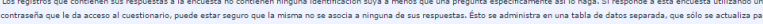

ircicer que be 


\section{SEGUNDA ENCUESTA COORDINADA}

Definición y Objetivo:

Encuesta para conocer el tipo de herramientas que utilizan los formadores de profesores, y otros profesionales de la educación para acceder y compartir contenidos digitales, así como para saber si forman o han formado parte de comunidades de práctica, y si usan servicios de la Web Semántica.

Fecha: Mayo de 2011 [35]

Informantes: Formadores de Profesores, Profesores de Educación Infantil, Primaria y Secundaria, Profesionales educativos

Número de informantes: 202

Contacto cara a cara, listas de e-mail, contactos de los miembros del consorcio responsables.

Técnicas de recogida de datos:

Encuesta online (mediante Limesurvey ${ }^{111}$ ), traducido a las diferentes lenguas.

\section{RED SOCIAL NING - ACTUALMENTE INACTIVA}

Objetivo de su lanzamiento: Red social que pretendía dar a conocer Share.TEC en el contexto hispanohablante, obtener nuevos usuarios para el portal (para satisfacer uno de los objetivos del proyecto), y ser lugar de encuentro de los informantes en las diferentes pruebas del portal.

Fecha de lanzamiento:

11 de noviembre de 2009 (actualmente extinguida)

Participantes: Personas interesadas en la compartición de contenido digital en el ámbito de la formación del profesorado. Principalmente, formadores de profesores del ámbito nacional

Número de participantes: 120

Para dar a conocer la comunidad a los usuarios se generaron listas de correo de profesores de didáctica y organización escolar en España, contacto directo, diseminación en conferencias, redes sociales (Facebook y Twitter), etc..

Técnicas de recogida de datos:

- Recogida automática de datos gracias a la interacción de los usuarios en la red.

111 https://www.limesurvey.org/ Herramienta gratuita de código abierto para la generación y compartición online de encuestas. 


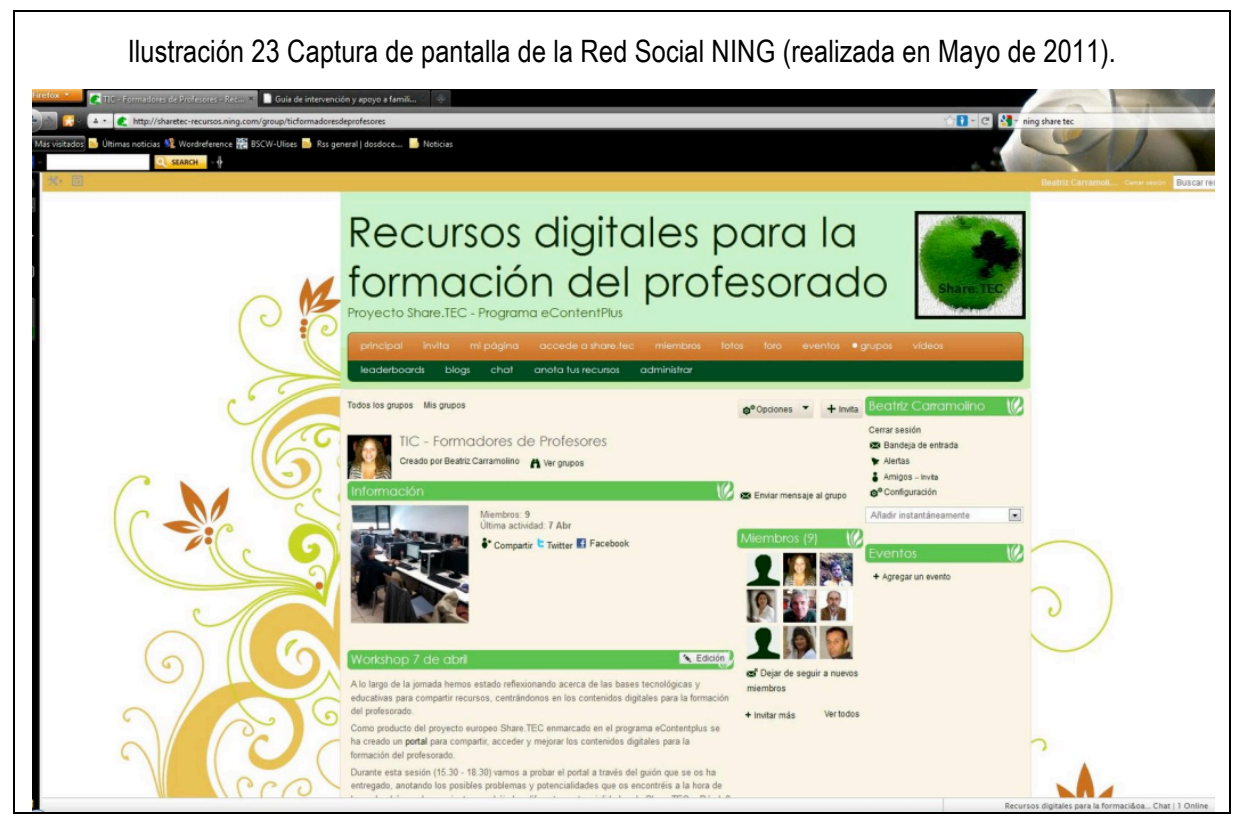

\section{C) Recogida de datos en Fase 2: Intermedia}

Durante esta fase se realizó el análisis de la información recopilada a lo largo del proyecto (durante la Fase 1), atendiendo a los objetivos de esta investigación, y en concreto, a los del estudio de caso Share.TEC. En esta última fase también se procedió a la recogida de datos a través de un cuestionario sobre la opinión y uso de Share.TEC y otros portales de contenidos digitales por parte de formadores de profesores e ingenieros relacionados con las TICs en educación.

\section{Cuestionario Share.TEC y portales UVa}

Objetivo: Conocer la opinión de los usuarios finales de Share.TEC tras la finalización del proyecto (ya que se habían producido cambios), y cotejar, ampliar y complementar la información de las evidencias recogidas con anterioridad.

Fecha: Mayo de 2011 [44]

Informantes: Formadores de profesores y profesionales de tecnologías de la información y la comunicación.

Número de informantes: 19

Para conseguir informantes se utilizó la comunicación directa (cara a cara) y envío de emails a contactos de la investigadora.

Técnicas de recogida de datos:

Generación y Aplicación de un cuestionario creado con Google Forms. 


\section{Google Analytics}

Definición y Objetivo:

Recogida automática de logs de eventos a través de la herramienta Google Analytics, con el objetivo de recolectar datos cuantitativos sobre la interacción de los usuarios en el portal en cuanto al acceso.

Fecha: Mayo de 2011

Informantes: Personas o servidores que accedieron a cualquier página del portal Share.TEC Técnicas de recogida de datos:

Recogida automática de eventos con Google Analytics (datos recogidos en las fases 1 y 2)

llustración 24 Captura de pantalla de las visitas al portal Share.TEC, datos recogidos automáticamente por Google Analytics.

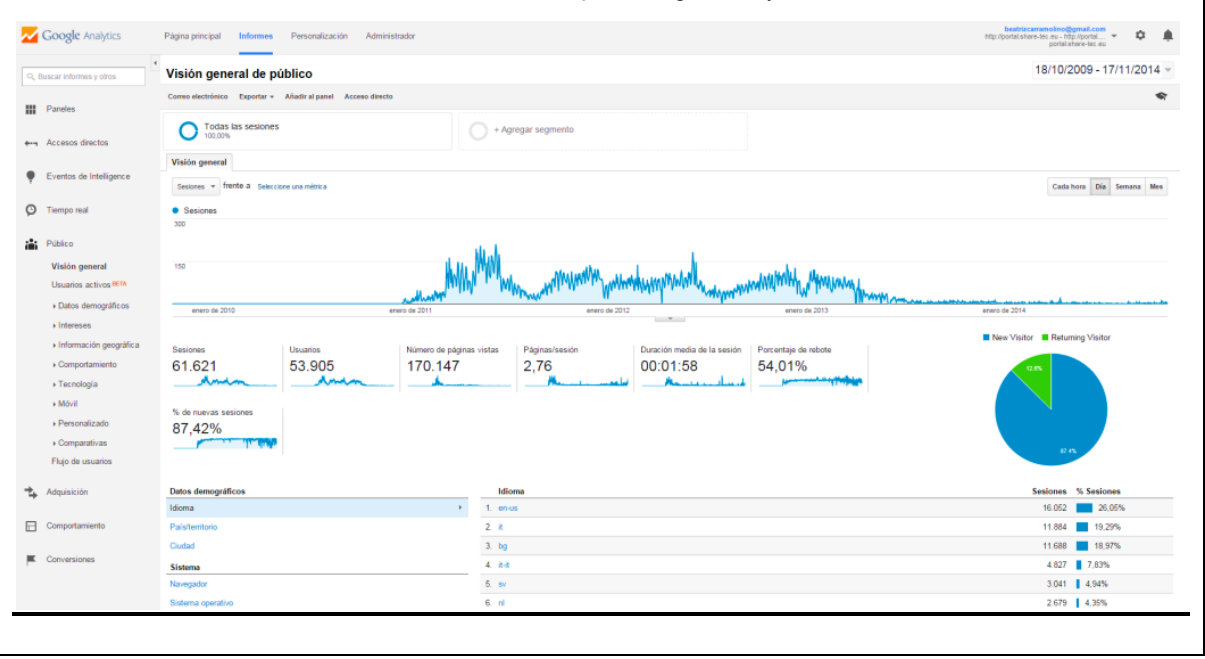

En la siguiente llustración 25 mostramos el esquema de las fases de la investigación multimétodo del caso de estudio Share.TEC enmarcadas en su contexto. En el cuadrante superior izquierdo, en morado, observamos los hitos relevantes del desarrollo del portal Share.TEC en una línea temporal. Entre paréntesis, indicamos el mes en el que se llevaron a cabo las tareas, siendo (0) el inicio del proyecto. A la derecha de este cuadrante, observamos un gran cuadro azul que recoge las tres fases de la investigación, en correspondencia con la línea temporal que vemos a la izquierda del cuadro. En este cuadro azul, en la parte superior izquierda, contemplamos en morado las técnicas de recogida de datos, 
indicando la técnica empleada, el mes en que se llevo a cabo (entre paréntesis), y el tipo de datos (CUAL -cualitativos; CUAN- cuantitativos). Apreciamos que algunas técnicas tienen flechas que unen unas con otras, representando las interdependencias (pues los análisis de unas pruebas sirvieron para la generación de otras). Tal y como vemos en la llustración 25, la prueba [17] se llevó a cabo teniendo en cuenta los resultados del análisis preliminar de (9) y (11). El cuestionario [44], se generó tras la finalización del proyecto, atendiendo al análisis preliminar de los datos recogidos en las fases 1.1 y 1.2 .

Las técnicas de recogida de datos ubicadas en las fases 1.1 y 1.2 se realizaron durante el proyecto Share.TEC.

Volviendo a la línea temporal, entre finales de 2011 y 2015 se desarrolla la investigación (propiamente dicha) de esta tesis doctoral. Se definen los objetivos de la tesis y se delimitan sus estudios, siendo uno de ellos el caso de estudio Share.TEC. Se definen los objetivos de la tesis, y los issues del estudio instrumental de casos y se analizan las pruebas atendiendo a estos objetivos. Se genera la prueba 44 teniendo en cuenta los análisis preliminares de los datos de las fases anteriores (1.1 y 1.2). Los datos cualitativos y cuantitativos se analizan de forma individual, y posteriormente se genera la integración de los datos (fase 3), como también representamos más adelante en la llustración 26. Las evidencias obtenidas integran datos cuantitativos y cualitativos, 4 pruebas tienen orientación CUAL-cuan y 1 CUAN-cual; también 2 pruebas incluyen evidencias exclusivamente cualitativas y 3 pruebas, cuantitativas.

Hay que tener en cuenta que a lo largo de las fases 1.1 y 1.2 (duración del proyecto Share.TEC) fuimos recabando información relativa al proyecto y elaborando informes referentes a las tareas de evaluación con informantes del proyecto. Simultáneamente fuimos realizando una revisión bibliográfica de aspectos educativos, sociales y técnicos, y generando una visión holística de la integración de estos tres ámbitos, con el objetivo de definir los objetivos de esta investigación. Además, a partir del lanzamiento del prototipo (mes 12 del proyecto), comenzó a realizarse un seguimiento de eventos producidos en el portal Share.TEC mediante la utilización de la aplicación gratuita de Google Analytics. La recogida de logs de eventos constituye una fuente de información cuantitativa, que tal como se ve en la llustración 25 y en la llustración 26, formó parte de las evidencias que fueron analizadas e integradas con el resto de datos. Principalmente se recogieron los datos de interacción con el portal (número de accesos únicos, accesos reincidentes, países, fecha, etc.). 
Por ello, en la fase 2 se produce el análisis en profundidad de los datos obtenidos en las diferentes pruebas del proyecto, atendiendo a los objetivos del presente trabajo, organizando la información y dando sentido a lo acontecido en el desarrollo del portal Share.TEC y a las opiniones aportadas por los formadores.

Esta compleja estructura de recogida y análisis de los datos, integrando datos cualitativos y cuantitativos, nos lleva a la configuración de nuestro estudio de caso mediante la metodología multimétodo. 
Ilustración 25 Fases de investigación multimétodo del caso de estudio Share.TEC enmarcadas en su contexto.

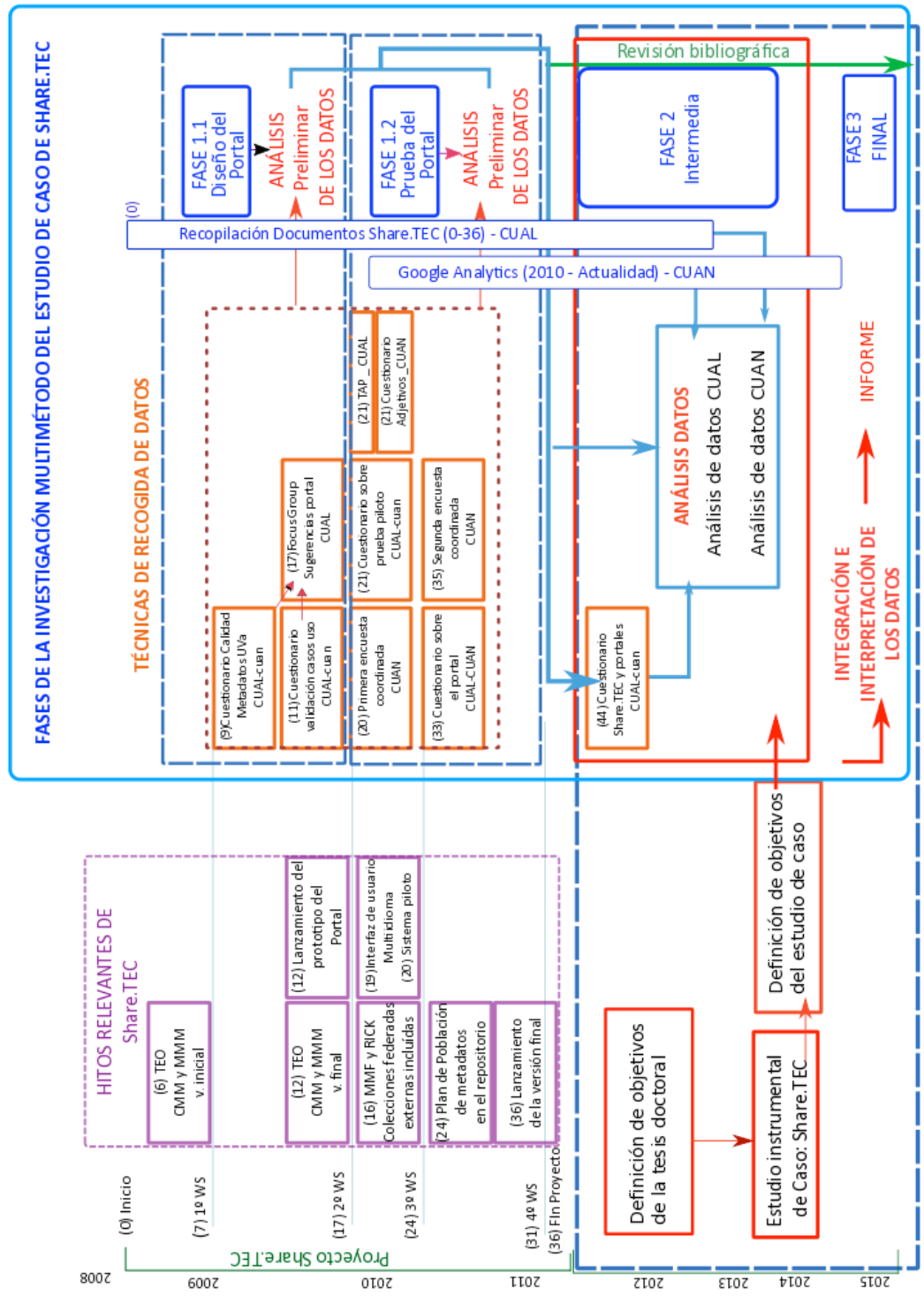




\subsubsection{Aproximación multimétodo para el análisis de los datos:}

Teniendo cuenta los objetivos generales de la tesis y sus preguntas de investigación, definimos los objetivos particulares de este caso de estudio, planteando una definición de issues, declaraciones temáticas y preguntas informativas.

El análisis de los datos se divide en tres subetapas (Miles et al., 2014): 1 "Reducción de datos"; 2 "Muestra de los datos"; y 3 "Conclusiones".

1. Reducción de datos: los datos cualitativos obtenidos en las fases 1.1 y 1.2 del estudio de caso (Fase 1: Inicial), así como los recogidos específicamente para esta tesis doctoral (Fase 2), atravesaron dos procesos de análisis de datos realizados mediante el método de análisis de contenido (identificando los vínculos entre los datos, los conceptos, las categorías y la teoría que conecta las categorías emergentes) (Bergman, 2010:385).

Inicialmente seleccionamos aquellos documentos y pruebas recogidos en el proyecto que aportaban respuestas a nuestros objetivos investigativos, y ampliamos estas pruebas para conocer en mayor profundidad la opinión de los usuarios sobre los aspectos a indagar en esta tesis. Además de la selección documental, generamos unas categorías de análisis vinculadas con nuestras preguntas de investigación. En ellas catalogamos la información, centrada en aspectos pedagógicos, tecnológicos y sociales, relativa a las necesidades de los usuarios sobre los portales de contenido digital.

Las categorías fueron evolucionando a medida que se sucedían los ciclos de recodificación (ver juego de líneas azules y moradas en la fase 2 de la llustración 26. Los datos fueron analizados desde los conocimientos, experiencias y perspectivas metodológicas con las que abordamos esta investigación. A estos procesos de "filtrado" que aplicamos para analizar nuestra información, tradicionalmente han sido denominados procesos de reducción anticipada 0 condensación de los datos (Miles et al., 2014; Patton, 2002) (representado mediante las líneas discontinuas moradas en la llustración 26 y el texto "x2"12).

112 En el gráfico "x2" hace referencia a "por dos veces". 
Ilustración 26 Fases y técnicas de recogida de datos del estudio de caso Share.TEC enmarcadas en su contexto.

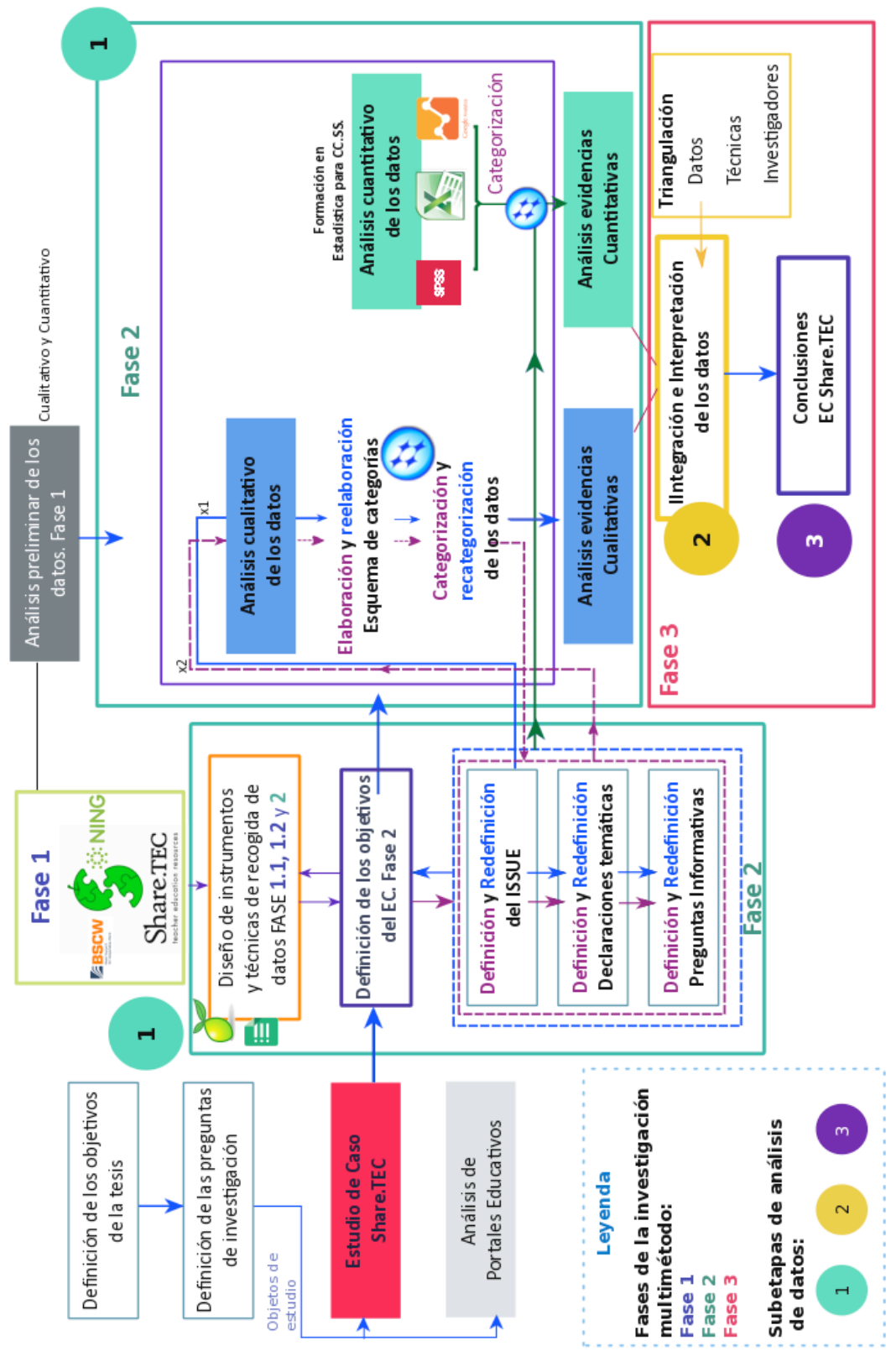


Realizamos dos procesos completos de etiquetado de los datos con el software de análisis cualitativo de datos NVivo 8.0; a medida que se realizaba el análisis, las categorías se iban redefiniendo, y el issue, las declaraciones temáticas y preguntas declarativas se iban depurando. Finalmente, realizamos una categorización final de los datos con el esquema definitivo de categorías.

El análisis cuantitativo de los datos se realizó de forma posterior al cualitativo; en primer lugar, porque la investigadora tuvo que formarse en metodología cuantitativa y en el uso del software SPSS para aprender a transformar y tratar los datos; y en segundo lugar, porque queríamos realizar el análisis basándonos en el esquema definitivo de categorías éticas y émicas nacidas del análisis cualitativo. Los datos cuantitativos de los que disponíamos habían sido obtenidos a partir de pruebas diseñadas en el proyecto, por lo que contábamos con diversidad de número de informantes, roles, y tipos de preguntas entre los distintos instrumentos de recogida de datos que fueron diseñados. Los datos de los que disponíamos no tenían un gran potencial estadístico en la mayoría de los casos, pero hemos aplicado las pruebas estadísticas más apropiadas en función de las características de los datos, tales como el número de sujetos de la muestra, distribución, varianzas, etc. (e.g., Chicuadrado de Pearson, tablas de contingencia, matrices estadísticas descriptivas). Además del programa de análisis cuantitativo SPSS, hemos utilizado como complemento el software Excel para la generación de gráficos y en casos puntuales se ha utilizado también para el tratamiento y análisis estadístico de los datos. También hemos obtenido datos cuantitativos procedentes de los logs de eventos del portal Share.TEC gracias a Google Analytics (profundizaremos en estas herramientas de recogida de datos en la sección 5.2.7. de este capítulo).

En la siguiente Tabla 8 detallamos qué metodología ha sido llevada a cabo para el análisis de cada una de las fuentes de las que hemos obtenido información: 
Tabla 8 Métodos de análisis de datos por cada fuente de datos

\begin{tabular}{|c|c|}
\hline Fuentes de datos & Método de análisis de datos: \\
\hline $\begin{array}{l}\text { 1. Validación de } \\
\text { casos de uso [11] }\end{array}$ & $\begin{array}{l}\text { Análisis cuantitativo de las respuestas del cuestionario y } \\
\text { compartición de los resultados con los responsables de esta tarea } \\
\text { en el proyecto (Realizado en fase } 1.1 \text { con datos obtenidos en esa } \\
\text { misma fase). } \\
\text { Análisis cuantitativo de las respuestas (obtenidas en fase 1.1). }\end{array}$ \\
\hline $\begin{array}{l}\text { 2. Test de } \\
\text { Evaluación de la } \\
\text { calidad de los } \\
\text { Metadatos [12] }\end{array}$ & $\begin{array}{l}\text { Análisis cualitativo: codificación abierta de las repuestas } \\
\text { cualitativas mediante NVivo } 8.0 \text { (Obtenidas en la Fase } 1.1 \text { ). } \\
\text { Análisis cualitativo de las opiniones de los sujetos (recogidos en la } \\
\text { Fase 1.1). } \\
\text { Análisis cuantitativo: cálculo de la media y desviación típica de } \\
\text { cada recurso; cálculo de la media y desviación típica total } \\
\text { (recopilados en Fase 1.1). }\end{array}$ \\
\hline $\begin{array}{l}\text { 3. Focus Group } \\
\text { Uva [17] }\end{array}$ & $\begin{array}{l}\text { Transcripción de la grabación de audio (obtenido en fase } 1.1 \text { ) } \\
\text { Análisis cualitativo - codificación abierta de la grabación de audio } \\
\text { con NVivo } 8.0 \text { en base a las categorías predefinidas (realizado en } \\
\text { fase } 2 \text { con datos obtenidos en 1.1). }\end{array}$ \\
\hline $\begin{array}{l}\text { 4. Primera } \\
\text { Encuesta } \\
\text { coordinada[20] }\end{array}$ & $\begin{array}{l}\text { Análisis cuantitativo de las respuestas, en relación con los } \\
\text { objetivos de esta investigación. Análisis en Excel (descriptivos) y } \\
\text { SPSS (descriptivos y test estadísticos) (datos obtenidos en la Fase } \\
\text { 1.1). }\end{array}$ \\
\hline $\begin{array}{l}\text { 5. Pilot del portal } \\
\text { Share.TEC. } \\
\text { Think Aloud } \\
\text { Protocol [21] }\end{array}$ & $\begin{array}{l}\text { Informe de las verbalizaciones más frecuentes e importantes de los } \\
\text { usuarios (realizado en fase 1.2) y codificación abierta cualitativa } \\
\text { de los datos con NVivo } 8.0 \text { (obtenidos en fase } 1.2 \text { ). } \\
\text { Análisis cuantitativo descriptivo de los datos del cuestionario - } \\
\text { datos automáticos de "Limesurvey" (obtenidos en fase } 1.2 \text { ). } \\
\text { Análisis cualitativo de los datos del cuestionario con NVivo } 8.0 \\
\text { (datos obtenidos en fase 1.2). }\end{array}$ \\
\hline
\end{tabular}




\begin{tabular}{|c|c|}
\hline Fuentes de datos & Método de análisis de datos: \\
\hline $\begin{array}{l}\text { 5. Pilot del portal } \\
\text { Share.TEC. } \\
\text { Evaluación de los } \\
\text { adjetivos } \\
\text { seleccionados por } \\
\text { los informantes } \\
\text { para describir el } \\
\text { portal [21] }\end{array}$ & $\begin{array}{l}\text { Traducción al español de los adjetivos y de los comentarios } \\
\text { creados por cada usuario para cada uno de sus } 6 \text { adjetivos elegidos } \\
\text { (búlgaro, sueco, italiano y holandés) mediante "Google Translator", } \\
\text { refinando los resultados con "Wordreference" (datos obtenidos en } \\
\text { fase 1.2). } \\
\text { Análisis cualitativo - Codificación abierta de los adjetivos con } \\
\text { NVivo 8.0. (tratados en la fase 2). } \\
\text { Análisis cuantitativo de los adjetivos con Excel: se clasifican los } \\
\text { adjetivos en cuatro categorías, consensuadas por dos evaluadores } \\
\text { diferentes (concordancia entre jueces). Además, cada juez otorga } \\
\text { a cada adjetivo un valor positivo o negativo. Dos evaluadores (la } \\
\text { investigadora de esta tesis) y un investigador del área de } \\
\text { telecomunicaciones realizaron una evaluación independiente de } \\
\text { cada adjetivo, decidiendo en cuál de las cuatro categorías } \\
\text { encajaba. Se aúnan las categorizaciones de los dos "jueces", y se } \\
\text { consensuan razonando verbalmente en qué categoría tenían que } \\
\text { ubicarse. Para analizar los datos se realizó una relativización de las } \\
\text { frecuencias, suponiendo que existían tantos adjetivos positivos } \\
\text { como negativos, y tantos adjetivos en un área como en otra (datos } \\
\text { tratados en la fase 2). Todos estos procedimientos aparecen } \\
\text { recogidos en el [Anexo 30] } \\
\text { La Integración de los datos cualitativos y cuantitativos se produce } \\
\text { en el análisis e interpretación de los datos. }\end{array}$ \\
\hline $\begin{array}{l}\text { 6. Workshop } \\
\text { nacional } \\
\text { Share.TEC. [33] }\end{array}$ & $\begin{array}{l}\text { Análisis cualitativo de los datos recopilados, y puesta en común } \\
\text { con los datos de CENEC (datos obtenidos en fase } 1.2 \text { y puestos en } \\
\text { común en fase } 1.2 \text { ) (elaboración conjunta de informe). } \\
\text { Análisis cuantitativo de los datos del cuestionario con SPSS (datos } \\
\text { de la fase } 1.2 \text { ). } \\
\text { Análisis cualitativo: codificación abierta de las observaciones } \\
\text { recopiladas en notas en un documento mediante el software } \\
\text { NVivo } 8.0 \text { (datos de la fase } 1.2 \text { ). }\end{array}$ \\
\hline $\begin{array}{l}\text { 7. Segunda } \\
\text { encuesta } \\
\text { coordinada [35] }\end{array}$ & $\begin{array}{l}\text { Análisis cuantitativo con SPSS (test estadísticos y estadística } \\
\text { descriptiva) de los resultados del cuestionario en relación a los } \\
\text { objetivos de la presente tesis (datos recogidos en la fase } 1.2 \text { ). }\end{array}$ \\
\hline $\begin{array}{l}\text { 8. Red Social } \\
\text { NING - (inactiva } \\
\text { actualmente) }\end{array}$ & $\begin{array}{l}\text { Análisis cualitativo - Reducción anticipada de datos de la } \\
\text { información cualitativa recopilada, con NVivo } 8.0 \text {. (recogida de } \\
\text { datos en fases } 1.2 \text { y } 2 \text { ). }\end{array}$ \\
\hline $\begin{array}{l}\text { 9. Cuestionario } \\
\text { Share.TEC y } \\
\text { portales Uva [44] }\end{array}$ & $\begin{array}{l}\text { Análisis cualitativo - Reducción anticipada de datos con la ayuda } \\
\text { del software NVivo } 8.0 \text { (datos recogidos en fase } 2 \text { ) } \\
\text { Análisis cuantitativo con SPSS (datos recogidos en fase 2) }\end{array}$ \\
\hline
\end{tabular}




\begin{tabular}{|ll|}
\hline Fuentes de datos & Método de análisis de datos: \\
\hline 10. Google & Análisis cuantitativo automático de los logs de eventos en el \\
Analytics & sistema: accesos al sistema y ubicación desde la que acceden los \\
& usuarios a lo largo de la existencia de Share.TEC y tras su \\
& finalización (fases 1.2 y 2). Selección y descripción de los datos \\
& recogidos de forma automática.
\end{tabular}

2. Muestra de los datos: Una vez finalizado el análisis cuantitativo, hemos categorizado mediante análisis de contenido en NVivo los informes realizados para cada prueba, en los que se incluían las gráficas, tablas y una explicación que nos facilitara la integración de los datos (Anexo $24^{113}$ ). De este modo, la información cualitativa y cuantitativa analizada aparece conjuntamente en el proyecto creado en NVivo, integrando ambos tipos de información en gráficos, tablas y texto; a este proceso se le llama muestra integrada de los datos (Lee \& Greene, 2007; Miles \& Huberman, 1984; Onwuegbuzie \& Dickinson, 2008).

En este sentido, hemos realizamos una matriz de análisis en la que hemos recogido cada técnica de recogida datos con sus preguntas 0 tópicos correspondientes que dan respuesta a cada declaración temática y pregunta informativa (ver Anexo 25144). Esta forma de integrar los datos nos ha facilitado en gran medida el análisis e interpretación de la información, tanto para este Estudio de Caso, como para la integración de los datos de las dos investigaciones de esta tesis.

\subsubsection{Roles implicados}

A lo largo del estudio de caso han participado un número elevado de informantes pertenecientes al mundo de la educación y la tecnología educativa. Podemos

113 Este archivo fue creado con el software de análisis de datos cualitativos NVivo en su versión 8.0. En él se incorporan los datos cualitativos y cuantitativos (tratados para el análisis cualitativo). Este software nos permitió generar la integración de los datos en torno a las categorías que fuimos perfilando tras las iteraciones de análisis.

114 Recomendamos la visualización del Anexo 25. En él aparecen diferenciadas las evidencias cuantitativas resaltadas en color rojo; en negro, las cualitativas. Este cuadro está organizado en torno a las preguntas informativas y declaraciones temáticas del estudio intrínseco de caso, con el objetivo de resumir las evidencias de diferentes pruebas que nos permiten triangular los datos. 
distinguir dos perfiles de personas entre los informantes, de acuerdo a las funciones o roles desempeñados por las mismas:

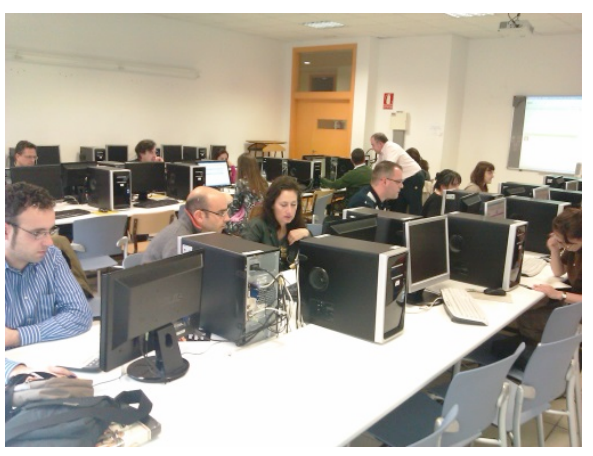

El primer perfil lo componen los miembros que conformaron el consorcio del proyecto Share.TEC, que como ya indicamos con anterioridad, pertenecían al mundo de la investigación y el ámbito empresarial. El equipo de Share.TEC estaba conformado por más de 30 personas entre colaboradores $y$ miembros del consorcio del área de: pedagogía, psicología, informática, telecomunicaciones, biblioteconomía, economía, marketing, etc. Todos ellos adoptaron un rol relevante en el desarrollo del producto del proyecto, el portal Share.TEC, cubriendo los diversos aspectos del portal. La confluencia de todos estos actores otorga al proyecto una particular idiosincrasia y devenir, por lo que muchos de ellos aparecerán a lo largo de los documentos recopilados y pruebas que integran este trabajo de investigación.

El segundo perfil de informantes corresponde a los los verdaderos protagonistas que han facilitado la existencia de esta tesis doctoral, los usuarios finales del portal. Estas personas participaron de forma voluntaria en el desarrollo de Share.TEC, contribuyendo con su opinión y experiencia en la mejora de los aspectos tecnológicos, sociales y pedagógicos del portal. Estos informantes proceden, principalmente, de diversos países pertenecientes al consorcio (pues cada equipo realizó pruebas nacionales y locales con personas relacionadas con la formación del profesorado), y también de países externos.

\subsubsection{Herramientas software de apoyo a la investigación}

A lo largo del desarrollo del estudio de caso Share.TEC, utilizamos diferentes herramientas y software tecnológico que nos facilitaron la recogida y análisis de datos durante las tres fases del multimétodo. En el apartado anterior hemos hecho mención a algunas de estas, pero veamos en detalle en qué consiste cada una, y cómo fueron utilizadas.

A) Herramientas para el análisis de datos cualitativos:

- NVivo 8.0 (QSR International Pty Ltd, 2008): es un software Ltd que facilita el análisis cualitativo de diversos documentos de texto, imágenes y vídeos de un 
proyecto o investigación. Este programa, con licencia de pago, nos ha permitido recoger y analizar la gran cantidad de documentos relativos al proyecto Share.TEC (informes, proyectos de trabajo, observaciones, grupos de discusión, respuestas cualitativas de cuestionarios, etc.), y refinar las categorías de análisis de nuestro caso de estudio. El programa, nos permite etiquetar los datos y organizar automáticamente esta información, facilitando la recuperación ordenada de la misma. Gracias a él, hemos realizado las tareas de microanálisis (codificación abierta).

B) Herramientas para el análisis automático de datos cuantitativos:

- Lime Survey ${ }^{115}$ y Google Forms ${ }^{116}$

Ambas son herramientas web para la creación de cuestionarios y encuestas, permitiendo generar diversos tipos de preguntas cualitativas y cuantitativas, dicotómicas, de múltiple elección, abiertas, matrices, de elección de una lista, etc. Estos servicios incluyen la posibilidad de exportar los datos a Excel, software que utilizamos para tratarlos, y además incluyen la posibilidad de generar informes descriptivos y con gráficos de los datos obtenidos. Estos formularios pueden enviarse a los usuarios a través de un enlace público o privado.

C) Herramientas para el análisis de datos cuantitativos

- SPSS 15.0.1117: es un software de analítica predictiva muy utilizado tanto en los campos de ciencias sociales como en medicina. Sus siglas, en inglés, significan "Paquete Estadístico para las Ciencias Sociales". Permite analizar datos categóricos y numéricos, y generar gráficas de los datos (aunque como considerábamos que estas no eran de una buena calidad gráfica, hemos decidido utilizar Excel para estos casos). Este software, actualmente, ha sido comprado por la empresa IBM y se encuentra en su versión 22. Nosotros hemos decidido utilizar la versión 15, de 2006, porque no estaba programada en lenguaje java, como las posteriores de las que disponíamos de licencia, y nos acarreaba menos problemas y errores a la hora de traspasar y tratar los datos. Este software ha sido el utilizado preferentemente para el tratamiento de los datos cuantitativos y categóricos de nuestra investigación.

- Excel, Office Professional Plus 2010118. Es un programa informático que sirve para gestionar y analizar datos; incluye funciones de tratamiento estadístico y

$115 \mathrm{https}: / / w w w . l i m e s u r v e y . o r g / e s /$

$116 \mathrm{http}: / / w w w . g o o g l e . c o m / f o r m s / a b o u t /$

117 http://www-01.ibm.com/software/analytics/spss/

$118 \mathrm{https://products.office.com/en-us/excel}$ 
representación gráfica. Es un programa simple y versátil que nos ha permitido generar la representación gráfica de muchos de nuestros datos, así como el tratamiento inicial, en algunos casos, y final, en otros, de los datos cuantitativos de la presente investigación.

D) Herramientas para el registro automático de logs de eventos

- Google Analytics ${ }^{119}$ es un servicio de Google que ofrece una versión gratuita para recoger los eventos predefinidos que quieren analizarse en una determinada Web de la que se es administrador. Ha de crearse una configuración del seguimiento desde Google Analytics, y generar un código que ha de insertarse en la página que se quiere rastrear. En nuestro caso hemos utilizado esta herramienta para rastrear los eventos sucedidos tanto en el portal Share.TEC, como en la red Ning ${ }^{120}$ creada como plataforma social para la difusión del portal Share.TEC en el contexto español.

E) Herramientas de apoyo a la gestión de información:

- $\mathrm{BSCW}^{121}$, plataforma online colaborativa para la gestión interna de los documentos del proyecto, donde utilizamos principalmente las funcionalidades de foro de discusión y repositorio.

F) Herramientas para la comunicación por videoconferencia:

- Skype ${ }^{122}$, software que permite la comunicación síncrona y asíncrona con otras personas mediante videoconferencia y chat.

- The flashmeeting ${ }^{123}$, un software creado por el KMI (Knowledge Management Institute- Instituto de la Gestión del Conocimiento) de la Open University de Reino Unido, que permitía realizar votaciones, compartir pantallas, dibujar y contactar con múltiples usuarios simultáneamente. Teníamos acceso a este servicio porque uno de los socios, OUNL, era colaborador del proyecto.

Utilizamos estas herramientas para la coordinación en los diferentes paquetes de trabajo.

G) Herramientas para el procesamiento de información

- Software de transcripción de "Olympus", que permitía acelerar/decelerar el ritmo de la voz, junto con el hardware de un pedal de transcripción conectado

$119 \mathrm{http}: / / w w w . g 00 g l e . e s / i n t / / e s / a n a l y t i c s /$

$120 \mathrm{http}: / /$ sharetec-recursos.ning.com/

121 http://bscw.ou.nl/bscw/bscw.cgi/15795

$122 \mathrm{http} / / / w w w . s k y p e . c o m / e s /$

${ }^{123} \mathrm{http}$ ://flashmeeting.e2bn.net 
mediante usb, que permitía retroceder y avanzar en la grabación, facilitaron la tarea de transcripción del grupo de discusión que fue transcrito.

- Procesador de texto: Microsoft office Word, para la elaboración de diferentes guiones de pruebas de usuarios, redacción de informes, y del presente trabajo; combinada en varias ocasiones con el software Acrobat Professional para la generación de archivos más compatibles ".pdf"

H) Herramientas sociales

- NING ${ }^{124}$ fue una red social generada específicamente para el proyecto, que tenía como objetivo difundir los resultados y las publicaciones de Share.TEC para la difusión del proyecto. Inicialmente, en 2009, esta herramienta la creamos cuando el servicio era gratuito. Cuando creamos la página y teníamos usuarios activos, la página cambió su licencia a servicio de pago, por lo que decidimos realizar el pago de la cuota anual para mantener la página hasta 2011. Este servicio fue afectado por Spam en más de una ocasión, lo que nos acarreó ciertas molestias, como administradores y usuarios.

I) Herramientas de diseño gráfico:

- Tagxedo http://www.tagxedo.com/app.html herramienta para la visualización de conceptos, que tiene en cuenta la frecuencia de repetición de cada etiqueta (utilizada en el capítulo 4 para mostrar los adjetivos más frecuentes seleccionados por los informantes en el análisis de la prueba [21] 


\section{Estudio 2: Sistemas para compartir contenidos digitales}

En el campo de la compartición de contenidos digitales a través de la red encontramos una amplia dispersión de estos en diferentes tipos de sistemas (blogs, pequeñas comunidades de práctica educativa, repositorios institucionales universitarios, páginas que recopilan automáticamente contenido por palabras clave -curated content (contenidos seleccionados)-; Sistemas de gestión de contenidos de aprendizaje - LCMS (Learning Content Management System)-, etc.). El principal problema de esta dispersión radica en la dificultad para recuperar y reutilizar estos contenidos digitales en otros contextos educativos, así como la dificultad de encontrar contenidos digitales que se ajusten de forma precisa a las necesidades específicas de los docentes (Betancur, Moreno, \& Ovalle, 2009; Grosse Kathoefer \& Leker, 2012; Lichtenthaler \& Ernst, 2006).

Como hemos comentado en el capítulo 1 y en el estudio de caso de Share.TEC, surgen diferentes iniciativas financiadas por programas que emanan de las políticas de innovación e investigación de diferentes lugares del mundo que favorecen la recopilación de numerosos contenidos digitales educativos.

Las características y potencialidades o limitaciones técnicas de los sistemas para compartir contenidos digitales, influirán de forma decisiva en la calidad de los sistemas y la sostenibilidad de los mismos. El hecho de que un repositorio de contenidos digitales para la formación del profesorado sea compatible a nivel técnico con la estructura de datos descriptores de los contenidos digitales de otros sistemas (es decir, que tenga en cuenta la interoperabilidad de metadatos), facilitará la integración automática de un mayor número de descripciones relativas a contenidos digitales. Así mismo, la calidad de las descripciones de los recursos, la multiculturalidad de los sistemas, las funciones sociales y la facilidad para recuperar, comentar y contribuir con los propios recursos, facilita su perdurabilidad.

A lo largo de esta investigación no hemos encontrado ningún repositorio o sistema de compartición contenidos digitales para la formación del profesorado que sea utilizado de forma masiva y que reúna las características técnicas, pedagógicas y sociales suficientes para poder ser un referente en España o en Europa. Por este motivo, consideramos que es de vital importancia analizar cuáles son las características de los principales repositorios de contenidos digitales para la formación del profesorado existentes en la actualidad a nivel técnico y pedagógico. Con el presente propósito, a lo largo de esta sección realizaremos un análisis detallado de las principales características de los sistemas basándonos en las 
categorías que hemos extraído a partir de una selección de fuentes de la literatura que abordan el análisis de contenidos digitales educativos, así como aquellas que han emanado del estudio de caso de Share.TEC. A partir del análisis individual de los repositorios, realizaremos un estudio comparativo entre ellos y determinaremos cuáles son las características más apropiadas y estables para compartir contenidos digitales en el ámbito de la formación del profesorado. La experiencia en la creación de un repositorio de contenidos digitales para la formación del profesorado aportará una visión crítica al análisis de estos repositorios, puesto que ya son conocidas algunas de las características que más valoran los usuarios en este tipo de sistemas.

Diversos programas, financiados por algunos países han avanzado en el conocimiento de las barreras y potencialidades de los repositorios y sistemas de objetos de aprendizaje. Este es el caso de Reino Unido, donde los programas Digital Repository programme ${ }^{125}$, Supporting Digital Preservation and Asset Management in Institutions ${ }^{126}$ y el consecuente de ellos, Repositories and Preservation Program ${ }^{127}$, han avanzado en el conocimiento y creación de repositorios de contenidos de aprendizaje cada vez más útiles para sus usuarios. De este modo destacamos el proyecto CD-LOR (Community Dimensions of Learning Objects Repositories) ${ }^{128}$, enmarcado en el último programa mencionado. Este proyecto detecta que las principales barreras se refieren a aspectos culturales, pedagógicos, técnicos y organizativos, tal y como reflejan en los informes del proyecto finalizado en 2007 (Milligan, 2007). Las principales recomendaciones socioculturales, pedagógicas, organizativas y tecnológicas sugeridas son las siguientes:

En lo referente a las barreras socioculturales aconsejan que los repositorios de objetos aprendizaje (ROA) deben estar basados en la comprensión de las normas culturales y las expectativas de los usuarios de la comunidad.

Las principales soluciones aportadas para los aspectos pedagógicos hacen mención a:

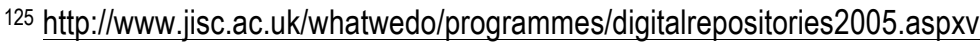

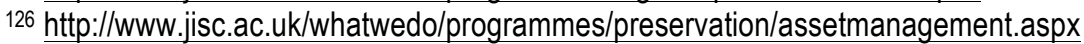

${ }^{127} \mathrm{http}: / /$ webarchive.nationalarchives.gov.uk/20140702233839/http://www.jisc.ac.uk/whatwed o/programmes/reppres.aspx

128 Dimensiones de la Comunidad de los Repositorios de Objetos de Aprendizaje. 
- Crear los ROA partiendo de los aspectos pedagógicos y no tanto de los técnicos.

- Desarrollar los ROA con equipos multidisciplinares (incluyendo a personas del área de Documentación, de Tecnología Educativa y a los propios Docentes).

- Proporcionar buenas prácticas de ejemplos de enseñanza-aprendizaje

- Desarrollar modelos de ROAs que tengan en cuenta la co-construcción de recursos por parte de los discentes.

- Demostración del impacto para el aprendizaje y valor añadido para usuarios individuales

- Apoyo para la alfabetización tecnológica de los usuarios y su desarrollo.

Atendiendo a las soluciones para los aspectos organizativos y de gestión de la información, sugieren:

- Otorgar incentivos y recompensas vinculadas a las necesidades y objetivos de la comunidad.

- ROAs vinculados a estrategias y objetivos organizativos.

Finalmente, sobre los aspectos tecnológicos invitan a:

- Facilitar la sencillez de uso, atracción para que los usuarios utilicen el portal, la eficiencia y efectividad pedagógica.

- Conceptualización de ROAs como un entorno contextual más que herramientas aisladas.

- Políticas y prácticas efectivas para la creación de Metadatos.

Estamos totalmente de acuerdo con la toma en consideración de todos los aspectos planteados, pues hemos podido detectar su necesidad tras la creación de Share.TEC y el estudio y análisis de las opiniones de los usuarios potenciales, y que ampliaremos en los capítulos 3 y 4 de esta tesis.

\subsection{Objetivos y función}

El análisis comparativo de los sistemas para la compartición de contenidos digitales y experiencias educativas en el ámbito de la formación del profesorado es clave para complementar el "Estudio 1" de esta tesis, y dar una respuesta satisfactoria a sus objetivos y preguntas de investigación. Los objetivos principales que guían este estudio son 2: 
- a) Generar un modelo de evaluación de portales educativos basado en otros modelos existentes.

- b) Evitar duplicidad de esfuerzos, analizando las buenas prácticas pedagógicas, tecnológicas, sociales, de personalización y económicas reflejadas en los portales educativos que permiten la compartición de contenido digital y experiencias educativas.

La consecución de estos objetivos permitirá aproximarnos a la segunda pregunta de investigación de esta tesis, proporcionando ideas para el diseño conceptual de portales educativos para la formación del profesorado. De este modo, la pregunta que queremos conocer a través de este estudio es:

¿Qué buenas prácticas y prácticas mejorables pueden extraerse de una selección de portales educativos?

\subsection{Metodología de investigación}

En la siguiente llustración 27 resumimos la metodología de investigación que hemos llevado a cabo para este estudio. Desde el una visión epistemológica y ontológica interpretativa hemos aplicado técnicas cualitativas para el análisis e interpretación de los datos. En primer lugar, seleccionamos una muestra de portales educativos (mediante el método de muestra de juicio) de acuerdo a unos criterios que predefinimos (véase apartado 6.2.1 de este capítulo).

Posteriormente, utilizando del esquema de categorías que emerge del análisis del caso de estudio Share.TEC y realizando un análisis de la literatura relativa a la evaluación de portales educativos de contenido digital, generamos un esquema de análisis para estos (véase 6.2.2).

Una vez definido el modelo de análisis, pusimos en marcha dos fases de análisis. La primera de ellas consistió en un análisis individual de cada portal mediante la observación y exploración. En la segunda fase hacemos un análisis comparativo reflejado en el capítulo 5 de esta tesis doctoral. En el capítulo 6 integramos las conclusiones de ambos capítulos y realizamos una propuesta de recomendaciones a considerar para la generación o remodelación de portales educativos para la compartición de contenido digital y experiencia educativa. 
Ilustración 27 Metodología de la investigación del estudio de portales para compartir contenido digital

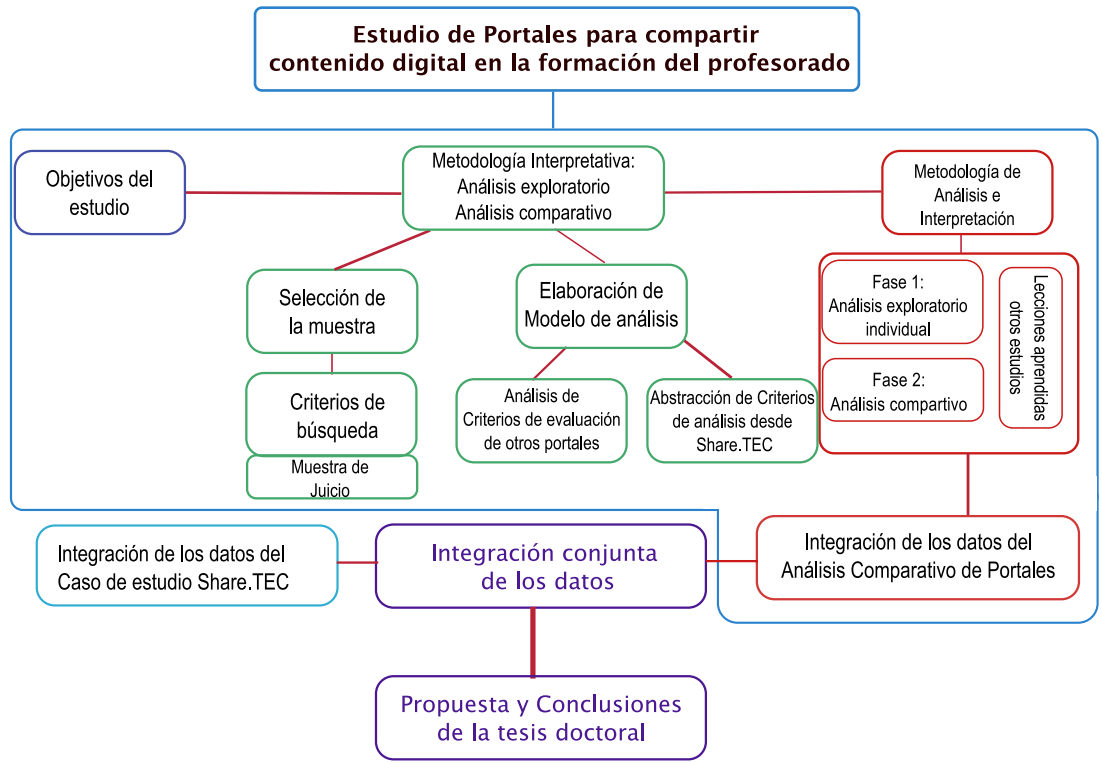

\subsubsection{Selección de los portales y fuentes de recogida de datos}

La población que constituye el foco de interés de esta investigación son los portales para la compartición de contenidos digitales en la formación del profesorado, o aquellos que contengan contenidos digitales para este ámbito.

Somos conscientes de que no era abarcable en esta investigación realizar un análisis exhaustivo de toda la población existente de este tipo de sistemas, así como trazar su existencia, por lo que hemos decidido seleccionar una parte de la población a partir de un muestreo no probabilístico, concretamente, una muestra discrecional (también conocida como muestra de juicio (D. Anderson, Sweeney, \& Williams, 2005, p. 276; Hernández Sampieri et al., 2006; Perez Tejada, 2008, p. 186), donde el investigador selecciona a los sujetos atendiendo a sus conocimientos y a su juicio, eligiendo aquellos portales representativos de una población.

Para ello, atendiendo a nuestros conocimientos previos basados en la experiencia adquirida durante el desarrollo del portal Share.TEC (y durante los 
procesos de investigación que habían iniciado sobre el "Estudio 1"), así como en la revisión de la literatura, establecimos 7 criterios que debían cumplir los portales para formar parte de nuestro estudio:

- Que fueran portales educativos.

- Que el contenido apareciera en español y o inglés.

- Que las páginas estuvieran en funcionamiento.

- Que el contenido para la formación del profesorado estuviera disponible.

- Que el contenido hiciera referencia a las diversas áreas de formación del profesorado (genérico).

- Que tuviera un número significativo de contenidos digitales (más de 1000).

- Que fueran abiertos para cualquier usuario (ya sea necesario crear una cuenta o no).

Para realizar la selección de los portales se realizaron consultas en Google utilizando varios conjuntos de palabras clave (ver Anexo 26). Una vez realizada la consulta, se tuvieron en cuenta tanto los portales/sistemas encontrados, como las publicaciones que recogían portales educativos que cumplían nuestros criterios de selección. Se planteó la selección de 15 portales educativos para tener una muestra suficientemente amplia y poder realizar un trabajo abarcable para esta investigación. Entre los resultados que eran adecuados a nuestras restricciones, filtramos aquellos que nos parecieron más interesantes, completos y adecuados gráficamente y de acuerdo con los indicadores establecidos anteriormente.

Por tanto, esta selección siguió criterios subjetivos (fundados en nuestra experiencia y basados en los criterios que definimos) y objetivos (aquellos que cumplían los requerimientos). De este modo, los portales indagados fueron los siguientes:

- Internet en el Aula

- Education World

- MIT OCW

- Merlot

- Commonwealth of learning

- Connexions
- Share.TEC

- PBS Learning

- Open Learn

- Teachertube

- OER Commons.

Además de estos portales decidimos analizar otros que nos parecían interesantes antes de realizar la búsqueda, que a pesar de estar pensados para los 
niveles de Primaria y Secundaria, considerábamos que podrían ser útiles para aportar conocimiento sobre este tipo de sistemas, a saber:

- Wikieducator

- Tiching
- Merli

- Agrega

La muestra seleccionada constituye la fuente de recogida de datos de nuestro estudio, ya que a través de su acceso y exploración partiendo de un esquema generado ad hoc, hemos realizado un análisis e interpretación de las características de los portales, extrayendo unas conclusiones que nos permiten fortalecer nuestra propuesta para la generación de portales educativos en la formación del profesorado.

Hemos aplicado la metodología cualitativa exploratoria y comparativa para llevar a cabo esta investigación.

Para generar el modelo de análisis de portales educativos, en primer lugar realizamos una revisión de la literatura seleccionada, de la que recopilamos las principales características descriptivas de portales educativos (eminentemente de repositorios). Además, incorporamos las categorías de análisis que emergieron en la reducción anticipada de los datos del "Estudio 1". Integrando todas estas fuentes, presentamos el modelo de evaluación de diversas características de portales para compartir contenido digital y experiencias educativas. Una de las dificultades que presentó este proceso fue encontrar subcategorías que podrían formar parte de varias de nuestras categorías, cuestión que solventamos decidiendo incluirlas en aquellas que nos resultaran más clarificadora a la hora de analizar los datos (e.g., interfaz, puesto que podría incluirse en aspectos técnicos, pero hemos decidido incorporarla en el apartado aspectos visuales).

\subsubsection{Análisis individual y comparativo de los portales}

\section{A) Fuentes para la creación del modelo de análisis}

El modelo de evaluación de portales educativo fue generado a partir de las principales fuentes de la literatura que abordaban soluciones para la evaluación 0 generación de portales educativos, ya que constituían una referencia de los aspectos que debíamos tener en cuenta tanto para la creación como para el análisis de este tipo de portales. Presentamos en el capítulo 5 el resultado del análisis, así como las categorías que seleccionamos de cada uno de ellos. 


\section{B) Análisis individual y comparativo}

Definimos a continuación las categorías del modelo de evaluación creado, puesto que consideramos que algunos términos pueden resultar confuso. De este modo, consideramos necesario aportar una breve descripción de la interpretación que otorgamos a aquellos que consideramos que contienen un mayor nivel de abstracción:

1. Datos descriptivos:

1.1. Nombre del Repositorio o Sistema.

1.2. URL repositorio: dirección http en la que se encuentra.

1.3. Descripción: explicación de las características principales.

1.4. Último Acceso que se ha realizado a cada portal/sistema, para recoger datos sobre él.

2. Aspectos técnicos:

Se incluyen en esta categoría todos aquellos aspectos que están relacionados con la arquitectura del sistema.

2.1. Tipo: describiremos en este apartado qué tipo de repositorio es el que analizaremos: repositorio, referatorio, Open Courseware, sistema de gestión del aprendizaje o repositorio institucional.

2.2. Funciones: en esta categoría se describirán las actividades que el sistema permite realizar a los usuarios. La forma de describir los datos será realizar un listado con los nombres de cada función.

2.3. Derechos de acceso: recogeremos la existencia o ausencia de derechos de acceso al sistema, recogiendo si: puede accederse mediante el registro, puede accederse sin registrarse, puede accederse sin registrarse pero con limitaciones en los permisos, etc.

2.4. Ontología: comprobaremos si existe o no una ontología en la que se apoyan los modelos de metadatos, y trataremos de describirla brevemente en los casos en los que exista.

2.5. Interoperabilidad del sistema: el sistema sigue especificaciones $y / 0$ estándares, así como si permite la adaptación de otros esquemas.

2.6. Seguridad: tipo de funciones que permiten la seguridad del portal, servicios antispam, etc.

2.7. Persistencia de los links: realizaremos una comprobación puntual de 5 links por cada portal, de modo que aleatoriamente, comprobaremos que todos ellos funcionan. 
2.8. Internacionalización: determinaremos si contempla la coexistencia de varios idiomas.

2.9. Administración del sistema: nos encargaremos de conocer si el sistema es administrado por entidades privadas o públicas, y de saber si los contenidos digitales son filtrados o no por los administradores.

2.10. Búsqueda simple: describiremos cómo es el buscador básico del portal.

2.11. Búsqueda avanzada: describiremos los campos que se pueden filtrar con la búsqueda avanzada, lo que nos permitirá saber más sobre cómo se estructuran los metadatos del portal/sistema.

2.12. Accesibilidad: en términos de e-learning, la accesibilidad hace referencia a dos acepciones. Por una parte, encontramos la "Accesibilidad informática", haciendo referencia a la usabilidad de un ordenador por usuarios individuales. Esta concepción engloba discapacidades tales como daltonismo, dislexia y dificultades de destreza manual. La accesibilidad a la Web, en general, se refiere a la práctica cada vez más común de diseñar las páginas Web accesibles para todos los usuarios, teniendo en cuenta las diferencias de calidad de conexión de los diferentes usuarios (Mason \& Rennie, 2006). Atendiendo a estas características, conseguiremos aproximarnos a la idea de educación distribuida, donde todos pueden colaborar en la evolución del contenido de la Red. Por tanto, la accesibilidad también tiene en cuenta las preferencias de acceso a la información de los diferentes usuarios integrando diferentes tipos de estímulos en la red: texto, iconos, sonidos, etc. Por otro lado, la accesibilidad hace referencia a la facilidad de acceder a la información a través de cualquier explorador o tecnología web, sin enfrentarse a problemas de compatibilidad.

3. Metadatos

3.1. Estándar/no estándar: conoceremos si los metadatos que integra el sistema están estandarizados o no, o si son algún perfil de aplicación de algún estándar.

3.2. Posibilidad de personalización de metadatos: trataremos de conocer si el portal nos deja modificar los metadatos ya existentes o no, bien a través de la inclusión, modificación o eliminación de los mismos.

3.3. Etiquetado social: trataremos de conocer si los usuarios pueden comentar, votar, o etiquetar con folksonomías los contenidos digitales.

3.4. Mapeo: vinculación existente entre la ontología y metadatos. 
3.5. Esquema mínimo de metadatos: conoceremos qué tipo de campos son obligatorios a la hora de compartir contenido digital en un portal.

4. Almacenamiento

4.1. Objetos en múltiples formatos técnicos (sí o no). Si integra audio, video, texto, imagen en diversos formatos o no.

4.2. Derechos de acceso: comprobaremos si hay que registrarse o no en el portal, y si los contenidos que aloja son gratuitos, de pago, el tipo de licencia que tienen, o si tienen variedad de contenidos respecto a esta categoría.

4.3. Organización jerárquica

4.4. Reutilización de metadatos: veremos si el portal permite la reutilización de metadatos para etiquetar nuevos contenidos.

4.5. Sistema de versiones: comprobaremos si existe o no, de forma visible para el público.

5. Interfaz

5.1. Organización del contenido: describiremos cómo se organiza visualmente el contenido de la web/sistema/portal, etc.

5.2. Miniaturas: contemplaremos si incluyen o no miniaturas de los recursos, y si estas funcionan correctamente.

6. Sostenibilidad

6.1. Propietario: reflejaremos quién es el propietario del portal.

6.2.Gestión de contenidos: determinaremos el modo en el que se gestionan los contenidos, si son revisados por otros usuarios o por los propietarios/trabajadores de la página.

7. Aspectos educativos

7.1. Nivel/es educativos: estableceremos los niveles educativos para los que está pensado el sistema.

7.2. Temáticas: contemplaremos las áreas educativas que integra el portal.

7.3. Destinatarios: incluiremos una breve descripción de para qué personas está orientado este portal.

8. Contribución al sistema

8.1. Campos obligatorios: que hemos de introducir al crear un contenido digital 
8.2. Campos opcionales: los no obligatorios, pero que nos permiten cumplimentar la información.

8.3. Requisitos.

8.4. Formato.

9. Aspectos sociales

9.1. Redes: las redes sociales con las que puede interconectarse el sistema para compartir su contenido.

9.2. Forma de establecimiento de redes/mantenimiento de usuarios.

9.3. Contacto con otros profesionales: se permite o no, y qué mecanismos utilizan para ello.

9.4. Interacción con recursos: qué tipo de acciones se nos permite hacer con un contenido digital, a nivel social.

9.5. Contribución social de recursos: es decir, si se nos permite o no aportar contenido digital.

9.6. Contribución social de etiquetado: se nos permite 0 no etiquetar en formato de comentarios, votos o folksonomías los recursos.

9.7. Comunidades: ¿integra comunidades?, ¿son externas o generadas en el propio portal?.

9.8. Número de personas de la comunidad.

10. Contenidos

10.1. Contenidos Gratuitos/de pago.

10.2. Tipo de contenidos, a nivel pedagógico: Webquests, artículos, presentaciones de clase, etc.

10.3. Formato técnico: extensión de los archivos.

10.4. Calidad de los recursos: son contenidos filtrados, seleccionados, de buena calidad, o qué tipo de calidades existen.

10.5. Número de contenidos.

10.6. Número de recursos.

10.7. Premios del portal/página.

Una vez realizado el análisis de la literatura, hemos procedido a la creación de una hoja de evaluación en Excel (Anexo 43), donde hemos contemplado las categorías de análisis, y hemos completado su descripción analizando individualmente cada portal. El método seguido para ello, ha sido el registro en cada servicio, y la exploración, bien a través de lo observado en el portal, o bien a través 
de la búsqueda de información de cada página en artículos científicos o divulgativos de cada portal.

Tras esta primera fase, proseguimos con el análisis comparativo de los portales. Para ello, recogimos las buenas prácticas y prácticas mejorables de los diferentes portales (que recogemos en el capítulo 4 de esta investigación), y abstraemos las características que, basándonos en nuestra experiencia y en lo aprendido en el estudio de caso de Share.TEC, consideramos que deben manifestar los servicios que integran contenido digital en nuestro ámbito de interés.

Para realizar el análisis de los portales hemos utilizado principalmente el software Microsoft Excel, puesto que nos permitió generar una tabla para poder introducir la descripción individual de cada portal y visualizar globalmente todos los portales para poder compararlos.

En este capítulo hemos recogido los procedimientos mediante los que hemos llevado a cabo esta tesis doctoral, describiendo los objetivos y preguntas de investigación que la guían. Para ello, hemos explicado el proceso de indagación seguido en cada uno de los dos estudios (con los objetivos particulares y preguntas de investigación que guían cada uno de ellos) que iluminan las preguntas de esta tesis. En los siguientes capítulos, 4 y 5, reflejamos el análisis e interpretación de los datos desarrollado para cada uno de los estudios. 


\section{Capítulo 4}

\section{Análisis e Interpretación: Estudio 1}

\section{Estudio de caso Share.TEC}

El propósito de este capítulo es presentar el análisis e interpretación de los datos recogidos en el estudio de caso de Share.TEC. Introducimos el capítulo recordando la metodología en la que nos basamos. Posteriormente presentamos el análisis e interpretación de los datos que hemos llevado a cabo, dividiendo los resultados en las declaraciones temáticas que han guiado nuestro estudio y las preguntas informativas en las que se desglosa cada una de ellas: aspectos pedagógicos, técnicos, sociales, de personalización y económicos. Con el objetivo de garantizar la credibilidad de las interpretaciones, presentaremos las evidencias siguiendo un procedimiento de triangulación severa conjugando diversas fuentes, técnicas e informantes. Concluimos el capítulo iluminando el issue que guía el estudio de caso a través de la interrelación entre los aspectos en los que nos enfocamos y reflejando la respuesta que realiza este estudio a las dos preguntas de investigación planteadas en la tesis doctoral.

\section{Introducción}

Como explicamos en el capítulo anterior hemos seguido una aproximación multimétodo para el análisis de nuestros datos.

El análisis de datos cualitativos constituye una práctica compleja y ambigua en la que debe tenerse en cuenta que la información depende tanto de las técnicas y procedimientos con los que las hemos recogido, como de las acciones, verbalizaciones y escritos de los sujetos participantes e investigadores, así como de las interpretaciones que realiza el sujeto investigador, fundamentadas desde una 
determinada óptica paradigmática. En este sentido, estos datos son difícilmente reproducibles en otras situaciones o contextos, dado que la obtención de unos $u$ otros datos depende de muchas variables subjetivas (Miles, Huberman, \& Saldaña, 2014:342; Rodríguez Gómez, Gil Flores, \& García Jiménez, 1996: 198-201). El fin de nuestro estudio instrumental de casos es conocer en profundidad la realidad Share.TEC, y utilizar sus lecciones aprendidas para contribuir a la mejora de otros portales educativos similares. Para ello, en este capítulo avalamos las evidencias obtenidas mediante la triangulación de fuentes cualitativas y cuantitativas de investigación.

\section{Análisis e interpretación del estudio de caso Share.TEC}

\subsection{Aclaraciones para el lector}

A lo largo del análisis del caso Share.TEC se mostrarán datos cualitativos y cuantitativos. A la hora de representar las evidencias cuantitativas hemos optado por representar los datos en porcentajes, para facilitar la comprensión de lectura ${ }^{129}$.

Las interpretaciones que realizamos a lo largo del documento están avaladas por la triangulación de datos, fuentes y técnicas (y su combinación, diferente para cada interpretación) con el objetivo de iluminar nuestro aserto de partida (véase apartado 0 del capítulo 3). Las interpretaciones a las que hemos llegado a través del análisis de las pruebas e instrumentos puestos en marcha con nuestros informantes aparecen representados en este formato. El objetivo de representarlas así es facilitar al lector las los principales hallazgos que encontramos para cada declaración temática y pregunta informativa.

En la siguiente Tabla 9 recogemos la información principal para comprender la procedencia de los datos, por lo que sintetizamos: en la primera columna la fase en la que se obtuvo la información; en la segunda, la técnica o instrumento de recogida de datos y carácter de los datos (cuantitativos y/o cualitativos); en la tercera la información de los informantes (roles y número de informantes por cada rol) o en su defecto, la información disponible; y en la última columna los anexos donde pueden

129 Somos conscientes de la ausencia de significatividad de la muestra para ser representada por porcentajes, puesto que en diversas pruebas estas son menores a 100 personas, pero utilizamos esta estrategia para agilizar la comprensión de los datos. 
encontrarse los documentos originales y los informes y archivos que recopilan el análisis de la información.

Tabla 9 Información de los participantes de las pruebas y explicación de su nomenclatura

\begin{tabular}{|c|c|c|c|}
\hline Fase & $\begin{array}{l}\text { Técnica/ } \\
\text { Instrumento }\end{array}$ & $\begin{array}{l}\text { Información de los } \\
\text { participantes }\end{array}$ & Anexos \\
\hline $\begin{array}{l}\text { Inicial } \\
1.1\end{array}$ & $\begin{array}{l}{[09]^{130} \text { Evaluación de }} \\
\text { calidad de } \\
\text { metadatos UVa } \\
\text { Cual-Cuan }\end{array}$ & $\begin{array}{l}\mathrm{N}^{\circ} \text { total de informantes: } 5 \\
\text { Formadores de } \\
\text { Profesores (FP): } 4 \text { (F: } 2 ; \\
\text { M: } 2)^{131} \\
\text { Ingenieros (Ing): } 1 \text { (F: 0; } \\
\text { M: 1) }\end{array}$ & $\begin{array}{l}\text { Anexo } 32 \text { - descripción de } \\
\text { la prueba, análisis e } \\
\text { interpretación. } \\
\text { Anexo } 38 \text { - datos } \\
\text { originales } \\
\text { Anexo } 24 \text { - Análisis en } \\
\text { NVivo. }\end{array}$ \\
\hline $\begin{array}{l}\text { Inicial } \\
1.1\end{array}$ & $\begin{array}{l}\text { [17] Transcripción } \\
\text { del Focus Group UVa } \\
\text { Cual }\end{array}$ & $\begin{array}{l}\mathrm{N}^{\circ} \text { total de informantes: } 7 \\
\text { Formadores de } \\
\text { Profesores (FP): } 6 \text { (F: 3; M } \\
3 \text { ) } \\
\text { Ingenieros (Ing): } 1 \text { (F: 0; } \\
\mathrm{M}: 1 \text { ) }\end{array}$ & $\begin{array}{l}\text { Anexo } 39 \text { - transcripción. } \\
\text { Anexo } 24 \text { - Análisis en } \\
\text { NVivo. } \\
\text { Anexos no referenciados- } \\
\text { Datos SPSS - } 9\end{array}$ \\
\hline $\begin{array}{l}\text { Inicial } \\
1.2\end{array}$ & $\begin{array}{l}\text { [20] Primera } \\
\text { encuesta coordinada } \\
\text { (Italia, Bulgaria, } \\
\text { España) } \\
\text { Cuan }\end{array}$ & $\begin{array}{l}\text { No total de informantes: } \\
\frac{69}{\text { Formadores de }} \\
\text { Profesores: } 40 \\
\text { Educación Secundaria y } \\
\text { Especialistas: } 25 \\
\text { Datos Perdidos: } 4\end{array}$ & $\begin{array}{l}\text { Análisis en Anexo } 33- \\
\text { Preguntas e } \\
\text { interpretación de análisis } \\
\text { cuantitativo } \\
\text { Anexo Datos SPSS - } 20\end{array}$ \\
\hline
\end{tabular}

130 Recordemos que el número entre corchetes indica el mes en el que se recogieron los datos, así la prueba realizada en el mes 17 (contando 0 como el inicio del proyecto Share.TEC), aparecerá en el formato [17]. Siguiendo esta nomenclatura, las pruebas realizadas tras el proyecto se representan también en el mes en el que se llevaron a cabo tomando como referencia el inicio mencionado (de este modo, la prueba llevada a cabo en el mes 44 aparecerá representada como [44]).

131 "F" hace referencia a informantes de género femenino; "M", de género masculino. 


\begin{tabular}{|c|c|c|c|}
\hline Fase & $\begin{array}{l}\text { Técnica/ } \\
\text { Instrumento }\end{array}$ & $\begin{array}{l}\text { Información de los } \\
\text { participantes }\end{array}$ & Anexos \\
\hline $\begin{array}{l}\text { Inicial } \\
1.2\end{array}$ & $\begin{array}{l}\text { [21] Análisis de } \\
\text { adjetivos (diversos } \\
\text { países del consorcio) } \\
\text { Cual-Cuan }\end{array}$ & $\begin{array}{l}\mathrm{N}^{\circ} \text { total de informantes: } \\
\underline{67}\end{array}$ & $\begin{array}{l}\text { Anexo } 21 \text { - Método, } \\
\text { concordancia entre } \\
\text { jueces, traducción de } \\
\text { adjetivos y comentarios } \\
\text { originales, Datos para } \\
\text { imagen tagxedo. } \\
\text { Anexo Datos SPSS - } 21 \\
\text { Anexo } 24 \text { - Análisis en } \\
\text { NVivo. }\end{array}$ \\
\hline $\begin{array}{l}\text { Inicial } \\
1.2\end{array}$ & $\begin{array}{l}\text { [33] Workshop local } \\
\text { y nacional (España) } \\
\text { Cual-Cuan }\end{array}$ & $\begin{array}{l}\frac{N^{\circ} \text { total de informantes: }}{26} \\
\text { Formadores de } \\
\text { Profesores (FP): } 17 \text { (F: 7; } \\
\mathrm{M}: 10) \\
\text { Estudiantes máster de } \\
\text { Educación Secundaria } \\
\text { (EM): } 4 \text { (F: } 3 ; \mathrm{M}: 1) \\
\text { Especialistas y otros } \\
\text { formadores (SF): } 5 \text { (F: } 1 \text {; } \\
\mathrm{M}: 4)\end{array}$ & $\begin{array}{l}\text { Anexo } 35 \text { - Preguntas e } \\
\text { interpretación de análisis } \\
\text { Cuan } \\
\text { Anexo } 41 \text { - Preguntas y } \\
\text { respuestas Cual } \\
\text { Anexo } 24 \text { - Análisis en } \\
\text { NVivo. } \\
\text { Anexo Datos SPSS - } 33\end{array}$ \\
\hline $\begin{array}{l}\text { Inicial } \\
1.2\end{array}$ & $\begin{array}{l}\text { [35] Segunda } \\
\text { encuesta coordinada } \\
\text { (Italia, España, } \\
\text { Suecia) } \\
\text { Cuan }\end{array}$ & $\begin{array}{l}\frac{N^{\circ} \text { total de informantes: }}{198} \\
\text { Profesores de Secundaria: } \\
137 \\
\text { Formadores de } \\
\text { Profesores: } 30 \\
\text { Educación Infantil y } \\
\text { Primaria: } 17 \\
\text { Especialistas: } 7 \\
\text { Formación profesional y } \\
\text { otros: } 7 \\
\text { Nacionalidad: } \\
\text { Italia: } 172 \\
\text { España: } 16 \\
\text { Suecia: } 10\end{array}$ & $\begin{array}{l}\text { Anexo } 36 \text { - Preguntas y } \\
\text { análisis de datos Cuan } \\
\text { Anexos Datos SPSS - } 35\end{array}$ \\
\hline
\end{tabular}




\begin{tabular}{|c|c|c|c|}
\hline Fase & $\begin{array}{l}\text { Técnica/ } \\
\text { Instrumento }\end{array}$ & $\begin{array}{l}\text { Información de los } \\
\text { participantes }\end{array}$ & Anexos \\
\hline $\begin{array}{l}\text { Inter- } \\
\text { media }\end{array}$ & $\begin{array}{l}\text { [44] Cuestionario } \\
\text { sobre Share.TEC y } \\
\text { portales de } \\
\text { contenido digital } \\
\text { (España) Cuan Cual }\end{array}$ & $\begin{array}{l}\frac{\mathrm{N}^{\circ} \text { total de informantes: }}{19} \\
\text { Estudiantes máster de } \\
\text { Secundaria (EM): } 4 \text { (F: 4; } \\
\mathrm{M}: 0 \text { ) } \\
\text { Formadores de } \\
\text { Profesores (FP): } 12 \text { (F: 6; } \\
\mathrm{M}: 6 \text { ) } \\
\text { Ingenieros (Ing): } 3 \text { (F: } 1 ; \\
\mathrm{M}: 2 \text { ) }\end{array}$ & $\begin{array}{l}\text { Anexo } 37 \text { - Preguntas del } \\
\text { cuestionario y análisis e } \\
\text { interpretación Cuan } \\
\text { Anexo } 42 \text { - Combinación } \\
\text { de análisis cuan (anexo } \\
\text { 37) y respuestas cual. } \\
\text { Anexo } 24 \text { - Análisis en } \\
\text { NVivo. } \\
\text { Anexo Datos SPSS - } 44\end{array}$ \\
\hline $\begin{array}{l}\text { Todas } 1.2, \\
2 \text { y } 3\end{array}$ & $\begin{array}{l}\text { Google Analytics del } \\
\text { Portal Share.TEC } \\
\text { [mes 30-Actualidad] } \\
\text { Cuan }\end{array}$ & $\begin{array}{l}\text { Logs de eventos } \\
\text { recopilados } \\
\text { automáticamente } \\
\text { (interacciones de usuarios } \\
\text { y máquinas en el portal). }\end{array}$ & $\begin{array}{l}\text { Google Analytics del } \\
\text { portal Share.TEC (acceso } \\
\text { web privado) }\end{array}$ \\
\hline Inicial1.2 & $\begin{array}{l}\text { Workshop Bologna: } \\
\text { Observación tarea } \\
\text { [mes 13] Cual }\end{array}$ & $\begin{array}{l}\text { Número de informantes: } 2 \\
\text { M Formadoras de } \\
\text { profesores }\end{array}$ & $\begin{array}{l}\text { Anexo } 8 \text { - Anexo } \\
\text { Share.TEC, Observación } \\
\text { Pareja B en evaluación del } \\
\text { portal Workshop } \\
\text { (realizado por la } \\
\text { investigadora) }\end{array}$ \\
\hline Inicial 1.2 & $\begin{array}{l}\text { Workshop Bolonia: } \\
\text { notas de reunión del } \\
\text { proyecto [mes 24] } \\
\text { Cual }\end{array}$ & $\begin{array}{l}\text { Miembros del proyecto } \\
\text { asistentes al workshop }\end{array}$ & $\begin{array}{l}\text { Anexo } 11-\text { Informe del } \\
\text { Workshop del Bolonia } \\
\text { (realizado por la } \\
\text { investigadora) }\end{array}$ \\
\hline Inicial1.2 & $\begin{array}{l}\text { Informe de } \\
\text { Sugerencias de } \\
\text { mejora del portal } \\
\text { Share.TEC } \\
\text { [mes 23] Cual }\end{array}$ & $\begin{array}{l}\text { Elaborado por: } \\
\text { Dos personas del equipo } \\
\text { OUNL }\end{array}$ & $\begin{array}{l}\text { Anexo } 16-2010 \\
\text { sugerencias de mejora del } \\
\text { portal de OUNL }\end{array}$ \\
\hline Inicial 1.2 & $\begin{array}{l}\text { Notas de Reunión } \\
\text { del proyecto [mes } \\
\text { 25] Cual }\end{array}$ & $\begin{array}{l}\text { Informantes: } \\
\text { Miembros del Consorcio y } \\
\text { evaluadora del consorcio }\end{array}$ & $\begin{array}{l}\text { Anexo } 27 \text { - Anexo } \\
20100701 \text { Reunión de } \\
\text { proyecto }\end{array}$ \\
\hline Inicial 1.1 & $\begin{array}{l}\text { Notas de Workshop } \\
\text { de Venecia [mes 7] } \\
\text { Cual }\end{array}$ & $\begin{array}{l}\text { Informantes: } \\
\text { Miembros del consorcio y } \\
\text { asesores externos del } \\
\text { proyecto. }\end{array}$ & $\begin{array}{l}\text { Anexo } 4 \text { - Informe del } \\
\text { Workshop de Venecia } \\
\text { (realizado de la } \\
\text { investigadora) }\end{array}$ \\
\hline
\end{tabular}




\begin{tabular}{|c|c|c|c|}
\hline Fase & $\begin{array}{l}\text { Técnica/ } \\
\text { Instrumento }\end{array}$ & $\begin{array}{l}\text { Información de los } \\
\text { participantes }\end{array}$ & Anexos \\
\hline $\begin{array}{l}\text { Inicial } \\
1.1\end{array}$ & $\begin{array}{l}\text { Informe del impacto } \\
\text { del portal [mes 35] } \\
\text { Cuan }\end{array}$ & $\begin{array}{l}\text { Informantes: } 39 \\
\text { Roles: } \\
\text { Profesor: } 6 \\
\text { Formador de Profesores: } \\
21 \\
\text { Otros: } 12 \\
\text { Nacionalidad: } \\
6-\text { Italia } \\
6 \text { - Suecia } \\
1 \text {-Holanda } \\
26 \text { - España }\end{array}$ & $\begin{array}{l}\text { Anexo } 29 \text { - Impacto del } \\
\text { Portal Share.TEC (OUNL, } \\
\text { UVa, ITD, NIS-SU, SU, } \\
\text { TCD, CLUEB) }\end{array}$ \\
\hline Inicial 1.2 & $\begin{array}{l}\text { Plan de } \\
\text { sostenibilidad [mes } \\
\text { 27] Cual }\end{array}$ & $\begin{array}{l}\text { Realizado por: } \\
2 \text { personas de CLUEB }\end{array}$ & $\begin{array}{l}\text { Anexo } 22 \text { - Plan de } \\
\text { sostenibilidad }\end{array}$ \\
\hline
\end{tabular}

Para identificar los informantes de las evidencias cualitativas, en algunos casos hemos utilizado una nomenclatura específica. En la Tabla 10 mostramos las etiquetas utilizadas para estos instrumentos o pruebas (en función de los datos de los que disponemos para cada una de ellas)(e.g., pregunta de la prueba, rol, edad, etc., según corresponda).

Tabla 10 Nomenclatura de las evidencias cualitativas del estudio de caso Share.TEC

\begin{tabular}{ll}
\hline $\begin{array}{l}\text { [09] Prueba de evaluación de } \\
\text { los metadatos de UVa. }\end{array}$ & $\begin{array}{l}\text { Ejemplo en el texto: [09] S3_29M_B1 } \\
\text { Significado: [09]Sujeto“ } x^{\prime \prime} \text { EdadGénero } \\
\text { _NomenclaturadePregunta. }\end{array}$ \\
\hline $\begin{array}{ll}\text { [17] Transcripción del Focus } \\
\text { Group a profesores de UVa }\end{array}$ & $\begin{array}{l}\text { Ejemplos en el texto: [17] p11, R_FP; [17] p11, E_Ing } \\
\text { Significado: [17] PreguntaNúmero, Inicial del nombre_Rol }\end{array}$ \\
\hline [33] Workshop local y & [33] 5.18. FP_29_M \\
nacional (España) & [33] Pregunta.Sujeto. Rol_Edad_Género \\
\hline $\begin{array}{l}\text { [44] Cuestionario España } \\
\text { sobre Share.TEC y otros } \\
\text { portales de contenido digital } \\
\text { (Mayor descripción en Anexo }\end{array}$ & [44] 20.5_24_F_EM \\
37 y Anexo 42) & \\
\hline
\end{tabular}




\subsection{Issues, Preguntas informativas y declaraciones temáticas}

Para exponer las evidencias obtenidas en el estudio de caso de Share.TEC, partiremos de las Declaraciones Temáticas y Preguntas Informativas que encontramos en el apartado 5.5.4 del Capítulo 3.

\section{A) Aspectos Pedagógicos:}

La primera declaración temática se centra tanto en los aspectos pedagógicos que subyacen a Share.TEC, como a los sistemas para compartir contenido digital en general. Para ello, analizaremos las características de talante educativo vinculadas con el portal, cómo lo usaron los usuarios, qué opinión otorgan tanto al portal como a los contenidos y a su organización pedagógica, etc. Además, aprehenderemos de los usuarios los usos y hábitos de compartición y reutilización que hacen de los contenidos digitales y los portales para compartirlos, así como sugerencias pedagógicas que han de incorporarse a sistemas de intercambio de contenido digital educativo. Esta declaración temática constituye una de las más importantes de este estudio, puesto que analizamos las evidencias recogidas de los principales protagonistas de los portales educativos, los usuarios, quienes nos ilustran sobre sus opiniones y necesidades (o no) reales.

B) Aspectos Técnicos

En esta declaración temática analizamos tanto la opinión de los usuarios sobre las funcionalidades técnicas e interfaz que oferta el portal Share.TEC como las funcionalidades que éstos demandan en los sistemas de compartición de contenido digital.

\section{C) Aspectos Sociales}

A partir de esta declaración temática, examinamos la opinión de los formadores de profesores con respecto a la compartición de contenido digital, y conoceremos las redes profesionales en las que participan. A partir del análisis de los datos conoceremos las fortalezas y debilidades de los aspectos sociales de Share.TEC, e identificamos aquellas características sociales que, de acuerdo con los usuarios, deben tener estos sistemas.

D) Aspectos Personales

Abordamos desde esta declaración temática los temas vinculados a la flexibilidad de los sistemas para adaptar las características del portal y los contenidos a las preferencias del usuario. 


\section{E) Aspectos Económicos}

En esta declaración temática recogeremos los aspectos vinculados con los modelos de negocio, con los costes de los contenidos digitales y con la gestión y necesidades relativas a los sistemas para compartir contenido digital.

\subsection{Análisis e interpretación}

\section{A) Aspectos pedagógicos}

\section{A.1 ¿Qué modelo pedagógico subyace a Share.TEC?}

Share.TEC fue diseñado según las bases del constructivismo social. De este modo, ofrece la interacción tanto con los materiales como con otros individuos a partir de diversas funcionalidades que facilitan el contacto social y la generación de grupos de interés/comunidades: compartir contenidos, recibir y aportar comentarios sobre recursos y entre miembros de la comunidad, dar una puntuación a los recursos, crear grupos vinculados a una temática concreta, etc. Además de esta perspectiva tan social, incorpora una perspectiva de tipo cognitivista y constructivista (Vygotsky, 1978) (permitiendo que los usuarios interaccionen de forma asíncrona con otros usuarios, accediendo a contenidos digitales por habilidades cognitivas que trabajan los recursos y niveles educativos, etc.). Cuando nos referimos a los modelos pedagógicos que perfilan Share.TEC, apuntamos hacia el tipo de interacción del usuario con el portal, y hacia el carácter pedagógico de las funcionalidades que integra (no analizamos los contenidos digitales en sí mismos, ya que Share.TEC es un referatorio). Cada recurso educativo sigue diferentes planteamientos y estrategias pedagógicos (aunque esta información no está disponible en la estructura de metadatos).

La intencionalidad del proyecto radicaba en la consecución de un amplio número de usuarios que actuaran como comunidad aportando sus propios recursos (en el apartado "Ofrecer") y sus propias reflexiones/usos contextuales sobre los materiales, generando grupos de interés en el apartado usar, etc. En este sentido, el portal está estructurado de tal forma que posibilita el intercambio de conocimiento entre usuarios de forma asíncrona (mediante comentarios públicos y mensajes privados). Sigue la filosofía 2.0 (O'Reilly, 2005), siendo posible el acceso al portal desde cualquier lugar en el que se tenga acceso a Internet y en varios idiomas, permite identificar contenidos digitales etiquetados con información educativa, posibilita la comunicación asíncrona entre diferentes usuarios (profesores, 
proveedores de contenido, estudiantes, diseñadores de currículo, permite comentar y votar los recursos así como ver las votaciones de otros, etc.). Algunas funcionalidades del portal ofrecen recomendaciones de recursos para usuarios de acuerdo con su perfil (e.g. idioma, área, etc.) y de acuerdo con resultados similares a los encontrados en búsquedas anteriores por el propio usuario, remitiéndonos a una filosofía 3.0, de acuerdo con las ideas de Moravec (2008).

Uno de los aspectos más valiosos de Share.TEC radica en la ontología educativa bajo la cual están etiquetados los metadatos de los contenidos digitales incluidos en el portal, de la que aportamos información más adelante. Gracias a esta clasificación, que incluye un amplio número de materiales, se facilita la reutilización de contenido digital para diferentes contextos educativos e incluso de diferentes países, pues pueden buscarse materiales por tipo de estructuración pedagógica, tipo de estrategia didáctica, tipo de material educativo, temática y nivel de aplicación del contenido, tipo de institución educativa, etc. (Lavagnino et al., 2010). La utilidad pedagógica del portal radica en la ayuda a los formadores de profesores para la preparación de material docente, como elemento de referencia para crear el propio material o como medio de reutilización del contenido.

Uno de los elementos más valiosos para los profesores es el contacto social con sus iguales, como medio para la mejora del material, elemento evaluador de la calidad del material creado por los docentes y guía para modelar, recrear o generar los propios materiales o poner en marcha experiencias pedagógicas (Matzat, 2013) (reflexiones que avalamos en el apartado 2 "C)"del presente capítulo). Conocer otras experiencias anima a los docentes a desarrollar las suyas propias, guiados por el aprendizaje vicario de las experiencias de otros docentes. De este modo, se genera el medio adecuado para que tenga lugar el aprendizaje distribuido en el que los diferentes usuarios del portal aportan sus conocimientos y experiencia, tanto para mejorar el material existente como para debatir sobre cualquier tema expuesto en los grupos o comentado en los recursos. Share.TEC, como lugar de confluencia de personas vinculadas a la formación del profesorado, contenía los mecanismos suficientes para permitir el contacto con otros profesionales, pudiendo buscar el perfil de los mismos a través de los grupos creados o a través de los contenidos que potencialmente generaran estos profesores.

La calidad del contenido digital introducido inicialmente por los socios del proyecto estaba filtrada por los pedagogos participantes en el proyecto, quienes proveyeron recursos de diferentes bases de datos fiables y de calidad de cada uno de los países participantes en el proyecto. La idea inicial de Share.TEC fue poblar el 
portal con contenidos digitales de calidad para la formación del profesorado, de forma que se consideraba que este mecanismo favorecería que los formadores de profesores se animaran a utilizar este portal. Lo cierto es que las estadísticas actuales del portal nos indican que apenas existen recursos subidos por los usuarios del portal (1425 miembros inscritos) y que no existe interacción en las 68 comunidades creadas por ellos.

Muchas de las subcomunidades existentes en Share.TEC fueron creadas en las pruebas piloto del portal, para probar esta funcionalidad o para generar grupos de trabajo como experiencias puntuales (aprender a utilizar Share.TEC en cursos de formación de maestros). La media de miembros por cada subcomunidad de es de 2.75; siendo la moda 1, y el valor máximo 16 (únicamente un grupo), seguido por dos grupos de 9 personas.

\section{A.2 ¿Es compartida la ontología subyacente a Share.TEC y su modelo común de metadatos?}

La ontología de Share.TEC es, en general, compartida por la comunidad de profesores, aunque no todos están de acuerdo con utilizar una ontología.

A lo largo de las pruebas realizadas con los usuarios, encontramos diversidad de respuestas a las preguntas relacionadas con este tópico. Tras un análisis de los diversos documentos podemos determinar que para la mayoría de los formadores de profesores y profesoras que contestaron a esta pregunta Share.TEC oferta una ontología, en general, compartida por su comunidad educativa, aunque consideramos que contiene campos mejorables o matizables.

En la prueba [09], realizada con una pequeña muestra de 5 usuarios de la Universidad de Valladolid, los profesores tenían dificultades para comprender la ontología de Share.TEC o partes de ella. Dos de los 5 usuarios no comprendían la ontología:

[09] S4_35M_B1 “No entiendo el etiquetado, no comparto la ontología que hay por detrás y por lo tanto no estoy de acuerdo con el etiquetado que se ha hecho del recurso"

[09] S3_29M_B1_La información me parece útil, excepto en el caso de Classifications, que no entiendo la ontología, por lo que es difícil ver la utilidad de las categorías elegidas. 
Con cuatro de los usuarios de la prueba [9] y otros adicionales se realizó una prueba piloto [21] en la que los usuarios entendieron parte de la ontología, pero no integramente.

En la prueba [33], contestada por 26 usuarios, 7 opinaron que la ontología (o la forma en la que se presenta en el portal) no era adecuada, frente a 5 usuarios que sí la consideraban adecuada. La mayoría, 12, manifestaron que sí era adecuada, pero debían incluirse modificaciones; 2 usuarios no contestaron. Entre quienes consideraron que había que realizar modificaciones, varios usuarios comentaron que los campos eran muy exhaustivos. Los motivos que aportaron quienes consideraban que era mejorable, fueron que algunos conceptos debían precisarse más (4 usuarios); los campos de búsqueda eran demasiado extensos (4 usuarios); excluyentes (1), rígidos (1) y farragosos y confusos (1).

[33] SF_31_M_Sí, son adecuados, si bien en ciertos campos (que yo conozca) se podría acotar aún más. Por ejemplo, en el ámbito de la formación profesional, con la formulación que actualmente tiene en Share.TEC, el único "campo" que he encontrado es el de "Instituto de Formación Profesional". Con esa formulación queda demasiado vago (mejor "institución" que "instituto"), ya que puede generar una asociación mental con los institutos de formación profesional reglada (ciclos formativos), excluyendo (en cierta forma) el otro gran subsistema de la formación profesional: la formación profesional para el empleo, y obviando entidades como los Centros Integrados o los Centros de Referencia Nacional, que tras las últimas reformas legislativas juegan un papel fundamental.

[33] SF_34_F "Considero que hay que seleccionar demasiadas categorías para hacer una búsqueda. La ontología no se corresponde en su totalidad con la realidad de las demandas del profesorado"

En la prueba [44], contestada por 19 usuarios, 15 usuarios (78,95\%) comprendieron todos los campos de la ontología. La mayoría de los usuarios, 16 (el $85.21 \%$ ), consideraron que los términos que aparecen en los campos de filtrado de búsqueda eran compartidos con su comunidad. En cuanto al formato para realizar las búsquedas avanzadas, 8 usuarios $(42,11 \%)$, consideraron que los campos debían mejorarse, versus 11 usuarios que lo mantendrían como estaba.

[09] S4_35M_B1 “No entiendo el etiquetado, no comparto la ontología que hay por detrás y por lo tanto no estoy de acuerdo con el etiquetado que se ha hecho del recurso"

[44] 20.5_24_F_EM “En mi comunidad educativa sí que usamos los mismos términos" 
[44] 20.15_27_F_FP "Creo que es un vocabulario fácilmente comprensible por la comunidad"

El portal Share.TEC integraba una ontología traducida a 5 idiomas diferentes, y un modelo común de metadatos para los contextos de los 5 países en los que se hablan estos idiomas.

Parece coherente que, debido a la multiculturalidad presente en el portal, donde coexisten personas de diferentes países, regiones y modelos pedagógicos personales, sea necesaria la formación de los usuarios en el uso del portal, y la comprensión de su ontología, pues no existe una ontología ni modelo de metadatos estandarizado para la formación del profesorado que incluya aspectos educativos avanzados. Recordemos que el Modelo Común de Metadatos generado en el portal está basado en LOM-IEEE e incorpora campos pedagógicos adicionales a este modelo.

[33] 22.8. SF_38_M_Sí pero requieren de formación y ajuste a la concepción educativa de cada profesor. Es necesaria la formación.

En el campo de la formación del profesorado etiquetar los contenidos digitales por nivel educativo, modo de empleo (a distancia, presencial o blended learning), habilidades que se desarrollan/trabajan con el recurso, y contexto de práctica docente, puede carecer de sentido, ya que un mismo material puede tener múltiples aplicaciones en función de cómo se utilice. Asimismo, esta especificidad puede provocar la pérdida de resultados encontrados tras realizar una búsqueda.

En la descripción de los contenidos digitales se incluía un campo (metadato) que definía para qué nivel estaba pensado el contenido digital. En ocasiones tenía sentido catalogar los contenidos educativos en función del nivel (por ejemplo, los materiales destinados a formar profesores de las primeras etapas escolares, Educación Infantil y Primaria, puede que tengan una idiosincrasia específica puesto que los niños de cada etapa tienen características muy particulares y divergentes entre ellas). En otros casos, el hecho de que un contenido educativo esté etiquetado para un nivel u otro puede ser irrelevante, puesto que es posible que el material sea apto para varios niveles: por ejemplo, categorizar un artículo relativo a la metodología de investigación en educación, puede ser apto tanto para estudiantes de grado de educación infantil como para estudiantes de postgrado de psicología.

[33] 4.14. FP_54_M Casi todos los campos son útiles, pero tal vez sean demasiados. Aquellos en los que no resulta fácil asignar valores, tal vez tampoco sean útiles en las búsquedas por falta de precisión. Por ejemplo: 
"Modo de empleo", "Habilidades generales" o "Contexto de Práctica docente".

[09] S4_35M_R1_A5_2 El recurso aparece etiquetado como "Postgraduate" y "Primary Education" y desconozco qué criterio se ha seguido para hacerlo. El valor añadido del etiquetado estaría en describir posibles usos del recurso en los distintos niveles en los que se podría aplicar. En principio que se me diga desde qué tipo de institución se ha generado el recurso no me aporta mucho... y tampoco que se diga de forma totalmente aleatoria en qué nivel educativo podría emplearse.

Por estos motivos, algunos usuarios comentaron que consideraban que existían metadatos que podían ser eliminados:

[33] 21.1. SF_34_F "Eliminaríamos alguno de los ítems de la búsqueda avanzada como: Institución educativa, Habilidades Generales, Tipo no estructurado pedagógicamente [...]"

Más que metadatos descriptivos, los usuarios indican que les gustaría poder ver metadatos que aporten información pedagógica y contextual sobre la tipología pedagógica del recurso.

A pesar de que la ontología de Share.TEC permitía catalogar los materiales por tipo de formato técnico y tipo de contenido digital (estructurado pedagógicamente/no estructurado pedagógicamente, y un listado de tipologías dentro de cada uno de estos), los usuarios echaban en falta una descripción más pedagógica de los recursos (si es un aplicación didáctica, una WebQuest, etc.), e incluso datos contextuales del contenido digital: orientaciones de uso, valoraciones de los contenidos, etc. Además de la penúltima evidencia que acabamos de plasmar ([09] S4_35M_R1_A5_2), otros comentarios de informantes avalan esta interpretación, e.g.:

[09] S1_30M_B2_echo en falta información entendible pedagógicamente; por ejemplo, si un material es una aplicación didáctica, si es una WebQuest...

[09] S2_45F_B2_Sí, me parecen poco claras las categorías. No incluyen datos que a mí me puedan en principio resultar interesantes: valoración desde un punto de vista tecnológico, si contiene material aplicable en mis asignaturas, si es poco/mucho interactivo

[09] S4_35M_B2_Lo que me interesaría como formador es que el sistema me ofreciera información de un etiquetado proveniente del etiquetado social de experiencias de uso concretas de recursos determinados. 
[44] 10.4."29_F_ING_- Pocos recursos de los encontrados tenían asociada una votación. Sería útil una opinión directa por parte de aquellos usuarios que hayan utilizado el recurso, no sólo una votación [...].

En las diferentes pruebas con los usuarios finales de Share.TEC (profesores 0 formadores de profesores) encontramos que presentaban confusión ante la diferencia entre los idiomas en los que aparecían descritos los metadatos y los idiomas en los que se presentaba el propio recurso.

Share.TEC es mayoritariamente un referatorio y no un repositorio. La mayoría de las descripciones de los contenidos digitales que integra el portal aparecen etiquetadas en diversos idiomas (al menos en el original y en inglés). Los usuarios presentaban dudas sobre si era el contenido digital el que se presentaba en un idioma concreto, o sobre si únicamente era la descripción del contenido digital, tal y como se desprende de los siguiente extractos:

[21] FP_F_35_Aclarar los términos de búsqueda y los idiomas en los que van a aparecer los recursos.

[44] 18.18 36_F_FP_Cuando hice la búsqueda en castellano me fue más difícil hallar resultados que en inglés. Quizás fuera conveniente advertirlo, pues encontré recursos en otros idiomas, pero con palabras clave en inglés.

[33] 18.3.47_M_FP_en una puse "historia", me devolvió más de 4 mil documentos, los 10 primeros en cirílico en otra puse "'Teacher Primary ICT", y me devolvió 6 mil documentos, los 10 primeros muy parecidos".

La llustración 28 ilustra una captura de pantalla de la interfaz de Share.TEC, mostrando cómo visualizan los metadatos de un recurso cuando accedemos a su descripción. Los idiomas en los que el recurso muestra información disponible aparecen con una bandera representando un país en el que se habla ese idioma, y el idioma del propio contenido digital aparece en la descripción "idioma del recurso (resource language)". 
llustración 28 Ejemplo de visualización de la interfaz que aparece en Share.TEC tras la búsqueda y selección de un recurso. Idioma del recurso vs. idioma de los metadatos.

\begin{tabular}{|c|c|}
\hline Creator & $\begin{array}{l}\text {-Francisco Formica, -Gustavo Carnelli, - Marcela } \\
\text { Cristina Falsetti, - Mabel Rodríguez }\end{array}$ \\
\hline Title & $\begin{array}{l}\text { Integrated perspective of the Education and the } \\
\text { Learning of the Mathematical one: a glance to the } \\
\text { Mathematical Education (2) }\end{array}$ \\
\hline Resource location & http://www.fisem.org/descargas/9/Union_009_015.pd \\
\hline Resource language & aes \\
\hline Keywords & -training, -mathematics \\
\hline
\end{tabular}

\section{A.3 ¿Qué necesidades manifiestan los formadores de profesores sobre el etiquetado de contenidos digitales y qué opinan sobre el etiquetado de Share.TEC?}

Los profesores y formadores de profesores consideran que carece de sentido etiquetar contenidos digitales enmarcados en la categoría "sin estructura pedagógica" con "competencias y habilidades" y "modo de empleo".

La mayoría de los recursos aportados los socios UVa del proyecto Share.TEC eran artículos de revistas educativas relacionados con la formación del profesorado, en formato ".pdf". En función del contexto en el que el formador quiera aplicar el recurso y de las actividades educativas que se planteen en torno a él, se desarrollarán un tipo u otro de habilidades y competencias. Así, atendiendo a las opiniones de los informantes y a nuestra experiencia, consideramos que carece de sentido la categorización por habilidades y competencias de los contenidos digitales "no etiquetados pedagógicamente", si no se añade la información contextual de uso del recurso. Extendemos esta ausencia de sentido a la catalogación de "modo de empleo" (presencial, aprendizaje mixto o a distancia) para este tipo de contenidos digitales.

[09] S1_30M_R1_A6_Depende mucho de lo que quiera hacer con este recurso. A lo mejor me sirve para trabajar en clase el tema de superdotados. Entonces se convierte en presencial y no a distancia, como está etiquetado [09] S4_35M_R1_A5_2_ El recurso aparece etiquetado como "Postgraduate" y "primary education" y desconozco qué criterio se ha seguido para hacerlo. El valor añadido del etiquetado estaría en describir posibles usos del recurso en los distintos niveles en los que se podría 
aplicar. En principio que se me diga desde qué tipo de institución se ha generado el recurso no me aporta mucho... y tampoco que se diga de forma totalmente aleatoria en qué nivel educativo podría emplearse.

En la prueba [9] pedimos a los usuarios que valoraran del 1 (totalmente mala) al 5 (totalmente buena) la catalogación de los contenidos digitales que proporcionamos el equipo UVa como miembro del consorcio de Share.TEC. Como vimos en el capítulo 3, la mayoría de los recursos que aportamos fueron artículos de revista en formato ".pdf'. La puntuación media para el conjunto de los ítems realizada por los 5 usuarios fue de 1,6 sobre 5 y una $\sigma$ de 1.9 (Tabla 11) pues en general, los usuarios consideraban que el etiquetado era completamente aleatorio y acontextual.

Los formadores de profesores y profesionales de la educación no necesitan tanta especificidad técnica en la descripción de los contenidos digitales, y sí más pedagógica.

Existe confusión entre los formadores de profesores a la hora de comprender los conceptos técnicos que describen el formato de los contenidos digitales, tales como "aplicación, .pdf". En la prueba de evaluación de los primeros metadatos catalogados por UVa, para la persona del área de ingeniería que participó como informante de la prueba, los campos aparecían etiquetados correctamente en los cuatro recursos evaluados; en cambio, el resto de usuarios (formadores de profesores) encontraba poco sentido a esta clasificación.

[09] S3_29M_R1_A4 "Parece todo correcto" (Sujeto 3, ingeniero de telecomunicaciones, profesor de ingeniería en Educación Superior y formador de profesores)

[09] S1_30M_R1_A4 "Se trata de texto, no de una aplicación" (Formador de profesores de Pedagogía)

[09] S2_45F_R1_A4 "En este caso, al tratarse de un texto PDF, no creo que haya más que añadir En el apartado "Type" se etiqueta como "application" y en el "subtype" aparece "pdf"; no lo comprendo. (Formadora de Profesorado de Expresión Musical)

Mostramos en el Cuadro 3 las preguntas cuantitativas que realizamos a los usuarios de la prueba [09], y las medias y desviaciones típicas obtenidas para cada respuesta en la Tabla 11.Muchos aspectos eran considerados mejorables, e.g., el nivel educativo, el nivel de habilidad y el modo de empleo, pues o bien no tenía sentido aportar esa información para este tipo de recursos (artículos), o bien habían sido etiquetados arbitrariamente. 
Cuadro 3 Preguntas cuantitativas de la prueba 09 "Evaluación de la Calidad de los metadatos".

[09] Preguntas de la evaluación de la calidad de los metadatos: "Valore los siguientes aspectos": ${ }^{132}$

- A1) En general: Identificador del recurso, Título, Descripción, Idioma del recurso, palabras clave.

- A1.1) La descripción de los recursos y palabras clave no tienen faltas de ortografía y la construcción de las frases es correcta

- A2) Ciclo de vida del recurso (fecha de creación, creador)

- A3) Metametadatos (creador del etiquetado del recurso)

- A4) Aspectos Técnicos: del recurso etiquetado. Formato del recurso

- A5.1) Clasificación - Disciplina (Contexto y Taxonomía). Puntúa del 1 al 5 el contenido que aparece etiquetado.

- A5.2) Clasificación - Nivel educativo

- A5.3) Clasificación - Nivel de competencia/habilidad

- A6) Pedagógicos: modo de empleo (a distancia, presencial o mixto), tipo de interactividad y tipo de contenido digital)

* Las respuestas se basan en una escala Likert de 1 a 5 , siendo 1 totalmente en desacuerdo/malo y 5 totalmente de acuerdo/bueno

Tabla 11 Prueba [09]. Respuestas cuantitativas '"Evaluación de la Calidad de los metadatos": Media $(\mu)$ y Desviación Típica $(\sigma)$

\begin{tabular}{llll}
\hline & Pregunta & $\mu$ & $\sigma$ \\
\hline Identificación descripción & A1 & 2,69 & 1,18 \\
Ortografía gramática & A1.1 & 3,00 & 1,08 \\
Ciclo de vida & A2 & 2,77 & 1,01 \\
Metametadatos & A3 & 3,23 & 1,36 \\
Aspectos Técnicos & A4 & 3,00 & 1,58 \\
Disciplina & A5 & 2,62 & 0,51 \\
Nivel educativo & A5.1 & 1,85 & 0,85 \\
Nivel de habilidad & A5.2 & 1,92 & 0,86 \\
Modo de empleo & A6 & 2,31 & 0,95 \\
\hline
\end{tabular}

En la Tabla 11 se aprecia que las desviaciones típicas para cada ítem son relativamente pequeñas (menor a 1,0 en torno a 1); las mayores variaciones las obtenemos en la puntuación de la opinión del etiquetado de los aspectos técnicos, con una media de 3 sobre 5 y una $\sigma$ de 1.58 (pregunta A4); Los metadatos mejor etiquetados, según estos informantes, son los referentes a un dato objetivo (el

132 Las respuestas se basan en una escala Likert de 1 a 5 , siendo 1 totalmente en desacuerdo/malo y 5 totalmente de acuerdo/bueno 
creador del recurso, principalmente) $(\mu 3,23 ; \sigma 1,58)$. Fueron peor considerados los relativos al nivel educativo $(\mu 1,85 \sigma 0,85)$. Sólo tres aspectos de los metadatos son aceptables para los usuarios (puntuación media mayor o igual a tres): ortografía y gramática, meta-metadatos, y aspectos técnicos. El resto de aspectos informativos (identificación/descripción del recurso, ciclo de vida) y pedagógicos (disciplina, nivel educativo, nivel de habilidad y modo de empleo) no fueron evaluados como adecuados por estos informantes. Gracias a la detección temprana de la inadecuación del etiquetado detectada por los evaluadores, se mejoró proceso de etiquetado a partir de este momento (tanto en la traducción de los metadatos a inglés como en el contenido de las descripciones y los aspectos pedagógicos descriptivos de los mismos). Una persona fue contratada para esta tarea, y el procedimiento de mejora consistió en hacer saber a esta persona los resultados de la evaluación, quien mejoró los etiquetados, así como la revisión de otra persona de su trabajo.

Otro aspecto relevante a considerar en el etiquetado de los contenido digitales educativos hace referencia al idioma:

Los informantes de Share.TEC demandan la posibilidad de etiquetar las descripciones de los contenidos digitales en varios idiomas. Cuando los usuarios subían contenidos digitales desde el propio portal, únicamente podían aportar la descripción en un idioma; en cambio, si generaban contenidos con la herramienta RICK, podían aportar descripciones en múltiples idiomas. En cualquier caso, esta herramienta no podía descargarse desde el portal Share.TEC, por lo que los usuarios desconocían la existencia de esta herramienta.

[44] 15.4.29_F_ING_Falta la opción de incluir descripciones en otra lengua. Al dar sólo da soporte a una, no se puede ofrecer la descripción en la lengua original y en inglés, lo cual puede ser un problema al tratarse de una plataforma de uso a nivel europeo.

\section{A.4 ¿Los contenidos que ofrece Share.TEC son útiles para los formadores de profesores?}

Una de las sugerencias iniciales de la evaluadora del proyecto consistió en la definición del término "calidad" de los contenidos y de los metadatos. Posteriormente, esta evaluadora, al ver la complejidad de la definición de "calidad" y las implicaciones de carga de trabajo que conllevaba aportar contenidos y metadatos de calidad al sistema, concretó que al menos, los contenidos digitales debían ser para formadores de profesores (pues había contenidos digitales que 
estaban enfocados a otros niveles educativos, pero no para la formación del profesorado en sí).

[Anexo 27]. Claire comenta que la calidad debería estar referida a contenidos relevantes para formadores de profesores. Como requisito mínimo, pide que los contenidos del sistema deben ser de Teacher Educators. Un miembro de TCD comenta que el proyecto consiste en etiquetar metadatos de contenidos digitales existentes, y que la calidad debe centrarse en los metadatos. (Notas de la investigadora).

En cuanto a la calidad de los metadatos, para homologar el etiquetado de los contenidos digitales y asegurar el cumplimiento de unos niveles mínimos, en una de las reuniones de proyecto, uno de los miembros del equipo de NIS-SU propuso un sistema de clasificación que fue refinado posteriormente entre todos los miembros del proyecto. El sistema establecía la siguiente clasificación en función de si presentaban o no los metadatos que se incluían en cada categoría:

- Bronce: Modo de empleo (distancia, presencial o mixto)

- Plata: Modo de empleo y tipo de interactividad (con el tutor, con el material, etc.)

- Oro: Tipo de Interactividad, Modo de empleo, Disciplina y campo pedagógico.

De este modo, todos los contenidos digitales aportados por los miembros de Share.TEC debían cumplir como mínimo con los requisitos de calidad bronce (además del título, autor, resumen y palabras clave). La propuesta de este criterio básico aseguró el éxito de la calidad de los metadatos en la evaluación del proyecto realizada por la comisión europea.

Tal y como acordó el consorcio, el resto de contenidos digitales que quisieran aportar nuevos colaboradores, podrían no cumplir los requisitos de "calidad bronce". La inclusión de los metadatos de los contenidos digitales tuvo tendencia a completarse en la etapa final del proyecto (debido principalmente a la inclusión de otras colecciones de recursos en los tres últimos meses del proyecto). Asimismo, en los últimos tres meses del proyecto hubo un claro incremento de la calidad del etiquetado (bajo los criterios mencionados con anterioridad), de los contenidos digitales, tal y como puede observarse en el Gráfico 4: 
Gráfico 4 Evolución de la calidad de los metadatos en Share.TEC.

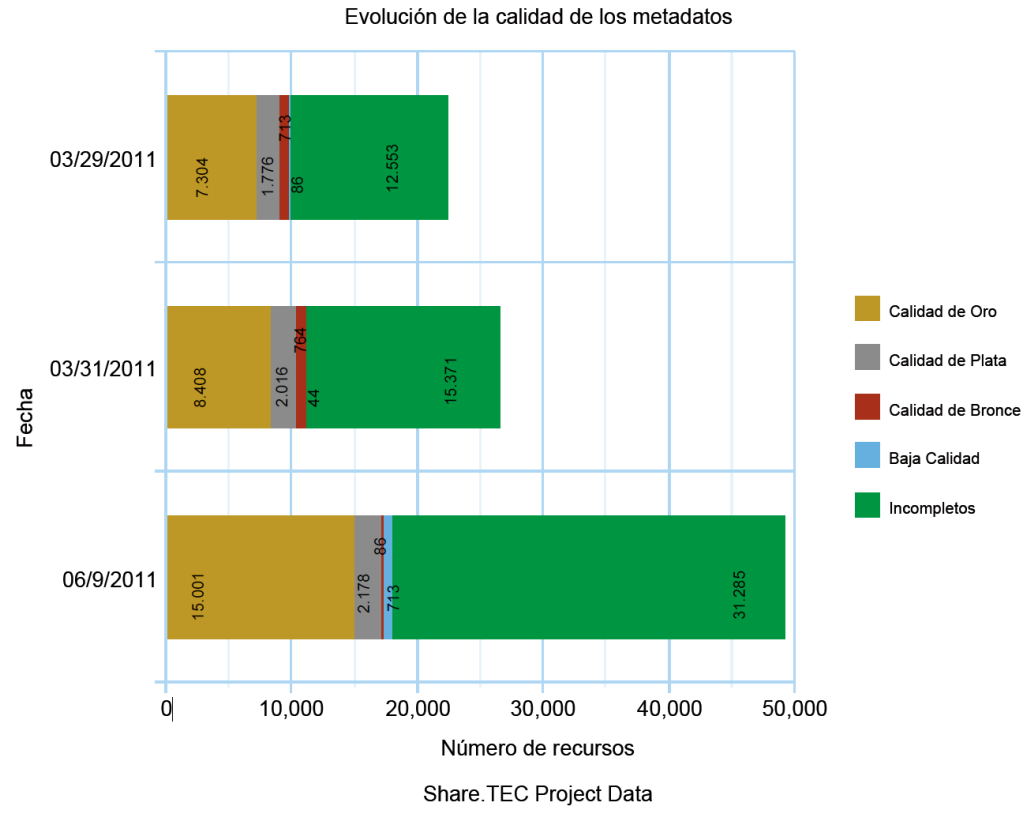

Como vemos en el gráfico, en el eje de abscisas hemos colocado la fecha en la que se realizó el análisis automático de la calidad de los metadatos con la herramienta "Analizador de metadatos" generada por el equipo TCD del proyecto Share.TEC, atendiendo a los criterios descritos previamente. En primer lugar, mostramos el mes, y después el día y año.

El número de recursos de calidad oro incrementó en un $205,38 \%$ en menos de tres meses; el número de recursos de calidad plata incrementó un 153\%; el número de recursos de calidad bronce descendió un $868,18 \%$ (puesto que muchos de estos recursos evolucionaron a calidad oro o plata). El número de recursos de baja calidad incrementó un $1620 \%$ y los recursos incompletos un $249 \%$ (este incremento elevado de recursos fue debido a que en estos últimos meses se introdujeron colecciones de recursos procedentes de servicios externos -de manera adicional a los prometidos por los socios de Share.TEC- e.g., "MUEP_Collection"; "DMG_Lib_Collection").

Por tanto, la evaluación del número de registros y de datos del portal fue una estrategia realmente útil para que los miembros del consorcio Share.TEC consiguieran 
federarse con más repositorios de contenidos digitales y mejoraran sus técnicas para cumplimentar los datos del portal Share.TEC (bien a través de la herramienta RICK o bien a través de repositorios con datos en los formatos compatibles con Share.TEC - Dublin Core y LOM).

El número de metadatos incorporados en el sistema tras finalizar los plazos del proyecto fue de 49263, aunque los metadatos comprometidos inicialmente fueron 72801. En cualquier caso, tras negociaciones posteriores con otros proveedores de metadatos, el portal cuenta actualmente con 71626 registros de metadatos de contenidos digitales, cifra muy próxima a la prometida inicialmente.

Gráfico 5 Tipología pedagógica y cantidad de metadatos catalogados referentes a contenidos educativos alojados en Share.TEC.

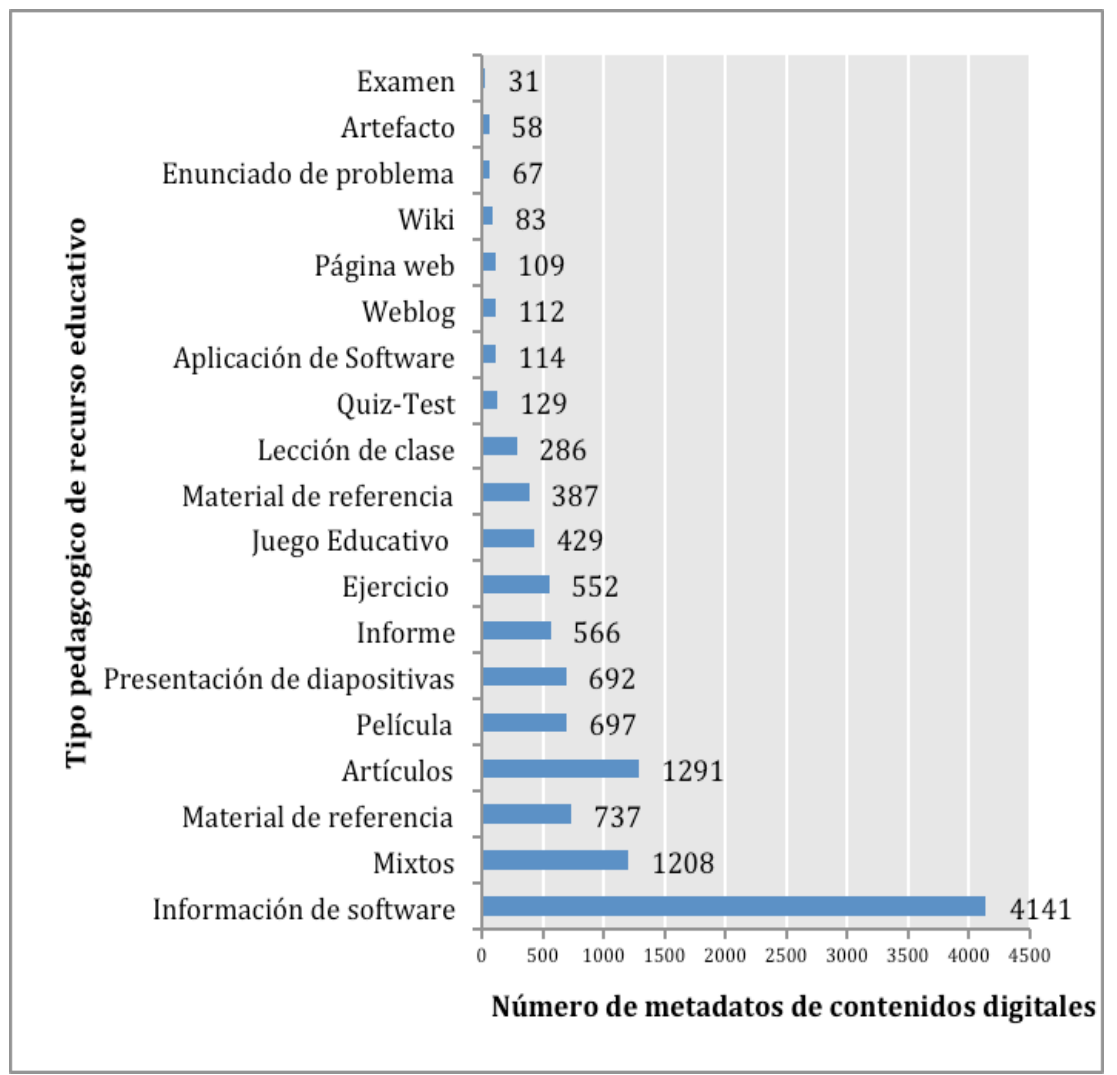


Otro criterio que suele considerarse cuando se menciona la calidad de los contenidos digitales de un sistema, hace referencia a la diversidad de tipologías pedagógicas de recursos (Gráfico 5). En el documento inicial del proyecto, Technical Annex (p.62), se recogía que la mayoría de lo metadatos harían referencias a libros, seguidos por tutoriales, unidades didácticas y programaciones. Los metadatos de la plataforma Share.TEC recogen la variedad inicialmente planteada y presentan la distribución que podemos ver en el Gráfico 5. Apreciamos que el número de recursos representados en la gráfica es inferior al número total de recursos (11.123 vs. 71626$)$; es decir, sólo el $15.53 \%$ de los recursos muestran esta información). Esto es debido a que no todos los registros de metadatos de cada contenido digital incluyen la descripción de este campo (no disponemos de esta información). En esta gráfica faltaría incorporar un importante número de contenidos no etiquetados entre los que, en número, destacarían diversos materiales de referencia (libros), y páginas Web.

En el caso del tipo de contenido técnico (Gráfico 6), podemos apreciar un mayor número de recursos etiquetados con esta información (43.929), es decir, el 61,33\% de los recursos disponen actualmente de esta información (esto se debe a que este metadato suele estar presente en los contenidos digitales etiquetados en LOM y DC, por lo que la recuperación de este dato es automática).

Además, el tipo de contenido pedagógico o formato del recurso, como hemos visto en el apartado A.3 del presente capítulo, no siempre ha sido etiquetado de manera correcta en los casos en los que el etiquetado ha sido manual o partiendo de metadatos incorrectos, tal y como he podido observar a la hora de explorar el sistema y de acuerdo a lo detectado en diferentes pruebas con usuarios finales del portal. 
Gráfico 6 Formato técnico de los contenidos educativos descritos en Share.TEC.

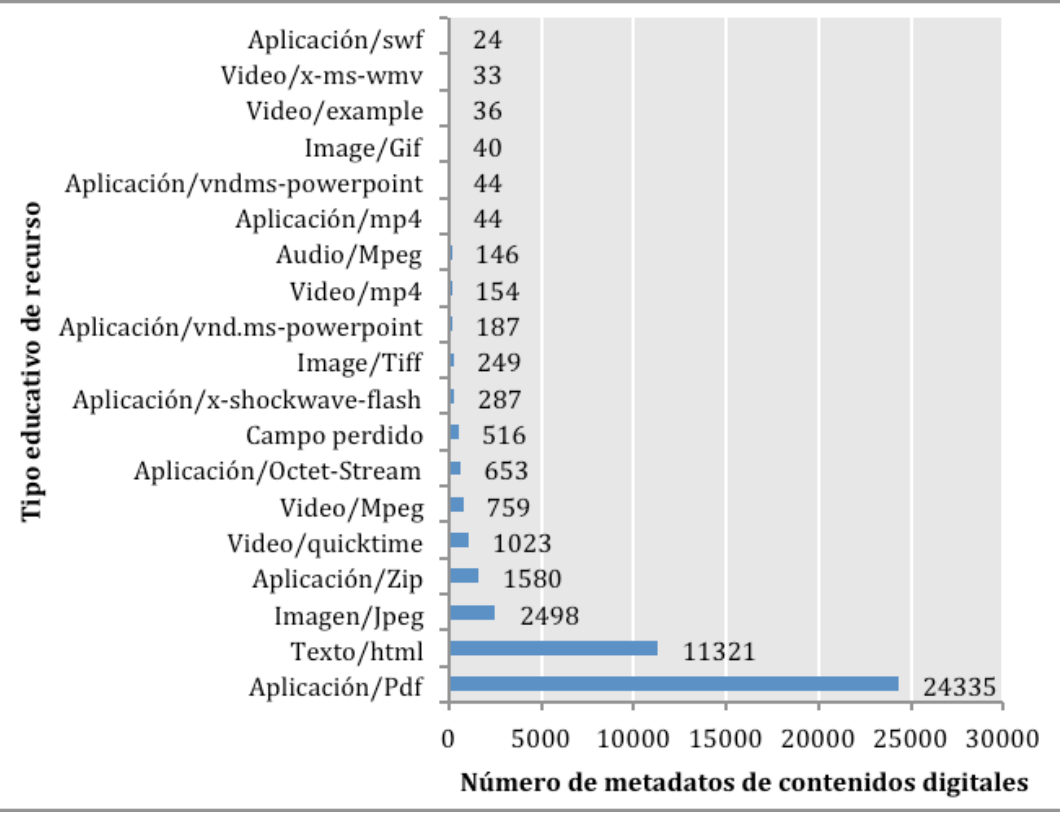

Una vez recopilados los aspectos relativos a la calidad de los metadatos de los contenidos digitales que incorporaba el portal, veamos las consideraciones que conciernen a la calidad pedagógica de los mismos.

En el proyecto Share.TEC no se tomaron medidas para evaluar la calidad pedagógica de los contenidos.

El proyecto esperaba inicialmente un número de usuarios activos en el portal, y se esperaba que fueran estos usuarios potenciales quienes aportaran los datos relativos a la calidad pedagógica de los materiales mediante la incorporación de votaciones y comentarios en los recursos. Esto no fue posible, dado que no se logró la integración ni generación de una comunidad real activa en el portal.

En el caso de UVa, al principio del proyecto (mes 9), aprovechando la prueba de la evaluación de la calidad de los metadatos, decidimos preguntar a nuestros usuarios por la calidad de los contenidos digitales que les presentamos (como ya hemos mencionado, artículos de investigación educativa y Webquests). De la evaluación realizada se obtuvieron las siguientes evidencias: 
El hecho de que los contenidos digitales contengan partes mal traducidas afecta a la visión que el usuario tiene sobre la calidad del contenido digital:

[09] S4_35M_R5_A4 Aparece etiquetado como "application" y "pdf" y vuelvo a no compartir la clasificación. Este recurso es un artículo de calidad más que cuestionable (ver primera línea abstract en inglés "In this study we proposes...") dentro de una revista... y no se proporciona esta información.

Los artículos en sí mismos, al no aportar información pedagógica contextual, sirven meramente de ejemplos para ilustrar, y no para trabajar otras competencias más complejas.

[09] S4_35M_R5_A00_En principio cualquier repositorio de comunicaciones periódicas tiene un uso potencial en la formación... pero un tiesto, una piedra e incluso un pañuelo de papel podrían servir de igual manera.

[09] S2_45F_R1_A01_Puede resultar un ejemplo práctico de elaboración de material. En sí, este artículo no me parece especialmente útil, sino simplemente descriptivo de la experiencia llevada a cabo.

En cualquier caso, los artículos pueden ser útiles como vías para la comprensión de las preocupaciones investigativas de la comunidad científica, tanto para la formación del profesorado como para la formación permanente.

[09] S4_35M_R1_A00_En principio considero que artículos sobre innovaciones educativas, que no investigaciones educativas, pueden resultar de interés tanto para la formación inicial de profesorado como para la formación permanente. Pueden ayudar a acercar la práctica educativa real a las aulas de formación.

Evaluar la calidad de un contenido digital en sí mismo, es una tarea compleja y subjetiva.

La única manera de poder evaluar con mayor precisión un contenido digital es el uso social del mismo, es decir, comentarios, votaciones y experiencias de uso en torno a él. Cuantas más personas evalúen y comenten un recurso, se puede hacer una mejor estimación de la calidad de los mismos. En el caso de Share.TEC, al no existir una comunidad real activa dentro del portal, pocos contenidos tenían uso social, y los que lo tenían, habían sido valorados por pocos usuarios.

[44] 12.4."29_F_ING_- Aunque ofrezca información sobre las votaciones, muy pocos recursos disponen de tal información y casi ninguno la ofrece con un número considerable de votos (la mayoría tiene 1 voto). - Los datos 
ofrecidos no van mucho más allá de los que se pueden encontrar en cualquier repositorio bibliográfico. - Se echa en falta algún dato sobre cómo usar/cómo se ha usado o para qué ha sido creado el recurso"

(pág.10) Iv_FP: Y hay un ejemplo claro de eso, que tiene que ver con las revisiones de los artículos que enviamos a revistas. Hay veces que es increíble cómo el mismo artículo uno te lo propone como Best paper award y el otro te funde los plomos, y dices... "a ver, cómo es posible, ni es tan malo ni es tan bueno".

Además, en la prueba [35] preguntamos a los usuarios si querían que sus redes de profesores estuvieran basadas en intercambio de recursos y comentarios, respondiendo que sí la mayoría de ellos (178/192, es decir, el 92,71\%).

\section{A.5 ¿Es la multiculturalidad un aspecto demandado y útil en este tipo de sistemas para los formadores de profesores?}

La multiculturalidad fue uno de los aspectos más indefinidos durante el desarrollo del proyecto Share.TEC. La evaluadora del proyecto recomendó aclarar cómo iba a abordar el portal la multiculturalidad, ya que era uno de los aspectos que se mencionaban en la solicitud del proyecto. Finalmente, la multiculturalidad nunca llegó a definirse, y los esfuerzos de Share.TEC, principalmente, se centraron más en aspectos multilingüísticos.

[Anexo 28] Claire Belise, la evaluadora del proyecto europeo, comenta "respecto a la multiculturalidad, a pesar de haber realizado algún avance, deberíais ir más allá" (Notas de la investigadora).

En algún caso sí que se llevaron a cabo iniciativas multiculturales, tal y como ocurrió en la generación del MMM (Modelo Multicultural de Metadatos). Este trabajo, como ya mencionamos, consistió en la adaptación del Modelo Común de Metadatos a las peculiaridades de los sistemas educativos de cada país participante en el proyecto. La adaptación de las ontologías a los contextos nacionales constituye un primer esfuerzo de generación de un modelo común, aunque somos conscientes de la imposibilidad de abarcar con éxito y precisión los contextos más locales (por ejemplo, en España, la materia de Educación es competencia no sólo del Estado, sino también de las Comunidades Autónomas y Locales). Es por ello, que los aspectos multiculturales constituyen un espacio en el que tienen lugar relaciones complejas es difícil definir en qué consisten.

[Anexo 4] [...] El usuario necesita una explicación clara de los términos adoptados, especialmente debido a la naturaleza multicultural de 
Share.TEC. La repercusión de la aproximación multicultural de TEO (Ontología Educativa para Profesores) es crítica y debe ser evaluada necesariamente por los usuarios finales [...].

En otros casos, ciertos contenidos digitales podrían considerarse universales cuando están exentos de lenguaje verbal o textual, tales como las imágenes.

[Anexo 11] NIS-SU (Bulgaria) "algunos recursos son imágenes; el lenguaje carece de importancia en este caso, donde el multi-idioma es útil”.

Los formadores de profesores creen que es adecuada la existencia de un sistema multicultural, teniendo en cuenta el mundo globalizado en el que vivimos y las posibilidades tecnológicas que nos dan acceso a múltiples recursos:

[09] S2_45F_B4 Bien, hoy en día creo que es fundamental. Pero ello no mejora la calidad de los datos per se, sólo los abren a la posibilidad de búsqueda en otros entornos lingüísticos.

[09] S3_29M_M_B5No por el hecho de estar anotado en inglés. Seguramente no, dependiendo de cuántas "nociones" tenga del idioma. Sólo si puedo leer en el idioma bien lo intentaría.

En el apartado "Ofrecer" del portal Share.TEC puede encontrarse una guía del Modelo Común de Metadatos para que los usuarios puedan etiquetar de forma adecuada los materiales que incluyen en el portal (H. Thomas \& Arnedillo, 2010). Cuando los usuarios realizan las búsquedas no tienen acceso a los conceptos de esta guía (no aparecen en ventanas emergentes ni se proporciona acceso a esta guía en la búsqueda avanzada del apartado "Acceder").

Uno de los aspectos de la multiculturalidad es el idioma en el que se presentan los contenidos y los metadatos de estos. Ahondamos en este aspecto en el apartado A.9, donde contemplamos los hábitos de acceso de los formadores de profesores atendiendo al criterio del idioma.

En cuanto a la cantidad de contenidos digitales, las pruebas se fueron realizando a medida que se iba desarrollando y perfeccionando el portal, El número de contenidos digitales incrementó sustancialmente en los últimos meses del proyecto. Por ello, en las pruebas realizadas con anterioridad, los profesores comentaban que no encontraban muchos recursos acordes a sus búsquedas y que el portal contenía pocas referencias de contenidos digitales, tal y como se desprende de los siguientes argumentos de los informantes: 
[21] Adjetivo seleccionado: No útil; Justificación: No son muchos los recursos.

[33] 18.2.27_M_ING_He encontrado recursos relacionados con preguntas "generalistas", como "English grammar" o "escritura de informes". Ahora bien, cuando he consultado cuestiones más específicas, como "arquitecturas RISC", no he encontrado nada relacionado con lo que buscaba.

[44] 27.5.24_F_EM_Si hay algún inconveniente es el inevitable, al ser novedoso, le faltan algunas matizaciones y mejoras, y más contenidos, pero con el tiempo se podrá mejorar fácilmente.

\section{A.6 ¿Ofrece ventajas pedagógicas Share.TEC frente a otro tipo de sistemas?. En caso afirmativo, ¿Cuáles?}

El portal Share.TEC cuenta con ventajas y desventajas pedagógicas que los usuarios resaltaron a lo largo de las diferentes pruebas que se realizaron con ellos.

En cuanto a las ventajas pedagógicas, los usuarios destacan las siguientes:

1) Una de las principales aportaciones del portal Share.TEC es la posibilidad de interacción de los usuarios en torno a los contenidos digitales, pues pueden comentarlos, votarlos, contactar con usuarios de similares áreas de interés, etc. Este hecho permite enriquecer los contenidos del portal y potenciar el conocimiento y su intercambio entre los usuarios.

[33] 10.8. SF_38_M_Amplía la visión a un entorno europeo y además es personalizable al grupo de profesionales con intereses similares

[33] 13.23. FP_27_F_Las aplicaciones sociales del portal me parecen una opción muy interesante que otros portales que proporcionan recursos no contemplan. Es decir, veo el valor añadido del portal, y es precisamente la parte social.

[Anexo 29] 54\% de los usuarios afirman que Share.TEC podría ayudarles a encontrar recursos creados por otras personas de su mismo campo

[44] 26.15.27_F_FP_Que las personas que comparten los recursos son expertos en el tema y se crea una comunidad. Además es más fácil encontrar a personas relevantes por este medio y poder compartir recursos. Creo también que es bastante accesible y el hecho de que haya comentarios y valoraciones de cada recurso es muy bueno para conocer la experiencia previa de otros profesionales. 
2) Los usuarios opinan que es un portal deseable por los formadores de profesores, pues ayuda a su labor profesional, facilitando el desarrollo profesional docente y la formación inicial.

[21] Adjetivo: Deseable "Es una herramienta deseable. A todo el profesorado nos gustaría poder usarla"

[21] Adjetivo: Útil "Es muy útil disponer de todos los recursos que necesitan los educadores reunidos en un lugar que se puede recuperar con relativa facilidad"

[21] Adjetivo: Colaboración "portal de gran ayuda en la investigación, ofrece una amplia variedad de textos"

[21] Adjetivo: Profesional "Es algo que debe utilizarse para el desarrollo profesional"

[21] Adjetivo: Beneficioso "Los materiales propuestos pueden ser utilizados en la formación"

[Anexo 29] 23\% de los usuarios afirman que Share.TEC podría ayudarles a diseñar y planificar sus recursos

[Anexo 29]54\% de los usuarios afirman que Share.TEC podría ayudarles a contrastar lo que hacen con las producciones de otros usuarios de su misma área de interés.

En la prueba [33], realizada con formadores de profesores y profesores de educación superior españoles, 19 usuarios consideran que Share.TEC es un sistema útil para compartir sus materiales, mientras 7 consideran que no, resaltando la complejidad de la herramienta y los campos que han de completarse:

[33] 10.12 EM_41_M_Me parece una herramienta interesante; quizás sea un poco complicada para compartir recursos debido a la gran cantidad de información que se ha de rellenar. Por otro lado me parece que los campos que hay que rellenar debiesen tener una ayuda.

3) En relación con el punto anterior, poder ver las producciones de otros usuarios permite inspirar a los docentes en la elaboración de sus propios recursos, contrastar lo que ellos hacen en su labor docente con el trabajo de otros.

[21] Adjetivo: Profesional "puede ayudar a la labor de los docentes"

[21] Adjetivo: Inspirador "Te inspira a pensar qué puedes hacer"

[21] Adjetivo: Inspirador "Me ofrece visualizar otros recursos que podría no haber planeado buscar, por lo que resulta inspirador"

[21] Adjetivo: Estimulante "Los pensamientos de otros permiten estimular los tuyos" 
[21] Adjetivo: Significativo "Es emocionante tomar ideas de otras personas" [33] 8.18. FP_29_M Compartir con otros usuarios que tienen intereses en común puede ser muy interesante para la construcción del conocimiento.

4) El portal aúna contenidos digitales dispersos en la red de varias áreas de formación, y además, lo hace a nivel europeo, dando cabida a múltiples visiones culturales y lingüísticas, cualidad que enriquece el portal.

[21] Adjetivo: Atractivo "Solventa el problema profesional de los contenidos dispersos, los aúna"

[33] 19.10. FP_46_M_Permite enlazar recursos de fuentes muy diversas.

[21] Adjetivo: Valioso "Esto será enormemente valioso para muchos educadores de toda Europa"

[21] Adjetivo: Deseable "Fue una herramienta que no conocía, estaba esperando algo que me permitiera buscar documentos y recursos destinados exclusivamente al sector de la educación. Creo que puede ser una herramienta indispensable para evitar la dispersión de los conocimientos que se producen a diario por profesionales de la educación"

[33] 13.11. EM_49_M_Creo que es un proyecto ambicioso por abarcar todos los niveles y ámbitos educativos, pero por ello, muy interesante.

[33] 19.1. SF_34_F_Poder acceder a información tanto nacional como de otros países y muy específica es una ventaja.

[33] 19.8. SF_38_M_El carácter europeo y la facilidad de uso son ventajas del portal.

[33] 19.18. FP_29_M_Centralizar los recursos y federar los repositorios acompañados de descripciones y la creación de etiquetas sería uno de los puntos fuertes más destacables de Share.TEC.

[33] 5.18. FP_29_M_Considero muy interesante que se puedan centralizarse los recursos y los repositorios, mediante este proyecto se podría lograr este objetivo.

[44] 26.4.29_F_ING_La posibilidad de encontrar recursos específicos a nivel europeo de formación del profesorado

5) Posibilita el acceso inmediato a los contenidos digitales con sus descripciones de metadatos pedagógicos. Además, los contenidos iniciales disponibles en el portal fueron filtrados por los miembros del proyecto, lo que hace que algunos usuarios resalten que el portal tiene el potencial de ahorrar tiempo en sus búsquedas, además de ofertar búsquedas de mayor calidad, ya filtradas por personas de la comunidad. 
[21] Adjetivo: Calidad alta "El principio de "calidad", en la indexación y la fabricación de materiales y el contenido seleccionado por el personal manifiesta intenciones claras [...]"

[21] Adjetivo: Ahorra Tiempo "Con suerte, si se desarrolla, puede ahorrar mucho tiempo [...]"

[Anexo 29] 31\% de los usuarios afirman que Share.TEC podría ahorrarles tiempo

[33] 19.4. EM_27_F_El poder encontrar los recursos que necesitas rápidamente, sin tener que dedicarle mucho tiempo.

[33] 19.16. FP_57_M_Que los contenidos que se presentan tienen una selección y una garantía de calidad.

[33] 5.19. FP_46_M_Es interesante para localizar recursos etiquetados pedagógicamente

[44] 26.11.33_F_FP_Que están seleccionados por una Comunidad de Práctica.

6) Permite el acceso y compartición de contenidos digitales, visualizar y etiquetar pedagógicamente los contenidos, y aportar los propios recursos.

[33] 19.20 FP_45_F_Las ventajas son la organización de los recursos y la posibilidad de compartir

[33] 19.19. FP_46_M_una búsqueda sobre recursos pedagógicos; la posibilidad de mejorar el etiquetado (ventajas).

[44] 26.9. 31_M_FP_Ofrece descripciones detalladas y te permite hacer búsquedas dirigidas

7) Potencia la cultura de la colaboración entre los formadores de profesores.

[44] 29.10. 54_M_FP_interesante. Es una buena iniciativa que permite compartir y promover una cultura profesional diferente, más colaborativa.

[33] 19.24. FP_51_F_El enfoque colaborativo. La posibilidad de vincular nuevos repositorios y crear una gran masa de información. Posibilidad de buscar los recursos, añadir valoraciones y propuestas de uso."

8) Algunos usuarios destacan la originalidad y valía del portal (utilidad, organización y rapidez)

[21] Adjetivo: Original "Nunca había utilizado un portal tan sofisticado"

[33] 19.17. FP_36_M_Ser un sitio único de referencia para la búsqueda y el compartir recursos 
En general, los 67 usuarios de los diferentes países que realizaron la prueba de evaluación de los adjetivos [21] opinan que el sistema es útil (64,38\% de adjetivos positivos frente a $35,62 \%$ negativos) y eficiente $(62,41 \%$ de votos positivos frente a $37,59 \%$ ). La mayoría de los usuarios consideran que la apariencia del portal es susceptible de ser mejorada, de acuerdo a los adjetivos negativos que fueron utilizados para describirla $(55,61 \%$ adjetivos negativos, frente a $44,39 \%$ adjetivos positivos).

Otros adjetivos positivos seleccionados por los informantes (19 sujetos) del cuestionario [44] $]^{133}$ fueron:

- Colores agradables (13; 1 usuario seleccionó colores feos);

- Sistema organizado (12; 2 seleccionaron sistema desorganizado-)

- Rápido (11; ninguno consideró que el sistema fuera lento)

- Útil (11; 1 usuario seleccionó sistema inútil)

- Colaborativo (11).

Otros adjetivos también fueron seleccionados por casi la mitad de los usuarios:

- (9/19): Intuitivo (9 sujetos) -versus enredoso (6)-, lo que nos indica que no hay una tendencia clara, sino que para unos usuarios era de un modo u otro;

- Fácil de usar (9/(19) -versus difícil de usar (4 usuarios)-. Estos datos nos indican que el sistema era considerado fácil de usar para más informantes que los que indicaron que les resultaba difícil (aunque no debemos obviar que no es fácil para todos).

El adjetivo "Creativo" es mencionado únicamente por 1 informante.

Además, en la prueba [33], los informantes validan la utilidad del portal en la siguiente pregunta:

133 En el cuestionario [44] se mostró una selección de los adjetivos que habían sido elegidos con más frecuencia por los usuarios en la prueba [21], contribuyendo con el opuesto de cada uno de los más frecuentes, obteniendo un total de 26 adjetivos. Entre los 26 posibles adjetivos a elegir, los sujetos podian seleccionar todos aquellos que consideraran que se ajustaban a su opinión sobre el sistema Share.TEC. 
Tabla 12 Prueba [33] Puntúa el portal del 1 al 5 como recurso para acceder a los contenidos digitales para la formación del profesorado

\begin{tabular}{lll}
\hline Utilidad & $\mathrm{N}=26$ & $\%$ \\
\hline 1 -Ninguna utilidad & 0 & $0 \%$ \\
2- Poca Utilidad & 3 & $12 \%$ \\
3- Utilidad aceptable & 5 & $19 \%$ \\
4- Bastante utilidad & 15 & $58 \%$ \\
5- Una gran utilidad & 3 & $12 \%$ \\
\hline
\end{tabular}

Podemos ver que para la mayoría de los informantes el portal ofrece bastante utilidad; ninguno de los ellos consideró que el portal no fuera de utilidad, aunque para 3 personas tenía poca.

Las principales dificultades/retos pedagógicos hacen referencia a los siguientes aspectos:

1) La complejidad de la gestión y del control del contenido del portal.

[21] Adjetivo: Básico "Es un portal que aúna recursos educativos. El problema es cómo se asegurará la calidad de los recursos, ¿habrá una revisión de ellos?"

Los recursos, actualmente, son revisados por uno de los miembros de NIS-SU, pero desde que se sube el recurso hasta que aparece en el portal puede pasar tiempo (hasta que acepta su inclusión). Además, la persona encargada de gestionar el sistema carece de competencias en algunos de los idiomas en los que se podrían incorporar recursos (por lo que no es capaz de valorar su adecuación). Este proyecto es actualmente mantenido por voluntad del socio NIS-SU.

[21] Adjetivo: Calidad alta "[...] Creo que el riesgo puede recaer en la gestión de la cantidad de datos que con el tiempo será un problema a resolver"

2) La interfaz de usuario es poco deseable para los usuarios potenciales. Es una plataforma demasiado rígida dividida innecesariamente en tres partes diseccionadas por completo, que restringen su usabilidad.

[33] 5.21. FP_48_F_Encuentro la plataforma muy rígida y poco flexible [33] 27.9 FP_31_M_Es hermético y cuadriculado. Yo quiero buscar recursos y también compartiré recursos, pero principalmente quiero una plataforma para VER recursos, así que juntaría los tres verbos en uno que se llamara Share.TEC y ofreciera un sistema de búsqueda de recursos. Página principal. Lo del botón USAR podría ir ahí, donde se ve una única vez cual es el más 
popular y el más visitado y si te interesa bien, sino pasa a hacer tu búsqueda. Lo de subir recursos es algo circunstancial, lo más importante es que se compartan fácilmente y se puedan acceder, por lo que subir un recurso podría estar en una de las opciones. Hay que tener en cuenta que Acceder está demasiado "Googlelizado. Cuando entro en Share.TEC podría interesarme ver quién ha accedido a mis recursos, cuántas veces ha sido visto, y cosas así. Recursos recomendados.

En el apartado B.3 de este capítulo se especifica de forma más detallada la opinión de los usuarios sobre la interfaz de Share.TEC.

3) Es un portal demasiado técnico, no está pensado por formadores de profesores, y requiere un aprendizaje inicial por parte de los usuarios para comprender su estructura y funcionamiento, aspecto que puede limitar el uso del portal.

[21] Adjetivo: Demasiado técnico "Muy técnico a la hora de encontrar los recursos"

[33] 27.3. FP_47_M_requiere una formación pedagógica $y$, al tener que generar un etiquetado tan sofisticado, puede hacer poco deseable utilizarlo.

4) Las búsquedas dificultan el uso del portal, debido a que no está muy bien desarrollado el motor de búsqueda, y ante conceptos similares, pero no exactos, se obtienen diferentes resultados (falta indexación de los conceptos).

[21] Adjetivo: Confuso "Yo no sé cuándo utilizar un término y cuándo utilizar otro. Me pierdo"

[21] Adjetivo: Inquietante "El buscador tiene defectos, y encuentras resultados diferentes en función de la combinación o no de palabras clave"

En el apartado B.1 se ampliará la opinión de los usuarios sobre las búsquedas en el portal.

5) No presenta los contenidos de forma multimodal. El portal es eminentemente textual, siendo requerida por los usuarios la presencia de imágenes y de sonidos, además de texto.

[21] Adjetivo: Estéril "No ofrece la información de forma multimodal. Me hubiera gustado que hubiese más imágenes en miniatura, más color. Tampoco había ningún sonido"

En el apartado B.3 se expondrá de forma más detallada cómo se presentan los contenidos a nivel visual en la plataforma. 
6) Los buscadores genéricos ofrecen mejores búsquedas que el portal en su estado actual. En su estado actual, no aporta un gran valor a otros portales existentes.

[33] 10.14. FP_54_M_Es bastante útil, pero se consiguen resultados similares con herramientas ya establecidas y muy completas como los buscadores específicos.

[33] 10.25. ES_43_M_No aporta prácticamente nada a otros recursos existentes.

[33] 26.5. EM_24_F_No creo que tenga ventajas específicas, sino que lo considero igual de útil que otros para obtener contenidos didácticos.

[33] 20.14. FP_54_M_El número de registros no es comparable al de buscadores como Google Scholar u otros similares

[21] Adjetivo: Ahorra Tiempo "[...] Actualmente se percibe que Google es más simple y eficaz"

7) El portal tiene gran potencial, pero hay ausencia de usuarios activos, recursos, anotaciones y comentarios de uso sobre ellos.

[33] 12.4. 29_F_ING_Aunque ofrezca información sobre las votaciones, muy pocos recursos disponen de tal información y casi ninguno la ofrece con un número considerable de votos (la mayoría tiene 1 voto). - Los datos ofrecidos no van mucho más allá de los que se pueden encontrar en cualquier repositorio bibliográfico. - Se echa en falta algún dato sobre cómo usar/cómo se ha usado o para qué ha sido creado el recurso

[33] 27.4.29_F_ING_La falta de anotación de los recursos. Su utilidad sería mucho mayor si estuvieran mejor descritos.

[33] 27.5. EM_24_F_ Si hay algún inconveniente es el inevitable, al ser novedoso, le faltan algunas matizaciones y mejoras, y más contenidos, pero con el tiempo se podrá mejorar fácilmente.

[33] 10.3. EM_26_M_El potencial es tremendo porque está en sus inicios, pero ese es su principal problema, que hasta que no despegue de manera estable mucha gente no colaborara.

[44] 26.16.45_M_FP_Si mucha gente sube sus recursos puede ser un sistema interesante para los profesionales de la educación dado que es un sistema específico para ello y evita tener que buscar por toda la red.

[44] 29.2.27_M_ING_Me ha parecido una buena iniciativa y estoy seguro de que será muy útil si se consigue que una comunidad de educadores lo utilicen de manera habitual. Lo difícil será conseguir dicha comunidad.

8) La personalización del portal es limitada, no se da acceso a datos estadísticos básicos sobre el uso del portal. Este elemento de control de la interacción podría ser de 
gran motivación para los usuarios, pues podrían ver quién ha consultado/descargado sus recursos, ponerse en contacto con usuarios interesados en el tema, etc.

[21] Adjetivo: Personalizable "En términos de gráficos pareció un poco frío, sé que no es un requisito importante... pero en mi opinión, el impacto visual tiene mucho valor"

10) La generalidad del portal lo convierte en un proyecto muy interesante, pero a la vez, muy ambicioso, pues involucrar a comunidades diversas incrementa su dificultad.

[33] 13.11. EM_49_M_Creo que es un proyecto ambicioso por abarcar todos los niveles y ámbitos educativos, pero por ello, muy interesante.

[33] 8.23. FP_27_F_Creo que todavía existen bastantes fallos técnicos como para que el sistema en general me parezca fiable. La idea que hay detrás del repositorio me parece muy interesante, es decir, que los usuarios puedan comentar y votar los recursos me parece que marca la diferencia respecto a otros buscadores existentes, sin embargo creo que habría que mejorar la estabilidad del sistema

\section{A.7 ¿Es necesaria la existencia de un sistema similar a Share.TEC?}

Algunos usuarios consideran muy oportuna la existencia de un sistema similar a Share.TEC, como lugar de congregación de contenidos digitales específicos para la formación del profesorado, así como espacio de encuentro e intercambio entre la comunidad. Existen muchos repositorios de contenidos digitales, comunidades de práctica dispersas, etc., pero ninguna que ofrezca, potencialmente, tantos servicios específicos para la formación del profesorado.

[33] 10.1. SF_34_F_ Contar con una red de profesorado multidisciplinar puede favorecer la creación de recursos diversos para el uso compartido.

[33] 10.9. SF_38_M_ Me parece una muy buena idea el poder compartir y utilizar recursos, categorizados y revisados por otra gente que tiene unos interés similares a los míos.

[44] 29.14. 36_F_FP_Creo que es un buen portal y necesario, porque no hay muchos de este tipo y creo que si empezamos a utilizarlos y a subir recursos podría ser muy útil

[33] 10.6. SF_39_F_Es de gran utilidad poder tener un foco común de información, documentación e intereses que se retroalimente continuamente con profesionales de tu campo de trabajo 
[Anexo 29] El acceso a los contenidos digitales en la educación del siglo XXI es un asunto principal(Pregunta: ¿Compartirías tus contenidos digitales en Share.TEC?)

Un porcentaje amplio de los usuarios que respondieron a las pruebas [33] y [44] dicen que recomendarán a sus compañeros de trabajo el portal Share.TEC.

44) La percepción general sobre el sistema está bien definida por el hecho de que el $85 \%$ (39 personas) de los usuarios, sugeriría Share.TEC a sus compañeros de trabajo.

Pregunta 12 de la prueba [33]: ¿Sugerirías a tus compañeros suscribirse al Portal Share.TEC? Sí, 23 (88\%); no 3 (12\%)

Otros usuarios son escépticos en la utilización de este tipo de sistemas, debido a la falta de tiempo de los miembros de la comunidad para compartir y etiquetar contenidos digitales, y a la existencia de múltiples servicios automáticos personalizables que pueden satisfacer en cierto modo de forma rápida sus necesidades, tales como buscadores genéricos (e.g., Google) o aplicaciones que permiten la captación automática de contenido personalizado mediante servicios de Web Semántica.

[33] 20.14.FP_54_M_Que el número de registros no es comparable al de buscadores como Google Scholar u otros similares

[33] 13.16. FP_57_M_De gran importancia y aunque ya lo hacemos, se puede sistematizar o estructurar

\section{A.8 ¿Cómo ha sido utilizado el portal Share.TEC?}

En este apartado diferenciamos dos fases sobre la utilización del portal. Una primera fase, cuando el proyecto aún estaba vigente, desde el inicio del registro de datos de uso en Google Analytics (17/12/2010 hasta un mes después de su finalización 01/07/2011); y una segunda fase desde el 2/07/2011 hasta la actualidad, 02/12/2015.

En la primera fase el portal Share.TEC fue utilizado principalmente para realizar pruebas con usuarios de diferentes países, coincidiendo los picos de actividad con las fechas en las que se desarrollaron pruebas, como apreciamos en el Gráfico 7.

Vemos en el gráfico de área (véase Gráfico 7) que el número máximo de visitas alcanzado por día es de 211 (el 7 de Junio de 2011). Hay que tener en cuenta que durante estas fechas los miembros del proyecto llevamos a cabo muchas de estas 
sesiones (pues necesitábamos explorar el portal para incorporar mejoras y para generar y llevar a cabo las pruebas piloto del portal). El número total de sesiones abiertas durante el transcurso proyecto fue de 14.015, llevadas a cabo por 11.137 usuarios (por tanto el $79,46 \%$ fueron usuarios nuevos). Cada usuario visualizó una media de 6.14 páginas por sesión, y la duración media fue de 4:33 minutos. El $46,06 \%$ de las visitas únicamente accedieron solo a una página y posteriormente salieron del portal (luego apenas existió interacción).

Por tanto, estas estadísticas registran que la mayoría de los usuarios que acceden al portal son usuarios nuevos (al menos, acceden desde diferentes IPS).

Gráfico 7 Sesiones de Share.TEC durante el proyecto (17/12/2010 - 01/07/2015)

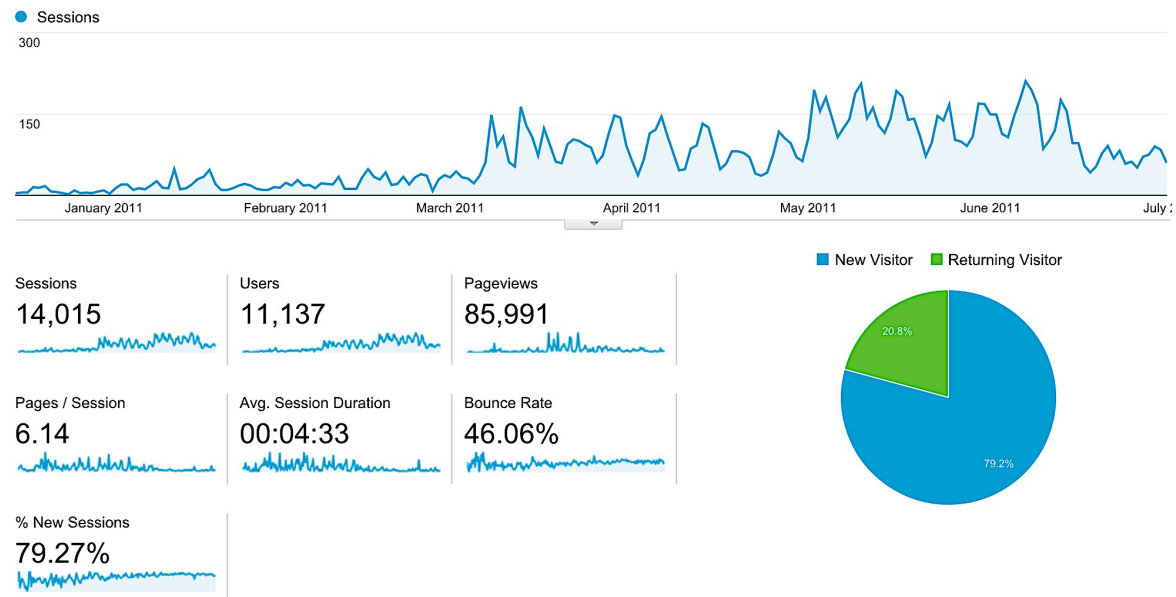

Las actividades de difusión del proyecto impulsaron su uso.

Dentro de las tareas del proyecto, en el paquete de trabajo de Diseminación, se plantearon diversas actividades locales desarrolladas por cada grupo perteneciente al consorcio, en el que además de probar el portal, se pretendía difundir el proyecto. El consorcio de Share.TEC planteó tres niveles de acción para dar a conocer el proyecto (Anexo 29 y Anexo 22):

- Nivel 1: Redes profesionales vinculadas con la formación del profesorado

- Nivel 2: Universidades, Departamentos Universitarios y Escuelas de profesionalización de Educación Superior

- Nivel 3: Redes de profesores y formadores de profesores activas 
Entre las actividades que propiciaron el conocimiento de Share.TEC, y el consiguiente incremento de su uso, encontramos la difusión del proyecto en 60 conferencias nacionales e internacionales, 48 workshops locales, 31 artículos científicos. Además, el sistema Share.TEC fue referenciado y utilizado en 9 cursos universitarios. A partir de estas actividades se estableció una vinculación del proyecto con 20 universidades e Instituciones de Educación Superior, 19 agencias públicas, oficinas y servicios educativos, 18 redes de profesores y asociaciones, 15 proyectos y programas, 5 espacios escolares, 4 publicadores, 2 bibliotecas, 1 asociación privada y 1 asociación de otro tipo (Share.TEC Consortium, 2011).

Los países desde los que más usuarios accedieron fueron, en general, aquellos que mayor vinculación tienen con el portal (Italia y Bulgaria), y desde los países de procedencia de otros miembros del consorcio (exceptuando Alemania y EEUU).

Durante las fechas de duración del proyecto (desde que tenemos registros de Google Analytics, 17 de diciembre de 2010), los países que más sesiones abrieron fueron aquellos que representaban los miembros del consorcio (Tabla 13). El país que contemplaba más sesiones abiertas fue Bulgaria, país de los miembros de NISSU (los principales responsables de la creación y mantenimiento del portal, que además han llevado y siguen llevando acabo experiencias con usuarios), con un $32,90 \%$ del total de visitas; seguido por Italia (que contaba con tres miembros del consorcio procedentes de este país, y uno de ellos era el grupo líder del proyecto) con un $27.40 \%$. La actividad de estos dos países supone más de la mitad de las sesiones abiertas en el portal. El resto de países de los miembros del consorcio también aparecen representados entre los 10 más frecuentes (Suecia, Holanda, España, Reino Unido y Bélgica, aunque con porcentajes menores a los mencionados anteriormente). En esta lista también aparecen países como EEUU y Alemania. En la última fila apreciamos "non set", es decir, no especificado, pues el sistema no ha sido capaz de detectar el origen de estas visitas. El resto de países supuso menos del $1 \%$ de las visitas según los datos consultados en Google Analytics.

En cuanto a la intensidad de uso del portal, España fue el país con una duración media de visita mayor entre los países de la tabla (4:30 minutos), seguido por Bulgaria (2:56). Vemos que el resto de visitas fueron más breves. Los usuarios, en promedio, realizaron visitas cortas al portal. En la media de páginas por sesión España presentó 5,98 de media, seguida de nuevo por Bulgaria (3.77), siendo las siguientes 2.35 (Suecia) y 2.33 (Italia). De nuevo, España y Bulgaria presentaron el 
menor índice de abandono del portal en la página tras la primera visita (como apreciamos en la última columna de la Tabla 13).

Tabla 13 [Google Analytics]. Estadísticas sobre las sesiones abiertas en el portal Share.TEC por países (sólo los 10 con mayor número de sesiones).

\begin{tabular}{|c|c|c|c|c|c|c|c|}
\hline & & $\begin{array}{l}\text { Total } \\
\text { sesiones }\end{array}$ & $\begin{array}{l}\% \text { de } \\
\text { sesiones }\end{array}$ & $\begin{array}{l}\text { Páginas/ } \\
\text { sesión }\end{array}$ & $\begin{array}{l}\text { Duración } \\
\text { media/ } \\
\text { sesión }\end{array}$ & $\begin{array}{l}\% \text { Nuevas } \\
\text { sesiones }\end{array}$ & $\begin{array}{l}\text { Visitas de } \\
1 \text { sola } \\
\text { página }\end{array}$ \\
\hline 1 & Bulgaria & 22143 & $32.90 \%$ & 3.77 & $00: 02: 56$ & $82.87 \%$ & $46.39 \%$ \\
\hline 2 & Italy & 18442 & $27.40 \%$ & 2.35 & 00:01:33 & $89.43 \%$ & $57.22 \%$ \\
\hline 3 & Sweden & 4905 & $7.29 \%$ & 2.33 & 00:01:24 & $89.52 \%$ & $62.65 \%$ \\
\hline 4 & Netherlands & 3085 & $4.58 \%$ & 1.99 & 00:01:00 & $92.74 \%$ & $60.00 \%$ \\
\hline 5 & United & 2868 & $4.26 \%$ & 1.43 & 00:00:31 & $95.85 \%$ & $66.56 \%$ \\
\hline 6 & Spain & 1922 & $2.86 \%$ & 5.98 & 00:04:30 & $79.71 \%$ & $38.29 \%$ \\
\hline 7 & United & 1900 & $2.82 \%$ & 1.48 & 00:00:56 & $93.89 \%$ & $55.58 \%$ \\
\hline 8 & Germany & 1460 & $2.17 \%$ & 1.42 & 00:00:45 & $90.62 \%$ & $63.01 \%$ \\
\hline 9 & Belgium & 815 & $1.21 \%$ & 2.67 & 00:02:03 & $88.71 \%$ & $60.12 \%$ \\
\hline 10 & (not set) & 636 & $0.94 \%$ & 1.58 & 00:00:59 & $89.94 \%$ & $66.67 \%$ \\
\hline
\end{tabular}

Los países con mayor número de sesiones activas tras la finalización del proyecto no difieren en gran medida de los que encontramos en la tabla anterior, como podemos apreciar en el siguiente Gráfico 8 . Mostramos en las barras rojas los porcentajes de sesiones de cada país sobre el total en la fase del proyecto; en azul, los datos relativos a la fase posterior al proyecto hasta la actualidad, y en gris, la media a lo largo de todo el periodo.

Bulgaria fue el país más activo (por los motivos recién expuestos), y en proporción total fue más utilizado en la fase del proyecto que en la fase final (también el portal era menos conocido por la comunidad, y no había tantos intentos de acceso desde servidores de múltiples países). El siguiente país más activo fue Italia, que incrementó su uso en la fase posterior al proyecto. A este, le sigue Suecia 
(el equipo sueco, entre otras funciones, se encargó de generar los productos de marketing y la página web del proyecto -no el portal-). Los países que mostraron un mayor número de sesiones durante la fase del proyecto fueron Bulgaria, Suecia, España (tres de los países que más pruebas realizaron con los usuarios) y Australia. El resto de países han incrementado el número de accesos desde la finalización del proyecto (Italia, Holanda, Reino Unido, Bélgica, Estados Unidos, México, Alemania y el promedio del resto de países). Estados Unidos, México y Alemania no tenían miembros representantes en el consorcio de Share.TEC, pero gracias a la difusión del portal en diversos foros y webs, se ha permitido la expansión de su uso. 
Gráfico 8 Porcentaje de sesiones en Share.TEC, por fases del proyecto y países. Datos de Google Analytics.

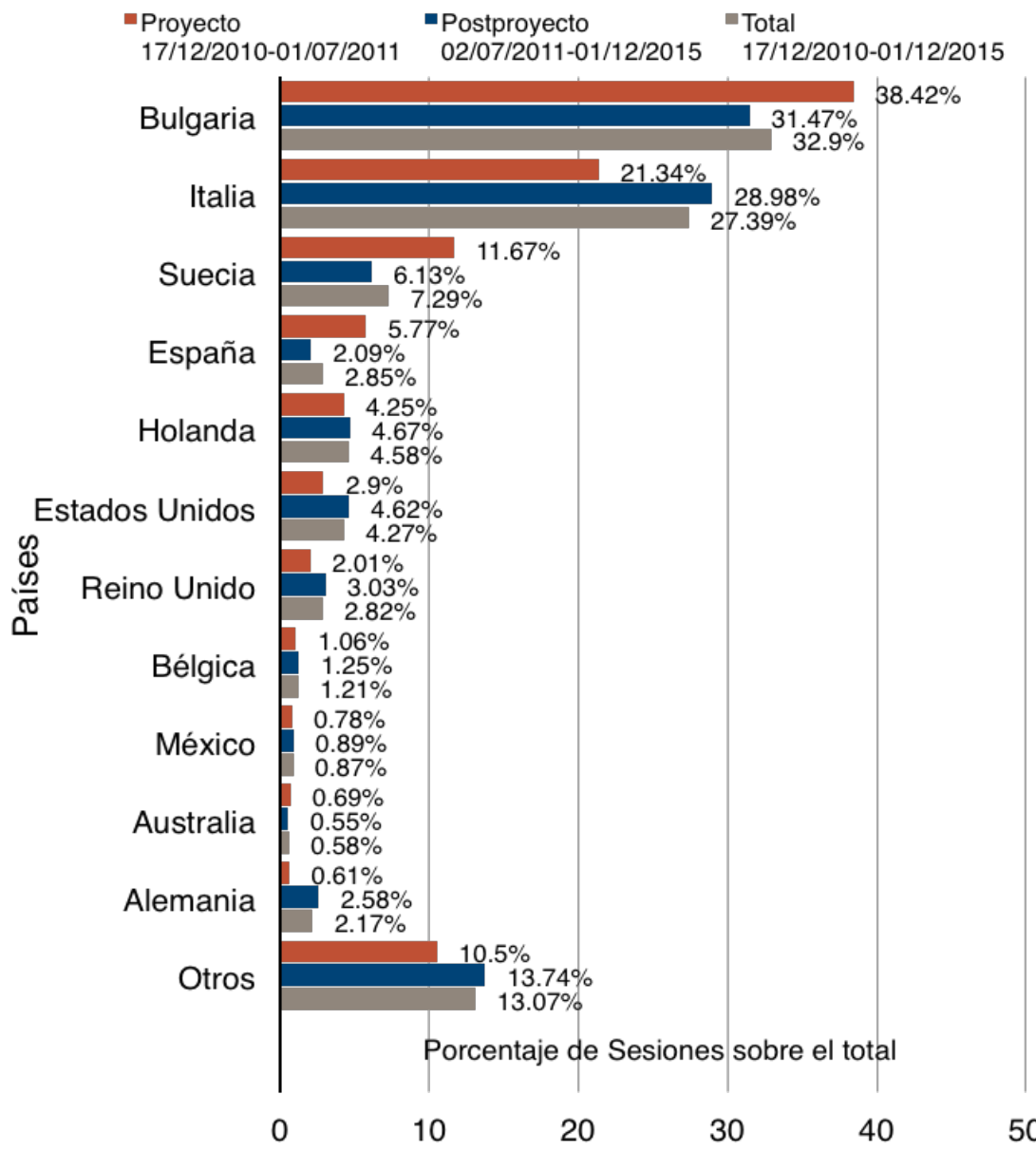

En la Tabla 14 podemos apreciar que durante la fase de proyecto se consultaban más páginas por sesión y con una mayor duración.

Comparando los datos recogidos por Google Analytics durante las fechas del proyecto, y los recogidos tras su finalización, apreciamos un cambio relevante en el número promedio de páginas por sesión (descendiendo de 6.14 visitas a páginas/sesión en la fase del proyecto; y 2.74 en la fase postproyecto). Las sesiones decrecen de 273 segundos de media a 117. El porcentaje de sesiones 
nuevas incrementa, del $79.22 \%$ en la fase proyecto al $87.63 \%$. Este dato es importante, pues la mayoría de las sesiones son nuevas (no de los mismos usuarios). Existe un incremento, también, del número de visitas de 1 sola página al portal (del $46.06 \%$ al $54.54 \%$ ).

Tabla 14 [Google Analytics]. Estadísticas sobre las sesiones abiertas en el portal en la fase del proyecto vs. en la fase posterior al proyecto

\begin{tabular}{llllll}
\hline & $\begin{array}{l}\text { N total } \\
\text { Sesiones }\end{array}$ & $\begin{array}{l}\text { Páginas } \\
\text { /sesión }\end{array}$ & Segundos & $\begin{array}{l}\text { Nuevas } \\
\text { sesiones \% }\end{array}$ & $\begin{array}{l}\text { \% Visitas 1 } \\
\text { sola página }\end{array}$ \\
\hline $\begin{array}{l}\text { Fase del } \\
\text { proyecto }\end{array}$ & 14015 & 6.14 & 273 & 79,22 & $46.06 \%$ \\
$\begin{array}{l}\text { Fase } \\
\text { postproyecto }\end{array}$ & 67373 & 2.74 & 117 & 87,63 & $54.54 \%$ \\
\hline
\end{tabular}

La fase post proyecto inicia con un periodo de inactividad y posteriormente aparece una reactivación del uso del portal.

En una visión general de los datos de Google Analytics (Gráfico 9) desde que tenemos registros de uso del portal, apreciamos que desde el 1 de Julio de 2013 hasta el 1 de enero de 2015, apenas ha existido actividad en el portal. Desde el 1 de enero de 2015 se percibe una reactivación en la actividad. A través de la exploración de los países con más actividad durante la última etapa, vemos que Bulgaria e Italia son los países con mayor número de sesiones activas; además, en el portal Share.TEC detectamos la inclusión de nuevos recursos en estas dos lenguas.

En la línea de color azul claro del Gráfico 9 se representa el número de visitas de una sola página realizadas en el portal; el porcentaje medio de abandono del portal tras la primera página es de $54,54 \%$, y las páginas vistas por sesión 2,74.

En esta fase postproyecto encontramos accesos con duraciones de 00:00 segundos y de poca duración.

Encontramos un dato curioso, y es que en 22 países se registran sesiones de una duración de 0 segundos, y en 102 países menores a 1 segundo. Desconocemos con certeza el dato, pero creemos que existen accesos automáticos al portal desde ciertos servidores. Además, desconocemos los motivos del acceso: intento de phising, intento de acceso para recuperar información y ofrecerla en otros portales, intento de acceso de usuarios, etc. 
Gráfico 9 Google Analytics desde 17/12/2010 (lanzamiento del portal) hasta 01/12/2015 (fecha final de recogida de datos para esta tesis).

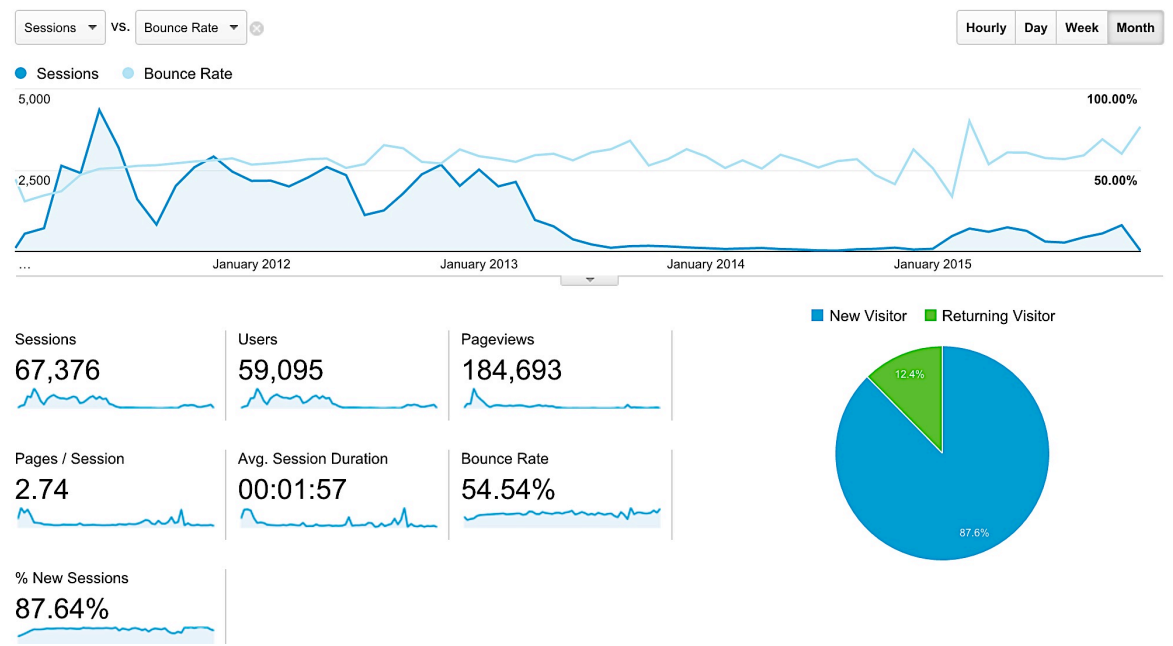

Involucrar a usuarios para la utilización de una plataforma es una tarea compleja. Este hecho ve incrementada su dificultad si no se puede "importar" directamente una comunidad existente o "exportar" el sistema a esta comunidad; y aún más si no existe un producto final sólido, consistente y útil, que aporte un valor añadido a las soluciones existentes.

[33] 5.24. FP_51_F_Una vez que se mejoren los sistemas de búsqueda y se añadan más recursos podrá ser muy útil. Y me gustará participar

[33] 10.21. FP_48_F "Quizás se deba a la poca cantidad de recursos introducidos y a la falta de usabilidad de la plataforma"

[33] 20.14. FP_54_M Desventaja de Share.TEC: "el número de registros no es comparable al de buscadores como Google Scholar u otros similares"

[33] 10.3. EM_26_M_El potencial es tremendo porque está en sus inicios, pero ese es su principal problema, que hasta que no despegue de manera estable mucha gente no colaborara

Durante el desarrollo del proyecto, se preguntó a los usuarios sobre su intencionalidad de uso del portal Share.TEC. En la prueba [33], 20 usuarios comentaron que sí que lo usarían y 6 que no. 23 usuarios comentaron que subirían sus recursos y 3 que no. A pesar de estos datos referentes a su intención de uso, en realidad, los usuarios no han contribuido con contenidos digitales a la plataforma (como podemos ver en el Gráfico 10, el número de registros aportados por cada 
colección de Share.TEC, sólo existen 16 registros de metadatos aportados por los usuarios).

Gráfico 10 Número de registro de metadatos de contenidos digitales aportados por cada colección (miembros del consorcio, otros proveedores y usuarios)

- Numero de registros de metadados de contenidos digitales

40000

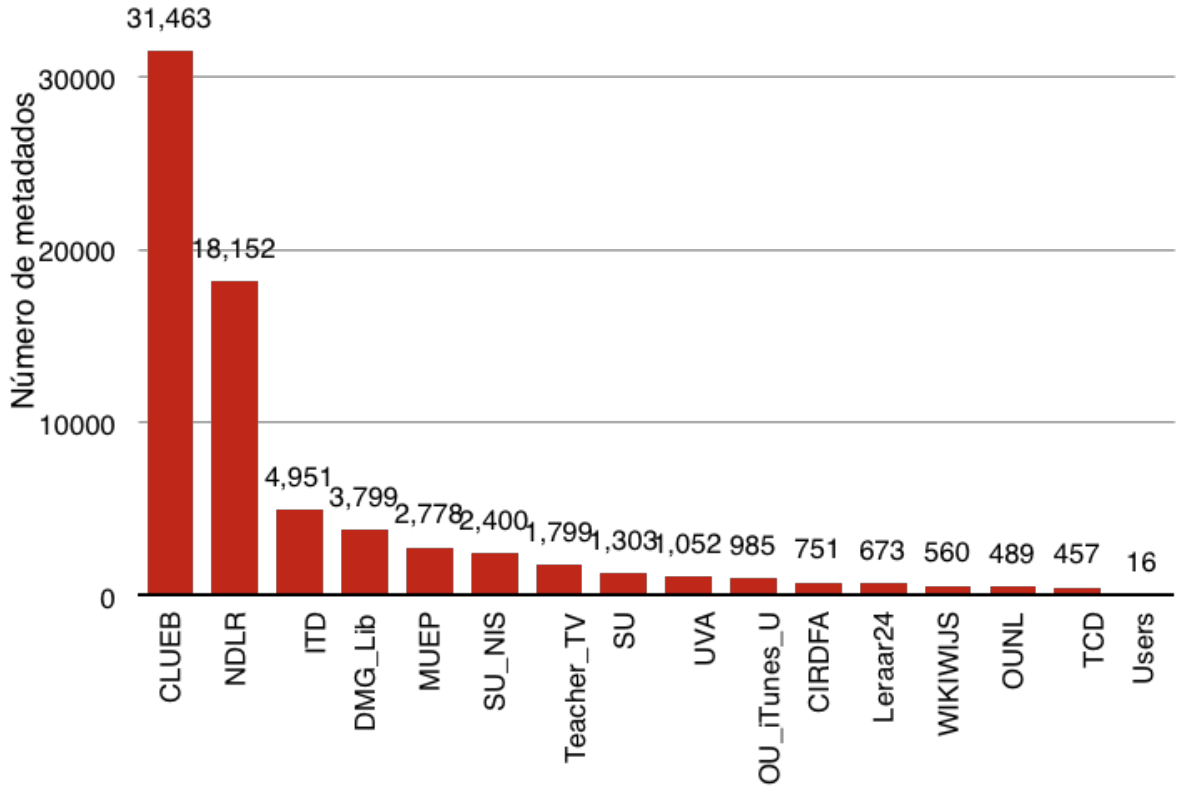

Colecciones

En otra de las pruebas [21], se preguntaba a los usuarios por los motivos cualitativos referentes a la intencionalidad de uso de la plataforma. En esta pregunta, los usuarios manifestaron la importancia de la calidad de la interfaz y del motor de búsqueda de un sistema, así como la capacidad de personalización a los intereses particulares.

S19_FP_F_35_Si sus sistemas de búsqueda y sus términos se ajustan más a mis intereses, seguro que sí.

S20_FP_F_45_Tal vez, si mejora la forma de presentación. Hay demasiadas dificultades en la forma de realizar la búsqueda, con grandes diferencias si 
se utiliza la palabra de búsqueda en singular o en plural, no hace sugerencias para facilitar otros términos en el idioma de la búsqueda, y es poco "amigable". Parece difícil encontrar Sin embargo, cuando finalmente encuentra la fórmula adecuada de preguntar por la búsqueda parece ser bastante eficaz. Pero hasta que se llega a ello, es poco intuitiva y hay que reintentar la búsqueda varias veces para lograr encontrar resultados.

S17_FP_F_32_Si no mejora la interfaz creo que no. Me parece poco intuitiva.

\section{A.9 ¿Qué hábitos de acceso, uso, compartición y reutilización de contenidos digitales presentan los formadores que usaron Share.TEC?}

Consideramos que esta pregunta informativa consta de gran importancia para el conocimiento de las necesidades de los usuarios potenciales, con el objetivo de adaptar de forma eficaz los servicios destinados a la interacción de los usuarios interesados en el ámbito de la formación del profesorado con contenidos digitales y con su comunidad de interés. Con el fin de presentar la información de forma organizada para el lector, hemos dividido esta pregunta en tres secciones: 1) Hábitos de Acceso; 2) Hábitos de Compartición; 3) Hábitos de reutilización.

\section{1) Hábitos de Acceso}

\section{1.a) Idioma de búsqueda de los contenidos digitales}

Hoy en día la proliferación del aprendizaje de otras lenguas diferentes a la lengua materna es un hecho, no sólo para los niños y nuevos estudiantes, sino para los trabajadores de edad más avanzada. En el mundo académico, la lengua inglesa constituye el idioma de intercambio más expandido en la comunidad.

Esta reflexión se sustenta con el análisis de los datos cualitativos y cuantitativos obtenidos en las diferentes pruebas.

Para tratar los datos cuantitativos aplicamos test estadísticos específicos, por lo que nos es necesario plantear hipótesis para pode aceptar o rechazar diferencias entre los grupos que componen cada muestra.

En este caso, como apreciamos en la Tabla 15, aceptamos la hipótesis $\mathrm{H}_{0}$ que nos planteamos:

$H_{0}$ No Existen diferencias entre los países de procedencia y las preferencias de idioma que utilizan para la búsqueda de contenido digital. 
Tabla 15 Prueba [20]. Idioma de preferencia de búsqueda de contenidos digitales.

\begin{tabular}{llllll}
\hline \multirow{2}{*}[20]{ Primera encuesta coordinada. Nacionalidad } & \multicolumn{3}{l}{ Nacionalidad } & & \multirow{2}{*}{ Total } \\
\cline { 3 - 6 } & & Italia & Bulgaria & España & \\
\hline \multirow{2}{*}{ Idioma que utilizas para } & Lengua nativa & 16 & 4 & 15 & 35 \\
buscar objetos & Inglés & 7 & 8 & 5 & 20 \\
digitales, artículos, & Lengua nativa e inglés & 1 & 2 & 4 & 7 \\
páginas web & Cualquier lengua que conozco & 3 & 2 & 0 & 5 \\
& Lengua nativa y francés & 0 & 1 & 0 & 1 \\
\hline Total & & 27 & 17 & 24 & 68 \\
\hline
\end{tabular}

Apreciamos que no existen diferencias significativas entre las preferencias de búsqueda por nacionalidad, aunque no podemos aportar un valor estadístico chi fiable, ya que el $60 \%$ de las casillas cuenta con una frecuencia esperada menor a 5 , y más del $20 \%$ menor a 1).

La mayoría de los usuarios de los tres países utilizan su lengua nativa, seguida por el inglés. Un menor número de usuarios utiliza ambas, (nativa e inglés), o incluso cualquiera de las que tenga nociones. Solamente un búlgaro utiliza lengua nativa y francés (pues este idioma era más estudiado en Bulgaria que el inglés).

La mayor parte de los informantes españoles de la prueba [44] (19 personas) buscan contenidos digitales en español e inglés (17/19), y adicionalmente, utilizan lenguas próximas (portugués, francés, italiano). Sólo dos personas utilizan el español únicamente para realizar sus búsquedas (S7_27_F_Estudiante de Máster de Secundaria; S13_43_M_Profesor de Didáctica de la Expresión Corporal) (Tabla 16).

Tabla 16 Prueba [44]. Idiomas que utilizan para realizar búsquedas de contenidos digitales para la formación del profesorado.

Seleccione los idiomas que utiliza para buscar contenidos educativos digitales para la formación del profesorado

\begin{tabular}{lll}
\hline & Frecuencia & Porcentaje \\
\hline Español e Inglés & 8 & 42,11 \\
Español, Inglés, Portugués & 1 & 5,26 \\
Español, Inglés, Francés & 3 & 15,79 \\
Español, Inglés, Italiano, Portugués & 1 & 5,26 \\
Español, Inglés, Otros & 1 & 5,26 \\
Alemán, Español, Francés, Inglés & 1 & 5,26 \\
Español, Inglés, Italiano & 2 & 10,53 \\
Español & 2 & 10,53 \\
Total & 19 & 100,00 \\
\hline
\end{tabular}


Tampoco encontramos diferencias significativas en cuanto al idioma en el que escriben los términos para hacer búsquedas obteniendo resultados muy similares a la tabla anterior.

Por tanto, aquellos usuarios pertenecientes a un determinado país, tenderán a utilizar su propio idioma además de otros (inglés, francés, etc.) para acceder a contenidos digitales. En aquellos países en los que se hable un idioma poco frecuente en otras poblaciones, y con una población no muy elevada, como es el caso de Bulgaria, se tenderán a utilizar otros idiomas para ampliar las oportunidades de encontrar contenidos digitales. Cuando exista una cantidad amplia de contenidos digitales en la lengua nativa, es posible que la mayoría de los usuarios tiendan a utilizar primero estos, debido a la facilidad de la comprensión de los mismos. Con el paso del tiempo estas tendencias evolucionarán hacia otras formas, pues cada vez más, en todos los países europeos de habla no inglesa, hay mayor presencia de escuelas bilingües en inglés y español, fundamentalmente, aunque también están en auge otros idiomas (chino, francés, alemán, etc.)

[21] Escala: de 1 a 5, siendo 1 totalmente en desacuerdo y 5 totalmente de acuerdo. Pregunta: Cuando consulto recursos en motores de búsqueda, suelo ejecutar la búsqueda en otros idiomas. El resultado obtenido fue una $\mu$ (media) de 3,71, con una $\sigma$ (desviación típica) de 0,95.

En el mismo formato se preguntó a los profesores si les resulta molesto encontrar recursos en otros idiomas cuando realizan búsquedas [21], obteniendo una $\mu$ de 2,43 con una $\sigma$ de 1,13 . Esto significa que para la mayoría de los usuarios no es molesto ni agradable encontrarse contenidos en otros idiomas, pero hay a quienes sí puede resultarles molesto, y quienes agradecen poder ver contenidos en otros idiomas. Creemos que la causa para que los usuarios contestaran que les parecía molesto o poco agradable, era que era confusa la distinción entre el idioma del contenido digital en sí mismo, y el idioma de su etiquetado, además de que los usuarios tenían que aplicar un filtro a la búsqueda para evitar obtener resultados no deseados en Share.TEC, incluso aunque hubieran especificado su idioma de preferencia en su perfil. Este dato desvela que la capacidad de personalización de los sistemas es un hecho relevante a considerar.

[33] 10.10. FP_46_M_Resulta muy útil tener acceso a recursos utilizados en distintos países.

[33] Ventaja de Share.TEC: 19.1 SF_34_F_Poder acceder a información tanto nacional como de otros países y muy específica. 
[33] 10.13. EM_29_M_Debería mejorarse la traducción de los idiomas y que el portal fuera más sencillo de utilizar: no tantos campos, más rápida la subida de recursos...

La coexistencia de múltiples idiomas en una plataforma puede ser beneficiosa, pues existen más usuarios que pueden proporcionar comentarios y recursos al portal, así como aportar múltiples perspectivas; pero si la personalización del portal lingüística, en este caso, no está bien definida, puede ser un elemento incómodo.

Este hecho se visualizaba en mayor medida en el apartado Usar del portal Share.TEC (como mencionamos, el portal se distribuía en tres apartados: Acceder, Usar y Ofrecer) (ver llustración 16 del capítulo 3). Al entrar en esta sección, lo primero que veíamos era una interfaz en la que aparecía un listado de los últimos recursos sobre los que cualquier persona había realizado alguna actividad (comentar, visualizar, votar, etc.). Ya que el portal fue principalmente gestionado por NIS-SU, el equipo búlgaro del proyecto, muchos contenidos digitales aparecían en este idioma, hecho que era muy poco valorado por los usuarios de otros países, ya que no sólo no les aportaba nada, sino que además, constituía un elemento disonante:

[44] Sobre la sección usar. 14.9."31_M_Ing [...] Si la población que accede a Share.TEC está desequilibrada (entiéndase en término poblacional) significará que el número de publicaciones, comentarios y puntuaciones a recursos en Búlgaro -por ejemplo- serán las más visibles, pero también las más inútiles para mí. Ni siquiera hay filtro para quitar las que vienen en idiomas que no sé pronunciar [...]

[44] Sugerencia: 13.3.47_M_FP_quizá un filtrado por idioma, porque en todas las búsquedas tuve problemas con el idioma

\section{1.b) Actitudes hacia el registro en servicios de contenidos digitales}

Los formadores de profesores consideran el registro en los servicios como un elemento de confianza hacia el portal, ya que les aporta la sensación de tener cierto filtro como medida de seguridad para evitar SPAM.

Cuando el sitio les aporta cierta confianza, no les supone una barrera el hecho de tener que registrarse, siempre que tengan tiempo en el momento de consulta para hacerlo. 
[17] p8, Q_FP. yo depende de la confianza que me dé el recurso, lo mismo que " $R$ ". Si veo que es una cosa de andar por casa, pues no. También depende del tiempo que tengas en ese momento [...]

[17] p8, I_FP: P8 yo no sé por qué, pero tengo la sensación de que generalmente cuando hay un registro de por medio, me ofrece más confianza. [...] los sitios con recursos educativos más potentes... quiero decir, los que más servicios ofrecen, generalmente necesitas crearte una cuenta.

[17] p8, S_FP depende de la confianza que te dé el recurso.

Si no es así, es posible que algunos usuarios no se registren y no exploren el portal.

[17] p8, E_Ing. En mi caso es motivo de buscar otra página que no me lo exija

El hecho de ofrecer diferente nivel de servicios para usuarios registrados y no registrados, de acuerdo con las opiniones de los informantes, parece una buena solución, tanto para preservar la seguridad del contenido de portal como para fomentar el uso del mismo por un mayor número de usuarios.

\section{1.c) Factores de credibilidad de los materiales}

Los formadores de profesores consideran ciertos factores como avales de la calidad de un material, tales como:

\section{La Universidad o Institución de la que proviene la publicación}

[09]Q.P9 De todas maneras, hay veces que los prejuicios hacen perdernos cosas interesantes. $Y$ de hecho el único tema, es que a veces no venga avalado por una Universidad... que de todas maneras a veces no es un aval tal, es que te genera más tiempo a la hora de investigar si realmente te merece la pena detenerte en eso. Entonces yo creo que es muy importante que haya una información visual de parte del que publica... pues yo que sé... cuatro referencias, o un título sugerente, o un miniresumen de cabecera... o algo así.

La existencia de filtros para la subida de contenidos en el portal.

[33] 10.4. EM_27_F_Pienso que podría ser un portal muy útil siempre y cuando los contenidos que tuviera, o que se subieran, fueran buenos, es decir, si tuviera un filtro que no dejara subir cualquier tipo de contenido. 
Los filtros pueden incorporar datos educativos del material, incorporar una revisión de otros usuarios o de los administradores del portal, un sistema de puntuación de los mismos, de reporte a los administradores de contenido poco adecuado, etc., tal y como se desprende de los siguientes argumentos:

El nombre del autor y la puntuación que otros han realizado del recurso:

En el cuestionario [35] se preguntó a los educadores qué información consideraban relevante para entender la calidad de un recurso, en formato de multielección, pudiendo elegir entre tres opciones: nombre del autor, puntuación y anotaciones. La muestra estaba compuesta por 198 formadores de profesores de Italia (172), España (16) y Suecia (10). La muestra la integraban Profesores de Ed. Secundaria (137), Formadores de profesores (30); Profesores de Ed. Infantil y Primaria [17]; Especialistas (7) y Educadores de formación profesional y otros (7). Nos planteamos la siguiente hipótesis:

$\mathrm{H}_{0}$ No existen diferencias significativas entre el rol y la preferencia de un criterio u otro a la hora de comprender la calidad de los recursos.

Aceptamos $\mathrm{H}_{0}$ con un nivel de confianza del $95 \%$ tras aplicar un test de $\chi^{2}$. Los usuarios consideran que la información que les convence para entender la calidad de un recurso son la "Puntuación" y el "Nombre del autor", siendo las anotaciones menos votadas. Es interesante comparar estas opiniones con las referentes a los criterios que les aportarían confianza para seleccionar un recurso.

Tabla 17 Prueba [35]. Opinión de los informantes sobre la información relevante para entender la calidad de los recursos y para seleccionar recursos

\begin{tabular}{|c|c|c|c|}
\hline & Nombre del autor & Puntuación & Anotaciones \\
\hline \multicolumn{4}{|c|}{ Información relevante para entender la calidad de un recurso } \\
\hline Sí\% & $52,53 \%$ & $59,09 \%$ & $25,76 \%$ \\
\hline \multicolumn{4}{|c|}{ Información que te convencería para seleccionar un recurso } \\
\hline Sí\% & $40,91 \%$ & $29,80 \%$ & $10,10 \%$ \\
\hline
\end{tabular}

En la Tabla 17 puede observarse que estos tres criterios tienen más relevancia a la hora de entender la calidad de un recurso (especialmente nombre del autor y puntuación); en cambio, estos mismos criterios no son los que les guiarían a la hora de seleccionar un recurso (siendo elegidos por menos de la mitad de los usuarios):

[09] I. P9 Yo creo que con la afiliación y una dirección de contacto a mí me sobra. Más que nada, porque si tienes algún problema, es de agradecer cuando alguien incluye su dirección y directamente contactas con esa 
persona. Y la afiliación, por saber un poco el contexto. No es lo mismo un recurso creado en Suecia para la educación superior allí, que uno creado en Malabo, o sea, no es igual.

Los recursos elegidos por otros usuarios

Preguntamos a los usuarios sobre si les gustaría ver las selecciones realizadas por otros compañeros. Planteamos la hipótesis:

$H_{0}$ no existen diferencias entre los roles y la preferencia por ver o no las selecciones realizadas por sus compañeros.

Aceptamos la hipótesis de independencia entre esta variable y la variable rol (con valor 1,929, p-valor de 0,587 a un nivel de confianza del 95\%). Los usuarios que prefirieron en mayor porcentaje ver las selecciones de sus compañeros fueron los profesores de Educación Secundaria (73,84\% - 96/130), seguidos por los formadores de profesores (73,33\% -22/30 usuarios), Profesores de Educación Infantil y Primaria $(70,58 \% ; 12 / 17)$ y educadores de Formación Profesional y Otros $(54,54 \% \%-6 / 11)$. Por tanto, esta característica parece ser relevante para todos los profesionales de la educación de la muestra.

Por tanto, poder ver la selección de recursos que hacen otros compañeros de profesión es un elemento interesante para los formadores de cualquier nivel:

[21] Adjetivo: Ocurrente "La selección de otros maestros puede permitirme conocer los cánones de la selección funcional"

Los contenidos curriculares de educación infantil, primaria y secundaria están estandarizados en cada país en la mayoría de países europeos, por lo que a la luz de los datos nos parece coherente ver el alto porcentaje de profesores de estos niveles a los que les gustaría ver los recursos que seleccionan sus compañeros. Es de destacar el alto porcentaje de formadores de profesores a los que le parece interesante visualizar esta información (pues los planes de formación no están estandarizados, pero este dato revela que esta información constituye otro aval de calidad para los usuarios).

\section{1.d) Frecuencia de Acceso}

En general, no existen diferencias en cuanto al tipo de rol (formador de educación superior vs. profesor de educación secundaria / especialista) y la utilización de los 
diferentes tipos de contenidos digitales, exceptuando algunos casos que exponemos a continuación.

En la prueba [20], respondida por 61 sujetos pertenecientes a dos grupos (Formadores de Educación Superior; Profesores de Educación Secundaria y Especialistas), planteamos la siguiente hipótesis:

HO Los diferentes tipos de roles vinculados con la educación utilizan con la misma frecuencia los siguientes tipos de contenido digital:

Aplicamos un Alfa de Cronbach para comprobar la fiabilidad de la escala (diferentes tipos de formato de contenidos digitales): de 1 a 5.

Tabla 18 Prueba [20]. Fiabilidad de la escala frecuencia de uso del tipo educativo de contenido digital. Alfa de Cronbach.

\begin{tabular}{llll}
\hline & & $\mathrm{N}$ & $\%$ \\
\hline \multirow{3}{*}{ Casos } & Válidos & 46 & 66,7 \\
& Excluidos(a) & 23 & 33,3 \\
& Total & 69 & 100,0 \\
\hline
\end{tabular}

Estadísticos de fiabilidad: Alfa de Cronbach $^{134}: 0,958 ; n$ de elementos: $32 .{ }^{135}$

Determinamos que el valor es bastante próximo a 1 , por lo que consideramos que la escala es adecuada.

Tras la aplicación de un test de Chi-cuadrado $\left(\mathrm{X}^{2}\right)$ contrastamos las respuestas de cada grupo en cuanto a las preferencias de cada tipo de contenido digital.

Aceptamos HO para la mayoría de los casos analizados, es decir, que no existen diferencias entre las preferencias de Formadores de Educación Superior y profesores de Secundaria y otros profesionales respecto a la frecuencia de uso del tipo contenido digital

${ }^{134}$ El Alfa de Cronbach es un estadístico que cuanto más se acerca al valor 1, mayor es la fiabilidad de la escala. Los valores superiores a $0,7 \circ 0,8$, son suficientes para garantizar la fiabilidad de la escala.

135 Para contrastar las respuestas de cada grupo en cuanto a las preferencias de cada tipo de contenido digital, valoramos la aplicación del test ANOVA de un factor, pero lo rechazamos por el incumplimiento de uno de los criterios fundamentales para la utilización de esta prueba (normalidad de la distribución). En cambio, aplicamos un test de Chicuadrado ( $\mathrm{x}$ ) para contrastar las respuestas de cada grupo en cuanto a las preferencias de cada tipo de contenido digital. 
(Animación, Artefacto, Buenas prácticas, Mapa conceptual, Diagrama, Conjunto de datos, Demostración, plantilla de software educativo, examen, ejercicio, experimento, Glosario, Gráfico, Conjunto de imágenes, Clase magistral, Micromundo, Películas, Apuntes, Informe, Simulación, Aplicación de Software, Guía de estudiante, Tabla, Página Web, Weblog y Wiki). Los datos siguen una distribución $x^{2}$, respecto a la frecuencia de uso del tipo de contenido digital, medidos en una escala Likert de 1 a 5 - donde 1 es nunca, 2 es rara vez, 3 es algunas veces, 4 es frecuentemente y 5 es diariamente) entre los tres tipos de roles (1Formadores de Educación Superior, 2- Educación Secundaria y otros profesionales).

En cambio, el p-valor o significación (con un intervalo de confianza del 95\%) de los siguientes tipos de contenido digital denota diferencias significativas sobre su preferencia en función de si los formadores pertenecen al campo de la educación superior o no:

\section{a. Quiz-Test:}

Tabla 19 Prueba [20]. Frecuencia de acceso a contenido digital tipo: Quiz-test. Diferencias entre roles

\begin{tabular}{lllll}
\hline \multirow{2}{*}{ En qué sector trabajas } & $\begin{array}{l}\text { Educación } \\
\text { Superior }\end{array}$ & $\begin{array}{l}\text { Educación } \\
\text { Secundaria y } \\
\text { Especialistas }\end{array}$ & Total \\
\hline \multirow{4}{*}{ Quiz-test } & Nunca & 9 & 1 & 10 \\
& Rara vez & 16 & 5 & 21 \\
& Algunas veces & 8 & 7 & 15 \\
Total & Frecuentemente & 6 & 9 & 15 \\
\hline
\end{tabular}

Chi-cuadrado de Pearson: valor 8,772; g.I. 3; p. valor 032.

1 casillas (12.5\%) han esperado un recuento menor que 5 . El recuento mínimo esperado es 3.61 .

Tal y como se observa en la Tabla 19, los formadores de educación superior utilizan en su mayoría nunca o rara vez los "quiz-test"; en cambio, parece ser un recurso utilizado con mayor frecuencia (frecuentemente y algunas veces) por los profesores de Educación Secundaria y Especialistas. Ninguno de los usuarios encuestados afirmó utilizarlos diariamente.

El resto de contenidos digitales es utilizado (a un nivel de confianza del 95\%) con una frecuencia bastante diferente entre los dos grupos de usuarios en los siguientes casos, a pesar de carecer de rigor estadístico (dado el número de la 
muestra), pues el número de casillas que presenta una frecuencia menor a la esperada supera el 20\% (ver Tabla 19).

\section{b. Lista de preguntas frecuentes}

La Tabla 20 muestra que los profesores de educación secundaria y especialistas utilizan con mayor frecuencia "las listas de preguntas frecuentes" respecto al uso realizado por los profesores de educación superior

Tabla 20 Prueba [20]. Frecuencia de acceso a contenido digital tipo: lista de preguntas frecuentes.

Diferencias entre roles

\begin{tabular}{lllll}
\hline & & $\begin{array}{l}\text { Educación } \\
\text { Educación } \\
\text { Superior }\end{array}$ & $\begin{array}{l}\text { Secundaria y } \\
\text { Especialistas }\end{array}$ & Total \\
\hline Lista de preguntas & Nunca & 11 & 3 & 14 \\
frecuentes & Rara vez & 17 & 4 & 21 \\
& Algunas veces & 10 & 9 & 19 \\
Total & Frecuentemente & 2 & 5 & 7 \\
\hline
\end{tabular}

Chi-cuadrado de Pearson: valor 8,9; g.l. 3; p. valor 031.

3 casillas (37.5\%) han esperado un recuento menor que 5 (siendo el mínimo esperado $2.41)^{136}$, por lo que las diferencias no son estadísticamente significativas.

\section{c. Figura:}

Observando las frecuencias de la Tabla 21 podemos apreciar que las "figuras" son uno de los tipos de contenido digital más utilizado por los profesores de educación Secundaria y especialistas (todos ellos las utilizan alguna vez) respecto a la frecuencia de acceso realizada por el profesorado de Educación Superior.

136 Este tipo de resultados es debido a que no tenemos una muestra suficiente para tener representatividad estadística en todos los datos. 
Tabla 21 Prueba [20] Frecuencia de acceso a contenido digital tipo: Figura. Diferencias entre roles

\begin{tabular}{lllll}
\hline $\begin{array}{l}\text { En qué sector trabajas y cuál es } \\
\text { tu rol principal }\end{array}$ & $\begin{array}{l}\text { Educación } \\
\text { Superior }\end{array}$ & $\begin{array}{l}\text { Educación } \\
\text { Secundaria y } \\
\text { Especialistas }\end{array}$ & Total \\
\hline \multirow{4}{*}{ Figura } & Nunca & 3 & 0 & 3 \\
& Rara vez & 12 & 1 & 13 \\
& Algunas veces & 7 & 3 & 10 \\
& Frecuentemente & 13 & 14 & 27 \\
\hline
\end{tabular}

Chi-cuadrado de Pearson: valor 9.547; g.l. 4; p. valor 049.

6 casillas $(60.0 \%)$ han esperado un recuento menor que 5 . El recuento mínimo esperado es 1.05 .

\section{d. Enunciado de problema:}

Según los datos obtenidos (ver Tabla 22) observamos que los profesores de Secundaria y especialistas utilizan con mayor frecuencia los "enunciados de problema" que los formadores de educación superior, quienes utilizan con poca frecuencia este tipo de recurso.

Tabla 22 Prueba [20]. Frecuencia de acceso a contenido digital tipo: Enunciado de problema. Diferencias entre roles

\begin{tabular}{lllll}
\hline $\begin{array}{l}\text { En qué sector trabajas y cuál es } \\
\text { tu rol principal }\end{array}$ & $\begin{array}{l}\text { Educación } \\
\text { Superior }\end{array}$ & $\begin{array}{l}\text { Educación } \\
\text { Secundaria y } \\
\text { Especialistas }\end{array}$ & Total \\
\hline \multirow{4}{*}{$\begin{array}{l}\text { Enunciado de } \\
\text { Problema }\end{array}$} & Nunca & 8 & 5 & 13 \\
& Rara vez & 15 & 1 & 16 \\
& Algunas veces & 8 & 7 & 15 \\
& Frecuentemente & 7 & 7 & 14 \\
& Diariamente & 0 & 1 & 1 \\
\hline
\end{tabular}

Chi-cuadrado de Pearson: valor 9.936; g.l. 4; p. valor .042.

4 casillas $(40.0 \%)$ han esperado un recuento menor que 5 . El recuento mínimo esperado es .36 . 


\section{e. Cuestionario:}

Observando las frecuencias, podemos apreciar que el "cuestionario" es un recurso, en general, utilizado por ambos grupos, aunque los formadores de educación accedan a él con una frecuencia más elevada que los de educación superior.

Tabla 23 Prueba [20]. Frecuencia de acceso a contenido digital tipo: Cuestionario. Diferencias entre roles

\begin{tabular}{lllll}
\hline $\begin{array}{l}\text { En qué sector trabajas y cuál es } \\
\text { tu rol principal }\end{array}$ & $\begin{array}{l}\text { Educación } \\
\text { Superior }\end{array}$ & $\begin{array}{l}\text { Educación } \\
\text { Secundaria y } \\
\text { Especialistas }\end{array}$ & Total \\
\hline \multirow{4}{*}{ Cuestionario } & Nunca & 7 & 2 & 9 \\
& Rara vez & 10 & 3 & 13 \\
& Algunas veces & 12 & 9 & 21 \\
& Frecuentemente & 8 & 1 & 9 \\
& Diariamente & 1 & 7 & 8 \\
\hline
\end{tabular}

Chi-cuadrado de Pearson: valor 13,622; g.l. 4; p. valor ,009.

4 casillas $(40.0 \%)$ han esperado un recuento menor que 5 . El recuento mínimo esperado es 2.93 .

\section{f. Presentación de diapositivas:}

Observando las frecuencias, podemos apreciar que "las presentaciones de diapositivas" son un recurso altamente utilizado por ambos grupos de roles (en nuestra muestra, parece ser utilizado con mayores frecuencias en los profesores de Educación Secundaria y Especialistas). En cambio, una mayor proporción de profesores de Educación Superior lo utilizan diariamente, tal y como se refleja en la Tabla 24:

Tabla 24 Prueba [20]. Frecuencia de acceso a contenido digital tipo: Presentación de diapositivas.

Diferencias entre roles

\begin{tabular}{lllll}
\hline $\begin{array}{l}\text { En qué sector trabajas y cuál es } \\
\text { tu rol principal }\end{array}$ & $\begin{array}{l}\text { Educación } \\
\text { Superior }\end{array}$ & $\begin{array}{l}\text { Educación } \\
\text { Secundaria y } \\
\text { Especialistas }\end{array}$ & Total \\
\hline \multirow{3}{*}{$\begin{array}{l}\text { Presentación } \\
\text { de }\end{array}$} & 6 & 1 & 7 \\
diapositivas & Rara vez & 6 & 0 & 6 \\
& Algunas veces & 7 & 4 & 11 \\
& Frecuentemente & 13 & 15 & 28 \\
& Diariamente & 8 & 2 & 10 \\
\hline
\end{tabular}

Chi-cuadrado de Pearson: valor 9,726; g.l. 4; p. valor ,045. 
6 casillas $(60.0 \%)$ han esperado un recuento menor que 5 . El recuento mínimo esperado es 2.13 .

En resumen, atendiendo a nuestra muestra, compuesta por personas de Italia, Bulgaria y España, pertenecientes a los grupos de 1) Formadores de Profesores y 2) Formadores de Educación Secundaria y Otros profesionales de la Educación (psicólogos e investigadores), podemos afirmar que al no existir diferencias de frecuencias, entendemos que el profesorado (tanto de educación superior como de educación secundaria y especialistas) presenta unas pautas de frecuencia de búsqueda similares. Hemos encontrado diferencias estadísticamente significativas para el uso de "quiz-test", utilizado con mayor frecuencia por los formadores de profesores. También hemos encontrado diferencias (aunque no estadísticamente significativas debido al tamaño de la muestra) en varios tipos de contenido digital educativo ("lista de preguntas frecuentes", "figura", "enunciado de problemas", "cuestionario" y "presentación de diapositivas"), todos ellos utilizados con más frecuencia por los formadores de educación secundaria y especialistas que por los formadores de profesores.

La segunda hipótesis que nos planteamos fue la siguiente:

$H_{0}$ Los diferentes roles usan con igual frecuencia objetos de aprendizaje pertenecientes a los siguientes tipos de aprendizaje:

Aplicamos el estadístico alfa de Cronbach para determinar la fiabilidad de la escala. En este caso, el alfa de Cronbach de la escala de los diferentes tipos de aprendizaje es de 0,927 ( $n$ de elementos =15), por tanto estimamos que el instrumento ha sido creado con una alta fiabilidad ${ }^{137}$.

Tabla 25 Prueba [20]. Fiabilidad escala tipos de aprendizaje. Alfa de Cronbach

\begin{tabular}{llll}
\hline & & $\mathrm{N}$ & $\%$ \\
\hline \multirow{3}{*}{ Casos } & Válidos & 53 & 76,8 \\
& Excluidos(a) & 16 & 23,2 \\
& Total & 69 & 100,0 \\
\hline
\end{tabular}

137 Rechazamos la aplicación de ANOVA de un factor por no constituir una distribución normal; aplicamos la prueba no paramétrica de $\chi^{2}$ para comprobar si hay discrepancia entre la distribución observada y la teórica. 
Aplicamos un test estadístico chi-2, y aceptamos $\mathrm{H}_{0}$ para las frecuencias de uso de los diferentes roles para todos los tipos de aprendizaje que fueron preguntados: Aprendizaje multisensorial, Aprendizaje basado en casos, Aprendizaje basado en incidentes críticos, Demostración, Grupo de discusión, Ejercicios de repetición y prácticas, Juego educativo, Aprendizaje Exploratorio, Aprendizaje basado en escenarios por objetivos, Aprender diseñando, Aprendizaje por proyectos, Aprendizaje Basado en problemas, Aprendizaje basado en recursos, Juego de roles y Tutorial.

Es decir, estadísticamente no existen diferencias significativas entre el tipo de rol (formadores de profesores vs. formadores de educación secundaria y especialistas) y las frecuencias de uso de contenidos digitales de las diferentes tipos de aprendizaje (atendiendo a la muestra consultada).

A continuación, presentaremos los datos que apoyan las siguientes aseveraciones.

\section{1.e) Lugar de acceso}

En la prueba [35] apreciamos que el grupo de formadores de profesores utiliza en mayor medida que otros roles (profesores de Educación Secundaria, Infantil y Primaria, y Formación Profesional y otros) diferentes servicios online para buscar contenidos digitales.

Este hecho confiere a los formadores de profesores un carácter especial, más cercano a la utilización de herramientas web para acceder a contenidos digitales (atendiendo a los informantes de la muestra). 
Gráfico 11 [35] Porcentaje de informantes de cada área que utiliza cada tipo de herramienta para buscar contenidos digitales.

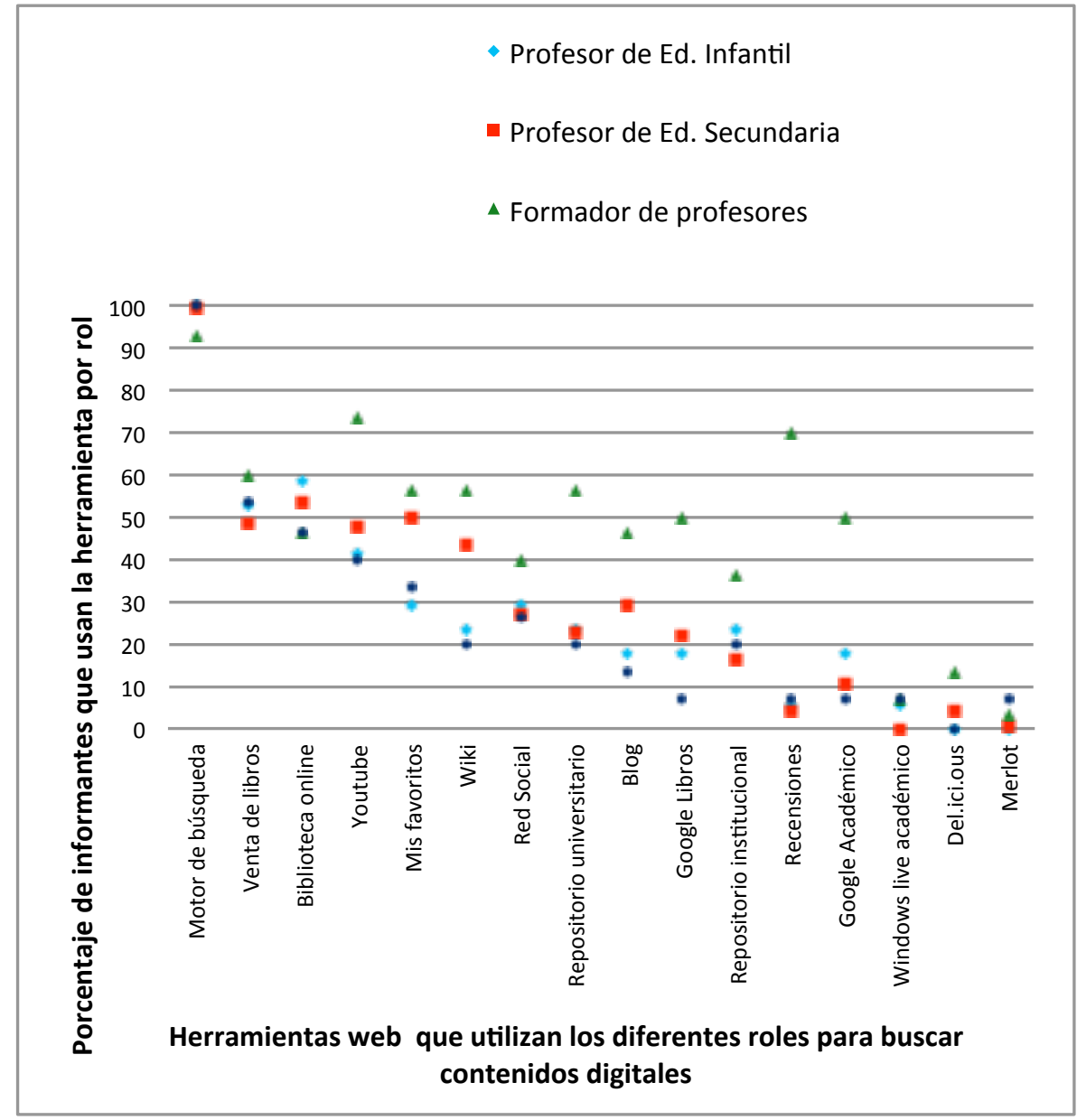

En el Gráfico 11 apreciamos la frecuencia de uso de las herramientas Web por parte de los diferentes roles que nos proporcionaron información en esta encuesta [35], en porcentaje (dado que contamos con un número diferente de respondientes en cada grupo). Los datos aparecen organizados de mayor a menor uso, de izquierda a derecha (atendiendo a la media de los 4 grupos de roles). 
De acuerdo con los datos obtenidos en el Gráfico 11, puede observarse que los formadores de profesores mostraban una tendencia mayor a utilizar casi todas las herramientas (de hecho los porcentajes de informantes que utilizaban todas ellas supera el $50 \%$ exceptuando los blogs, repositorios institucionales y redes sociales). En algunos casos, esta diferencia es significativa o muy significativa. Por ejemplo, apreciamos que los formadores de profesores afirmaban realizar un uso mayor de "Servicios online de venta de libros", "YouTube", "Herramientas de mis marcadores", "Wiki", "Redes Sociales", "Blog", "Repositorios Institucionales", y "Del.ici.ous". Puede apreciarse aún una diferencia mayor con respecto a los otros grupos en el uso de: "Repositorio Universitario", "Google Books", "Recensiones" y "Google académico", coincidiendo estas con las variables con mayor diferencia entre grupos en las pruebas de Chi-Cuadrado realizadas en [35], como veremos a continuación.

En la misma prueba, [35]138, preguntamos a los usuarios cuáles de los 15 servicios que utilizaban para realizar búsquedas de contenidos digitales (pudiendo elegir entre 15 opciones, en formato dicotómico: Sí usa o No usa) ${ }^{139}$.

Hemos aplicado una prueba Alfa de Cronbach para comprobar que la escala es fiable, obteniendo un Alfa de Cronbach de 0,760, con $\mathrm{N}=16$ elementos. Todos los valores de las preguntas referentes al tipo de herramientas sociales que utilizan online se hallan comprendidos entre 0,2 y 0,8 , en su valor correlación elemento-total corregida, excepto "Motores de búsqueda". Esto puede deberse a que casi de la totalidad de los usuarios utiliza esta herramienta.

[17] IV_FP. [...] en la biblioteca no hay lo que necesito y porque en red lo tengo todo.

Aceptamos $\mathrm{H}_{0}$ en la mayoría de las opciones: Motor de búsqueda, Web de biblioteca, Página de venta de libros, Mi barra de herramientas/mis favoritos, Windows Live Académico, Repositorio Institucional, Red Social, Del.ici.ous, YouTube, Blog, Wiki, Merlot.

$H_{0}$ : no existen diferencias entre los tipos de herramientas web que utilizan los usuarios para buscar contenidos digitales en internet ${ }^{140}$

138 Prueba [35], preguntas de la 7 a la 22.

139 Realizamos unas tablas de contingencia en SPSS entre estas variables: 7-21 cotejadas con el Rol. 
En cambio, rechazamos $H_{0}$ para las siguientes variables, en las que encontramos diferencias significativas por roles ${ }^{141}$ :

Tabla 26 Prueba [35] Chi cuadrado con diferencias estadísticamente significativas entre roles.

\begin{tabular}{|c|c|c|c|}
\hline $\begin{array}{l}\text { Prueba de Chi } \\
\text { cuadrado }\end{array}$ & Valor & $\mathrm{Gl}$ & $\begin{array}{l}\text { Significación asintótica } \\
\text { bilateral }\end{array}$ \\
\hline \multirow[b]{2}{*}{$\begin{array}{l}\text { Recensiones } \\
\text { online }\end{array}$} & 97.65 & 3 & ,000 \\
\hline & \multicolumn{3}{|c|}{ 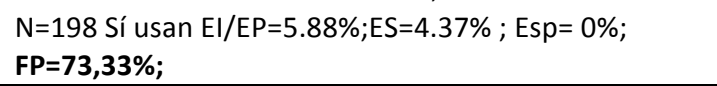 } \\
\hline \multirow[b]{2}{*}{$\begin{array}{l}\text { Google } \\
\text { Scholar }\end{array}$} & 35.95 & 3 & ,000 \\
\hline & \multicolumn{3}{|c|}{$\begin{array}{l}N=198 \text { Sí usan } E I / E P=17.64 \% ; E S=10.21 \% ; E s p=0 \% \text {; } \\
\text { FP=53.33\% }\end{array}$} \\
\hline \multirow[b]{2}{*}{ Google Libros } & 13.66 & 3 & ,003 \\
\hline & \multicolumn{3}{|c|}{$\begin{array}{l}\mathrm{N}=198 \text { Sí usan } \mathrm{El} / \mathrm{EP}=17.64 \% ; \mathrm{ES}=21^{\prime} 9 \% ; \mathrm{Esp}=7.14 \% \text {; } \\
\mathbf{F P}=\mathbf{5 0 \%}\end{array}$} \\
\hline \multirow{2}{*}{$\begin{array}{l}\text { Repositorio } \\
\text { universitario }\end{array}$} & 18.76 & 3 &, 000 \\
\hline & \multicolumn{3}{|c|}{$\begin{array}{l}\text { N=198 Sí usan El/EP=23.53\%;ES=22.62\%;Esp=16.67\% } \\
\text { FP=60\% }\end{array}$} \\
\hline
\end{tabular}

Como vemos, los únicos datos estadísticos en los que encontramos diferencias significativas a un nivel de confianza del $95 \%$ son los que encontramos en la tabla, todos ellos, muestran un uso muy superior por parte de los formadores de profesores con respecto al resto de roles.

Este tipo de recursos son frecuentemente utilizados para la investigación o para la búsqueda de materiales para abordar en clase. Los más utilizados por parte de los formadores de profesores son: las recensiones en línea $(73,33 \%)$, seguidas por los repositorios universitarios (60\%) (donde pueden encontrar recursos específicos para el nivel de Universidad), posteriormente Google Scholar (53,33\%) y finalmente Google Libros (50\%) (bien utilizados como consulta o bien como pre-evaluación para la decisión de compra de un material).

140 Este tipo de variables tienen una respuesta dicotómica (Si/No). Disponemos de 4 grupos de roles. Descartamos la aplicación de pruebas paramétricas, ya que no cumple los criterios necesarios. Hemos decidido aplicar un test no paramétrico: tablas de contingencia, con el estadístico Chi-cuadrado.

141 Utilizamos la terminología "El/EP" para referirnos a los profesores de "Educación Infantil"; "Es", a los profesores de "Educación Secundaria"; "Esp", a otros formadores y especialistas de la educación, y "FP" a "formadores de profesores". 
Hemos visto en las pruebas [09], [21] y [44] (apartado A.9 de este capítulo) que Google era el motor más popular entre los informantes para realizar búsquedas de contenidos digitales. Además de este servicio, buscan en lugares especializados de sus áreas, y además, piden asesoramiento directo a otros profesionales:

[17] Investigadora P4 “¿Qué tipos de motores de búsqueda utilizáis? Por ejemplo, Google, Yahoo, o Google books, Google Académico. ¿A qué soléis recurrir?

[17]R.P4_FP Pues yo creo que depende también del recurso que quieras, pero bueno, el más generalizado, tal vez sea Google, con todas sus variantes, Google Books, Google Scholar, pero bueno, Yahoo muy pocas veces. El que más utilizamos, bueno en mi caso es Google, pero bueno, si tienes que irte porque no encuentras en Google tal cosa, recurres a otros buscadores o a otras bases de datos".

[21] FP_M_30 Por Internet, en revistas especializadas, en páginas concretas.

[21] FP_F_45 A través de varios recursos: comentarios con otros profesionales, consulta en buscadores generales, consulta en páginas digitales especializadas de mi sector profesional.

[21] FP_F_27 En Internet y en bases de datos relacionadas con mi área.

[33]15.16. FP_57_M Google, web de asociaciones por ejemplo aire comunicación o revista comunicar.

Un formador de profesores de educación física considera que los resultados más óptimos se encuentran en portales específicos de esta materia.

[17] Investigadora: P4 “¿Y en dónde encuentras más resultados óptimos?:

[17] Q. P4_FP Pues bueno, portales específicos. Hay una revista que se llama EF deportes, que hay una producción cada vez más mala, pero de mayor cantidad. Hay un par de webs latinoamericanas que ahora no recuerdo sobre ocio y recreación bastante potentes e interesantes y puff... depende, depende de las temáticas".

En la segunda encuesta coordinada obtuvimos que el $77 \%$ de los formadores de profesores realizaba sus búsquedas en la Web; aún así, existía un amplio porcentaje de formadores que recibía contenidos digitales de los compañeros pertenecientes a sus propias instituciones y centros educativos (54\%) 0 de compañeros que trabajan en otras instituciones diferentes a las suyas (69\%); y un porcentaje menor, pero también significativo (33\%) de formadores que encontraban sus recursos en redes sociales (datos de Anexo 29). 
En cuanto a los tipos de espacios públicos online que utilizan los formadores de profesores, profesores y otros profesionales de la educación, en la prueba [33] preguntamos a los informantes en formato de pregunta abierta este aspecto, obteniendo los siguientes espacios:

- Repositorios de archivos, revistas o aplicaciones científicas, como Dialnet, DOAJ $^{142}$, Redalyc ${ }^{143}$, DIM $^{144}$

- Espacios sociales: Blogs

- Herramientas colaborativas: wikis

- Herramientas sociales: Facebook, Ning, Slideshare

- Buscadores Web genéricos: Google.

- Webs específicas de recursos educativos: cooltoolforschools ${ }^{145}$, TeacherTube ${ }^{146}$, etc.; los estudiantes de máster de profesorado de Educación Secundaria del Área de Economía hicieron mención a recursos específicos de su área, tales como ecobachillerato ${ }^{147}, \mathrm{AEHE}^{148}, \mathrm{y}$ Webeconomía ${ }^{149}$.

1.f) Lugar de Almacenamiento de los contenidos digitales.

La diversidad de servicios y métodos para almacenar los contenidos digitales, y la ausencia de una metodología personal concreta para hacerlo, crea una sensación de desorden y caos en los formadores de profesores para volver a reutilizar contenidos digitales que alguna vez encontraron y marcaron o guardaron para su reutilización posterior.

En una de las pruebas realizadas a los formadores de profesores [09], nos dimos cuenta de que sería oportuna la existencia de alguna aplicación unificadora que permitiera recuperar los marcadores y documentos relevantes de forma

142 Directorio de Revistas de Acceso Libre https://doaj.org/

143 Red de Revistas Científicas de América Latina y el Caribe, España y Portugal http://www.redalyc.org/

${ }^{144}$ Revista: Didáctica, Innovación y Multimedia

http://dim.pangea.org/revistaDIM19/revistanew.htm

145http://cooltoolsforschools.wikispaces.com/?responseToken=998574f1a2d1f129b78a6ea88f

b04381

$146 \mathrm{http}: / / w w w . t e a c h e r t u b e . c o m /$

${ }^{147}$ www.ecobachillerato.com, www.profes.net

148 http://www.aehe.net/

$149 \mathrm{http://webeconomia.com/}$ 
organizada. Existían opciones que solucionaban total o parcialmente este problema, tales como portafolios digitales, páginas web que permitían almacenar los marcadores y compartirlos socialmente (e.g., Pearltree ${ }^{150}$, Paper.li; aunque estas no permiten almacenar documentos), así como la posibilidad de crear espacios personales en portales educativos (e.g., "mi Share.TEC" en el portal Share.TEC; pero tampoco permite el almacenamiento de documentos). Desde aquel momento, gracias a la constante evolución de las herramientas web y la tecnología, han surgido soluciones (e.g., "Evernote"151, Bibsonomy ${ }^{152}$ o ReadCube ${ }^{153}$ ) que permiten ordenar marcadores y documentos de forma unificada.

Los formadores de profesores utilizan su propio correo electrónico, sus carpetas del ordenador, documentos con enlaces y marcadores de sus navegadores para almacenar los contenidos interesantes.

[17] p.5 Q_FP: A mí me ha jugado también malas pasadas eso, confiar en: "ino, no lo guardo que lo encuentro a través de esto!". Y luego hay alguna cosa muy friqui que me da miedo confesarla, que es que me la autoenvío a mi correo electrónico para tenerla en cabecera.

[17] p.2 In_FP Pues o bien lo apunto, o lo guardo en una carpeta o en un Word, y voy poniendo los enlaces, o en favoritos, o depende de lo que sea.

Algunos profesores utilizan sistemas de clasificación basados en categorías para recuperar los contenidos que guardaron.

Utilizar categorías como método de recuperación de materiales dentro de un área específica puede entrañar dificultades, pues si los materiales no están suficientemente definidos, o categorizados de forma dispar, será difícil su recuperación.

[17] p2. Q_FP: Yo utilizo también palabras clave, y lo que trato de ponerme son los límites, porque la red es la red, te lleva hacia sitios donde no debes ir, a veces me dejo llevar, y lo que hago es que suelo tener unas carpetas donde voy introduciendo cosas con palabras clave.

[17] p2. S_FP. ¿Normalmente cuando lo encuentro qué hago? También lo meto en carpetas como $Q$, incluso cosas que me pueden parecer

\footnotetext{
$150 \mathrm{http}: / /$ www.pearltrees.com/

151 https://evernote.com

$152 \mathrm{http://www.bibsonomy.org/}$

153 https://www.readcube.com/
} 
interesantes que no están relacionadas con lo que estoy buscando en ese momento, pero que quizá en un futuro me puedan servir, entonces por carpetas en el ordenador las voy distribuyendo. O también añado a marcadores en internet la página, y ya está. Lo que pasa que luego también, volver a esos recursos que tú en un momento has encontrado, también a veces, quizá, no es la mejor estrategia porque a veces no te acuerdas.

[17] p2 I_FP A mí me pasa muchas veces, que cuando estoy buscando algo, y por ejemplo pongo un marcador, le pongo una etiqueta que luego no soy capaz de identificar. O sea, luego vuelvo sobre el millón de marcadores... no sé exactamente... claro, lo haces un año después.

Esto ocurre igualmente con los recursos que etiqueta una sola persona, por lo que incorporar soluciones de etiquetado social en los portales educativos puede ampliar la definición de los contenidos digitales, y de este modo, facilitar su recuperación.

Actualmente, los sistemas operativos incorporan buscadores que exploran el contenido de los documentos del ordenador, lo que facilita la recuperación de material almacenado en él.

[17] p.5. Iv_FP Yo antes era mucho más organizado para esto, pero ahora tengo un buscador dentro del ordenador, con lo cual me permite no ser tan organizado, pongo no sé qué, y ya me lo encuentra.

\section{1.g) Necesidades que generan el acceso}

Los profesionales de la educación acceden a portales y repositorios de contenidos digitales con frecuencia para su desarrollo profesional, para investigar, preparar clases, y buscar materiales para utilizarlos directamente en clase (con pocas o ninguna modificación).

Como veremos en la interpretación de la Tabla 29, referente a la prueba [33], los informantes utilizaban los repositorios de diferente forma en función de los roles (formador de profesores, estudiante de máster de Secundaria, y otros formadores y especialistas). El motivo más común de acceso a estos portales para todos los roles era para investigar. En el caso de los informantes formadores de profesores, también era frecuente su acceso para utilizarlos en clase (modificándolos, principalmente).

Además de estos fines, los profesionales de la educación, según 196 de los 197 usuarios de la prueba [35], afirmaron utilizar Internet para su desarrollo profesional 
(99,4\% de los informantes). El único profesor que decía no utilizarlo era un profesor de Educación Secundaria de Italia.

\section{1.h) Qué buscan los formadores de profesores}

Los formadores de profesores buscan contenidos digitales que atiendan a su nivel, área y materia educativa específica, pero tienen dificultades para encontrar resultados apropiados.

[17]p7, Q_FP: O sea, puedo encontrar 7, pero este es demasiado elevado de tono, este toca otro tema... va mejorando, pero la cultura de lectura del alumnado todavía deja bastante que desear, y es una cosa con la que hay que afinar, porque si les mandas muchas cosas, al final no van a leer nada. A mí es una cosa que me preocupa metodológicamente, el encontrar un artículo estrella que realmente sea lo suficientemente importante como para que a ellos les cale y entre dentro de lo que tú quieres transmitir.

Algunos profesores buscan la opinión de otros profesionales cuando encuentran contenidos digitales.

[17 p7, S_FP: A mí, lo que me pasa es que cuando yo encuentro un recurso que a priori yo pienso que puede ser interesante, tanto para mí como para el alumnado, por mi desconfianza, siempre procuro preguntar a alguien, a otros profes, "oye, he encontrado esto, qué te parece"

En el Gráfico 12, prueba [20], y en el apartado A.9, 1.e) veíamos la frecuencia de uso de los contenidos digitales y recogíamos los materiales que más buscaban los profesionales de la educación que informaron esta prueba, diferenciando a los formadores de profesores de otros roles. Atendiendo al tipo pedagógico encontrábamos que los recursos más buscados son webs, diapositivas, clases magistrales, figuras, wikis, tablas, etc.; y los menos frecuentes los micromundos, artefactos, listas de preguntas frecuentes, exámenes, demostraciones, etc. Estos resultados tienen sentido si los comparamos con los resultados de la Tabla 27: 
Tabla 27 Prueba [20] Contenidos digitales de mayor interés para los informantes tras realizar búsquedas (pregunta 1)

\begin{tabular}{lll}
\hline Contenido Digital & Frecuencia & Porcentaje \\
\hline Un artículo, capítulo de libro o libro & 56 & 81,2 \\
Ejercicios resueltos & 3 & 4,3 \\
Unidades didácticas o Programaciones & 9 & 13,0 \\
Un test, examen o cuestionario & 1 & 1,4 \\
\hline Total & 69 & 100,0 \\
\hline
\end{tabular}

Los materiales preferidos fueron, de orden ascendente a descendente: artículo, capítulo de libro o libro $(81,2 \%)$; Unidades didácticas o programaciones $(13 \%)$; Ejercicios resueltos $(4,3 \%)$, Test, examen o cuestionario (1,4\%). Es decir, la gran mayoría de los profesores eligieron fuentes originales de libros 0 artículos.

Como podemos ver en la Tabla 28, no existían muchas diferencias entre los dos tipos de roles (profesor de Educación Superior vs. profesor de Educación Secundaria y Especialistas). En proporción, eran más los formadores de Secundaria y especialistas (24\%) los que encontraban más interesantes las unidades didácticas o programaciones (vs. al 7,5\% de formadores de profesores). Los ejercicios resueltos eran los recursos menos interesantes, entre las tres opciones, para los dos tipos de roles. El $90 \%$ de los profesores de Educación superior encontraba más interesantes los artículos o capítulos de libros que el resto de recursos (vs. al $68 \%$ de los profesores de Educación Secundaria y especialistas).

Tabla 28 Prueba [20] Rol * Tipo de material más interesante entre artículo/capítulo, ejercicios resueltos y unidades didácticas/programaciones

\begin{tabular}{|c|c|c|c|c|c|}
\hline \multirow[b]{2}{*}{ Rol } & \multirow{3}{*}{$\begin{array}{l}\text { Educación Superior } \\
\text { Educación Secundaria } \\
\text { y Especialistas }\end{array}$} & \multirow{2}{*}{$\begin{array}{l}\text { Un artículo, } \\
\text { capítulo de libro } \\
\text { o libro } \\
36\end{array}$} & \multirow{2}{*}{$\begin{array}{l}\text { Ejercicios } \\
\text { resueltos } \\
1\end{array}$} & \multicolumn{2}{|c|}{$\begin{array}{l}\text { Unidades } \\
\text { didácticas o } \\
\text { Programaciones }\end{array}$} \\
\hline & & & & 3 & 40 \\
\hline & & 17 & 2 & 6 & 25 \\
\hline Total & & 53 & 3 & 9 & 65 \\
\hline
\end{tabular}

\section{1.i) Modo de búsqueda}

La gran mayoría de los formadores de profesores y otros tipos de profesores que contestaron a nuestras pruebas, realiza sus búsquedas por palabras clave.

En la prueba [20] -Primera Encuesta coordinada-, tras la aplicación de un test estadístico Chi-2, determinamos que a un nivel de confianza del $95 \%$, no existen 
diferencias estadísticamente significativas entre los dos tipos de roles, "profesor de Educación Superior", versus profesor de "Educación Secundaria y Especialistas". La mayoría de los informantes afirmó haber realizado búsquedas mediante palabras clave (59 usuarios; $85,5 \%$ ), versus al 14,5\% (10 usuarios), que indicó realizar búsquedas avanzadas.

[17] p.2. Investigadora: "O sea ¿que buscas por keywords normalmente?"; I. [17] p.2. I_FP "Es que no hay otra manera de buscar. Bueno, sí que hay otras maneras, pero los buscadores comerciales al uso y los más potentes funcionan por palabras clave".

[17] p2. E_Ing "Pero también sucede que a veces sabes lo que quieres y simplemente no sabes dónde está, entonces utilizas un servicio para obtener el documento concreto que quieres; el BSCW de mi grupo de investigación [...] sería un ejemplo, y sé qué documento quiero pero no sé exactamente dónde está".

Cuando los profesores buscan recursos, exploran por palabras clave el contenido de la red. En ocasiones encuentran dificultades para encontrar contenido digital que se ajuste a sus fines educativos, ya que si las palabras clave no se ajustan concisamente a las de los metadatos del contenido, resulta complicada la búsqueda. Además, utilizan códigos entendibles por los buscadores para filtrar búsquedas. Por la rapidez de los resultados obtenidos afirman recurrir a Google, tal y como sugieren las siguientes evidencias:

[17] p.2. I_FP [...] Yo por ejemplo, lo único que tengo claro es lo que quiero hacer... o más o menos claro lo que quiero hacer. Y luego ponerte a buscar; hasta que encuentras la palabra clave que te ofrece o que te devuelve en Internet los recursos o el recurso que tú necesitas, es un período muy complicado... lleva muchísimo tiempo, y la mitad de las veces no encuentras nada que se ajuste a lo que tú buscas... Y fundamentalmente no porque no lo haya, sino porque no encuentras.... Yo creo que es algo que nos encontramos con la tesis de "persona X". Que claro, cuando haces una búsqueda por palabras, o sabes qué palabra tienes que poner 0 es una tragedia.

[17] p.2. R_FP Yo creo que también, se busca por palabras clave, porque muchas veces no sabes qué recurso necesitas exactamente o cuál es el que se ajusta a lo que estás buscando, entonces vas buscando diferentes recursos que se van adaptando a lo que necesitas en ese momento.

[17] p.2. Q_FP si es cierto. Yo realmente, bueno, vas aprendiendo con el tiempo, pero las cabeceras de las entradas del buscador... al final el tiempo es limitado. Y tienes 10, y tú vas pinchando en las que intuyes que son tal. 
Yo a veces sí que utilizo, para buscar sobre todo artículos, la búsqueda avanzada: pues asterisco .pdf, o .ppnt, etc. Antes más, ahora menos. Y luego coincido con ellos, en que para búsquedas, hago browser a Google, la primera, ¡Puum!.

Las personas tienen diferentes preferencias a la hora de aprender y acceder a la información, por lo que algunos profesores valoran la idea de que los portales presenten los contenidos de forma multimodal, y no sólo con entradas textuales.

[09] B. P4 O sea, que tener una idea visual cuando estáis buscando un contenido visual, ¿os ayuda a hacer una criba?

Iv. P4 A mí sí, pero eso depende de cada cuál, cómo estructure la información en su cabeza. Es una cuestión de tiempo en mi caso. O sea, para mí es mucho más fácil hacerme cargo de una página con una estructuración por imágenes de lo que voy buscando, que una página con todas las entradas en texto que tengo que ir pinchando y a veces se te escapan cosas, pero eso depende.

\section{1.j) Frecuencia de uso}

En la prueba [20] preguntamos a los informantes sobre las Frecuencias de uso de los diferentes tipos de Contenido Digital (siendo 1 nunca; 2 rara vez; 3 algunas veces; 4 frecuentemente; 5 diariamente): 
Gráfico 12 Prueba [20] Frecuencia de uso de los diferentes tipos educativos de contenido digital y desviación típica

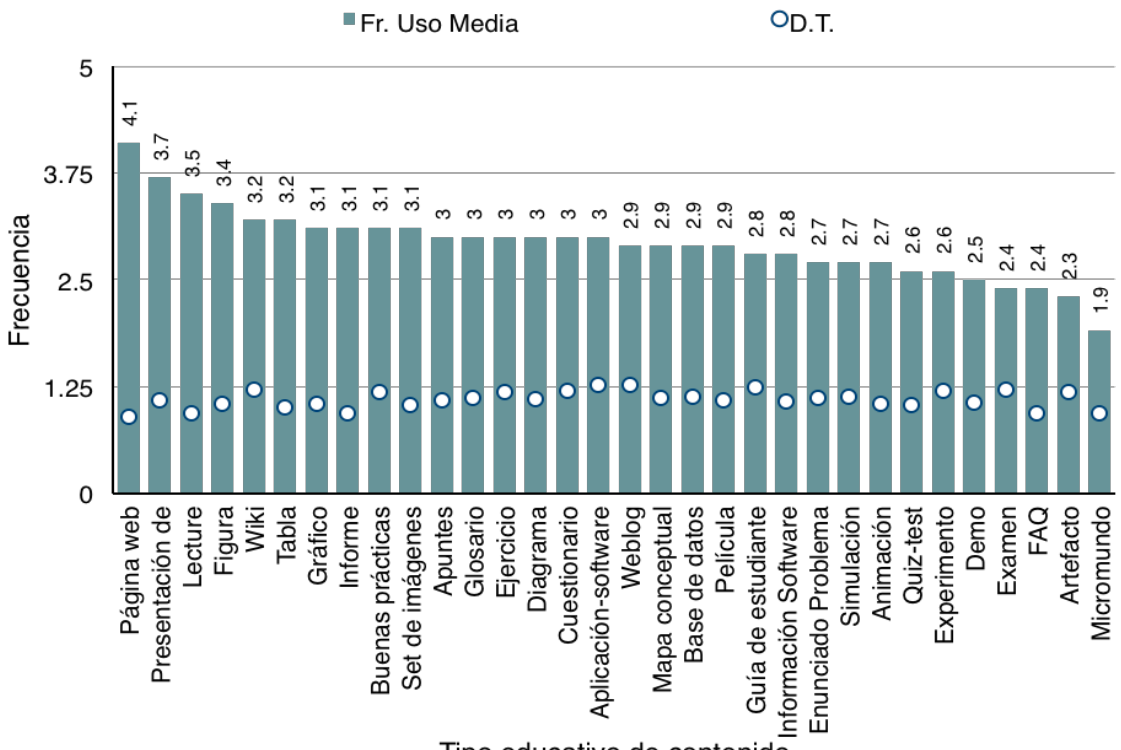

Tipo educativo de contenido

Apreciamos, a través de los datos del Gráfico 8, que los usuarios afirmaron utilizar diversidad de tipologías pedagógicas de contenido digital, siendo las más utilizadas las páginas Web, presentaciones de diapositivas y lecciones; y las menos utilizadas "artefactos" y "micromundos".

Las desviaciones típicas de todos los datos oscilan entre una D.T. mínima de 0,89 (páginas web), que nos indica que la mayoría de los usuarios usa frecuentemente este recurso (con una frecuencia con $\mu=4.1$ ); y una $\sigma$ máxima de 1,27 (Weblog), que indica que las variaciones entre las frecuencias señaladas por los informantes son diversas.

En la prueba [33], preguntamos a los 26 usuarios que realizaron la evaluación del portal sobre la frecuencia con la que utilizaban los repositorios para acceder a contenidos digitales, así como el propósito. En nuestra muestra encontramos cuatro grupos de roles: formador de profesores, estudiantes de Máster de Educación Secundaria y especialistas/investigadores. Mostramos a continuación una tabla de contingencia que muestra las tres variables (rol, frecuencia de uso de repositorio y fin de uso del repositorio- preguntas 13, 14 y 8 de la prueba [33]: 
Tabla 29 Prueba [33] Tabla de contingencia. Frecuencia de utilización de los repositorios de contenidos digitales y motivo de su utilización. (preguntas 13, 14 y 8 )

\begin{tabular}{|c|c|c|c|c|c|c|c|}
\hline \multirow[t]{2}{*}{ Rol } & & & \multicolumn{4}{|c|}{ ¿Para qué utilizas los repositorios digitales? } & \multirow{2}{*}{ Total } \\
\hline & & & Investigar & $\begin{array}{l}\text { Preparar clases } \\
\text { (referencia) }\end{array}$ & $\begin{array}{l}\text { Usar en } \\
\text { clase sin } \\
\text { adaptar }\end{array}$ & $\begin{array}{l}\text { No los } \\
\text { utilizo }\end{array}$ & \\
\hline \multirow[t]{6}{*}{ FP } & \multirow{5}{*}{$\begin{array}{l}\text { ¿Con qué frecuencia } \\
\text { utilizas estos } \\
\text { repositorios? }\end{array}$} & $<1 \mathrm{vez} / \mathrm{mes}$ & 1 & 0 & 0 & & 1 \\
\hline & & $1 \mathrm{vez} / \mathrm{mes}$ & 2 & 2 & 1 & & 5 \\
\hline & & 2 veces/mes & 0 & 2 & 0 & & 2 \\
\hline & & $\begin{array}{l}\text { Varias veces a } \\
\text { la semana }\end{array}$ & 1 & 1 & 1 & & 3 \\
\hline & & $\begin{array}{l}\text { Con gran } \\
\text { frecuencia }\end{array}$ & 3 & 2 & 1 & & 6 \\
\hline & Total & & 7 & 7 & 3 & & 17 \\
\hline \multirow[t]{4}{*}{$\overline{E M}$} & \multirow{3}{*}{$\begin{array}{l}\text { ¿Con qué frecuencia } \\
\text { utilizas estos } \\
\text { repositorios? }\end{array}$} & Nunca & 0 & & & 2 & 2 \\
\hline & & $1 \mathrm{vez} / \mathrm{mes}$ & 1 & & & 0 & 1 \\
\hline & & $\begin{array}{l}\text { Con gran } \\
\text { frecuencia }\end{array}$ & 1 & & & 0 & 1 \\
\hline & Total & & 2 & & & 2 & 4 \\
\hline \multirow[t]{4}{*}{ Esp } & ¿Con qué frecuencia & $<1 \mathrm{vez} / \mathrm{mes}$ & 1 & 0 & & & 1 \\
\hline & utilizas estos & 2 veces/mes & 0 & 1 & & & 1 \\
\hline & repositorios? & $\begin{array}{l}\text { Con gran } \\
\text { frecuencia }\end{array}$ & 3 & 0 & & & 3 \\
\hline & Total & & 4 & 1 & & & 5 \\
\hline
\end{tabular}

Atendiendo a los datos recogidos en esta prueba, no apareados, no paramétricos, dicotómicos, multinomiales y con un $n$ menor a 30 , consideramos inadecuado aplicar cualquier test estadístico, por lo que analizamos los datos mediante estadística descriptiva.

Tal y como puede verse en la Tabla 29, todos los formadores de profesores de la prueba [33] (aquellos que atendieron a los workshops: Local y Nacional, realizados para presentar el proyecto Share.TEC), afirmaron haber utilizado los repositorios de contenidos digitales, y además, de forma frecuentemente.

Los dos motivos más frecuentes (entre los tres preguntados) para utilizar los repositorios están representados por el $41,18 \%$ de los informantes, "como ayuda para preparar las clases, utilizándolos como material de referencia" y el $41,18 \%$, "para investigar". El 17.64\% "utiliza los contenidos digitales alojados en ellos directamente, sin apenas modificaciones". En cuanto a las frecuencias de uso, la 
mayoría de ellos afirmaron haberlos empleado al menos una vez al mes, y el $52,94 \%$ aseguró hacerlo varias veces a la semana o con gran frecuencia.

De los cuatro estudiantes de máster de la muestra, dos utilizaron los repositorios "para investigar" (uno de ellos 1 vez al mes, y otro, con gran frecuencia). Dos de los estudiantes no utilizaron nunca los repositorios. No disponemos de muchos datos de alumnos, pero consideramos que es un ámbito pendiente de explorar (véase la Tabla 20).

Los especialistas decían utilizar estos repositorios tanto "para investigar" como "para usarlos como material de referencia", no los empleaban directamente ${ }^{154}$. De entre ellos, quienes los usaban con gran frecuencia, era "para investigar" (más de dos veces a la semana), y con una frecuencia quincenal (2 veces al mes) "para usarlos como material de referencia".

En términos generales, el conjunto total de informantes utiliza los repositorios de contenidos digitales educativos con las siguientes frecuencias (de mayor a menor): a) gran frecuencia, un $38,5 \%$ de los informantes; b) una vez al mes, el 23, 1\%; c) varias veces a la semana, un $11,5 \%$; d) dos veces al mes, el $11,5 \%$; e) menos de una vez al mes, el 7,7\%; y f) Nunca, el 7,7\%.

A la luz de los datos que acabamos de plasmar, podemos concluir que la mitad de los informantes de [33] (relacionados con el ámbito educativo) utiliza al menos una vez a la semana los repositorios de contenidos digitales.

En la prueba [44] se preguntó a los usuarios sobre la frecuencia de uso de contenidos digitales (ver Tabla 30):

154 Nuestra muestra es pequeña, pero tiene sentido que los adapten para atender a sus necesidades contextuales. 
Tabla 30 Prueba [44]. Frecuencia de uso de contenido digital por rol

\begin{tabular}{|c|c|c|c|c|c|c|c|}
\hline & 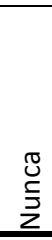 & 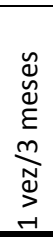 & 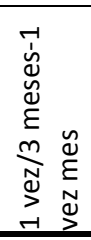 & 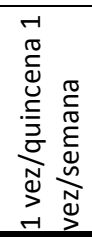 & 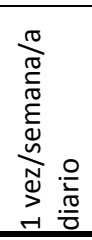 & $\begin{array}{l}.0 \\
\frac{1}{10} \\
\frac{0}{0} \\
4 \\
\end{array}$ & $\begin{array}{l}\bar{T} \\
\stackrel{0}{\circ} \\
\end{array}$ \\
\hline \multirow{2}{*}{$\begin{array}{l}\text { Estudiante de Máster de } \\
\text { Secundaria Economista } \\
\text { Formador de Profesores }\end{array}$} & 1 & 1 & 0 & 1 & 1 & 0 & 4 \\
\hline & 2 & 3 & 2 & 2 & 2 & 1 & 11 \\
\hline $\begin{array}{l}\text { Ingeniero, formador e } \\
\text { investigador }\end{array}$ & 1 & 1 & 0 & 1 & 0 & 0 & 3 \\
\hline Total & 4 & 5 & 2 & 4 & 3 & 1 & 19 \\
\hline
\end{tabular}

Ante los datos de la Tabla 30 apreciamos que el 9 de los 19 informantes no utilizaba "nunca" o "una vez cada 3 meses" contenidos digitales. En cambio, 4/17 informantes utilizaban con frecuencias elevadas (entre "una vez a la semana y a diario") los contenidos digitales. Dos informantes formadores de profesores los usaban entre "1 vez cada 3 meses y 1 vez al mes"; y cuatro informantes (2 formadores de profesores, 1 estudiante de máster y 1 ingeniero e investigador), entre "1 vez al mes y 1 vez quincenalmente". Observamos que no existen diferencias entre estos informantes (las frecuencias están distribuidas de forma homogénea).

Atendiendo a los datos obtenidos de nuestra muestra observamos que, a pesar de los distintos esfuerzos que se han puesto en marcha los últimos 10-15 años por parte de distintas instituciones y políticas para promover la creación y acceso a recursos digitales (e.g., los programas europeos eContent eContentplus), todavía son muchos los formadores de profesores y otros profesionales de la educación que infrautilizan o no usan ni comparten los contenidos digitales que tienen a su alcance.

\section{2) Hábitos de Compartición}

\section{2.a) Frecuencia de compartición}

Los profesores a los que consultamos en nuestras pruebas [33] y [44] afirman, en su mayoría, compartir contenidos digitales. 
En la prueba [33] (véase Tabla 31) representamos de forma conjunta los datos de esta prueba sobre la compartición y la utilización de contenido digital de sus informantes. Encontramos que los formadores de profesores y especialistas eran quienes más compartían, frente a los Estudiantes de Máster de Educación Secundaria, que en su mayoría no los ofrecían (pero no haremos hincapié en la diferenciación por grupos, ya que la muestra de los Estudiantes y Especialistas es muy pequeña) y la comparación estadística de chi-2 entre los datos de los roles carece de significatividad a un nivel de confianza del $95 \%$.

Tabla 31 Prueba [33] Comparten recursos en su comunidad vs. usan recursos creados por otros

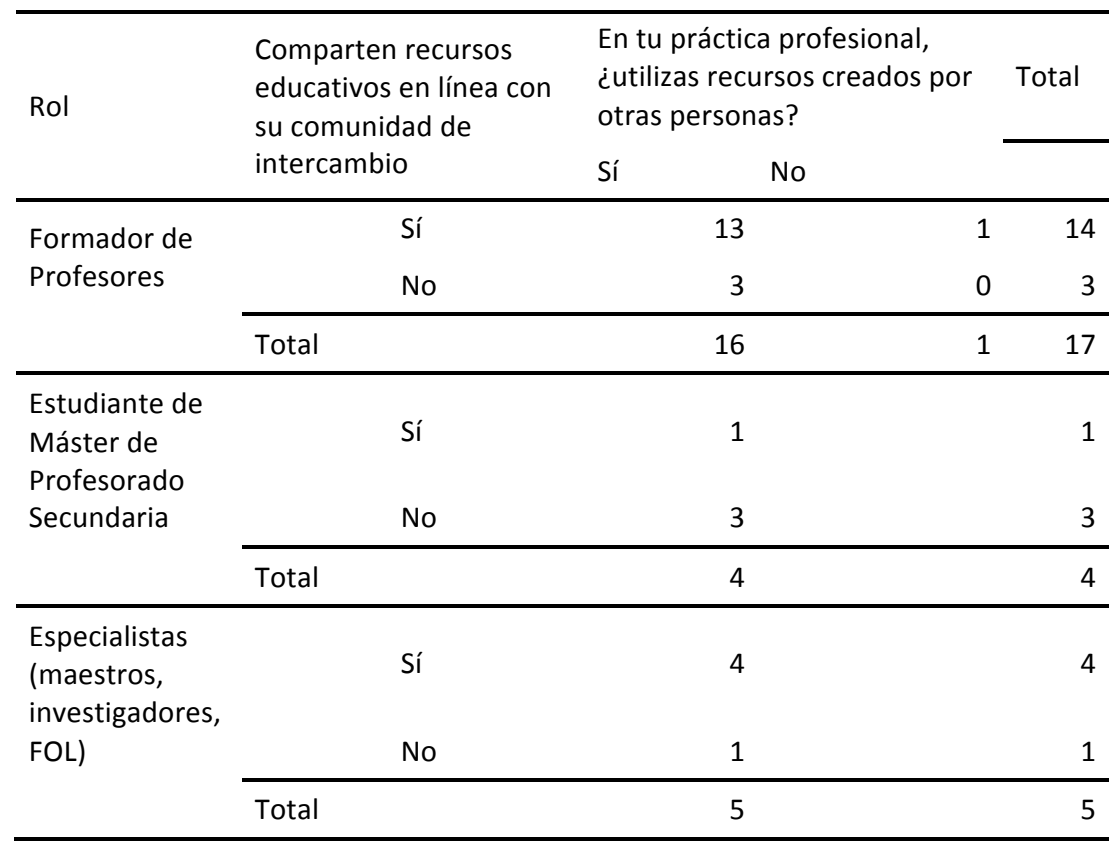

El 73,07\% (14/26) de los informantes de esta prueba comparte contenido digital (14 -el 82,35\%- de los 17 "formadores de profesores", comparten). Todos los "especialistas" y "estudiantes de máster" utilizaban recursos creados por otras personas, pero 1 "formador de profesores", a pesar de que sí compartía, no empleaba los recursos de otros. Es decir, el 92,85\% (16/17) de los "formadores de profesores" de esta muestra utilizaban contenidos digitales creados por otros. 
Como apreciábamos en la Tabla 29 de la prueba [33], aproximadamente la mitad de los informantes compartían con poca o muy poca frecuencia, y la otra mitad, con una frecuencia elevada o bastante elevada. Ocurre algo similar con los informantes de la prueba [44], aunque existía una menor frecuencia de compartición que la manifestada por los de la prueba [33].

En cuanto a los informantes de la prueba [44] (Tabla 32) podemos observar las frecuencias de compartición de contenido digital distinguidas por roles. 8 de los 19 no comparten nunca (entre ellos, $3 / 11$ formadores de profesores); 0 entre nunca y 1 vez cada 3 meses. Los informantes que comparten entre a diario (entre ellos 3 formadores de profesores) y una vez a la semana ( 1 formador de profesores y un estudiante de Máster) son 5/19. El resto comparten entre 1 vez cada 3 meses 1 vez al mes (4 informantes) y una vez mes -1 vez quincenalmente. Vemos de nuevo, al igual que en la utilización de contenido digital, que apenas existen diferencias entre roles, aunque los únicos informantes que compartían entre 1 vez a la semana y 1 vez a diario eran formadores de profesores.

Tabla 32 Prueba [44] Frecuencia de compartición de contenido digital por rol

\begin{tabular}{|c|c|c|c|c|c|c|c|}
\hline 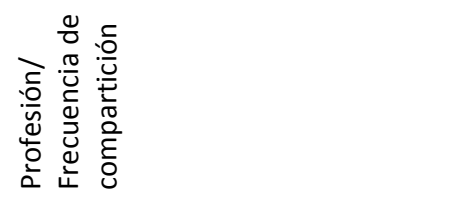 & $\begin{array}{l}\text { ֻ } \\
\stackrel{5}{z}\end{array}$ & 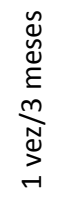 & $\sum_{\substack{N \\
\sim}}^{m}$ & 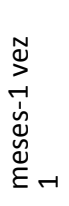 & 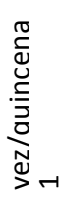 & 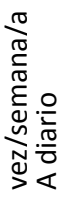 & $\begin{array}{l}\bar{\pi} \\
\stackrel{0}{0} \\
\bullet\end{array}$ \\
\hline Estudiante de Máster de Secundaria & 1 & 1 & 1 & 0 & 1 & 0 & 4 \\
\hline Formador de Profesores & 3 & 1 & 2 & 2 & 1 & 3 & 11 \\
\hline Ingeniero, formador e investigador & 1 & 1 & 1 & 0 & 0 & 0 & 3 \\
\hline Total & 5 & 3 & 4 & 2 & 2 & 3 & 19 \\
\hline
\end{tabular}

El la prueba [44] (Tabla 33), al igual que en la [33], preguntamos por las frecuencias de uso y compartición de contenidos digitales. De los resultados obtenidos, las personas que sí que usaban contenidos digitales, al menos 1 vez cada 3 meses, constituían un $79 \%$, porcentaje algo mayor que aquellos que compartían (74\%).

Los resultados de los informantes de la prueba [44] que afirmaron usar contenido (79\%), difieren con el porcentaje obtenido del obtenido en la prueba [33], pues en ella un 
96,15\% sí que decían utilizar contenidos. En cualquier caso, quienes compartían en [44], lo hacían con una frecuencia elevada.

Como apreciamos en la Tabla 33, eran menos los usuarios que compartían, pero estos lo hacían con una frecuencia elevada. El $21 \%$ y el $27 \%$ de los informantes de la muestra de [44], aseguraban utilizar y compartir contenido digital, respectivamente, con una frecuencia elevada (desde cada día a una vez a la semana). Las personas que no utilizaban ni compartían contenidos digitales nunca eran tres, dos formadoras de profesores ([44] 36_F_FP_Psicología; y [44] 44_F_FP_Pedagogía ${ }^{155}$ ); y una ingeniera profesora e investigadora ([44] 29_F_Ing_Telecomunicaciones). Dos personas compartían contenidos digitales, pero nunca los utilizaron ([44] 36_F_FP_Pedagogía; [44] 25_F_EM_Economía) y una persona los utilizaba, pero nunca los compartía ([44] 24_F_EM_Economía).

Tabla 33 Prueba [44]. Comparación entre utilización vs. compartición de contenido digital

Frecuencia

(1) Nunca

(2) 1 vez cada 3 meses

(3) Entre 1 vez al mes 1 vez quincenalmente

(4) Entre 1 vez quincenalmente 1 vez a la semana

(5) Entre 1 vez a la semana - a diario

(6) Cada día
Utilización

$4-21 \%$

5- $26 \%$

2- $11 \%$

$4-21 \%$

3- $16 \%$

$1-5 \%$
$\mathrm{F}(\mathrm{r})$ acumulada Compartición

45

$5-26 \%$

3- $16 \%$

4- $21 \%$

1112

1514

1816

1919
$2-11 \%$

2- $11 \%$

$3-16 \%$

En el siguiente Gráfico 13 representamos de forma visual estos datos, incluyendo en el eje de abscisas la frecuencia de utilización de contenido digital, y en el de ordenadas, la frecuencia de compartición de contenido digital. Además, distinguimos a cada rol con un color (de este modo, los "formadores de profesores" aparecen representados en azul, los "estudiantes de Máster de Secundaria" en Rojo, y los "ingenieros formadores e investigadores", en verde:

155 El código de identificación de estas personas es Edad_Género_Rol_Área. FP hace referencia a formador/a de profesores; Ing a Ingeniero/a y EM a estudiante de máster de profesorado de educación Secundaria). 
Gráfico 13 [44] Compartición y utilización del contenido digital diferenciada por roles

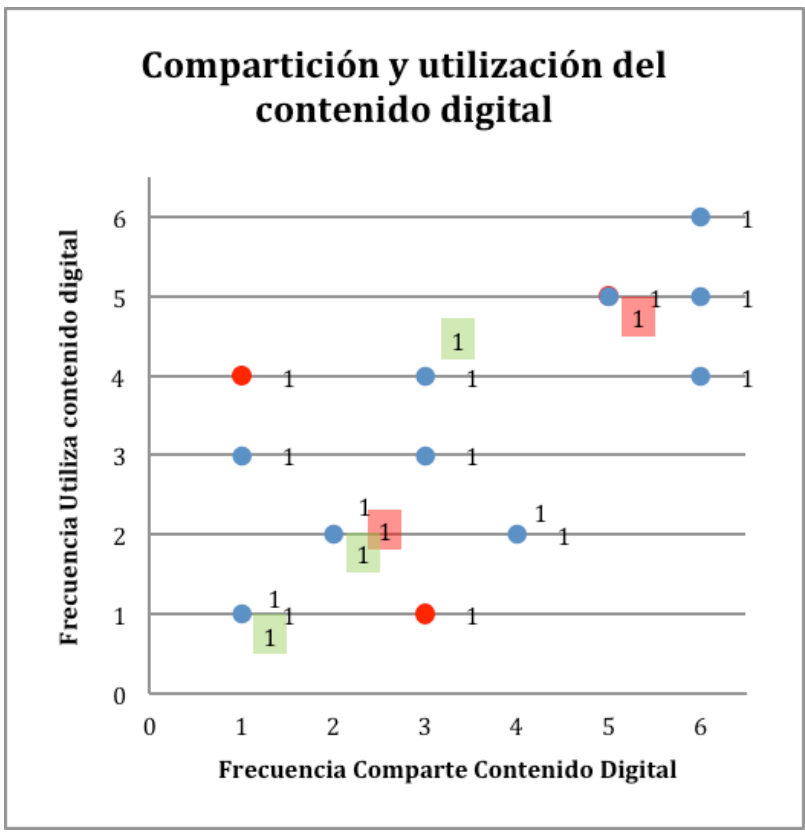

\section{Roles}

Formador de profesores

Máster Ed. Secundaria

(Economista)

Ingeniero, formador e investigador

\section{Frecuencias}

1 - Nunca

2 - 1 vez cada 3 meses

3 - Entre 1 vez mes/1 vez quincena

4 - entre 1 vez/quincena-1 vez semana

5 - entre 1 vez semana/a

diario

6-a diario

\section{2.b) Frecuencia de compartición con herramientas Web}

En la prueba (20, pr.6), preguntamos a los usuarios sobre la frecuencia con la que utilizaban herramientas web para compartir contenidos digitales. Para analizar los resultados planteamos la siguiente hipótesis nula:

$H_{0}$ No hay diferencias de utilización de herramientas para la compartición entre roles (formadores de educación superior y Profesores de Educación Secundaria-Especialistas)

Tabla 34 [20] Tabla de contingencia: frecuencia de uso de herramientas Web para compartir archivos *

Rol

\begin{tabular}{llll}
\hline & $\begin{array}{l}\text { Educación Superior } \\
(\text { ES) }\end{array}$ & $\begin{array}{l}\text { Educación } \\
\text { Secundaria y } \\
\text { Especialistas (Esp) }\end{array}$ & Total \\
\hline Frecuentemente & $1(2,5 \%)$ & $1(4 \%)$ & $2(1,5 \%)$ \\
Ocasionalmente & $23(57,5 \%)$ & $15(60 \%)$ & $38(58,5 \%)$ \\
Nunca & $16(40 \%)$ & $9(36 \%)$ & $25(38,5 \%)$ \\
\hline Total & 40 & 25 & 65 \\
\hline
\end{tabular}


Para comprobar la hipótesis aplicamos un test de Chi-cuadrado de Pearson, y aceptamos $\mathrm{H}_{0}$ con un $\mathrm{p}$-valor de 0,908 a un nivel de confianza del $95 \%$ (2 gl y valor $0,193)$. De acuerdo con lo ejemplificado en la Tabla 34 , la mayoría de los profesores utilizan ocasionalmente las herramientas web para compartir archivos ( $E S=57,5 \%$; $E s p=60 \%$ ); entre un $36 \%$ (ES) y $40 \%$ (Esp) no las utiliza nunca, y entre un $2 \%$ (ES) y $4 \%$ (Esp) las utiliza frecuentemente.

No existen diferencias significativas a nivel de confianza del 95\% entre los dos tipos de roles, profesor de educación Superior, versus profesor de educación Secundaria y Especialistas respecto a la frecuencia de uso de las herramientas Web para compartir archivos. El $58 \%$ las utilizaba ocasionalmente, un número reducido de la muestra (2,9\%) lo hacía frecuentemente. En cambio, sorprende que un $39,1 \%$ afirmaba no hacerlo nunca. Esto apoya la teoría de que los profesores, en general, por diversas circunstancias, comparten con poca frecuencia o nunca contenidos digitales.

\section{2.c) Intencionalidad de Compartición en Share.TEC}

En referencia a la intencionalidad de los usuarios sobre la compartición o no, de sus recursos en Share.TEC, recogimos la siguiente información respecto a la compartición de contenidos digitales en su comunidad y su intencionalidad de compartir estos en el portal Share.TEC (véase Tabla 35): 
Tabla 35 Prueba [33] p.1.) 5.) 8.) Tabla de contingencia ¿Compartes recursos educativos en línea? (Comunidad de intercambio?) * ¿Compartirías tus recursos digitales en Share.TEC? ¿Por qué? * Rol

\begin{tabular}{|c|c|c|c|c|c|}
\hline \multirow[t]{2}{*}{ Rol } & \multirow{2}{*}{\multicolumn{2}{|c|}{$\begin{array}{l}\text { Comparten recursos educativos en } \\
\text { línea con su comunidad de } \\
\text { intercambio }\end{array}$}} & \multicolumn{2}{|c|}{$\begin{array}{l}\text { Compartirías tus } \\
\text { recursos digitales en } \\
\text { Share.TEC }\end{array}$} & \multirow[t]{2}{*}{ Total } \\
\hline & & & Sí & No & \\
\hline Formador de & & Sí & 12 & 2 & 14 \\
\hline \multirow[t]{2}{*}{ Profesores } & & No & 3 & 0 & 3 \\
\hline & Total & & 15 & 2 & 17 \\
\hline $\begin{array}{l}\text { Estudiante de } \\
\text { Máster de }\end{array}$ & & Sí & 1 & 0 & 1 \\
\hline \multirow{2}{*}{$\begin{array}{l}\text { Profesorado } \\
\text { Secundaria }\end{array}$} & & No & 2 & 1 & 3 \\
\hline & Total & & 3 & 1 & 4 \\
\hline \multirow{3}{*}{$\begin{array}{l}\text { Especialistas (Esp) } \\
\text { (maestros, } \\
\text { investigadores, } \\
\text { FOL }^{156} \text { ) }\end{array}$} & & Sí & 4 & & 4 \\
\hline & & No & 1 & & 1 \\
\hline & Total & & 5 & & 5 \\
\hline
\end{tabular}

De acuerdo con los datos mostrados en la Tabla 35, la mayoría de los usuarios de la muestra sí comparten contenidos digitales y sí afirmaron que contribuirían con sus recursos en Share.TEC ( $F P=12$ informantes de 17; 70.58\%; $E M=1 / 4 ; 25 \%$; y $E s p=4 / 5 ; 80 \%)$; encontramos sólo dos casos, y pertenecientes al grupo de formadores de profesores, en los que los usuarios sí que compartían, pero no lo harían en Share.TEC ( $F P=2 / 17 ; 11,76 \%)$. Otros informantes, afirmaron que habitualmente no compartirían, pero consideran que sí lo harían en Share.TEC $(F P=17,64 \% ; \quad E M=50 \% ; \quad E s p=20 \%)$. Este hecho puede ser debido al desconocimiento o deshabituación a la hora de compartir contenidos digitales en este tipo de portales. Únicamente un usuario, estudiante de máster de Secundaria no compartía sus contenidos digitales y no lo haría tampoco en Share.TEC $(E M=1 / 4 ; 25 \%)$.

En la prueba [44] se entregó a los usuarios una guía de ejercicios para probar el portal, y entre ellos, se encontraba la compartición de un recurso en el portal Share.TEC. Pedimos a los usuarios, en el cuestionario que contestaron tras la realización de la prueba, que eligieran libremente entre las 13 afirmaciones

156 FOL hace referencia a los profesores de "Formación y Orientación Laboral". 
disponibles aquellas con las que estaban de acuerdo a la hora de compartir un recurso en Share.TEC.

Los datos que destacamos de esta prueba se concretan en los siguientes aspectos (véase Tabla 36): a los usuarios les parecía un proceso de tiempo medio (8/19) o largo (6/19) el hecho de compartir recursos en el sistema; la mayoría de usuarios entendía los campos que debía seleccionar para catalogar su recurso (11/19), aunque 4 usuarios no los entendían; hay más usuarios (6) a los que compartir un recurso les parecía fácil, aunque 4 decían que les había parecido complicado; el hecho de subir una tarea les resultó tedioso para 7 usuarios, en cambio, ninguno consideró que hubiera sido un proceso no aburrido; 8 usuarios se pronunciaron sobre su intención de sí volver a subir recursos a Share.TEC; en cambio, 2 seleccionaron que no lo harían; la mayoría de los usuarios (11) decían que emplearían Share.TEC para compartir recursos con otras personas; en cambio, 1 expresaba que no lo utilizaría.

Tabla 36 [44] Compartición de contenidos digitales en Share.TEC: afirmaciones con las que los usuarios están de acuerdo

Seleccione las afirmaciones con las que esté de acuerdo a la hora de compartir su propio recurso en el sistema Share.TEC (Múltiple elección)

\begin{tabular}{lll}
\hline Afirmación (múltiple elección libre) & $\mathrm{n}(\mathrm{N}=19)$ & $\%$ \\
\hline Me ha parecido un proceso largo & 6 & $33 \%$ \\
Me ha parecido un proceso corto & 1 & $6 \%$ \\
Me ha parecido un proceso medio de tiempo & 8 & $44 \%$ \\
\hline No entendía los campos que debía seleccionar & 4 & $22 \%$ \\
Entendía los campos que debía seleccionar & 11 & $61 \%$ \\
\hline Me ha parecido complicado & 4 & $22 \%$ \\
Me ha parecido fácil & 6 & $33 \%$ \\
\hline Se me ha hecho pesada la tarea & 7 & $39 \%$ \\
Lo he completado sin aburrirme & 0 & $0 \%$ \\
\hline Volvería a subir otros recursos a Share.TEC & 8 & $44 \%$ \\
No volvería a subir más recursos a Share.TEC & 2 & $11 \%$ \\
\hline Utilizaré Share.TEC para compartir mis recursos con otras personas & 11 & $61 \%$ \\
No utilizaré Share.TEC para compartir mis recursos con otras personas & 1 & $6 \%$ \\
\hline
\end{tabular}

Para varios de los informantes de [44], subir recursos en el portal Share.TEC, por tanto, fue un proceso largo y con algún tipo de dificultad (aburrido, complicado, difícil de comprender), elemento que puede obstaculizar la deseabilidad del usuario 
a la hora de volver a utilizar el portal para compartir sus recursos. En algunos casos, se produjeron dificultades técnicas:

[44] 15.18. 36_F_FP_ No he logrado "Ofrecer" un enlace Web. En principio, los datos introducidos eran los requeridos, pero no me permitía realizar el proceso, que consideraba a falta de algunos datos.

\section{2.d) Comparación entre compartición y utilización entre pruebas:}

A la vista de los resultados, podemos afirmar que los profesionales de la educación, en su mayoría, comparten y utilizan contenidos digitales con su comunidad de intercambio.

Veamos a continuación una comparación entre los datos obtenidos en las pruebas [20], [33] y [44] respecto a la compartición y utilización de contenido digital. Debido a que la muestra de cada una de estas pruebas integra una distribución diferente de tipos y grupos de roles, establecemos la comparación atendiendo exclusivamente a dos grupos: formadores de profesores, y otros formadores y especialistas (véase Tabla 37).

Tabla 37 Diferencia de uso y compartición en las pruebas [20], [33] y [44] entre formadores de profesores vs. la media del conjunto de roles de cada prueba

\begin{tabular}{lllll}
\hline Acción & Rol & Prueba & & \\
& & {$[20]$ (33 FP) } & {$[33]$ (14 FP) } & [44] (12 FP) \\
\hline Usan & FP & *diferencias por & $92,85 \%$ & $83,33 \%$ \\
& Otros & tipos de contenido & $55,55 \%$ & $71,43 \%$ \\
\hline \multirow{2}{*}{ Comparten } & FP & $60 \%$ & $82,35 \%$ & $75 \%$ \\
& Otros & $64 \%$ & $55,55 \%$ & $71,43 \%$ \\
\hline
\end{tabular}

- En las tres pruebas apreciamos que los "formadores de profesores" usaban y compartían en mayor porcentaje que el resto de roles unificados (excepto en la prueba [20], donde los "formadores de profesores" decían compartir menos que los otros profesionales ( $60 \%$ vs. $64 \%$ ).

- El porcentaje de uso por parte de los "formadores de profesores" era muy elevado (92,85\% en [33]; y $83,33 \%$ en [44]). Hemos de señalar que ambas pruebas fueron realizadas en el contexto español, y que en [33], la mayoría de los formadores pertenecían al área de tecnología educativa, hecho que puede hacernos pensar que las personas de esta área tienen una mayor inclinación a la compartición de estos contenidos. 
- Presenta la misma tendencia el porcentaje de compartición, es decir, los informantes de la prueba [33], formadores de profesores compartían algo más que los de la prueba [44] (82,35\% vs. $75 \%)$.

- En cuanto a la compartición, encontramos mayores diferencias entre las tres pruebas, pues decían compartir el $60 \%$ de los "formadores de profesores" en [20]; el $82.35 \%$ en [33]; y el $75 \%$ en [44]. Esto puede ser debido a que en la prueba 20 había una representatividad mayor de formadores de Educación Superior de otras áreas diferentes a la Educación, dentro de los formadores de profesores.

- Atendiendo exclusivamente a los formadores de profesores de las pruebas [33] y [44], encontramos que los informantes formadores de profesores de diversas nacionalidades de la prueba [33] comparten y utilizan proporcionalmente más que los informantes exclusivamente formadores de profesores de la prueba [44] pertenecientes al ámbito español (hemos de tener en consideración que la muestra de informantes, en ambos casos, es muy limitada, y que en la muestra [33], la mayoría de formadores de profesores pertenecían al área de Tecnologías de la Información y la Comunicación). Parece que existe cierta coherencia entre los datos, pues la mayoría de formadores de profesores comparte y utiliza, siendo los porcentajes de compartición menores que los de utilización.

- En cuanto a la compartición de contenido atendiendo a los "otros formadores y especialistas", presentan una tendencia algo más homogénea entre pruebas, pues el $64 \%$ de [20], el $55,5 \%$ de [33] y el $71,43 \%$ de [44] decían compartir sus contenidos digitales.

- Notamos que el porcentaje de compartición de la prueba [20] es menor que en el resto de las pruebas [33] y [44] (véase Tabla 37). Este hecho puede ser debido a que en la prueba [20] preguntamos con qué frecuencia utilizaban herramientas web para compartir contenido digital con otros, y es posible que sí que compartieran contenido por otros medios (e.g., memoria flash). En cambio, en las pruebas [33] y [44] preguntamos, en general, con qué frecuencia compartían (sin especificar los medios).

Comparación intrapruebas (formadores de profesores vs. conjunto de informantes)

- En la prueba [33], existe una diferencia bastante significativa entre el porcentaje de "formadores de profesores" que utilizaban contenidos digitales vs. al "resto de formadores y otros especialistas" ( $92,85 \%$ vs. $55,55 \%)$. 
- En cuanto a la compartición que reflejaban los informantes en la prueba [33], ocurre algo similar a la utilización, pues lo hacían el 82,35 de los "formadores de profesores comparten", vs. el $55.55 \%$ de los "otros profesionales relacionados con la educación"

- De este modo, apreciamos que en la prueba [33] los formadores de profesores accedían a contenidos digitales más que compartían $(92,85 \%$ vs. $82,35 \%)$, aunque, en cualquier caso, realizaban las dos acciones con elevada frecuencia.

- Existe una diferencia menor sobre la utilización en la prueba [44] entre los "formadores de profesores que utilizaban contenido digital" vs. los "otros formadores y especialistas" (83,33\% vs. $71.43 \%)$.

- Y siguiendo esta misma tendencia, la diferencia de compartición entre "formadores de profesores" y "otros formadores y especialistas" (75\% vs $71,43 \%)$, es aún menor que la diferencia de uso.

- La prueba 20 también indica que los dos grupos, "formadores de profesores" y "otros profesionales de la educación" compartían con frecuencias similares (60\% vs. $64 \%)$.

\section{2.e) Con quién comparten}

En el cuestionario de impacto del portal Share.TEC, segunda encuesta coordinada [35], se preguntó a los usuarios con quién compartían sus recursos (se pidió a los informantes que eligieran una de las tres opciones, en función de la frecuencia con la que lo hacían). El $38 \%$ de los formadores y profesores afirmaron compartir sus recursos con estudiantes, El $38 \%$, con sus compañeros de trabajo, y el $24 \%$, con cualquiera que los necesitara, ya fueran de su propio colegio 0 institución o no.

En otras pruebas [17] y [33], también preguntamos a los usuarios si compartían recursos, qué les parecía el hecho de compartirlos, y con quién lo hacían. Los informantes lo hacian habitualmente con sus compañeros de trabajo 0 de área, es decir, en sus micro-comunidades o comunidades profesionales.

[17] p2. Q_FP [...] a mí hay una cosa que me gusta hacer, que es un poco colaborativo. Es el tema de que a veces encuentro cosas que a mí no me interesan nada, pero siempre tengo en la cabeza a alguien que le puede interesar y lo suelo enviar. [...] Y yo creo que eso sería... el promover ese tipo de historias, porque pierdes 5 segundos, y el beneficio que haces a la otra persona es bastante grande. 
[33] p9.19. FP_46_M_sí, con compañeros de mi propio departamento [17] p.6. I_FP nosotros también utilizamos alguna vez "Sinergeia", que es la versión de BSCW, que está cerrada, claro. Incluso las wikis, y eso [33] p8.4. EM_27_F_Actualmente ya lo hacemos, de una manera similar, en mi oficina.

[33] p13.19. FP_46_M_que es interesante entre compañeros que trabajan en la misma materia

[33] p13.25. ES_43_M_Me parece muy bien, de hecho yo lo hago con mi grupo.

Estos datos cualitativos guardan relación con los datos que obtuvimos en la prueba [33] (véase Tabla 29) de los motivos por los que compartían contenido digital, recordemos que el $41,18 \%$ de los informantes los empleaba como ayuda para preparar las clases (es decir, material de referencia), El 17.64\% los utilizaba directamente en clase, sin adaptaciones. y el $41,18 \%$, para investigar.

Es decir, muchos formadores (independientemente del ámbito -ya sea formación del profesorado, educación secundaria, etc.-) compartían los recursos que elaboran 0 encontraban con sus estudiantes con propósitos de enseñanza-aprendizaje; en cambio, la compartición con otros compañeros de profesión, atendiendo a los datos obtenidos por nuestros informantes en las diferentes pruebas, no era muy alta, y cuando comparten tendían a hacerlo con personas cercanas, profesionalmente o físicamente (compañeros de su institución/departamento/grupo de investigación). Estos datos avalan la falta de cultura de compartición de contenido digital en las áreas de la formación, por lo que se justifica la necesidad de concienciación de este aspecto en los planes de formación del profesorado.

\section{2.f) Lugar de compartición}

Existe cierta cultura de compartición de contenidos digitales difícilmente trazable mediante sistemas automáticos, ya que muchos usuarios recurren a métodos privados para tal fin (e.g., en grupos de profesores o estudiantes concretos mediante entornos virtuales de aprendizaje como Moodle, a través de memorias flash, correos electrónicos, etc. Aún parecen tener relevancia los métodos tradicionales para la compartición del contenido, pero los métodos digitales están en auge (e.g., Blogs, Wikis, Portales de contenido digital, etc.).

Los formadores de profesores y profesores de otros niveles, utilizan diversos tipos de recursos para la compartición del contenido digital (tanto públicos, como privados o semiprivados). Tras el análisis de los datos, observamos que aproximadamente la mitad de los informantes utilizan servicios públicos para 
compartir sus archivos, en cambio, aún constituye un porcentaje elevado el número de personas que comparten sus contenidos en medios únicamente privados.

En la prueba [33], los 26 informantes podían elegir varias de las siguientes opciones, obteniendo los resultados que presentamos a continuación:

- (46\%), 12 formadores comparten en Plataformas públicas;

- (46\%), 12 formadores comparten en plataformas privadas;

- (27\%) 7 en plataformas semiprivadas (cualquier formador que esté interesado en utilizar una plataforma, puede solicitar su acceso);

- (31\%) 8 lo hacen a través de la compartición de memorias flash con sus compañeros; $y$

- (8\%) 2, mediante otros medios.

Recordemos que 17 de los 26 informantes de esta prueba eran formadores de profesores del área de tecnologías educativas de la información y la comunicación, y es posible que si tuviéramos una muestra más representativa y diversa, los resultados fueran diferentes. Aún así, los datos nos llaman la atención, pues existe un alto porcentaje de compartición en medios privados o semiprivados.

Valiéndonos de los resultados de la prueba [33], en la prueba [44] volvimos a preguntar a los informantes sobre las herramientas Web que utilizaban para acceder a contenidos digitales. Atendiendo al siguiente Gráfico 14, vemos que las más frecuentes son: Dropbox y e-mail (espacios privados o semiprivados); seguidos de Facebook (espacio público); Moodle (diferentes tipos de privacidad), Twitter (público), Blogs (diferentes tipos de privacidad), etc. 
Gráfico 14 [44] Herramientas que utilizan los informantes para compartir contenidos digitales

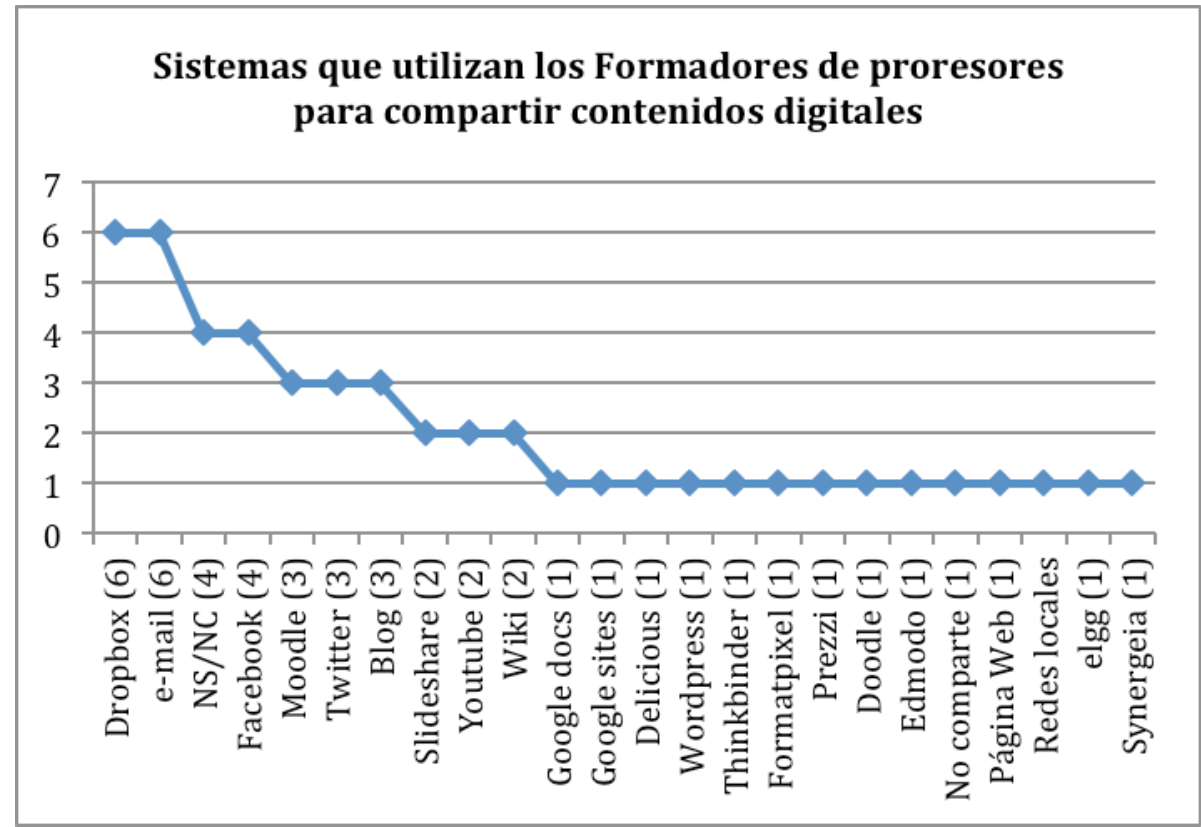

Los informantes, en la prueba [17], relataron un incremento cada vez mayor de la exposición pública de sus contenidos digitales, pero también se siguen utilizando espacios privados

[17] p6. ¿Qué soléis utilizar para publicar vuestros recursos digitales, o recursos en formato digital?

[17] p6. Iv_FP.: yo creo que cada vez publicamos más en línea. Yo en mi página personal publico prácticamente todo. Quiero decir, salvo los problemas de los derechos de autor de los papers, el resto, todo, todo; o sea, desde un diario personal on-line, hasta... no sé, o sea, todo.

[17] p6. V_FP: los colgamos en wiki, sea pública (tipo Wikispaces), o de la nuestra, la que está alojada en nuestro servidor del grupo de investigación, pero que en muchos casos es pública. En otros casos, si la información es un poco sensible, pues hemos tenido que cerrarla.

[17] p6. E_Ing: pues para una comunidad concreta como los participantes del curso de Buendía, utilizábamos el BSCW, que tenían acceso restringido a ciertas carpetas, y fuera de esa comunidad no se podía acceder a los documentos. Y aparte de eso, páginas Web alojadas en el servidor del 
grupo. Ahora más la wiki, pero antes hacíamos las páginas un poco más a pelo.

[17] p6. R_FP.: y con alumnos, alguna vez hemos utilizado YouTube, para colgar algunos vídeos. O Slideshare.

[17] p6. In_FP.: Nosotros también utilizamos alguna vez Sinergeia, que es la versión de BSCW, que está cerrada, claro... incluso las wikis, y eso.

\section{2.g) Facilitadores y obstáculos para la compartición}

En la prueba [33] preguntamos a los usuarios si creían que Share.TEC podría ser una herramienta útil para la creación de sus materiales, a lo que 19 usuarios contestaron que sí lo era, mientras que 7 dijeron que no. Si la herramienta que existe en un determinado servicio para compartir contenidos digitales no es útil y adecuada, provocará que los usuarios no tengan deseo de compartir sus materiales en el sistema.

Algunos de los elementos que identificamos entre los que podían conducir al usuario a compartir contenidos en un sistema similar a Share.TEC fueron los siguientes:

- La existencia de un servicio que dé cobertura y facilidades técnicas a una red multidisciplinar de profesorado donde poder compartirlos, tal y como se evidencia en los siguientes comentarios:

[33] p8.1. SF_34_F_contar con una red de profesorado multidisciplinar puede favorecer la creación de recursos diversos para el uso compartido.

[33] p8.5. EM_26_F_sí, si hubiera herramientas para ello.

- La obtención de feedback por parte de otras personas sobre los recursos que comparte el usuario puede ser un elemento motivador para subir recursos a un portal profesional, así como un potenciador de la mejora de los materiales del profesor:

[33] p8.9. SF_38_M_Para la creación no lo sé, pero si puede ser muy útil para la remodelación, debido a que otra gente puede dar su opinión acerca de mis recursos.

[33] p8.11. EM_49_M_ofrece la posibilidad de compartir documentos, remodelarlos, etc.

- Los informantes consideraron que en comunidades más cerradas y pequeñas, se propicia más la compartición, atendiendo a los siguientes argumentos:

[33] p8.16. FP_57_M_Sobre todo cuando ese grupo pertenece a una asociación de profesionales o a un colectivo que participa en un curso. 
[33] p9.19. FP_46_M_sí, con compañeros de mi propio departamento

- Uno de los incentivos más importantes para la utilización de un determinado servicio, puede ser la seguridad de acceder a contenido de buena calidad:

[33] p10.4 EM_27_F_Pienso que podría ser un portal muy útil siempre y cuando los contenidos que tuviera, o que se subieran, fueran buenos, es decir, si tuviera un filtro que no dejara subir cualquier tipo de contenido.

Entre los aspectos que dificultan la compartición de los contenidos digitales, podemos destacar los siguientes:

Los profesionales de la educación utilizan los sistemas de contenido digital con más frecuencia para acceder a materiales que para compartirlos, como veíamos en la Tabla 31 y en la Tabla 33, correspondientes, respectivamente, a las pruebas [33] y [44].

[33] p8.14. FP_54_M_La gente utiliza más este tipo de herramientas para obtener que para dar.

[33] p8.25. ES_43_M_El problema no es tanto la herramienta, hay muchas parecidas, sino las condiciones de trabajo y la cultura inercial de (no) colaboración.

[33] p5.8. SF_38_M_Si por la formación que tengo pero creo que el profesorado necesita formación y mentalidad a la hora de compartir.

Esto se debe a diferentes motivos, que no constituyen objeto de estudio de esta tesis, pero entre los más mencionados por los usuarios se encuentran la facilidad de compartición en el sistema y el tiempo del que dispone el usuario para compartirlos.

[33] p9.18. FP_29_M_En principio sí, pero siempre dependerá de la dedicación y el tiempo disponible

[33] p9.24. FP_51_F_De momento no lo hago porque todo requiere tiempo, pero lo podría recomendar a otros educadores.

Algunos usuarios afirman que no tendrían problema en compartir sus contenidos, siempre que el proceso de etiquetado fuera automático:

[33] p5.25. ES_43_M_Siempre que no tuviera que entrarlos yo.

La existencia de múltiples servicios para la obtención de contenido digital, favorece no sólo la dispersión del contenido, si no, también la dispersión de los usuarios. Estos motivos pueden conducir a la sobrecarga del usuario y propiciar que no utilice más servicios. 
[33] P9.25. ES_43_M_Porque participo de otros entornos y ya es demasiado.

\section{2.h) Opinión sobre la compartición}

Además de estos elementos que facilitan y obstaculizan la compartición de contenido digital para la formación del profesorado, en la prueba [33] preguntamos a los usuarios su opinión sobre la adecuación de la existencia de servicios para la compartición de contenido digital similares a Share.TEC. Todos los usuarios de la muestra creían que era un servicio necesario. Los motivos más relevantes, expuestos por los usuarios fueron los siguientes:

- La importancia de compartir para generar una red donde contribuir y acceder a contenidos digitales, tanto para establecer un relación con los contenidos como con las personas de la red.

[33] p5.1. SF_34_F_el profesorado demanda recursos digitales para sus prácticas docentes y no siempre dispone de los medios para poder acceder a ellos por lo que es importante que todos compartamos los recursos de los que disponemos para poder de esta manera, crear una gran comunidad de aprendizaje compartido.

- El valor de compartir y cooperar con otros profesionales, proporcionando y adquiriendo recursos y opiniones sobre los mismos, de forma que se potencie la innovación profesional.

[33] p5.5. EM_26_F_Porque creo que el material es bueno compartirlo y que los demás profesionales puedan seguir trabajando y desarrollando una idea para que haya innovación educativa y se progresó en este ámbito.

[33] p5.9. SF_38_M_Pueder ser bastante útil, no solo para que otra gente pueda utilizar mis recursos, sino para que lo puedan modificar y mejorar.

[33] p5.13. EM_29_M_Para que sean de utilidad para otras personas. Creo que es muy enriquecedor que haya portales de este tipo donde se comparten recursos, es una manera eficiente de aprovechar el trabajo de otros y el tuyo propio.

- La necesaria existencia de un servicio de contenidos digitales como lugar de referencia de contenido y como elemento impulsor del conocimiento y las buenas prácticas.

[33] p5.10. FP_46_M_En la universidad de la imprenta la biblioteca era un elemento central. En la universidad del siglo XXI el acceso a los recursos digitales se convierte en un elemento clave. 
[33] p5.7. SF_31_M_Creo que siempre es positivo generar un red de conocimiento en todos los campos

[33 p5.11. EM_49_M_es la esencia del mismo funcionamiento del sistema...compartir el conocimiento.

[33] p13.22. FP_35_F_me parece buena idea el poder compartir recursos para mejorar las buenas prácticas

- Los informantes enfatizaron la ventaja de poder localizar contenidos digitales con etiquetas pedagógicas.

[33] p5.19. FP_46_M_Es interesante para localizar recursos etiquetados pedagógicamente

\section{3) Hábitos de Reutilización}

\section{3.a) Reutilizan o no}

La mayoría de informantes de la prueba [44] afirmaron reutilizar contenido digital; al parecer, los usuarios a los que encuestamos en la prueba [35], no reutilizaron el contenido digital que encontraron en Share.TEC, aunque desconocemos los motivos de este hecho (calidad del material, ausencia de tiempo desde que encontraron el material para poder compartirlo, etc.).

La mayoría de informantes de la prueba [33] afirmaron que reutilizaban los contenidos digitales que encontraban en la red (25/26). La persona que respondió que no, dijo no confiar en la reutilización de materiales, aunque consideraba que podría ser interesante para otros:

[33] p8.17. FP_36_M_No confío en la reutilización de materiales, pero creo que es interesante para mucha gente.

Los usuarios que probaron Share.TEC en la prueba piloto perteneciente a la segunda encuesta coordinada [35], no reutilizaron el material que encontraron, en su mayoría. Únicamente el $31 \%$ de los usuarios lo utilizaron, el $62 \%$ dijeron no haberlo utilizado (el 7\% de los informantes no contestó a esta pregunta).

\section{3.b) Cómo reutilizan}

En la prueba [44] (p.7), preguntábamos a los informantes si modificaban los recursos que recuperaban de otros autores para su práctica educativa o si los utilizaban sin alterarlos. De los 19 sujetos de la muestra, 11 dicen modificarlos, mientras 8 no lo hacen. 
Quienes modifican los contenidos digitales to hacen atendiendo a las necesidades de su contexto educativo o temática a abordar, tal y como sugieren los siguientes extractos.

[44] p8.15. 27_F_FP_Adaptaría los contenidos a las necesidades de mi alumnado, siempre reconociendo la autoría de la persona que ha diseñado el recurso.

[44] p8.14. 36_F_FP_Pues los adapto en función de la temática o el contexto, o a lo mejor lo que hago es acortar el texto o coger solo una parte del artículo o del documento.

[44] p8.10. 54_M_FP_adaptando a mi realidad, actualizando, contextualizando la temática.

[44] p8.9. 31_M_FP_Rehago los esquemas y diagramas para no introducir notación que confunda. Completo con información que adapte los contenidos de la materia.

También lo hacen teniendo en cuenta su propio estilo docente:

[44] p8.7.27_F_EM_Intento adaptarlo a mí manera de dar clase, y sacar lo mejor de cada recurso o material

Otros profesionales utilizan extractos del contenido que recuperan para ilustrar:

[44] p8.18. 36_F_FP_Cito los datos de la investigación del autor para ejemplificar la docencia.

\section{B) Aspectos técnicos del sistema Share.TEC}

\section{B.1 ¿Qué opinan los formadores de profesores del servicio de búsqueda ofrecido por Share.TEC?}

Para el 77\% - 20- de los informantes de la prueba [33] (p.3) fue fácil de utilizar el buscador para encontrar contenidos digitales en Share.TEC; no siéndolo para 6 usuarios $-23 \%$ -

En relación con la facilidad de uso del buscador de Share.TEC, en el cuestionario [44] (p.25), consultamos a los formadores lo fácil o difícil que les parecía encontrar recursos en el sistema, siendo 1 totalmente imposible, y 5 , totalmente fácil. Como vemos en la Tabla 38 , a ningún usuario le pareció totalmente fácil; para a un amplio porcentaje, fue bastante fácil (8; $42 \%)$; para el $21 \%$, mientras que para un $1,5 \%$ de los encuestados fue imposible o bastante difícil $(3,16 \%)$. E 
resto de los informantes valoró que esta característica del sistema presentaba una dificultad media $(7 ; 37 \%)$.

Por tanto, para la mayoría de informantes de la prueba [33] el buscador de Share.TEC fue fácil de utilizar; en relación a este dato, la facilidad de la en el portal también fue considerada asequible para la mayoría de los informantes de la prueba [44], ya que la puntuación media fue de 3,16 , con una $\sigma$ de 0,898 .

Tabla 38 Prueba [44]: Respuestas de los informantes sobre la facilidad de búsqueda de contenidos digitales en Share.TEC

\begin{tabular}{llr}
\hline Hacer búsquedas en Share.TEC.. & $\mathrm{n}$ & \multicolumn{2}{c}{$\%$} \\
\hline 1. Me resulta imposible & 1 & $5 \%$ \\
2. Me resulta bastante difícil & 3 & $16 \%$ \\
3. Me resulta de dificultad media & 7 & $37 \%$ \\
4. Me resulta bastante fácil & 8 & $42 \%$ \\
5. Me resulta totalmente fácil & 0 & $0 \%$ \\
\hline
\end{tabular}

En ambas pruebas [33] y [44] coinciden los resultados de las opiniones de los informantes sobre la facilidad de uso y la facilidad de encontrar contenidos digitales. El porcentaje de aquellos que consideraron imposible utilizar el buscador, o bastante difícil, supusieron un $21 \%$; resultado similar al $23 \%$ de la prueba 33 , que consideró que el buscador era difícil usar.

A la hora de realizar búsquedas, debido a la baja calidad del buscador, que no contemplaba la búsqueda de palabras similares por campo semántico, ni tenía en cuenta errores de escritura, el número de resultados que se encontraban era menor que el número de recursos que contenía el sistema. Por ello, los profesores demandaban la necesidad de generar diferentes soluciones, tales como la inclusión de un tesauro, o guiado para realizar las búsquedas, tal y como se evidencia en los siguientes extractos:

[Anexo 11]: -Propuesta de UVa: ¿Es posible que necesitemos un tesauro para solventar las dificultades a la hora de encontrar recursos para evitar la pérdida de resultados cuando se introducen palabras clave poco acertadas o escritas incorrectamente? -TCD: La inclusión de un tesauro es una idea excelente

[33] p4.10. SF_38_M Echo de menos un poco de "guiado" acerca de las palabras claves para emplear en las búsquedas. 
[21] "El buscador tiene defectos, y encuentras resultados diferentes en función de la combinación o no de palabras clave".

[21] FP_F_45 [...] Hay demasiadas dificultades en la forma de realizar la búsqueda, con grandes diferencias si se utiliza la palabra de búsqueda en singular o en plural, no hace sugerencias para facilitar otros términos en el idioma de la búsqueda, y es poco "amigable" [...].

Las búsquedas simples tenían un funcionamiento mucho más óptimo que las búsquedas avanzadas. La razón es simple, y es que las búsquedas avanzadas eran demasiado rígidas, y si se seleccionaban varios campos, no se permitía la opción de encontrar resultados próximos (no exactos), tanto obviando alguno de los campos "avanzados" seleccionados o realizando búsquedas aproximadas (palabras clave cercanas).

[44] p24.4 29_F_ING_Dado que muchos recursos no están completamente etiquetados, al incluir a la búsqueda por palabras (la misma utilizada en la búsqueda simple) la restricciones de idioma=italiano y nivel educativo=educación universitaria, no se han obtenido resultados. Sin embargo, al revisar los obtenidos con la búsqueda simple sí había recursos que satisfacían dichas características.

[44] p24.14 36_F_FP_He tenido dificultades, porque no me encontraba las palabras que yo ponía, sobre todo cuando marcaba las $\mathrm{X}$ en las secciones de categorías. Al final he tenido que poner solo la palabra, y entonces sí que me ha salido.

[21] Adjetivo: Poco refinado. "Porque las búsquedas son muy generales y las palabras clave no se encuentran".

[21] Adjetivo: Ineficaz. "Los criterios de búsqueda son no claros, por lo que al final, pierdes tiempo y paciencia".

[21] Adjetivo: Inquietante. "El buscador tiene defectos, y encuentras resultados diferentes en función de la combinación o no de palabras clave".

Por estos motivos, los usuarios consideran que necesitarían algún tipo de guía para poder realizar búsquedas más óptimas:

[33] p4.10.SF_38_M_Los de la búsqueda avanzada sí, pero echo de menos un poco de "guiado" acerca de las palabras clave a emplear en las búsquedas.

Además, el miembro del consorcio OUNL (Holanda), propuso que, en la búsqueda avanzada, cuando los contenidos digitales no tuvieran etiquetados ciertos metadatos, desaparecieran los campos de elección a medida que se iba filtrando: 
[Anexo 16] Problema: el usuario no puede elegir "formato de idioma" y "formato del recurso" en Búsqueda avanzada. Sugerencia: si están vacías, no deberían mostrarse.

Veamos la opinión de los usuarios sobre cada uno de los tres tipos de opción de búsqueda: simple, avanzada y mediante la utilización de filtros.

\section{Búsqueda simple}

Como hemos visto al principio de este apartado, los usuarios no tienen dificultades para realizar sus búsquedas con la opción de búsqueda simple del sistema, y consideran que las búsquedas se obtienen de forma rápida:

[21] Adjetivo: Ahorra tiempo "Buscando era rápido"

[21] Adjetivo: Eficaz. "Recibí los resultados necesarios"

\section{Búsqueda avanzada}

Para acceder a la búsqueda avanzada, el usuario tenía que hacer clic en el link "Avanzada" (advanced) que apreciamos en la llustración 29 y accedía a la siguiente interfaz (llustración 30), donde encontraba las opciones de: filtrar buscando con varias palabras, con una frase exacta, con al menos algunas palabras, sin algunas palabras, por autor, idioma del recurso, modo de empleo (presencial, a distancia 0 blended learning), tipo de contenido digital, según si querían encontrar recursos con estructura pedagógica o sin ella, área de conocimiento, contexto educativo de aplicación del material, tipo de institución educativa, y competencias/habilidades que se desarrollan con el recurso.

llustración 29 Interfaz de búsqueda simple en Share.TEC

TAKE USE GIVE

Advanced | Browse | Sign in

Search in Share.TEC 
llustración 30 Interfaz de búsqueda avanzada

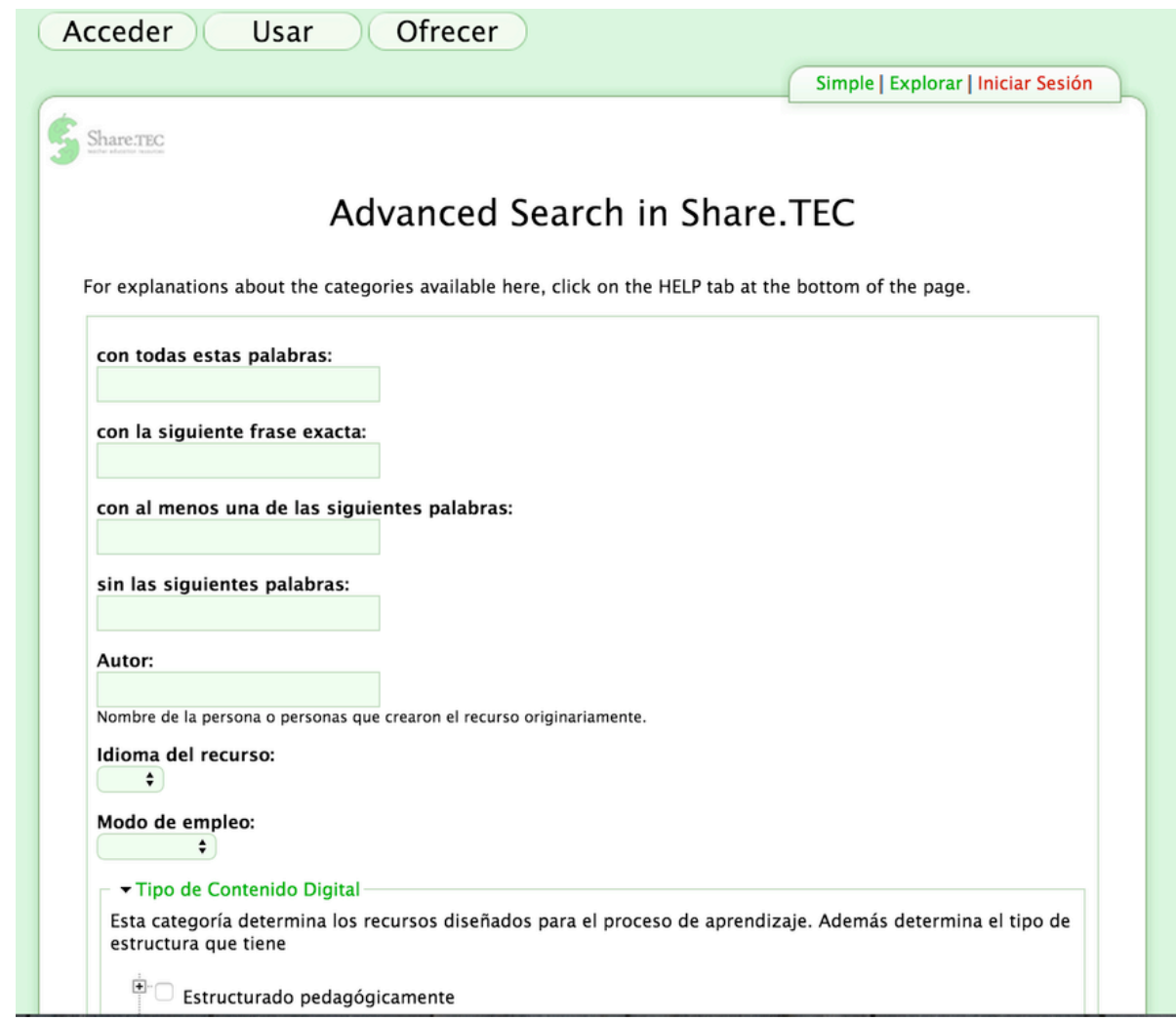

Algo más de la mitad de los informantes de la prueba [44], pr.12, (12 de 19 personas), afirmaban que la búsqueda avanzada les funcionó correctamente y obtuvieron los resultados que esperaban; en cambio, no fue así para 7 de los 19 informantes.

En la prueba [21] preguntamos a los usuarios, en una escala Likert de 1 a 5 (siendo 1, "totalmente en desacuerdo", 2, "poco desacuerdo"; 3, "ni acuerdo ni desacuerdo", 4, "bastante de acuerdo", 5, "totalmente de acuerdo") su opinión sobre tres afirmaciones (de las que reflejamos la media y desviación típica de la puntuación):

- Los usuarios estuvieron de acuerdo en que la búsqueda en el sistema no era muy natural (siendo la media $\mu 2,14$, con una pequeña $\sigma, 0,38$ ). 
- La mayoría de los usuarios, en promedio, constaron que las opciones de búsqueda avanzada (widgets) (título, descripción, idioma de trabajo, etc.), era las que utilizan con frecuencia cuando realizan búsquedas $(\mu 3,57 ; \sigma 0,79)$.

[44] p24. 44_F_FP Me parece completa, con diferentes opciones en función de la concreción de la búsqueda que se quiera realizar

- En cuanto a la cantidad de widgets de búsqueda, opinaron no estar ni de acuerdo ni en desacuerdo en que eran escasos ( $\mu$ 3,00; $\sigma$ 1,15). La puntuación media de este ítem es el que más desviación típica presentaba, por lo que algunos usuarios sí que los consideraba escasas, mientras que otros no. llustramos un extracto de la observación realizada en una prueba piloto del portal, donde la informante consideraba escasos los widgets:

[Anexo 8] Las dos formadoras de profesores que están realizando la prueba piloto han descubierto el menú derecho en la interfaz de usuario de Share.TEC, filtrando su búsqueda por idioma (han aparecido 20 WebQuests que cumplen los requisitos de su búsqueda). Una formadora dice: "la búsqueda avanzada es incompleta".

Atendiendo a los resultados obtenidos, la búsqueda avanzada es mejorable, pues los informantes no obtenían de forma suficiente todos los resultados que buscaban -7 de 19 personas de la prueba [44] constituye una proporción significativa-; a pesar de que los informantes consideraron que los campos de búsqueda son avanzados - $\mu$ 3,57; $\sigma 0,79$-, por lo que concluimos que si se flexibiliza el motor de búsqueda aportando resultados próximos, y se muestran resultados que atiendan si no a todos, a algunos de los criterios especificados (mostrando primero los resultados que cumplen más criterios, y especificando cuáles no cumplen), se incrementarían los resultados obtenidos en el portal.

\section{Búsqueda por filtrado}

La mayoría de los usuarios, en la prueba [44], consideraron que los campos de filtrado eran compartidos conceptualmente por su comunidad educativa (16/19), en cambio, no fue así para tres usuarios.

Las funcionalidades de filtrado valoradas como más útiles por los usuarios, de mejora a peor puntuadas, son: filtrar por idioma ( $\mu 4,10 ; \sigma 1.12$ ), seguida por formato $(\mu 3,58, \sigma 1,04)$, institución $(\mu 3,27 ; \sigma 0,93)$, coste $(\mu 2,89 ; \sigma 1,21)$ y colección ( $\mu 2,79, \sigma$ 0.95). De este modo, tanto el coste como la colección, no alcanzan la puntuación media, luego fueron consideradas como las menos útiles; en cambio, especialmente el idioma, constituía uno de los filtrados más útiles de los 
usuarios, así como el formato. En el Gráfico 15 apoyamos visualmente estos datos para complementar su comprensión, indicando con un color diferente cada grado de utilidad, y el número de personas que puntúan estos grados en cada filtro.

Gráfico 15 Prueba [44]. Valoración de los informantes sobre los diferentes filtros que ofrece Share.TEC

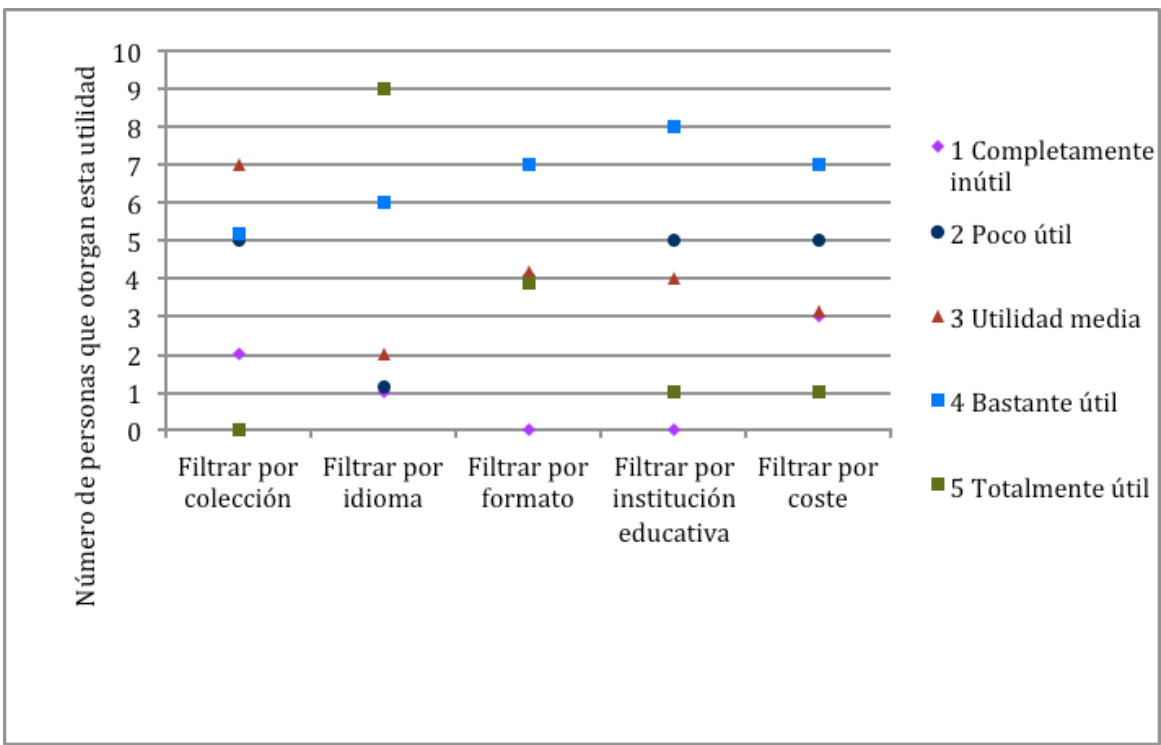

Los usuarios aprecian estas funcionalidades de personalización de los resultados:

[33] p4.15. FP_53_M_he hecho una búsqueda y he encontrado un buen y variado tipo de recursos. Me parece interesante la clasificación por tipología (texto, videos, etc.)

Algunas de las opciones que los informantes echan en falta en las opciones de filtrado, son las de poder elegir recursos en más de una lengua (ya que actualmente sólo permite filtrar una), y poder establecer límites temporales (es decir, seleccionar de una cierta fecha a otra).

[44] p27_F_EM_Lo dicho sobre el idioma. Me gustaría seleccionar varios. [44] p44_F_FP_C Por antigüedad, es decir poder usar límites temporales. 


\section{B.2 ¿Qué funcionalidades demandan los formadores de profesores para este tipo de sistemas y qué opinan de las ofrecidas en Share.TEC?}

Las funcionalidades que se ofertaban en el portal Share.TEC, fueron valoradas, en general, de forma positiva por los usuarios.

Dividimos las funcionalidades en dos tipos: generales y específicas.

Nos referimos a las funcionalidades generales de acuerdo con las tres opciones principales que oferta el portal: Acceder, Usar y Ofrecer. Cuando preguntamos a los informantes por su opinión, en general, respecto a estas tres, todas ellas aprueban ante la valoración de los informantes. En la Tabla 39 apreciamos que la puntuación media de las tres opciones es superior a 3 , a pesar de que hay usuarios que las desaprueban, y otros que las consideran notables, tales como vemos en las medias y desviaciones típicas de estas preguntas de la prueba [44]. En ellas podían valorar del 1 al 5 los siguientes apartados (siendo 1, "totalmente inadecuado"; y 5, "totalmente adecuado") atendiendo a la valoración general teniendo en cuenta todas sus características (aspecto visual, interacción, calidad de la descripción de las contenidos, etc.).

Tabla 39 Prueba 44. Valoración general de los apartados Acceder, Usar y Ofrecer

\begin{tabular}{llll}
\hline $\mathrm{N}$ Válidos $(\mathrm{n}=19)$ & Valore de 1 al 5 & $\mu$ & $\sigma$ \\
\hline 19 & Acceder & 3,37 & 0,761 \\
18 & Usar & 3,28 & 0,826 \\
19 & Ofrecer & 3,37 & 0,955 \\
\hline
\end{tabular}

Denominamos funcionalidades específicas a aquellas que encontramos dentro de las generales.

Todas las funcionalidades específicas del apartado "usar" fueron puntuadas de forma positiva 0 bastante positiva. Mostramos en el siguiente Gráfico 16 la valoración de los usuarios sobre la utilidad, facilidad de uso (usabilidad) y calidad de la interfaz de las funcionalidades, en una escala de 1 a 5 (siendo 1 la puntuación más baja, y 5 la más alta): 
Gráfico 16 Prueba [44]. Opinión sobre la Utilidad, Facilidad de Uso e Interfaz de las Funcionalidades del apartado Usar de Share.TEC

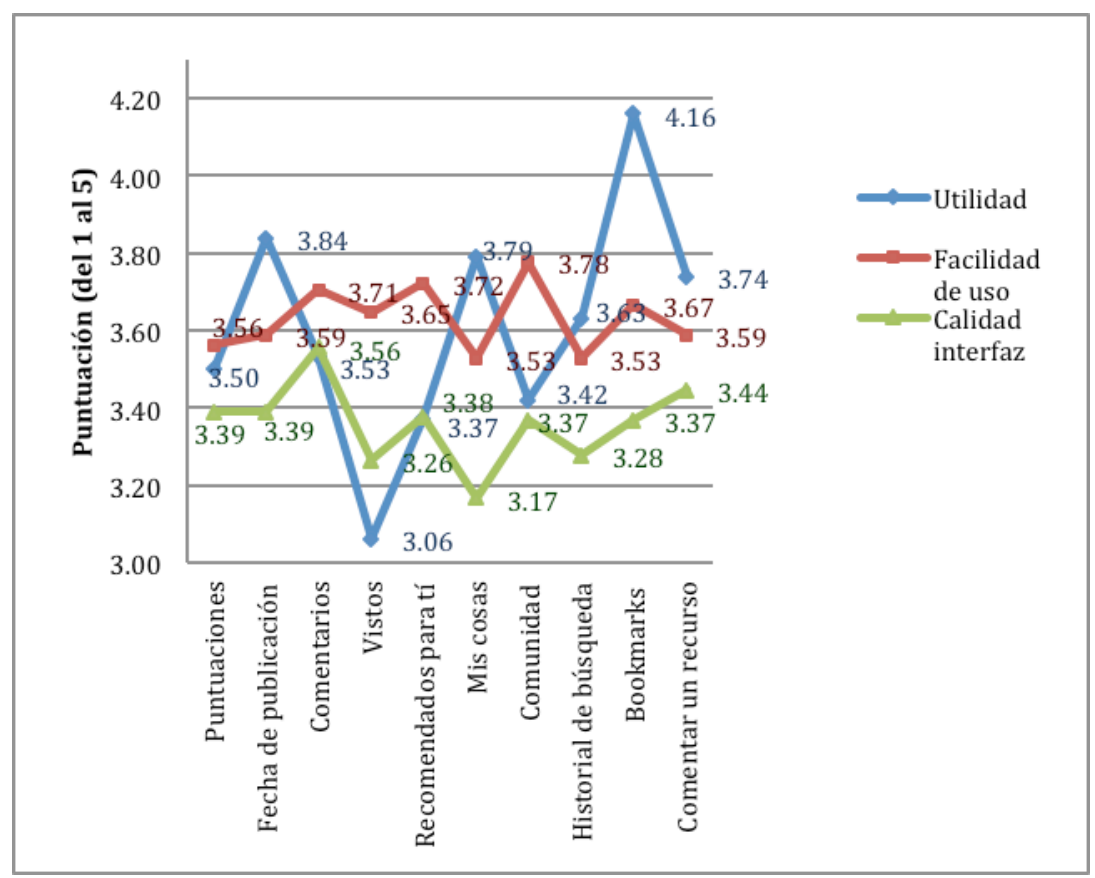

Las funcionalidades destacadas más positivamente por los informantes, en general, teniendo en cuenta la utilidad, facilidad de uso e interfaz, fueron: "Bookmarks", "Fecha de publicación" y "Comentarios"; las menos puntuadas atendiendo conjuntamente a los tres criterios fueron "Vistos", "Historial de búsqueda" y "Puntuaciones" (y aún así, como hemos comentado anteriormente, fueron puntuadas positivamente por los usuarios, superando todas las puntuaciones de las tres categorías ("utilidad", "facilidad de uso" y "calidad de la interfaz") el valor medio, $\mu 3,00$.

La categoría menos puntuada fue la "Calidad de la interfaz" de la sección "Usar", pero, en cualquier caso, fue valorada como adecuada por los usuarios. Las puntuaciones de "Facilidad de uso" y de "Calidad de la interfaz" fueron bastante homogéneas (Calidad de la interfaz: mínimo: $\mu$ 3,17; y máximo: $\mu 3,56$; oscilando las desviaciones típicas entre $\sigma$ 0,91 y $\sigma$ 1,05; Facilidad de uso: mínimo $\mu$ 3,53; y máximo: $\mu 3,78$, variando sus desviaciones típicas entre $\sigma 0,83$ y $\sigma 0,98$ ). 
En cambio, las puntuaciones medias más variables eran las correspondientes a la categoría "Utilidad" (que oscilaron entre un mínimo: de $\mu 3,06$; y un máximo de: $\mu$ 4,16 , variando las desviaciones típicas entre $\sigma 0,85$ y $\sigma 1,09$ ). Las funcionalidades mejor y peor valoradas por los usuarios respecto a la "Utilidad", "Facilidad de uso" y "Calidad de la interfaz" fueron:

- Utilidad: "Bookmarks" (siendo notablemente el dato más destacado por los usuarios), "Fecha de publicación" y "Mis cosas"; las menos útiles: "Vistos", "Recomendados para ti" y "Comunidad".

- Las funcionalidades puntuadas como "más fáciles de usar": "Comunidad", "Recomendados para ti" y "Comentarios"; las menos fáciles son: "Historial de búsqueda", "Mis cosas" y "Puntuaciones".

- En cuanto a la "Calidad de la interfaz", se consideraron mejor: "Comentarios", "Comentar un recurso" y "Fecha de publicación". Las peor puntuadas fueron: "Mis cosas", "Vistos" e "Historial de búsqueda".

Un dato a destacar es que los "Bookmarks" fueron la funcionalidad más "Útil" según la opinión de los informantes. En cambio, existe un desajuste entre la puntuación de su "Utilidad" versus la "Calidad de su interfaz" y su "Facilidad de uso" (pues la puntuación media de estas dos últimas fue menor).

La funcionalidad "Vistos" es "Fácil de usar", en cambio, fue la menos "Útil" para los formadores de la muestra.

La "Comunidad" resultó muy "Fácil de usar", pero fue la segunda funcionalidad "Menos útil" para los formadores, tal y como está desarrollada en Share.TEC.

En general, las puntuaciones más bajas fueron las relativas a la "Calidad de la interfaz", y las puntuaciones más elevadas fueron las relativas a la "facilidad de uso" (en primer lugar) y la "utilidad". En cualquier caso, las puntuaciones de las tres categorías, mayoritariamente, se encuentran entre los valores 3 y 4 (en una escala del 1 al 5 en cada una de las 3 categorías), por lo que los usuarios están satisfechos y valoran positivamente las funcionalidades del apartado Usar de Share.TEC.

Un dato a destacar respecto a las opiniones de algunos informantes sobre la funcionalidad puntuaciones, es que no constituía un elemento de fiabilidad total. Algunos estaban de acuerdo en que podía tomarse como una referencia cuando el número de resultados era muy amplio, pero los profesores son conscientes de la subjetividad de la puntuación en función de numerosos factores, por ejemplo, la 
valoración de la utilidad que un formador encuentra en el recurso puede depender de cómo satisfaga o no su búsqueda inicial.

[17] p10, Q_FP A mí no. No me fijo en ello. Me fijo, veo las estrellas que tiene, pero no me da una información fiable.

[17] p10, V_FP: como cosa informativa, yo creo que puede estar bien. Pero yo creo que la persona que accede al recurso tiene que ser capaz de desplegar sus propias capacidades críticas [...].

[17] p10, R_FP en mi caso, tampoco me fío mucho de los ranking, porque según tu interés, puedes puntuar muy bien un artículo, porque se haya acercado a lo que estabas buscando, a tu interés... lo puedes valorar muy bien, y una persona que estaba buscando otra cosa... ha dicho, pues no me interesa nada. Entonces al final los ranking, no se ajustan a la calidad del artículo, si no a tus expectativas sobre lo que estas buscando.

En cualquier caso, como vemos en el Gráfico 16, la puntuación media de la "Utilidad "de este criterio fue superior a la valoración media de la escala.

Los informantes consideraron en la prueba [33] que la funcionalidad de "Grupos" de Share.TEC podía ser útil para la creación/remodelación de sus materiales (13/17 informantes) (ver Tabla 40); y un número similar: 12/17 informantes, opinaron que el portal Share.TEC era útil para la remodelación.

Existe relación entre los informantes que consideran que la función "Grupos" de Share.TEC podía ser una herramienta útil para la creación-remodelación de sus materiales y aquellos que pensaban que Share.TEC, en general, era útil para la creación de sus materiales (la mayoría de usuarios que respondieron sí en una de las opciones, contestaron afirmativamente en la otra).

Para la mayoría de los usuarios de cada rol sí que era útil tanto el portal Share.TEC como la función "Grupos" para la creación de sus materiales (65,38\% del total; $\mathrm{FP}=58.82 \%$; $E M=75 \%$; $E s p=80 \%$ ). Para otros usuarios no resultaba útil ni la función de "Grupos" ni el portal para crear contenidos digitales $(11,53 \%$ del total; $\mathrm{FP}=11,76 \% ; \mathrm{EM}=0 \%$; $\mathrm{Esp}=20 \%$ ).

En algunos casos, la función social de "Grupos" sí fue valorada como útil para crear materiales, en cambio no el portal en general (15,38\% del total; $F P=17,65 \%$; $\mathrm{EM}=25 \%$ ); en otros casos ocurría de manera inversa, considerando que el portal en general era útil, pero no la función grupos (7,69\% del total; $11,76 \%)$. 
Por tanto, la funcionalidad "Grupos" fue ligeramente mejor valorada por los informantes de esta prueba, quizá por la posibilidad de que otras personas opinaran sobre los recursos publicados, y pudiera discutirse socialmente el recurso, recibiendo y aportando experiencias de su uso.

Tabla 40 [33] Opinión de los informantes sobre la función "Grupos" vs. el conjunto del portal Share.TEC como herramientas para la creación/remodelación de sus materiales

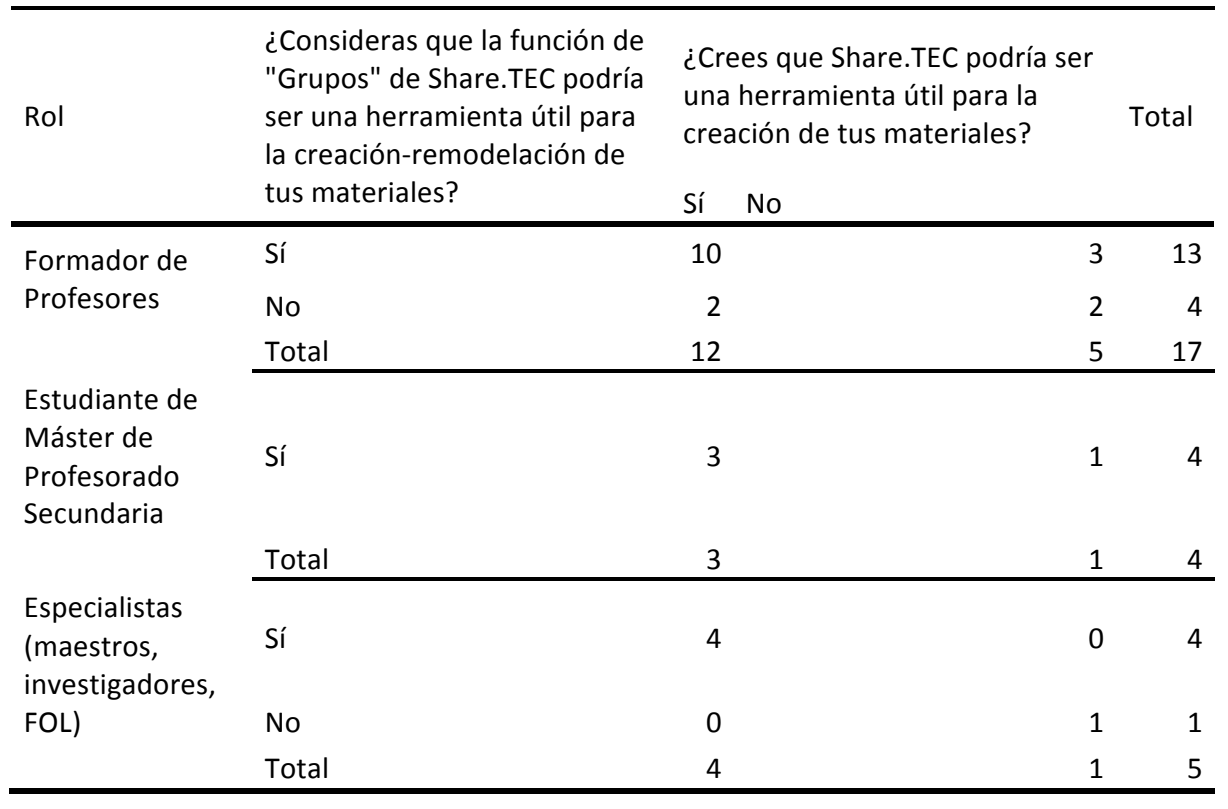

Los 19 informantes de [44] valoraron la funcionalidad "Ver más"157 del apartado "Acceder" positivamente, considerando, en promedio, que era una funcionalidad relativamente útil $(\mu 3,26$, con una de $\sigma 0,87)$, y relativamente completa $(\mu 3,11$, con algo más de dispersión entre las opiniones, $\sigma 1,05)$.

Es decir, aunque en general los informantes aprueban la funcionalidad "Ver más", podría mejorarse permitiendo una visualización más rápida de los datos del recurso, quizá mediante sistemas de iconos visuales que permitan rápidamente obtener información del mismo, tal y como sugerían las siguientes evidencias:

157 Funcionalidad que permite ampliar la información básica que se visualiza de un recurso, dando acceso completo al registro de metadatos. 
[44] p12.5. 24_F_EM_En mi opinión, con las búsquedas que he realizado, he quedado muy satisfecha cuando he hecho clic en ver mas, ya que me ha parecido muy completa y bien ordenada la información que he obtenido.

[44] p12.9. 31_M_FP_Me parece información demasiado profunda, prefiero una descripción del recurso más general, para algo tan completo prefiero abrir el recurso)

Sugerencias aportadas sobre los usuarios sobre las funcionalidades del portal:

1) Visualización del número total de recursos:

Algunos usuarios sugirieron que Share.TEC presentara el número total de recursos disponibles para cada palabra clave, de modo que les permitiera formarse una idea de cuántos recursos existían con esas palabras clave. Únicamente mostraba 10 resultados y 10 números enlazados de páginas de resultados; mediante sistemas de flechas podían visualizarse más páginas de resultados, pero no se visualizaba la información del número total de recursos que existían bajo los parámetros de búsqueda definidos.

[44] p21.4_29_F_ING_Sería útil tener un esquema con todos los conceptos que definen los recursos y el número de recursos que hay que cumplan cada parámetro (como puede verse en otro tipo de buscadores como es el caso de "Destinia", "Booking.com" o "eBay")

[44] p.21.3 47_M_FP_creo que el tipo de decisiones del profesor está muy bien organizado. Otra cosa es que los profesores se paren a pensar en todas esas cosas cuando buscan documentos para sus clases.

\section{2) Atención a la privacidad del usuario:}

A la hora de crear un portal web con usuarios, hay que tener en cuenta los elementos de privacidad, pues estas páginas están expuestas a problemas de seguridad y protección de datos. Además, si se pretende dar acceso a comunidades concretas, existe la posibilidad de que sea necesario bloquear ciertos elementos para que sean accesibles únicamente a grupos concretos.

[17] (p6) E. En otros casos, si la información es un poco sensible, pues hemos tenido que cerrarla.

[17] p6, Iv_FP pero ¿cerrarla a una comunidad?

[17] p6, E_Ing pues para una comunidad concreta como los participantes del curso de Buendía, utilizábamos el BSCW, que tenían acceso restringido a 
ciertas carpetas, y fuera de esa comunidad no se podía acceder a los documentos [...].

En el caso de Share.TEC, la privacidad del usuario estaba controlada y apenas había contribución de recursos por parte de usuarios (y esta función también estaba controlada por un administrador), por lo que no ha habido incidencias conocidas de privacidad. Además, para poder realizar cualquier tipo de contribución en el sistema, el usuario debía registrarse e introducir el código de un "CAPTCHA".

3) Garantizar la calidad y mantenimiento de la herramienta y sus materiales:

En la prueba [33] preguntamos a los informantes sobre las desventajas que podría tener un sistema como Share.TEC, y uno de los usuarios hizo mención a un aspecto clave para la sostenibilidad de este tipo de sistemas: la garantía de la calidad de la herramienta, de los materiales y de la gestión de la plataforma.

[33] p20.8. SF_38_M_Ninguna, pero hay que asegurar el mantenimiento de la herramienta y control sobre los materiales compartidos, así como la dinamización de la plataforma.

\section{4) Flexibilización y mejora del motor de búsqueda:}

En general, los formadores de profesores y otros profesionales de la educación, consideraron que el motor de búsqueda debía mejorar, ser más flexible cuando se introdujeran palabras (de modo que se acepten búsquedas por proximidad o por conceptos relacionados), y quizá simplificar las opciones que se ofertaban. En cambio, la búsqueda por filtrado ha sido una de las funcionalidades de Share.TEC que más han apreciado los usuarios, ya que les permitía personalizar sus búsquedas.

[33] Pr20.S23. FP_35_F_A veces hay demasiada información global. Búsqueda por palabras avanzada (desventajas).

[44] 29_F_ING_Sería útil tener un esquema con todos los conceptos que definen los recursos y el número de recursos que hay que cumplan cada parámetro (como puede verse en otro tipo de buscadores como es el caso de Destinia, Booking o eBay).

\section{5) Personalización de los servicios de Share.TEC para cada usuario:}

Otro de los servicios que demandan los informantes a los que hemos consultado es la personalización de las funcionalidades de Share.TEC ajustándolas a su perfil de usuario. 
[44] p25. 29_F_ING_Serían interesantes si la información ofrecida estuviera relacionada con el perfil de usuario.

Los profesores podían describir su perfil, y en función de este podían acceder desde el apartado "Usar" a una funcionalidad de recursos "Recomendados para ti"; a pesar de que era poco visible (aparecía en un menú lateral izquierdo de la interfaz de ese apartado). Inicialmente, los usuarios del portal no podían elegir entre muchos tipos de perfil (sólo perfiles de áreas ingenieriles que fueron incluidas como prueba para el portal); posteriormente añadieron más roles de formadores de profesores por área.

6) Mejora de la información mostrada en la descripción de los recursos

Entre el tipo de mejoras que podrían incorporarse a "Ver más", los usuarios hicieron mención a:

- Que los recursos ofrecieran información contextual en su descripción, es decir, comentarios de otros formadores en relación al uso del recurso:

[44] p12.2. 27_M_ING_La información que se obtiene está bien. Me hubiese gustado también obtener información relacionada con el uso de esos recursos por parte de terceros. Pero para eso la red social debe alcanzar un número importante de usuarios.

- La inclusión de opciones de personalización de la función "Ver más":

[44] p12.18. 36_F_FP_Cuando he hecho uso de dicha función, la primera vez me resultaba confusa tanta información; quizás hubiera preferido haber solicitado previamente qué quería ver (seguramente existía esa funcionalidad y yo no la conocía).

Consideramos importante mencionar que las opiniones de los informantes fueron tenidas en cuenta a posteriori, cuando la arquitectura del sistema, los sistemas de búsqueda, las estructuras ontológicas y de metadatos, la interfaz, etc., ya estaban generados. Este hecho dificultó la posterior remodelación estructural de todos estos aspectos, por lo que las modificaciones sugeridas por los usuarios se realizaron ad hoc, y sólo cuando no requerían de una remodelación profunda de la arquitectura del sistema. Consideramos que para prevenir este problema hubiera sido necesario seguir un proceso de "Diseño centrado en el usuario"158 previo a la construcción de

${ }^{158}$ Esta filosofía de diseño es ampliada en el capítulo 6 de esta tesis doctoral. 
la arquitectura del portal. El proyecto, por restricciones temporales y por su tipología (proyecto de Innovación y Desarrollo), no pudo focalizarse en estos procesos.

\section{B.3 ¿Es apropiada la interfaz de Share.TEC?}

En todas las pruebas en las que hemos preguntado a nuestros informantes sobre su opinión acerca de la interfaz de Share.TEC, hemos encontrado puntos de vistas dispares. En general, los usuarios consideraron que había varios aspectos que debían cambiarse para mejorar la interfaz y adaptarla a sus potenciales usuarios.

En la prueba [44], preguntamos a los usuarios si mejorarían la interfaz de alguna de las tres funcionalidades principales de Share.TEC (Acceder, Usar y Ofrecer) (ver Tabla 41).

Tabla 41 Opinión general de los usuarios sobre la interfaz de Share.TEC en los apartados Ofrecer, Acceder y Usar del Portal. ¿Mejoraría la forma de visualizar las funcionalidades?

\begin{tabular}{lllll}
\hline Ofrecer & Acceder & Usar & \multicolumn{2}{c}{ Total } \\
\cline { 3 - 4 } & & No & Si \\
\hline No & No & 10 & 0 & 10 \\
& Si & 2 & 2 & 4 \\
& Total & 12 & 2 & 14 \\
Sí & No & 1 & 1 & 2 \\
& Si & 0 & 3 & 3 \\
& Total & 1 & 4 & 5 \\
\hline
\end{tabular}

En la tabla de contingencia (Tabla 41) se muestran los resultados integrados de la opinión de los 19 informantes sobre la interfaz de cada apartado. Atendiendo a los resultados del cuestionario:

- 10 usuarios consideraron que eran adecuadas las tres interfaces.

- 2 usuarios afirmaron que mejorarían solo "Acceder" y "Usar", considerando que "Ofrecer" es correcta.

- 1 usuario mejoraría únicamente "Ofrecer".

- 1 usuario mejoraría "Ofrecer" y "Usar", considerando adecuada "Acceder".

- 3 usuarios mejorarían la forma de visualizar las tres funcionalidades. 
- En total, 2 usuarios mejorarían la interfaz de "Acceder"; 4 mejorarían la de "Usar" y 5 mejorarían la de "Ofrecer".

Por tanto, la funcionalidad mejor valorada, según los 19 usuarios de la prueba [44], fue "Acceder" (considerada positivamente por 17 usuarios), seguida por "Usar" (15) y "Ofrecer" (14). Para la mayoría de las usuarios la forma de visualizar las funcionalidades fue adecuada. De la interpretación del análisis de los adjetivos [21], abstraemos las siguientes interpretaciones de los datos:

- El portal tiene un aspecto claro, calmado y limpio, a pesar de que los usuarios preferirían un look \& feel intermedio, ni muy recargado ni muy simple.

- El estilo es algo anticuado y monótono, no invita al usuario a interactuar en el portal.

- Es impersonal, y los usuarios creen que debería tener su propio carácter.

- Desaprovecha mucho el espacio, pues solamente hay contenido en la parte central de la página, pudiendo aprovechar los laterales para incluir más información o contenido.

- Es unimodal, ya que apenas contiene iconos y los que contiene no son atractivos. Los usuarios valorarían que incluyera más imágenes, iconos y sonidos.

\section{Sobre el apartado acceder:}

Ha de mejorarse la interfaz de búsqueda avanzada

[33] Suj20.Pr17. FP_36_M_Entorno poco amigable, la interfaz de búsqueda avanzada no invita a la búsqueda.

[33] Suj21.Pr17. FP_36_M_En búsqueda avanzada simplificaría la interfaz.

A 7 usuarios sí les gustaría visualizar los campos de búsqueda de otra manera, frente a 12 que le parecía bien como estaban ([33] p.22).

El usuario encuentra molesto encontrarse con información en idiomas que no domina (e.g., el búlgaro, idioma cirílico):

[33] p10.3 47_M_FP "Da información. El problema es que aparecen en primer lugar resultados en un idioma que no domino (creo que oriental)".

Algunos usuarios consideraban que era demasiado larga la descripción de los recursos que encontraron, preferían acceder a la descripción completa si iban a visualizar tanta información; y otros creían que la información es adecuada, porque podían hacerse una idea del recurso rápidamente: 
[33] p10.9. 31_M_Ing Se presenta con una descripción, pero para ver su utilidad siempre tengo que abrirla. Las descripciones son demasiado largas, para no leerlo entero prefiero abrir y ojear para ver si es lo que estoy buscando.

[33] p10.11. 33_F_FP Me parece adecuado, porque puedes acceder a el rápidamente, y te da la información básica.

Es necesario clarificar cuál es la licencia del recurso, y si es de pago o gratuito, pues puede hacer perder tiempo a los usuarios.

[33] p10.17. 44_F_FP Es muy confuso cómo acceder directamente al recurso, muchos piden una contraseña o licencia.

La información de "Ver más" era satisfactoria para los usuarios.

[33] p12.5. 24_F_EM En mi opinión, con las búsquedas que he realizado, he quedado muy satisfecha cuando he hecho clic en ver mas, ya que me ha parecido muy completa y bien ordenada la información que he obtenido.

Sobre el apartado Ofrecer:

Algunos usuarios opinan que existe una gran complejidad a la hora de incorporar contenidos en el portal.

[33] p20.12.EM_41_M_gran complejidad de introducción de recursos

Otros opinan que los documentos que se quieren compartir se suben al portal rápidamente.

[44] p15.13.43_M_FP_Rapidez en subir documentos

Sobre el apartado Usar:

En este apartado, explicado previamente en el Gráfico 16 (referente a la prueba [44]), los usuarios aprobaban todas las funcionalidades del apartado, aunque eran menos puntuadas que su utilidad y facilidad de uso.

Como explicamos en el capítulo 3: "El proceso de investigación", en la prueba [21] aplicamos en los diferentes países del consorcio una prueba ("Kit de deseabilidad") a través de una aplicación informática en la que los 67 informantes, pertenecientes a diferentes países, debían seleccionar 6 de entre 118 adjetivos ( $40 \%$ con cariz negativo, y $60 \%$, positivo). 
En esta prueba, de los 118 adjetivos elegibles por los usuarios evaluadores, 93 fueron seleccionados (aquellos que los informantes de la prueba decidieron que definían mejor el portal). Cada usuario seleccionaba 6 adjetivos del listado completo, describiendo brevemente por qué había elegido concretamente ese adjetivo.

De entre los adjetivos iniciales, el $60 \%$ hacía referencia a adjetivos positivos y el $40 \%$ a negativos (Tabla 43). Para poder trabajar con los datos obtenidos, hemos decidido normalizar los datos por cada categoría y equilibrarlos de modo que consideráramos la existencia de un número igual de positivos y negativos, trabajando únicamente con los objetivos que fueron elegidos por los usuarios (93/118). Tras realizar las operaciones necesarias para la normalización [Anexo 31], hemos obtenido los siguientes datos (véase Tabla 42).

- En general, los usuarios encontraron que el sistema era "Útil" $(64,38 \%$ de adjetivos positivos frente a $35,62 \%$ negativos) y "Eficiente" (62,41\% de votos positivos frente a $37,59 \%$ ).

- Las opiniones de los informantes sobre la "Apariencia" y la "Usabilidad" estaban bastante dicotomizadas entre adjetivos positivos y negativos: la apariencia era mejor definida por adjetivos negativos (44,39\%; frente a un $55,61 \%$ de adjetivos positivos); sobre la usabilidad del sistema, escogieron más adjetivos positivos $(53,72 \%)$ que negativos $(46,28 \%)$.

- En proporción, los adjetivos más elegidos entre los usuarios fueron aquellos relativos a Usabilidad $(29,48 \%)$, seguidos por los referentes a "Utilidad" $(25,64 \%)$, "Apariencia" $(24,10 \%)$ y "Eficiencia" $(20,79 \%)$. Por ello, podemos decir que los adjetivos escogidos para cada categoría están relativamente equilibrados, aunque con las mínimas diferencias recién explicitadas.

- En proporción, existe un $12,02 \%$ más de adjetivos positivos referentes al portal $(56,01 \%)$ que negativos $(43,98)$.

En la Tabla 43 recogemos el porcentaje de adjetivos con cariz positivo y negativo existente entre los adjetivos elegibles, que fue acordado mediante la metodología de concordancia de jueces (apartado 5.2.5 del capítulo 3) [ver Anexo 31]. En la Tabla 42, tras la aplicación de esta misma metodología para la determinación de qué adjetivos se incluyen en cada clase ("Apariencia", "Eficiencia", "Usabilidad" y "Utilidad"), recopilamos los adjetivos que pertenecen a cada clase atendiendo a su cualidad positiva o negativa. 
Tabla 42 [21] Adjetivos positivos y negativos concordados por los jueces sobre "Apariencia", "Eficiencia", "Usabilidad" y "Utilidad" seleccionados por los 69 usuarios de diferentes países

\begin{tabular}{lllll}
\hline & Apariencia & Eficiencia & Usabilidad & Utilidad \\
\hline $\begin{array}{lllll}\text { Porcentaje Total de Adjetivos } \\
\text { elegidos referentes a }\end{array}$ & 24,10 & 20,79 & 29,48 & 25,64 \\
\cline { 2 - 5 } Adjetivos Positivos & 44,39 & 62,41 & 53,72 & 64,38 \\
Adjetivos Negativos & 55,61 & 37,59 & 46,28 & 35,62 \\
\hline & 100,00 & 100,00 & 100,00 & 100,00 \\
\hline
\end{tabular}

Tabla 43 Cariz positivo y negativo de los adjetivos seleccionables concordados por los jueces

Adjetivos elegibles inicialmente : $60 \%$ positivos, $40 \%$ negativos

65,59

Elegidos Positivos

34,41

Elegidos Negativos

Hay que tener en cuenta que esta prueba fue llevada a cabo en marzo-mayo de 2010, momento en el que el portal no contaba con una gran población de recursos y existía un número elevado de fallos técnicos en el sistema, muchos de los cuales fueron corregidos posteriormente.

Otro de los puntos de nuestro interés consistía en saber cuántos usuarios valoraban con qué número de adjetivos positivos y negativos el sistema, por lo que sustituimos cada adjetivo por un 0 (adjetivo negativo) o un 1 (adjetivo positivo), obteniendo de este modo un gráfico que ilustra que el $73 \%$ de los informantes de la prueba [21] puntúa el sistema con 3 o más adjetivos positivos, mientras que un $27 \%$ de los usuarios, lo califica con tres o más adjetivos negativos.

Este dato nos indica que, en general, la mayoría de los usuarios valora positivamente de forma global el sistema, mientras que para un $27 \%$ el portal presenta características negativas para ellos.

Como hemos mencionado, los sujetos seleccionaban 6 adjetivos de entre los 118 disponibles. Algunos de los adjetivos fueron seleccionados por un número significativo de sujetos, teniendo en cuenta la amplitud de opciones disponibles. Por ello, hemos considerado como los más relevantes aquellos elegidos por más de un $10 \%$ de los participantes en la evaluación del portal (ver Gráfico 17). 
Entre ellos, el más frecuente es "útil" (20 sujetos; $29,85 \%$ ) de los 67 participantes; seguido por la facilidad de uso (15; 22,39\%), Organizado (13; $19,40 \%)$; Profesional (13; $19,40 \%)$, etc. Los negativos más frecuentes describen la confusión que genera el sistema (12 sujetos; $17,81 \%$ ), el aspecto poco atractivo (11; $16,43 \%)$, el funcionamiento simple $(9 ; 13,43 \%)$ y aburrido $(9 ; 10,45 \%)$, etc.

Gráfico 17 Adjetivos de Share.TEC seleccionados por más del 10\% de los 67 informantes (debían elegir 6 de un listado de 118)

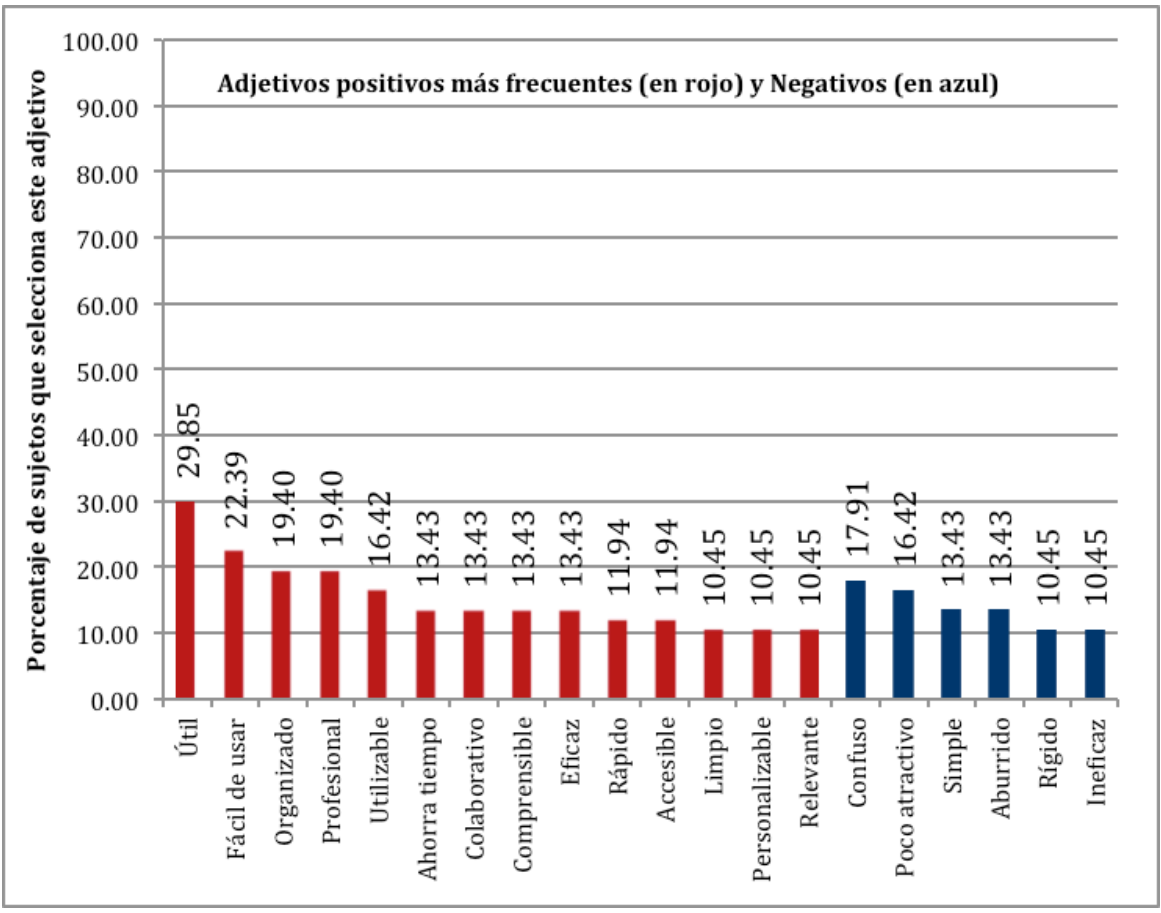

Teniendo en cuenta los adjetivos más votados en esta prueba, seleccionamos los trece adjetivos más frecuentes, e incluimos su opuesto (ver Tabla 44) con el objetivo de comparar la dispersión de opiniones entre los usuarios. En una prueba aplicada tras la finalización del proyecto [44] pedimos a los usuarios que seleccionaran aquellos adjetivos que consideraban que mejor definían el portal: 
Tabla 44 Selección de adjetivos descriptivos de Share.TEC de la prueba [44]. Los 19 informantes podían elegir cualquiera de los adjetivos del listado

\begin{tabular}{llllll}
\hline Rápido & 11 & $58 \%$ & Colaborativo & 11 & $58 \%$ \\
Lento & 0 & $0 \%$ & Novedoso & 6 & $32 \%$ \\
Intuitivito & 9 & $47 \%$ & Poco original & 0 & $0 \%$ \\
Enredoso & 6 & $32 \%$ & Creativo & 1 & $5 \%$ \\
Colores agradables & 13 & $68 \%$ & Poco refinado & 5 & $26 \%$ \\
Colores feos & 1 & $5 \%$ & Claro & 4 & $21 \%$ \\
Visualmente elegante & 8 & $42 \%$ & Confuso & 6 & $32 \%$ \\
Visualmente soso & 2 & $11 \%$ & Completo & 0 & $0 \%$ \\
Estable & 4 & $21 \%$ & Fácil de usar & 9 & $47 \%$ \\
Inestable & 3 & $16 \%$ & Difícil de usar & 4 & $21 \%$ \\
Útil & 11 & $58 \%$ & Cómodo & 7 & $37 \%$ \\
Inútil & 1 & $5 \%$ & Incómodo & 3 & $16 \%$ \\
Organizado & 12 & $63 \%$ & & & \\
Desorganizado & 2 & $11 \%$ & & & \\
\hline
\end{tabular}

Entre los 26 posibles adjetivos a elegir, los sujetos podían seleccionar todos aquellos que consideraran que se ajustaban a su opinión sobre el sistema Share.TEC. La mayoría de los adjetivos denotaba una cualidad y su opuesta, obteniendo los resultados de la tabla.

Entre los diferentes adjetivos a elegir, pudiendo ser elegidos todos los que consideraran que describían el sistema, de la muestra de 19 sujetos, la mayoría de los usuarios selecciona: "colores agradables" (13; uno selecciona "colores feos"), "sistema organizado" (12; 2 seleccionan sistema desorganizado), "rápido" (11; ninguno considera que el sistema sea lento), "útil" (11; 1 usuario selecciona sistema inútil) y "colaborativo" (11). Otros adjetivos, también son seleccionados casi por la mitad de los usuarios (9/19): "intuitivo" (9 sujetos), versus "enredoso" (6), lo que nos indica que no hay una tendencia clara, si no que para unos usuarios es de un modo u otro; "fácil de usar" (9 usuarios), versus "difícil de usar" (4 usuarios), lo que nos indica que, de la muestra, para más usuarios supone un sistema "fácil de usar" que "difícil", aunque no debemos obviar que hay 4 usuarios que consideran que es "difícil".

Los adjetivos menos frecuentes de los no mencionados, fueron: poco original $(0$ usuarios consideran esta opción; aunque sólo 1 considera que es un sistema creativo); completo (0 usuarios seleccionan esta opción, aunque no encontramos la opción incompleto, por lo que no podemos contrastar este adjetivo). 
Para hacernos una idea de los adjetivos más y menos frecuentes, podemos visualizar la nube de etiquetas creada con la aplicación web "Tagxedo 159", donde se recogen las frecuencias de cada adjetivo, de modo que visualizamos más grandes aquellos adjetivos escogidos con mayor frecuencia por los usuarios [44]:

llustración 31 [21] Nube de adjetivos por frecuencia de selección por parte de los usuarios. Imagen creada con Tagxedo.

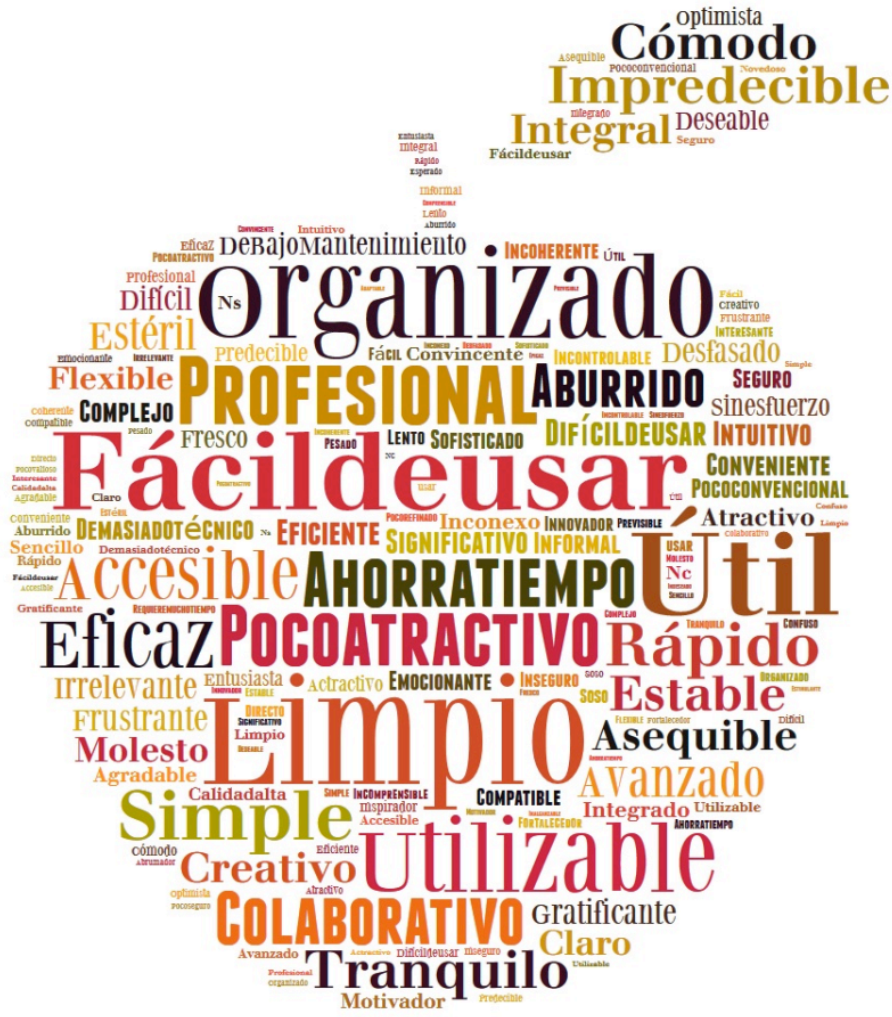

$159 \mathrm{http}: / /$ www.tagxedo.com/. El motivo por el que representamos la nube de adjetivos en forma de manzana es porque el icono del portal Share.TEC es una manzana en forma de puzle. 
Uno de los asesores expertos del proyecto Share.TEC (O'Connor), recomendó que para el éxito de un sistema para compartir contenidos digitales, debía crearse una interfaz y una estructura de metadatos lo suficientemente sencillas como para que cualquier profesor se animara a subir recursos a esta herramienta (ver [Anexo 4]). En febrero de 2009, los diferentes expertos asistentes al workshop consideraron que esta era una de las debilidades con las que contaba el proyecto hasta el momento, y se recomendaba tener en cuenta al usuario antes de desarrollar la arquitectura y la interfaz del sistema, así como su CMM:

Notas del Workshop de Venecia (Beatriz Carramolino) "Es necesario pensar para quién va destinada la herramienta que se va a generar, cómo va a realizar las búsquedas el usuario, y qué datos son los que serán relevantes la hora de buscar un recurso".

[Anexo 27]: Claire Belise comenta que la interfaz del sistema es un tema que debería haberse resuelto mucho antes, puesto que es necesario para poder involucrar a usuarios (Notas de la investigadora).

[33] 20.9. SF_38_M_Necesitaría un cambio de aspecto visual para que fuese más agradable y menos cansado. A veces son pantallas demasiado largas.

\section{B.4 ¿Constituye Share.TEC un sistema usable y accesible?}

\section{Usabilidad}

A lo largo de este análisis e interpretación hemos ido recogiendo aspectos vinculados a la usabilidad del portal, debido a que es una característica inseparable de la interfaz, de las funcionalidades, de las búsquedas, etc., pero profundizamos un poco más sobre ella este apartado.

Como veíamos en el apartado B.2 del presente capítulo, en la prueba [21], los informantes seleccionaban tanto adjetivos positivos como negativos relativos a la usabilidad del sistema. Existía un equilibrio en cuanto a adjetivos positivos y negativos.

Los usuarios que evaluaron el portal Share.TEC encontraron difícil la adaptación inicial al sistema, pero a medida que fueron probando el portal y comprendiendo su organización y funcionamiento, consideraban que era fácil de entender.

[21] Adjetivo: Duro. "FP: Sinceramente, al principio me pareció un poco incomprensible, pero a medida que te vas familiarizando se entiende perfectamente". 
La mayoría de los usuarios creían que el portal estaba organizado, pero quizá podía mejorarse atendiendo a las preferencias de sus usuarios potenciales, e incluso dotarle de un entorno más amigable que invitara al usuario a utilizar el portal:

[21] Adjetivo: Organizado "Hay que investigar si está estructurado o no de una forma amigable para el usuario"

[21] 19. FP_F_45_Formato más amigable, con mayores facilidades. El aspecto es, además de un verde sufrido, bastante aburrido y poco incitador a permanecer en él, excepto estrictamente para un concepto "aburrido" del trabajo .

[21] Adjetivo: Disponible "En general veo un buen nivel de usabilidad, con especial referencia a ciertos aspectos como la investigación. [...]

[33] p20.24. FP_27_F [...] Algunos aspectos del portal deberían mejorarse para que fueran más intuitivos para los potenciales usuarios"

En las diferentes pruebas realizadas, tanto durante el proyecto, como tras su finalización, se encontraron diversos problemas técnicos en el portal que mermaron la opinión positiva de los informantes sobre el sistema.

[33] p29.3. 47_M_FP_en todas las búsquedas realizadas me salía un mensaje de error: "Ocurrió un error HTTP 0 . http://portal.sharetec.eu/es/apachesolr_autocomplete"" y pulsando el botón aceptar se arreglaba.

[21] Adjetivo: Fácil "Existen problemas técnicos"

[33] p8.23. FP_27_F_Creo que todavía existen bastantes fallos técnicos como para que el sistema en general me parezca fiable. La idea que hay detrás del repositorio me parece muy interesante, es decir, que los usuarios puedan comentar y votar los recursos me parece que marca la diferencia respecto a otros buscadores existentes, sin embargo creo que habría que mejorar la estabilidad del sistema

[33] p22.12. EM_41_M_Me parece bien en cuanto a búsquedas, sin embargo tendría que haber un interfaz más amigable para la introducción de recursos.

En la descripción de los metadatos, en ocasiones, los informantes encontraron faltas de ortografía:

[09] S1_30M_R1_A1_Existen algunas faltas de ortografía debidas al copypaste hecho.

[09] S4_35M_R5_A2_El nombre del autor no aparece escrito de manera correcta. 
Había informantes que no comprendían la estructuración del portal Share.TEC en tres funciones parceladas: "Acceder", "Usar" y "Ofrecer", así como la dotación de la misma importancia a cada una de las tres funciones. Por ello, algunos usuarios pensaban que su estructura era rígida.

[44] p15.9."31_M_Ing_(Opinión sobre la sección “Ofrecer"): Una vez más se le da más importancia a subir un recurso que a la búsqueda de recursos. Subir recursos se hará pocas veces y no es necesario más que una botón de "subir recurso". La mentalidad en el planteamiento "Acceder" + "Usar" + "Ofrecer" obliga al usuario a pasar por un proceso para utilizar la aplicación con todo su potencial. Cuando un usuario lo que quiere es hacer las cosas a su manera, no que le impongan una forma de pensar. Si un usuario buscando un recurso quiere ofrecer otro, no tiene por qué salirse del menú de la búsqueda para subir el recurso, puede darle a un botón de "'subir recurso"". Si le doy a Ofrecer y luego a "Anotar"... ¿vuelvo a "Usar"? Es inservible esta opción [...].

[33] p5.21. FP_48_F_Encuentro la plataforma muy rígida y poco flexible.

[33] p20.22. FP_48_F Rigidez, estructura cerrada, deficiencias de implementación.

[33] p20.25 FP_51_F_Estructura muy rígida y poco amigable. Necesidad de revisar las categorías de búsqueda Poco intuitivo y auto explicativo."

Entre las sugerencias, se encontraba la posibilidad de mejorar la interfaz dotando de más flexibilidad a la interacción con la plataforma, por ejemplo:

- no teniendo que introducir palabras clave de forma obligatoria por cada comentario que se realizaba en la sección usar:

[33] p8.20. FP_45_F_Tiene poca usabilidad cada comentario requiere que introducir cada vez la palabra clave.

- introduciendo menos campos obligatorios a la hora de compartir un recurso:

[33] p10.12. EM_41_M_Me parece una herramienta interesante; quizás sea un poco complicada para compartir recursos debido a la gran cantidad de información que se ha de rellenar. Por otro lado me parece que los campos que hay que rellenar debiesen tener una ayuda.

- mejorando la facilidad para incluir recursos en el sistema y mejorando las traducciones multi-idioma del portal:

[33] p10.13. EM_29_M_Debería mejorarse la traducción de los idiomas y que el portal fuera más sencillo de utilizar: no tantos campos, más rápida la subida de recursos... 
Inicialmente, el portal no preservaba las palabras clave introducidas, de forma que, tras previsualizar un recurso, al volver a la búsqueda, ya no estaban esas palabras. Gracias al feedback de los usuarios, esta funcionalidad se mejoró tras la prueba [21], y actualmente ya se mantienen guardadas.

[21] Adjetivo: Inquietante. "No guarda lo que escribí por última vez en el recuadro de búsqueda".

En general, consideran adecuada la usabilidad de la búsqueda avanzada, ya que creían que es intuitiva. En cualquier caso, recomendaron incluir una guía para saber qué palabras emplear en las búsquedas.

[44] p24.36_F_FP_Este apartado creo que es bastante intuitivo, lo que se agradece.

[33] p4.10. SF_38_M [...] echo de menos un poco de "guiado" acerca de las palabras claves para emplear en las búsquedas.

Los usuarios estaban cómodos con los modelos de interfaz conocidos, a no ser que se propusiera una innovación que mejore lo ya existente:

[44] p21.9 31_M_Ing Si no van a mejorar el formato de búsqueda de Google, entonces mejor que se parezca a lo que estoy acostumbrado. Por tanto, está bien.

En la búsqueda avanzada se ofertan, como hemos visto, amplias categorías para filtrar el material, tanto en relación a su formato técnico, como a su uso pedagógico. Habría que ahondar más en si los profesores necesitan tantos campos de metadatos para buscar recursos:

[44] p21.3 47_M_FP_creo que el tipo de decisiones del profesor, están muy bien organizadas. Otra cosa es que los profesores se paren a pensar en todas esas cosas cuando buscan documentos para sus clases.

Algunas de las sugerencias de los usuarios respecto a las funcionalidades que ofrece son las siguientes:

- Que el chat, de algún modo, notifique al usuario que le han escrito -[33] p25.5 EM_26_F

- Que se integre videoconferencia - [33] p25.8 SF_38_M

Existen aspectos que los informantes definieron como mejorables en Share.TEC para aumentar la usabilidad del sistema, por ejemplo, integrar las tres funcionalidades principales del portal en una misma pantalla, mejorar la visibilidad de las opciones 
personales (mis marcadores, por ejemplo), permitir conocer al usuario el número de recursos que hay en función de sus restricciones de búsqueda, evitar que se cambie de pantalla cuando se abre un recurso en "Ver más", etc., tal y como se refleja en los siguientes extractos:

[44] p21.4."29_F_ING_Sería útil tener un esquema con todos los conceptos que definen los recursos y el número de recursos que hay que cumplan cada parámetro (como puede verse en otro tipo de buscadores como es el caso de "Destinia", "Booking" o "eBay"). Otra opción sería utilizar una visualización gráfica en la que se representara el volumen de recursos que se obtienen a medida que se van incluyendo restricciones."

[44] p13.9."31_M_FP_Añadiría los "saber más" de forma desplegable y no cambiaría de ventana pues puede que sólo quiera ver parte de la descripción por curiosidad. Cargar una página más por darle a un "Ver más" hace que la aplicación sea lenta y aparatosa. [...] Los filtros deberían ser cajas seleccionables y no sólo la opción de filtrar por un único idioma. Lo mismo se puede aplicar al resto de filtros. La gente habla más de un idioma y puede buscar en más de una colección ¿Dónde están mis bookmarks? ¿y si yo quiero buscarlos en acceder?.

[44] p25.14 36_F_FP Me ha parecido interesante la opción de "marcadores", aunque al no estar familiarizada me resultó difícil encontrarla por primera vez.

Hay que tener en cuenta la importancia de la usabilidad del portal, ya que si hay factores que fallan, puede que los usuarios no vuelvan a acceder al portal.

[Anexo 11] Un formador de profesores comenta: "si los usuarios tienen problemas con el sistema, se irán a otro repositorio o base de datos"

\section{Accesibilidad}

A la hora de registrarse en el portal, los usuarios encontraron dificultades técnicas:

- Por ejemplo, cuando un usuario olvidó su contraseña, el sistema tardó tiempo en enviarle la nueva:

[44] p16.15. 27_F_FP_Sí, como ya estaba registrada de cuando hice el Taller anteriormente, he pedido la contraseña nueva pero no me la ha mandado a mi correo electrónico por lo que no me he podido registrar. Estoy usando el portal sin estar registrada. 
[Anexo 8] "La usuaria vuelve a la página de registro de Share.TEC y trata de registrarse de nuevo, introduciendo su dirección de correo en el perfil. Comprueba el e-mail, pero no lo recibe. Esperan unos segundos, recargan la página, pero el e-mail no llega. La otra usuaria vuelve a comprobar su correo, y ya lo ha recibido. Logran acceder al portal"

La funcionalidad acceder con Facebook al portal da problemas a los usuarios, se requiere borrar el historial del navegador para que te permita acceder por este medio si ya se ha accedido previamente (esto sigue ocurriendo actualmente). En cualquier caso, a la mayoría de usuarios les pareció muy adecuada esta función porque les facilitaba el acceso al portal y evitaba la memorización y olvido de contraseñas. En la prueba [44], preguntamos a los informantes sobre la utilidad de la funcionalidad registrarse con Facebook. De los 19 informantes, el 89\% (17 personas) sí lo consideran útil, mientras que el 11\%, 2 personas, no.

[44] p17.14. 36_F_FP_Porque a veces si no empleas mucho estos portales, está muy bien que te lo recuerden desde Facebook o redes sociales.

El portal es accesible a través de diferentes dispositivos (ordenadores, móviles, tabletas) y sistemas operativos, pero básicamente su aspecto es eminentemente textual, no integra sonidos ni imágenes, de modo que ve limitadas sus opciones de accesibilidad para personas con dificultad para acceder a determinados tipos de información (por ejemplo, disléxicos). No tiene en cuenta la visualización con contraste alto para personas con dificultades visuales, ni se facilita el acceso a personas con dificultades motóricas (tendrían que utilizar software de accesibilidad específicos para su discapacidad)

\section{C) Aspectos sociales}

\section{C.1 ¿Qué piensan los Formadores de profesores sobre compartir CDFP?, y}

\section{C.2 ¿Qué utilidades sociales oferta Share.TEC y cómo han sido utilizadas?}

Share.TEC oferta un apartado "Usar" en el que se permite a los usuarios crear grupos de interés por áreas, y generar un hilo de discusión en formato de foro, donde puede verse el perfil de las personas que comentan.

Los usuarios dieron valor positivo a la opción "Grupos", puesto que consideraron que interactuar con otras personas del mismo área permitía ampliar el conocimiento, aportar y 
recibir feedback sobre los trabajos realizados, de modo que se potenciara la remodelación los materiales, etc.

[33] p8.7. SF_31_M La interacción con personas de tu mismo ámbito siempre ayuda a incrementar y ensanchar la perspectiva, el feedback siempre es positivo.

[33] p8.8. SF_38_M Además puede servir en su etiquetado para ajustar y redefinir los procesos.

[33] p8.9. SF_38_M Para la creación no lo se, pero si puede ser muy útil para la remodelación, debido a que otra gente puede dar su opinión acerca de mis recursos.

[33] p8.13 EM_29_M Considero la función "grupos" de gran utilidad. Es una manera rápida de compartir recursos con grupos de tu mismo interés, intercambiar opiniones...

[33] p9.23. FP_27_F Sí. Precisamente es la "función social" la que más valoro de este repositorio de contenidos

En la prueba [21], "Primera encuesta coordinada", los informantes respondieron, en general, que era bastante valioso para ellos la posibilidad de establecer contacto con otros formadores de profesores de diferentes países (de los 67 informantes, el ítem obtuvo una puntuación $\mu$ de 3,43 y $\sigma$ de 1,13 - sobre una escala de 1 a 5 , siendo 1 , nada valioso y 5 , totalmente valioso).

El portal, también ofrece la posibilidad de comentar los recursos disponibles en el portal, votarlos y visualizar un ranking y el número de usuarios que han valorado el recurso (como veíamos en el apartado B.2 del presente capítulo), destacando muy positivamente la opción de "comentar".

En cuanto al grado de utilidad sobre la funcionalidad de "compartir los recursos en redes sociales" (ya que incluía iconos que enlazaban a diferentes redes), en una escala del 1 al 5 , siendo 1 nada útil y 5 , totalmente útil, los usuarios valoran con una $\mu$ de 3,84 y $\sigma$ de 1,07 esta funcionalidad. Es decir, en general, los usuarios consideran que tiene bastante utilidad.

[44p11.11. 33_F_FP_Evidentemente, ahora las redes sociales difunden a una gran velocidad el conocimiento. Todos los enlaces en este sentido mejoran la herramienta.

Los motivos que resaltaron los informantes de [33] para defender la utilidad del sistema hacían referencia a la utilidad de integrar herramientas, ya que ahorraba tiempo al 
usuario, tanto para registrarse como para no tener que recordar múltiples contraseñas de los diferentes servicios que utilizan; y potenciaba la difusión de los contenidos, de forma rápida, a través de las diferentes redes sociales a las que pertenezcan los usuarios, de acuerdo con los siguientes extractos:

[33] p17.3. 47_M_FP_por la vinculación entre herramientas me facilita los usos.

[33] p17.4. 29_F_ING_Por el ahorro de tiempo que supone el no tener que dedicar tiempo a introducir los datos personales. Sin embargo, debería "fomentarse" el cumplimentar los datos relativos al perfil de cada usuario dado que puede ser útil para crear comunidades o redes de usuarios con características comunes.

[33] p17.9. 31_M_FP Creo que combinarlo con redes sociales puede aumentar su funcionalidad.

[33] p17.10. 54_M_FP Porque es más rápido y evite mas duplicidades, con tanta contraseña

[33] p17.11. 33_F_FP [...] Porque facilita el acceso a las redes sociales y a la velocidad de la información.

[33] p11.4.29_F_ING_Es una forma fácil y sencilla de diseminar un recurso y de hacérselo llegar a personas cuyas necesidades/inquietudes puedan tener puntos en común.

[33] p11.7.27_F_EM_Me parece una manera muy fácil y rápida de acceder a recursos y materiales que te pueden proporcionar desde todas las partes del mundo y compartir información, opiniones y materiales.

Los usuarios consideraban que esta aplicación permitía compartir contenido y conocimiento de forma rápida, sencilla y sin barreras espaciales. Además, permitía la distribución del conocimiento que diferentes personas encuentran de forma individual en un solo espacio.

[44] p11.7. 27_F_EM_Me parece una manera muy fácil y rápida de acceder a recursos y materiales que te pueden proporcionar desde todas las partes del mundo y compartir información, opiniones y materiales.

[33] p11.19. 33_F_FP_Millones de usuarios compartiendo millones de recursos genera un inmenso conocimiento.

[44] p11.15. 27_F_FP_Yo suelo utilizar estos medios para compartir recursos y la gente comparte recursos conmigo. Es imposible abarcar mucha información uno sólo. El compartir te enriquece y enriquece a los demás. 
Otra de las ventajas que los usuarios encontraban en este tipo de funcionalidades es la de servir de medio facilitador para el establecimiento de contacto con otros compañeros profesionales.

[44] p11.16. 45_M_FP_Permite de forma rápida contactar con otros interesados

Algunos formadores de profesores, a través de las diferentes pruebas realizadas con ellos, mencionaron la necesidad de la existencia de un portal que congregara contenidos digitales (o metadatos de los mismos) del área de la formación del profesorado, ya que actualmente existe una gran abundancia de contenido difuminado en la red, difícil de localizar, y no existen servicios específicos para este ámbito. Los usuarios veían Share.TEC como un proyecto con potencial para solventar la necesidad de aunar recursos y repositorios para este área.

[33] 5.1. SF_34_F El profesorado demanda recursos digitales para sus prácticas docentes y no siempre dispone de los medios para poder acceder a ellos por lo que es importante que todos compartamos los recursos de los que disponemos para poder de esta manera, crear una gran comunidad de aprendizaje compartido

[33] p5.10. FP_46_M En la Universidad de la imprenta la biblioteca era un elemento central. En la universidad del siglo XXI el acceso a los recursos digitales se convierte en un elemento clave.

[33] p5.13. EM_29_M Para que sean de utilidad para otras personas. Creo que es muy enriquecedor que haya portales de este tipo donde se comparten recursos, es una manera eficiente de aprovechar el trabajo de otros y el tuyo propio.

[33] p5.18. FP_29_M Considero muy interesante que se puedan centralizarse los recursos y los repositorios, mediante este proyecto se podría lograr este objetivo.

A su vez, algunos informantes comentaron la importancia de la existencia de una red profesional de formadores de profesores donde se pueda compartir y construir contenidos y conocimiento, unificada, que funcionara de forma cooperativa y colaborativa. Los profesores ya comparten sus contenidos digitales, como veíamos en el apartado A.2, 2) Hábitos de Compartición, pero consideraban que habría que involucrar a la comunidad de formadores de profesores de forma realista, y sistematizar la compartición.

[33] p5.6. SF_39_F Solo de forma colaborativa y cooperativa podrán funcionar este tipo de plataformas 
[33] p5.7. SF_31_M Creo que siempre es positivo generar un red de conocimiento en todos los campos,

[33] p8.1. SF_34_F contar con una red de profesorado multidisciplinar puede favorecer la creación de recursos diversos para el uso compartido.

[33] p8.10. FP_46_M Una característica de la ciencia actual es que el saber se produce en comunidad.

[33] p8.18. FP_29_M Compartir con otros usuarios que tienen intereses en común puede ser muy interesante para la construcción del conocimiento.

[33] p10.1. SF_34_F Contar con una red de profesorado multidisciplinar puede favorecer la creación de recursos diversos para el uso compartido.

[21] Adjetivo: Estimulante. "Los pensamientos de otros permiten estimular los tuyos".

Asimismo, consideraban necesaria la inclusión de la cultura de compartir desde la formación del profesorado.

[33] p5.8. SF_38_M Si por la formación que tengo pero creo que el profesorado necesita formación y mentalidad a la hora de compartir.

[33] p8.25.ES_43_M El problema no es tanto la herramienta, hay muchas parecidas, sino las condiciones de trabajo y la cultura inercial de (no) colaboración.

Una de las grandes ventajas de sistemas similares a Share.TEC, es la posibilidad de conocer a usuarios con perfiles profesionales e intereses similares, como lugar de encuentro en el que pueden compartir y construir, aunar esfuerzos, mejorar sus contenidos educativos, aprender, mejorar su práctica docente, etc.

[33] p5.9. SF_38_M Puede ser bastante útil, no solo para que otra gente pueda utilizar mis recursos, sino para que lo puedan modificar y mejorar.

[33] p8.2. EM_27_F Porque ver otros materiales ayuda en la creación del material propio.

[33] p8.7. SF_31_M La interacción con personas de tu mismo ámbito siempre ayuda a incrementar y ensanchar la perspectiva, el feedback siempre es positivo.

[33] p8.12. EM_41_M Me parece interesante porque es una forma conectar a docentes con las mismas inquietudes y con la misma necesidad de recursos.

[33] p13.13. EM_29_M Mejora la distribución de la información. Evitar la duplicidad de trabajos. 
[33] p10.6. SF_39_F Es de gran utilidad poder tener un foco común de información, documentación e intereses que se retro alimente continuamente con profesionales de tu campo de trabajo [Anexo 11] Formador de profesores holandés: "Si encuentro un recurso similar a lo que estoy buscando, puedo contactar con otras personas"

La mayoría de los formadores que contestaron a la encuesta [35] (p28) (194 de 198 informantes) estaban interesados en trabajar online con compañeros de profesión para resolver problemas relativos a su trabajo (89,69\%; 174 usuarios). A luz de los datos ${ }^{160}$, observamos que parece no haber diferencias entre los diversos roles.

\section{C.3 ¿En qué redes profesionales participan los usuarios de Share.TEC y qué ofrecen éstas en oposición a Share.TEC?}

El la primera encuesta coordinada [20] preguntamos a los usuarios a cuántas redes pertenecían, en los siguientes rangos:

Tabla 45 Prueba [20] Redes sociales a las que pertenecen los informantes

\begin{tabular}{lll}
\hline Redes a las que pertenecen & Frecuencia & Porcentaie \\
\hline Más de 4 & 24 & 34,8 \\
Entre 1 y 3 & 31 & 44,9 \\
En ninguna & 14 & 20,3 \\
Total & 69 & 100 \\
\hline
\end{tabular}

Tras aplicar un test de Pearson (estadístico Chi-Cuadrado), apreciamos que no existen diferencias significativas a nivel de confianza del $95 \%$ entre los dos tipos de roles, profesor de educación Superior, versus profesor de educación Secundaria y Especialistas. Como ilustramos en la Tabla 45 , el 20,3\% de los usuarios de la muestra no está registrado en ninguna red social; en cambio, un $44,9 \%$ lo está en entre 1 y 3 redes sociales, y un $34,8 \%$ en más de 4 . Podemos decir que la mayoría de los profesores sí están conectados en red, y que un número considerable está registrado en varias redes.

160 No podemos aportar evidencias estadísticas significativas mediante la aplicación del test Chi-cuadrado de Pearson, ya que $20 \%$ de las casillas es inferior a 5. 
En la prueba [35], segunda encuesta coordinada entre diferentes miembros del consorcio, apreciamos diferencias entre la utilización de las redes sociales atendiendo al rol, aunque no cumplimos con los requisitos para la aplicación de un test de Chi-cuadrado fiable, ya que hay menos valores de los esperados en las casillas, por lo que realizamos dos tablas de contingencia para comprobar los resultados. En ellas obtuvimos los siguientes resultados:

- Más de la mitad de los formadores de educación Infantil y Primaria no utilizan redes sociales (10/17; 58,82\%); Únicamente 1 de los que no utiliza redes sociales sí utiliza folksonomías, y ninguno utiliza sistemas RSS. De los profesores que sí utilizan redes sociales, solo 2 utilizan folksonomías y 2 , servicios RSS (en total, un $17,64 \%$ usan las folksonomías, y un $11,76 \%$ usan los servicios RSS).

- Algo similar ocurre con los profesores de educación Secundaria, pues 75/132 $(56,81 \%)$ no participan (la mayoría de informantes de este rol eran italianos). Entre ellos, 9 sí utilizan folksonomías y 7 RSS. Entre los 57 profesores de Secundaria que sí participan en redes sociales, 11 de ellos utiliza folksonomías y 13 RSS (en total, un $15,15 \%$ usan las folksonomías, y un $15,15 \%$ usan los servicios RSS).

- En cuanto a los educadores de formación profesional y otros especialistas, 5/19 $(26,32 \%)$ no utilizan redes sociales, luego la mayoría de ellos, sí lo hace; de hecho es el grupo del estudio que más participa en ellas. De entre ellos, solo 1 sí que utiliza folksonomías y ninguno RSS. El resto, 12/19, sí utiliza redes sociales, y 2 de ellos sí utilizan folksonomías, y 3 RSS (en total, un 15,79\% usan las folksonomías, y un $15,79 \%$ usan los servicios RSS).

- Finalmente, el grupo de Formadores de profesores 9/30 no las utilizan (30\%); de ellos, 3 sí utiliza folksonomías, y 3 usan RSS. La gran mayoría de este subgrupo, 21/30 (70\%), sí utiliza redes sociales, y entre ellos, 6 sí utilizan folksonomía y más de la mitad de ellos, 11 , usan RSS. (en total, un $30 \%$ usan las folksonomías, y un $43,33 \%$ usan los servicios RSS)

Por tanto, en proporción, los educadores de formación profesional y especialistas de nuestra muestra son quienes más utilizan las redes sociales, seguidos por los formadores de profesores, profesores de Educación Infantil y Primaria, y profesores de Educación Secundaria. Una posible causa de este bajo resultado de utilización de las redes sociales en los profesores de Infantil, Primaria y Secundaria, puede deberse a que estos colectivos tienden a trabajar en su propia comunidad. Además, puede que no perciban la necesidad de participar activamente en redes sociales con el alumnado, ya que hasta los 16 años no podrían crearse 
perfiles en las redes más conocidas. Además, hay que tener en cuenta que la mayoría de profesores de Educación Secundaria eran italianos, por lo que desconocemos si estos datos serían diferentes si se integraran datos de más países.

El subgrupo de la muestra que más utiliza, en proporción, tanto las folksonomías, como los servicios RSS, son los formadores de profesores.

En todos los grupos apreciamos que, a pesar de que los RSS y las folksonomías no son muy utilizadas por los formadores, son más utilizadas por aquellas personas que sí usan redes sociales. Es decir, existen perfiles de personas con una actitud más propensa al uso de servicios tecnológicos en general que otras.

Uso de las folksonomías:

En la prueba [35, p. 30] preguntamos a los informantes: ¿Utilizas las folksonomías disponibles en los sistemas 2.0?. Tras aplicar un test Chi-cuadrado aceptamos la Hipótesis " $\mathrm{H}_{0}$. No existe relación entre el rol y el uso de este servicio" (con un valor de 3,695, y una significación de 0,296 a un nivel de confianza del 95\%; $\mathrm{N}=191$ ). La mayoría de los usuarios no utilizaba las folksonomías (etiquetado social) de los sistemas Web 2.0, sólo las usaba el $17,80 \%$ de los informantes de esta encuesta. De los diferentes roles, quienes más afirmaron utilizarlas fueron los formadores de profesores $(30 \% ; 9 / 30)$, seguidos por los especialistas de educación Infantil y Primaria $(21,42 \%$; 3/14), Profesores de Educación Secundaria (17,86\%; 20/112) y Educadores de Formación Profesional y Otros (16,67\%).

Uso de servicios de Sindicación de contenido (RSS):

En la prueba [35] (p.30) preguntamos a los informantes: "¿Utilizas las los servicios RSS disponibles en los sistemas 2.0?”. Tras la aplicación del estadístico Chi-cuadrado aceptamos la hipótesis de independencia entre esta variable y la variable rol (con un valor de 7,628, y una significación de 0,054 a un nivel de confianza del 95\%; $\mathrm{N}=163$ ). Los usuarios que más decían utilizar los servicios RSS eran los formadores de profesores $(36,66 \%-11 / 30$ usuarios), seguidos por los educadores de Formación Profesional y Otros (33,3 \% -3/9), profesores de Educación Secundaria (18,51\% - 20/108), y Profesores de Educación Infantil y Primaria $(14,86 \% 2 / 16)$. 


\section{Comunidad de práctica}

En la prueba [35], (p. 24 y 25), preguntamos a los informantes si sabían lo que era una comunidad de práctica y si habían pertenecido a alguna. No hemos podido aplicar un test estadístico Chi-cuadrado para conocer si existe diferencias entre los grupos, puesto que más del $20 \%$ de los datos tiene una frecuencia inferior a 5 . En cualquier caso, a la luz de los datos, parece que sí hay diferencias entre los grupos atendiendo a nuestra muestra:

- de 107 respondientes, la mayoría de los formadores de profesores $(69,23 \%$; 18/26), y de los profesores de Educación Secundaria (61,53\%; 40/65), que decían saber lo que es una comunidad de Práctica, habían pertenecido a una, al menos.

- En cambio, entre los profesores de Educación Infantil o Primaria que conocían lo que era [17], sólo contestaron 11, entre los cuales sólo 2 pertenecían 0 habían pertenecido a una $(18,18 \%)$.

- De los educadores de formación profesional y otros especialistas, 14 conocían lo que era una comunidad práctica, pero sólo contestaron 5 . De entre ellos, 2 habían pertenecido a una (40\%).

En esta misma prueba [25], en la (p. 26), les preguntamos si eran miembros de alguna comunidad de Práctica a nivel nacional o Internacional.

Encontramos diferencias con significación estadística entre el Rol y la pertenencia a una comunidad de Práctica a nivel nacional 0 internacional (véase Tabla 46). El 66,6\% (20/30 sujetos) de los Formadores de profesores pertenece a una comunidad de Práctica, y el $62,5 \%$ de los educadores de Formación Profesional y Otros). En cambio, sólo un $21,8 \%$ de los profesores de Educación Secundaria pertenecen a este tipo de comunidades y un $41,6 \%$ de los profesores de Educación Infantil o Primaria. Por tanto, rechazamos la hipótesis de independencia $\mathrm{H}_{0}$ ("No hay diferencias entre los sujetos que de un determinado rol, y su pertenencia o no a una comunidad práctica), por lo que según los informantes de esta prueba el rol tiene influencia en la pertenencia o no a una Comunidad de Práctica, con un valor de 23.624, una significación de ,000 y un nivel de confianza del $95 \%$. 
Tabla 46 [35] Chi-cuadrado entre roles sobre: "Conocimiento de Comunidad de Práctica"; "Conocen y han pertenecido" y "Es miembro de comunidad práctica"

\begin{tabular}{|c|c|c|c|}
\hline & Valor & gl & $\mathrm{p}$-valor \\
\hline \multirow{3}{*}{$\begin{array}{l}\text { Conocimiento de } \\
\text { qué es una } \\
\text { comunidad } \\
\text { práctica }\end{array}$} & 17.178 & 3 & ,001 \\
\hline & \multicolumn{3}{|c|}{ N=195 Sí conocen } \\
\hline & \multicolumn{3}{|c|}{$E I / E P=64.70 \% ; E S=48.51 \% ; E s p=35.8 \% F P=86.6 \%$} \\
\hline \multirow{3}{*}{$\begin{array}{l}\text { Si conocen y Han } \\
\text { pertenecido }\end{array}$} & 9.501 & 3 & 023 \\
\hline & \multicolumn{3}{|c|}{ N=107 Sí conocen y han pertenecido } \\
\hline & \multicolumn{3}{|c|}{$E I / E P=18.18 \% ; E S=61.53 \% ; E s p=40 \% F P=69.23 \%$} \\
\hline \multirow{3}{*}{$\begin{array}{l}\text { Miembro de } \\
\text { comunidad } \\
\text { práctica nacional } \\
\text { o internacional }\end{array}$} & 23.624 & 3 & ,000 \\
\hline & \multicolumn{3}{|c|}{ N=193 Sí pertenecen } \\
\hline & \multicolumn{3}{|c|}{$E I / E P=41.6 \% ; E S=21.8 \% ; E s p=62.5 \% F P=66.6 \%$} \\
\hline
\end{tabular}

En esta misma Tabla 46 contrastamos las hipótesis de independencia $\mathrm{H}_{0}$ : "no hay dependencia entre Rol y:

- conocer qué es comunidad práctica":

Rechazamos la hipótesis de independencia, y atendiendo a los resultados, los formadores de profesores conocen de forma mucho más amplia que el resto de roles qué es una comunidad práctica, seguidos por los profesores de educación Infantil y Primaria, y por los profesores de Educación Secundaria - 48,51\% (dato poco coherente porque en la pregunta de "conocen y han pertenecido", el 61,53\% de los profesores responde afirmativamente). Desconocemos los motivos de esta incoherencia, pero puede deberse a que en la segunda pregunta entienden que pertenecen a una comunidad educativa, aunque no entiendan el concepto "comunidad práctica".

- el conocimiento y pertenencia a una comunidad práctica":

En este caso, también rechazamos la hipótesis de independencia, pues los profesores de Educación Infantil y Primaria de nuestra muestra están mucho menos involucrados en comunidades de práctica que los profesores de Educación Secundaria y los Formadores de profesores (que lo hacen en un porcentaje similar).

Comparando los valores obtenidos en las tres preguntas anteriores, encontramos datos concordantes y datos contradictorios. Veamos una tabla de 
contingencia (Tabla 47) de las variables "Conocen qué es una comunidad" y "Han sido miembros de una comunidad de profesores a nivel nacional o internacional".

Tabla 47 Tabla de contingencia: conocen lo que es una comunidad de práctica vs. es miembro de una comunidad de práctica por Rol.

\begin{tabular}{|c|c|c|c|c|c|}
\hline \multirow[t]{2}{*}{ Rol } & \multirow[t]{2}{*}{$\begin{array}{l}\text { Sabes lo que es } \\
\text { una } \\
\text { Comunidad de } \\
\text { Práctica }\end{array}$} & \multicolumn{4}{|c|}{$\begin{array}{l}\text { Eres miembro de una } \\
\text { comunidad de profesores a nivel } \\
\text { nacional o internacional }\end{array}$} \\
\hline & & No & Sí & & \\
\hline \multirow{3}{*}{$\begin{array}{l}\text { Educación } \\
\text { Infantil/Primaria }\end{array}$} & No & & 5 & 1 & 6 \\
\hline & Sí & & 7 & 4 & 11 \\
\hline & Total & & 12 & 5 & 17 \\
\hline \multirow{3}{*}{$\begin{array}{l}\text { Profesorado } \\
\text { Educación } \\
\text { Secundaria }\end{array}$} & No & & 57 & 11 & 68 \\
\hline & Sí & & 47 & 18 & 65 \\
\hline & Total & & 104 & 29 & 133 \\
\hline \multirow{4}{*}{$\begin{array}{l}\text { Formación } \\
\text { Profesional y } \\
\text { otros } \\
\text { especialistas }\end{array}$} & No & & 4 & 4 & 8 \\
\hline & Sí & & 4 & 1 & 5 \\
\hline & Total & & 8 & 5 & 13 \\
\hline & No & & 0 & 4 & 4 \\
\hline \multirow{2}{*}{$\begin{array}{l}\text { Formación del } \\
\text { profesorado }\end{array}$} & Sí & & 10 & 16 & 26 \\
\hline & Total & & 10 & 20 & 30 \\
\hline
\end{tabular}

Existen profesionales que decían no conocer qué era una comunidad de Práctica, pero afirman pertenecer a una "comunidad de profesores a nivel nacional 0 internacional” (El/EP: 9,09\%; ES: 16.92\%; Esp: 80\%; 15,38\%).

Es decir, en los tres casos existen diferencias significativas entre roles atendiendo a los datos proporcionados por los informantes de [35] sobre la pertenencia a "comunidades práctica", "conocimiento de comunidad", y "haber pertenecido". Entendemos que el origen de los datos contradictorios obtenidos puede deberse a diversas razones, entre las que barajamos, por ejemplo: que existe una disociación conceptual entre lo que es una Comunidad de Práctica y una Comunidad de Profesores, entre algunos profesionales de la educación; que puede que pertenezcan a redes sociales de profesores, sin que se impliquen en contribuir o recabar información de la comunidad, por lo que puede que sean 
miembros pero no sientan que pertenecen a una comunidad práctica, etc. Es posible, asimismo, que estas contradicciones se deban a un error de formulación en la pregunta.

\section{D) Aspectos personales}

\section{D.1 ¿Las funcionalidades de personalización ofrecidas por Share.TEC son adecuadas para los usuarios?}

A lo largo de las diferentes pruebas aplicadas con los informantes, hemos podido comprobar cómo los usuarios demandan servicios que permitan personalizar el sistema a sus preferencias.

Un ejemplo lo encontramos en el orden de preferencia de la organización de los resultados de contenidos digitales encontrados tras la búsqueda que realizan en el portal [35] (p.32). Descartamos la aplicación del test Chi-cuadrado de Pearson por la ausencia de datos (el $71.4 \%$ de las casillas tiene un recuento menor a 5 debido a la diversidad de opciones y ausencia de muestra suficiente). Esta pregunta permitía la elección de 1 de entre 7 opciones (recordemos que le número de informantes eran 198):

- Primero los recursos más próximos a mi perfil (119-60,41\%);

- Primero los recursos evaluados positivamente por otros (24 - 12,18\%);

- No me importa el orden (20 -10,15\%);

- Ns/Nc (15-7,61\%);

- Primero los resultados que otros escogieron con términos de búsqueda similares $(9-4,57 \%)$

- Otros (7-3,55\%);

- Primero los recursos que más clics tienen de otros usuarios $(3-1,52 \%)$.

De acuerdo con los resultados obtenidos, la mayoría de los usuarios, sin distinción del tipo de rol, preferían recursos personalizados a su perfil. El resto de opciones es poco relevante para nuestra muestra.

Estos datos nos muestran que es adecuado incluir opciones de personalización de cómo desean visualizar los resultados desde su perfil, puesto que cada usuario manifestaba preferencias diferentes.

Entre los comentarios recogidos en las diferentes pruebas relativos a los aspectos de personalización del portal, los más frecuentes hacen referencia a su característica "impersonal": 
[21] Adjetivo: Impersonal. "Te obligan a logearte para descargar los recursos, y no puedo subir imágenes para personalizar mi perfil".

[21] Adjetivo: Básico. "Poco personalizable".

[21] Adjetivo: Difícil. "Había muchos recursos que no estaban en inglés, el resto no son útiles para $\mathrm{mi}^{\prime}$.

El portal podría incrementar su personalización incluyendo las opciones y funcionalidades explicitadas por las voces de los usuarios:

Como hemos comentado anteriormente, una de las solicitudes más frecuentes respecto a la creación de un perfil de usuario en Share.TEC hacía referencia a la inclusión de más opciones en la categoría "área de interés", pues inicialmente no contemplaban más áreas de "Ciencias" o "Matemáticas", ya que se establecieron estas como prueba, y no se incrementaron antes de la presentación del portal a los usuarios.

Este dato es relevante, pues los usuarios quieren personalizar las herramientas a su perfil concreto.

Sería deseable que los usuarios pudieran ver el historial de su interacción con el portal, pues puede que quieran recuperar algún contenido o interacción, y que no recuerden cómo accedieron a ella, tal y como extraemos del siguiente argumento:

[44] Opinión sobre la sección "Usar" 14.9." 31_M_Ing [...] Creo que el Historial de búsqueda debería ser manipulable. Yo podría querer borrar el historial de búsqueda."

Como hemos visto en apartados anteriores, los usuarios podían incluir en la descripción de su perfil el idioma de preferencia, pero en cambio, no podían configurar los idiomas en los que querían que apareciera el contenido, por lo que una de las demandas que hicieron fue la incorporación de esta función.

[21] 4.9. La configuración del perfil puede desarrollarse para adecuarlo a búsquedas en función del idioma y preferencias.

En cuanto a la funcionalidad "Ver más" de los recursos, los usuarios no pueden elegir qué información quieren visualizar de la existente, pues cada usuario tiene unas preferencias.

12.18. 36_F_FP Cuando he hecho uso de dicha función, la primera vez me resultaba confusa tanta información. Quizás hubiera preferido haber 
solicitado previamente qué quería ver (seguramente existía esa funcionalidad y yo no la conocía).

Preguntamos a los usuarios si les gustaría recibir sugerencias de contenidos de su comunidad o de un servicio automático [35] (p.27). De nuestra muestra de 198 informantes contestaron 57 personas, debido a que muchos de los sujetos no sabían o no contestaron a esta pregunta. Una de las posibles causas de este bajo índice de respuesta creemos que es debido a que esta encuesta se contestó online, y no estaba debidamente contextualizada. De la muestra que contestó a la pregunta, podemos deducir que tras aplicar un test estadístico Chi-cuadrado, no existen diferencias significativas entre los diferentes roles. La mayoría de los usuarios de nuestra muestra $(77,19 \%, 44$ usuarios), consideró que sí que le gustaría recibir sugerencias por parte de la comunidad o por parte de un servicio automático $66,7 \%$ de los Profesores de Educación Infantil y Primaria $-3 / 5 ; 75 \%$ de los profesores de Educación Secundaria - 21/28; 75\% de los educadores de formación profesional y Otros $-3 / 4$, y el $85 \%$ de los formadores de profesores $-17 / 20$ ).

Es decir, parece que los sistemas de recomendación personalizada fueron valorados muy positivamente por los profesionales de la educación, y en especial, por los formadores de profesores.

En [35, pr.38] consultamos a los usuarios sobre qué información les convencería más a la hora de seleccionar un recurso online en un sistema similar a Share.TEC.

En la muestra de 198 profesionales, aceptamos la hipótesis de independencia entre la pertenencia a un rol y su preferencia para elegir una u otra variable, a un nivel del $95 \%$ en todas las variables, excepto en "Abstract (resumen)", donde rechazamos la hipótesis de independencia $\mathrm{H}_{0}$ (valor 12.326, $3 \mathrm{gl}$, sig. 0,006) afirmando que existen diferencias en el grupo de formadores de profesores, donde la mayoría de los usuarios $(83,33 \%)$ consideran relevante este criterio, pues sería decisivo para seleccionar o no un recurso; en cambio, como apreciamos en la tabla, el resto de usuarios se distribuye de forma bastante homogénea entre las opciones "Sí" y "No" (Tabla 48). 
Tabla 48 Prueba [35]. Información relevante para la elección de un recurso por roles: "Abstract"

\begin{tabular}{lllll}
\hline & & $\begin{array}{l}\text { [Abstract] } \\
\text { No }\end{array}$ & Sí & Total \\
\hline Rol & $\begin{array}{l}\text { Educación } \\
\text { Infantil/Primaria }\end{array}$ & 8 & 9 & 17 \\
& $\begin{array}{l}\text { Profesorado Educación } \\
\text { Secundaria }\end{array}$ & 71 & 66 & 137 \\
& $\begin{array}{l}\text { Formación Profesional y y } \\
\text { otros especialistas }\end{array}$ & 6 & 8 & 14 \\
& $\begin{array}{l}\text { Formación del } \\
\text { profesorado }\end{array}$ & 5 & 25 & 30 \\
Total & 90 & 108 & 198 \\
\hline
\end{tabular}

En promedio, el resto de roles (si eliminamos el grupo "Formadores de Profesores" para que no interfiera en el resultado), casi la mitad de informantes, el $49,4 \%$ considera que el "Abstract" es decisivo para elegir o descartar un recurso (ver Tabla 48).

Teniendo en cuenta a todos los roles (ver Tabla 49), el elemento más decisivo para seleccionar un recurso era el "Área de conocimiento de un recurso" $(50,1 \%)$, seguido de "Tipo de recurso" (44,44\%), "Nombre del autor" (40,91\%), "Puntuación" $(29,80 \%)$ y por último, "Anotaciones", seleccionado por un 10,10\%. ${ }^{161}$. En todas estas variables no existen diferencias por grupos (a diferencia del elemento "Abstract"), como veíamos en el párrafo anterior.

Tabla 49 [35] Opinión de los informantes sobre los elementos decisivos para seleccionar un recurso. Elementos sin diferencias significativas entre roles (tras la aplicación de un Chi-2).

\begin{tabular}{lllll}
\hline Rol & & & \\
$\begin{array}{l}\text { Nombre del } \\
\text { autor }\end{array}$ & $\begin{array}{l}\text { Área de conocimiento del } \\
\text { recurso }\end{array}$ & $\begin{array}{l}\text { Tipo de } \\
\text { recurso }\end{array}$ & Puntuación & Anotaciones \\
No 117 & 95 & 110 & 139 & 178 \\
Sí 81 & 103 & 88 & 59 & 20 \\
\hline
\end{tabular}

161 Consideramos que deberíamos haber preguntado a los usuarios por la posibilidad de visualizar: "Comentarios". 
En [35] (p. 47), comprobamos que a la mayoría de los usuarios les gustaría ver la selección de recursos que realizan sus compañeros, no existiendo diferencias estadísticamente significativas entre los diferentes roles:

Aceptamos la hipótesis de independencia entre esta variable y la variable rol significación, con valor 1,929, p-valor de 0,587 a un nivel de confianza del 95\%). Los usuarios que preferían ver las selecciones de sus compañeros, en mayor porcentaje, fueron los profesores de "Educación Secundaria" (73,84\% - 96/130), seguidos por los "formadores de profesores" (73,33\% -22/30 usuarios), "Profesores de Educación Infantil y Primaria" (70,58\%; 12/17) y "educadores de Formación Profesional y Otros" (54,54\% \% -6/11).

Por tanto, poder visualizar la selección de materiales que realizan los compañeros era relevante para la mayoría de los profesionales de la educación de la muestra.

En cuanto a la información que les gustaría ver de entre la que seleccionan otros usuarios [35] ( $p .48 / 49 / 50)$, los informantes de la muestra $(n=198)$ eligieron, en primer lugar, "lo que han descargado" ( $40.40 \%$ de los informantes), seguido por "lo que han visto" (48.48\%), y "lo que han comprado" (el 13.63\%). Tras la aplicación de un test Chi-cuadrado vemos que no hay diferencias significativas entre roles.

Desconocemos las causas del bajo porcentaje de informantes interesados en ver lo que otros han comprado, pero una de las posibles causas puede que radique en que algunos usuarios no están dispuestos a comprar contenido digital, como veremos en el siguiente apartado E.1), pudiendo encontrar otros recursos educativos abiertos de gran calidad.

\section{E) Aspectos económicos}

\section{E.1 ¿Qué hábitos de compra manifiestan los FP que utilizaron Share.TEC?}

En la primera encuesta coordinada [20] preguntamos a los informantes de Bulgaria, Italia y España si compraban contenidos digitales. Tras aplicar un estadístico Chi-Cuadrado, no encontramos diferencias con significatividad estadística entre los dos grupos de roles. En total, el $66,67 \%$ de los informantes de la muestra, nunca compra contenidos digitales, un $25,40 \%$ lo hace algunas veces, y el 7,93\% de ellos compra materiales diariamente. 
Tabla 50 Prueba [20] Frecuencia de pago de recursos diferenciada por roles

\begin{tabular}{|c|c|c|c|c|}
\hline \multirow[b]{2}{*}{ Rol } & \multicolumn{3}{|c|}{ Pago de recursos } & \multirow[t]{2}{*}{ Total } \\
\hline & Nunca & Algunas veces & Diariamente & \\
\hline Educación Su & 24 & 11 & 4 & 39 \\
\hline \multicolumn{5}{|l|}{ Educación } \\
\hline $\begin{array}{l}\text { Secundaria y } \\
\text { Especialistas }\end{array}$ & 18 & 5 & 1 & 24 \\
\hline Total & $42(66,77 \%)$ & $16(25,40 \%)$ & $5(7,93 \%)$ & 63 \\
\hline
\end{tabular}

Como vemos, pocos profesionales de la formación de nuestra muestra compraban contenidos digitales, ya que, de acuerdo con lo comentado por algunos de nuestros informantes, normalmente podían encontrar material útil de acceso gratuito en Internet, o de pago a través de las bibliotecas o servicios de su institución (acceso a bases de datos científicas, revistas, artículos, software, etc.).

[17] p11, E_Ing. Yo, la verdad, es que recursos para la enseñanza no he comprado nunca, sólo espero que la Universidad los compre [...].

Cuando compran, lo hacen normalmente en editoriales online o puntos de venta de confianza que les ofrecen un buen servicio a un precio competente (tales como Amazon o La casa del libro -en el caso de los informantes de la prueba [17], españoles).

[17] p11, R_FP: En editoriales on-line. Es que comprar como tal... tampoco mucho, porque normalmente está en Internet todo lo que solemos buscar. [...] alguna vez sí que compro recursos on-line, pero muy pocas veces [...]. Y cuando lo hago es en una editorial on-line, o páginas dedicadas a la venta de libros, artículos, etc.

[17] p11, I_FP: Yo utilizo fundamentalmente Amazon y Casa del Libro, porque son los que más tienen y los más baratos. Y luego también [...] he comprado alguna suscripción a Doodleboard, algún pequeño software que no tengo y que necesito para algo.

Un recurso que los profesores usan para comprobar su interés por un determinado libro es "Google Books", donde pueden previsualizar si el material les es de utilidad, y si tienen mucho interés en él, compran el libro.

[17] p11, V_FP: Yo, normalmente, a la hora de comprar un artículo on-line, por ejemplo, en el caso de un libro que esté puesto en Google Books [..] te puedes leer, más o menos te haces una idea en la cabeza, de qué va ese libro... y dices... ah, pues puede ser interesante, en ese caso lo compro, en caso contrario, no [...]. 
En el caso de Share.TEC hemos visto que los usuarios quieren saber claramente si el contenido al que acceden es de pago o gratuito, por lo que es necesario marcar adecuadamente y de forma visible los derechos de uso de los recursos, así como las restricciones que conllevan, pues puede darse el caso de encontrar contenido digital limitado a zonas concretas de la Unión Europea 0 de otros países/regiones del mundo:

[Anexo 8] En la tarea 3 de la plantilla de actividades en el workshop de Dublín, estoy observando a dos formadoras de profesores. Tratan de explorar recursos, y escriben como palabra clave: "English Video Share.TEC". Encuentran un recurso: "Teachers.TV"; se dan cuenta de que este recurso sólo permite su visualización en Reino Unido; "K" dice: "qué pena, ¿̇sólo puedes utilizarlo en Reino Unido?".

\subsection{Conclusiones}

En este capítulo hemos recogido el análisis de los datos recopilados durante la vigencia del proyecto Share.TEC y los recopilados posteriormente. Mediante una metodología multimétodo (utilizando técnicas y métodos cualitativos y cuantitativos de análisis e interpretación de datos), desde un enfoque interpretativo, hemos analizado y dado significado a una abundante diversidad de fuentes, datos e informantes. Este proceso nos ha permitido dar respuesta a las preguntas informativas y declaraciones temáticas del caso de estudio Share.TEC para iluminar el issue que planteamos en este estudio de caso:

¿Cómo se relacionan los servicios que ofrece Share.TEC a nivel pedagógico, tecnológico y social para atender las necesidades requeridas por los usuarios potenciales de los sistemas de acceso y compartición contenido digital en el ámbito de la formación del profesorado?

Así mismo, nos han permitido dar respuesta al aserto que guiaba nuestra investigación: "Consideramos que los servicios que ofrece Share.TEC a nivel tecnológico, pedagógico y social se adaptan a las necesidades requeridas por los formadores de profesores cuando acceden y publican en portales web contenido digital y experiencias educativas en el ámbito de la formación del profesorado".

A lo largo del presente capítulo hemos apreciado las dependencias entre unos y otros factores a través de las interpretaciones que hemos ido extrayendo (resaltadas en este formato). Durante el capítulo hemos analizado aspectos relativos exclusivamente al ámbito de nuestro estudio de caso Share.TEC, de los que 
podemos aprehender sus elementos esenciales para poder aplicar las lecciones aprendidas a la generación de nuevos portales educativos, así como aspectos que los usuarios identifican como deseables sobre plataformas educativas para la compartición de contenido digital.

A modo de síntesis, en la presente sección recopilamos las principales cuestiones que dan respuesta al issue y al aserto planteados, organizando el contenido a partir de la estructura de las declaraciones temáticas planteadas. En ella podemos ver cómo los aspectos tecnológicos, sociales y educativos se interconectan y tienen dependencias entre ellos:

\section{A) Aspectos Pedagógicos}

\section{A.1 El modelo pedagógico que subyace a Share.TEC}

Se basa en los postulados cognitivistas constructivistas tal y como se manifiesta en la estructura ontológica y de metadatos del portal (e.g., incluyendo la opción de poder etiquetar las competencias que se desarrollan potencialmente con los contenidos digitales), así como en las herramientas tecnológicas que oferta que fomentan la participación e intercambio de conocimiento entre profesionales (e.g., comentarios a los recursos, votación, recomendación en redes sociales, etc.)

\section{A.2 Ontología de Share.TEC y}

\section{A.3 Necesidades pedagógicas de los formadores de profesores}

Es compartida ampliamente por los formadores de profesores (y otros profesionales de la educación de los niveles de Educación Infantil, Primaria, Secundaria, Psicólogos, Formadores de profesores de educación profesional, etc.). La ontología de Share.TEC se muestra al usuario en formato "Modelo Común de Metadatos", de forma que cuando los usuarios etiquetan recursos pueden ver las capas más superficiales de las conexiones existentes en la ontología (facilitando su comprensión y uso). Es decir, los usuarios pueden ver parte de la estructura ontológica cuando ven cómo están etiquetados los recursos o cuando ellos mismos etiquetan los suyos en el sistema. Actualmente no existe una ontología estandarizada a nivel europeo para el ámbito de la formación del profesorado, aunque la generada en Share.TEC podría servir como base para la generación de una ontología compartida (a través de una evaluación con los usuarios implicados en esta), de modo que facilitara la generación de servicios para este público. 
Creemos conveniente destacar que cada contexto presenta su peculiar idiosincrasia que ha de respetarse con el fin de preservar su identidad cultural, aspecto que Share.TEC resuelve mediante la incorporación de un modelo multicultural de metadatos que permite, dentro de un modelo común, integrar las diferencias de cada contexto (en este caso simplificados a un modelo por cada idioma, manteniendo presente que en cada país existen importantes diferencias culturales entre regiones). Es decir, los usuarios consideran positiva la existencia de sistemas comunes que faciliten la búsqueda y recuperación de información, sin olvidar la integración de las características particulares de cada realidad contextual.

Los informantes que valoraron el etiquetado de los contenidos educativos de Share.TEC consideraron que era mejorable. Share.TEC podría haber mejorado la cantidad de descripciones pedagógicas de muchos de los recursos (además de los campos técnicos y los campos educativos del modelo LOM en el que se basa) mejorando así la calidad de pedagógica de los metadatos. Además de estos datos, podría haberse incrementado la calidad de los metadatos del portal integrando etiquetado social -descripciones de uso de los recursos-, de forma adicional a los metadatos preexistentes (facilitando así la revitalización de los recursos basada en las experiencias de uso de los profesionales.

Entre los campos pedagógicos adicionales que los usuarios añadirían (además de los existentes) se encuentra el modelo pedagógico en el que se sustentan los contenidos digitales, elemento que puede condicionar la decisión de utilizar recurso para un determinado fin educativo.

Un elemento que aportó bastante confusión a informantes de diferentes pruebas y países fue la presencia de contenidos en un idioma, y de metadatos asociados a este contenido etiquetados en varios idiomas. Es importante que la interfaz muestre claramente esta diferencia, ya que este hecho generaba desconcierto entre los usuarios.

Es conocida la importancia de diseñar los portales y productos para los usuarios finales a los que se destina para incrementar su usabilidad (Lowdermilk, 2013; UsabilityNet, 2003, 2006). Un aspecto criticado y poco comprendido por muchos de los informantes de diversas pruebas hacía referencia a la categoría de formato técnico de los contenidos digitales (e.g., en el caso de los recursos etiquetados como "Aplicación - .pdf", los informantes no entendían qué sentido tenía incluir la especificad de "Aplicación"; para ellos sería más útil incorporar descripciones más sencillas y frecuentes en su día a día, tales como la descripción educativa más básica que no integraba, tales como: "Artículo científico" o "WebQuest"). 
Además de este tipo de cuestiones menores, tener en cuenta la opinión de los usuarios desde las etapas más iniciales del desarrollo de portales educativos, mediante filosofías de diseño de productos (e.g., diseño centrado en el usuario -(Liu, 2008)-) es un aspecto relevante. En la experiencia de Share.TEC pudimos comprobar cómo la arquitectura del portal fue eminentemente diseñada por personal técnico y las opiniones de los usuarios sobre el diseño fueron tenidas en cuenta a posteriori, hecho que dificultó la adaptación completa a los requerimientos de los informantes. Es justo destacar los esfuerzos que los miembros de Share.TEC realizaron por adaptar el portal a las necesidades de los usuarios mediante diferentes ciclos iterativos de evaluación y mediante el reajuste de ciertas funcionalidades. Gracias a estos procesos, como hemos recogido a lo largo del capítulo, el portal realizó mejoras importantes. El portal se creó gracias a la financiación de un proyecto europeo, por lo que consideramos que la temporalización del proyecto y las presiones por generar y evaluar con rapidez el producto, fueron las que determinaron la ausencia de un mayor número de iteraciones de diseño centrado en el usuario previas a la construcción de la arquitectura del portal.

\section{A.4 Contenidos digitales útiles para los formadores de profesores}

En general, los contenidos digitales que contiene Share.TEC son valorados por encima de la puntuación media en las diversas pruebas realizadas con informantes de diversos contextos y roles, como hemos mostrado en el análisis cualitativo y cuantitativo de los datos de este capítulo.

Un aspecto relevante a resolver durante la realización del proyecto, motivado por la evaluadora externa del mismo, Claire Belise, fue definir qué se consideraba calidad de los contenidos digitales, y si la calidad hacía referencia a los metadatos 0 a los contenidos en si mismos. La conclusión a la que llegamos es que "calidad del contenido digital" es un término complejo que hace referencia:

- A la calidad de los metadatos (datos descriptivos técnicos, pedagógicos y cantidad de campos del Modelo Común de Metadatos que cubre). Recordemos los sistemas de clasificación de la calidad de los contenidos que hemos descrito: metadatos de calidad oro, plata y bronce.

- Para que exista calidad en los contenidos digitales de un portal, ha de contemplarse la diversidad pedagógica y técnica de ellos (múltiples formatos, niveles, áreas, etc.) 
- Calidad de los propios recursos, donde han de contemplarse aspectos tales como la fuente de la que proviene (aval - autor, institución, etc.), valoración que realizan los expertos del recurso, valoración de la comunidad, etc.

\section{A.5 ¿Es Share.TEC un portal multicultural?}

Share.TEC se ofrece como portal multicultural en la propuesta del proyecto. Este aspecto conceptual fue uno de los más complejos de resolver, junto a la definición de qué se consideraba calidad.

La multiculturalidad se manifestó en el modelo multicultural de metadatos, donde se integraban pequeños matices que incluían especificaciones diferentes para incluir, por ejemplo, titulaciones existentes en unos países ausentes o bifurcados en otros (especialmente atendiendo a las ramas de la formación profesional) en función del idioma que se seleccionara en el portal.

En cualquier caso, a nivel de usuario, Share.TEC es más un portal multilingüístico que multicultural, pues las funcionalidades existentes no potencian la identidad cultural y convivencia de los matices idiosincráticos, si no que el portal sirve como punto de coexistencia de recursos en diversos idiomas. Para algunos usuarios esta mezcla llegó a resultar molesta, pues en la interfaz de usuario del apartado "Usar" se presentan idiomas mezclados.

Otro aspecto a destacar es la ausencia de un sistema de iconos gráficos para representar los tipos de contenido y sus descripciones.

\section{A.6 Ventajas y desventajas pedagógicas de Share.TEC}

Las principales ventajas pedagógicas que ofrece Share.TEC son las siguientes:

- El etiquetado pedagógico de los contenidos facilita la localización de materiales en torno a características pedagógicas como el tipo de interacción con el material (presencial, blended-learning 0 a distancia), habilidades que se trabajan con el contenido, área y nivel educativo para el que están pensados, etc. (estos son campos adicionales al modelo estandarizado de metadatos LOM-IEEE en el que se basa el Modelo Común de Metadatos de Share.TEC y una de sus mayores contribuciones conceptuales para el campo de la formación del profesorado).

- Dispone de las herramientas básicas necesarias para potenciar la interacción con los usuarios, realizar comentarios en los recursos, votarlos, generar grupos, etc. 
- La mayoría de los usuarios de una de las pruebas [33] consideraba que la existencia de un portal de contenido digital para la formación del profesorado similar a Share.TEC era deseable, pues fomenta la cultura de la colaboración entre el profesorado.

- Aúna contenidos dispersos en la red, permitiendo congregar espacios en un único lugar que podría convertirse en sitio de referencia.

- Posibilita el acceso inmediato a contenidos digitales de calidad (filtrados por los propios miembros del consorcio), ahorrando tiempo en las búsquedas (tal y como opinan muchos de los informantes).

- La funcionalidad de "Mi portal" ofertada en Share.TEC permite acceder a los últimos recursos vistos, visualizar los grupos a los que uno pertenece, ver recursos recomendados para el usuario atendiendo a la definición de su perfil, sus bookmarks, etc. Este servicio facilita que los usuarios puedan almacenar los materiales del portal más interesantes para ellos de forma sencilla.

- Constituye un espacio novedoso, pues no existían portales específicos para la formación del profesorado que integraran todas las potencialidades pedagógicas, sociales y tecnológicas que oferta Share.TEC.

En cuanto a las limitaciones 0 aspectos que podrían mejorarse:

- El portal podría mejorar la gestión de la calidad de las descripciones de los metadatos, contando con personas que revisen estos (especialmente los metadatos pedagógicos).

- La interfaz de usuario y algunos errores técnicos y de traducción hacen que algunos formadores de profesores tengan poca predisposición a utilizar el portal.

- El portal es muy técnico, diversos usuarios comentaron que requerían de ayudas en el portal para poder entender cómo funcionaba, especialmente qué significados tenían los campos de búsqueda avanzada y los campos para etiquetar los contenidos que se pueden aportar (modelo común de metadatos). Aunque el portal integra una sección de ayuda, esta es complicada de encontrar (debería ser más accesible y visible para el usuario). Una solución podría ser un guiado automático inicial una vez se crea la cuenta de usuario (si el usuario lo desea).

- Los informantes dejan manifiesto que la búsqueda es un aspecto relevante del portal, y que prefieren sistemas similares a los buscadores que ya conocen (e.g., búsqueda de Google), a no ser que superen la calidad/funcionalidad de los existentes (ya que Google, aunque ofrece poca especificidad pedagógica 
en las búsquedas, ofrece un gran número de recursos). Se podrían mejorar tanto los campos como la interfaz de búsqueda avanzada, incluir búsquedas por aproximación textual (para encontrar resultados a pesar de que se introduzcan errores), búsquedas semánticas (ofrecer resultados por conceptos relacionados), etc. En diversas pruebas los informantes opinaron que Share.TEC ahorraba tiempo en las búsquedas de material educativo dado que integra filtros pedagógicos.

- Según el estado actual del buscador y la cantidad de contenidos ofertados (y etiquetados de forma pedagógica), hay informantes que opinan que oferta pocas ventajas frente a buscadores genéricos. En cambio, otros informantes sí que son conscientes del potencial que puede proporcionar un sistema como Share.TEC: si existe una comunidad de usuarios activa en torno al portal, dinamizada por moderadores, con contenidos educativos que aporten descripciones de uso contextual de los recursos y sobre todo, etiquetas pedagógicas que faciliten la recuperación "acertada" de los contenidos (por habilidades que se trabajan con el recurso, tipo de interactividad, tipo pedagógico de recurso, etc.).

- No hay acceso a los datos estadísticos de los recursos (personas que los han visualizado, accedido a los links que vinculan hacia el contenido digital, datos de uso del portal, contenidos vistos por otros usuarios, etc.). Además, los informantes valoran de forma positiva la presencia de estadísticas accesibles y visibles de forma fácil en el portal.

\section{A.7 Necesidad de Sistemas similares a Share.TEC para formadores de profesores}

Los formadores de profesores consideran necesaria y útil la existencia de un sistema similar a Share.TEC. En varias pruebas [21] y [33], se recoge explícitamente la creencia de que Share.TEC es un sistema útil. Valoran positivamente la existencia de un sistema como Share.TEC:

- específico para el área de la formación del profesorado

- que integre diferentes áreas de la formación del profesorado (multidisciplinar)

- consideran buena y necesaria su existencia, por la escasa oferta de soluciones de este tipo enfocadas al ámbito concreto de la formación del profesorado

- como lugar potencial de encuentro de las comunidades de la formación del profesorado para la compartición y redefinición de materiales educativos y prácticas docentes. 
En varias pruebas [44] y [33] los informantes manifestaban su voluntad positiva para recomendar a sus compañeros de trabajo la utilización de este portal.

\section{A.8 Cómo han utilizado los usuarios el portal}

El portal ha sido utilizado eminentemente como repositorio de contenidos digitales más que como portal interactivo, tal y como podemos ver en el apartado "Usar" del portal (donde observamos que no existen "grupos" activos que intercambien contenidos ni experiencias). Los usuarios apenas han contribuido con sus recursos al portal (sólo existen 16 recursos de usuarios; actualmente existen 1423 usuarios registrados ${ }^{162}$; el resto son visitantes), y además esta tarea se ha visto ralentizada por el visto bueno para la publicación de los contenidos por el administrador del portal (de procedencia búlgara). Consideramos que la escasísima contribución de materiales de los usuarios al portal se debe a la ausencia de una comunidad activa entorno al portal.

En los datos estadísticos del uso del portal (registrados con "Google Analytics") apreciamos ciclos de activación, desactivación y reactivación del uso del portal, y detectamos que tras la finalización del proyecto los lugares desde los que más se accede son desde Italia y Bulgaria (debido al uso que se realiza de ellos, especialmente, desde actividades formativas lideradas por miembros del consorcio y personas cercanas a ellos). Existen acceso desde las diferentes partes del mundo (aunque son escasos y desconocemos si son máquinas automáticas o personas las que los realizan).

A pesar de la alta deseabilidad de uso demostrada por parte de los informantes en las diferentes pruebas, sólo han existido 60.000 sesiones abiertas desde el inicio del seguimiento de las estadísticas de uso del portal.

\section{A.9 Los hábitos de acceso, uso y compartición}

\section{Acceso:}

Los usuarios acceden principalmente al portal en su idioma, a pesar de que las personas de los diferentes países cada vez estudian más idiomas (la mayoría de los usuarios, independientemente del país de origen, utilizan su lengua nativa e inglés para acceder a material educativo). Los informantes opinan que la coexistencia de

162 Última fecha de actualización de este dato: 3 de diciembre de 2015. 
diversos idiomas es un aspecto beneficioso para los portales educativos (siempre que la visualización de determinados idiomas sea configurable).

Hemos podido apreciar la diversidad de necesidades y preferencias manifestadas por los usuarios a lo largo de las diferentes pruebas, concluyendo la necesidad de incluir funcionalidades que permitan la personalización del acceso, personalización de funcionalidades y servicios, configuración visual, idioma de los contenidos y/o metadatos que quieren ver, etc.

Los usuarios son favorables al registro en portales educativos siempre que sepan que esta acción les reporta ventajas (acceso a más servicios que un usuario no registrado, seguridad de su información, oferta de beneficios con respecto a otros portales similares, etc.). A nivel práctico, poder conectarse en portales de este tipo mediante otras cuentas frecuentes (e.g., Google o Facebook) evita la duplicidad de perfiles de acceso a diferentes portales y agiliza el proceso.

\section{Uso:}

Los informantes son más propensos a la utilización de materiales educativos elaborados por otras personas cuando existen ciertos avales de calidad:

- Universidad o Institución de procedencia del creador del material.

- Nombre del autor (si es una persona reconocida por la comunidad de práctica).

- Puntuación otorgada por otros usuarios.

- Número de descargas del material.

- Comentarios sobre el contenido.

- Existencia de filtros para subir contenido (e.g., CAPTCHA).

- Recursos vistos por otros usuarios.

A la luz de las evidencias aportadas apreciamos que no existen diferencias significativas de acceso a la mayoría de tipos pedagógicos de contenido digital entre profesionales de cada rol, a pesar de que los profesores de educación Secundaria y especialistas acceden más a contenidos del tipo: "quiz-test", "lista de preguntas frecuentes", "figura" "enunciado de problema", "cuestionario" y "presentación de diapositivas" que los formadores de profesores.

Los contenidos digitales más utilizados eran: las Webs, diapositivas, clases magistrales, figuras, wikis, tablas, etc.; los menos utilizados eran: micromundos, artefactos, listas de preguntas frecuentes, exámenes, demostraciones. Hemos observado en los análisis de las pruebas que los profesionales de la educación de nuestras muestras utilizan gran diversidad de tipologías pedagógicas de material. 
Existe una diferencia entre los formadores de profesores y el resto de profesionales de la educación, y es que, a diferencia de otros profesionales de la educación, la mayoría de ellos utiliza repositorios de contenidos digitales para preparar las clases e investigar, principalmente.

Los formadores de profesores recurren principalmente a los "motores de búsqueda", "YouTube", "recensiones" y "libros" para acceder a contenido digital. En general, casi la totalidad de los profesionales de la educación (independientemente del rol) utilizan los "motores de búsqueda" para acceder a contenido y en general, no existen diferencias por roles entre el uso de herramientas Web para buscar contenido digital educativo. Hemos encontrado diferencias estadísticamente significativas a un nivel de confianza del 95\%, tras la aplicación de un Chi-2, en la utilización de las "recensiones online", "Google Scholar", "Google libros" y los "repositorios institucionales" para acceder a contenido digital comparando los roles, pues los formadores de profesores acuden con una frecuencia mucho mayor que el resto de profesionales de la educación a este tipo de espacios para buscar contenido.

Los lugares de acceso más frecuentes por parte de los formadores de profesores a contenidos digitales son el motor de búsqueda de "Google" y las "revistas especializadas" de cada área/temática educativa. Los profesionales de la educación, en general, acceden a sus búsquedas eminentemente por búsquedas mediante keywords (la gran mayoría) y por búsqueda avanzada (un porcentaje minoritario -en torno al 15\% atendiendo a nuestras muestras).

Los formadores de profesores suelen almacenar contenidos digitales de forma local (en su ordenador), siendo a veces difíciles de volver a encontrar si no están organizados por etiquetas 0 si no se escribe la palabra clave adecuada. A nivel de portal educativo, ocurre lo mismo, es decir, los usuarios contribuyen con sus contenidos digitales utilizando ciertas etiquetas, pero es posible que otras personas escriban otros términos para acceder a contenidos similares.

Otra de las preguntas que nos interesaba conocer era para qué y qué buscan contenidos digitales los formadores de profesores. Las razones principales por las que acceden a portales educativos son, entre otras: para desarrollarse profesionalmente, investigar, preparar las clases, recuperar material para emplearlo en sus clases, etc. En general buscan materiales por nivel y área, y algunos formadores consultan a otros profesionales de confianza sobre la opinión de los materiales que encuentran. 
Entre los formadores de profesores, la mayoría usa y comparte contenido digital (a pesar de que afirman usar ligeramente en mayor proporción que compartir). A la luz de los datos hemos detectado que existen ciertos perfiles de persona más altruistas a la hora de compartir contenido que otras, a los que llamaremos "altruistas activos", pues quienes comparten lo hacen con mayor frecuencia que quienes utilizan contenido digital (pero los "altruistas activos" son mucho menores en proporción). Los datos, basados en nuestras muestras, nos desvelan que los formadores de profesores comparten más que los profesores de Educación Secundaria.

\section{Compartición:}

La funcionalidad de compartición de Share.TEC (que se encuentra en el apartado "Ofrecer") se encuentra poco visible para los usuarios y consta de un formulario denso y complejo para quien no conoce el modelo de metadatos de Share.TEC, hecho que restringe la contribución de contenido digital por parte de usuarios).

Los formadores de profesores comparten sus recursos con otros formadores, estudiantes, o con cualquier persona que necesite estos recursos. Aunque nuestros datos desvelan diferencias en las respuestas sobre la compartición de material educativo por parte de los informantes, en general es necesario aumentar la cultura de compartición mediante los planes de formación y políticas educativas. Un problema existente en torno a la compartición es que muchos usuarios comparten contenido exclusivamente de forma privada (correo electrónico, plataformas privadas, memorias flash, etc.), o de forma dispersa (en diferentes plataformas educativas, redes sociales, etc.), por lo que aún resalta la ausencia de espacios unificados que compilen material educativo para la formación del profesorado.

A lo largo de las diferentes pruebas llevadas a cabo con los informantes hemos extraído una serie de elementos que facilitan y dificultan la compartición:

Entre los elementos que limitan el hecho de compartir contenido digital encontramos:

- Condicionamiento hacia la no compartición de contenido digital si la herramienta no es útil.

- Tendencia a utilizar más que a compartir en este tipo de espacios.

- "Cultura de no colaboración" incardinada en los profesionales de la educación. 
- escaso uso de material educativo diseñado por otros, conocido como el síndrome del "not invented here" (Bryant, 2009; Grosse Kathoefer \& Leker, 2012).

- Ausencia de formación en el profesorado sobre sistemas para compartir contenido digital, etiquetarlo, concienciar sobre la importancia de su uso y de la compartición de contenidos abiertos, etc.

- Ausencia de tiempo para la contribución de materiales.

- Existencia de sobreinformación distribuida en múltiples servicios difundidos en la red, que fomentan la dispersión de las comunidades.

Entre los elementos que facilitan la compartición destacamos los siguientes:

- A pesar de los datos del portal Share.TEC nos indican que los usuarios no utilizaron este portal realmente para compartir sus contenidos, la mayoría de los usuarios de las pruebas explicitaban su utilidad como espacio para la compartición de este tipo de contenidos.

- El hecho de disponer de una red multidisciplinar estimula la posibilidad de coexistencia de diversas comunidades en el portal, y por tanto, la diversificación y aumento de la cantidad de contenido digital.

- Espacios como Share.TEC permiten la obtención de feedback de los materiales generados por uno mismo por parte de otros profesionales de la educación; esta posibilidad puede estimular la mejora de las prácticas docentes.

- Disponer de material de calidad facilita que los usuarios utilicen el portal y se animen a compartir su material en él.

\section{B) Aspectos Técnicos}

A través del caso de estudio "Share.TEC", y de las diferentes pruebas realizadas con informantes, hemos aprehendido algunas de las funcionalidades demandadas por los usuarios potenciales de sistemas para compartir contenidos digitales para la formación del profesorado, entre las que destacan:

- Puntuación (sistema de puntuación de recursos, por ejemplo, mediante estrellas o nota media, que permita saber cuántos usuarios han puntuado el material); cuantas más personas han puntuado un recurso, mayor credibilidad tiene esta funcionalidad para los usuarios (en Share.TEC los recursos apenas tenían valoraciones de comentarios ni de puntuaciones).

- Comentarios (posibilidad de comentar las experiencias de uso de los materiales por parte de otros usuarios). 
- Funcionalidad de recomendación personalizada de contenido e información (basada en las consultas previas realizadas por un usuario y en las especificaciones de preferencias detalladas en su perfil).

- Marcadores (recursos destacados por el usuario accesibles en sesiones posteriores) e historial de búsqueda.

- Comunidad (espacio social que permita la visibilidad de perfiles similares y de otros usuarios - aspecto poco logrado en Share.TEC).

- Recursos descargados por otros usuarios.

- Poder visualizar el número total de recursos

- Dar atención a la privacidad del usuario

- Garantizar la calidad y el mantenimiento del portal

- Proporcionar sistemas de búsqueda flexibles y de calidad similares a los ya conocidos (e.g., el motor de búsqueda de Google) (el motor de búsqueda de Share.TEC fue uno de los aspectos considerados como importantes para los usuarios y muy mejorable en su caso).

- Ofrecer servicios personalizables

- Visualizar de forma sencilla y rápida los comentarios y datos de uso de los recursos, quizá incorporando sistemas visuales (iconos) que representen el tipo de material, área, nivel educativo, etc. (visualizando una leyenda en un menú lateral que permita identificar claramente los recursos).

La interfaz de Share.TEC es uno de los elementos peor valorados por los informantes de las diferentes pruebas, en oposición a la facilidad de uso (valorada de forma bastante positiva por los usuarios), Los únicos iconos que podíamos encontrar en la página web eran banderas para identificar visualmente el idioma del contenido digital. Representar por banderas los idiomas puede provocar sentimientos de exclusión a personas de países en los que se habla el mismo idioma (e.g., una persona de argentina habla español, y verá el contenido representado con la bandera de España, que no representa su identidad).

La interfaz mejor valorada de Share.TEC fue la del apartado de "Acceder"; en cambio, el apartado "Ofrecer" fue poco adecuado para más usuarios. Entre los aspectos positivos de la interfaz destacamos su claridad y aspecto limpio destacado por los usuarios; entre los negativos más resaltados por los usuarios se encontraban los calificativos de en una interfaz impersonal, monótona (que invita poco a interactuar en ella), con mucho espacio desaprovechado y unimodal (sólo texto).

A través de los informantes de las pruebas y las conversaciones con profesionales de la educación sobre la interfaz de Share.TEC, consideramos que es 
muy mejorable su presentación y organización (integrando las funcionalidades "acceder", "usar" y "ofrecer" de forma conjunta y no parcelada - hecho que limitaba su usabilidad). Los formadores de profesores y profesionales de la educación, como usuarios de la web, tienen mayor predisposición a utilizar espacios atractivos, simples, usables, etc.

Hemos de destacar que la mayoría los informantes de las diferentes pruebas tenían una tendencia a valorar positivamente la utilidad y usabilidad del portal. En cualquier caso, hemos encontrado dicotomías entre las opiniones de los usuarios sobre estos aspectos, por lo que consideramos oportuno repensar especialmente la interfaz, pero también mejorar la usabilidad del portal.

Atendiendo a la usabilidad del portal las principales críticas se centraban en:

- La falta de guías/tutoriales fácilmente accesibles que permitieran a los usuarios conocer el funcionamiento del portal de forma autónoma.

- Problemas técnicos del portal (en ocasiones salían mensajes de error automáticos que dificultaban el acceso a enlaces o funcionalidades en el portal, e.g., el acceso al portal mediante la funcionalidad de Facebook).

- Existencia de faltas de ortografía en las traducciones de los recursos (disminuyendo la credibilidad de los materiales y del portal).

- Parcelamiento de las funcionalidades del portal (acceder, usar y ofrecer) que podrían ser accesibles desde cada página del portal mediante menús fijos.

- Poca visibilidad de algunas funcionalidades (e.g., acceso a bookmarks; compartir contenidos).

Algunas de las sugerencias de mejora que se proponen son:

- Flexibilizar la obligación de introducir una keyword por cada comentario

- Introducir menos campos obligatorios cuando se comparte un recurso, y que estos puedan ser enriquecidos por otros usuarios

- Mejorar la facilidad a la hora de contribuir los propios recursos (tanto la visibilidad de esta funcionalidad como su interfaz y exigencia de campos).

- Mejorar las traducciones multiidioma del portal

- Mejorar la presentación de los recursos (e.g., existe la posibilidad de ver miniaturas de ellos, pero la mayor parte de los contenidos carece de previsualización; incorporar descripciones más visuales, por ejemplo, mediante sistemas de iconos, como ya hemos comentado). 
- Preservar las keywords introducidas en las búsquedas tras cambiar de ventana del explorador (en Share.TEC esta funcionalidad fue incorporada en la etapa final del proyecto gracias a las opiniones de los usuarios).

- Copiar modelos de interfaz conocidos (e.g., el motor de búsqueda de Google; en Share.TEC la usabilidad de la búsqueda simple era bien valorada por los usuarios).

- Incorporar herramientas de notificación visibles en el propio portal (e.g., notificar con algún tipo de alerta -por ejemplo imitando las notificaciones visuales y sonoras de Facebook- la interacción de otros usuarios contigo en el portal para poder conocer si alguien comenta recursos que tú has comentado, valorado 0 compartido, actualizaciones de determinadas personas, mensajes nuevos, etc.).

En algunos casos existen servicios de contenido que detectan el país desde el que se conecta el usuario y restringen el acceso para otros países (e.g., Teachers.TV, era un servicio que sólo podía utilizarse desde Reino Unido); este tipo de limitaciones deberían ser especificadas para evitar a los usuarios perder tiempo en sus búsquedas.

\section{C) Aspectos Sociales}

Una de las funcionalidades mejor valoradas por los informantes de las pruebas realizadas en Share.TEC (a pesar de su bajo uso, tal y como podemos apreciar en la web del portal) fueron los "Grupos" del portal. Idealmente los profesionales de la educación consideraron muy positivo poder aportar feedback a los recursos creados por otros y recibirlo a los creados por ellos mismos, permitiendo la remodelación de los materiales, así como la incorporación de sugerencias y reflexiones para la mejora de las prácticas docentes. Además, los usuarios destacaron la posibilidad por poder re-etiquetar los contenidos subidos al portal (pues en función de los objetivos educativos de las actividades que se realicen, pueden servir para diferentes áreas y niveles, para desarrollar diferentes competencias, etc.).

La funcionalidad de "compartir en redes sociales" fue valorada de forma positiva por los informantes, pues permite difundir el contenido a las otras comunidades a las que pertenece el usuario y con las que comparte similares intereses e inquietudes. Otro hecho destacado con estos recursos es la celeridad con la que se puede compartir la información y distribuirla a cualquier lugar del mundo, pudiendo ser enriquecidos los contenidos desde diferentes visiones culturales y educativas. Un efecto indirecto de esta funcionalidad es el aumento de la visibilidad del portal, ya que se publicita en otros espacios su existencia. 


\section{D) Aspectos de personalización}

Hemos comprobado que la personalización es un aspecto que resulta relevante para los usuarios, pues permite ahorrar tiempo a los usuarios a la hora de realizar búsquedas y recuperar contenidos, y además adaptarse a sus preferencias de visualización de recursos (por idioma, tipo, área, presentación visual, etc.).

La personalización es un aspecto tácito y explícito demandado por los usuarios en las diferentes pruebas. Como hemos podido comprobar es difícil amoldarse a las preferencias de los diferentes usuarios y dar cobertura completa a las necesidades de todos, por lo que disponer de servicios flexibles y personalizables puede fomentar el uso de portales educativos de este tipo, partiendo de características preferidas de forma más amplia por los usuarios.

A lo largo de nuestro análisis, hemos identificado que cuando los profesionales de la educación seleccionan contenidos educativos valoran, de mayor a menor porcentaje: el área de conocimiento del recurso, el abstract, tipo educativo de recurso y nombre del autor. Las puntuaciones son poco valoradas por los usuarios. Poder definir en el perfil qué información quieren que aparezca en la muestra de las descripciones básicas y completas de los recursos puede facilitar el deseo de los usuarios de usar el portal.

En cuanto al apartado social, poder tener acceso a lo que otros compañeros visualizan y descargan es relevante para los usuarios.

\section{E) Aspectos económicos}

Los informantes a los que hemos preguntado en determinadas pruebas del "estudio de caso" tienen escasos hábitos de compra de contenido digital (suelen recurrir a recursos gratuitos online). Incluso, un porcentaje reducido de usuarios tiene interés en visualizar qué han comprado otras personas en el portal (pues no tienen intención inicial de comprar). Entre los recursos más comprados por los formadores de profesores encontramos libros, artículos científicos, suscripciones a servicios educativos y determinados software. Los informantes explicitan su deseo de visualizar con claridad en los portales educativos si los contenidos son gratuitos 0 de pago, así como las licencias bajo las que se encuentran (no identificables en Share.TEC, pues sólo pueden saber si es contenido gratuito o de pago).

La financiación de los portales educativos por entidades públicas garantiza su existencia e independencia de intereses económicos concretos (evitando cambios en los modelos de negocio, e.g., la red social NING que se ofrecía inicialmente de 
forma gratuita y que utilizamos para diseminar el proyecto Share.TEC desde el equipo UVa del proyecto comenzó a cobrar cuotas tras el primer año de su creación).

En conclusión, en este capítulo se han presentado los hallazgos encontrados en el caso de estudio Share.TEC a través del análisis de los datos recogidos e interpretados mediante diferentes técnicas e instrumentos de carácter cualitativo y cuantitativo. Tanto a lo largo del capítulo como en este apartado de conclusiones, apreciamos las relaciones e interdependencias entre los aspectos pedagógicos, tecnológicos, sociales, de personalización y económicos que hemos presentado.

Como estudio instrumental de caso, no sólo hemos determinado qué aspectos delimitaron Share.TEC y cuál fue la opinión de los usuarios sobre los servicios que ofertaba; además, hemos podido extraer y abstraer una serie de recomendaciones propuestas por los propios usuarios para diseñar o reconfigurar los sistemas de compartición de contenido digital de forma más acorde al ámbito específico de la formación, y en concreto, al de la formación del profesorado. Estas propuestas se recogen en el capítulo 6 de esta tesis.

A continuación, en el capítulo 5, mostramos el análisis e interpretación del segundo estudio que compone esta tesis: los portales para la compartición de contenido digital y experiencias educativas. De él aprehenderemos un conjunto de buenas prácticas y aspectos mejorables de este tipo de portales, que complementarán la propuesta que presentamos en capítulo 6. 


\section{Capítulo 5}

\section{Análisis e Interpretación: Estudio 2}

\section{Estudio de portales de contenidos digitales educativos para la formación del profesorado}

En los capítulos 2 y 3 de esta tesis doctoral abordamos el marco teóricometodológico en el que se sustenta este estudio y su diseño de investigación de acuerdo a los objetivos de la tesis, respectivamente. En este capítulo presentamos, en primer lugar, cómo hemos llevado a cabo la construcción de la herramienta de análisis de los portales educativos, partiendo de fuentes existentes de la literatura y de las categorías de análisis que emergieron en el análisis del estudio de caso Share.TEC. Posteriormente detallamos cómo realizamos la selección de los portales educativos mediante una muestra de juicio. Para finalizar, realizamos una comparación de los portales educativos, obtenida gracias al análisis individual previo de los portales.

\section{Construcción de la herramienta de análisis}

\subsection{Análisis de fuentes de la literatura}

Para elaborar la herramienta de evaluación de los portales para la compartición de contenido digital y experiencias, nos hemos basado en las principales fuentes de la literatura que han abordado soluciones para la evaluación o generación de portales educativos, y que son una referencia de los aspectos que debemos tener en cuenta tanto para la creación como para el análisis de este tipo de portales.

De este modo, a continuación presentamos cada una de las fuentes que hemos contemplado como relevantes, comentamos por qué hemos considerado su inclusión para la generación de nuestro propio esquema, e integramos las 
categorías que contemplan realizando una síntesis de aquellas que consideramos más oportunas.

\section{A) Red Europea de Repositorios Educativos (EdReNe, 2011)}

EdReNe es una red europea de repositorios educativos, que surge a través del desarrollo de un proyecto eContent plus financiado por la Unión Europea (EdReNe, 2013). La red está formada por 37 miembros de la mayoría de los países europeos, y contempla principalmente repositorios de los niveles K-12 (Educación Infantil y Primaria), Educación Secundaria y Bachillerato. A pesar de centrarse en estos niveles, consideramos relevante considerar los informes de EdReNe como referentes para la creación de nuestro esquema de categorías de análisis, pues existe una estrecha relación entre las características y problemáticas de estos repositorios y los destinados a la educación superior (EdReNe, 2009, 2010). Los aspectos que toman en consideración para realizar la descripción y evaluación de los portales son los siguientes:

- Descripción del portal

- Número de recursos

- URL

- Aspectos visuales (interfaz)

En 2009, EdReNe (EdReNe, 2009) realizó un estado del arte de los principales repositorios europeos de contenidos digitales educativos. En este informe recopilaron información sobre diferentes categorías de análisis que se detallan a continuación. En esta tesis doctoral nos ha parecido conveniente tenerlas presentes puesto que indican aspectos que son relevantes para comprender el rol de los repositorios de contenidos digitales para la formación del profesorado.

- Estándares en los que se basan los metadatos.

- Interoperabilidad (Flinders, 2014; Thompson, 2010)

- Derechos de autor del contenido digital.

- Método de captación de usuarios del servicio.

- Proveedores que proporcionan contenido para el portal.

\section{B) Repository Guidelines de Charlesworth et al. (2008a, 2008b)}

Este documento recopila las buenas prácticas de 70 repositorios de materiales educativos, y propone una serie de recomendaciones en torno a ocho áreas. El 
trabajo fue desarrollado por miembros de BECTA ${ }^{163}$ (Charlesworth et al., 2008a, 2008b)

- Estándares y especificaciones de los metadatos y del portal.

- Mecanismos de compartición del contenido.

- Opciones de marketing (contenidos gratuitos o de pago; acceso al portal).

- Interfaz de usuario.

- Seguridad de internet.

- Accesibilidad al repositorio.

- Calidad de los materiales.

- Derechos de autor y Copyright de los recursos.

Consideramos interesante la consideración de este estudio, puesto que era una fuente relevante que recopiló mediante encuestas la información de 70 repositorios.

C) Criterios de valoración y análisis de sitios web sobre drogodependencia (Carabantes Alarcón, García Carrión, \& Beneit Montesinos, 2004)

Los autores presentan un estudio sobre la evaluación de sitios web de drogodependencia. A pesar de ser ésta una temática ajena a la de esta tesis doctoral, valoramos oportuna la consideración de los siguientes aspectos en nuestro esquema de evaluación de los repositorios:

- La filosofía que sigue cada uno de los sitios o la información que nos ofrece sobre el origen y desarrollo de su sitio Web/ propósito.

- La organización de los contenidos.

- La actualización de los recursos.

163 Las siglas BECTA corresponden a Brithish Educational Communications and Technology Agency - en español, Agencia Británica de Comunicación y Tecnología Educativa. BECTA fue una organización pública no departamental, fundada en 1998 por el Departamento de Educación de Reino Unido, y abolida en 2011 como parte del plan de ahorro de servicios públicos del país. Esta entidad pretendía proporcionar a las escuelas públicas de paquetes tecnológicos económicos y asesoramiento en tecnologías de la información y comunicación educativas (Flinders, 2014; Thompson, 2010). 


\section{D) Guía de evaluación de páginas Web Educativas (Lesley University, 2007)}

Esta fuente proporciona una serie de criterios para evaluar la apropiación de sitios web para su inclusión en el aula. Consideramos relevante considerar su integración en nuestro esquema de evaluación de los portales, ya que han sido elaborados específicamente para evaluar su inclusión en ámbitos educativos. Este recurso fue creado por los servicios de la biblioteca de la universidad de Lesley (Cambridge, Massachussetts).

Proponen ocho categorías que integran los siguientes elementos:

- Propósito: hace referencia a la intencionalidad del sitio Web (si es un sitio comercial, informativo, educativo, de entretenimiento, persuasivo, institucional, personal, etc.). Además sugiere considerar quién es el productor del sitio observando la URL de su página Web (.org, .edu, etc.).

- Autoridad: hace referencia a quién es el autor, cuáles son sus credenciales, quién subvenciona o promociona el sitio web, etc.

- Objetividad: debemos tener en cuenta si el contenido está o no sesgado, si el sesgo es explícito o implícito, si la identidad del autor supone un sesgo, y cómo impacta el sesgo sobre la utilidad de la información.

- Adecuación y relevancia: hacen referencia a lo oportuna que es la información para su utilización en un contexto determinado, a si el contenido es adecuado para el nivel de edad, si está bien escrito, si es relevante para el propósito educativo que se pretende.

- Difusión: se centra en conocer si la página web está actualizada, si se conoce cuándo han sido editadas las páginas, si hay "dead links", es decir, enlaces caducados, si hay diferencia entre la fecha en la que la página fue creada con la que fue actualizada, etc.

- Responsabilidad: se refiere a si los autores son fácilmente visibles para responsabilizarse del contenido, si es posible contactar con ellos, si los autores referencian la información que han utilizado, si hay una lista de referencias, etc.

- Claridad: respecto a la presentación del contenido, la nitidez, legibilidad y formato del texto (si permite la lectura fácil), si los gráficos aportan información o son elementos distractores, a la interferencia o no de los anuncios de la página si los contuviera, sobre si hay errores de escritura 0 utilización de las palabras; la organización adecuada de las páginas. 
- Accesibilidad: evalúa si se puede acceder o no al servicio, si el sitio carga de forma rápida, si se puede navegar fácilmente, si se puede acceder en otro momento al material (en un segundo acceso), si existen alternativas para personas con discapacidad visual.

\section{E) UsabilityNet ${ }^{164}$ (2006)}

Usability.Net fue un proyecto financiado por la Unión Europea, que tuvo lugar entre 2001 y 2003. Su pretensión era la de promover la usabilidad y el diseño centrado en el usuario. Siguiendo los estándares internacionales para las interacciones humanas por ordenador y la usabilidad propuesta por UsabilityNet (2003), podemos clasificar las categorías de los estándares en función de:

- La utilización del producto (eficacia, efectividad y satisfacción en un contexto de uso particular).

- La utilización de la interfaz de usuario y la interacción con el sistema.

- El proceso utilizado para desarrollar el producto.

- La capacidad de una organización para aplicar diseño centrado en usuario.

- Además de estos aspectos debemos tener en cuenta:

- Quién financia el portal y en consecuencia, qué tipo de control hay sobre los contenidos

- Si es un repositorio federado o es un repositorio en sí mismo.

- El tipo de estándar en el que están basados y los datos que contienen sus contenidos digitales.

\section{F) Herramientas de evaluación de LORs SWITCH y Catalyst (Kurilovas \& Dagiene, 2009)}

Kurilovas \& Dagiene (2009) publican un artículo en el que proponen una herramienta comprensiva para la evaluación de los repositorios de objetos de aprendizaje. Hemos tomado esta fuente como referencia porque recopila las principales herramientas de evaluación de LOR y entornos virtuales de aprendizaje, realiza una revisión de la literatura sobre la temática y propone un modelo integrador.

164 http://www.usabilitynet.org/tools/r_international.htm Estándares para determinar la usabilidad de los sistemas 
En su artículo destacan que en una de las reuniones que tuvo lugar en un seminario de EdReNe en 2008 con miembros del proyecto y expertos externos, se determinó que asegurar la calidad de los objetos de repositorios de aprendizaje era el aspecto de mayor prioridad, siendo determinada como esencial por un $58,8 \%$ de los asistentes, y como importante por un 38,3\% (Kurilovas \& Dagiene, 2009, p. 141).

Los autores afirman que los investigadores suelen dividir el criterio de evaluación de los componentes de los sistemas e-learning en los aspectos: tecnológicos, pedagógicos y organizativos. Existen diferentes herramientas de evaluación de la calidad de los repositorios de objetos de aprendizaje y entornos virtuales de aprendizaje, entre los que los autores destacan tres herramientas conocidas: SWITCH, Catalyst IT y OMII. En nuestro caso nos interesan los dos primeras, ya que OMIl se centra más en aspectos técnicos y de difusión del repositorio, no tan relacionados con los objetivos de la presente tesis:

La herramienta de evaluación de la calidad de repositorios de objetos de aprendizaje SWITCH, examina cinco criterios de repositorios de objetos de aprendizaje (Kurilovas \& Dagiene, 2009, p. 143; Switch, 2007), que se utilizaron para evaluar los repositorios de objetos de aprendizaje DSpace y Fedora:

- Arquitectura: hace referencia a aspectos de flexibilidad y modulabilidad del sistema para poder ir adecuando el sistema a la evolución de las necesidades del repositorio con el paso del tiempo. Contempla la posibilidad de utilizar los repositorios como parte de una federación de ellos, una API (Application Programming Interface - interfaz de programación de aplicaciones) para el motor de almacenamiento, una API para los derechos de acceso de los usuarios, una API para la federación de funciones, búsqueda de metadatos con esquemas heterogéneos, búsqueda de texto completo, rendimiento, escalabilidad, seguridad, interoperabilidad, persistencia de los links, internacionalización.

- Metadatos: esquema mínimo de metadatos; conjunto de metadatos predefinidos; metadatos personalizables, mapeo (relación) de metadatos para búsqueda de metadatos, apoyo Unicode (caracteres del sistema), etiquetado social.

- Interfaz Gráfica de usuario: estándar de interfaz de usuario completo, estándar de interfaz de usuario extensible, estándares múltiples de interfaz de usuarios, interfaz de usuarios personalizables, utilización del protocolo de autenticación AAA (Autenticación, Autorización y contabilización), licencias asociadas de derechos, distribución directa, distribución multimedia en directo, protocolos alternativos para cargar datos. 
- Almacenamiento: posibilidad de que el objeto pueda ser de cualquier tipo de formato, objetos en diversos formatos técnicos, derechos de acceso, organización jerárquica, herencia de propiedades y de metadatos (reutilización y extensibilidad), sistema de versiones (indica que el sistema evoluciona), gran número de objetos.

- Otros: solidez del desarrollo de la comunidad, solidez de la comunidad de usuarios, código de calidad, documentación de calidad, facilidad de instalación

La segunda herramienta, CatalystIT: se utilizó para evaluar DSpace, EPrints y Fedora (herramientas que permiten la construcción de repositorios). La herramienta examinaba los siguientes criterios:

- Escalabilidad: capacidad del sistema para adaptarse a nuevas modificaciones, servicios, etc.

- Facilidad de trabajar en una base de código (es decir, en la colección de código fuente que definen la aplicaciones o sus componentes)

- Seguridad informática.

- Interoperabilidad entre sistemas.

- Facilidad de despliegue de la herramienta en otros servicios.

- Administración del sistema (cómo se realiza la gestión técnica de los servicios del repositorio)

- Internacionalización (capacidad para permitir la coexistencia de diversos idiomas).

- Código abierto (si ofrece o no).

- Comunidad basada en el conocimiento: haciendo referencia a la calidad y lo completa que aparece la información de los productos del sitio web; el tamaño y el nivel de actividad en el desarrollo de la comunidad; el tamaño y el nivel de actividad en la comunidad de usuarios; la disponibilidad y la utilización de diferentes canales de comunicación; disponibilidad de la historia del software/solución para dar fe de su sostenibilidad y vitalidad, documentación sobre cómo configurar y manejar un repositorio.

G) Criterios para la elección de software para repositorios (Taylor, 2004) de la Asociación Australiana para la sostenibilidad de los repositorios

Taylor (2004), investigador de la universidad de Queenslad perteneciente a la Asociación Australiana para la Sostenibilidad de los Repositorios, creó una tabla 
para seleccionar los repositorios más apropiados basándose en los siguientes ítems:

- Nombre del Servicio.

- Servicio de la plataforma (en qué lenguaje se basa y dónde está alojada).

- Ausencia o presencia de proveedor de contenido.

- Posibilidad de almacenar los propios recursos.

- Modo de Gestión del contenido (permite gestionarlo o no y cómo), campos de búsqueda simple, campos de búsqueda avanzada, forma de visualización, modo de exploración de objetos, y el apartado otras características.

Consideramos apropiado tener en cuenta esta fuente, ya que el informe fue publicado por una asociación centrada en la sostenibilidad de los repositorios y ofrece criterios que son relevantes para potenciar este aspecto.

H) Dimensiones relevantes de los repositorios de aprendizaje, por Margaryan, Currier, Littlejohn, \& Nicol (2006)

Estos autores participaron en un proyecto denominado "Dimensiones de Comunidad de los repositorios de objetos de aprendizaje" (conocido como CDLOR, que se desarrolló entre 2006 y 2007 y financiado por JISC). En él, extrajeron las principales dimensiones para el análisis de los LORs a través de revisiones de la literatura y actividades de grupos focales llevados a cabo con representantes de diversos repositorios. Extrajeron las siguientes características (Margaryan et al., 2006, en Margaryan \& Littlejohn, 2008, p. 334). Incluimos esta fuente en consideración de nuestro esquema de categorías, ya que estas categorías emergieron de la revisión de los estudios de la literatura y de la consideración de expertos en los repositorios.

- El propósito del repositorio;

- Los temas/disciplinas (mono-disciplinarios; multidisciplinarios);

- El ámbito (departamental, institucional, regional, nacional o internacional);

- El sector de uso prioritario (colegios, enseñanza superior, educación a la

- Distancia/educación continuada, profesionales, personas en general);

- Contribuyentes (profesores, alumnos, instituciones, empleados, grupos de entusiastas)

- El modelo de negocios que gobierna las operaciones y la configuración gerencial que apuntala al repositorio. 


\section{I) Evaluación de la usabilidad del portal Share.TEC (F. De Vries, 2009)}

En el proyecto Share.TEC, como hemos visto en los capítulos 3 y 4 de esta tesis doctoral, se construyeron diferentes herramientas para que los usuarios pudieran evaluar diversos aspectos del portal Share.TEC. En una de ellas, realizamos una evaluación centrada en la usabilidad del portal, por lo que consideramos muy importante, por nuestra experiencia, tener en cuenta los siguientes campos para incluirlos en nuestra herramienta de evaluación de los portales:

- Usabilidad: dificultad y comprensión (fácil- difícil).

- Utilizarías esta herramienta en tu práctica diaria.

- Estilo de la interfaz.

- Funcionalidades del portal.

- Motor de búsqueda simple.

- Campos de la búsqueda avanzada.

- Naturalidad de las búsquedas (si es farragoso o fácil realizar búsquedas).

- Terminología técnica y pedagógica utilizada.

- Posibilidad de buscar contenidos digitales en otros idiomas.

- Posibilidad de contactar con otros formadores de profesores .

\section{J) Cómo evaluar sitios y recursos educativos de Internet (Sosisky, Perazzo, Bardi, \& Ruíz, 2007)}

Estos autores comparten un recurso para docentes en el portal de educación argentino Educ.ar ${ }^{165}$, con el objetivo de que los profesores sean capaces de evaluar los recursos y escoger los más oportunos (atendiendo al perfil, intereses y expectativas de sus destinatarios y a las características del contexto social y de su comunidad de pertenencia). Los autores consideran que la selección y análisis de los recursos ha de atender a criterios claros, pertinentes y relevantes:

- Autoridad: responsable del sitio web.

- Actualización: frecuencia con la que se incorporan y actualizan los recursos

- Navegabilidad: facilidad para moverse por el sitio web.

- Organización: lógica de ordenación del contenido y facilitación para la recuperación mediante estructuras indexadas.

165 http://www.educ.ar/ 
- Selección de contenidos: calidad de los contenidos y relevancia para los niveles a los que se destinan.

- Legibilidad: del sitio web, adecuación de la interfaz gráfica del sitio.

- Adecuación al destinatario: comprobar que el portal se adapta a sus destinatarios (padres, niños, docentes, etc.).

Integramos estas categorías por considerarlas una aportación en torno a la organización del contenido educativo, relevante para los educadores, tal y como hemos visto en el análisis de datos del capítulo 4 .

\subsection{Integración de las categorías obtenidas de la literatura y selección de las fuentes a incluir en nuestra herramienta de análisis}

Una vez detectadas las categorías de análisis de repositorios que integran las diez fuentes ${ }^{166}$ que acabamos de recopilar, procedemos a integrarlas en un cuadro comparativo, y seleccionamos aquellas que nos parecen más relevantes para nuestro estudio (ver Tabla 51).

En la última columna de la Tabla 51 recogemos la selección de las categorías que emergen con las fuentes de la literatura, incluyendo la mayoría de ellas. Hemos omitido la incorporación de algunas por los siguientes motivos:

- escalabilidad y seguridad de internet (ya que por el carácter técnico de estos criterios resulta de gran dificultad evaluarlo por parte de la investigadora);

- captación de usuarios (ya que es difícil conocer cómo realiza cada portal esta tarea, y conllevaría el contacto con el personal de cada uno de estos repositorios, así como una investigación mucho más profusa y alejada del propósito de esta tesis);

- captura de imagen (pues consideramos que esta no proporciona información relevante para nuestros propósitos, y ya describimos cómo son las interfaces de los sitios web);

- almacenamiento de los recursos de los propios usuarios (incluimos en las descripciones de las funcionalidades de los portales este criterio en los casos

166 Veremos más adelante que aparecen 11 fuentes, puesto que F) integra dos herramientas: SWITCH y Catalyst. 
Construcción de la herramienta de análisis. Construcción de la herramienta de análisis.

Integración de las categorías obtenidas de la literatura y selección de las fuentes a incluir en nuestra herramienta de análisis

en los que aparece, pero no como criterio de análisis, pues el propósito de los sitios que analizamos es muy diverso).

Tabla 51 Comparación de las categorías para la evaluación de los repositorios extraídas de las fuentes de la literatura y propuesta de nuestro modelo.

\begin{tabular}{|c|c|c|c|c|c|c|c|c|c|c|c|c|}
\hline & 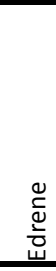 & 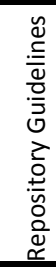 & 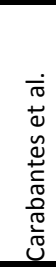 & 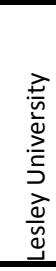 & 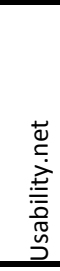 & 号 & 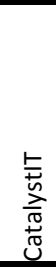 & $\begin{array}{l}\cup \\
\frac{0}{\pi} \\
\stackrel{0}{*}\end{array}$ & 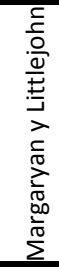 & 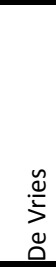 & & 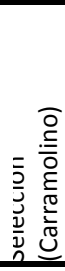 \\
\hline Número de Recursos & $x$ & & & & & & & & & & & $x$ \\
\hline URL & $\mathrm{X}$ & & & & & & & & & & & $\mathrm{X}$ \\
\hline Captura de imagen & $\mathrm{x}$ & & & & & & & & & & & \\
\hline Captación de usuarios & $\mathrm{X}$ & & & & & & & & & & & \\
\hline $\begin{array}{l}\text { Proveedores de } \\
\text { contenido/promotores }\end{array}$ & $\mathrm{x}$ & & & $\mathrm{x}$ & $\mathrm{X}$ & & & $x$ & $x$ & & & $x$ \\
\hline Estándares especificaciones & $x$ & $x$ & & & $x$ & & & & & & & $x$ \\
\hline Interoperabilidad & $x$ & & & & & & $x$ & & & & & $x$ \\
\hline Derechos de autor & $\mathrm{X}$ & & & & & $x$ & & & & & & $\mathrm{X}$ \\
\hline Mecanismos de compartición & & $x$ & & & & & & & & & & $\mathrm{X}$ \\
\hline $\begin{array}{l}\text { Opciones de marketing } \\
\text { (Gratuitos/Pago) }\end{array}$ & & $x$ & & & & & & & & & & $x$ \\
\hline Interfaz usuario & & $x$ & & & & $x$ & & & & & $x$ & $x$ \\
\hline Accesibilidad & & $x$ & & $x$ & & & & & & & & $\mathrm{x}$ \\
\hline Seguridad de internet & & $x$ & & & & & $x$ & & & & & \\
\hline Filosofía/Propósito & $x$ & & $x$ & $x$ & & & & $x$ & & & & $x$ \\
\hline Organización de contenidos & & & $x$ & & & & & & & & $x$ & $x$ \\
\hline $\begin{array}{l}\text { Actualización de los } \\
\text { recursos/sitio web, Versiones }\end{array}$ & & & $x$ & $x$ & & $x$ & & & & & $x$ & $x$ \\
\hline Objetividad/validez & & & & $x$ & & & & & & & & $x$ \\
\hline Adecuación y Relevancia & & & & $x$ & $x$ & & & & & & & $\mathrm{X}$ \\
\hline Contacto con autor & & & & $x$ & & & & & & & & $x$ \\
\hline Interfaz & & & & $x$ & $x$ & & & $x$ & & $x$ & & $x$ \\
\hline $\begin{array}{l}\text { Control de los } \\
\text { contenidos/administración }\end{array}$ & & & & & $x$ & & $x$ & $x$ & & & & $x$ \\
\hline Escalabilidad & & & & & & $x$ & $\mathrm{x}$ & & & & & \\
\hline Metadatos & & & & & & $x$ & & & & & & $x$ \\
\hline
\end{tabular}




\begin{tabular}{|c|c|c|c|c|c|c|c|c|c|c|c|c|}
\hline & 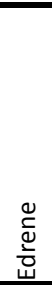 & 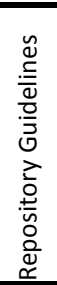 & 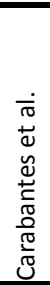 & 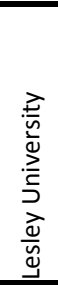 & 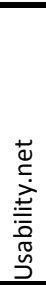 & 点 & 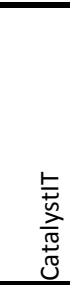 & $\stackrel{u}{\stackrel{0}{\grave{\sigma}}}$ & 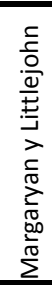 & $\begin{array}{l}\stackrel{\mathscr{\omega}}{\nu} \\
\stackrel{\nu}{\nu}\end{array}$ & 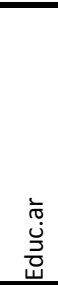 & 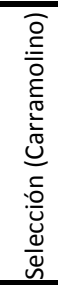 \\
\hline Multiformato de contenidos & & & & & & $x$ & & & & & & $\mathrm{x}$ \\
\hline Calidad de los objetos & & & & & & $x$ & $x$ & & & & & $x$ \\
\hline $\begin{array}{l}\text { Solidez/Tamaño/Actividad de } \\
\text { la comunidad }\end{array}$ & & & & & & $x$ & $x$ & & & & & $x$ \\
\hline $\begin{array}{l}\text { Canales de comunicación de } \\
\text { la comunidad }\end{array}$ & & & & & & & $x$ & & & $\mathrm{x}$ & & $x$ \\
\hline Usabilidad & & & & & & $x$ & & & & $x$ & $x$ & $x$ \\
\hline Open Source & & & & & & $x$ & & & & & & $x$ \\
\hline Servicio de la plataforma & & & & & & & & & & & & $x$ \\
\hline $\begin{array}{l}\text { Almacenamiento recursos } \\
\text { propios del usuario }\end{array}$ & & & & & & & & $x$ & & & & \\
\hline Búsqueda simple/Avanzada & & & & & & & & $\frac{n}{x}$ & & $x$ & & $\mathrm{x}$ \\
\hline Disciplinas & & & & & & & & & & & & $\mathrm{x}$ \\
\hline Ámbito & & & & & & & & & & & & $x$ \\
\hline Modelo de negocio & & & & & & & & & & & & $x$ \\
\hline Funcionalidades & & & & & & & & & & $x$ & & $x$ \\
\hline Multi-idioma & & & & & & & & & & $x$ & & $x$ \\
\hline
\end{tabular}

\subsection{Propuesta de nuestra herramienta de análisis de portales educativos}

Basándonos en los criterios recogidos en la última columna de la Tabla 51 (emanados tras el análisis de la literatura), y realizando una integración con las categorías de análisis del caso de estudio Share.TEC (que emergieron mediante la técnica de codificación abierta de los datos del estudio, apoyada por el software de análisis cualitativo NVivo 8.0), generamos la siguiente estructura para el análisis individual de los portales educativos (véase Tabla 52). Ésta constituye nuestra herramienta de análisis, que nos permitirá posteriormente realizar una comparación de los mismos y extraer conclusiones sobre el análisis. Recordemos que en el capítulo 3 recogimos esta estructura junto con la descripción de los elementos que lo componen, que sirvió como guía conceptual para la evaluación de los diferentes portales y sitios web educativos. 
Construcción de la herramienta de análisis. Construcción de la herramienta de análisis.

Propuesta de nuestra herramienta de análisis de portales educativos

Tabla 52 Categorías de análisis de portales de contenidos digitales para formadores de profesores

\section{Datos descriptivos}

1.1. Nombre del Repositorio

1.2. URL repositorio

1.3. Descripción

1.4. Último Acceso

\section{Aspectos técnicos}

2.1. Tipo

2.2. Funciones

2.3. Derechos de acceso

2.4. Ontología

2.5. Seguridad

2.6. Interoperabilidad

2.7. Persistencia de los links

2.8. Internacionalización

2.9. Administración del sistema

2.10. Búsqueda simple

2.11. Búsqueda avanzada

\section{Metadatos}

3.1. Estándar/no estándar

3.2. Posibilidad de personalización de metadatos

3.3. Etiquetado social

3.4. Mapeo

3.5. Esquema mínimo de metadatos

\section{Almacenamiento}

4.1. Objetos en diversos formatos

4.2. Derechos de acceso

4.3. Organización jerárquica

4.4. Reutilización de metadatos

4.5. Sistema de versiones

\section{Interfaz}

5.1. Organización del contenido

5.2. Miniaturas

\section{Sostenibilidad \\ 6.1. Propietario \\ 6.2. Gestión de contenidos}

\section{Aspectos educativos}

7.1. Nivel/es educativos

7.1. Temáticas

7.2. Destinatarios

\section{Contribución al sistema}

8.1. Campos obligatorios

8.2. Campos opcionales

8.3. Requisitos

8.4. Formato

\section{Aspectos sociales}

9.1. Redes

9.2. Forma de establecimiento de redes/mantenimiento de usuarios

9.3. Contacto con otros profesionales

9.4. Interacción con recursos

9.5. Contribución social de recursos

9.6. Contribución social de etiquetado

9.7. Comunidades

9.8. Número de personas de la comunidad

\section{Contenidos}

10.1. Contenidos Gratuitos/de pago

10.2. Tipo de contenidos

10.3. Formato técnico

10.4. Calidad de los recursos

10.5. Número de contenidos

10.6. Número de recursos

10.7. Premios 


\section{Comparación de los portales seleccionados}

En el apartado 6.2.1 del capítulo 3 de esta tesis explicábamos el procedimiento de cómo seleccionamos la muestra de los portales educativos de este estudio. Como veíamos, a través de una muestra de juicio, escogimos aquellos portales que cumplían los prerrequisitos que definimos (tras llevar a cabo búsquedas sistemáticas mediante keywords en el motor de búsqueda de Google). De este modo, a continuación presentamos el análisis comparativo de los 15 portales educativos de esta selección (analizados previamente de forma individual siguiendo el esquema de la Tabla 52). Los portales que hemos estudiado son los siguientes:
1- Internet en el Aula
6- Connexions
11- OER Commons
2- Education World
7- Share.TEC
12- Tiching.com
3- MIT OPENCOURSEWARE
8- 8- PBS Learning
13- Agrega
4- Merlot
9- Open Learn 10
14- WikiEducator
5- Commonwealth of Learning
10- Teacher Tube 11
15- MERLÍ

El número que hemos acompañado para nombrarlos, es el que utilizaremos para referimos a ellos durante el análisis e interpretación de los datos que presentamos a continuación:

\subsection{Aspectos técnicos de los portales}

\subsubsection{Funciones}

Los portales educativos seleccionados (ver apartado 6.2.1 del capítulo 3) a partir a los criterios que definimos con anterioridad, están construidos para la consecución de diferentes propósitos. En la siguiente tabla recogemos qué tipo de funciones cumplen cada uno de ellos:

- Observamos que la mayoría de los portales seleccionados cumplen la función de repositorio de contenidos digitales (12/15).

- Algunos de ellos, además de repositorios (es decir, además de alojar los contenidos digitales en su sistema), son referatorios (describen con metadatos contenidos digitales alojados en otros portales) (4/15).

- Sólo Merlí es exclusivamente referatorio (1/15). 
- 4/15 portales son sistemas de gestión de contenidos 0 de gestión de aprendizaje. Estos cuatro portales, además son repositorios; y uno de ellos es también red social).

- 8/15 portales son redes sociales que comparten contenidos y conocimiento (uno de ellos no coexiste con otras funcionalidades). Finalmente encontramos una Wiki, que además integra funcionalidades de red social.

\subsubsection{Derechos de acceso y coste de contenidos digitales}

En cuanto a los derechos de acceso y coste de los materiales, los portales presentan las siguientes características desde la perspectiva del usuario ${ }^{167}$ (véase Tabla 53).

Entre los contenidos gratuitos encontramos portales que integran:

- Contenidos copyleft sin especificar la licencia (Internet en el aula, Education World, MIT OCW, Merlot, Commonwealth of Learning), Share.TEC, TeacherTube; Tiching.com, WikiEducator (aunque en esta página se sobreentiende que todos son OER).

- Recursos educativos abiertos etiquetados con diversas licencias: Creative Commons (MIT OCW, Merlot, Connexions, Open Learn, OER Commons, Agrega y Merlí) y copyright (algunos contenidos de los portales Agrega, Tiching y Share.TEC).

- Portales que indican el tipo de usos permitido para cada recurso (pero no existe un buscador que facilite el filtrado por esta funcionalidad) (PBS Learning Media).

- Materiales gratuitos que redirigen hacia la compra de materiales con copyright y/o de pago: encontramos algunos contenidos disponibles en MIT OCW que enlazan a la compra de materiales de pago con copyright (e.g., enlazan a libros de Amazon), a materiales con copyright y ciertas restricciones de uso (e.g., Open Learn enlaza en algunos recursos a vídeos de la BBC).

167 Especificamos "desde la perspectiva del usuario", porque algunas plataformas están alojadas en servicios de pago, por ejemplo, Internet en el Aula está alojada en NING, y es INTEF (el Instituto Nacional de Tecnologías Educativas y de Formación del Profesorado de España) quien se hace cargo de los pagos. 
Tabla 53 Derechos de acceso y coste de contenidos digitales: : tabla comparativa

\begin{tabular}{lllll}
\hline & $\begin{array}{l}\text { Acceso sin } \\
\text { registro }\end{array}$ & $\begin{array}{l}\text { Acceso con } \\
\text { registro para } \\
\text { más opciones }\end{array}$ & $\begin{array}{l}\text { Contenidos } \\
\text { gratuitos }\end{array}$ & $\begin{array}{l}\text { Contenidos de } \\
\text { pago }\end{array}$ \\
\hline $\begin{array}{l}\text { 1- Internet en el } \\
\text { Aula }\end{array}$ & $\mathrm{X}$ & $\mathrm{X}$ & \\
2- Education World & $\mathrm{X}$ & $\mathrm{X}$ & $\mathrm{X}$ & \\
3- MIT & $\mathrm{X}$ & & $\mathrm{X}$ & \\
OPENCOURSEWARE & & $\mathrm{X}$ & $\mathrm{X}$ & \\
4- Merlot & $\mathrm{X}$ & $\mathrm{X}$ & \\
5- Commonwealth & $\mathrm{X}$ & $\mathrm{X}$ & \\
of Learning & & $\mathrm{X} 8$ & $\mathrm{X}$ & \\
6- Connexions & $\mathrm{X}$ & $\mathrm{X}$ & $\mathrm{X}$ & \\
7- Share.TEC & $\mathrm{X}$ & $\mathrm{X}$ & $\mathrm{X}$ & \\
8- PBS Learning & $\mathrm{X}$ & $\mathrm{X}$ & $\mathrm{X}$ & \\
9- Open Learn & $\mathrm{X}$ & $\mathrm{X}$ & $\mathrm{X}$ & \\
10 - Teacher Tube & $\mathrm{X}$ & $\mathrm{X}$ & $\mathrm{X}$ & \\
11 -OER Commons & $\mathrm{X}$ & $\mathrm{X}$ & $\mathrm{X}$ & \\
12 - Tiching.com & & $\mathrm{X}$ & $\mathrm{X}$ & \\
13 - Agrega & $\mathrm{X}$ & $\mathrm{X}$ & $\mathrm{X}$ & \\
14 -WikiEducator & $\mathrm{X}$ & $\mathrm{X}$ & $\mathrm{X}$ & \\
15 - MERLí & $\mathrm{X}$ & &
\end{tabular}

Como vemos, algunos portales sí integran contenidos etiquetados con sus licencias asociadas, mientras que otros no lo las especifican.

Únicamente en los portales OER Commons, Share.TEC, Agrega y Merlí: podemos filtrar de algún modo los recursos por el tipo de licencia o coste de los mismos. En OER Commons y Agrega podemos filtrar los recursos antes de realizar la búsqueda por el tipo de licencia específica de los recursos. En Share.TEC, sólo nos permite esta opción en las opciones de filtrado de búsqueda que se ofrecen tras realizar una consulta, y sólo permite hacerlo por dos categorías (de pago o gratuito). En el resto de portales hay que acceder a cada recurso para poder visualizar el tipo de derechos asociados al material.

168 Actualmente esta página ha generado un repositorio para alojar el contenido http://oasis.col.org 


\subsubsection{Ontología, Metadatos, y etiquetado de los recursos}

En la Tabla 54 recogemos de forma sintetizada los aspectos relativos a la ontología, interoperabilidad, esquema de metadatos, posibilidad de personalización de los metadatos y etiquetado social de los portales.

Apreciamos que la mayoría de los portales se basan en una ontología para clasificar su contenido (excepto la Red Social "Internet en el Aula", alojada en NING, que utiliza folksonomías gracias al etiquetado de los usuarios de sus contenidos; y WikiEducator (que organiza el contenido por menús automáticos). Entre los demás portales, varios de ellos se basan en modelos ontológicos y de metadatos estandarizados (e.g., OER Commons se basa en IEEE-LOM), aunque realizan especificaciones adaptándolas a los contextos educativos y fines del portal (e.g., $\mathrm{MMM}^{169}$ del portal Share.TEC).

Tabla 54 Ontología, metadatos y coste de lo portales: tabla comparativa

\begin{tabular}{|c|c|c|c|c|c|}
\hline & Ontología & $\begin{array}{l}\text { Interopera- } \\
\text { bilidad }\end{array}$ & $\begin{array}{l}\text { Metadatos } \\
\text { Estándar }\end{array}$ & $\begin{array}{l}\text { Posibilidad de } \\
\text { personalizar } \\
\text { metadatos } \\
\text { existentes } \\
\end{array}$ & $\begin{array}{l}\text { Etiquetado } \\
\text { social }\end{array}$ \\
\hline $\begin{array}{l}\text { 1- Internet en el } \\
\text { Aula }\end{array}$ & No & - & No & No & Sí \\
\hline $\begin{array}{l}\text { 2- Education } \\
\text { World }\end{array}$ & Sí & Sí & No & No & No \\
\hline $\begin{array}{l}\text { 3- MIT OPEN } \\
\text { COURSE-WARE }\end{array}$ & Sí & Sí $\left(O K I^{170}\right)$ & $\begin{array}{l}\text { SCORM; METS, } \\
\text { IS-CO }\end{array}$ & No & No \\
\hline
\end{tabular}

169 Recordemos que en los capítulo 3 y 4 explicamos la TEO (Teacher Educator Ontology Ontología para la Formación del profesorado) y el Modelo Común de Metadatos (CMM) traducido y adaptado a varios contextos europeos, dando lugar al Multicultural Metadata Model -Modelo Común de Metadatos- (MMM). Como vimos, el MMM es un perfil de aplicación del estándar IEEE-LOM, al que añadimos campos pedagógicos para adaptarlo al contexto de la formación del profesorado en Europa.

170 Open Knowledge Initiative, iniciativa que define una arquitectura flexible que proporciona especificaciones para las interfaces entre los componentes de entornos educativos de aprendizaje. Está orientada al campo de la tecnología educativa, especialmente, para los niveles de educación superior (Collier \& Robson, 2002). 


\begin{tabular}{|c|c|c|c|c|c|}
\hline & Ontología & $\begin{array}{l}\text { Interopera- } \\
\text { bilidad }\end{array}$ & $\begin{array}{l}\text { Metadatos } \\
\text { Estándar }\end{array}$ & $\begin{array}{l}\text { Posibilidad de } \\
\text { personalizar } \\
\text { metadatos } \\
\text { existentes }\end{array}$ & $\begin{array}{l}\text { Etiquetado } \\
\text { social }\end{array}$ \\
\hline 4- Merlot & Sí & Sí & $\begin{array}{l}\text { LOM Modifi- } \\
\text { cado }\end{array}$ & $\begin{array}{l}\text { Sólo los que } \\
\text { proporcionas }\end{array}$ & $\begin{array}{l}\text { Sólo Votación, } \\
\text { Comentarios, } \\
\text { Revisión de } \\
\text { pares }\end{array}$ \\
\hline $\begin{array}{l}\text { 5- Commonwealth } \\
\text { of Learning }\end{array}$ & Sí & Sí & No & No & No \\
\hline 6- Connexions & Sí & $\begin{array}{l}\text { Sí (XML, } \\
\text { MathML, } \\
\text { QML, Bib- } \\
\text { TeXML) }\end{array}$ & No & $\begin{array}{l}\text { Sí, pero sólo tú } \\
\text { puedes visualizar } \\
\text { los cambios }\end{array}$ & $\begin{array}{l}\text { Sólo si los } \\
\text { publicas como } \\
\text { nuevo material }\end{array}$ \\
\hline 7- Share.TEC & $\begin{array}{l}\text { Sí (TEO, } \\
\text { basada en } \\
\text { LOM) }\end{array}$ & $\begin{array}{l}\text { Sí (Conecta } \\
\text { diversos } \\
\text { repositorios } \\
{ }_{171} \text { ) }\end{array}$ & $\begin{array}{l}\text { Especificación } \\
\text { IEE-LOM + } \\
\text { Campos peda- } \\
\text { gógicos }\end{array}$ & $\begin{array}{l}\text { Sólo los que } \\
\text { realizas. }\end{array}$ & $\begin{array}{l}\text { Sólo votación y } \\
\text { comentarios. }\end{array}$ \\
\hline 8- PBS Learning & Sí & $\begin{array}{l}\text { Sí (TI Tool } \\
\text { provider; } \\
\text { basado en } \\
\text { especifica- } \\
\text { ción LTI) }\end{array}$ & $\begin{array}{l}\text { Especificacio- } \\
\text { nes basadas en } \\
\text { estándares }\end{array}$ & $\begin{array}{l}\text { Sí, puedes reutili- } \\
\text { zarlos y publi- } \\
\text { carlos como } \\
\text { material nuevo. }\end{array}$ & No \\
\hline 9 - Open Learn & $\begin{array}{l}\text { Sí y Linked } \\
\text { Data }\end{array}$ & $\begin{array}{l}\text { Sí (MS } \\
\text { Common } \\
\text { Cartridge - } \\
\text { RDF y } \\
\text { Linked Data) }\end{array}$ & $\begin{array}{l}\text { LRMI-based } \\
\text { Schema.org, } \\
\text { RDFa Lite }\end{array}$ & $\begin{array}{l}\text { Sí, puedes añadir } \\
\text { etiquetas a los } \\
\text { recursos, pero } \\
\text { sólo las visualizas } \\
\text { tú. }\end{array}$ & No \\
\hline 10 - Teacher Tube & Sí & $\begin{array}{l}\text { Sí (RDFs, } \\
\text { SPARQL - de } \\
\text { w3C) }\end{array}$ & $\begin{array}{l}\text { Especificación } \\
\text { similar a DC }\end{array}$ & $\begin{array}{l}\text { Sí, puedes sugerir } \\
\text { cambios que } \\
\text { aprueban los } \\
\text { administradores. }\end{array}$ & $\begin{array}{l}\text { Sólo etiquetas; } \\
\text { colecciones } \\
\text { que creas de } \\
\text { recursos } \\
\text { existentes. }\end{array}$ \\
\hline 11 -OER Commons & $\begin{array}{l}\text { Sí (LOM, } \\
\text { DC) }\end{array}$ & $\begin{array}{l}\text { Sí. (Learning } \\
\text { Registry } \\
\text { Metadata } \\
\text { Initiative - } \\
\text { LRMI) }\end{array}$ & LOM y DC & $\begin{array}{l}\text { Sí. No modificar, } \\
\text { sí añadir etique- } \\
\text { tas del estándar } \\
\text { educativo del } \\
\text { contenido. }\end{array}$ & $\begin{array}{l}\text { Sí, etiquetas } \\
\text { (keywords); } \\
\text { votación; } \\
\text { comentarios; } \\
\text { añadir nivel } \\
\text { educativo. }\end{array}$ \\
\hline
\end{tabular}

171 Share.TEC ofrece una interoperabilidad semántica, lingüística cultural y técnica (Sarti, 2011, p. 4).

172 Utilizan LRMI-based Schema.org codificado a RDFa Lite. Utilizan RDFa Lite porque es totalmente compatible con los principios de la web semántica; .Schema.org es una colección de etiquetas de metadatos que puede añadirse a páginas web, y permite a los motores de búsqueda devolver mejores resultados. 
Comparación de los portales seleccionados. Comparación de los portales seleccionados.

\begin{tabular}{|c|c|c|c|c|c|}
\hline & Ontología & $\begin{array}{l}\text { Interopera- } \\
\text { bilidad }\end{array}$ & $\begin{array}{l}\text { Metadatos } \\
\text { Estándar }\end{array}$ & $\begin{array}{l}\text { Posibilidad de } \\
\text { personalizar } \\
\text { metadatos } \\
\text { existentes }\end{array}$ & $\begin{array}{l}\text { Etiquetado } \\
\text { social }\end{array}$ \\
\hline 12 - Tiching.com & Sí & Sí & No & No & - \\
\hline 13 - Agrega & $\begin{array}{l}\text { Sí (basado } \\
\text { en LOM) }\end{array}$ & $\begin{array}{l}\text { Sí (IMS-DRI; } \\
\text { OAI; SQI) }\end{array}$ & $\begin{array}{l}\text { LOM ES v.1.0 } \\
\text { Norma YNE- } \\
71361: 2010\end{array}$ & $\begin{array}{l}\text { Sí, puedes revisar } \\
\text { metadatos de } \\
\text { registros existen- } \\
\text { tes. }\end{array}$ & $\begin{array}{l}\text { Sí, puedes } \\
\text { etiquetar los } \\
\text { contenidos con } \\
\text { keywords. }\end{array}$ \\
\hline 14 -WikiEducator & No & - & No & No & $\begin{array}{l}\text { No, pero se } \\
\text { construye } \\
\text { socialmente. }\end{array}$ \\
\hline 15 - MERLÍ & $\begin{array}{l}\text { Sí (basado } \\
\text { en LRE) }\end{array}$ & $\begin{array}{l}\text { Sí (APXTEC: } \\
\text { (LOM ES + } \\
\text { AP CELE- } \\
\text { BRATE) }\end{array}$ & LOM Es & - & No \\
\hline
\end{tabular}

En la segunda columna de la Tabla 54 recogemos la interoperabilidad de los portales, determinando si tienen mecanismos ("Si") o si no hemos sido capaces de encontrar esta información ("-"). Según el Portal de Administración Electrónica del Gobierno de España, la interoperabilidad es la capacidad de los sistemas de información y de los procedimientos a los que éstos dan soporte, de compartir datos y posibilitar el intercambio de información y conocimiento entre ellos (2015). Hemos detectado mecanismos de interoperabilidad en 13 de los 15 portales, permitiendo la importación o exportación automática de metadatos, y facilitando la reutilización del contenido digital en otras webs. Algunos de los mecanismos que favorecen la interoperabilidad son la inclusión de formatos RDF, o LRMI (Learning Resource Exchange Metadata Initiative).

En cuanto a los estándares de metadatos encontramos seis portales que no se basan en estándares sus metadatos; mientras que el resto (nueve), sí lo hacen. El formato más popular de los portales estudiados es IEEE-LOM (utilizado mediante especificaciones) en cinco portales, seguido por DC y RDF (presente en un portal cada uno de ellos).

Atendiendo a los metadatos (cuarta columna de la Tabla 54), encontramos diversos permisos a la hora de poder modificar, o no, los metadatos existentes:

- Portales que permiten realizar cambios en los registros de los metadatos de los recursos: OER Commons (permite añadir keywords a la descripción del recurso, así como etiquetar otros estándares educativos predefinidos; son publicadas sin la revisión del moderador); TeacherTube y Agrega permiten 
revisar el etiquetado del recurso y modificarlo, bajo la supervisión de un moderador.

- Portales que aprueban modificar los metadatos de recursos subidos por otros, pero estos son sólo visibles para el usuario: Connexions; Open Learn también es de este tipo de portal, y además, permite agregar etiquetas.

- Portales que sólo consienten la modificación de los registros de metadatos de los contenidos que proporciona el propio usuario: Share.TEC y Merlot.

- Portales que vuelven a publicar como nuevo material los materiales que los usuarios vuelven a reetiquetar: PBS Learning.

Para comprender mejor las opciones de permiso de modificación de metadatos de los portales, veamos el siguiente Gráfico 18: 
Comparación de los portales seleccionados. Comparación de los portales seleccionados.

Aspectos técnicos de los portales

Gráfico 18 Tipos de permisos de modificación de metadatos de los portales analizados (Elaboración propia)

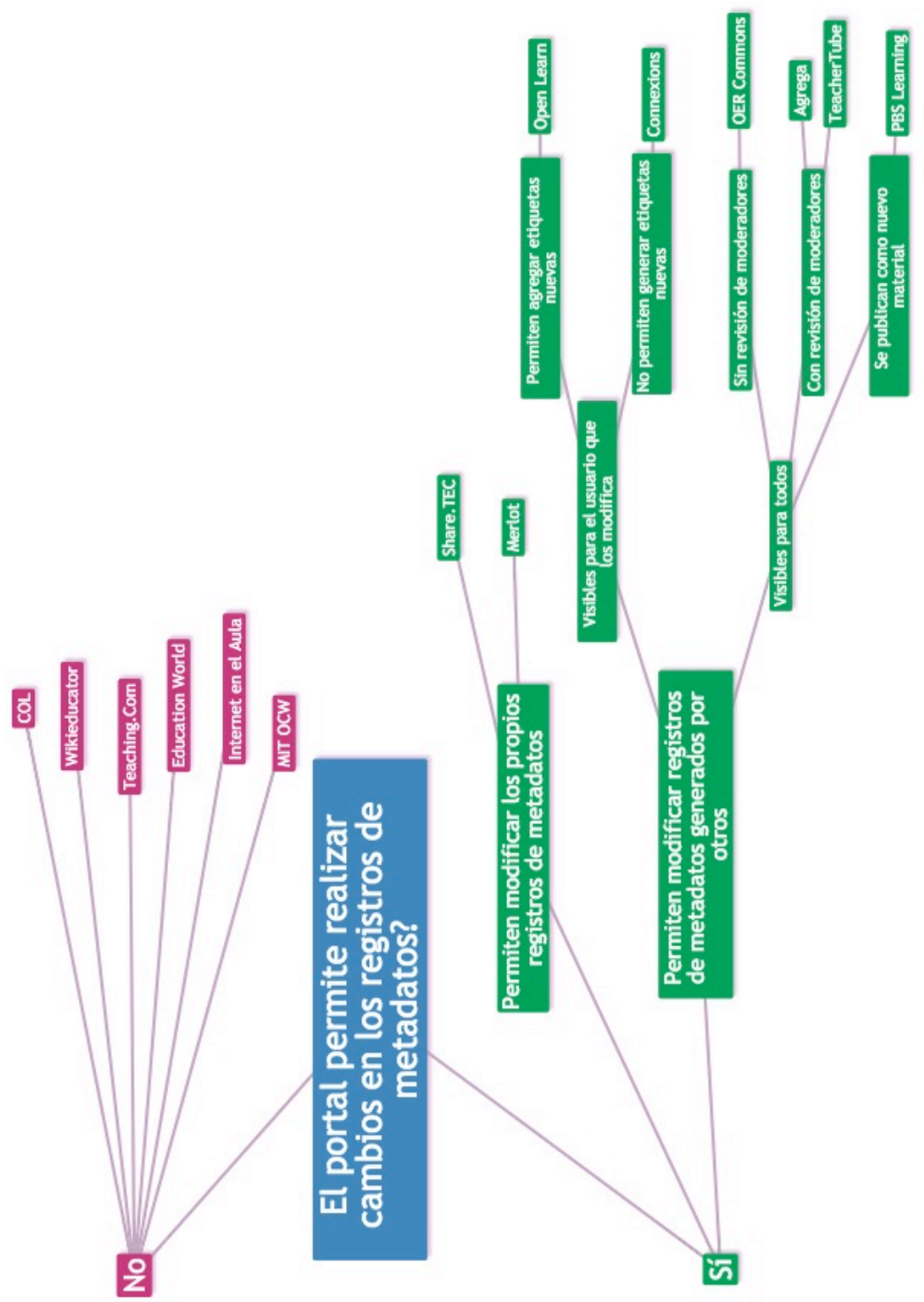


Los portales deben preservar la seguridad del contenido y la calidad del mismo, por lo que aquellos espacios que permiten una mayor interacción del usuario tanto con el contenido, como con la comunidad, solicitan el registro del usuario utilizando diversos mecanismos de seguridad (CAPTCHAS ${ }^{173}$, confirmación de cuentas mediante correo electrónico, solicitud de admisión a los grupos, etc.), que, además, evitan el Spam de publicidad o de servicios automáticos. De este modo, previenen de la introducción automática de contenidos no deseados en los portales o la recuperación automática de información (datos de los usuarios).

Aquellos portales en los que puedes modificar los metadatos proporcionados originalmente en los recursos, disponen de personas encargadas de moderar el contenido (que pueden ser los propios administradores del sistema, y/o usuarios específicos de la comunidad y/o el conjunto de usuarios.

En cuanto al etiquetado social (última columna de la Tabla 54), seis de los quince portales sobre los que profundizamos no disponen de esa función. En los demás portales, se consienten los siguientes etiquetados sociales:

- Permiten votar recursos y añadir comentarios: Merlot, Share.TEC, OER Commons y TeacherTube.

- Permiten etiquetar el recurso cuando se crean o se reeditan, generando un nuevo recurso: Connexions.

- Internet en el Aula es una red social, de manera que el contenido es generado por los miembros de la comunidad a través de post, foros, participación en grupos, etc., en los que los usuarios pueden aportar comentarios sobre los distintos recursos etiquetados.

- En WikiEducator, los contenidos pueden editarse colaborativamente, pero no hay un etiquetado social como tal.

173 CAPTCHA hace referencia a Completely Automated Public Turing Test (en español, Test de Turing Público Completamente Automático). Es un mecanismo de seguridad que utilizan los ordenadores para diferenciar a las máquinas de humanos (e.g., para evitar el SPAM o el robo de información de determinadas páginas). 


\subsubsection{Búsquedas simples y avanzadas}

Como veíamos en el portal Share.TEC, existen principalmente tres tipos de búsqueda: por exploración, por búsqueda simple y por búsqueda avanzada. Veamos cómo permiten los portales analizados realizar cada uno de estos tipos de búsqueda:

Los portales pueden ofrecer diferentes formas de búsqueda para acceder a los materiales con diversas funcionalidades.

A) Exploración ${ }^{174:}$ : en este tipo de búsqueda, la navegación por áreas es la funcionalidad más frecuente entre los portales estudiados, ofrecida por cuatro portales:

- Por categorías de: "área", "materia", "unidades didácticas", "desarrollo profesional", "tecnología", "administradores", "recursos para escuelas", "especialidades", "educación infantil", "estilo de vida", "materias" y "actividades divertidas" [2] $]^{175}$ (véase correspondencia de los números entre corchetes con el portal al que representan en la página 374).

- Por "áreas"[9], [7], [2], [14].

- Por "colecciones" [7].

- Por "vídeos", "audios", "fotos", "documentos", "grupos", "clases", "perfiles", "colecciones" [10].

B) Búsquedas simples: todos los portales analizados permiten realizar este tipo de búsqueda mediante la introducción de palabras clave. Dentro de la búsqueda simple cada portal ofrece diversos mecanismos, como por ejemplo, sugerir palabras mientras escribes las keywords, o incluso ofrecer alternativas a tu búsqueda (bien mediante conceptos relacionados o mediante palabras de escritura similar, en el caso de una posible equivocación al escribirlas). Para que el primer mecanismo sea

174 Nos referimos a exploración a la navegación del usuario en el portal mediante las categorías y subcategorías que se muestran en los portales de forma predeterminada, sin realizar búsquedas por keywords. En cambio, nos referimos a búsquedas simples a aquellas consultas en las que introducimos palabras clave para encontrar resultados etiquetados con estas.

175 Ver Tabla 54 para recordar la correspondencia entre el número entre corchetes y el portal al que referencia. 
posible, ha de existir una ontología tras los conceptos (de modo que existan relaciones entre ellos). Otros portales ofrecen búsquedas teniendo en cuenta las últimas búsquedas llevadas a cabo en Google.

- Palabras clave [1], [2], [3], [4],[5], [6], [7], [8], [9], [10], [11], [12], [13],[14], [15].

- El buscador sugiere palabras aproximadas mientras escribes [3], [7].

- El buscador te sugiere que puedes haberte equivocado al realizar la búsqueda si no encuentra las palabras, y te ofrece búsquedas aproximadas [13], [15].

- Acotar la búsqueda simple por tipo de recurso (materiales, ejercicios, miembros, librerías) [4], o por módulos o colecciones [5].

- Acotar la búsqueda simple por lugar en el que quieres que busque (e.g., sólo en el portal Agrega o en el Instituto de Tecnología Educativa del Ministerio de Educación) [13].

- Oferta del número de resultados que ofrece la/s palabra/s que estás introduciendo, a medida que escribes la búsqueda [7], [11].

- Sistema que accede a las últimas búsquedas llevadas a cabo en tus navegadores, y te ofrece sugerencias de términos de búsqueda [8].

- Motor de búsqueda de Google integrado en el sistema [9], [10].

C) Búsquedas avanzadas: en este último formato de búsquedas, encontramos estrategias diversas, que consisten básicamente en la inclusión de funcionalidades de filtro de búsqueda por diversos tipos de categorías. La más frecuente entre los portales de nuestra muestra es la búsqueda por áreas de conocimiento o materias curriculares (presente en 8 portales de los 15 analizados), y en general, permiten la selección de varios filtros simultáneamente. Tres portales, destinados a educación infantil, primaria y secundaria, permiten filtrar por estándares educativos (en el caso de los americanos), contenidos del currículo o competencias (en el caso de los españoles). En cambio, no existe tal tipo de estandarización en los portales que dedican el contenido digital a la formación específica del profesorado (pues no existe tal estandarización). Es de destacar que hay tres portales que permiten acceder a materiales en función de su accesibilidad (atendiendo en este caso a personas con distintas capacidades sensoriales o físicas), a pesar de que el número de recursos que aparecen etiquetados es aún limitado. Veamos de forma detallada las funcionalidades que permite cada portal:

- Explorar en foros por categorías (materiales didácticos, herramientas, competencias, metodología, formación, etc.) [1].

- Por Áreas de conocimiento/materias curriculares [6], [7], [8], [9], [10], [11], [13], [15]. 
- Filtrar por lo más activo [1].

- Filtrar por últimas noticias [2].

- Filtros de búsqueda (todas las palabras, sólo con las palabras, etc.) [3], [4], [7].

- Selección de uno o varios filtros simultáneos: título, autor, palabra clave, colecciones, autor, formato técnico, etc. [4], [6], [7], [8], [11], [15].

- Selección de filtros educativos: modo de empleo, tipo de contenido digital , niveles[7], [10], [11], [12], [13], [15].

- Filtrar por

- estándares educativos [6], [8], [10], [11] (los cuatro portales son de EEUU y contienen muchos recursos para la Educación Primaria y Secundaria"K-12") o contenidos del currículo [12], [13], [15].

- competencias (o habilidades) [7] (formación del profesorado), [12], [13], [15] (Educación Infantil, Primaria y Secundaria).

- Filtrar por materiales revisados por otros [4].

- Filtrar por coste y derechos de uso [4], [7], [8], [9].

- Filtrar por idioma [4], [7], [8], [12], [13].

- Filtro por Accesibilidad de los materiales [8], [10], [11].

- Filtrar por comunidad [9].

- Filtrar por Centro Educativo [15].

En el caso de Share.TEC [7], únicamente permite aplicar un filtro por cada categoría de filtrado (como veíamos en el texto de la página 305 correspondiente al filtrado por idiomas) (e.g., una vez realizada la búsqueda, te permite seleccionar entre varias categorías de filtrado, como por ejemplo, idioma; si seleccionas como filtro el idioma español, no te deja seleccionar más idiomas), siendo muy deseable que se permitiera al usuario seleccionar varios simultáneamente (en este ejemplo, el usuario podría desear que se mostraran los recursos disponibles en inglés y español).

De los 15 portales analizados, casi la mitad (7) ofrecen estrategias para filtrar contenidos por: estándares educativos nacionales (4 portales del contexto americano), competencias o habilidades específicas 3 portales, uno de ellos destinado a la formación del profesorado y tres de ellos destinados a los niveles de educación infantil, primaria y secundaria. 


\subsubsection{Interfaz de organización del contenido}

La interfaz de organización del contenido es diferente en cada caso, y en función del tipo de portal educativo, encontramos diferentes soluciones adoptadas. En el siguiente listado apreciamos mediante qué tipo de estrategias se organiza el contenido en cada portal:

- En Foros [1] ${ }^{176 .}$

- En Grupos [1], [6], [10].

- Resultados organizados de 10 en 10 (por página) [2], [13].

- Indicadores del número total de páginas. [2].

- Indicadores de que hay más páginas, sin especificar número [7].

- Indicadores del número total de recursos [6].

- Indicadores de número total de recursos a medida que se filtran las búsquedas [7].

- Avaladores del contenido [6], [2].

- Recursos enmarcados en rectángulos [2], [7], [8], [12], [13] o divididos por líneas [15].

- Número de votos que tiene el recurso [2], [7], [8], [10], [12], [13].

- Puntuación media del recurso (sistema de estrellas y numérico) [2], [8], [12], [13], [7], [15].

- Se visualizan los comentarios en los recursos [2], [4], [5], [7], [12], [15].

- Icono que representa el formato de material (audio, vídeo, texto, web, etc.) [8], [9], [13], [15].

- Visualización de miniaturas/previsualización del contenido [3], [6], [7], [8], [9], [10], [11], [12], [13].

- Visualización de tipo de contenido por iconos [3], [8], [7] ${ }^{177}$, [9], [11].

- Se muestra de forma sencilla y permanente la sección de contribuir tus propios recursos en el sistema. [2], [6], [8].

- Fe de finalización de cursos [3].

- Menú fijo (encabezado y/o pie de página) con opciones principales [5], [6], [9], [10], [11].

- Menú lateral fijo o semifijo con opciones de filtrado [6], [7], [12], [15].

176 Ver Tabla 54 para recordar la correspondencia entre el número entre corchetes y el portal al que referencia.

177 Integra la funcionalidad de visualizar miniatura pero no las carga correctamente. 
- Icono/botón de donación [6].

- Criterios de accesibilidad, posibilidad de personalizar visualización[8], [10], [11].

- Visualización gráfica de los derechos de uso [8].

- Menús "Contenido de Página" de las Wikis [14].

Entre las estrategias para mostrar al usuario el contenido, encontramos que algunas de ellas permiten visualizar datos, tales como el número de votos del recurso (6 portales), la puntuación media del recurso (6 portales), el número total de páginas (dos); y opciones ofrecidas sólo por un portal (como visualizar que existen más páginas -aunque no concreta el número de ellas-; visualizar el número total de recursos del portal; y el número total de recursos mientras se escriben keywords).

En 8 de los 15 portales analizados, hemos encontrado que presentan menús 0 funcionalidades importantes visibles en cada página del portal.

En 5 portales encontramos encabezados o pies de página que nos permiten navegar por el portal sin perder la orientación en el mismo, y acceder a las diversas opciones que muestra siempre desde este menú.

En 4 portales visualizamos menús laterales fijos o semifijos (presentes en casi todas las páginas del portal) que nos permiten diversas opciones de filtrado del contenido disponible.

Varios portales incorporan, además de la descripción textual, elementos visuales para categorizar los recursos y realizar una evaluación rápida de los mismos por esta vía. La estrategia más común en cuanto a la organización del contenido es precisamente la de mostrar miniaturas o una previsualización del contenido (nueve portales). Otras estrategias que permiten filtrar los contenidos son mostrar el formato técnico (cuatro portales) o pedagógico (cinco portales) del material; o los derechos de uso del recurso (sólo u portal muestra visualmente esta característica).

Todos los portales analizados comparten los siguientes elementos relativos a la interfaz:

- Fondo blanco

- Letras de imprenta fácilmente legibles

- Letras del contenido principal en color oscuro (negro, azul oscuro), resaltando sobre el fondo

- Títulos resaltados en negrita con otro color.

- Hipervínculos con otro color. 
Además, utilizan estrategias organizativas como enmarcar los contenidos que atienden a los criterios de búsqueda en cuadrados (4 portales) o dividirlos mediante líneas (1 portal).

En el caso de Internet en el Aula [1], los recursos se presentan de una forma caótica, pues hay que explorar en los foros o en los grupos para encontrar recursos, y no aparecen ordenados mediante ninguna estrategia. Esta página está pensada como red social y no como página para la gestión del contenido; en cualquier caso, resulta complejo acceder a los recursos que se comparten en ella.

\subsubsection{Funcionalidades de los portales}

Las funcionalidades que ofertan los portales, son compartidas en muchos casos, y únicas en otros. Veamos las principales agrupadas por tipología:

\section{A) Funciones Sociales}

- Acceso a Blogs [1], [2], [5], [14], [8], [10] ${ }^{178}$.

- Creación de Blogs [1], [2].

- Acceso al perfil de otros [1], [7], [12].

- Foros/Debates [1], [2], [9], [14].

- Crear eventos [1].

- Visualizar eventos [1], [5], [14].

- Webinarios [1].

- Ver cumpleaños [1].

- Crear/unirse a Grupos [1], [2], [4], [7], [11], [12], [14].

- Enviar mensajes/contactar con otros usuarios [1], [2], [4], [11], [12], [14].

- Compartir los contenidos digitales en otros espacios/redes sociales/correo electrónico mediante un clic [3], [4], [5], [7], [9], [10], [12], [13], [15].

- Espacio de oferta de ayuda a otros profesionales, mediante conferencias 0 ayuda para las clases [4].

- Organizar autores de recursos por disciplinas [4].

- Sistema de iconos para identificar roles de los usuarios en el portal (revisor de pares, autor, ponente virtual, etc.) [4].

178 Ver Tabla 54 para recordar la correspondencia entre el número entre corchetes y el portal al que referencia. 
- Sistema de reconocimiento social, "Badges" [4],[9],[10].

- Contenido seleccionado por editores/organizaciones/individuos [4], [6], [9].

- Usuarios en línea [1], [7].

- Usuarios similares a tu perfil [12].

- Crear preguntas para estudiantes, docentes. [12].

- Compartir enlaces [12].

- Espacios colaborativos de trabajos, donde las personas de la comunidad pueden realizar tareas pertenecientes a diferentes proyectos, con recompensas económicas [14].

- Cambios recientes en la Wiki [14].

Las funciones sociales utilizadas con más frecuencia en estos portales son: la generación 0 unión a grupos, el contacto con otros profesionales en el propio sistema (más adelante, en los apartados 2.2.5, 2.2.6 y 2.2.7 detallaremos mediante qué medios) y la compartición de contenidos digitales del portal en otros espacios sociales.

\section{B) Funciones de Personalización}

- Organización de la visualización del contenido:

- Más votados/populares [2], [6], [7], [8], [9], [10], [14], [15].

- Más compartidos [2].

- Recursos por autor [4].

- Material revisado [6].

- Interacciones más recientes (votados, comentados) [7],[15].

- Por estándares educativos [8]

- Más recientes/fe [9], [12], [15].

- Título [15].

- Organización visualización grupos:

- Más activos [2]..

- Por destinatarios [2].

- Por temáticas del recurso [2].

- Nuevos [7].

- Mis grupos [7].

- Por comunidades [2].

- "Mi espacio" en el portal [2], [6], [7], [10], [11].

- Sugerencias automáticas acordes con tu perfil [4].

- Crear colecciones/carpetas de recursos [4], [6], [10], [11] , [12]. 
- Visualizar colecciones de recursos [4], [6], [7].

- Herramienta de traducción integrada en el sistema (Google) [4].

- Multi-idioma [3], [6], [7].

- Historial de búsquedas personales [7].

- Configurar la visualización en función del rol [8].

- Ver estadísticas de tus contenidos [10].

- Gestionar los derechos de acceso a tu recurso [10], [11].

Entre las estrategias de personalización más presentes en el conjunto de los 15 portales, encontramos las de "organizar la visualización del contenido" entre las más populares (e.g., permite a los usuarios poder ver el contenido mejor valorado por otros usuarios, pero a la vez puede dificultar la visualización de recursos de calidad que no han tenido la oportunidad de ser revisados).

Casi todos los portales tienen la opción "mi espacio" (denominada de diferentes formas), dentro del propio sistema, cada una de ellas ofertando diferentes posibilidades al usuario (e.g., acceder a los recursos que guardas como favoritos, acceder a los recursos que has definido para cada curso, ver los comentarios que has realizado en recursos, ver tus contactos dentro del portal, etc.). También es frecuente la estrategia de organizar los recursos marcados como favoritos o creados en colecciones o carpetas, para facilitar su localización.

\section{C) Los idiomas de los portales seleccionados}

- español: [1]; [12] ${ }^{179}$.

- inglés $180:$ [2], [5], [6], [8], [3], [9], [10], [11], [14].

- varios idiomas (más de 2): [4], [7], [13], [15].

179 Tiching.com [12], está pensado para los países de habla española (de España y Latinoamérica), y los materiales aparecen estructurados adaptados a las peculiaridades educativas de cada país. Se incluyen materiales de otros idiomas hablados en estos países (e.g., en el apartado España, encontramos materiales en catalán, a pesar de que no se puede buscar por idioma

180 OER Commons, TeacherTube están pensados, eminentemente, para el contexto educativo de Estados Unidos, ya que integran el etiquetado de los contenidos en base a los estándares educativos (equivalentes a los contenidos mínimos por áreas existentes en el currículo de España). 
MIT OCW [3] ofrece la posibilidad de adaptar los cursos a otros idiomas, a pesar de que la interfaz aparece únicamente en inglés.

El portal TeacherTube [10] está en inglés, pero contiene vídeos en varios idiomas (el mayor número de contenidos está en inglés). Ocurre lo mismo en WikiEducator [14], donde encontramos recursos en otros idiomas, a pesar de que no están catalogados en base a esta categoría.

Agrega [13], incluye contenidos digitales de las lenguas vernáculas de España.

Los portales traducidos a varios idiomas ofrecen:

- La integración de la extensión de traducción de Google (Merlot [4], su idioma principal es inglés, pero puede realizarse una aproximación a la traducción de otros idiomas con esta herramienta).

- La traducción del portal completo a lenguas habladas en diversos países europeos: inglés, español, búlgaro, sueco e italiano [7]

- La traducción del portal en distintas lenguas vernáculas del país, además de inglés: en Agrega [13] el portal está traducido a castellano, catalán, valenciano, gallego, vasco e inglés; en Merlí [15], en castellano, catalán e inglés.

\section{D) Funciones Contenido digital}

- Acceso a contenidos digitales (en múltiples formatos, audio, vídeo, texto) [1], [2], [4], [5], [6], [7], [8], [9], [10], [11], [12], [13], [14], [15]

- Acceso a cursos [3],

- Crear contenidos digitales [1], [2], [4], [7], [8], [10], [11], [12], [13], [14]

- Votar y ver puntuación [2], [4], [7], [10], [13]

- Comentar recursos [2], [4], [7], [9], [10], [13]

- Descargar [2], [3], [13]

- Citar el material [3]

- Novedades/ Contenido destacado/Noticias [5], [6], [8], [15]

- Información sobre Legislación Educativa [5],

- Reutilización de contenido digital en el propio sistema [6], [8], [11], [13]

- Marcadores/favoritos [6], [7], [10],

- Buscar por material revisado [6]

- Crear clases con estudiantes [10], [12].

- Asignar/recibir tareas a grupos concretos/subgrupos de alumnos mediante código [8], [10]. 
Todos los portales permiten acceder al contenido digital o a los cursos. 10 de los 15 portales ofertan a los usuarios generar y compartir contenido digital en el propio portal. Cinco portales permiten votar los recursos y visualizar la puntuación media de los mismos, así como visualizar número de usuarios que votó los recursos.

Cuatro portales facilitan la reutilización del material en el propio sistema, generando nuevo material, y adaptándolo a las necesidades de cada contexto.

En tres portales se puede descargar directamente el contenido digital.

Para promocionar el contenido y como estrategia de reclamo para los usuarios, cuatro portales muestran en su página principal las últimas novedades, noticias 0 contenidos destacados del sistema.

\section{E) Funciones de Accesibilidad}

- Exploración visual por etiquetas [9].

- Legible con software procesador de voz [6], [7], [9] ${ }^{181}$ [10], [11], [13] ${ }^{182}$

- Navegación con teclado [6], [7], [9], [11], [13]

- Barra de herramientas para personalizar la accesibilidad al portal ${ }^{183}$ [11].

\section{F) Funciones de Aspectos técnicos}

- Aportar sugerencias de mejora a los administradores del portal/reportar errores/contactar para resolver dudas [1], [2], [3], [7], [9], [10], [12].

- Visualizar/leer tutoriales para comprender y utilizar el portal y sus características [2], [4], [5], [7], [15].

- Recibir notificaciones de e-mail sobre eventos que ocurren o que el usuario realizas en el portal (e.g., el usuario recibe un mensaje cuando otro usuario te

181 W3C Standards

182 Cumple con los estándares establecidos por el World Wide Web Consortium (W3C), consorcio que define los estándares de los nuevos medios digitales, y las pautas de accesibilidad de Web Content Accessibility Guidelines (WCAG).

183 Trabaja con las herramientas de FLOE components (Flexible Learning for Open Education) http://www.floeproject.org/. FLOE es un proyecto que proporciona los recursos necesarios para personalizar el acceso al aprendizaje de cada persona y para eliminar las barreras para el aprendizaje (permitiendo elegir opciones de voz, velocidad de lectura, idioma de lectura, contraste de colores, tamaño de los elementos de la interfaz, dispositivos de escritura, etc.). 
agrega a su red de contactos, posibilidad de recibir información sobre boletines, mensajes de agradecimiento por contribuir a la subida de materiales a través de la plataforma, etc.) [2], [4]

- Recibir información actualizada sobre el portal a través de la suscripción a un lector de RSS [4], [5], [6], [10], [14].

- Exportar los recursos para integrarlos en entornos virtuales de aprendizaje [13]

\section{G)Funciones de Sostenibilidad}

- Realizar donaciones [3].

- Posibilidad de exportar un widget de contenido dinámico e insertarlo en otras webs [13].

- Otorgan premios a los mejores recursos compartidos en el portal, promocionando la contribución de contenidos en ellos [4], [8], [14].

Atendiendo a los criterios que acabamos de reflejar, extraídos del análisis del conjunto de los 15 portales, mostramos a continuación, en el, las funcionalidades que cubre cada portal ${ }^{184}$.

Las funcionalidades están representadas en porcentaje en el Gráfico 19 (podemos ver el número total de las elegibles de cada criterio a la derecha de cada ítem, en la leyenda). Los siguientes porcentajes se han calculado teniendo en cuenta el número de funcionalidades de cada tipo que hemos detectado previamente (es decir, en base a las características detectadas en nuestro análisis).

- Los portales con más funcionalidades sociales son: la red Social de Ning "Internet en el Aula" (50\%), seguida del portal Merlot $(36,6 \%)$ y WikiEducator $(27,27 \%)$.

- En general, las funciones que hemos seleccionado en el análisis y que están más presentes en el conjunto de los portales ${ }^{185}$ son las de contenidos digitales

184 El número de funcionalidades que hemos extraído, no indica que el portal tenga mayor 0 menor calidad, simplemente hemos realizado este análisis con un propósito comparativo para comprender mejor el perfil de cada portal.

185 Para calcular este parámetro de comparación hemos tenido en cuenta el porcentaje de criterios presentes en cada uno de los portales; posteriormente, hemos calculado la media de cada funcionalidad en los 15 portales; e.g., existen 14 funcionalidades de contenidos digitales; hemos calculado cuántas aparecen en cada portal, de modo que si aparecen las 
(presentes en con una media de $25,71 \%$ ); seguidos de los aspectos técnicos (los 5 criterios tienen una representatividad del 24\% entre los diferentes portales); funciones de accesibilidad (los 4 criterios están presentes con una media de $21,67 \%)$, funciones sociales $(16,6 \%)$, funciones de personalización $(13,06 \%)$ y funciones de sostenibilidad $(11,11 \%)$. Estos porcentajes sólo son orientativos, no pretendemos realizar una comparación estadística de ellos, si no simplemente tener en cuenta que la mayoría de los portales integran más funciones de las que hemos contemplado relativas al contenido digital, cercanas al porcentaje de inclusión de los criterios de los aspectos técnicos; en cambio, se incluyen menor número de funcionalidades sociales 0 de personalización por cada portal.

- Los que integran un mayor número de funcionalidades de personalización son Share.TEC $\left(33,33 \%\right.$ de las 24 detectadas), Education World ${ }^{186}(29,19 \%)$, Connexions (25\%) y Merlot $(20,83 \%)$.

- Los que ofertan un mayor número de funcionalidades para interactuar con el contenido son: TeacherTube (42,85\% de las funcionalidades detectadas), seguido de Education World, Connexions, Share.TEC, PBS Learning y Agrega (todas ellas un $(35,71 \%)$.

14 , cada portal tendría un $100 \%$ de presencia de las funcionalidades, y si tuviera 0 , un $0 \%$; posteriormente hemos realizado la media del porcentaje de presencia de las funciones de contenidos digitales presentes en los portales, con el fin de comparar cuáles son las más presentes atendiendo a los criterios que hemos seleccionado).

186 En su versión de 2012, no en la actual de 2015. 
Gráfico 19 Perfil de las funcionalidades de los portales analizados

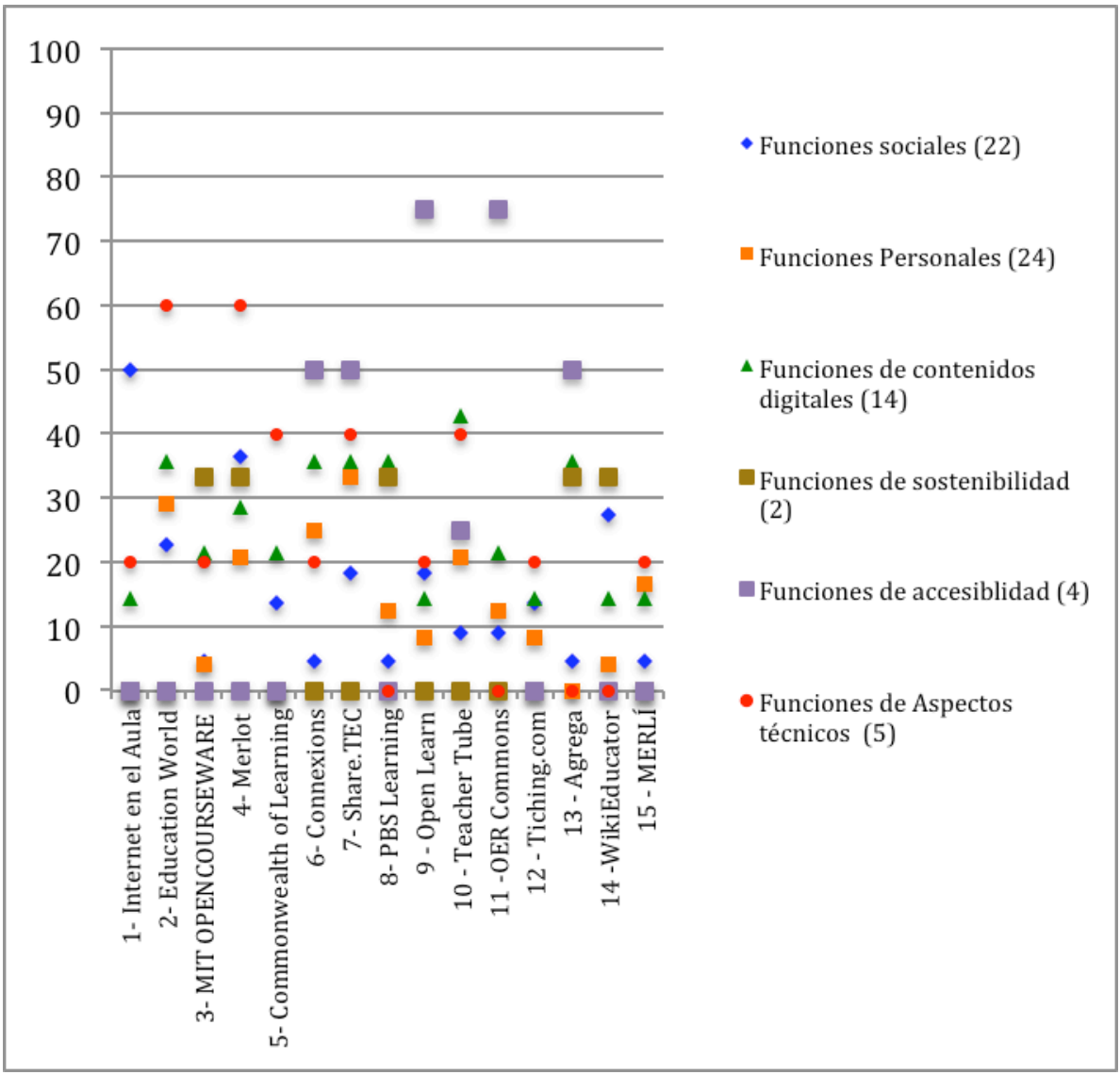

- Los portales más accesibles son Open Learn y OER Commons (que presentan 3 de las 4 funcionalidades seleccionadas), seguidos de Connexions, Share.TEC y Agrega (que integran 2).

- En cuanto a la sostenibilidad, sólo hemos considerado tres criterios, en nuestro análisis, y los cumplen MIT Open Courseware, WikiEducator, PBS Learning, Merlot y Agrega a pesar de que los demás portales siguen otro tipo de estrategias (ser el producto de entidades relevantes con solvencia económica, ofrecer servicios para alojar el propio contenido de los usuarios o crear sus 
comunidades, etc.). No hemos hecho mucho hincapié en este aspecto por su complejidad y por no ser objeto de estudio de la presente tesis.

- Los que ofrecen más funcionalidades técnicas (entre las 5 que hemos destacado), son Education World y Merlot (3 de las 5 propuestas).

- Los portales que más funcionalidades incluyen, en cantidad, son Merlot $(29,85 \%$ de todas las funcionalidades contempladas), seguido por Share.TEC $(29,54 \%)$, Education World (24,60\%), Agrega (20,60\%), TeacherTube (40\%) y Open Learn $(22,63 \%)$.

\subsubsection{Navegabilidad de los portales}

En los diferentes portales analizados hemos encontrado aspectos muy adecuados y aspectos mejorables respecto a la navegabilidad de los mismos:

Sobre los aspectos positivos, encontramos las siguientes características:

- Contenido organizado por categorías [1], [2], [3], [4].

- Apenas hay que desplazar la barra lateral para ver todo el contenido de cada página [1].

- Menús fijos (en la parte superior y/o lateral [2], [3], [4], [5], [6], [8], [9], [10], [11].

- Páginas de navegación sencilla [2], [3].

- Presentación del número de contenidos que atienden a los criterios de búsqueda especificados [5], [7].

- Ordenación de los materiales encontrados tras una búsqueda de 10 en 10, con un menú que te permite cambiar de página de resultados. [4], [5], [7], [15].

- Menú textual de situación (menú que te indica en qué categoría/subcategorías se encuentra el usuario, por ejemplo: "Home, Educación, Enseñar a estudiantes con dislexia") [7], [9].

- Muestra de contenidos relacionados con la consulta realizada por el usuario en la misma página del recurso [9].

- Personalización del número de entradas que ves en cada página [3], [14].

La presencia de menús fijos permite que los usuarios sean conscientes e todo momento de las funcionalidades que oferta el portal, permitiendo el acceso a un sitio $u$ otro sin perder la referencia.

Realizando la evaluación de los diferentes portales hemos encontrado diversos aspectos que dificultan la navegación en algunas de las páginas Web: 
- El portal [1], cuando navegamos en una página y queremos acceder a un recurso, nos abre una página nueva en la misma pestaña (esta acción podría mejorarse si los recursos pudieran visualizarse directamente en la propia página).

- La interfaz del portal [2] muestra páginas muy largas. Es necesario bajar con el cursor lateral en las páginas para acceder al menú del que dispone en la parte inferior de ellas (donde se hipervinculan los diferentes espacios del portal); para mejorar la navegabilidad, sugerimos la incorporación de menús en la parte superior de la interfaz.

- Tras realizar una búsqueda avanzada, y acceder a un recurso, se borran los elementos que hemos preseleccionado [3] (a no ser que retrocedamos con el propio navegador Web).

- Páginas demasiado largas, que obligan a desplazar el cursor vertical bastante (no se ve de forma simple el contenido completo de cada página) [6].

- Funcionalidades parceladas, es decir, el usuario no puede acceder a todas las opciones desde cada página, por lo que puede resultar compleja a la hora de navegar y encontrar la funcionalidad que se busca [7].

- Dificultad para encontrar el número de recursos y el tipo [9], [11].

- Dificultad para encontrar los recursos [14]: en el menú de este servicio, en este caso, una Wiki, podrían incluir un apartado que hipervinculara hacia la página en la que se encuentran las categorías de los recursos, pues antes de poder llegar a los contenidos hay que explorar varias páginas del portal.

- El menú con los hipervínculos a otras páginas de resultados (además de la primera), aparece en la parte inferior de la interfaz [15].

Cuando tenemos funcionalidades poco accesibles, estas pierden utilidad, pues es posible que no capten nuestra atención y no saquemos el potencial completo que ofrece el portal. Las funcionalidades deberían aparecer visibles en todo momento.

La forma de solventar el hecho de que los portales no guarden las búsquedas es permitiendo esta funcionalidad en los portales, o incluso abriendo los contenidos seleccionados en pestañas nuevas (aunque esta opción podría dejarse a la elección personal del usuario).

En los casos en los que el material no está catalogado de forma estructurada, se hace difícil la recuperación de la información porque te puede devolver entradas irrelevantes, al poder explorar únicamente mediante palabras clave (como en el caso de Internet en el Aula [1] y WikiEducator [14]. En estos casos, el usuario debe 
perder tiempo explorando los recursos uno a uno para obtener la información que está buscando.

\subsection{8. ¿Quién administra y mantiene los portales analizados y su contenido?}

Como vemos en la Tabla 55, 5 de los 15 portales estudiados están financiados por distintas instituciones gubernamentales regionales, nacionales o internacionales; 4 por empresas; 6 universidades, en su mayoría afiliadas con Organizaciones No Gubernamentales y Fundaciones. Todos los portales tienen responsables que gestionan su contenido. En el caso de WikiEducator, son los propios participantes de la red quienes filtran la calidad del contenido, aunque adicionalmente es revisado por los administradores responsables.

Tabla 55 Administración, financiación y gestión del contenido

\begin{tabular}{|c|c|c|c|}
\hline & $\begin{array}{l}\text { Administración del } \\
\text { sistema }\end{array}$ & Entidad que financia & Gestión del contenido \\
\hline $\begin{array}{l}\text { 1- Internet en } \\
\text { el Aula }\end{array}$ & $\begin{array}{l}\text { Institución Nacional de } \\
\text { Tecnologías Educativas } \\
\text { y de Formación del } \\
\text { profesorado }\end{array}$ & Gobierno de España & $\begin{array}{l}\text { Los propios usuarios de la } \\
\text { red y Administrador. }\end{array}$ \\
\hline $\begin{array}{l}\text { 2- Education } \\
\text { World }\end{array}$ & $\begin{array}{l}\text { Empresa (Education } \\
\text { World) }\end{array}$ & Empresa & $\begin{array}{l}\text { Empresa, Asociaciones, } \\
\text { usuarios. Administrador de } \\
\text { la empresa. }\end{array}$ \\
\hline $\begin{array}{l}\text { 3- MIT OPEN- } \\
\text { COURSEWARE }\end{array}$ & $\begin{array}{l}\text { Universidad (Mas- } \\
\text { sachusetts Institute of } \\
\text { Technology - MIT) }\end{array}$ & Universidad (MIT) & $\begin{array}{l}\text { Universidad (MIT) y usua- } \\
\text { rios que traducen cursos. } \\
\text { Administrador de MIT. }\end{array}$ \\
\hline 4- Merlot & $\begin{array}{l}\text { Universidad (California } \\
\text { State University) }\end{array}$ & $\begin{array}{l}\text { California State University } \\
\text { System, instituciones } \\
\text { educativas, sociedades } \\
\text { profesionales e Industria. }\end{array}$ & $\begin{array}{l}\text { Revisión de pares seleccio- } \\
\text { nados por MERLOT. }\end{array}$ \\
\hline $\begin{array}{l}\text { 5- Common- } \\
\text { wealth of } \\
\text { Learning (COL) }\end{array}$ & $\begin{array}{l}\text { Institución Guber- } \\
\text { namental (COL) }\end{array}$ & $\begin{array}{l}\text { Institución Gubernamen- } \\
\text { tal (COL) }\end{array}$ & $\begin{array}{l}\text { Institución Gubernamental } \\
\text { (COL) }\end{array}$ \\
\hline 6- Connexions & $\begin{array}{l}\text { Universidad (Rice } \\
\text { University) }\end{array}$ & $\begin{array}{l}\text { Universidad (Rice Uni- } \\
\text { versity) y Fundaciones } \\
\text { Educativas }\end{array}$ & $\begin{array}{l}\text { Universidad (Rice } \\
\text { University) }\end{array}$ \\
\hline 7- Share.TEC & $\begin{array}{l}\text { Universidad - Centro de } \\
\text { Investigación Cientí- } \\
\text { fica(NIS-SU Bulgaria) }\end{array}$ & Comisión Europea & $\begin{array}{l}\text { Universidad: Centro de } \\
\text { investigación científica NIS- } \\
\text { SU e ITD-CNR (Instituto } \\
\text { Superior para la Tecnología } \\
\text { Educativa de Italia). }\end{array}$ \\
\hline $\begin{array}{l}\text { 8- PBS } \\
\text { Learning }\end{array}$ & Empresa (PBS Learning) & $\begin{array}{l}\text { Empresa (PBS Learning) y } \\
\text { fundaciones educativas }\end{array}$ & $\begin{array}{l}\text { Empresa (PBS Learning) y } \\
\text { fundaciones educativas }\end{array}$ \\
\hline
\end{tabular}




\begin{tabular}{|c|c|c|c|}
\hline & $\begin{array}{l}\text { Administración del } \\
\text { sistema }\end{array}$ & Entidad que financia & Gestión del contenido \\
\hline 9 - Open Learn & $\begin{array}{l}\text { Universidad (Open } \\
\text { University de Reino } \\
\text { Unido) }\end{array}$ & Royalty (Open University) & $\begin{array}{l}\text { Universidad (Open Univer- } \\
\text { sity de Reino Unido) }\end{array}$ \\
\hline $\begin{array}{l}10 \text { - Teacher } \\
\text { Tube }\end{array}$ & Empresa (TeacherTube) & Empresa (TeacherTube) & Empresa (TeacherTube) \\
\hline $\begin{array}{l}11 \text {-OER Com- } \\
\text { mons }\end{array}$ & $\begin{array}{l}\text { ONG - Institute for the } \\
\text { study of Knowledge } \\
\text { Management in Educa- } \\
\text { tion (ISKME). }\end{array}$ & ONG (Donaciones) & $\begin{array}{l}\text { ISKME, Asociaciones, usua- } \\
\text { rios (Con el visto bueno de } \\
\text { los administradores) }\end{array}$ \\
\hline $\begin{array}{l}12 \text { - } \\
\text { Tiching.com }\end{array}$ & Empresa (Tiching.com) & $\begin{array}{l}\text { Empresa (Tiching.com) } \\
\text { (inversión pública y } \\
\text { privada) }\end{array}$ & $\begin{array}{l}\text { Empresa (Tiching.com) } \\
\text { proporciona contenidos y } \\
\text { valida los contenidos que } \\
\text { aportan usuarios. }\end{array}$ \\
\hline 13 - Agrega & $\begin{array}{l}\text { Administradores con- } \\
\text { tratados por el Go- } \\
\text { bierno de España. }\end{array}$ & $\begin{array}{l}\text { Gobierno de España, } \\
\text { INTEF, Red.es, Gobiernos } \\
\text { de las Comunidades } \\
\text { Autónomas de España, } \\
\text { Unión Europea }\end{array}$ & $\begin{array}{l}\text { Las entidades que lo finan- } \\
\text { cian, Usuarios, contenido } \\
\text { revisado por administrado- } \\
\text { res. }\end{array}$ \\
\hline $\begin{array}{l}14 \text {-WikiEduca- } \\
\text { tor }\end{array}$ & $\begin{array}{l}\text { Administradores del } \\
\text { Politécnico de Otago }\end{array}$ & $\begin{array}{l}\text { ONG - Open Education } \\
\text { Resource Foundation }\end{array}$ & $\begin{array}{l}\text { Cualquier persona puede } \\
\text { contribuir contenido en la } \\
\text { wiki, revisado por adminis- } \\
\text { tradores y usuarios. }\end{array}$ \\
\hline 15 - MERLí & $\begin{array}{l}\text { Administradores del } \\
\text { portal }\end{array}$ & $\begin{array}{l}\text { Departamento de Educa- } \\
\text { ción de la Generalitat de } \\
\text { Cataluña }\end{array}$ & $\begin{array}{l}\text { Departamento de } \\
\text { Educación de la Generalitat } \\
\text { de Cataluña }\end{array}$ \\
\hline
\end{tabular}

\subsection{Aspectos educativos y sociales de los portales}

\subsubsection{Niveles, temáticas y destinatarios}

En cuanto al espectro de niveles educativos a los que se destinan los contenidos de los portales analizados, en la Tabla 56 apreciamos que los portales [1], [6], [10] y [14] y [15] son los que ofrecen un mayor rango, pues integran recursos desde Educación Infantil, hasta la educación universitaria y postuniversitaria. Algunos portales se centran más en la educación universitaria y desarrollo profesional ([3], [4] y [5], [7] y [9]); otros están destinados a ofrecer contenidos desde los niveles de educación infantil hasta bachillerato, además de ofrecer recursos para el desarrollo profesional de los docentes y/o la formación del profesorado [2], [8], [11], [12]; y Agrega, que como hemos mencionado sólo ofrece contenidos para educación infantil [13]. 
En relación con los niveles a los que se enfocan los materiales hemos analizado los destinatarios a los que va dirigido el portal. Recordemos que el nexo común que buscábamos en los portales que hemos seleccionado (recogidos en la página $305)$, era que incluyeran contenidos para la formación del profesorado; tal y como puede apreciarse en la Tabla 56, la mayoría los incluye (excepto Agrega, que es un portal orientado exclusivamente a la Educación Infantil, Primaria y Secundaria y fue seleccionado por su relevancia y éxito en el contexto español).

La mayoría de los portales analizados incluyen contenidos para diversas áreas y son exitosos (en cuanto al número de usuarios que los utilizan, calidad de sus contenidos, comunidades que integran, tal y como destacan las publicaciones que hemos analizado para determinar su selección y los premios e instituciones que avalan su calidad). Este hecho nos hace reflexionar sobre la adecuación de la generación de portales versátiles y que den cobertura en un mismo espacio a diferentes destinatarios. En cualquier caso, hay portales específicos para la educación superior que también son célebres y han sido reconocidos por premios internacionales, como es el caso de OpenLearn ${ }^{187}$.

187 http://www.open.edu/openlearn/ 
Tabla 56 Aspectos Educativos de los portales: Niveles, temáticas y destinatarios.

\begin{tabular}{|c|c|c|c|c|c|c|c|c|c|c|c|c|c|c|c|}
\hline $\begin{array}{l}\text { *Est=estudiantes } \\
\text { *Dsrrllo=desarrollo } \\
\text { *Form=formadores }^{*} \text { *Edts=editoriales }\end{array}$ & 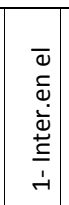 & $\dot{\sim}$ & $\begin{array}{l}3 \\
0 \\
0 \\
\qquad \\
\sum \\
\dot{m}\end{array}$ & $\begin{array}{l}\frac{+}{0} \\
\frac{0}{d} \\
\sum_{j} \\
\dot{J}\end{array}$ & $\begin{array}{l}\overrightarrow{0} \\
\text { Ù } \\
\text { ம่ }\end{array}$ & 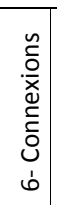 & 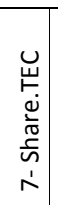 & $\begin{array}{l}\tilde{\infty} \\
a \\
\infty \\
\infty\end{array}$ & $\begin{array}{l}\frac{1}{1} \\
0 \\
0 \\
1 \\
\sigma\end{array}$ & 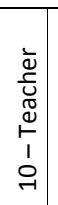 & 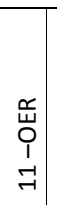 & $\stackrel{1}{\underset{7}{7}}$ & 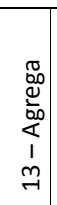 & $\begin{array}{l}4 \\
\dot{1}\end{array}$ & 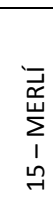 \\
\hline \multicolumn{16}{|c|}{ Niveles educativos de los materiales } \\
\hline Educación infantil & $\mathrm{x}$ & $\mathrm{x}$ & & & & $\mathrm{x}$ & & $\mathrm{x}$ & & $\mathrm{x}$ & $\mathrm{x}$ & $\mathrm{x}$ & $\mathrm{x}$ & $\mathrm{x}$ & $\mathrm{x}$ \\
\hline Educación Primaria & $\mathrm{x}$ & $\mathrm{x}$ & & & & $\mathrm{x}$ & & $\mathrm{x}$ & & $\mathrm{x}$ & $\mathrm{x}$ & $\mathrm{x}$ & $\mathrm{X}$ & $\mathrm{X}$ & $\mathrm{x}$ \\
\hline Educación Secundaria & $\mathrm{x}$ & $\mathrm{x}$ & $\mathrm{x}$ & & & $\mathrm{x}$ & & $x$ & & $\mathrm{x}$ & $\mathrm{x}$ & $\mathrm{x}$ & $\mathrm{x}$ & $\mathrm{x}$ & $\mathrm{x}$ \\
\hline Bachillerato & $x$ & $x$ & & & & $x$ & & $x$ & & $x$ & $\mathrm{x}$ & $x$ & $x$ & $x$ & $x$ \\
\hline Formación Profesional & $\mathrm{x}$ & & & & & $\mathrm{x}$ & $\mathrm{x}$ & & & $\mathrm{x}$ & & & & $\mathrm{x}$ & $x$ \\
\hline Universidad & $x$ & & $\mathrm{x}$ & $\mathrm{x}$ & $\mathrm{X}$ & $x$ & $\mathrm{x}$ & & $\mathrm{x}$ & $\mathrm{x}$ & & & & $\mathrm{x}$ & $\mathrm{x}$ \\
\hline $\begin{array}{l}\text { Formación del } \\
\text { profesorado }\end{array}$ & $\mathrm{x}$ & $\mathrm{x}$ & $\mathrm{X}$ & $\mathrm{x}$ & $\mathrm{x}$ & $\mathrm{X}$ & $\mathrm{x}$ & & $\mathrm{x}$ & $\mathrm{X}$ & $\mathrm{x}$ & $\mathrm{x}$ & & $\mathrm{x}$ & $\mathrm{x}$ \\
\hline *Dsrrllo. Profesional & $\mathrm{x}$ & $\mathrm{x}$ & $\mathrm{x}$ & $\mathrm{x}$ & $\mathrm{x}$ & $\mathrm{x}$ & $\mathrm{x}$ & $\mathrm{x}$ & $\mathrm{x}$ & $\mathrm{x}$ & $\mathrm{x}$ & $\mathrm{x}$ & & $\mathrm{x}$ & \\
\hline \multicolumn{16}{|l|}{ Temáticas de los contenidos } \\
\hline $\begin{array}{l}\text { Todas las disciplinas } \\
\text { universitarias }\end{array}$ & & & $\mathrm{x}$ & $\mathrm{x}$ & & $\mathrm{x}$ & $\mathrm{x}$ & & $\mathrm{x}$ & $\mathrm{x}$ & & & & $\mathrm{x}$ & $\mathrm{x}$ \\
\hline $\begin{array}{l}\text { De Formación } \\
\text { profesorado/*Dsrrllo } \\
\text { profesional }\end{array}$ & $\mathrm{x}$ & $\mathrm{x}$ & $\mathrm{x}$ & $x$ & $\mathrm{x}$ & $\mathrm{x}$ & $\mathrm{x}$ & $x$ & $x$ & $\mathrm{x}$ & $\mathrm{x}$ & $\mathrm{x}$ & & $\mathrm{x}$ & $x$ \\
\hline $\begin{array}{l}\text { Materias para *est. } \\
\text { IE/EP/ES y FP }\end{array}$ & & $x$ & & & & $\mathrm{x}$ & & $x$ & & $x$ & $\mathrm{x}$ & $\mathrm{x}$ & $\mathrm{x}$ & $x$ & $x$ \\
\hline \multicolumn{16}{|c|}{ Destinatarios del portal y de los contenidos } \\
\hline${ }^{*}$ Est. Ed. Obligatoria & & $\mathrm{X}$ & & & $\mathrm{X}$ & $\mathrm{X}$ & & $\mathrm{x}$ & & $\mathrm{x}$ & $\mathrm{X}$ & $\mathrm{X}$ & $\mathrm{X}$ & $\mathrm{X}$ & $\mathrm{x}$ \\
\hline *Est. Bachillerato & & $\mathrm{X}$ & & & $\mathrm{x}$ & $\mathrm{x}$ & & $\mathrm{X}$ & & $\mathrm{x}$ & $\mathrm{X}$ & $\mathrm{X}$ & $\mathrm{X}$ & $\mathrm{X}$ & $\mathrm{X}$ \\
\hline Familia & & $\mathrm{x}$ & & & & $\mathrm{x}$ & & & & $\mathrm{x}$ & & $\mathrm{x}$ & $\mathrm{x}$ & & $\mathrm{x}$ \\
\hline *Est. Universidad & & & $\mathrm{x}$ & $\mathrm{x}$ & $\mathrm{x}$ & $x$ & $\mathrm{x}$ & & $\mathrm{x}$ & $\mathrm{x}$ & & & & $\mathrm{x}$ & $x$ \\
\hline Futuros profesores & $\mathrm{x}$ & $x$ & $\mathrm{x}$ & $\mathrm{x}$ & $\mathrm{x}$ & $\mathrm{x}$ & $\mathrm{x}$ & $\mathrm{x}$ & $\mathrm{x}$ & $\mathrm{x}$ & $\mathrm{x}$ & $\mathrm{x}$ & & $\mathrm{x}$ & $\mathrm{x}$ \\
\hline *Form. De profesores & $\mathrm{x}$ & $\mathrm{x}$ & $\mathrm{x}$ & $x$ & $\mathrm{x}$ & $x$ & $\mathrm{x}$ & $x$ & $\mathrm{x}$ & $\mathrm{x}$ & $\mathrm{x}$ & $\mathrm{x}$ & & $x$ & $x$ \\
\hline Prof. Universidad & $x$ & & $x$ & $x$ & & & $x$ & $x$ & $x$ & $x$ & & & & $x$ & $x$ \\
\hline Prof. Ed. Obligatoria & $\mathrm{x}$ & $\mathrm{x}$ & $\mathrm{x}$ & & & $\mathrm{x}$ & $\mathrm{x}$ & $x$ & & $\mathrm{x}$ & $\mathrm{x}$ & $x$ & $\mathrm{x}$ & $\mathrm{x}$ & $x$ \\
\hline Form. Profesional & $\mathrm{x}$ & $\mathrm{x}$ & $\mathrm{x}$ & & & $\mathrm{X}$ & $\mathrm{x}$ & & $\mathrm{X}$ & $\mathrm{X}$ & & $\mathrm{x}$ & & $\mathrm{X}$ & $\mathrm{x}$ \\
\hline *Edts /Creadores & & & & & & $\mathrm{x}$ & $\mathrm{x}$ & & & $\mathrm{x}$ & & & $\mathrm{x}$ & $\mathrm{x}$ & $\mathrm{x}$ \\
\hline Investigadores & $\mathrm{x}$ & $x$ & & & $x$ & & & & & & & & & & \\
\hline $\begin{array}{l}\text { Personal de } \\
\text { Administración }\end{array}$ & & & & & $x$ & & & & & & & & & & \\
\hline Autoaprendizaje & & & $\mathrm{x}$ & & & & & & $\mathrm{x}$ & $\mathrm{x}$ & $\mathrm{x}$ & & & & \\
\hline Legisladores & & $\mathrm{x}$ & & & $\mathrm{x}$ & & & & & & & & & $x$ & \\
\hline ONGs & & & & & $\mathrm{x}$ & & & & & & & & & & \\
\hline Total & 6 & $a$ & $r$ & $\theta$ & $\sigma$ & $a$ & N & 6 & 0 & $\exists$ & 6 & $r$ & เ & 우 & 우 \\
\hline
\end{tabular}




\subsubsection{Contenidos educativos y premios de los portales}

En la siguiente Tabla 57 presentamos la información relativa a la gratuidad o no de los contenidos de los portales que hemos indagado y el formato educativo de los materiales que contienen ${ }^{188}$.

Todos los portales que hemos analizado integran contenidos gratuitos (pues este era un criterio de selección de la muestra) en diferentes formatos de copyleft (diversos tipos de licencias de Creative Commons o materiales de dominio público) y Copyright (pero gratuitos). Cuatro de los portales ([4], [5], [7] y [11]) siguen un modelo híbrido (integrando contenidos de pago y contenidos gratuitos). En el estudio de caso Share.TEC nuestros informantes utilizaban mayoritariamente contenido gratuito.

La mayoría de los portales analizados contienen recursos educativos en diferentes formatos: a) presentaciones, material de referencia, y/o apuntes; b) simulaciones, animaciones, vídeos, y/o juegos; y c) animaciones, de a la información presentada en la Tabla 57.

Aquellos portales que se enfocan más hacia los profesores o la formación del profesorado, integran en sus materiales unidades didácticas y/o programaciones didácticas, ya que son de ayuda para la planificación docente y su formación.

Atendiendo a la información recopilada en la Tabla 57, los recursos con menor presencia en los portales analizados son: ePortafolio, exámenes, programas de radio, y fichas/plantillas (en cambio, consideramos que este último recurso sería muy frecuente si analizáramos exclusivamente portales de educación Infantil, e incluso Primaria). En general, los portales contienen los mismos tipos de formato educativo, algunos incluyendo más tipologías que otros.

188 Algunos portales no contienen los materiales en el mismo portal, es decir, son referatorios. Para realizar esta tabla hemos obviado este hecho y hemos recogido el formato de los materiales que contienen los propios portales o que describen (metadatos). 
Tabla 57 Aspectos educativos de los contenidos 1. Gratuidad y Formato del contenido digital

\begin{tabular}{|c|c|c|c|c|c|c|c|c|c|c|c|c|c|c|c|}
\hline & 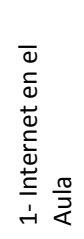 & 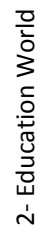 & $\begin{array}{l}3 \\
\text { O } \\
\text { 衣 } \\
\dot{m}\end{array}$ & $\frac{+}{\frac{1}{2}}$ & $\begin{array}{c} \\
\text { Oे } \\
\text { ம่ }\end{array}$ & 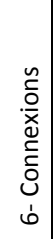 & 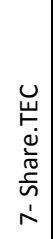 & 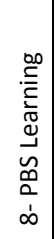 & 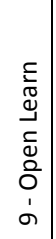 & 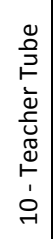 & 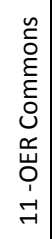 & 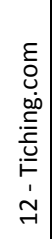 & 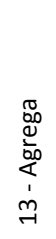 & 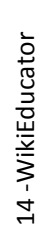 & 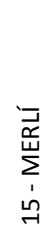 \\
\hline \multicolumn{16}{|c|}{ Pago de los contenidos } \\
\hline Gratuitos & $x$ & $x$ & $x$ & $x$ & $x$ & $x$ & $x$ & $x$ & $x$ & $\mathrm{X}$ & $x$ & $x$ & $x$ & $x$ & $x$ \\
\hline De pago & & & & $x$ & $x$ & & $x$ & & & & & $x$ & & & \\
\hline \multicolumn{16}{|l|}{ Formato Educativo } \\
\hline $\begin{array}{l}\text { Unidades Didác- } \\
\text { ticas/ Progra- } \\
\text { maciones }\end{array}$ & $x$ & $x$ & & & & $x$ & $x$ & $x$ & & $x$ & $x$ & $x$ & $x$ & & $x$ \\
\hline $\begin{array}{l}\text { Estrategias didácti- } \\
\text { cas/ Competencias }\end{array}$ & $x$ & & & & & $x$ & $x$ & & & & $x$ & $x$ & $x$ & & $x$ \\
\hline WebQuests & $\mathrm{X}$ & & & & & & $x$ & & $x$ & & & $X$ & $X$ & & \\
\hline Buenas prácticas & $x$ & & & & & $x$ & $x$ & & & & & $x$ & & $x$ & \\
\hline Fichas/Plantillas & & $\mathrm{X}$ & & & & $x$ & & & & & & & & $\mathrm{X}$ & $x$ \\
\hline Clases magistrales & & & & & & & & & $\mathrm{X}$ & & $x$ & $\mathrm{x}$ & $x$ & & \\
\hline Actividades & & $x$ & $x$ & $x$ & & $x$ & $x$ & $x$ & $x$ & $x$ & $x$ & & $x$ & & $x$ \\
\hline $\begin{array}{l}\text { Animaciones/Vídeo } \\
\text { s/Simulaciones/ } \\
\text { juegos }\end{array}$ & & & $x$ & $x$ & & & $x$ & $x$ & $x$ & $x$ & $x$ & $x$ & $x$ & $x$ & $x$ \\
\hline $\begin{array}{l}\text { Herramientas } \\
\text { educativas }\end{array}$ & & & $x$ & $x$ & & & & $x$ & & & & $x$ & & & \\
\hline Libros de texto & & & & $x$ & $x$ & & $x$ & & & & $x$ & $x$ & $x$ & $x$ & \\
\hline $\begin{array}{l}\text { Presentaciones/ } \\
\text { Material de } \\
\text { referencia/Apuntes }\end{array}$ & & $x$ & $x$ & $x$ & & $x$ & $x$ & $x$ & $x$ & $x$ & $x$ & $x$ & $x$ & $x$ & $x$ \\
\hline $\begin{array}{l}\text { Investigaciones/ } \\
\text { Artículos }\end{array}$ & & $x$ & & $x$ & & & $x$ & & $x$ & & $x$ & & & $x$ & $x$ \\
\hline $\begin{array}{l}\text { Programas de } \\
\text { TV/Radio }\end{array}$ & & & & & & & $x$ & & $x$ & & & & & & \\
\hline Proyectos & & & $x$ & $x$ & & & & $x$ & & & $x$ & $x$ & $x$ & $x$ & \\
\hline Exámenes & & & $x$ & $x$ & & & $x$ & & & & & & & & \\
\hline e-Portafolio & & & & $x$ & & & & $x$ & & & & $\mathrm{X}$ & & & \\
\hline
\end{tabular}


En cuanto al formato técnico de los contenidos digitales, en la Tabla 58 observamos que los portales que alojan contenidos digitales (no sólo metadatos), nos permiten visualizar desde el propio portal recursos en diversidad de formatos (audio, sonido, vídeo, texto, aplicaciones o recursos interactivos, páginas Web, etc.).

Tabla 58 Aspectos Educativos de los contenidos 2: Formato técnico, calidad y reconocimientos ${ }^{189}$

\begin{tabular}{|c|c|c|c|c|c|c|c|c|c|c|c|c|c|c|c|}
\hline & 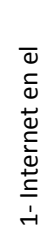 & 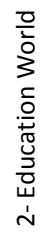 & $\begin{array}{l}3 \\
\text { O } \\
\stackrel{5}{\bar{z}} \\
\dot{m}\end{array}$ & $\begin{array}{l}\frac{\pi}{0} \\
\frac{1}{d} \\
\sum_{\dot{\sigma}}^{\prime}\end{array}$ & $\begin{array}{l}\vec{O} \\
\text { ○े } \\
\text { ம่ }\end{array}$ & 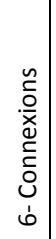 & 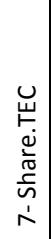 & 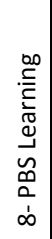 & 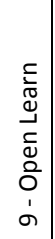 & 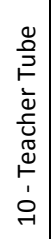 & 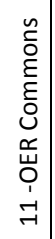 & 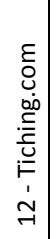 & 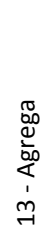 & 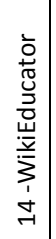 & 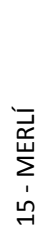 \\
\hline \multicolumn{16}{|l|}{ Formato técnico } \\
\hline Imagen & $\mathrm{X}$ & $x$ & $\mathrm{X}$ & $x$ & $x$ & & & $x$ & $x$ & $x$ & $x$ & $x$ & $x$ & & $x$ \\
\hline Sonido & & & & $x$ & & & & $x$ & $x$ & $x$ & $x$ & $x$ & $x$ & & $x$ \\
\hline Vídeo & $x$ & $x$ & $x$ & $x$ & $x$ & & & $x$ & $x$ & $x$ & $x$ & $x$ & $x$ & & $x$ \\
\hline $\begin{array}{l}\text { Aplicaciones/Interac- } \\
\text { tivo }\end{array}$ & & & $x$ & $x$ & & & & $x$ & $x$ & & $x$ & $x$ & $x$ & & $x$ \\
\hline Documento texto & $x$ & $x$ & $x$ & $x$ & $x$ & $x$ & $x$ & $x$ & $x$ & $x$ & $x$ & $x$ & $x$ & $x$ & $x$ \\
\hline Pág. Web & $x$ & $x$ & $x$ & $x$ & & $x$ & & $x$ & $x$ & $x$ & $x$ & & & & $x$ \\
\hline Otros & & $x$ & $x$ & $x$ & & & & $x$ & $x$ & & $x$ & & & & $x$ \\
\hline \multicolumn{16}{|l|}{ Calidad } \\
\hline Filtrados por usuarios & $x$ & $x$ & & $x$ & & $x$ & & & & $\mathrm{x}$ & & $x$ & $x$ & $x$ & \\
\hline $\begin{array}{l}\text { Filtrados por adminis- } \\
\text { tradores/responsa- } \\
\text { bles del contenido }\end{array}$ & & & $x$ & & $x$ & $x$ & $x$ & $x$ & $x$ & $x$ & $x$ & $x$ & $x$ & & $x$ \\
\hline $\begin{array}{l}\text { Sin control (o control } \\
\text { mínimo) }\end{array}$ & & & & & & $x$ & & & & $x$ & & $x$ & & & \\
\hline \multicolumn{16}{|l|}{ Premios/Reconocimientos } \\
\hline Galardonado & & $x$ & & & & $x$ & & $x$ & $\mathrm{X}$ & & $x$ & & $x$ & & \\
\hline Otorga premios & & & & $x$ & & & & $x$ & & & & & & $x$ & \\
\hline
\end{tabular}

En el caso de Share.TEC, al ser un referatorio (no aloja la mayoría de sus contenidos en su propio servidor), únicamente encontramos las descripciones textuales de los contenidos, en su mayoría, con hipervínculos a los contenidos

189 Analizamos el contenido que se encuentra en los portales. Algunos portales son referatorios, y sólo incluyen la descripción del contenido.

190 Nos referimos a control mínimo, cuando el administrador da por bueno el recurso, pero no revisa el contenido y etiquetado pedagógico del mismo. 
digitales (a pesar de que los materiales a los que referencia presentan los diversos formatos mencionados).

En Connexions encontramos material eminentemente textual (pues contiene, en su mayoría, libros de texto gratuitos); y en el caso de WikiEducator, encontramos hipervínculos textuales que enlazan a páginas Web en las que se aloja el contenido.

En la Tabla 58 podemos observar cómo la mayoría de los portales seleccionados, ofertan contenidos de calidad. Para asegurar la calidad de los recursos, los distintos portales siguen diferentes estrategias. En 11 de 15 casos, el contenido es seleccionado por los editores/administradores de portal. Entre estos, el portal Agrega [13] utiliza dos estrategias simultáneamente (filtro por parte de los usuarios y filtro por parte de los responsables del portal). Algunos portales (Connexions [6], TeacherTube [10] y Tiching.com [12]) integran los tres mecanismos para asegurar la calidad del material (revisión por parte de los usuarios y de los responsables del portal). Asimismo, para facilitar la contribución de los usuarios al sistema, también permiten la inclusión de recursos con un mínimo control. Únicamente estos portales mencionados son los que permiten esta estrategia (control mínimo o ausencia de control inicial para la compartición de contenidos), ya que disponen de otros mecanismos para asegurar la calidad y seguridad del portal.

Los portales más sociales (Internet en el Aula y WikiEducator), únicamente disponen de mecanismos de revisión de usuarios (característica de la que disponían portales, como observamos en la Tabla 58). La calidad de los recursos de estos portales es muy variada, y es filtrada por sus usuarios a través de diversas estrategias, e.g.: realizando comentarios, votando recursos, haciendo revisión de pares 0 informando a los administradores del portal sobre la ausencia de calidad 0 incumplimiento de las normas del portal de los recursos.

Entre el tipo de premios que otorgan algunos servicios, como Merlot, encontramos varias categorías que incluyen varios premios en cada una de ellas: premios a materiales ejemplares, premios al servicio de Merlot (tanto para las entidades que muestran un contrato estable en el tiempo como colaboradores en Merlot, como para usuarios individuales que prestan de forma voluntaria sus servicios a la comunidad merlot (contribuyendo en el sistema), y reconocimientos que premian la creatividad utilizando Merlot ("Aplicación de Merlot"). ${ }^{191}$

191 Puede accederse al listado completo de premios otorgados por Merlot en el siguiente enlace: http://info.merlot.org/merlothelp/index.htm\#merlot_collection.htm 


\subsubsection{Número de contenidos, miembros y comunidades de los portales}

En la Tabla 59 recopilamos las cifras relativas al número contenidos, miembros y comunidades de los portales analizados, atendiendo a la última fecha en la que se recopiló esta información. Para realizar la selección de la muestra, uno de los criterios que elegimos fue el de incorporar portales que integraran un número mayor de 1000 contenidos digitales para la formación del profesorado.

Tabla 59 Contenidos, miembros y comunidades de los portales analizados.

\begin{tabular}{|c|c|c|c|c|}
\hline & $\begin{array}{l}\text { Número de conteni- } \\
\text { dos }\end{array}$ & $\begin{array}{l}\text { Número de } \\
\text { miembros }\end{array}$ & $\begin{array}{l}\text { Número de } \\
\text { comunidades }\end{array}$ & $\begin{array}{l}\text { Último } \\
\text { Acceso }\end{array}$ \\
\hline $\begin{array}{l}\text { 1- Internet } \\
\text { en el Aula }\end{array}$ & $\begin{array}{l}\text { No listados (más de } \\
1000 \text { ) }\end{array}$ & 14991 & 239 & $23 / 08 / 2015$ \\
\hline $\begin{array}{l}\text { 2- Education } \\
\text { World }\end{array}$ & $\begin{array}{l}\text { No listados (más de } \\
1000 \text { ) }\end{array}$ & No hay & No hay & $22 / 08 / 2015$ \\
\hline 3- MIT OCW & $\begin{array}{l}2.000 \text { cursos ( } 30 \\
\text { específicos de } \\
\text { enseñanza y educa- } \\
\text { ción) }\end{array}$ & No hay & No hay & $22 / 08 / 2015$ \\
\hline 4- Merlot & $\begin{array}{l}40,000 \text { ( } 4.405 \text { de } \\
\text { formación del profe- } \\
\text { sorado) }\end{array}$ & 105,001 & 23 (por Áreas) $^{192}$ & $06 / 08 / 2015$ \\
\hline 5- COL & $\begin{array}{l}4857^{193} \text { ( } 632 \text { de } \\
\text { formación del profe- } \\
\text { sorado) }\end{array}$ & No hay & No hay & $05 / 08 / 2015$ \\
\hline $\begin{array}{l}\text { 6- } \\
\text { Connexions }\end{array}$ & 26.826 & $\begin{array}{l}\text { Desconocido. } \\
\text { Visitas: } 2.000 .000 \\
\text { (por mes) }\end{array}$ & $\begin{array}{l}\text { No hay. Existen } \\
\text { grupos a los que } \\
\text { puedes ser invitado o } \\
\text { invitar. }\end{array}$ & 08/08/15 \\
\hline 7- Share.TEC & $\begin{array}{l}71628 \text { (todos de } \\
\text { Formación Profeso- } \\
\text { rado) }\end{array}$ & 1.691 & $69^{194}$ & $12 / 08 / 15$ \\
\hline
\end{tabular}

192 Comunidades por áreas temáticas. Entre ellas, encontramos la comunidad de Formadores de profesores: http://teachereducation.merlot.org/teach.html. Además, existen 7 comunidades de apoyo académico y 39 comunidades de entidades asociadas con Merlot. 193632 contenidos digitales son específicos para la formación del profesorado, y puede accederse a ellos mediante el siguiente enlace: http://doer.col.org/handle/123456789/1648. La página ha cambiado la ubicación de los contenidos digitales desde que iniciamos la investigación hasta el momento actual.

194 La mayoría de estas comunidades no están activas, y fueron creadas para realizar pruebas en el portal. 


\begin{tabular}{|c|c|c|c|c|}
\hline & $\begin{array}{l}\text { Número de conteni- } \\
\text { dos }\end{array}$ & $\begin{array}{l}\text { Número de } \\
\text { miembros }\end{array}$ & $\begin{array}{l}\text { Número de } \\
\text { comunidades }\end{array}$ & $\begin{array}{l}\text { Último } \\
\text { Acceso }\end{array}$ \\
\hline $\begin{array}{l}\text { 8- PBS Lear- } \\
\text { ning }\end{array}$ & $\begin{array}{l}87.000 \text { ( } 2.263 \text { For- } \\
\text { mación Profesorado) }\end{array}$ & 1.500 .000 & $\begin{array}{l}\text { No hay (sólo clases } \\
\text { virtuales alum- } \\
\text { nos/profesores) }\end{array}$ & $07 / 08 / 15$ \\
\hline 9 - Open & 35.500 (más de 8,600 & No hay & No hay & \\
\hline Learn & $\begin{array}{l}\text { de formación del } \\
\text { profesorado) }\end{array}$ & & & $08 / 08 / 15$ \\
\hline $\begin{array}{l}10 \text { - Teacher } \\
\text { Tube }\end{array}$ & $\begin{array}{l}\text { +de } 400.000 \text { ( } 11.882 \\
\text { desarrollo profesional) }\end{array}$ & 1.500 .000 & $\begin{array}{l}3.840 \text { ( } 27 \text { de desa- } \\
\text { rrollo profesional) }\end{array}$ & 09/08/15 \\
\hline $\begin{array}{l}11 \text {-OER } \\
\text { Commons }\end{array}$ & $\begin{array}{l}78574 \text { (12632 of } \\
\text { "Education") }\end{array}$ & $\begin{array}{l}\text { 35.000 Fuente: } \\
\text { (Campbell, 2014) }\end{array}$ & 274 y 10 hubs. & $22 / 08 / 2015$ \\
\hline $\begin{array}{l}12 \text { - } \\
\text { Tiching.com }\end{array}$ & $\begin{array}{l}456106 \text { ( } 2756 \text { para la } \\
\text { formación del profeso- } \\
\text { rado). }\end{array}$ & 629634 & $\begin{array}{l}32 \text { grupos de docen- } \\
\text { tes }\end{array}$ & $06 / 08 / 2015$ \\
\hline 13 - Agrega & $91,477^{195}$ & $\begin{array}{l}\text { Se requiere de } \\
\text { privilegios para } \\
\text { poder acceder }\end{array}$ & $\begin{array}{l}\text { Se requiere de privi- } \\
\text { legios para poder } \\
\text { acceder }\end{array}$ & $23 / 08 / 2015$ \\
\hline $\begin{array}{l}14 \text {-WikiEdu- } \\
\text { cator }\end{array}$ & $\begin{array}{l}32.097 \text { (incluye recur- } \\
\text { sos para la formación } \\
\text { del profesorado no } \\
\text { listados) }\end{array}$ & $\begin{array}{l}1372 \text { miembros en } \\
\text { un grupo de Google } \\
\text { de WikiEducator. }\end{array}$ & $\begin{array}{l}14 \text { redes por áreas de } \\
\text { interés; } 9 \text { grupos de } \\
\text { trabajo }\end{array}$ & $11 / 08 / 15$ \\
\hline 15 - MERLÍ & $\begin{array}{l}64091 \text { (incluye recur- } \\
\text { sos para formación del } \\
\text { profesorado sin cata- } \\
\text { logar por esta catego- } \\
\text { ría) }\end{array}$ & $\begin{array}{l}\text { Se requiere de } \\
\text { privilegios para } \\
\text { poder acceder }\end{array}$ & $\begin{array}{l}\text { Se requiere de privi- } \\
\text { legios para poder } \\
\text { acceder }\end{array}$ & $15 / 08 / 2015$ \\
\hline
\end{tabular}

A continuación mostramos la interpretación de los datos contenidos en esta Tabla 59 de forma más pormenorizada en los siguientes apartados:

\section{A) Número de contenidos digitales en general y específicos para la formación del profesorado}

Tiching.com y TeacherTube son los portales que más contenidos integran, destacando de forma notable sobre el resto de portales (Tiching.com incluye 456106 recursos, de entre ellos, 2756 relativos a la formación del profesorado; TeacherTube contiene 400.000 materiales y 11882 específicos para el desarrollo profesional).

195 La página incluye un apartado con estadísticas de uso del portal: http://agrega.educacion.es/visualizadorcontenidos2/EstadisticasPortada/EstadisticasPortada. do. Es un hecho destacable que los términos de búsqueda más frecuentes son: "necesidades", "educativas", "apoyo", "animal", "dicotiledóneo"; estas palabras nos sugieren que entre los recursos más buscados se encuentran los recursos para personas con necesidades de apoyo educativo. 
Los siguientes portales más poblados son Merlí, con 100.000 recursos y Agrega, con 93.369, seguidos de cerca por PBS Learning, Tiching.com y Share.TEC, con $87.000,80.968$ y 71.628 recursos educativos, respectivamente).

El resto cuentan con entre más de 20.000 recursos y más de 60.000 (Merlot, Connexions, OER Commons y WikiEducator).

Los portales Internet en el Aula, Education World y COL no tienen listados los recursos ni una forma fácil de realizar una estimación de ellos, pero integran más de 1000 recursos para la formación del profesorado, como comprobamos tras exploración de los portales que se ajustaban a los criterios de selección).

MIT OCW recopila 2000 cursos; para todos ellos integran contenidos útiles para la formación del profesorado, aunque en algunos casos no existan categorías para describirlos).

Podemos visualizar con facilidad estos datos en el Gráfico 20, donde se representa el número total de recursos en las barras, y el porcentaje de los recursos para la formación del profesorado en los círculos. Dado que no disponemos de la información completa de todos los portales (pues a pesar de que existan recursos válidos para la formación del profesorado, no están etiquetados como tal), sólo hemos recogido aquellos portales en los que conocemos el número concreto de contenidos para la formación del profesorado, o una aproximación. 
Gráfico 20 Contenidos totales vs. contenidos para la formación del profesorado

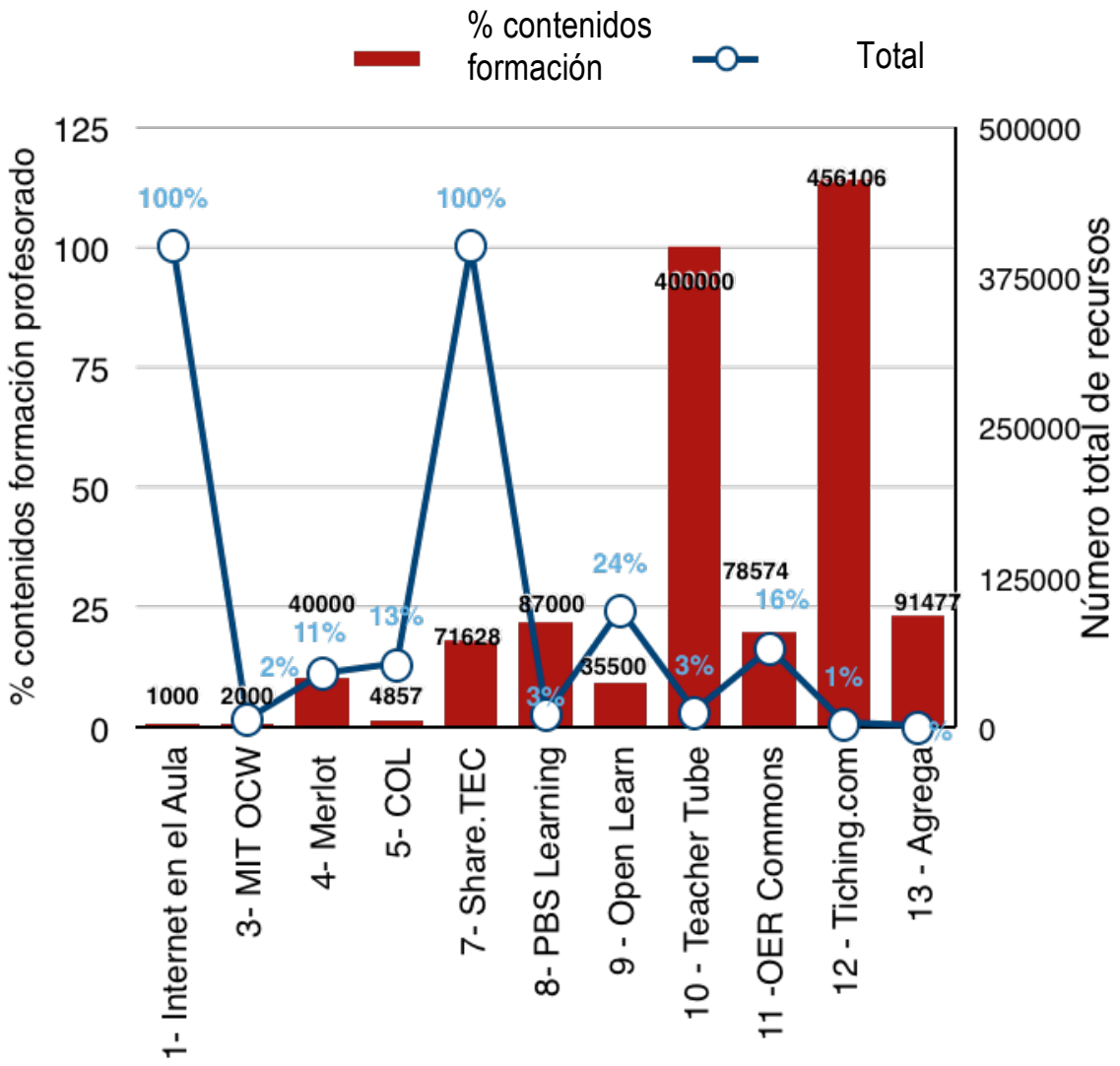

En porcentaje, los portales destinados de forma más especifica a la formación del profesorado son Share.TEC (el 100\% de sus contenidos es para este fin) e Internet en el aula (los contenidos que están destinados para diferentes áreas y niveles educativos, pero pueden servir para formar a los profesores, algunos específicamente y otros como ejemplificación de materiales) (véase Gráfico 20).

Tras estos portales, Open Learn incluye un $24 \%$ de materiales que sirven para la formación del profesorado, OER Commons un $16 \%$ y Merlot un 11\%; el resto de portales contiene menos de un $10 \%$ de materiales destinados a la formación del profesorado. TeacherTube y Tiching, los portales que más recursos integran en 
total, sólo presentan un 3\% (11882 recursos) y un 1\% (2756 recursos) destinados a la formación del profesorado, respectivamente; a pesar de ser pequeños porcentajes del número total de contenidos, siguen constituyendo una cantidad elevada. Recordemos que estos datos son estimaciones porque el etiquetado de los contenidos digitales no explicita que sean recursos "para la formación del profesorado" en muchos casos.

\section{B) Número de miembros}

En la Tabla 59 recopilábamos los datos relativos al número de comunidades y miembros de los portales analizado; en el Gráfico 21 representamos visualmente el número de usuarios en rojo, y el número de comunidades en azul.

Las comunidades que destacan por su número de miembros son: Connexions (2.000.000 de usuarios registrados); PBS Learning (que no dispone de comunidades); y TeacherTube (ambas con 1.500.000 usuarios registrados).

Estos están seguidos por: Tiching.com (que en los últimos 4 años ha incrementado de unos 10.000 usuarios a 629634, gracias a su expansión desde España a Latinoamérica); Merlot, con 105.001 usuarios; OER Commons (con más de 30.000), Internet en el aula (con 14991), WikiEducator (con 1372 miembros en Google Groups, aunque en las subcomunidades existen muchos más miembros sin listar); y Share.TEC (con 169 usuarios registrados).

En el caso de estos portales: [5] COL, [13] Agrega y [15] Merlí, desconocemos la información sobre el número de usuarios registrados.

Los portales [2] Education World, [3] MIT OCW, actualmente no incluyen comunidades. 
Gráfico 21 Número de comunidades y usuarios registrados en los portales analizados

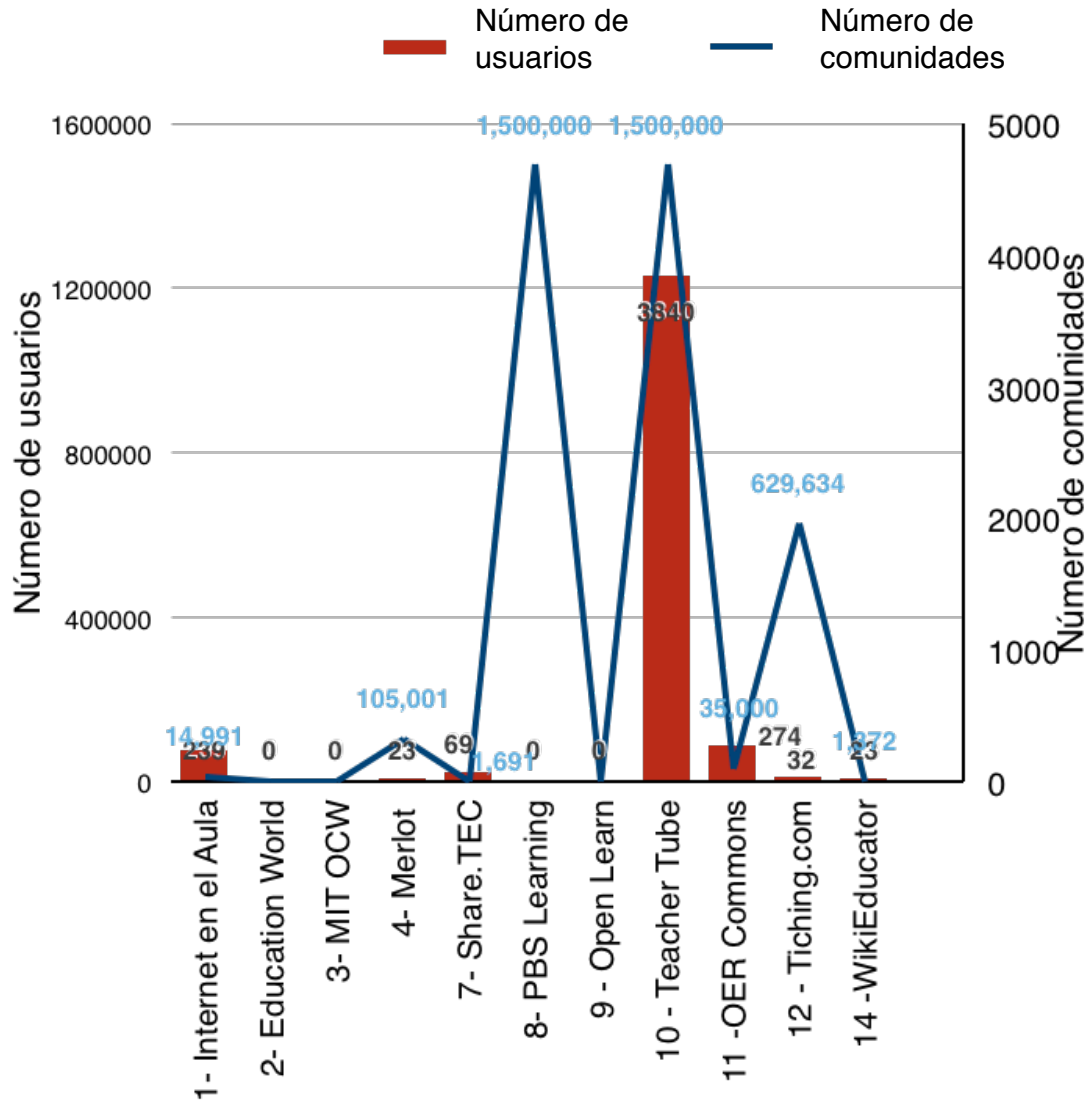

C) Número de comunidades

En cuanto al número de comunidades de los portales, destaca TeacherTube (véase la línea azul del Gráfico 21), que integra 3.840 grupos; seguido por OER 
Commons, que cuenta con 274 grupos; Internet en el Aula (donde encontramos 239 grupos, con mayor o menor nivel de actividad $\left.{ }^{196}\right)$.

Share.TEC dispone de 69 grupos, aunque no son activos (no hay interacción en ellos); en Merlot encontramos 23 grupos separados por áreas temáticas, que cuentan con responsables que gestionan los grupos; y en WikiEducator encontramos 23 redes por áreas de interés, donde los usuarios pueden colaborar.

Los portales [2] Education World, [3] MIT OCW, [5] COL, [8] PBS Learning, [9] Open Learn, [13], Agrega y [15] Merlí, no disponen de comunidades en el propio portal.

En cuanto al portal [6] Connexions, no disponemos de una forma de acceder al número de comunidades existentes, puesto que existen grupos públicos y privados no listados. Los grupos públicos no sirven para interaccionar con otros, si no para seleccionar contenido de calidad.

En el Gráfico 21 ilustramos de forma sintetizada esta información. En las barras se muestra el número de comunidades de las que dispone el portal, y en la línea azul el número de personas registradas en el servicio.

Entre los portales incorporados en el estudio, vemos que TeacherTube destaca por su alto número de contenidos en general, su número de comunidades y el número de usuarios registrados en el servicio.

Apoyándonos en el Gráfico 21, consideramos que existen portales con diferentes fines, y los usuarios eligen tanto unos como otros en función de los beneficios que pueden encontrar en ellos (es decir, en algunos portales el valor añadido será la comunidad y en otros, la buena organización y cantidad de los recursos). De este modo encontramos portales que disponen de un gran número de usuarios registrados en ellos, y que no disponen de comunidad (como es el caso de PBS Learning), y otros que ofertan la adhesión a numerosas comunidades existentes y la generación de nuevas (como es el caso de TeacherTube), que también consiguen la participación de numerosos usuarios).

196 Nos referimos con "nivel de actividad" al número de entradas, las fechas entre entrada y entrada, el número de interacciones, etc. 
En el siguiente Gráfico 22 mostramos una representación visual sencilla que nos permite ver el número de comunidades existentes por cada 100 usuarios (de los portales explorados en este estudio). Share.TEC es, con diferencia, el portal con más comunidades por cada 100 usuarios, seguido por WikiEducator, Internet en el Aula, OER Commons, TeacherTube, Merlot y Tiching.com. Creemos conveniente destacar que el hecho de que un portal tenga un mayor número de comunidades no implica que la actividad sea más prolífica o haya más interacciones entre los usuarios. A pesar de no disponer da datos estadísticos de actividad en las comunidades de los portales, a través de nuestra observación en los diferentes portales hemos percibido que portales con un menor número de comunidades, como Tiching.com (32 comunidades), presenta usuarios muy activos y una elevada interacción en algunas comunidades. En cambio, Share.TEC, aunque presenta un número elevado de comunidades/grupos, no dispone de actividad en ellos. A su vez, de acuerdo con lo comentado en el capítulo 4 de esta tesis, muchas de las comunidades existentes fueron creadas ad hoc en las pruebas piloto del portal.

Gráfico 22 Número de comunidades de los portales analizados por cada 100 usuarios

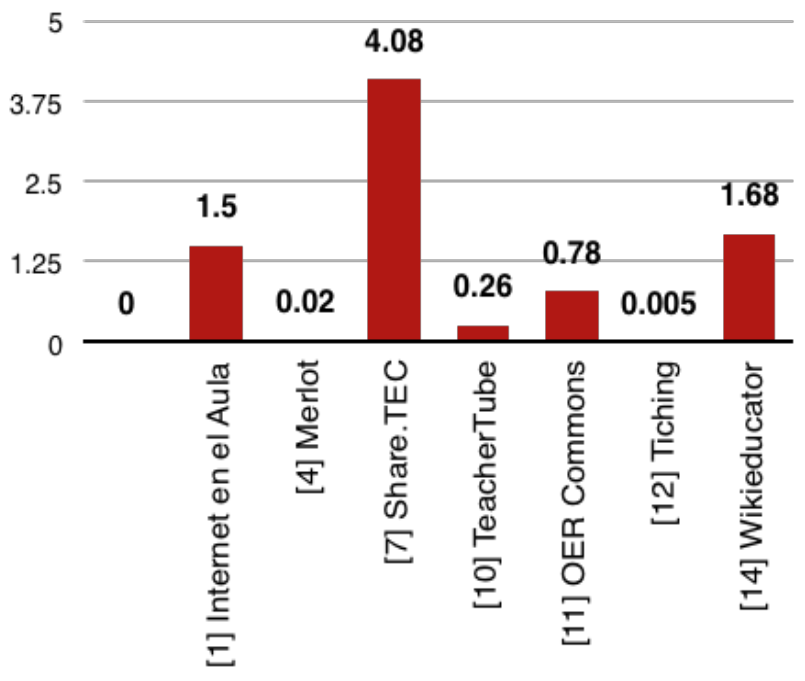




\subsection{4. ¿Cómo se organizan los grupos en los diferentes portales?}

Las estrategias que adoptan los portales analizados para la organización de los grupos son las siguientes:

- Por temáticas curriculares, con sub-comunidades por área [1], [2], [4].

- Grupos por temáticas curriculares y didácticas, sin sub-comunidades [12].

- Grupos autogestionados por áreas de interés [1], [7], [10], [11], [14] o grupos de trabajo/clases [6], [8], [10], [11].

- Grupos predefinidos gestionados por los administradores del portal [4].

- Grupos de trabajo por áreas en torno a temáticas de Recursos Educativos Abiertos [14].

- Redirección a Grupos de Google para la discusión sobre determinadas temáticas [14].

- Creación libre de grupos [6] ${ }^{197}$, [7], [8], [11].

- Grupos públicos o Grupos privados [1], [2], [7], [8], [10], [11].

- Grupos públicos [12].

- Generar grupos privados (no públicos) [6].

Comprobamos que la mayoría de los portales estudiados permiten la generación de grupos autogestionados (es decir, la creación libre de grupos por temáticas de interés de los usuarios) (5 portales), o espacios de colaboración entre otros profesionales 0 un grupo de alumnos (4 portales). En cambio, sólo 1 portal tiene grupos predefinidos no modificables por los usuarios (Merlot). Otra forma de organización de los grupos es por áreas curriculares (3 portales).

En cuanto a la privacidad, se dota al usuario de la posibilidad de controlar los permisos de adhesión a los grupos que genera (con carácter público o privado - 6 portales); y sólo un portal permite generar exclusivamente grupos públicos (Tiching.com).

${ }^{197}$ El portal Connexions permite generar tus propios grupos de trabajo, e invitar a personas registradas en el portal a que se vinculen a ellos. En cambio, no oferta la interacción entre los usuarios en los grupos. 


\subsection{5. ¿Cómo se establecen las redes y se mantiene a los usuarios en las redes?}

Además de las estrategias de contacto con otros profesionales recogidas en el apartado 2.2.7 (contacto con otros profesionales), los portales que permiten la creación/existencia de redes, lo hacen mediante:

- Solicitud de membresía al creador del grupo [1], [7], [10], [14], [4] ${ }^{198}$.

- Inscripción directa al grupo [1], [7], [10], [11], [14], [4].

- Adhesión a retos educativos planteados por los responsables del portal [11].

- Unión a debates [9].

- Creación de grupos [1], [6], [7], [10], [11].

- Apartado específico de solicitud/aportación de ayuda e ideas de otros usuarios relativa a aspectos educativos [1].

\subsubsection{Mantenimiento de los usuarios}

Entre los métodos que emplean los portales para lograr que los usuarios se involucren de forma activa en los portales y acudan a ellos de forma recurrente hemos encontrado las siguientes:

- Mantenimiento de redes gestionado por la propia comunidad [1].

- Por la calidad de los recursos del portal [3], [5], [6], [9], [10], [11], [13], [15].

- Aval de calidad: departamento/ministerio de educación [13], [15], institución educativa de gran calidad, e.g., MIT [3], [4] Commonwealth of Learning [5], instituciones relevantes [6], servicio de su tipo más utilizado de su país [8], empresas relevantes, e.g., Microsoft, USA Today, Yahoo, Enciclopedia Britannica, MSN [2].

198 El portal 4 fue analizado en profundidad antes del 11 de abril de 2014 por última vez. En esta fecha, el portal cerró sus servicios anteriores trasladando el contenido a la nueva página en la que se eliminaron la mayoría de los servicios de "comunidades". Actualmente únicamente se permite la interacción entre los miembros en el propio portal. Recopila la información directamente del navegador, detectando automáticamente tu conexión de Facebook, y te permite realizar comentarios con tu propio perfil de Facebook. En este análisis incorporamos los servicios que incluía anteriormente como estrategias que podemos considerar a la hora de generar servicios para la interacción social entre usuarios. 
- Envío de e-mails de notificaciones de la interacción de otros usuarios con tus recursos [11].

- Contacto con comunidades por áreas de interés [2], [10], [14].

- Suscripción RSS a las novedades del portal [4], [5], [6], [10], [14].

- Formación en seminarios/webinarios u otro tipo de formatos que se oferta en el portal [1], [11], [14].

- Oferta de Badges/Insignias [4], [9].

- Oferta de cursos/seminarios gratuitos [14].

- Feedback cuando otros usuarios acceden a tu contenido [11].

- Oferta de OERs [3].

- Interconexión con otros espacios: ver últimos tweets sobre OER Commons [6].

\subsubsection{Contacto con otros profesionales}

Hemos dividido las estrategias que utilizan los portales analizados para contactar con otros profesionales en su plataforma en cuatro categorías:

Estrategias de contacto mediante mensajes, comentarios, foros, etc.

- Envío de mensajes privados dentro del sistema [1], [12].

- Mediante correo electrónico [5], [6].

- Contacto con los creadores del recurso, mediante:

- Mensaje privado [2], [4].

○ e-mail [4], [5], [6].

- Comentarios [2], [4], [7], [10], [11], [12], [1].

- Contacto a través de un blog de la página [5].

- Envío de correo electrónico desde la plataforma [6].

Estrategias de visualización de información de usuarios:

- Generación de un blog automático que registra la interacción del usuario con el portal, y además le permite compartir contenido de forma manual. Los demás usuarios pueden visualizar este contenido [1].

- Visualizar los grupos de otros usuarios [1], [2], [7], [4], [10], [12]

- Visualizar los miembros que pertenecen a una comunidad [1], [10], [12].

- Visualización de información de otros usuarios cuando accedes a un contenido generado por ellos:

O Nombre [1], [2], [12], [4], [7], [10], [12]

- Localización [1], [2], [12], [4]. 
- Áreas de interés [12], [4].

- Fecha de nacimiento con avisos para felicitar en los cumpleaños [1].

- Recursos creados/vistos por otros [2], [12].

- Recursos compartidos por otros [1], [2], [4], [6], [12], [10].

- Cursos y clases creadas por el usuario [12].

- Recursos creados por otros usuarios [10].

Estrategias de contacto con los usuarios mediante estrategias de redes:

- Solicitudes de amistad con los miembros de la comunidad [1], [2], [12].

- Creación de eventos [1].

- Buscador de personas de la red (nombre, ubicación, rol, grupos, recursos creados, red de amigos, etc.) [1], [2].

- Suscripción a usuarios [10].

- Creación de redes de favoritos [12]

- Listas de correo [14].

- Visualización del rol de los usuarios [2].

- Visualización de los usuarios más activos [12]

- Docentes sugeridos [10]

Estrategias de contacto con los administradores para mejorar el portal o el contenido:

- Contacto con los administradores para proporcionar feedback sobre los recursos o el propio portal [1], [3] (ideas de mejora, contenido inapropiado, contenido etiquetado incorrectamente, etc.).

Los portales MIT OCW [3], PBS Learning [8], Agrega [13] y Merlí [15], no ofrecen herramientas de interacción con los usuarios en el propio portal. Son portales pensados para recuperar y compartir contenido y no para establecer comunidad en torno a ellos.

En cuanto a la cantidad de funcionalidades sociales, dentro de las detectadas, los portales que más herramientas integran para la interacción con otros usuarios son: la red social Internet en el Aula (integra 14 de las características descritas con anterioridad), Tiching.com [12] (7 características); la antigua versión de Education World (10 características) y Merlot [4] (9 características).

El procedimiento más repetido entre los diferentes portales es la de contactar con otros profesionales desde el recurso, comentándolo (7 portales contemplan esta 
característica); seguido por la posibilidad de visualizar el nombre de los usuarios de la red (6 portales) y los recursos compartidos por otros usuarios ( 6 portales).

Cada portal sigue sus propias técnicas. En general, apreciamos que pocos portales permiten visualizar el e-mail de los usuarios, con el objetivo de evitar el robo de direcciones por servicios no deseados y garantizar la seguridad de las páginas.

Una de las prácticas, presente en 3 portales, consiste en la posibilidad de generar subcomunidades personalizadas (mediante la solicitud de amistad con otros profesionales del portal).

Todas las estrategias son positivas ya que facilitan la interacción con otros profesionales y la posibilidad de conocer a personas que trabajan en áreas similares (permitiendo que los usuarios compartan contenidos y conocimiento en ellas, e incluso establezcan contactos profesionales).

\section{Conclusiones del Estudio 2}

Los portales sobre los que profundizamos en este capítulo cumplen diferentes funciones atendiendo a los propósitos de los mismos (red social o comunidad, repositorio, referatorio, sistema de gestión de contenidos y/o wiki). Este cariz determina la orientación y la densidad de las funcionalidades que ofrecen. Es decir, cuando tenemos un espacio eminentemente social para compartir contenido (e.g., Internet en el aula) encontraremos un mayor número de funcionalidades sociales que herramientas centradas en categorizar el contenido; en otros casos encontramos espacios más completos que centran su atención en diversos aspectos simultáneamente: catalogar contenidos, crear comunidades, establecer contacto con otros usuarios, etc.). A la hora de diseñar un portal, es primordial pensar en la orientación y objetivos que fundamentan sus bases, y a partir de esos principios, considerar cuáles son las funcionalidades que han de integrarse pensando en sus usuarios objetivo.

Entre los portales que hemos contemplado encontramos contenidos gratuitos en todos ellos (ya que era un criterio de selección de nuestra muestra), y también contenido de pago en algunos de ellos. Entre los contenidos gratuitos, encontramos Recursos Educativos Abiertos con diversas licencias de copyleft (entre las que se encuentran las licencias Creative Commons). Hemos hallado que en estos portales es difícil realizar una búsqueda rápida de los contenidos filtrándolos por el tipo de licencia con la que han sido creados, o resulta muy complejo encontrar esta 
información. Este hecho puede dificultar la reutilización del contenido digital por desconocimiento de los derechos de uso del recurso, pues muchos profesores evitan compartirlos en sus páginas webs por temor a posibles infracciones de copyright (I. De Vries, 2013; Downes, 2007).

Los contenidos digitales destinados a las áreas de la Enseñanza Infantil, Primaria y Secundaria (Infantil, Primaria, Secundaria) tanto de España como de otros países (e.g., Estados Unidos), se encuentran estructurados por áreas curriculares y contenidos mínimos (España) o estándares mínimos (EE.UU.), hecho que facilita la catalogación y recuperación del contenido digital. En cambio, en los niveles de educación postobligatoria es más complejo encontrar estructuras pedagógicas compartidas por los usuarios (como es el caso de los programas de formación de Maestros o profesores de Secundaria, donde cada universidad decide el plan de estudios para cada grado o máster). De este modo se hace necesario generar estructuras compresibles por la comunidad que utiliza los recursos, bien a través de la creación de folksonomías (mediante el etiquetado de los contenidos digitales por los propios usuarios), o mediante estructuras consensuadas entre usuarios de diferentes contextos (mediante la investigación de las necesidades y nomenclaturas que emplean los usuarios de la comunidad que vaya a utilizar el portal).

La mitad de los portales permiten realizar búsquedas por competencias 0 habilidades. Los modelos educativos europeos e internacionales tienden a valorar la importancia de la adquisición de éstas para dotar a las personas de las estrategias necesarias para adaptarse a las dinámicas y cambiantes exigencias sociales y laborales, como ocurre en el ámbito de la formación del profesorado (Bozu \& Canto Herrera, 2009; European Commission, 2010a, 2013e, 2013f; Rodríguez Rosell et al., 2013; Ruíz Requies, 2009).

La mayoría de los portales analizados se basan en ontologías y estándares de metadatos (e.g., aplicaciones de IEEE LOM O DC), e integran estrategias de interoperabilidad (e.g., formatos RDF, LRMI). Este tipo de estrategias son necesarias para facilitar la recuperación automática de contenido por las máquinas mediante la "Web semántica", por lo que consideramos que los portales que integran contenido educativo han de considerarlas (Alvino, Bocconi, et al., 2009; Ferran Ferrer \& Minguillón Alfonso, 2011; Minguillón et al., 2011; Yalcinalp \& Emiroglu, 2012).

Los espacios web investigados ofrecen diferentes estrategias de búsqueda: mediante exploración, búsqueda simple y búsqueda avanzada, cada una de ellas 
con diversas funcionalidades asociadas. A la hora de diseñar un portal educativo de contenido digital, consideramos de especial relevancia, atendiendo a los fines del mismo, realizar una combinación de diferentes estrategias que permitan a los usuarios encontrar los recursos más próximos a sus demandas (e.g., sugerir palabras mientras escribes en el portal, poder aplicar diversos filtrados en la búsqueda para poder refinarlas, permitir la búsqueda de los recursos encontrados en el propio portal e incluso integrar motores de búsqueda externos si se considera oportuno, etc.).

Existen prácticas comunes entre los portales sobre los que profundizamos en este estudio para organizar visualmente el contenido, como son presentar portales con interfaces limpias y sencillas, con fondos blancos, tipologías claras y colores que facilitan la legibilidad del contenido, etc. Este tipo de aspectos y otros relacionadas con la navegabilidad de los portales, muestran que estos han sido diseñados atendiendo a las recomendaciones de usabilidad de ISO/TR 16982:2002 (ISO, 2002), las diferentes partes del estándar ISO 9241 (ISO, 2015) y otras normas y estándares internacionales que pueden encontrarse en UsabilityNet (2006).

La inclusión de datos estadísticos (como el número total de recursos, número de páginas, recursos que integran las palabras que vamos escribiendo en el cajetín de búsqueda simple, número de votos y puntuaciones de recursos), permiten que los usuarios generen una idea del tipo de contenido que se les presenta. Esta información permite a los usuarios poder realizar una rápida evaluación de los recursos (e.g., si un recurso ha sido puntuado por 100 usuarios y la puntuación es de $4 / 5$, podríamos considerar que el recurso es evaluado positivamente por la comunidad y este dato determinaría nuestra deseabilidad de utilizar o no el mismo).

Resulta complejo en la mayoría de los portales conocer el número de recursos destinados específicamente a la formación del profesorado, pues en pocas ocasiones aparecen etiquetados como tal. Además, existen recursos en otras categorías (e.g., desarrollo profesional) que son igualmente válidos para la formación del profesorado, pero no disponen de esta información en sus metadatos. Este hecho nos hace pensar en la necesidad de ampliar las etiquetas predefinidas de los contenidos digitales con etiquetado social, pues como vimos en Share.TEC, un mismo recurso organizado con diferentes estrategias didácticas y objetivos, puede servir para varios niveles educativos (e.g., un recurso de educación primaria como una WebQuest, puede servir como ilustración de cómo se realiza y organiza una WebQuest, en este caso, para un estudiante de grado universitario de educación primaria). 
Es muy importante que los portales organicen de forma adecuada las estadísticas del sitio, que permitan a los usuarios hacerse una idea de la calidad del contenido, del número de usuarios activos, número de visitas que recibe el portal, número de contenidos de cada categoría, estadísticas de la evolución de los datos del sitio, etc. Estos datos permiten publicitar a los portales sus propios sitios, en caso de que incluyan estadísticas favorables, o incluso ser conscientes de los números desfavorables y tomar medidas al respecto (incorporando estrategias para involucrar a más usuarios, mejorar la cantidad de los contenidos, ofrecer soluciones pedagógicas que otros portales no ofrecen, etc.). En este sentido, sería apropiado que los usuarios pudieran acceder a los datos estadísticos de los portales para poder ver las comunidades más activas, los usuarios más activos, las últimas fechas de actividad en los grupos, etc., de forma que los usuarios conocieran cuáles son los temas más activos y de preocupación en la comunidad. Así, consideramos que los portales educativos podrían verse beneficiados por la tendencia actual del análisis automático de los datos ${ }^{199}$, de forma que puedan inferirse conclusiones sobre el uso de los portales educativos para mejorar los servicios ofertados (y la formación del profesorado, en nuestro caso).

Hemos podido comprobar cómo los portales de este estudio han ido evolucionando durante los últimos tres años, desde el inicio de su análisis hasta el momento actual. Los buscadores, interfaz y funcionalidades presentes en ellos, han ido mejorando a medida que los desarrolladores de los portales han incorporado nuevas estrategias tecnológicas (como por ejemplo, Tiching.com, que ha ido incorporando funcionalidades sociales, comunidades, etc., que anteriormente no existían).

El número de recursos educativos crece exponencialmente en los portales educativos (Cechinel, Camargo, Sánchez-Alonso, \& Sicilia, 2014), por lo que resulta compleja la tarea de encontrar resultados relevantes ajustados a las necesidades de los usuarios (Bienkowski \& Klo, 2014). Para mejorar la eficiencia de los portales educativos, estos han de tender a la inclusión de opciones que permitan una mayor adaptación a cada usuario. Este es el caso de los sistemas automáticos de recomendación. Estos sistemas utilizan tecnologías que permiten personalizar el

199 Data analytics o análisis de datos, es la ciencia de examinar datos en bruto con el propósito de iluminar conclusiones a través de esta información (Rouse, 2015). Este área actualmente se encuentra en expansión y mejora, como puede apreciarse a través de la oferta de numerosos cursos y trabajos de data analytics. 
contenido o modifican la configuración de las funcionalidades del portal atendiendo a: los parámetros definidos por el usuario en el perfil; el análisis de los metadatos sociales (Bienkowski \& Klo, 2014); la evaluación automática de los metadatos de los recursos educativos; la valoración numérica que realizan los usuarios (Cechinel et al., 2014); la evaluación automática de los comentarios de los usuarios sobre los recursos (Karampiperis, Koukourikos, \& Stoitsis, 2014), y otra serie de sistemas de recomendación (Manouselis, Drachsler, Verbert, \& Santos, 2014).

Entre los portales indagados, hemos categorizado las funcionalidades que ofrecen en cinco tipos: sociales, de personalización, relativas al contenido digital, de accesibilidad, técnicas y de sostenibilidad. No hemos detectado todas las características de cada uno de los tipos, si no aquellas que hemos considerado más relevantes y/o compartidas entre los diferentes portales. Como hemos visto en el análisis anterior, en ocasiones encontramos funcionalidades muy interesantes en los portales que tienen poca visibilidad para los usuarios que desconocen el portal 0 que únicamente utilizan las funcionalidades básicas. Consideramos que es importante que los portales muestren de forma sencilla todas las funcionalidades que permiten realizar a través de menús fijos en la parte superior o lateral de la interfaz de los portales, especialmente las relacionadas con la compartición o el etiquetado de los contenidos digitales (que permita a los usuarios enriquecer el contenido del portal de una forma sencilla e intuitiva).

Los portales que hemos analizados son financiados y/o cofinanciados por ONGs, instituciones gubernamentales, proyectos internacionales, nacionales o locales, usuarios que compran servicios, etc. Es importante que los portales educativos sean financiados por alguno de estos métodos durante el ciclo completo de vida de su existencia, pues los portales evolucionan, la tecnología avanza y las necesidades y perfil de los usuarios que acceden a los portales cambian de forma dinámica, por lo que requieren estar en constante adaptación atendiendo a todos estos factores. Además, hemos comprobado que la mayoría de los espacios web estudiados siguen diversas estrategias de control de los contenidos.

\section{Estrategias interesantes pedagógicas, sociales y técnicas adoptadas por los portales analizados}

A lo largo de este capítulo hemos encontrado algunas estrategias que consideramos muy interesantes a la hora de incluirlas en los portales para compartir 
contenido digital. Aquellas que destacamos por su originalidad y potencial educativo son las siguientes:

\section{A) Propuesta de retos educativos:}

OER Commons plantea retos educativos a los participantes del portal, con la intencionalidad de que los usuarios incrementen su motivación para crear material de calidad. A su vez, Internet en el Aula permite que las personas lancen foros en los que retan a los usuarios a compartir contenidos que cumplan determinados criterios: por ejemplo, "su contenido digital preferido", de forma que se estimula a los usuarios a que compartan sus materiales y reciban feedback de la comunidad.

B) Refuerzo social y personal para estimular la participación del usuario en la comunidad:

Las "Badges" (medallas) que utilizan Merlot, TeacherTube y Open Learn, suponen un estímulo positivo para los participantes, puesto que les permiten mostrar públicamente que han completado determinadas actividades o logros dentro de la plataforma. El usuario es capaz de ver qué tipo de acciones son aquellas que les permiten lograr medallas, por lo que hay usuarios que tratarán de cumplimentar las actividades necesarias para obtener su recompensa.

Además, como hemos visto, algunas de las plataformas analizadas, como Merlot, otorgan diferentes premios a los diferentes usuarios e instituciones que contribuyen con la comunidad (e.g., premio al uso innovador de Merlot, premio a la institución que muestre mejores formas de apoyar Merlot, premio al mejor voluntario del año, premios al mejor revisor de pares, etc.). En este caso publican un listado (accesible desde la web) con los galardonados; para tener cada premio debes alcanzar una serie de hitos, e.g., para ser galardonado con un premio de revisor has de haber revisado al menos 15 materiales en un año.

C) Grupos de contenido seleccionado por instituciones educativas o usuarios particulares:

El portal "Connexions" aporta "Lenses", que podríamos traducir como "Lentes" al castellano. Este apartado ofrece contenidos seleccionados por entidades de prestigio, por grupos o por personas, ofreciendo de esta forma material revisado por otros usuarios, y dotándole de cierta garantía de calidad.

D) Presentación del contenido priorizada por idiomas de preferencia: 
Merlot oferta un elemento interesante de accesibilidad y personalización, y es que presenta en primer lugar los materiales de tu idioma de preferencia (que puedes modificar en cualquier momento).

\section{E) Sugerencia de materiales similares:}

OpenLearn te sugiere en cada recurso encontrado otros materiales similares. Esta función permite la posibilidad de explorar contenidos relacionados con lo que estás buscando, y además, se ve facilitado por el hecho de que aparecen en la parte inferior de la interfaz de la página en la que estás consultando el recurso. Share.TEC también realiza sugerencias de contenidos relacionados con el seleccionado.

\section{F) Filtrado de búsquedas con estadísticas:}

Share.TEC te muestra el número de recursos, de personas que pertenecen al portal y de grupos que existen en el portal. Asimismo, cuando realizas filtrados, te permite conocer el número de contenidos que existen atendiendo a cada criterio. El hecho de que aparezcan estos indicadores es de utilidad al usuario, pues puede hacerse una idea del tipo de contenido y de comunidad que existe en el portal. Incluir datos es un elemento positivo para el usuario.

\section{G) Recopilación automática de contenido:}

Veíamos cómo Internet en el aula genera automáticamente un espacio para cada usuario del portal en formato "blog", donde se recogen todas las interacciones en discusiones, grupos a los que pertenece, posts que publica y comentarios que recibe, eventos que crea, amistades dentro de la red, etc., mostrando un formato de interfaz similar a la página principal de Facebook (ver lustración 32) 
Estrategias interesantes pedagógicas, sociales y técnicas adoptadas por los portales

lustración 32 Interfaz de la página personal de un usuario de Internet en el Aula

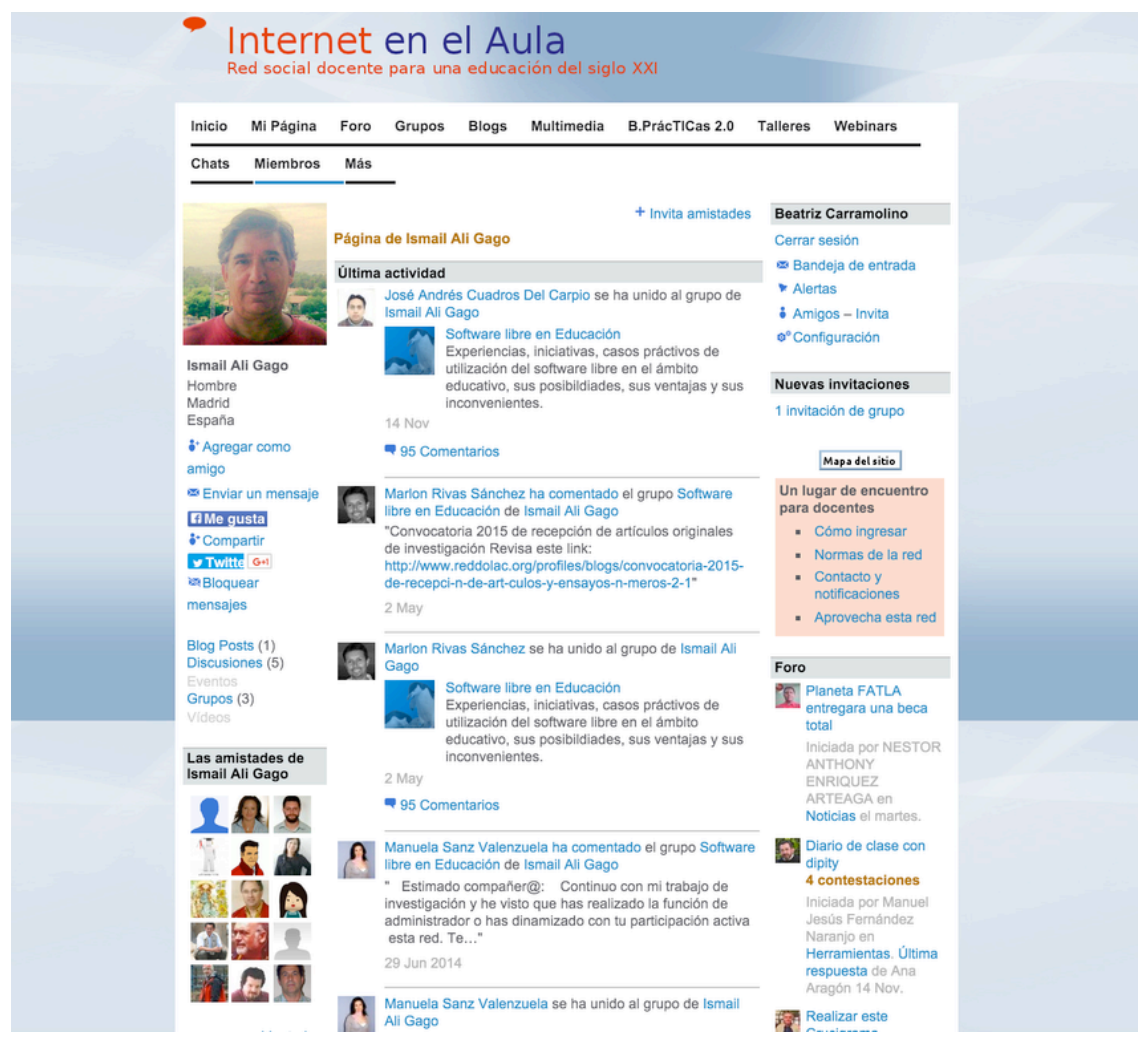

H) Oferta de diferentes niveles de servicios en función del tipo de suscripción (gratuita o de pago).

En el portal TeacherTube se ofrece la posibilidad de utilizar de forma gratuita todos los servicios que ofrece, con determinadas limitaciones, e.g., limitación de espacio para compartir archivos. Con una cuota mensual, trimestral o anual se amplían los servicios (espacio ilimitado de archivos, acceso a estadísticas avanzadas, no visualización de vídeos) a un precio asequible para los usuarios realmente interesados ( $40 \$$ anuales). La oferta de este tipo de servicios ayuda a garantizar la sostenibilidad económica del portal 
1) Widgets para integrar el portal en otros espacios web

El portal Tiching permite copiar el código .HTML de la página para dar a conocer el producto, ofreciendo cuatro servicios: 1) crear un widget para que el usuario comparta su perfil de Tiching mediante un código .HTML en cualquier página web; 2) integrar un buscador de recursos en un VLE (Moodle), Wordpress, o cualquier web o blog, copiando un código HTML o desde Moodle o Wordpress buscando la extensión; y 3) incluir un Widget con el icono y enlace de tiching.com que permite redirigir a los usuarios a este espacio. Este tipo de estrategias fomentan la eficacia de los blogs educativos y entornos virtuales de aprendizaje (pues permiten incluir la búsqueda de recursos desde el propio portal); además de aportarle una mayor visibilidad y difusión del espacio web. 


\section{Capítulo 6}

\section{Conclusiones, propuesta y trabajo Futuro}

Este capitulo constituye el resumen de las conclusiones finales al trabajo de investigación realizado. Hemos dividido el capítulo en tres secciones. En la primera de ellas unificamos las preguntas de investigación que guían esta tesis, así como las preguntas particulares de cada estudio, y explicamos cómo hemos dado respuesta a ellas. En la sección dos, expresamos las principales limitaciones de este trabajo. En la sección tres, recogemos las principales conclusiones obtenidas tras la elaboración de esta tesis doctoral y la propuesta conceptual de diseño de portales educativos, resumiendo de forma integrada las principales conclusiones de este estudio. Finalizamos el capítulo mostrando las líneas de trabajo futuro relacionadas con las conclusiones de esta tesis.

\section{Introducción}

En este capítulo intentamos compilar las principales aportaciones de este trabajo reflejando cómo hemos iluminado las preguntas de investigación que lo han guiado.

Para ello, recordamos la estructura general de investigación de la tesis, incluyendo las preguntas de investigación que han guiado este trabajo de investigación y cada uno de los dos estudios. Explicitamos cómo se ha dado respuesta a las preguntas de investigación pertenecientes a cada estudio, y qué objetivos y contribuciones se han alcanzado con cada uno de ellos.

En el segundo apartado recopilamos las limitaciones que presenta este estudio relativas al alcance, sesgos y procedimientos de la investigación.

En la tercera sección presentamos, de manera conjunta, las conclusiones de esta tesis y la propuesta conceptual para el diseño de portales educativos, basada en las evidencias que hemos obtenido en los dos estudios de este trabajo, con el fin de que sean consideradas para la creación o modificación de portales (u otro tipo de 
espacios web) destinados a la compartición de contenido digital y experiencias educativas. Esta propuesta está enfocada principalmente para el ámbito de la formación del profesorado, aunque consideramos que también podría ser útil para la generación de cualquier tipo de portal educativo que integre contenido digital. De este modo, este capítulo integra las principales aportaciones de los estudios 1 (estudio de caso Share.TEC) y 2 (análisis descriptivo y comparativo de portales para la compartición de contenido digital en el ámbito de la formación del profesorado), ya expresadas en los capítulos 4 y 5 de esta tesis, respectivamente. Estructuramos la propuesta y conclusiones congregadas en tres apartados: "recomendaciones institucionales"; "el portal educativo", y "contenido digital", donde abordamos los principales aspectos de cada una de ellas.

La parte final de este capítulo, así como de esta tesis, se centra en la discusión de futuras líneas de trabajo relacionadas con el diseño de portales para compartir contenido digital educativo y experiencias, con el fin de continuar mejorando y fomentando la compartición de estos en diferentes ámbitos educativos.

\section{Conclusiones}

\subsection{Discusión en torno a las preguntas de investigación}

En el capítulo 1 justificábamos la necesidad de esta tesis detectando que los servicios para la compartición de contenido digital y experiencias educativas específicos para la formación del profesorado eran escasos, y además, que los existentes no siempre se diseñaban atendiendo a las necesidades y preferencias de los potenciales usuarios. Para ello, nos propusimos alcanzar los objetivos generales que guían esta tesis doctoral (formulados en el apartado 3 del capítulo 3 de esta tesis). Las dos preguntas de investigación que han guiado este trabajo (véase Cuadro 4), fueron abordadas desde el paradigma pragmático de la investigación, a partir de una investigación multimétodo compuesta por dos estudios.

Nos aproximamos al conocimiento del primer estudio a través del método de estudio instrumental de caso (Stake, 1995, 2005) analizando la experiencia de creación y evaluación (por parte de sus potenciales usuarios) de un portal europeo para la compartición de contenido digital en el ámbito de la formación del profesorado, Share.TEC. 
Cuadro 4 Esquema-resumen de la tesis

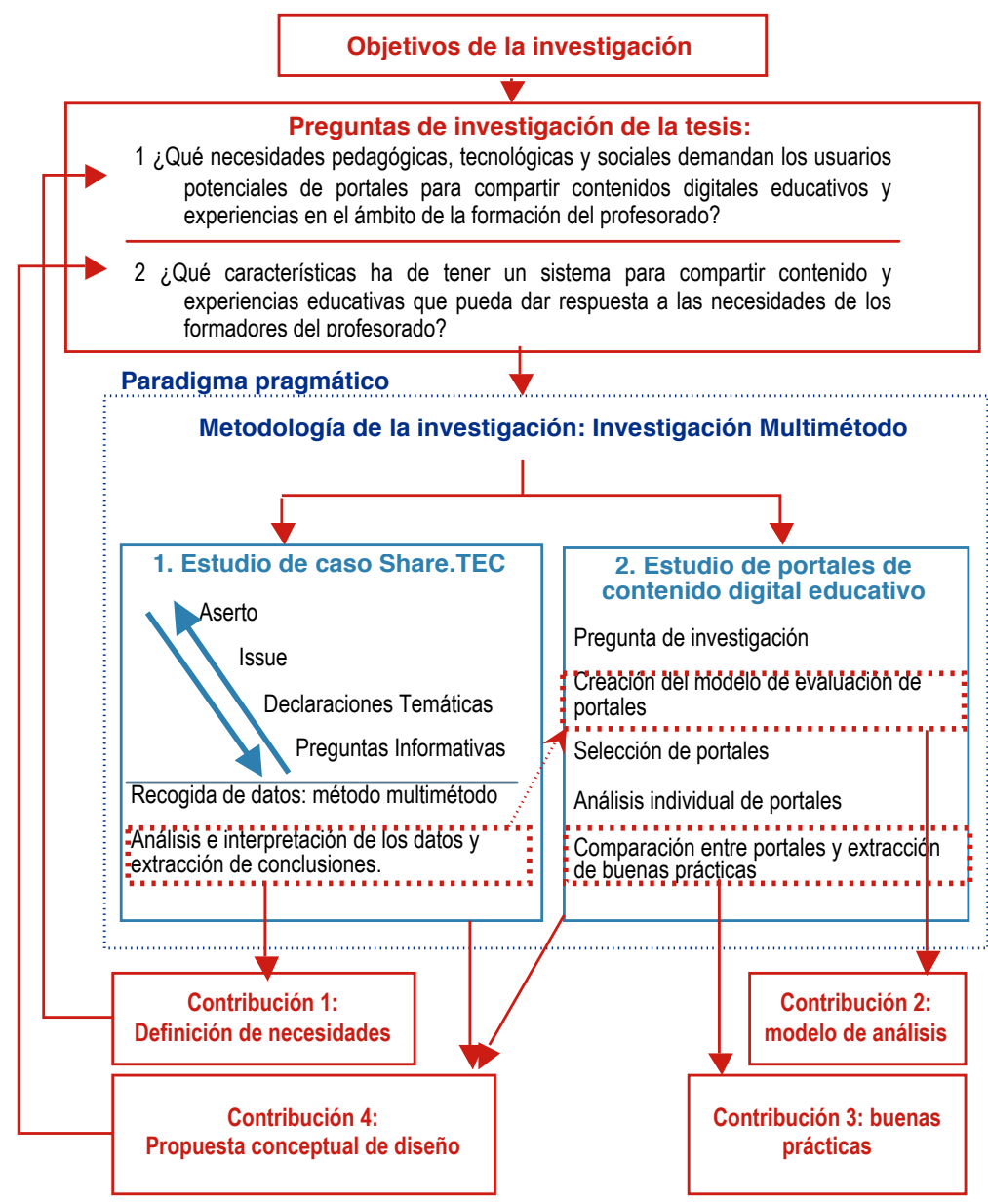

En el capítulo 3 de esta tesis doctoral establecíamos el aserto al que pretendíamos dar respuesta con el estudio de caso Share.TEC, definido en los siguientes términos:

200 Las flechas azules incorporadas en el Cuadro 4, en el recuadro central "1. Estudio de caso Share.TEC" representan el proceso de reducción anticipada de datos. 
"Consideramos que los servicios que ofrece Share.TEC a nivel tecnológico, pedagógico y social se adaptan a las necesidades requeridas por los formadores de profesores cuando acceden y publican en portales web contenido digital y experiencias educativas en el ámbito de la formación del profesorado"

Para iluminar el aserto expuesto, dentro de la estructura conceptual del estudio de caso Share.TEC, planteamos el issue o tensión del estudio de caso:

"¿Cómo se relacionan los servicios que ofrece Share.TEC a nivel pedagógico, tecnológico y social para atender las necesidades requeridas por los usuarios potenciales de los sistemas de acceso y compartición contenido digital en el ámbito de la formación del profesorado?"

Establecimos cinco declaraciones temáticas (véase la página 135) que nos permitieron conocer en profundidad los aspectos en los que nos centramos nuestra atención sobre la realidad del portal Share.TEC (mediante una serie de preguntas informativas para cada declaración). Estas fueron: "aspectos pedagógicos", "aspectos tecnológicos", "aspectos sociales", "aspectos de personalización" y "aspectos económicos"). En ellas indagamos sobre aspectos relativos tanto al portal Share.TEC, como a los hábitos y preferencias de los informantes sobre la compartición de contenido digital y experiencias educativas.

Organizamos las conclusiones del estudio de caso, recogidas en el apartado 2.4 del capítulo 4 , en torno a sus declaraciones temáticas y preguntas informativas. En ellas, se han interrelacionado los diversos aspectos planteados, iluminando, así, el issue planteado en Share.TEC. De esta manera, confirmamos el aserto establecido, matizando que:

"los servicios ofertados por el portal Share.TEC, se adaptan parcialmente a las necesidades planteadas por los formadores de profesores cuando acceden y publican contenido digital y experiencias en el ámbito de la formación del profesorado".

Aquellos aspectos que no fueron completamente satisfechos (como veíamos en el apartado 2.4 del capítulo 4) serán incorporados en la propuesta que presentamos en el apartado 2.2 del presente capítulo, donde congregamos de forma unitaria la integración de los datos de los dos estudios de esta investigación, las conclusiones principales y la propuesta conceptual de aspectos a considerar en el diseño de los portales educativos. 
El análisis e interpretación de este estudio ha satisfecho, en parte, las dos preguntas planteadas en esta tesis, debido a que:

1) Han sido detectadas necesidades tecnológicas, pedagógicas y sociales que demandan los formadores de profesores (y otros profesionales de la educación) para acceder y compartir contenido digital y experiencias educativas en el ámbito de la formación del profesorado. Este estudio tiene como resultado la "contribución 1" de esta tesis (véase en Cuadro 4).

2) La interpretación de las evidencias proporcionadas por los informantes del estudio nos han dado claves sobre ciertas características que han de poseer estos portales para dar respuesta a las necesidades de sus usuarios potenciales (proporcionando evidencias para la "contribución 4").

De este modo, el estudio contribuye a la consecución de los "objetivos A y B" de esta tesis (relacionados, respectivamente, con la detección de necesidades de uso de contenidos digitales; y con los hábitos de acceso, uso, y compartición de los profesores); y contribuye con aportaciones a la propuesta conceptual de diseño de portales de este tipo ("objetivo E") (véase el apartado 3, Objetivos, del capítulo 3), que veremos a continuación.

El estudio 2 (véase Cuadro 4), explora un conjunto de portales educativos para la compartición de contenido digital y experiencias educativas. Hemos alcanzado los objetivos particulares de esta investigación (expresados en el apartado 1.1 del capítulo 3):

- Creando el modelo de evaluación de portales educativos, basado en la conjunción de: el esquema de categorías de análisis emergido tras el análisis de los datos de Share.TEC, a través de la reducción anticipada de datos (realizada con el software NVivo) ${ }^{201}$; y las categorías que contemplaban diferentes fuentes relevantes de la literatura (relativas a repositorios digitales) (alcanzando el "objetivo a" particular de este estudio, y el "objetivo C" de esta tesis. Este modelo proporciona la "contribución 2" de nuestra investigación.

- Explorando y analizando las funcionalidades de cada portal, siguiendo nuestro modelo de análisis. De este modo hemos identificado las buenas prácticas más habituales de los portales (consiguiendo el "objetivo D" de la

201 Véase la flecha roja que relaciona el análisis de datos de Share.TEC con la "creación del esquema de categorías" del estudio 2, en Cuadro 4. 
tesis), así como aquellas que podrían mejorarse en ellos. Estos elementos han servido para proporcionar ideas conceptuales para el diseño de portales educativos (satisfaciendo el "objetivo b" particular de este estudio, y aportando contribuciones del "objetivo E" de la tesis). Así, se genera la "contribución 3" de esta tesis.

Tras el análisis e interpretación de los datos del "Estudio 2", hemos contestado la pregunta de investigación que guía este estudio (tal y como podemos apreciar en sus conclusiones, recogidas en el apartado 1 del capítulo 5):

“¿Qué buenas prácticas y prácticas mejorables pueden extraerse de una selección de portales educativos?"

Una vez reflejadas las contribuciones aportadas por cada estudio, procedemos a realizar la integración de los datos de los dos estudios, canalizada mediante la generación de las conclusiones de este estudio reflejadas en la siguiente propuesta.

\subsection{Integración global de los datos y propuesta conceptual de diseño de portales educativos.}

En las diferentes pruebas cualitativas y cuantitativas realizadas durante y tras el proyecto Share.TEC con los informantes hemos consultado la opinión de profesionales de la educación con diferentes perfiles (formadores de profesores, profesores de Educación Infantil y Primaria, profesores de Educación Secundaria, Profesores de Formación Profesional, Investigadores, Ingenieros, Psicólogos, etc.). A la luz de los datos existen muy pocas diferencias entre las preferencias sobre los aspectos técnicos, pedagógicos y sociales de los portales para la compartición de contenido digital educativo entre ellos. El único matiz destacable es que parece que los formadores de profesores son más propensos a utilizar TIC (aunque hemos de tener en cuenta que muchos de los formadores de profesores de las muestras -de juicio- tenían un perfil técnico, por su vinculación y proximidad con los miembros del consorcio del proyecto de cada país -ya que pertenecían a contextos afines a la Tecnología Educativa-). Este dato nos hace pensar que la mayoría de las propuestas que planteamos a continuación son igualmente útiles para los profesionales de los diferentes niveles del ámbito de la formación.

Organizamos la presente propuesta conceptual de consideraciones a tener en cuenta en el diseño de portales educativos en torno a cuatro apartados: recomendaciones institucionales, el portal educativo, aspectos pedagógicos y 
aspectos sociales. En cada uno de ellos reflexionamos sobre las aportaciones provenientes de los dos estudios.

Las consideraciones pedagógicas, tecnológicas y sociales que procedemos a reflejar, complementan y se sustentan en los hallazgos de otros estudios con elementos comunes, como los expuestos en el apartado 2 del capítulo 1 de esta tesis.

\subsubsection{Recomendaciones institucionales}

En el capítulo 1 de esta tesis recogimos las principales aportaciones del estudio de Kreijns et al. (2013). Los autores demostraban que existían diversas variables (a las que denominaron "distales") a tres niveles ("micronivel", "mesonivel" y "macronivel") que influían directamente sobre otras variables (a las que designaron el término "proximales") ("actitud hacia el uso de contenidos digitales", "norma subjetiva" -lo que crees que los demás esperan de ti sobre el uso de contenidos digitales educativos- y "percepción de autoeficacia").

\section{A) Recomendaciones a macronivel}

Para trabajar la motivación, mejorar la percepción de autoeficacia en el uso de las TIC, y la visión de la usabilidad y utilidad que tienen estas y los contenidos digitales en el ámbito educativo, consideramos necesario que las instituciones responsables a un "macronivel" (gobiernos nacionales, regionales y locales) generen programas y espacios que estimulen la generación, uso y compartición de contenido digital en el ámbito de la formación del profesorado. En el "Estudio 1" dimos cuenta de la baja frecuencia con las que los informantes compartían contenido digital, así como de la baja frecuencia con la que compartían estos contenidos de forma pública (véase apartado A.9 de la sección 2.3 del capítulo 4).

Por estos motivos consideramos necesario que los programas de formación de los profesionales de la educación aporten conocimientos y concienciación sobre: la importancia de los portales educativos; la relevancia de generar y compartir contenido digital, así como la creación y compartición de estos en contextos reales especialmente abordando los contenidos abiertos (OER) y sus diversas licencias-; etc. Asimismo a través de nuestra investigación hemos resaltado la relevancia de que los profesionales de la educación se vinculen e impliquen en comunidades de práctica presenciales y virtuales. Este hecho resulta fundamental si queremos ser coherentes con la sociedad actual en la que vivimos, donde los profesores que se 
están formando serán la referencia futura para las nuevas generaciones (ya que serán sus maestros y profesores), así como con las normativas europeas (en nuestro caso) de integración real y natural de las TIC en los sistemas educativos (European Commission, 2013c, 2014; European Higher Education Area, 2012b). Asimismo, es relevante abordar estos aspectos desde los diferentes cursos de desarrollo profesional ofertados a estos docentes.

La existencia de las comunidades educativas en torno a servicios de compartición de contenido digital, son el motor activador de estos espacios. Hay profesionales que tienen una mayor tendencia que otros a utilizar las TIC en educación, y las medidas europeas, nacionales y locales (al menos en España) respaldan su expansión e inmersión en los distintos ámbitos educativos. A un macronivel proponemos que los órganos e instituciones educativas internacionales, nacionales, regionales y locales generen medidas para fomentar la creación y utilización de espacios web compartidos por un número amplio de comunidades de formación del profesorado. Este tipo de medidas pueden consistir en:

1) La generación de legislación educativa que refleje la necesidad de utilizar, generar y compartir contenidos educativos con otros profesionales de la educación para mejorar las prácticas docentes, la innovación y la calidad de los materiales de enseñanza ajustados para cada contexto, coincidiendo con las ideas planteadas por Lund \& Højsholt-Poulsen (2010).

2) La generación de un portal de contenido digital centrado, principalmente, en objetos educativos abiertos (pues como explicitamos en el capítulo 1 la utilización de este tipo de contenidos impacta en los sistemas educativos de forma positiva). Sugerimos que sean organizaciones públicas, e.g., el INTEF (Instituto Nacional de Tecnologías Educativas y Formación del Profesorado) del Ministerio de Educación, Ciencia y Deporte (MECD) de España, las que mantienen estos espacios, garantizando la preservación gratuita del servicio y la sostenibilidad del sistema a lo largo del tiempo. Otra opción es la generación de estos espacios por parte de empresas privadas. En este caso, ha de considerarse la inclusión de modelos de negocio sostenibles (e.g., integrar servicios de pago, publicidad de eventos/servicios educativos, servicios adicionales de pago, etc., sin perder la integridad del portal) que garanticen unos servicios generales gratuitos. 
Cuando la base de los portales es adecuada para los formadores, consideramos posible la remodelación (o reutilización de código) de espacios existentes, como el portal "Procomún" (Red de Recursos Educativos Abiertos) ${ }^{202}$ del MECD español.

Nuestras evidencias nos demuestran que no existen grandes diferencias entre las necesidades de formadores de profesores y profesores de otros niveles educativos para compartir contenido digital y experiencias. Las mayores diferencias radican en la definición del modelo ontológico y de metadatos, adaptado para esos niveles, y consensuado por la comunidad educativa a la que va destinada.

3) La contratación de personal que diseñe y desarrolle el portal educativo (o para su adaptación), teniendo en cuenta las voces de los agentes implicados en el ciclo de vida del portal (Lund et al., 2010). El portal debería atender, entre otros, a los aspectos pedagógicos, tecnológicos y sociales, pudiendo partir de los que generamos en esta propuesta. Asimismo, para garantizar su éxito es adecuada la contratación de personas que asuman las necesidades de gestión y mediación del portal (e.g., gestor contenido, de resolución de problemas de los usuarios, de la comunidad, persona que difunda portal, etc.). Lund et al. (2010) sugieren que sean los propios usuarios los que dinamicen las comunidades, aunque es importante que exista un gestor que estimule y medie en los momentos en los que se requiera de su atención.

4) La repercusión en los planes de formación del profesorado de las distintas universidades españolas y europeas, formando a los futuros profesores en el uso de portales educativos que permitan compartir contenido y experiencia, así como sobre las características de los contenidos digitales, sus derechos de uso, dotación y conocimiento de los diferentes tipos de licencias, etc. Asimismo, es recomendable la oferta de cursos de formación continua para maestros que estimule la dinamización del portal/portales educativos y la

202 Este servicio, que se sustenta en el portal Agrega (analizado en el capitulo 5 de esta tesis), ha redefinido los diferentes servicios que proporcionaba. Por ejemplo, se han producido mejoras en la búsqueda (incorporando, entre otros, funcionalidades de etiquetado social además de los propios metadatos iniciales, servicios de web semántica para optimizar las búsquedas, y un servicio de redes social del profesorado que permite la compartición de experiencias). Este portal integra recursos educativos abiertos principalmente, para los profesores, alumnos y cualquier persona interesada en los contenidos de niveles de educación Infantil, Primaria, Secundaria y Formación Profesional; en cambio no está pensado para la formación del profesorado. 
compartición/reutilización de contenidos (e.g., ampliando la formación sobre esta temática desde el INTEF ${ }^{203}$ e instituciones regionales/locales de formación continua del profesorado a nivel español, y en las instituciones correspondientes a nivel europeo). Si los usuarios son competentes usando los contenidos digitales y la tecnología, los portales educativos tienen más predisposición a ser exitosos y utilizados, pues genera en los usuarios percepciones de confianza en sus habilidades para utilizarlos (Cheung et al., 2013; Di Paola, 2007; Kreijns et al., 2013). Hemos visto a través de la fundamentación teórica y de nuestros estudios, que existe una cultura limitada real a la hora de compartir, y muchas veces se comparte de forma privada (por lo que la comunidad educativa a niveles más generales no se beneficia de todo el material generado).

5) La generación de un portal educativo para profesionales vinculados con la formación del profesorado que funcione a dos niveles, para potenciar las ventajas de los distintos tamaños de las comunidades:

- por comunidades prácticas específicas existentes (e.g., comunidad de profesionales de Tecnologías de la Educación y la Comunicación)

- en un espacio en el que coexistan el conjunto comunidades específicas 0 usuarios independientes. Para ello, sería necesario que los usuarios pudieran personalizar el portal, eligiendo qué contenidos desean ver (idiomas, áreas, comunidades, usuarios, etc.).

\section{B) Recomendaciones a mesonivel y micronivel}

A un mesonivel, las universidades han de integrar en sus programas educativos y asignaturas, a nivel transversal, el uso de las TIC con sentido pedagógico en sus diferentes asignaturas (para amoldarse a las demandas políticas y sociales de la sociedad actual). De esta forma, potenciarán la normalización de la integración de las TIC entre su alumnado, promoviendo una mayor repercusión e innovación en las escuelas (pues consideramos que si el alumnado toma conciencia de la relevancia y ventajas de compartir experiencias y contenidos en comunidades de práctica online, serían más propensos a involucrarse activamente en este tipo de comunidades).

203 INTEF son las siglas que hacen referencia al Instituto Nacional de Tecnologías Educativas y de Formación del profesorado. Entre sus programas incorpora actuaciones para la formación del profesorado en temáticas que versan sobre Tecnología Educativa (e.g., Marco de desarrollo profesional docente y Plan de Cultura Digital en la Escuela) (MECD, 2016). 
A un micronivel, consideramos que la percepción de autoeficacia sobre el uso de las TIC por parte de los profesores podría mejorar si se les demandara formación en el uso de las TICs en educación (mediante formación continua, permitiéndoles estar actualizados en las tecnologías emergentes y las metodologías educativas y métodos para usarlas). Creemos que mediante la adopción de estas medidas los profesores ganarian seguridad y conocimiento para saber cómo integrar las TICs en su práctica docente. En este sentido, sugerimos proporcionar a los docentes formación para crear, utilizar y compartir contenido digital educativo. Del mismo modo, su actitud hacia el uso y la compartición de contenido digital sería, en términos de Kreijns et al. (2013), un factor que promovería su predisposición a integrar tecnología en sus prácticas docentes.

Atendiendo al estado actual de los portales educativos y contenidos digitales para la formación del profesorado, las políticas y visiones europeas y españolas sobre su utilización, los resultados de nuestros estudios y los hallazgos encontrados en estudios similares, ordenamos una serie de recomendaciones para diseñar/remodelar portales educativos específicos para las necesidades de profesionales del ámbito de la formación del profesorado. Estas recomendaciones están basadas en nuestra investigación, y son compatibles y complementarias a otros estudios similares sobre uso pedagógico de contenidos digitales, diseño de portales educativos, variables de éxito de los portales, etc., que veíamos en el apartado 2 del capítulo 1 de esta tesis doctoral (Cervone, 2012; Cheung et al., 2013; Di Paola, 2007; Kreijns et al., 2013; Lund \& Hojsholt-Poulsen, 2010; Warwick, 2012; Yalcinalp \& Emiroglu, 2012).

Hemos encontrado una gran coherencia entre nuestras evidencias y las recomendaciones propuestas por Lund et al. (2010) para generar portales educativos, pues a través de nuestro investigación hemos extraído recomendaciones muy similares a las que ellos realizaron. En nuestro caso, ampliamos estas propuestas y las enfocamos, especialmente, para el ámbito de la formación del profesorado.

\subsubsection{El portal educativo para la formación del profesorado}

A la hora de diseñar un portal, es primordial pensar en la orientación y objetivos que fundamentan sus bases, y partiendo de esos principios, considerar cómo se puede diseñar un portal fundamentalmente enfocado a dar respuesta a las necesidades de sus usuarios potenciales. Veamos a continuación las principales 
recomendaciones para la propuesta de diseño de portales educativos que hemos extraído de las conclusiones de nuestros dos estudios:

\section{A) Acceso al portal}

El acceso al portal educativo puede combinar, como ocurre en diversos portales de los analizados, una modalidad pública con acceso a servicios limitados, y una modalidad privada que conlleve el acceso al portal (como poder opinar, comentar, acceder a información y funcionalidades personalizadas - e.g., "mi portal", etc.). La modalidad privada, principalmente, es oportuna para preservar la seguridad de los usuarios y de la información privada que comparten.

A la luz de nuestros datos, es positivo ofrecer la posibilidad de registrarse mediante otras cuentas existentes (e.g., cuenta de Google o de Facebook, por ejemplo), entre otros motivos, para evitar el olvido de datos de acceso y evitar multiplicidad de cuentas.

Para preservar la seguridad, es útil la inclusión de CAPTCHAs que eviten la creación automática de cuentas y la propagación de SPAM dentro del portal.

\section{B) Arquitectura del portal}

En el estudio de caso Share.TEC apreciamos las dificultades que existieron para la incorporación de recomendaciones de mejora que hicieron los usuarios sobre el portal. La arquitectura se diseñó sin tener en cuenta previamente sus opiniones. Consideramos que una práctica óptima para construir/remodelar portales es presentar mock-ups del portal a los usuarios, e ir redefiniéndolos mediante ciclos de evaluación iterativos, para posteriormente generar la propuesta.

Es necesario diseñar portales flexibles y adaptables que permitan la interoperabilidad con otros sistemas (basándose en estándares) y la integración de herramientas y servicios existentes (Lund et al., 2010) (e.g., "tweets", "Hangouts", "importación de contactos de cuentas de correo", etc.) y futuros. No se trataría de "reinventar la rueda", si no de reutilizar herramientas y servicios útiles para los usuarios relacionados con el ámbito de la formación del profesorado, que pudieran ser presentadas de forma que facilitaran la cobertura de sus necesidades. Con la expresión "sistemas futuros" nos referimos a que los portales han de estar diseñados de forma que permitan la incorporación de las nuevas tecnologías que emergen a lo largo de los años (e.g., incorporar funciones que permitan recomendaciones automáticas personalizadas para cada usuario, cada vez más potentes, basándose en las tecnologías de la red semántica). 
Es interesante pensar en prácticas de federación de servicios o repositorios de contenidos digitales (como el portal Share.TEC), permitiendo minimizar el número de espacios a los que accede un usuario, facilitando de este modo la recuperación de contenidos.

\section{C) Búsqueda}

Como hemos visto en el análisis del "Estudio 2", los portales investigados ofrecen diferentes estrategias de búsqueda (a través de exploración, búsqueda simple y búsqueda avanzada), y cada una de ellas presenta diversas funcionalidades asociadas (véase Tabla 60).

Tabla 60 Tipos de búsqueda y funcionalidades existentes en los portales analizados en el "Estudio 2"

\begin{tabular}{|c|c|}
\hline $\begin{array}{l}\text { Tipos de } \\
\text { búsqueda }\end{array}$ & Funcionalidad \\
\hline Exploración & 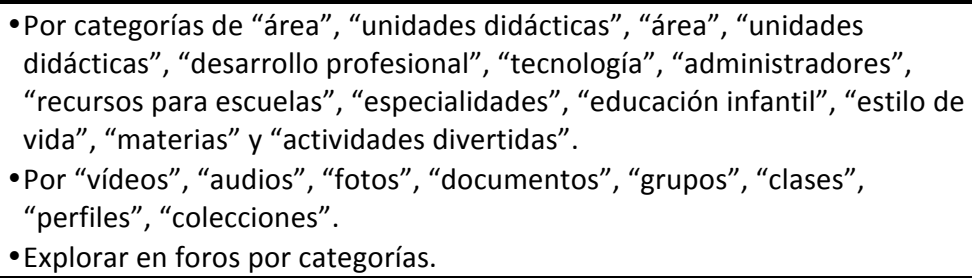 \\
\hline $\begin{array}{l}\text { Búsqueda } \\
\text { simple }\end{array}$ & $\begin{array}{l}\text { - Keywords } \\
\text { - Sugerencia de palabras mientras escribes } \\
\text { - Acotar la búsqueda simple por tipo de recurso } \\
\text { - Mostrar el número de resultados disponibles a medida que escribes las } \\
\text { "keywords" } \\
\text { - Sugerencias basadas en búsquedas llevadas a cabo en Google } \\
\text { - Motor de búsqueda de Google integrado en el sistema }\end{array}$ \\
\hline $\begin{array}{l}\text { Búsqueda } \\
\text { avanzada }\end{array}$ & $\begin{array}{l}\text { - Por áreas de conocimiento curriculares o temáticas } \\
\text { - Filtrar por lo más activo } \\
\text { - Filtrar últimas noticias } \\
\text { - Filtrar por "todas las palabras clave", "algunas", "excluir resultados con la } \\
\text { palabra clave", etc. } \\
\text { - Selección de filtros educativos (modo de empleo, tipo de contenido digital, } \\
\text { niveles, etc.) } \\
\text { - Filtrar por estándares educativos y competencias } \\
\text { - Filtrar por materiales revisados } \\
\text { - Filtrar por coste y derechos de uso } \\
\text { - Filtrar por idioma } \\
\text { - Filtrar por accesibilidad de los materiales }\end{array}$ \\
\hline
\end{tabular}


En el "Estudio 1" veíamos cómo los usuarios presentaban diferentes preferencias a la hora de buscar recursos, por lo que consideramos que sería oportuno ofrecer el mayor número de posibilidades de búsqueda posibles, para dar cobertura a las diversas necesidades de cada usuario.

Los informantes de Share.TEC definieron que se sentían más cómodos con modelos de interfaces conocidos a la hora de realizar la búsqueda; además, valoraron positivamente el sistema de búsqueda del portal. Por ello, sugerimos que la interfaz de búsqueda utilice formatos parecidos a los ofrecidos por los motores de búsqueda (e.g., el motor de búsqueda de Google).

\section{D) Interfaz}

Tras el análisis de los diferentes portales y espacios web analizados, hemos podido apreciar cómo los diversos portales comparten elementos comunes a nivel de interfaz: interfaces sencillas, fondos claros, tipos y colores de letra que favorecen la comodidad de lectura, etc. Consideramos útil incluir las buenas prácticas de otros portales (incluso no educativos) exitosos (e.g., "Destinia", "Amazon", "e-Bay", "Booking.com") y emular las características que pueden ser útiles (e.g., formas de filtrar resultados o presentarlos).

Es oportuno ofrecer aplicaciones sencillas que faciliten que los usuarios etiqueten sus recursos o enriquezcan los metadatos de otros existentes. Por este motivo creemos que es conveniente que estas funcionalidades aparezcan de forma visible (no seccionadas en el apartado "Usar", como ocurre en Share.TEC, si no presentándolas en forma de menú fijo en la interfaz de cualquiera de las páginas del portal). Es, por ello, adecuado disponer de botones que faciliten la rápida compartición de recursos en otros espacios (redes sociales, e-mail, y otro tipo de aplicaciones).

Para ello, es relevante diseñar espacios pensados en sus usuarios que tengan en cuenta recomendaciones existentes para el diseño de interfaces atendiendo a: la personalización, usabilidad (UsabilityNet, 2003), principios de interacción de las personas con los ordenadores $\left(\mathrm{HCl}^{204}\right)$, etc. (Bian, Jin, \& Zhang, 2010; Pynoo et al., 2012; Stone, Jarrett, Woodroffe, \& Minocha, 2005). Los espacios web, sin

204 Human Computer Interaction 
importancia del público al que están destinados, han de tener en cuenta las recomendaciones de usabilidad de ISO/TR 16982:2002 (ISO, 2002), las diferentes partes del estándar ISO 9241 (ISO, 2015) y otras normas y estándares internacionales que pueden encontrarse en Usability.Net (2006) para favorecer la usabilidad, navegabilidad y aspecto visual de los portales.

Tras el análisis del "Estudio 1" y del "Estudio 2", hemos visto que muchos portales integran funcionalidades "ocultas" muy útiles. Para poder sacar el máximo rendimiento de cada una de ellas, recomendamos la incorporación de menús fijos fácilmente accesibles (es decir, en la parte superior o lateral de la interfaz) que puedan verse en todas y cada una de las páginas del propio portal.

\section{E) Funcionalidades}

En el apartado 2.1.6 del capítulo 5 recopilábamos las funcionalidades sociales, de personalización, de idioma, de contenido digital, de aspectos técnicos y de sostenibilidad que ofertaba cada portal analizado. Pensamos que las funcionalidades que hemos detectado en los diferentes servicios pueden ser tenidas en cuenta para el diseño de los portales educativos atendiendo a las características de los usuarios potenciales y a los objetivos del mismo, pues como hemos visto en el "Estudio 2", el tipo de portal educativo determinaba la mayor presencia o ausencia de determinados tipos de funcionalidades (e.g., una "red social" para compartir contenidos incluye más funcionalidades sociales que relativas a la organización del contenido).

Las funcionalidades recabadas entre el conjunto de los portales son las siguientes:

Tabla 61 Funcionalidades Técnicas extraídas del análisis del "Estudio 2"

\section{Funcionalidades Técnicas}

- Espacio para aportar feedback a los responsables del portal

- Disposición de tutoriales o información para comprender las características del portal, su terminología, cómo utilizarlo, etc.

- Recibir información actualizada mediante RSS o Newsletters

- Exportar los recursos para integrarlos en Entornos Virtuales de Aprendizaje 


\section{Tabla 62 Funcionalidades sociales extraídas del análisis del "Estudio 2"}

\section{Funcionalidades Sociales}

- Acceso/creación de blogs de usuarios

- Acceso al perfil de otros

- Foros/debates

- Crear/visualizar eventos

- Webinarios

- Ver cumpleaños

- Crear/unirse a grupos

- Enviar mensajes/contactar con otros usuarios

- Compartir contenidos en otras redes sociales mediante un clic

- Enviar el material por correo mediante un clic

- Espacio para solicitar/ofertar ayuda

- Organizar autores de recursos por disciplinas

- Sistema de iconos para identificar los roles de los usuarios

- Sistema de reconocimiento social (Badges)

- Contenido "curado" por autor/institución/editorial

- Usuarios en línea

- Usuarios similares a tu perfil

- Crear preguntas para estudiantes/docentes

- Compartir enlaces

- Espacios colaborativos de trabajo

- Cambios recientes en el portal/Novedades

Tabla 63 Funcionalidades de Contenido Digital extraídas del análisis del "Estudio 2"

\section{Funcionalidades de contenido digital}

- Acceso a contenidos digitales en múltiple formato (audio, texto, imagen, etc.)

- Acceso a cursos de formación

- Herramienta para la creación de contenidos digitales

- Votar y ver puntuación de recursos

- Comentar recursos

- Descargar recursos

- Citar el material

- Novedades/contenido destacado/noticias

- Información sobre la legislación educativa

- Reutilización de contenido digital en el propio sistema

- Marcadores favoritos

- Filtrar búsquedas por materiales revisados

- Herramienta de Creación de clases con gestión de estudiantes

- Asignación de tareas a grupos concretos de alumnos mediante códigos autogenerados 
Tabla 64 Funcionalidades de personalización extraídas del análisis del "Estudio 2"

Funcionalidades de Personalización

- Organización de la visualización del contenido

o Más votados/populares

o Más compartidos

o Por autor

- Material revisado por cada usuario

o Interacciones de los recursos más recientes/más votados/más comentados

- Organización de la visualización de "grupos"

o Más activos

o Por destinatarios

o Por temáticas de recurso

o Nuevos

- Mis grupos

o Por comunidades

- Espacio personal del usuario en el portal

- Sugerencias automáticas acordes con el perfil del usuario

- Visualizar colecciones de recursos

- Herramientas de traducción integradas en el sistema (e.g., Google)

- Portal multilingüe con posibilidad de seleccionar el idioma preferido

- Historial de búsquedas personales

- Configurar la visualización en función del rol

- Ver estadísticas de contenidos

- Gestionar los derechos de acceso y licencias de los recursos subidos por los propios usuarios

Tabla 65 Funcionalidades de Accesibilidad extraídas del análisis del "Estudio 2"

Funcionalidades de Accesibilidad

- Exploración visual por etiquetas

- Legible con software procesador de voz

- Navegable con teclado

- Barra de herramientas para personalizar la accesibilidad al portal

- Herramientas FLOE

Tabla 66 Funcionalidades de sostenibilidad extraídas del análisis del "Estudio 2"

Funcionalidades de Sostenibilidad

- Recibir donaciones

- Exportar un Widget de contenido dinámico e insertarlo en otras Webs

- Otorgar premios a los mejores recursos compartidos en el portal para promover la contribución de contenidos

- Declarar cuál es el objetivo del portal en la página principal 


\section{F) Personalización}

El número de recursos educativos crece exponencialmente en los portales educativos (Cechinel et al., 2014), por lo que resulta compleja la tarea de encontrar resultados relevantes ajustados a las necesidades de los usuarios (Bienkowski \& Klo, 2014). Para mejorar la eficiencia de los portales educativos, estos han de tender a la inclusión de opciones que permitan una mayor adaptación a cada usuario. Este es el caso de los sistemas automáticos de recomendación. Estos sistemas utilizan tecnologías que permiten personalizar el contenido o modifican la configuración de las funcionalidades del portal atendiendo a: los parámetros definidos por el usuario en el perfil; el análisis de los metadatos sociales (Bienkowski \& Klo, 2014); la evaluación automática de los metadatos de los recursos educativos; la valoración numérica que realizan los usuarios (Cechinel et al., 2014); la evaluación automática de los comentarios de los usuarios sobre los recursos (Karampiperis et al., 2014), y otra serie de sistemas de recomendación (Manouselis et al., 2014).

Dos de los portales analizados (OpenLearn y Share.TEC) recomiendan al usuario materiales similares a los encontrados (pues sus metadatos contienen información similar, o se ajustan a las preferencias predefinidas en el perfil de cada usuario). Creemos conveniente integrar este, y otros tipos de sistemas de recomendación de contenido (de los mencionados anteriormente) para favorecer la reutilización de material educativo y la activación de las relaciones entre los miembros (mediante la sugerencia de usuarios similares, por ejemplo).

Otros elementos atractivos de los portales son los espacios particulares de cada usuario dentro del portal, que permiten congregar la interacción de éstos en el portal, teniendo acceso a sus recursos favoritos, los contenidos que han utilizado 0 compartido, conversaciones con otros usuarios, comunidades a las que pertenecen dentro del portal, etc. En el "Estudio 1" los usuarios valoraban positivamente la existencia de un espacio de este tipo, aunque en concreto el que ofrecía Share.TEC era mejorable (e.g., congregando las opciones que aparecian dispersas en diferentes páginas del portal. Proponemos tener en cuenta en el diseño de portales educativos la inclusión de espacios privados para cada usuario en el que se puedan 
configurar los módulos y funcionalidades que se quiere que aparezcan, su disposición, "look \& feel205", etc.).

A nivel de idioma, resulta un elemento clave dotar de opciones a los usuarios para poder personalizar los idiomas de la interfaz y de los contenidos que aparecerán en sus búsquedas. Es interesante el sistema que utiliza Merlot para ofrecer, en primer lugar, los resultados en el idioma preferido del usuario. Consideramos oportuna la integración de este tipo de función en los portales, de manera que sean personalizables desde cada búsqueda (mediante filtrado), aunque con la posibilidad de configurar unos parámetros predefinidos (los idiomas preferidos, por orden de preferencia - pudiendo seleccionar varios idiomas en el mismo nivel de preferencia-).

\section{G) Multiculturalidad}

Para resolver la multiculturalidad de los portales es importante utilizar estrategias que potencien la personalización de los portales, por ejemplo, mostrando a los usuarios recursos e información únicamente en los idiomas de preferencia que definan en su perfil).

Como vimos en el portal Share.TEC, el portal integraba muy pocos elementos gráficos. Otros portales, como vimos en el capítulo 4, introducían diferentes elementos que permitían el reconocimiento del tipo de recurso mediante iconos, o la previsualización de los recursos mediante imágenes en miniatura. Consideramos que la inclusión de sistemas de iconos que permitan a los usuarios, de manera independiente al idioma o idiomas que conocen, identificar la esencia de los contenidos digitales etiquetados, puede universalizar y facilitar el rápido reconocimiento de las características elementales de los contenidos.

El hecho de incluir folksonomías que se presenten a cada usuario en su idioma/idiomas de preferencia, puede favorecer la superación de las barreras multiculturales respecto al etiquetado de los recursos.

En relación al idioma, los informantes del "Estudio 1" opinaron que la coexistencia de varios idiomas en un mismo portal era un aspecto enriquecedor, siempre y cuando el usuario pudiera decidir los idiomas en los que desea visualizar

205 Término inglés utilizado frecuentemente a la hora de referirse a la interfaz de las páginas Web (colores, formas, disposición, tipografía, etc.). 
los contenidos (pues como vimos en el caso Share.TEC, podía resultar molesto ver contenidos en idiomas desconocidos al usuario).

Consideramos que ha de evitarse la representación de los idiomas mediante iconos de banderas, pues existen países en los que existen diferentes lenguas vernáculas, y un mismo idioma puede ser hablado en diferentes países, pudiendo provocar sentimientos de exclusión.

\section{H) Usabilidad}

Estudios de portales educativos demuestran que para que estos sean útiles para sus usuarios es necesario conocer las necesidades de su comunidad práctica (Abras, Maloney-Krichmar, \& Preece, 2004). A nivel de usabilidad los portales deben estar pensados para sus usuarios finales. Algunos estudios demuestran que los usuarios realizan rápidamente una evaluación del sitio web teniendo en cuenta su complejidad visual y las expectativas que tienen de la web en función del tipo de servicio que ofrece (Tuch, Presslaber, Stöcklin, Opwis, \& Bargas-Avila, 2012), demostrando que esta valoración influye sobre su deseo de utilizar o no el portal. Share.TEC fue valorada negativamente a nivel de interfaz por los usuarios, por lo que creemos que pudo ser uno de los elementos que determinó su baja utilización.

A la hora de diseñar los portales web existen normativas internacionales estandarizadas para la generación de aplicaciones y páginas web que permiten seguir la filosofía de "Diseño Centrado en el Usuario" (en ingles, user-centered design), como el estándar ISO 9241 (ISO, 2015), que integra diferentes subespecificaciones relativas a la "Usabilidad", "Interacción persona-ordenador" $(\mathrm{HCl})^{206}$, "Diseño centrado en las personas", "Navegabilidad", etc. ${ }^{207}$ Estas especificaciones y estándares permiten seguir ciertos protocolos para generar páginas web usables y accesibles para los usuarios, así como diseñar interfaces adecuadas para ellos.

En relación a los portales multiidoma que integran contenidos digitales en varios idiomas, ha de diferenciarse de forma correcta el idioma de los metadatos vs. el idioma de los contenidos digitales en sí. Además, las plataformas que integran

$206 \mathrm{HCl}$, siglas en inglés de Human Computer Interaction (interacción persona-ordenador).

207 Un ejemplo de esta normativa lo encontramos en el siguiente documento: "Ergonomics of human-system interaction- Part 210: Human-centred design for interactive systems"207 (Technical Committee ISO/TC, 2010). 
diversos idiomas deben aportar traducciones correctas de las diferentes funcionalidades para mejorar la confiabilidad de sus potenciales usuarios en la calidad del portal.

En el "Estudio 1" pudimos conocer otro aspecto importante respecto a la usabilidad: conocer el número de contenidos digitales que integraba el portal ShareTEC, así como el número de comunidades existentes y usuarios totales y dentro de cada comunidad. En el "Estudio 2" analizamos si los portales incluían o no estos datos. Recomendamos la inclusión de este tipo de datos estadísticos en el portal, puesto que consideramos que su incorporación permite al usuario hacerse una idea del tipo de portal ante el que se encuentra. En el caso de Share.TEC, una opción muy interesante era la visualización del número de recursos existentes a medida que se iban incorporando filtros. Permitía visualizar, además, cuántos recursos existían por cada opción de filtro.

\section{I) Accesibilidad}

En relación a la accesibilidad, es importante diseñar portales inclusivos que garanticen el acceso de cualquier persona, independientemente de sus características, a los portales educativos. Existen algunas iniciativas y proyectos (e.g., FLOE ${ }^{208}$ - (2015) - ) que proporcionan herramientas para eliminar las barreras de acceso a los portales/ espacios web y que pueden integrarse de forma gratuita.

Consideramos interesantes, las aportaciones del estudio de Yalcinalp \& Emiroglu (2012, pp. 479-480), sobre accesibilidad, quienes sugerían relevante dotar a los espacios de nombres atractivos y ofrecer acceso de forma gratuita.

\section{J) Sostenibilidad}

Sobre este aspecto destacamos algunas medidas que hemos considerado interesantes entre los portales analizados, como son: la posibilidad de realizar donaciones, poder acceder a unos servicios más avanzados si se paga una cuota mensual/anual (por ejemplo, estableciendo acuerdos con ciertas editoriales); incluir herramientas que permitan exportar el buscador del portal para integrarlo en otros

208 Flexible Learning for Open Education http://www.floeproject.org/index.html (Aprendizaje Flexible para la Educación Abierta). Proyecto de la Universidad OCAD de Canadá que ofrece recursos gratuitos para personalizar los espacios educativos eliminando las barreras de acceso al contenido (tanto en el diseño de webs como en el de los materiales educativos). 
servicios Web, generar otros widgets exportables para potenciar la visibilidad del portal, etc.

\subsubsection{Aspectos pedagógicos}

Los portales educativos deberían diseñarse dentro de los marcos constructivista y conectivista del aprendizaje. Para ello, se deberían integrar herramientas que posibilitaran a los usuarios establecer una colaboración e intercambio de contenidos y conocimientos entre los profesionales que acceden al portal. Por ello, es importante que estos portales cuenten con herramientas 2.0 (como las funcionalidades recogidas en la "2.2.2." "E)" y que faciliten la integración con herramientas externas (e.g., "Twitter", "Meet up", herramientas para la realización de "webinarios", etc.).

\section{A) Tipo de licencias de los contenidos}

Ha de fomentarse el uso y creación de recursos educativos abiertos y licencias abiertas para aumentar el impacto de la financiación y facilitar su reutilización (Lund et al., 2010). En el capítulo 1 de esta tesis recopilamos las ventajas que proporcionaba la utilización de este tipo de contenidos.

En los portales analizados en el "Estudio 2" apreciamos que era muy complejo encontrar en ellos la licencia de sus contenidos digitales. Este hecho puede dificultar la reutilización del contenido digital por desconocimiento de los derechos de uso del recurso, pues muchos profesores evitan compartirlos en sus páginas web por temor a posibles infracciones de copyright (I. De Vries, 2013; Downes, 2007). Proponemos la etiquetación manifiesta y la visualización sencilla de este dato asociada de forma visual a cada recurso (por ejemplo, mediante un sistema de iconos), así como incluir aspectos como el precio del material (para evitar que los usuarios tengan que explorar varias ventanas antes de poder conocer su valor económico).

\section{A) Ontologías y Etiquetado del contenido digital educativo}

La inclusión de ontologías y estándares de metadatos en este tipo de portales, constituyen estrategias necesarias para facilitar la recuperación automática de contenido por las máquinas mediante la "Web semántica" (Alvino, Bocconi, et al., 2009; Ferran Ferrer \& Minguillón Alfonso, 2011; Minguillón et al., 2011; Yalcinalp \& Emiroglu, 2012). 
En los niveles de Educación Obligatoria encontramos cierta homogeneidad curricular para las diferentes regiones o contextos locales de cada país, gracias a la existencia de un currículum con muchos elementos en común, aunque con diferencias entre países (pero fáciles de cotejar). En cambio, para el ámbito de la Educación Superior, y en el campo que nos atañe, la Formación del profesorado, existen estructuras más diversas, pues cada una de las universidades de cada país tiene libertad para decidir su currículo. De este modo se hace necesario generar estructuras compresibles por la comunidad que utiliza los recursos, bien a través de la creación de folksonomías diferenciadas por idiomas (mediante el etiquetado de los contenidos digitales por los propios usuarios), 0 mediante estructuras consensuadas entre usuarios de diferentes contextos (para lo que han de investigarse las necesidades y nomenclaturas que emplean los usuarios de la comunidad que vaya a utilizar el portal).

En relación al etiquetado pedagógico de los recursos, existen sistemas que automáticamente pueden recuperar los metadatos técnicos de un material, en cambio, actualmente es compleja la tarea de etiquetar educativamente los contenidos con sistemas automáticos (por lo que generalmente este trabajo deben hacerlo personas).

Debido a que muchos usuarios no están dispuestos a etiquetar manualmente los contenidos, se recomienda la inclusión de ontologías educativas (que faciliten la clasificación y recuperación del material de forma precisa) con folksonomías educativas (que permitan a los propios usuarios proporcionar etiquetas del material e incluso revisar las proporcionadas de otros usuarios). Las folksonomías poseen un valor educativo muy interesante, tanto como entidad que estimula la capacidad para abstraer el contenido de un mensaje como posibilitador de una experiencia de construcción colectiva de aprendizaje y significado (Blanco \& Ramos, 2009). Este tipo de etiquetas junto con los comentarios que los usuarios de la comunidad puedan proporcionar, dota a los recursos de una información compleja y completa que enriquece la información pedagógica del material.

En el etiquetado de los contenidos digitales planteamos la utilización de sistemas mixtos que:

1) hagan más probable la inclusión de información de los metadatos, pues si el enriquecimiento de los mismos se presenta a través de sistemas sencillos como incorporar descripciones por keyword del recurso, es posible que haya usuarios que se animen a etiquetarlos (si creen que este hecho puede ser de utilidad para ellos mismos o para otros). 
2) integren diferentes sistemas para que los metadatos estén más enriquecidos. Nos referimos a la combinación de folksonomías reeditables (mediadas por los propios usuarios y revisadas por administradores) que permitan incorporar descripciones mediante keywords a los metadatos existentes. Este hecho permitirá la recuperación de más información tras realizar búsquedas.

Como hemos visto en los diferentes portales analizados, en ocasiones encontrábamos recursos catalogados para un área o nivel concretos, pero podrían ser igualmente útiles para otros niveles. Por ello, planteamos las folksonomías como elemento que enriquece los datos del portal y sugerimos la posibilidad de poder asociar estas etiquetas a experiencias de uso del contenido por parte del usuario que las incorpora.

Un elemento a incluir en el etiquetado de los contenidos digitales son "las competencias" que aborda el material. De los portales que analizamos, la mitad de ellos etiquetan los contenidos con este campo. Las políticas educativas europeas tienden a valorar la importancia de la adquisición de éstas para dotar a las personas de las estrategias necesarias para adaptarse a las dinámicas y cambiantes exigencias sociales y laborales, como ocurre en el ámbito de la formación del profesorado (Bozu \& Canto Herrera, 2009; European Commission, 2010a, 2013e, 2013f; Rodríguez Rosell et al., 2013; Ruíz Requies, 2009).

Además, los campos que se consideran deben ser entendibles por la comunidad a la que van destinados (en el caso de Share.TEC, encontrábamos algunos campos muy técnicos que proporcionaban confusión a los usuarios, e.g., "aplicación - pdf"). Los informantes demandaban la inclusión de términos educativos con los que ellos estaban más familiarizados, por ejemplo, el tipo pedagógico o descriptivo de recurso (e.g., "Webquest", "rúbrica", "artículo de investigación", etc.). También concluimos a través de nuestros datos que incorporar el modelo pedagógico en el que se sustentan los contenidos digitales, es un elemento que puede condicionar la decisión de utilizar recurso (o no) para un determinado fin educativo.

\section{B) Calidad del material}

Poblar los repositorios es una tarea compleja. Para facilitar la inclusión de contenidos etiquetados han de utilizarse sistemas que permitan la etiquetación automática de la mayor información posible relativa al material, y para ello es necesario que se base en ciertos estándares educativos. Share.TEC propone una ontología educativa que es bastante aceptada por los usuarios de los diferentes 
países con los que hemos trabajado; proponemos partir de esta ontología y refinarla adaptándola mejor a las peculiaridades idiosincráticas de cada contexto. Clements et al. (2015) desvelan en su estudio que los portales educativos incipientes requieren de una mayor administración y gestión del contenido por parte de expertos, pues como apuntan Lund et al. (2010), la calidad que se oferta en los primeros momentos de los portales que integran comunidades educativas de usuarios, son claves para el éxito del portal. Posteriormente, se puede dotar de mayor independencia a los usuarios para gestionar los contenidos y focalizar los esfuerzos en la dinamización la comunidad. Clements et al. (2015) proponen en ese punto la inclusión de algunos mecanismos para la gestión de la calidad: revisión de pares, comentarios, etiquetado social, favoritos, suscripciones, rankings, etc.

En la siguiente Tabla 67 recogemos los principales aspectos que consideramos, a través de nuestra investigación, que son avales de la calidad de un contenido digital. Atendemos a tres dimensiones relacionadas con ellos: los metadatos que los describen, la diversidad del material, y aspectos relativos al contenido digital:

Tabla 67 Dimensiones y Elementos que definen la calidad de los contenidos digitales en un portal educativo

\begin{tabular}{|c|c|}
\hline Dimensión & Elementos \\
\hline Metadatos & Descripciones completas de metadatos pedagógicos y técnicos \\
\hline Diversidad & Variedad de contenidos por tipología educativa y formato técnico \\
\hline El contenido & $\begin{array}{l}\text { Contenidos útiles para las áreas a las que se destina, avalados por una } \\
\text { serie de criterios, basados en algunos autores (Clements et al., 2015; } \\
\text { Clements \& Pawlowski, 2012) y en las evidencias de Share.TEC } \\
\text { - Nombre del autor } \\
\text { - Reputación del autor } \\
\text { - Puntuación media } \\
\text { - Evaluaciones cualitativas de otros usuarios } \\
\text { - Etiquetado pedagógico } \\
\text { - Instrumentos colaborativos de calidad: } \\
\text { ○ Comentarios } \\
\text { o Revisión de pares } \\
\text { O Etiquetado social } \\
\text { O Favoritos } \\
\text { o Suscripciones } \\
\text { Integración de "OER" (Recursos educativos abiertos y gratuitos) que } \\
\text { pueden ser reutilizados por otros profesionales, e incluso, dependiendo de } \\
\text { las licencias del OER, pueden ser redefinidos y volver a compartirse en } \\
\text { estos espacios (proporcionando mejoras en la calidad de os contenidos) } \\
\text { (Hylén et al., 2012; Yuan et al., 2008). }\end{array}$ \\
\hline
\end{tabular}


Los criterios que más definían la calidad de un material, según los informantes a los que preguntamos en Share.TEC eran: el nombre del autor y la puntuación.

En el "Estudio 1" apreciamos la dificultad de evaluar la calidad de un contenido digital educativo, ya que muchos de sus datos son subjetivos (nivel para el que está destinado el material, competencias que trabaja, etc.). Esta subjetividad sólo puede mitigarse mediante la participación de una comunidad suficientemente amplia para tener diversidad de opiniones y una cierta convergencia en ellas.

Entre los portales analizados, el portal "Connexions" disponía de la funcionalidad "Lenses", que permitía a las personas o representantes de instituciones incorporar materiales "curados" (Guallar \& Leiva-Aguilera, 2013) (seleccionados manualmente por ser considerados interesantes 0 de valor).

\section{C) Diversidad del material}

Los informantes del estudio de caso "Share.TEC" desvelaron que utilizaban mucha diversidad de tipos de contenido digital, por lo que un sistema adaptado a sus requerimientos implica la diversificación de materiales, tanto en tipología de media (audio, video, imagen, texto) como en formato.

\subsubsection{Aspectos sociales}

El primer requisito para que un portal educativo sea aceptado y utilizado de forma amplia es la existencia comunidad que demanda el servicio. En segundo lugar, dada la diversidad y prolija cantidad de portales educativos existentes, estos han de incluir una serie de aspectos que garanticen el éxito del portal, combinando:

- la integración de elementos que superen a los que ofrecen las soluciones existentes (e.g., una ontología educativa para un campo específico que facilite la recuperación y reutilización del material).

- la oferta de servicios y contenidos educativos de calidad: en forma y fondo

- servicios accesibles y usables

A la luz de los portales investigados, abstraemos que el principal factor de éxito para la utilización de un portal web de contenidos digitales radica en la existencia de una comunidad de usuarios que comparten contenidos y experiencia en torno a ella. Algunas investigaciones demuestran que las redes se activan a medida que el número de actividades cooperativas que se producen en una red incrementan 
(Bessenyei, 2008). Hearn y White (2009) sintetizan las principales algunos de los aspectos que son relevantes para el sustento de las comunidades de práctica:

- Las comunidades más pequeñas permiten generar un mayor sentimiento de confianza, los participantes tienen menos miedo de participar en la evaluación del material que en un grupo grande y facilitan la experimentación e innovación.

- Los miembros de comunidades grandes pueden utilizar su buena reputación como expertos en su campo, generando ideas valiosas más allá de los límites de la comunidad e influir sobre el conocimiento de su área; asimismo, estas comunidades permiten la validación del conocimiento y fomentan la adopción de nuevas ideas y prácticas. Además, las comunidades grandes permiten la coexistencia de personas con múltiples concepciones, hecho que permite la revisión crítica del conocimiento. Estas comunidades permiten una mayor difusión de las buenas prácticas.

En el "Estudio 1" preguntamos sobre la necesidad de la existencia de un portal similar a Share.TEC, y los usuarios consideraron que sería un portal muy útil e interesante para la compartición de contenidos y experiencias educativas.

Atendiendo al tipo de temáticas a incorporar en el portal, los informantes consideraron que la existencia de una red de recursos multidisciplinar estimularía la compartición de más cantidad de contenidos digitales. De este modo, consideramos que la solución ideal es facilitar la potencialidad de ambos tipos de comunidades, generando espacios multidisciplinares con subcomunidades más específicas.

Además, creemos que este tipo de espacios podría proporcionarles recursos interesantes, de calidad ya filtrada por otros usuarios. Asimismo, las evidencias de sus aportaciones nos sugieren que poder ver lo que otros usuarios comparten estimula e inspira la compartición y remodelación de contenido digital y experiencias educativas.

De esta manera, secundamos las recomendaciones que Lund et al. (2010) recogen en su informe de EDRENE sobre las formas para involucrar a los usuarios al portal. A continuación las ampliamos y proponemos las siguientes sugerencias:

- Integrar herramientas sociales existentes tanto para el acceso al portal como para establecer redes de "amigos" dentro del portal educativo (importar usuarios mediante correo electrónico, nombre, importar amigos desde redes sociales o cuenta de correo) utilizando métodos tecnológicos similares a los que conocen (e.g., importar amigos desde una cuenta de Facebook). 
- Generar interfaces simples y similares a las existentes en los sistemas que usan habitualmente (redes sociales) para promover la interacción con otros usuarios.

- Contratar a un dinamizador del portal (además de los administradores) para activar la comunidad y ofrecer servicios informativos actualizados por temáticas (becas, recursos destacados, personas destacadas, información de plazas y bolsas de trabajo para los profesionales de la educación relacionados con la formación del profesorado, etc.)

- Involucrar a comunidades existentes en el portal, y potenciar su expansión. Además, proponemos la posibilidad de la coexistencia de subcomunidades dentro de la macro-comunidad de usuarios del portal, para poder aprovechar las potencialidades que ofrece cada tipo de comunidad según su tamaño. Es importante dedicar mucho esfuerzo a la activación de la comunidad, pues tanto estudios de la literatura (i.e., Clements et al., 2015; Minguillón et al., 2011, p. 35; Tosato et al., 2014) como Share.TEC, nos han enseñado que esta es una de las claves más relevantes para el éxito de este tipo de portales Consideramos muy oportuno seguir la recomendación de Lund et al. (2010) de construir confianza, reputación y crear marca, de forma que los usuarios se sientan seguros como parte de la comunidad.

- Explicitar la misión y visión del portal, así como la importancia de la existencia de una comunidad/comunidades de práctica entorno a ella. Comprobamos en Share.TEC que los usuarios no sabían para qué era el portal según accedían a su página principal.

- Dar refuerzos e incentivos para estimular la participación de los usuarios en el portal (participación en discusiones, valoración de contenidos, número de amigos, personas a las que invita que se han registrado, recursos con los que ha contribuido, etc.). Por ejemplo, consideramos muy útil la incorporación de insignias (badges), práctica importada de los modelos de gamificación educativa que se está expandiendo hacia diversos servicios educativos: portales de compartición de contenido educativo (e.g., Merlot), sistemas de Gestión del aprendizaje (Haaranen, Ihantola, Hakulinen, \& Korhonen, 2014), MOOCs y cursos online (e.g., MITx) (Young, 2012), instituciones educativas que ofrecen reconocimientos por contribuciones a ciertas temáticas --, etc. Hay estudios que demuestran que su uso motiva el aumento de participación por los beneficios de reputación social, autoestima, reconocimiento, etc. que genera (Gibson, Ostashewski, Flintoff, Grant, \& Knight, 2013; Haaranen et al., 2014; Hakulinen, Auvinen, \& Korhonen, 2013; Young, 2012). 
- Visibilizar la comunidad en cada página del portal, pues como hemos aprendido mediante la experiencia y a través de los usuarios, es un aspecto fundamental de estos entornos.

- Lund et al. (2010) afirmaron que las comunidades de usuarios funcionan mejor cuando pueden encontrarse en escenarios reales. Es positivo integrar herramientas para facilitar los encuentros presenciales, similares a "Meetup 209". Del mismo modo, es recomendable proporcionar herramientas que favorezcan los encuentros virtuales: integración de chat, videoconferencia (incluso reutilizando herramientas existentes como las que ofrece Google, estableciendo los convenios adecuados con ellos). De esta forma, se disponen los medios para que los usuarios de un espacio web puedan acrecentar el sentimiento de comunidad y generar encuentros tanto públicos en el portal- como privados, y presenciales como online. También es oportuno que se dinamicen webinarios (como los que se ofertan en Internet en el Aula).

- Recomendamos la incorporación de estadísticas del número de contenidos compartidos "hoy", "esta semana", "este mes", y las personas que más han compartido/contribuido con metadatos, etc., en esos periodos.

- Pensamos que plantear retos educativos a los participantes del portal puede ser una estrategia útil para potenciar la mejora de la calidad de los recursos que contiene (tal y como vimos en el portal OER Commons) y el estímulo hacia la compartición.

- Estimular la compartición de contenido, la participación social y la mejora de los materiales pidiendo a los usuarios que incorporen en el portal contenidos que cumplan un determinado criterio (e.g., un dinamizador de la comunidad de Internet en el Aula propone a los miembros que compartan "su contenido creado preferido".

\section{Limitaciones de la tesis}

Durante el desarrollo de este trabajo, hemos detectado una serie de limitaciones que presenta nuestra tesis doctoral. Entre las más relevantes destacamos:

209 Aplicación que permite a los usuarios encontrar a personas que crean grupos para realizar actividades de ocio, profesionales, etc., por localizaciones geográficas. Ofrece servicios gratuitos para la asistencia a eventos, y cuotas para las personas que gestionan los grupos http://www.meetup.com. 
En relación a las pruebas de evaluación realizadas con los usuarios, muchas de ellas fueron recabadas para proporcionar información al proyecto Share.TEC. Las pruebas se centraron principalmente en detectar los hábitos de utilización de tecnología que manifestaban los usuarios potenciales, así como evaluar los diferentes componentes del sistema Share.TEC. Este condicionante ha limitado la representatividad de las muestras de informantes. Como hemos visto en el capítulo 4, hemos realizado pruebas de significación estadística únicamente con aquellos datos que nos lo permitían. En futuras investigaciones sobre esta temática sería adecuado recoger muestras significativas para poder establecer comparaciones entre pruebas y aportar datos de fiabilidad de estas y de la validez de los resultados.

En el capítulo 4 hemos explicitado en dos ocasiones que la forma de formular alguna pregunta a los usuarios ha podido condicionar su respuesta (e.g., cuando preguntamos a los informantes de la prueba [35] si eran miembros de alguna comunidad de práctica, si conocían lo que era una comunidad de práctica, y si habían pertenecido a una; obtuvimos datos poco coherentes, pues fueron más los usuarios decían haber pertenecido a una comunidad que los que decían conocer qué era). En futuras investigaciones, ha de considerarse la revisión adecuada de los cuestionarios para formular preguntas con aclaraciones.

Otro de las limitaciones de esta tesis hace referencia al conocido "Efecto Hawthorne" (Chandler \& Munday, 2011; Macefield, 2007; Sedgwick \& Greenwood, 2015), que sugiere que el comportamiento natural de los participantes puede ver afectado por el simple hecho de saber que están siendo observados y estudiados. No podemos controlar si han existido variaciones en los datos producidas por este efecto cuando hemos realizado pruebas piloto del portal con ellos (pues estos fueron realizados congregando a los informantes en una misma sala).

En el caso del "Estudio 2", la muestra de portales se limitó a 15 portales, puesto que hemos pretendido analizar a fondo las características de nuestro modelo de evaluación, y hemos propuesto un número de portales que nos resultara abordable. Este estudio podría complementarse con una muestra más representativa del tipo de espacios web, y la selección de un mayor número de portales.

En relación a este caso, los portales fueron analizados en varios momentos durante los últimos 3 años. Los portales educativos evolucionan constantemente, se "escalan" (es decir, expanden sus funcionalidades) atendiendo a las necesidades que surgen por parte de sus usuarios y a las nuevas posibilidades que proporcionan las herramientas tecnológicas emergentes. Por este motivo, hemos tratado de 
actualizar los datos más relevantes a fechas actuales (los que no han sido actualizados han quedado reflejados en el capítulo 5 de esta tesis).

Una vez establecidas las principales limitaciones que hemos detectado en el desarrollo de esta tesis, procedemos a determinar las líneas de trabajo futuro que se realizarán tratando de superar estas limitaciones.

\section{Líneas de Trabajo futuro}

Una vez presentadas las concusiones generales de nuestra investigación, que complementan las conclusiones particulares del "Estudio 1" (resumidas en el apartado 2.4 del capítulo 4) y del "Estudio 2" (recopiladas en el apartado 1 del capítulo 5), así como las limitaciones detectadas, procedemos a definir las líneas de trabajo futuro vinculadas con este trabajo de investigación:

\subsection{Construcción de un portal web educativo para la comunidad de formadores de profesores de Tecnología Educativa en España.}

Tras definir las recomendaciones de diseño conceptual para la creación de portales educativos, nos centraremos en la prueba de concepto de un espacio web para la compartición de contenidos digitales y experiencias educativas en una comunidad educativa definida (formadores de profesores en Tecnología Educativa de España). Seleccionamos este contexto por ser una comunidad definida ${ }^{210}$ y activa en la generación de material educativo.

Para ello, en primer lugar, realizaremos un cuestionario con preguntas cualitativas y cuantitativas que nos permitan evaluar cada uno de los aspectos definidos con anterioridad en las conclusiones y propuesta de esta tesis. En este cuestionario debemos tener en cuenta las lecciones aprendidas para poder extraer datos estadísticos significativos sobre las necesidades en torno a la utilización y compartición de contenido digital y experiencias educativas que manifiesta esta comunidad.

210 Una de las asociaciones existentes de formadores de tecnología educativa en España es la "Red Universitaria de Tecnología Educativa" (RUTE) española que organiza eventos para difundir los avances y experiencias puestos en marcha en este ámbito http://www.rute.edu.es/ 
Realizaremos una revisión de los portales existentes en España y Latinoamérica que integran objetos educativos abiertos de calidad para la formación del profesorado, y consideraremos la opción de proponer a sus responsables la federación de los contenidos entre los portales existentes y el portal que queremos diseñar.

Siguiendo un diseño de método mixto (Creswell \& Plano Clarck, 2010; Creswell, 2003, 2014), se analizarán los datos del cuestionario y se creará un mock-up del portal, atendiendo a las recomendaciones establecidas por los estándares de usabilidad de espacios web. Además de utilizar estas guías, integraremos las funcionalidades y recomendaciones que hemos detallado en la propuesta.

A través de varios ciclos iterativos de diseño y evaluación, siguiendo la filosofía de user-centered design (e.g. Lowdermilk, 2013; UsabilityNet, 2003), seleccionaremos a cinco formadores de profesores del área por cada prueba (Nielsen, 2000). Redefiniremos el mock-up (que inicialmente será diseñado de forma básica, sin integrar colores para que los usuarios se centren en las funcionalidades; y posteriormente, será presentado en su versión final completa).

Asimismo, reelaboraremos la ontología educativa propuesta en Share.TEC (TEO) atendiendo a las recomendaciones incluidas por los formadores en el "Estudio 1" (e.g., añadiendo descripciones básicas del tipo de material: artículo de investigación, Webquest, capítulo de libro, portal educativo, etc.), y asimismo, el modelo común de metadatos.

Para realizar este trabajo necesitaríamos la colaboración de un equipo interdisciplinar que proporcione su conocimiento específico de área, por lo que sería oportuno que éste estuviera formado por personas del área de biblioteconomía, informática, sociología, economía y educación, para abordar de forma completa los aspectos que conforman un portal.

Propondríamos el portal al Ministerio de Educación y Ciencia español para que financiara su lanzamiento, difusión y mantenimiento (inicialmente, mediante la solicitud de un proyecto, y posteriormente, mediante la dotación de recursos para mantener los costes y gestión del mismo).

Una de las lecciones aprendidas a lo largo de esta investigación tiene que ver con tener en cuenta el diseño de arquitecturas flexibles, escalables e interoperables, que permitan la integración de nuevas comunidades de profesores de otras áreas en el portal, la inclusión automática de metadatos basados en estándares existentes (e.g., LOM, DC), y la inclusión de metadatos asociados a los recursos mediante 
"folksonomías" (facilitando así la multiculturalidad de los contenidos). Sería adecuada la federación con portales existentes, congregando de este modo el contenido educativo disperso en la red. Para completar el etiquetado de los materiales debería integrarse en el portal una aplicación de fácil gestión para el usuario (e.g., imitando la interfaz de etiquetado de Mendeley), que le permitiera etiquetar y modificar sus metadatos. Este hecho facilitaría en gran medida a los usuarios la contribución de sus materiales al portal, pues ahorraría tiempo -del que suelen acusar falta- para realizarlo (sirviendo como espacio de gestión de sus contenidos, y simultáneamente enriqueciendo los contenidos del portal para otros usuarios). La nueva web semántica abre una puerta a la recopilación de contenidos digitales, que junto con las herramientas adecuadas para la colaboración social, permiten la generación de grandes "bancos" de recursos contextualizados mediante breves descripciones y contribuciones de usuarios.

La construcción de este portal facilitaría la consecución de los objetivos planteados por las instituciones europeas relativos a la mejora de la formación del profesorado mediante la promoción de espacios de compartición de contenidos y experiencias educativas, tal y como recogimos en el capítulo 1 de esta tesis (European Commission, 2013b, 2013c, 2013f; UNESCO, 2003, 2011, 2013, 2014a; Unión Europea, 2007).

Consideramos muy relevante la activación de las comunidades, por lo que partiremos de comunidades localizadas y permitiremos la inclusión de diferentes estrategias que fomenten la participación e intercambio (de conocimiento y contenidos) por parte de los usuarios. Si la experiencia es exitosa, expandiríamos el modelo de metadatos y la ontología educativa para dar cabida a nuevos países. Inicialmente, trataríamos de involucrar activamente a usuarios de España (adaptando el portal a la idiosincrasia lingüística de cada región). Posteriormente, trataríamos de adaptar el portal para integrar a contextos latinoamericanos. Y por último, adaptaríamos el portal a otros contextos internacionales.

En el portal se incluirán diferentes estrategias de activación de las comunidades (e.g., badges, estrategias de gamificación, y otras estrategias que fomenten la participación, recompensa y reconocimiento del usuario dentro de la comunidad). En cuanto a las insignias (badges), como posible solución que facilitaría el desarrollo de software para generarlas, se podría integrar en estos espacios los reconocimientos de "Mozilla Backpack", software libre que permite a cualquier organización crear, expedir y verificar insignias digitales (designadas por Mozilla "open badges") (Mozilla, 2014). Esta medida es una buena práctica utilizada por Open Learn (portal 
de contenidos digitales de la Open University de Reino Unido), MiriadaX (plataforma española de MOOCs) y numerosas instituciones educativas.

Además, la plataforma debería contar con funcionalidades tecnológicas que faciliten la comunicación entre los participantes de la red, así como el establecimiento de colaboraciones entre profesionales de los diferentes contextos.

El tipo de contenidos del portal se centrará principalmente en la inclusión de OER (recursos educativos abiertos), ya que consideramos que aportan grandes beneficios a la educación, favorecen la reutilización y adaptación del material, y pueden ser utilizados a escala global, favoreciendo que las comunidades más desfavorecidas puedan tener acceso de recursos de calidad.

\subsection{Aplicación de las lecciones aprendidas al diseño de otro tipo de espacios educativos}

Otro de los retos que nos planteamos abordar en un futuro es la aplicación de las lecciones aprendidas en torno a los aspectos pedagógicos, tecnológicos y sociales, para la mejora de entornos educativos existentes, no sólo para la compartición de contenido digital, si no para la gestión del aprendizaje. Los tipos de entornos en los que nos podríamos centrar son:

\subsubsection{Entornos virtuales de aprendizaje (VLE y MUVEs):}

Para ello profundizaremos en las teorías de CSCL, adaptando los entornos mediante la integración de nuevas herramientas que permitan un aprendizaje más conectivista en estos espacios, así como espacios de creación colaborativa de material educativo. Seleccionaremos asignaturas españolas de formación en tecnología educativa para futuros maestros y realizaremos una investigación para detectar qué necesidades existen a nivel: educativo (tipo metodologías educativas y actividades de aprendizaje y evaluación que se desarrollan en estas asignaturas); tecnológico (en función de los aspectos pedagógicos, qué soluciones tecnológicas utilizan y cómo se podrían mejorar); y social (para permitir la colaboración entre los diferentes "actores" que participan en la asignatura) en estos contextos. Readaptaremos los entornos (e.g., Moodle) integrando las herramientas necesarias para la consecución de los objetivos educativos de los cursos, y la promoción de la colaboración entre diversos formadores y alumnos mediante la plataforma (de forma que puedan conocerse otras prácticas, redefinirse y mejorar los procesos educativos). A través de la red RUTE trataremos de potenciar que los profesores de 
tecnología educativa que pertenecen a ella fomenten en sus asignaturas la creación de OER por su parte, y por parte de los alumnos. Ha de tenerse en cuenta que los recursos educativos abiertos y gratuitos (OER) por sí mismos no mejoran el acceso y la calidad en educación superior; para asegurar que los contenidos son relevantes y con sentido pedagógico (Wong, Wong, \& Pang, 2015) deberían utilizarse mecanismos, como los definidos en esta tesis, para evaluar su grado de calidad (e.g., votación, comentario de otros autores, número de personas que evalúan el recurso, experiencias de uso del contenido, etc.).

Para ello, propondremos un webinario de formación para profesores de RUTE que quieran participar en este proyecto, y solicitaremos que compartan los recursos generados en portales de contenido digital (quizá, el definido en el punto 4.1 de este capítulo), así como que motiven a sus alumnos para que creen y compartan OERs.

\subsubsection{Plataformas de gestión de Cursos (MOOCs y SPOCs):}

Estos entornos de compartición y aprendizaje en ocasiones descuidan las pedagogías activas, convirtiéndose en meros repositorios de contenidos que proporcionan material estático y acreditan el aprendizaje mediante técnicas conductistas (test que verifican la consecución de los objetivos del curso). Planteamos el estudio de buenas prácticas educativas que potencien el aprendizaje constructivista y conectivista entre los participantes. Evaluaremos el papel de las herramientas tecnológicas en la promoción de estos tipos de aprendizaje, y realizaremos una propuesta de diseño de espacios web para MOOC y SPOCs que tengan en cuenta las lecciones aprendidas de esta tesis y las evidencias del análisis de buenas prácticas de diseño pedagógico, tecnológico y social de los portales. Para analizar las plataformas MOOC y SPOCs diseñaremos una herramienta de evaluación a partir de fuentes de la literatura, adaptando el esquema de nuestro modelo de análisis generado en el "Estudio 2" y focalizándolo en los procesos educativos que tienen lugar en estos entornos. Esta investigación podría realizarse en el contexto del proyecto RESET (Delgado Kloos, 2014) del equipo GSIC-EMIC, analizando qué elementos podrían tenerse en cuenta (a nivel social, tecnológico y pedagógico) para fomentar unos mejores usos de los OERs en los entornos de los MOOCs y de los SPOOCs. 


\subsection{Mejora del modelo de evaluación de portales educativos}

Integraremos el modelo de análisis de portales educativos del "Estudio 2" (que atiende a aspectos pedagógicos, tecnológicos y sociales) con el generado por otros investigadores del área de biblioteconomía (Santos-Hermosa, Ferran, \& Abadal, 2015), con los que podríamos trabajar colaborativamente ${ }^{211}$. Proporcionaremos un modelo de análisis de portales creado multidisciplinarmente. Posteriormente, se podría validar este modelo con expertos de las áreas de educación y biblioteconomía, redefiniéndolo con las mejoras sugeridas. Por último, generaríamos un análisis de los portales educativos actuales para facilitar las decisiones de los docentes sobre la utilización de los mismos.

Con estas líneas quiero concluir esta tesis doctoral con la esperanza de que la investigación que aquí presento facilite el camino a otras investigaciones y pueda servir de referencia para mi futuro trabajo.

211 Gracias a una estancia disfrutada en la Open University de Reino Unido (2012), pude conocer a la investigadora Santos-Hermosa, bibliotecónoma con la que tuve la oportunidad de colaborar durante tres meses. Actualmente ambas hemos realizado trabajos de investigación relacionados con el análisis de portales educativos partiendo de distintos enfoques y variables. Próximamente realizaremos una integración de ambos estudios. 


\section{Abstract}

Nowadays there are few teacher-education specialized portals for sharing digital content and educational experiences. Multiple educational resources can be found on the Internet, although they are frequently scattered through different services. Therefore, it might be difficult to find resources associated with pedagogical metadata for enabling the access and reuse of these resources. Recent international and European policies and programmes have promoted the creation of these services. However, little attention has been paid to the design of portals for teacher educators considering their needs and preferences.

This Ph.D. thesis identifies the pedagogical, technological and social needs and habits of teacher-educators for sharing, using and reusing educational content and experiences. The main contribution of this work is a conceptual proposal providing recommendations for designing these portals.

This thesis has followed a multi-method research integrating two studies. First, we performed an "intrinsic Case Study" of a European portal for sharing resources in the teacher education community (Share.TEC). We explored its lessons learnt throughout the analysis of the qualitative and quantitative evidences obtained by applying different instruments and techniques (e.g. Think Aloud Protocol, pilots of the portal, observations, questionnaires, surveys, etc.). Second, we analysed portals for sharing digital content selected from a discretionary sample. We carried out an individual and a comparative analysis of the portal adopting our evaluation model (created by combining the categories derived from the analysis of the first study and from those extracted from relevant related researches).

Evidence shows teacher educators proved more willingness than other educational professionals to use and share digital resources (although there are little statistically significant differences among roles regarding the kind of resources and frequencies they use these resources). Furthermore the community arises as one of the main factors that made successful these spaces. 
Finally, taking into account the needs and habits of the final users and the best practices identified in the educational websites and portals, an evidence-based conceptual design proposal is presented.

Keywords: Design, Multi-method, Digital Content, Educational Portals, TeacherEducation 


\section{Introduction}

Nowadays there are few teacher education specialized virtual spaces for sharing digital content (Carramolino Arranz \& Rubia Avi, 2013; Earp, Sarti, \& Bocconi, 2011; $\mathrm{EdReNe}, 2010$ ). Multiple digital resources for this field can be found, though they are usually scattered in multiple spaces. Therefore it is difficult to find resources with certain specific pedagogical features. Additionally, sharing and reusing digital content among teachers is not a common practice in the context of education. Some programs and projects have been proposed considering the education policies and international funding programs, both European and nationals (CORDIS, 2009; European Commission, 2005, 2008, 2010, 2011; Red.es, 2012) favouring the creation of web spaces to solve these problems.

However, there are many valuable educational portals that enable both digital content and sharing knowledge among their users. Furthermore, every day we experience technological advances leading to greater customization of services and improving the quality of tools for sharing content and creating professional networks.

An attempt to overcome this situation is the Share.TEC (Sharing Digital Resources in the Community Teacher Education) (Share.TEC Consortium, 2008) portal, which is the result of a project undertaken by a European consortium, funded by the eContentplus program (European Commission, 2008) of the 7th Framework Programme of the European Union. I had the opportunity to get involved in this project due to my membership to the Consolidated Research Unit of Castile and Leon GSIC-EMIC (Group of Intelligent and Information Systems - Education, Media, Information and Culture). I had the chance of actively participate on the construction and evaluation with final users, dealing with the educational and social issues. This research interest comes from delving into the topic with the aim of improving existing services devoted to education. This thesis explores the evolution of the portal creation and the valuable information provided by its final users along three research phases: phase of portal construction, launch phase and post-construction phase. We 
analyse this "Study 1" aiming to provide answers to the stated research questions and objectives.

\section{Objectives and Contributions}

Given this context, we propose five fundamental objectives in this doctoral thesis consisting in: A) to identify the educational, technological and social needs of teacher educators for sharing digital content and educational experiences; B) to identify and to know habits of using, sharing and reusing of digital content from teacher educators; $\mathrm{C}$ ) to design an evaluation model of educational portals based on existing evaluation models; D) to identify good practices in portals for sharing digital content; and $\mathrm{E})$ to propose recommendations to be considered in the design of online education portals for teacher training to enable sharing digital content and knowledge (see Figure 1).

To accomplish these goals, contributions and limitations detected in "Study 1" are analysed. The users' views of the portal are also investigated, as well as teachers' and teacher educators' habits and needs related to digital contents and educational portals/web services. A selection of educational portals is inquired aiming to enrich this information and formulate our proposal. Finally, good practices that solve users' needs detected in "Study 1" are abstracted.

As a consequence of this research, the objectives achieved give rise to the major contributions of the thesis: 1) The definition of pedagogical, technological and social needs of teacher educators and other education professionals on the use of portals for sharing digital educational content and experiences; 2) The proposal of a model for evaluating educational portals of digital content; 3 ) The identification of the good practices on educational portals and 4) A theoretical proposal for the creation / renovation of educational portals for teacher education (see Figure 1).

\section{Methodology}

Our methodology falls in a pragmatic worldview (Creswell, 2014) research, following the interpretative ontological and epistemological principles, where qualitative and quantitative research techniques were used. Multi-method research is the umbrella that covers all the studies of this thesis (Brewer \& Hunter, 2006; Hunter \& Brewer, 2003; Morse, 2003). We selected this method as the most appropriate to meet our research questions: 
1) What educational, technological and social needs do potential users require about portals to share digital content in the field of teacher training?

2) What characteristics should have a system for sharing educational digital contents and experiences for meeting the needs of teacher educators?

To illuminate these questions we have analysed and interpreted two studies that converge in the proposal of pedagogical, technological and social recommendations for creating/remodelling educational portals that enable sharing digital content, experiences and knowledge suited for teacher educators:

1) The portal Share.TEC case study.

2) The qualitative comparative analysis of portals for sharing digital educational content and educational experiences.

Besides general research objectives, we propose specific objectives (subobjectives) to achieve within the analysis of every study following their research questions (described in Chapter 3 of this dissertation).

In the "Study 1" we have applied a multi-method approach for gathering and analysing data (using qualitative and quantitative techniques that were independently carried out; they were integrated in the interpretation of the data). We have deployed an intrinsic case study method. Different techniques for collecting qualitative (questionnaires, focus groups, think aloud protocol, etc.) and quantitative (surveys, collecting data automatically through Google analytics) data were applied. Data has been collected in three phases: I) phase of the design of the portal; II) construction phase; III) phase of the evaluation of results. The analysis of qualitative data has followed a process of data reduction (Miles, Huberman, \& Saldaña, 2014; Miles \& Huberman, 1984); the quantitative analysis has been accomplished by various statistical and descriptive tests based on the data characteristics. After data analysis and interpretation, we state the conclusions of this study in Chapter 4. We have applied diverse techniques of reliability and validity (in the treatment of quantitative data) and credibility, through severe data triangulation (Denzin, 1970) (in the case of qualitative data). In chapter 4 and 6 we draw some conclusions about pedagogical, technological, social, business and personalization aspects of online educational portals/web services for sharing educational digital content and experiences, based on the opinions of informants from national and Europe-wide contexts (reaching in this way objectives in this study $A$ and $B$ of the investigation). 
We have applied qualitative research methods for analysing the selected educational portals ("Study 2) (exploratory analysis and comparative analysis). An evaluation model of web services/portals was designed through combining: sources from the literature review and the categories emerged in the data reduction of the "Study 1" (achieving the Objective C). Afterwards, we have analysed and compared every portal following the evaluation model. The main characteristics and good practices (pedagogical, technological, social, of personalization and economical) these portals share and differ from were abstracted (aiming objective $D$ ).

Finally, we draw the final conclusions (Chapter 6) through combining the two studies framed on the context of this research. We obtain evidences that demonstrate little differences among the teacher educators and other education professionals about the pedagogical, technological and social needs related to systems for sharing digital content and educational experiences. We agree with other researches (Clements, Pawlowski, \& Manouselis, 2015; Clements \& Pawlowski, 2012; Lund \& Hojsholt-Poulsen, 2010) and institutions (UNESCO, 2011) on the need of the establishment/existence of a community of practice as a necessary guarantee for the success of a portal. We detect the need of strengthen the culture of sharing and creating digital content from the teacher education programmes. This research is completed with the specification of a theoretical proposal of pedagogical, technological and social recommendations for designing and remodelling these portals (therefore satisfying the objective $E$ of this research).

\section{Structure of the document}

This document is structured in the following chapters:

We summarise the main theoretical framework of this work in Chapter 1. The chapter begins with an analysis of the changes that have occurred in the current society as a product of the evolution and integration of ICT in society and education. We take into account the main educational paradigms and its influence in ICT (that impact the organization and philosophy of the different types of educational portals). We state a brief description of the evolution of digital contents (highlighting open educational contents among them), reflecting on the issues that promote and restrict its use. Afterwards we introduce systems for sharing digital content in the teacher education context, demarcating the existent typologies and diverse ways of organizing content, as well as the social aspects they integrate. The final section of this chapter concludes with some lessons learnt in similar research experiences. 
Chapter 2 gathers the theoretical-methodological framework of this research. Different perspectives that lead inquiries in social sciences are described. We justify why we have chosen the pragmatic vision (Creswell, 2003, 2014) for guiding this research, and explain our axiological, ontological, epistemological and methodological viewpoints. In addition we explain the choice of the multi-method research methodology within this framework and synthetize the advantages and disadvantages of its use. Afterwards inquiry rationalities that lead this work are delimited. We highlight the interpretative philosophical position we mainly rely on for interpreting our evidences. This chapter ends with a description of the research methodology, methods, instruments and techniques used in every study.

Chapter 3 details the research process, objectives and questions that guide this work. After establishing the general aspects, we focus on each study. First, we describe in depth the research processes carried out in the Share.TEC intrinsic case study (Stake, 1995) - "Study 1". We contextualize the case, following the Stake (Comisión Europea, 2005) conceptual structure. Then, we explain the three phases followed during this research: I) Design of the portal; 2) Portal creation; 3) Portal evaluation. Later techniques/pilots applied during this study are described gathering the research techniques used, sample methods, sample features and data gathering and analysis techniques. The last section of this chapter narrates the research process followed in the "Study 2" (portals for sharing digital content and educational experiences). We explain how we built the evaluation model for educational portals, how we selected the portals and how we analysed them.

In chapter 4 we describe the analysis and interpretation of the Share.TEC case study ("Study 1"). Chapter begins with the "issue" that leads the study and its specification throughout topical questions and information questions. We integrate and triangulate the qualitative and quantitative analysis and interpretation of the data through a pragmatic research perspective and a multi-method research methodology. Last section of this chapter states the conclusions of this study following the structure of topical and information questions we set out for the study. The issue is enlightened in the conclusions of this chapter.

Chapter 5 gathers data analysis and interpretation of the descriptive and comparative studies of portals for sharing digital content in the teacher education community ("Study 2"). Firstly we describe how we created the educational portals evaluation model. Secondly, we show the comparative analysis of the technological, pedagogical and social aspects among portals. Finally we extract some conclusions and highlight relevant and novel features of the analysed portals. 
Finally chapter 6 integrates the conclusions that emerged from the two studies. We answer the thesis research question and show the limitations of the investigation. Based on the evidences, we create a proposal for creating/remodelling systems for sharing digital content in the teacher education community attending to: pedagogical, technological and social aspects. We conclude this dissertation with future work proposals (e.g. generating a mock-up based on our proposal and evaluate it with representative samples of international teacher educators).

\section{General outline}


Figure 5 General framework of the dissertation

\begin{tabular}{|c|}
\hline $\begin{array}{l}\qquad \text { Problem } \\
\text { Lack of portals for sharing and creating digital content and experiences } \\
\text { (designed for teacher educators based on their needs) } \\
\text { Digital content scattering } \\
\text { Limited tendency for reusing digital content } \\
\text { Share.TEC portal: low influence on the European teacher education community }\end{array}$ \\
\hline 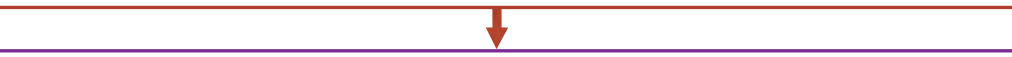 \\
\hline $\begin{array}{l}\text { Theoretical Framework } \\
\text { Society and education } 2.0 \text { towards society and education } 3.0 \\
\text { Influence on new pedagogical models in portals for sharing digital content } \\
\text { Teacher training: don't teach neither arise awareness of the importance of } \\
\text { creating and sharing digital contents in their professional communities. } \\
\text { Quick evolution of ICT: educational portals } \\
\text { Scattering of digital contents and OER } \\
\text { International, European and national policies and programs for gathering } \\
\text { scattered digital content } \\
\text { Standardization trends for promoting digital content retrieving and reuse }\end{array}$ \\
\hline
\end{tabular}

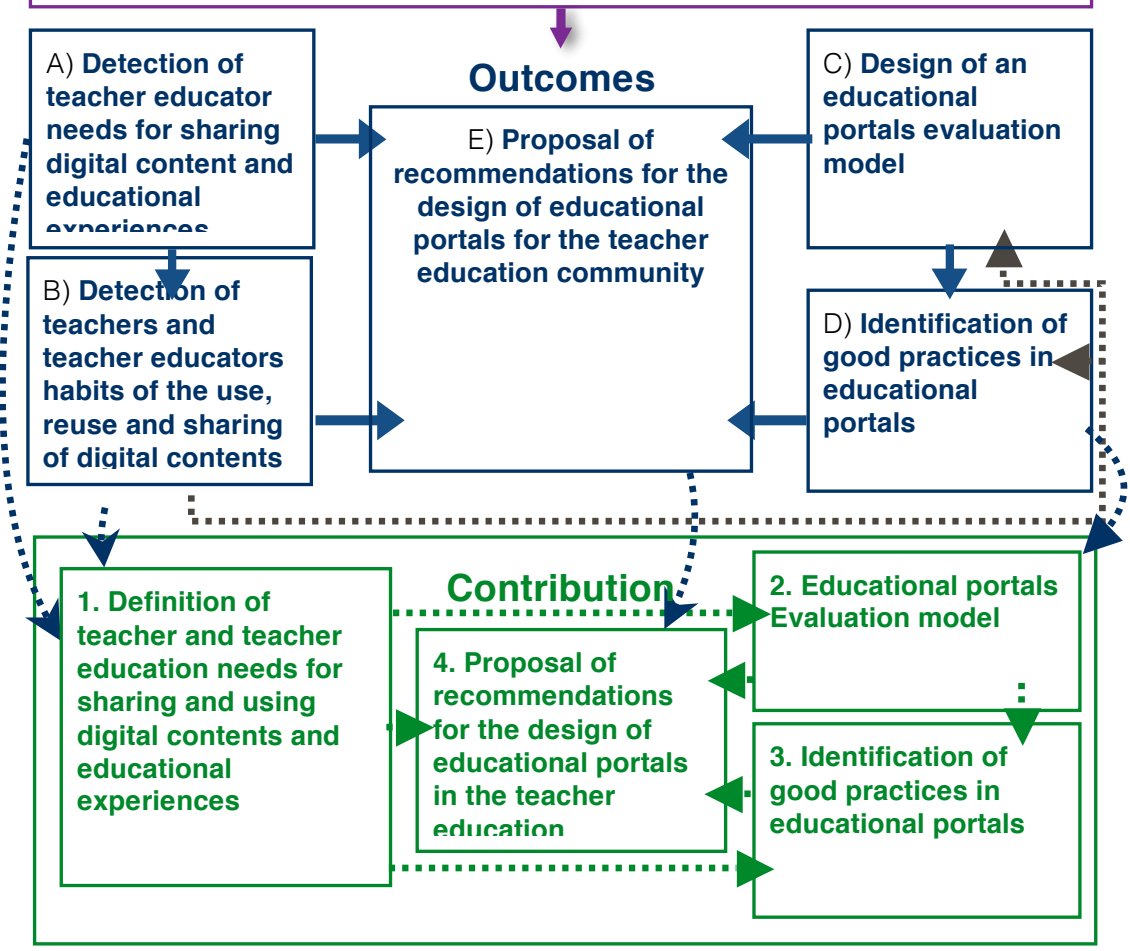





\section{Conclusions, proposal and future work}

This chapter summarizes final conclusions of this investigation. The chapter is divided into three sections. The first one gathers the two research questions guiding this thesis as well as the specific questions of each study. There is explained how we answered to them. Section two states the main limitations of this work. Section three combines the main conclusions obtained during the development of this thesis with the conceptual proposal for designing educational portals. The chapter ends describing future work related to the findings of this research.

\section{Introduction}

In this chapter we compile the main contributions of this work by reflecting how we shed some light to the research questions that guided it.

To do this, we recall the general structure of the thesis. We describe how the general research questions and how every specific study question has been responded. Furthermore we show the objectives and contributions that have been reached in each study.

In the second section there are collected the limitations of this study concerning the scope, biases and research procedures.

In the third section we integrate the findings of this thesis and the conceptual proposal for the design of educational portals, based on the evidence that we have obtained from the two studies of this work. The design proposal is presented with the aim of being considered for creating or remodelling portals (or other web spaces) for sharing educational digital content and experiences. This proposal is primarily intended for the field of teacher training. Nevertheless we believe it could also be useful for generating any type of educational portal that integrates digital content. Thus, this chapter includes the main contributions of the "Study 1" (Share.TEC case study) and the "Study 2" (descriptive and comparative analysis of portals for sharing 
digital content and experiences in the field of teacher education), as expressed in chapters 4 and 5 of this thesis, respectively. We structured the proposal and conclusions in three sections: "institutional recommendations"; "the educational portal"; and "digital content", where we address the main aspects of each.

The final part of this chapter focuses on the discussion of the future work lines related to the design of portals to share educational digital content and experiences. They aim to foster their sharing and improvement in different educational areas.

\section{Conclusions}

\subsection{Discussion of the research questions}

We justified in Chapter 1 the need of performing this thesis research by detecting the scarcity of services for sharing digital content and educational experiences for the community of teacher educators. Furthermore existing services are not always designed according to their potential users' needs and preferences. To do this, we proposed to achieve the overall objectives guiding this thesis (formulated in section 3 of Chapter 3). Aiming to reach these objectives we formulated the research questions that have guided this work (see Figure 1). Questions were addressed from the pragmatic research paradigm, following a multi-method research consisting of two studies.

We have approached "Study 1" through the instrumental case study (Stake, $1995,2005)$ research method. We have analysed the experience of the creation and evaluation (by potential users) of a European portal for sharing digital content in the field of teacher training, Share.TEC. 
Figure 1212 General research structure

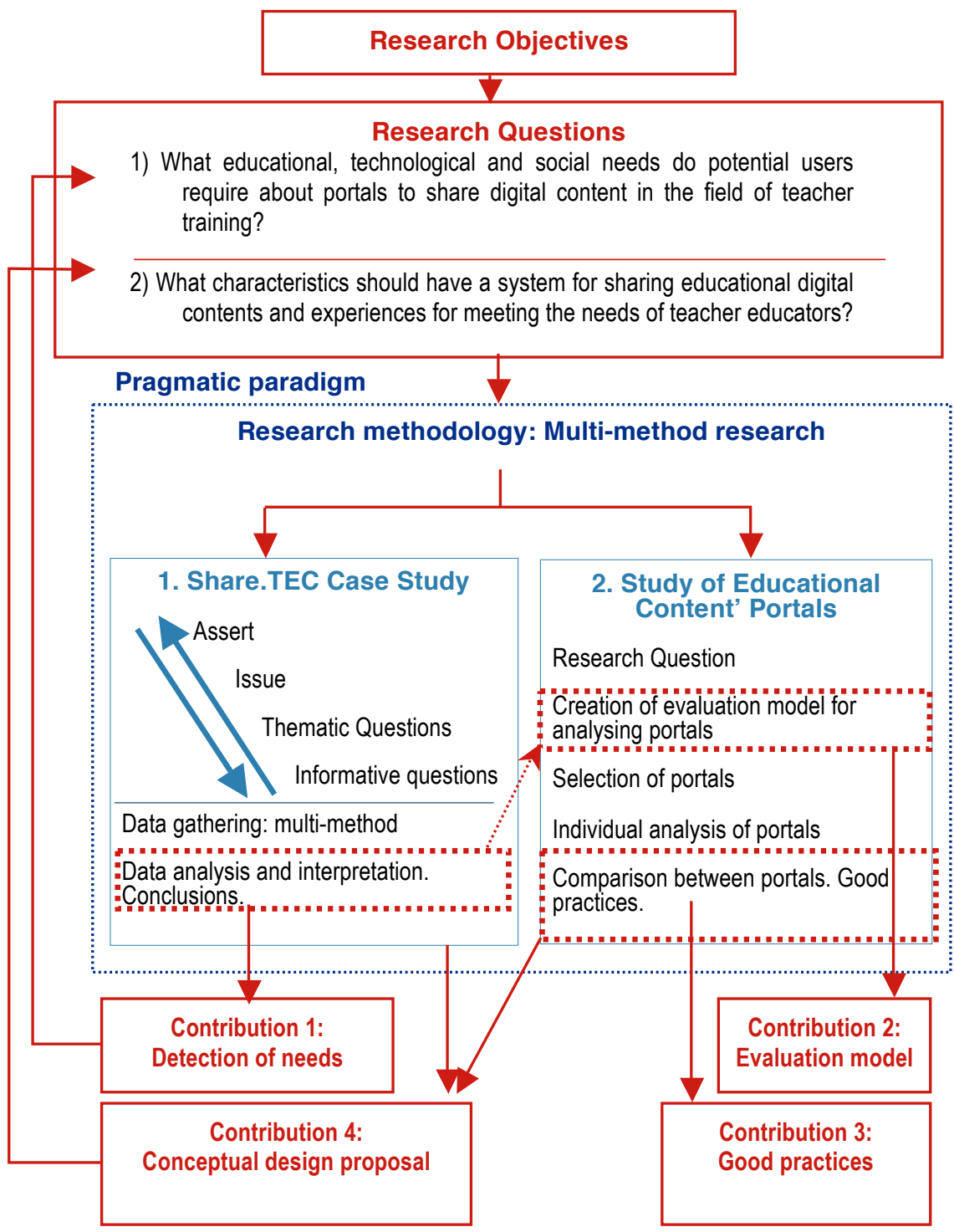

212 Blue arrows from the Share.TEC central box of Figure 1 represent the data reduction process. 
In Chapter 3 we established the "research assertion" we intended to illuminate through the Share.TEC case study, defined as follows:

"We believe that technological, educational and social services Share.TEC offers meet the needs required by teacher educators when they access web portals and publish educational digital content experiences in the field of teacher education"

To illuminate the stated assertion within the conceptual structure of Share.TEC case study, we raised the issue or case study tension:

"How are educational, technological and social Share.TEC levels interrelated to address the needs required by potential users of systems for sharing digital content in the field of teacher education?"

In Chapter 4 we established five topics that allowed us to learn more about the areas in which we focused our attention (through a series of informative questions for each statement). These were: "pedagogical issues", "technological issues", "social issues", "personalization issues" and "economics issues"). These questions inquired about aspects of both, Share.TEC portal and the habits and preferences of the informants about sharing digital content and educational experiences.

We organized the findings of the case study around research topics and information questions (contained in section 2.4 of Chapter 4). These aspects were interconnected in that section, illuminating the issue and confirming the established assertion taking into account some nuances:

"Services offered by Share.TEC portal partially met the needs raised by teacher educators when accessing and publishing digital content and experiences in the field of teacher training".

Those aspects that were not fully satisfied (as we saw in section 2.4 of Chapter 4) will be incorporated into the design proposal we present in paragraph 2.2 of this chapter. Therefore we integrate data from the two studies of this research; state the main general conclusions; and set up a conceptual design proposal reflecting on the main aspects that should be included in these portals. 
The analysis and interpretation of this study has partially met the two questions outlined in this thesis, because:

1) The technological, educational and social needs demanded by teacher educators (and other education professionals) for accessing and sharing digital content and educational experiences in the field of teacher education were identified. This study has resulted in the "contribution 1" of this thesis (see Table 4).

2) The interpretation of the evidences provided by "Study 1" gave us clues about certain features these portals require to meet the needs of potential users (delivering evidences for the "contribution 4").

Thus, the study contributes to the achievement of research "objectives A and B" (respectively associated with: the detection of users' needs for using digital contents; and with teachers' habits of using, sharing and accessing digital contents). In this way this study provides evidences for proposing the conceptual design proposal of this kind of portals ("objective E") (see section 3 of chapter 3 - "objectives") we describe below.

Study 2 (see Table 4) explores a set of educational portals for sharing digital content and educational experiences. We achieved the specific objectives of this research (expressed in paragraph 6.1 of Chapter 3 ) by:

- Creating an evaluation model of educational portals, based on the combination of: the categories scheme emerged after Share.TEC data analysis through data reduction (performed with NVivo213 software); and evaluation/description categories stated in relevant sources of literature (relating to digital repositories/portals). Thus we reached the particular Study 2 "sub-objective a", and "Objective C" of this thesis. This model provides "contribution 2" of our research.

- Exploring and analysing the features of each educational portal, following our evaluation model. Thus we have identified common best practices among portals (reaching research "Objective D" of the thesis), as well as those practices that could be improved. These elements have served to provide conceptual ideas for the design of educational portals (satisfying the Study 2

213 Figure 1: Watch red arrow linking "Study 1" data analysis with "Study 2" creation of the scheme of categories. 
"sub-objective b" and contributing to the thesis research "Objective E". As a result, "contribution 3 " is achieved.

After the analysis and interpretation from "Study 2" data, we answered the research question guiding this study (as we can see in its conclusions, contained in section 3 of Chapter 5 ):

"What good practices and improvable practices can be drawn from a selection of educational portals?"

Once the contributions of each study have been reflected, we proceed to show the two studies data integration. Next section combines the main conclusions of this thesis as well as our conceptual design proposal.

\subsection{Global integration of data and conceptual proposal for the design of educational portals.}

Along the different qualitative and quantitative tests and research instruments performed during and after the Share.TEC project, we inquired about the opinion of teachers with different profiles (teacher educators, Primary Education and Secondary Education teachers, researchers, engineers, psychologists, etc.). In light of the data there are very few differences among the different roles on their technical, educational and social preferences related to portals for sharing educational digital content. The only remarkable nuance is that it seems that teacher educators are more likely to use ICT (although we must bear in mind that many teacher educators within the samples had a technical background, since they were somehow related to educational technology). This fact makes us think that most of the proposals that we describe below are equally useful for professionals of different levels in the field of training.

We organize this conceptual proposal for designing educational portals around four topics: institutional recommendations; the educational portal; educational aspects; and social aspects. In each topic we reflect on the contributions from the two studies.

The following design considerations we describe both, complement, and are based on the findings obtained by similar researches that share common elements with our investigation (as aforementioned in section 2 of Chapter 1 of this thesis). 
Conclusions- Global integration of data and conceptual proposal for the design of educational portals.

\subsubsection{Institutional recommendations}

In Chapter 1 of this thesis we collected the main contributions of the Kreijns et al. (2013) research where authors showed there were several variables (which they called "distal") at three levels ("micro", "meso" and "macro") that directly influenced on other variables (which were denoted by the term "proximal"). Proximal variables were: "attitude towards the use of digital content", "subjective norm" (what you think others expect from you using educational digital content) and "perceived selfefficacy".

\section{A) Macro-level recommendations}

We consider it is necessary that "macro-level" institutions (national, regional and local governments) generate programs and spaces encouraging the creation, use and sharing of digital content in the field of teacher education. We think these bodies can undertake actions that would allow teachers: fostering motivation; improving the self-efficacy perception in the use of ICT; and promoting the usability and usefulness perception of ICT and digital content in education. In the "Study 1" we observed the low frequency with which informants shared digital content, and the low frequency with which this content was publicly shared (see section A.9 Section 2.3 of Chapter 4).

For these reasons we consider that macro-level institutions should launch training programs for education professionals promoting knowledge and awareness on: the importance of educational portals; the relevance of creating and sharing digital content in real contexts - especially addressing open content (OER) and its various licenses-; etc. Additionally, we have highlighted the relevance of teachers engaging and involving in virtual and face-to-face communities of practice. This is a crucial point if we want to be consistent with current society demands, where preservice teachers will be the reference for the new young generations; as well as consistent with European policies and guidelines (in the European context) related to ICT integration in educational contexts (European Commission, 2013b, 2014; European Higher Education Area, 2012). It is also important to address these issues from different lifelong learning courses promoting teachers' professional development.

Educational communities are the driving force for activating services for sharing digital contents. There are different patterns among educational professionals with respect of the will of using ICT on education. There are European, national and local 
measures (at least in Spain) sponsoring ICT expansion and immersion in the diverse educational contexts.

At a macro level we suggest international, national, regional and local educational bodies and institutions to propose measures to encourage the creation and use of a web space shared by a large number of teacher educator communities. Such measures may include:

1) The creation of education policies that reflect on the need of using, creating and sharing educational content among education professionals. We believe this measure could improve teaching practices, foster innovation and provide more quality to educational materials from every field, coinciding with ideas raised by (Lund \& Hojsholt-Poulsen, 2010).

2) The generation of a digital content portal primarily focused on open educational resources (as we described in Chapter 1, the use of these type of content positively impacts on educational systems). We suggest this portal should be managed by public organizations (e.g. National Institute of Educational Technologies and Teacher Training - belonging to the Ministry of Education, Science and Sports of Spain ${ }^{214}$ ). This could help ensuring the free existence and sustainability of the system over time.

Companies are alternative options for creating/managing portals. In this case, the inclusion of sustainable business models must be considered (e.g., integrating payment services; advertising events / educational services; offering additional paid services; etc.), without losing the integrity of the portal, to ensure free general services.

When escalable existent portals offer services of quality for teachers we suggest to escale them including good practices/new technologies. For instance, Spanish "Procomún" portal (Network of Open Educational Resources) ${ }^{215}$ is a quality portal

\footnotetext{
214 In Spanish this Ministry is known as "MECD".

215 This service is based on the former portal "Agrega" (discussed in chapter 5 of this thesis). This new portal has redefined the different services prevoously provided by Agrega. For instance, there have been made improvements in the search functionalities (it has been integrated, among others, folksonomies that complete initial metadata; Semantic Web services that optimize the searches; and a teachers' social network that enables sharing educational experiences). This portal mainly integrates OERs for teachers, students and anyone interested in the educational levels of "preprimary", "primary", "secondary" and "vocational training"; however it is not intended for "teacher training".
} 
Conclusions- Global integration of data and conceptual proposal for the design of educational portals.

that could be remodeled through the time for offering their users updated services and functionalities.

Our evidences show that there are no major differences between the needs of teacher educators and those from teachers from other educational levels when sharing digital content and experiences. Major differences lie in the ontology and metadata model. These should be aggreed by every educational community to which it is intended.

3) The recruitment of people for designing and developing (or remodeling) the educational portal listening to the heterogeneous voices from the "actors" involved in the life cycle of the portal (Lund \& Hojsholt-Poulsen, 2010). The portal should address, among others, educational, technological and social aspects. To ensure portal succes there should be people in charge of managing and administrating the portal the portal and activating its comunity (e.g., content manager, solving user problems, community manager, advertising agent, etc.). Lund et al. (2010) suggest that users themselves should activate communities, although it is important to have a community manager that encourages and mediates whenever it is required.

4) The impact on teacher education training plans from Spanish and European universities. We suggest to include in training plans courses that provide awareness and promote the developmentng competencies of future teachers for creating and reusing OERs and educational experiences in web portals. In relation with OERs there should be taught, for instance, aspects related with their usage rights, and knowledge of different licences types.

We also recommend educational institutions (such as INTEF 216 or other european bodies) to offer lifelong learning courses promoting the stimulation of educational portals for sharing OERs. When users are proficient using digital content and technology, educational portals are more prone to be successful and used, since this users perceive more confidence to use them and improve their self-efficacy feelings around their use (Cheung, Lee, \& Lee, 2013; Di Paola, 2007; Kreijns et al., 2013). As we saught in Chapter 1 through the theoretical foundation and through our "studies", there is a limited culture os

216 INTEF stands for the National Institute of Educational Technologies and Teacher Training. Among its programs includes actions for teacher training in subjects dealing with Educational Technology (e.g., Teacher Professional Development Framework and Plan for Digital Culture at the School) (MECD, 2016). 
sharing digital contents among teachers. Moreover, as we saught in "Study 1", contents are often privately shared (so that general educational community does not benefit from all the generated material).

5) The last macro-level measure we propose refers to the creation of an educational portal for educational professionals that takes advantage of the benefits provided by the different sizes of communities:

- By engaging existing specific communities of professional (e.g., community of professionals on Education Technology and Communication).

- Trying they use this space, where the set of specific communities and other independent users could coexist. To do so, users should be able to customize the portal and choose what content and how they would like to visualize it (languages, areas, communities, users, pictures, etc.)

\section{B) Meso-level and micro-level recommendations}

From a meso-level perspective, universities have to integrate the use of ICT into their educational programs and courses with a pedagogical sense (in order to suit to political and social demands of modern society). Thus, students would normalize the integration of ICTs in their educational practices. We believe that when pre-service teachers will be aware of the relevance and benefits of sharing educational digital content and experiences, they would be more prone to engage in these communities. Therefore, this could impact on schools innovation and improve their quality.

Finally, in the micro-level, we consider that ICT auto-efficacy perception of teachers could improve if they were required to get trained on ICTs for education (through lifelong learning training that would allow them get updated on the new technologies advances and educational methodologies and method to use them). We believe that by adopting this measure teachers would gain security and knowledge for integrate ICTs on their educational practices. In this sense, we suggest to train teachers in the use, creation and sharing of digital contents. In a similar way, their attitude towards the use and sharing of digital content would be, in terms of Kreijns et al. (2013), a factor that would encourage the willingness of use and integration of these technologies in teaching practices.

We propose a series of recommendations for designing/remodelling portals devoted to the teacher education context regarding the needs of their final users. 
These recommendations are based on the current state of educational portals and digital contents for teacher education, on the European perspectives and policies regarding their use, and on the results from our study and similar studies (Cervone, 2012; Cheung et al., 2013; Di Paola, 2007; Kreijns et al., 2013; Lund \& HojsholtPoulsen, 2010; Warwick, 2012; Yalcinalp \& Emiroglu, 2012). ${ }^{217}$ Our proposal integrates, combines and complements all these works recommendations.

We found a great coherence between our evidences and the recommendations proposed by Lund et al. (2010) to generate educational portals, since through our research we extracted very similar proposals. We extend their proposals and focus them on the field of teacher training.

\subsubsection{The educational portal for teacher training}

When designing a website, it is essential to think about the orientation and objectives underlying their basis. Based on these principles, it is necessary to consider how to design a portal satisfying the needs and preferences of their potential users. We describe below the main recommendations we suggest for designing educational portals:

\section{A) Portal access}

The access to the educational portal can combined several methods of access. As we analysed in various "Study 2" portals, a mix between public access to limited services, and private access could be combined. Private access involves signing up into the portal, and could allow users reviewing, commenting, accessing information and personalizing features - e.g., "my portal", etc.). This type of access is appropriate to preserve the safety of users and the private information they share.

In light of our data, it is positive to offer the possibility of registering through other existing services accounts (Google or Facebook, for example), among other reasons, to avoid forgetting access data and to avoid the multiplicity of accounts.

To ensure security, it is useful to include CAPTCHAs for preventing automatic accounts creation and SPAM within the portal.

217 These studies results have been gathered in section 2 from Chapter 1 . 


\section{B) Architecture of the portal}

In the Share.TEC project there were difficulties for improving the portal based on users recommendations, since the architecture was created before their evaluation. The architecture was designed without taking into account their views from the beginning. From our view, evaluating mock-ups of the portal through iterative evaluation before constructing it is a good practice. After several iterations, a portal that meets their final users needs and preferences can be created.

It is necessary to design flexible and adaptable portals that allow interoperability with other systems (based on standards), as well as the integration of "future" and existing tools and services (Lund \& Hojsholt-Poulsen, 2010) (e.g., "tweets", "Hangouts", "importing own contacts' e-mail accounts", etc.). There is no need of "reinventing the wheel", since there are useful tools and services that could be integrated in the architecture of new portals. These tools should be presented to its final users in a way that meet their needs. By integrating "future tools" we mean that portals must be designed to allow the incorporation of emerging technologies along the time (e.g., including features that enable each user customize automatic recommendations -functionalities that would be more powerful in a future- and features based on semantic technologies).

It is interesting to think about federating services or repositories of digital content (such as Share.TEC portal does). This practice allows minimizing the number of spaces users access to; therefore, it facilitates the content retrieval.

\section{C) Search}

As we saw in the analysis of the "Study 2", the investigated portals offer different search strategies (through exploration, simple search or advanced search). Every type of search has several associated features (see Table 60).

Table 68 Types of search and existing functionalities from "Study 2" analysed portals.

\begin{tabular}{ll}
\hline Search Types & Functionalities \\
& •By categories: "area", "learning unit", "subject", "professional \\
& development", "technology", "administrators", "resources for schools", \\
Exploration & "specialities", "pre-primary education", "way of life" and "funny activities". \\
& •By "videos", "audios", "forum", "pictures", "docs", "groups", "classes", \\
& "profiles", "collections".
\end{tabular}


Conclusions- Global integration of data and conceptual proposal for the design of educational portals.

- Explore forums by categories.

\begin{tabular}{ll}
\hline & - Keywords. \\
Simple & - - imit the simple search by type of resource. \\
search & - Show the number of results available as keywords are written. \\
& - Suggestions based on the searches performed so far. \\
& - Google Search engine integrated. \\
\hline & - By knowledge areas o thematic searches. \\
& - Filtering by the most active. \\
& - Filter most recent news. \\
& - Filtering by "all the keywords", "some", "exclude some keywords", etc. \\
Advanced & - Filtering by educational standards and competences. \\
search & - Filtering by reviewed materials. \\
& - Filtering by cost and usage rights. \\
& - Filtering by language. \\
& - Filtering by resource accessibility. \\
& - Filtering by "location/country". \\
& - Filtering by "institution".
\end{tabular}

In "Study 1" we saw how users had different preferences when searching for resources. We believe it would be appropriate to offer the greatest possible number of search functionalities, to cover the different needs and preferences of every user.

Share.TEC informants said they felt more comfortable with search interfaces that looked alike those they generally used. They valued positively the search system of the portal. Therefore, we suggest that search interfaces from portals/services should be designed like those offered by well-known search engines (e.g., the Google search engine).

\section{D) Interface}

We have detected common elements among the interfaces from the different analysed portals (in "Study 2"). They usually have simple interfaces, light backgrounds, comfortable font types and colours, etc. We consider useful to include best practices from other successful portals (not even educational) (e.g., "Destinia", 
"Amazon", "e-Bay", "Booking.com") copying their advantageous services/features (e.g., ways to filter results or present).

Thus, we believe convenient to provide simple applications for tagging metadata that enable users contributing with their resources and/or enriching other existing metadata. For this reason we recommend to show this function from every page of the portal/web service (not only located in the "Use" section, as we saw in Share.TEC). Therefore we believe advisable to have "rapid sharing" buttons to easily disseminate this content in other portals/services (e.g., through social networks, email, and other applications).

It is therefore relevant to design user spaces within the portals. This spaces should follow existing interface design principles (UsabilityNet, 2003) related to personalization, usability, human computer interaction (HCl), etc. (McGreal, 2010; Pynoo et al., 2012; Stone, Jarrett, Woodroffe, \& Minocha, 2005). Web spaces must take into account: the recommendations of usability from ISO/TR 16982: 2002 (ISO, 2002), the different parts of ISO 9241 (ISO, 2015) standard as well other guidelines and international standards that can be found in Usability.Net (2006) (among others) to promote usability, navigability and visual aspect of the portals.

After analysing "Studio 1" and "Studio 2", we saw that many portals integrated very useful "hidden" features. To make the most of these features we recommend the incorporation of fixed "general menus" easily accessible (i.e., at the top or side of the interface) from every page the portal.

\section{E) Features}

In section 2.1.6 from chapter 5, we collected the functionalities offered by the analysed portals related to: personalization, language, digital content, technical aspects and sustainability. We think that these features can be considered for the design of educational portals. The inclusion of ones and/or other functionalities will be more appropriated depending on the potential users and objectives from every portal. As we saw in "Study 2" the type of educational portal determines the greater or lower presence of certain types of functionalities (e.g., a "social network", where teachers share digital contents, tends to include more social features than those associated with content organization).

Functionalities collected from all the portals are: 
Conclusions- Global integration of data and conceptual proposal for the design of educational portals.

Table 69 Technical Features from portals analysed in "Study 2".

\section{Technical Features}

- A link/box for providing feedback to the owners of the site.

- Availability of tutorials or information to understand the characteristics of the site, its terminology, how to use it, etc.

- Configuration of RSS or Newsletters to receive updated information.

- Export resources to Virtual Learning Environments.

Table 70 Social features from portals analysed in "Study 2"

\section{Social Features}

- Access / creating users' blogs

- Access to others' profile

- Forums / debates

- Create / view events

- Webinars

- See birthdays from the user' network

- Create / join to groups.

- Send messages / contact with other users

- Share content on other social networks by one click

- Send material by mail by one click

- Space to request / offer help from/to others.

- Organize resources' authors by disciplines

- System of icons to identify the roles of users

- Social recognition systems (e.g. Badges)

- Curated content by author / institution / publisher

- Users online

- Profile of similar members

- Make questions for students / teachers in the portal.

- Share links

- Collaborative Workspaces

- Recent changes in the portal / News

Table 71 Features of Digital Content from portals analysed in "Study 2"

Features of Digital Content

- Access to digital content in multiple formats (audio, text, image, etc.)

- Access to training courses

- Tool for creating digital content

- Vote and visualize resources ranking

- Comment digital contents

- Download resources

- Quote materials

- New / featured content / news

- Information on educational laws 
- Re-use of digital content within the portal/web service

- Favourites / Bookmarks

- Filter by for reviewed materials

- Classrooms creation with students management tools

- Automatic code-generation tool to manage tasks

Table 72 Personalization features from portals analysed in "Study 2"

\section{Personalization features}

- Show content by:

- Top Rated / Popular

- Most shared

o Author

- Material reviewed by each user

o Interactions of the latest / Top Rated / Most commented resources

- Show groups by

o More active

o Final user

o Resource' topic

o News

- My Groups

- Communities

- "My space" function

- Automatic recommendations based on user profiles

- Display resource collections

- Translation tools built into the system (e.g., Google)

- Multilingual Portal that offers the possibility to select the preferred language

- Search history

- Set the display depending on the role

- See Stats content

- Manage access rights and licensing resources uploaded by users

Table 73 Accessibility features from portals analysed in "Study 2"

\section{Accessibility features}

- Visual Browsing by tags

- Legible with voice processing software

- Navigable with keyboard

- Toolbar for customizing the portal accessibility

- FLOE Tools 
Conclusions- Global integration of data and conceptual proposal for the design of educational portals.

Table 74 Sustainability features from portals analysed in "Study 2"

Sustainability features

- Receive Donations service

- Export contents through widgets for inserting dynamic content within other websites

- Awards for the best resources shared on the portal to stimulate the contribution of content

- Declare the aims of the website/portal in the homepage

\section{F) Personalization}

Educational resources exponentially increase year by year (Cechinel, Camargo, Sánchez-Alonso, \& Sicilia, 2014). This fact makes difficult the task of finding relevant content that meet the needs of users (Bienkowski \& Klo, 2014). Educational portals should include personalization functionalities in order to promote their efficiency. Automatic recommendation systems constitute one of those services. These systems allow content personalization and the modification of portal functionalities by taking into account several parameters: the preferences defined by users in their profile; the social metadata analysis (Bienkowski \& Klo, 2014); the automatic educational resources metadata evaluation; the rankings of the resources (Cechinel et al., 2014); the automatic evaluation of the users' comments; as well as other recommendation systems, such those described in Manouselis et al. (2014).

Two out of the fifteen analysed portals (Open Learn and Share.TEC) recommend materials for users. These contents are related to those they previously found (since resources metadata coincide, have similarities, or fit to users profiles). We consider convenient to integrate these and other kind of services that promote content sharing and reusing, and activating communities within the portal (for instance, by suggesting similar users).

Other appealing component is the creation of user-personal spaces in the portals. These spaces let users manage and see their interaction within the portal (e.g., by accessing: their bookmarked resources, their used or shared resources, their comments and conversations with other users, etc.; and by showing the communities they belong to).

In the "Study 1" users positively appreciated the existence of these spaces. Particularly the space offered by Share.TEC needed improvements based on our informants' views (e.g. by congregating scattered functionalities among pages). We suggest to educational portal creators to provide this functionality allowing 
personalization options (e.g. move/add/delete/modify functions modules, change look \& feel, etc.)

With respect to languages, there is a need of allowing users to personalize the interface, as well as the results they see in the portal. In this sense, we highlight Merlot portal, which shows in first place results in the language preferred by each user. We acknowledge appropriate the integration of these functions in portals so that they increment their personalization: by showing options for filtering results by language, and by showing in first place resources from their preferred languages.

\section{G) Multiculturality}

To solve multicultural issues portals might use personalization strategies such as showing resources and information to them only in their preferred languages (if they want to).

As seen in Share.TEC portal, it integrated little graphic elements. Other portals (such as those analysed in chapter 5 of this document) introduced different graphic elements that promoted the easy acknowledgment of the kind of resource (through icons or picture thumbnails of the resource).

We believe that the inclusion of icon systems that promote users the recognition of resources metadata might universalize and ease the fast recognition of main content features.

Including folksonomies personalized for each user (depending on their language preferences) could advocate overcoming resource tagging multicultural barriers.

Concerning language, informants from "Study 1" thought that coexistence of several languages enhanced the system (always that they were able to personalize the content languages they wanted to visualize in the system). As seen in chapter 4, informants identified as disturbing to see results in languages they did not controlled (e.g. an Spanish who does not know Bulgarian, sees his/her interface content in this language).

Furthermore, we consider portals might avoid visual language representation through icons of country flags, since there are different vernacular languages in some countries, besides a same language can be spoken in several languages. This action might cause exclusion feelings. 


\section{H) Usability}

Some studies reveal that portals in order to be useful for their users need to be focused and know their community of practice' needs (Abras, Maloney-Krichmar, \& Preece, 2004). Users tend to make a quick evaluation of web portals taking into account their visual complexity and expectations of the web depending on the service they offer (Tuch, Presslaber, Stöcklin, Opwis, \& Bargas-Avila, 2012). This judgment influences in their desirability of using the portal. The "Study 1" informants negatively evaluated Share.TEC interface. We think this might have been one of the factors that determined its low use.

There exist international standards for helping designing web portals and their applications following User-Centred Design methods, such as ISO 9241 (ISO, 2015). This standard includes "usability", "Human Computer Interaction", "user-centred design", "navigability", etc., sub-specifications. These specifications and standards allow following certain protocols supporting the creation of usable and accessible webs for their users. Moreover they assist on the design of appropriate interfaces for users.

Attending multi-language portals that integrate digital contents, there is a need of properly distinguishing the content language vs. the metadata languages (in cases where content have multi-language metadata descriptions). Furthermore, platforms integrating several languages should provide correct translations in their interfaces and functionalities in order to promote portal quality reliability of potential users.

We acknowledge the number of Share.TEC digital contents, communities and users per community through "Study 1". In "Study 2" we analysed if portals showed these data. We recommend portal designers to create statistical functionalities that automatically show and update the numeric data of the aforementioned aspects. We believe that including this statistics, users get an overview of the kind of portal they are in, and let them easily evaluate if it is worthwhile or they should look for other service. Share.TEC offered an interesting option, allowing the visualization of the number of metadata records as new filtres were added. 


\section{I) Accessibility}

In concern with accessibility it is important to design inclusive portals that guarantee access to everyone. There exist some initiatives and projects which provide free tools to overcome web access barriers (e.g., FLOE ${ }^{218}-(2015)$-).

We consider engaging Yalcinap \& Emiroglu (2012, pp. 479-480) research contributions about accessibility. These authors suggested providing appealing names to portals and giving free access to them.

\section{J) Sustainability}

Among the studies we have analysed we have found some interesting measures to increase portal sustainability. We highlight some of them: functionalities to let donors provide economical contributions; provide further access to interesting functionalities if they pay a monthly/annual fee (e.g. establishing partnerships with publishers); offer tools to maximize the visibility of the portal (e.g. export content of the portal to other web services (e-mail, social networks, etc.); exportable widgets).

\subsubsection{Pedagogical Issues}

Educational portals should be framed under constructivist and connectivist visions. To design portals under this umbrella, they should include tools for promoting users collaboration, and content and knowledge exchange. In this sense, web 2.0 tools might be included (such as those gathered in this chapter and chapter 5 , as well as functionalities allowing external tools integration (e.g. "Twitter", "Meet up", "webinars tools", etc.).

\section{A) Content licence}

The creation of open educational resources and open licences have to be promoted in order to increase their funding impact and reuse (Lund et al., 2010). In chapter 1 we gathered the advantages that provide the use of OERs (Open Educational Resources).

${ }^{218}$ Flexible Learning for Open Education http://www.floeproject.org/index.html / Project from the OCAD University that offers free resources for personalising educational spaces. These tools allow overcoming content access barriers (both in the web design and in the design of educational materials). 
Conclusions- Global integration of data and conceptual proposal for the design of educational portals.

We appreciated the complexity of finding the licences of digital contents from portals analysed in "Study 2". This fact entangles the reuse of digital content since teachers may feel unsecure about if they are breaking copyright issues (De Vries, 2013; Downes, 2007). To defeat this difficulty we propose to explicitly easily show licences associated to contents in web portals. We recommend showing this information through clear icons. In addition, we suggest portals showing the prices of contents (where applicable) to allow users save time in their searches (if they are not comfortable with buying contents).

\section{B) Ontologies and Metadata related to educational resources.}

Including ontologies and metadata standards in educational portals constitute a necessary strategy to promote metadata automatic harvesting through semantic web (Alvino, Bocconi, Boytchev, Earp, \& Sarti, 2009; Ferran Ferrer \& Minguillón Alfonso, 2011; Minguillón, Sicilia, \& Lamb, 2011; Yalcinalp \& Emiroglu, 2012).

We can find certain Primary and Secondary education common core standards in the diverse regions from different countries. Furthermore, these standards can be easily mapped among countries (nevertheless, cultural and curricular differences can be found). Regarding Higher Education, and in particular teacher education, there are multiple structures, since frequently every university have legal authority to decide their own curriculum. This means that it is necessary to create understandable structures for the various international communities of practice, allowing multicultural web spaces for this context. Some measures that can promote international web spaces are: the inclusion of shared vocabularies through folksonomies and agreed structures and vocabularies (through ontologies with different specification levels for every context and or community)

Currently there are systems that can automatically gather metadata from contents (if these follow certain standards and systems are interoperable). However, generally these systems do not cover pedagogical tagging, so that it has to be manually tagged.

Due to many users are no willing to manually tag digital contents, we recommend the inclusion of mixed systems: educational ontologies (which promote the access of resources through pedagogical searches) with folksonomies (allowing users to tag resources from their own and others' materials). Folksonomies hold high educational value; both for stimulating the ability of extracting the content of a message as well 
as for enabling collective construction of sense and learning (Blanco \& Ramos, 2009).

By creating this kind of mixed systems we believe that:

3) Probabilities of users enriching contents through comments and metadata increase if users have simple systems for doing it (e.g. tagging new keywords) and if they believe it is useful (for themselves and/or others)

4) Pedagogical tagging can improve along time if users can add new tags for resources and these are dynamic and reviewed by educational expert administrators or users with permissions. We believe that the existence of these "dynamic folksonomies" in a portal could lead to retrieving more pedagogical accurate resources.

As we have seen among the different analysed portals in this doctoral thesis, sometimes we found resources tagged for a concrete level or area. At all events, some of them could perfectly fit with other levels or areas depending on the pedagogical strategies and objectives they are used for. Therefore we raise folksonomies as a functionality that enriches portal content. We suggest portals allow users to create tags for the experience of use of the contents (we believe this measure can increase content reuse).

Competences must be included in the content pedagogical tagging metadata fields. Along analysed portals from this research, half of them tag their contents with this field. European educational policies tend to value the importance of acquiring competences to equip people with strategies for adapting the changing social and working demands. As part of the social system, Higher Education and teacher training also require this adaptation by achieving certain competences (Bozu \& Canto Herrera, 2009; European Commission, 2010, 2013c, 2013d; Rodríguez Rosell, Berlanga Fernández, \& Sedeño Valdellós, 2013; Ruíz Requies, 2009).

Moreover, metadata fields must be understandable by communities they are devoted to. In the Share.TEC case study we found highly tech metadata fields that caused confusion to its informants (such as "application - .pdf"). Informants requested the incorporation of familiar educational fields that were not included in Share.TEC ontology (e.g. "Webquest", "educational rubric", "research article")

In addition we conclude throughout our data that indicating the pedagogical principles every resource is based on can lead the decision to use or not a concrete 
pedagogical content (depending on the educational purpose and the level of structuration of the resource).

\section{C) Quality of content}

Populating repositories is a complex task. Systems that provide automatic pedagogical tags to resources should be promoted. Educational metadata standards are needed for enabling this. "Study 1" evidences suggests that the Share.TEC ontology was positively esteemed by its informants (from different countries). We suggest keep on working on refining the "Teacher Education Ontology" proposed by the Share.TEC project, creating a pedagogical metadata standard for teacher education based on LOM-IEEE (as well as the creation of its specifications for covering the different cultural contexts).

Clements et al. (2015) reveal in their research that emerging educational web portals/services require experts to provide more attention in their administration and their content management. Lund et al. (2010) state that the key of the success of an educational portal has to do with quality offered in its early stages.

Subsequently it can be given more independence to portal' users for managing content. At this stage, efforts have to be focused on engaging users in the community and activating it. Clements et al. (2015) propose integrating several mechanisms for managing quality (e.g. peer review, comments, social tagging, bookmarks, subscriptions, rankings, etc.) 
Table 1 gathers the main facets we consider (based on this research evidences) for guarantee quality content. These measure deal with three dimensions: metadata users descriptions, content variety, and the content itself:

Table 1 Digital content quality dimensions and components

\begin{tabular}{|c|c|}
\hline Dimension & Components \\
\hline Metadata & Complete pedagogical and technical metadata descriptions \\
\hline Diversity & Educational type and technical format content variety \\
\hline The content & $\begin{array}{l}\text { Useful contents for the educational areas they are devoted to, } \\
\text { accredited by these criteria (based on others' researches (Clements } \\
\text { et al., 2015; Clements \& Pawlowski, 2012) and on our research } \\
\text { evidences: } \\
\text { - Author name } \\
\text { - Author reputation } \\
\text { - Ranking (average) } \\
\text { - Qualitative evaluations from users } \\
\text { - Pedagogical Tagging } \\
\text { - Quality collaborative instruments: } \\
\text { O Comments } \\
\quad \text { O Peer review } \\
\quad \text { o Social Tagging } \\
\quad \text { o Favourites } \\
\text { o RSS } \\
\text { Presence of OERs in the portal. OERs could be re-used by other } \\
\text { professionals by remodelling them (if licence allows this) and re- } \\
\text { sharing their improved or re-contextualized version. Remodelling } \\
\text { and providing/receiving feedback can provide improvements in } \\
\text { content quality (Hylén, Damme, Dirk, Mulder, \& D'Antoni, 2012; } \\
\text { Yuan, MacNeill, \& Kraan, 2008). }\end{array}$ \\
\hline
\end{tabular}

Informants from "Study 1" thought that the "author name" and "ranking" criteria constituted the elements that more accurately described content quality. In this study we appreciate the difficulty of evaluating content quality, since, sometimes, pedagogical metadata provided to digital contents is very subjective and contextualdependent (e.g. educational level, competencies, etc.). This subjectivity can only be reduced by the participation of an active community constituted by a sufficient number of people that would allow diversity of opinions and simultaneously the convergence of ideas. 
Among analysed portals, "Connexions" offered "Lenses". This functionality allowed users, editors or managers from institutions sharing "curated content" (Guallar \& Leiva-Aguilera, 2013).

\section{D) Diversity of Content}

Informants from Share.TEC' case study revealed they used high diversity of digital content types. This means that a system for sharing and retrieving digital contents for this population has to offer a large variety of media types (audio, video, picture, text), as well as educational diversity.

\subsubsection{Social issues}

Firstly a portal needs a community requesting the service in order it is accepted and largely used by final users of certain context. Secondly, attending the high diversity end prolix quantity of existent educational portals, these have to include an outfit of aspects that guarantee the portal success, by combining:

- The integration of elements that improve existent solutions (e.g. a field-specific ontology which promotes retrieving and reuse of content).

- Offering quality services and quality digital contents: in form and content.

- Providing accessible and Usable services.

Portals need of communities of users engaged if they want to be successful. Some researches show that networks became active as number of cooperative activities increase in the portal (or web service) (Bessenyei, 2008). Hearn \& White (2009) synthetized main relevant aspects that support communities of practice:

- Smallest communities allow the promotion of a higher feeling of confidence than bigger communities. Participants have less fear of participating in the evaluation of content in the small communities. Furthermore, these communities promote the experimentation and innovation activities.

- Members of larger communities may use their good expert reputation in their field, creating valuable ideas and influencing in their knowledge area. In this sense, these communities allow knowledge validation and promote the adoption of new ideas and practices. Besides, users get benefits from the coexistence of people with multiple views, promoting the knowledge critical review. These communities allow a larger dissemination of best practices. 
In "Study 1" we asked users about the necessity of the existence of a portal similar to Share.TEC. Informants considered that this system would be very interesting and useful for sharing educational contents and experiences.

According to the type of areas the portal should include, informants reflected that a multidisciplinary network would stimulate sharing more number of contents. Thus we believe that an ideal solution would be to foster the coexistence of both types of communities (larger and smaller), by creating a large community hosting subcommunities.

In addition we think this kind of spaces could provide teachers resources of quality and interesting resources (since they have been filtered by other users). Likewise evidences informants provided suggest that the ability of watching what others shared stimulates and inspires sharing and remodelling educational digital content and experiences.

In this sense we support Lund et al. (2010) recommendations gathered in their EDRENE report dealing with ways of engage users in portals. Hereafter we expand them and provide the following suggestions:

- Integrating existent social tools for accessing the portal as well as for establishing "friends" networks inside the portal (sending invitations to friends by e-mail, name of other users if they are already registered, etc.); using similar technologies they are familiarized with (importing friends from Facebook, etc.)

- Creating simple interfaces that look like systems they frequently use (social networks) for promoting user interaction.

- Hiring a community manager (besides their administrators) for activating the community and offering updated information services by areas (scholarships, grants, highlights, highlighted person, employment offers for teachers/teacher educators, etc.).

- Engage existent communities of users for using the portal and foster its expansion. Furthermore we propose the possibility of the coexistence of subcommunities by area/topic inside a bigger community. This could serve for getting the most of the small and large communities. It is important to devote much effort on activating the community as researches from the literature (i.e., Clements et al., 2015; Minguillón et al., 2011, p. 35; Tosato, Carramolino Arranz, \& Rubia Avi, 2014) and Share.TEC show. These researches consider this aspect as one of the most relevant for communities' success. 
-We support Lund et al. (2010) research results considering relevant building trustiness, reputation and brand, promoting users feeling secure as part of the community.

- It is important to explicitly state mission and vision of the portal. We understand this fact through "Study 1", where users did not know what the portal was for at a first glance.

- There might be offered rewards and incentives for stimulating users participation in the portal (participating in discussions, ranking contents, showing the number of friends, showing persons who joined the portal after a user invited them, showing resources they have contribute with, etc.) For instance we believe it is very useful providing badges. This is a practice imported from "gammification" that is being expanded to learning management systems (Haaranen, Ihantola, Hakulinen, \& Korhonen, 2014), portals for sharing digital content (e.g. Merlot), MOOCs and online courses (e.g. MITx) (Young, 2012), educational institutions that offer acknowledgment to users for contributing in certain topics, etc. Some researches show that using badges encourage participation because users increase: social reputation, self-esteem, recognition, etc. (Gibson, Ostashewski, Flintoff, Grant, \& Knight, 2013; Haaranen et al., 2014; Hakulinen, Auvinen, \& Korhonen, 2013; Young, 2012)

- We recommend that the functionality community could be shown in every page of the interface. As we learnt from Share.TEC case study' informants this is a relevant aspect in these environments.

- Lund et al. (2010) stated that users' communities work better in real scenarios. In this sense we consider positive to integrate web tools that allow users organize face to face meetings, such as "Meetup ${ }^{219 " . ~}$

- Furthermore, we recommend providing tools to promote virtual meetings: chat, videoconference, etc. (even according agreements with existing web service providers, e.g. "Google tools"). In this way users have enough tools for increasing their sense of community and generating face to face and/or online public and/or private meetings. Webinars could also be dynamized (such as those offered in the "Internet en el Aula" educational network)

219 Social tool allows users to find people with similar interests (for leisure activities, professional activities, etc.) by location. The app offers free services to attendees and fees for those creating meetings http://www.meetup.com. 
- We suggest incorporating statistics of the number of resources "shared today", "shared this week", "shared this month", as well as the people who mot contributed with metadata or resources in those periods.

- We believe that launching educational challenges for users of the portal/web service could be a useful strategy for boosting the improvement of content' quality (as seen in "OER Commons" portal) and for encouraging sharing.

- Supporting sharing content can promote social participation and the improvement of digital resources (e.g. a community manager proposes members to share their "own-created" preferred digital content).

\section{Research limitations}

During the development of this work we have detected some research' limitations. Among the most relevant ones we underscore the following:

With respect to informants' evaluation instruments and tests many of them were gathered to provide information to the Share.TEC project. Research pilots and instruments mainly focused on finding informants' habits of using technology and their opinions about Share.TEC portal.

This constraint has limited the informants' sample representativeness. As seen in chapter 4, we performed statistical significance tests with data that allowed us to do this. We consider appropriate to select significant samples for future researches about this topic. This would allow comparing data tests/instruments and provide reliability and validity evidence.

As gathered in chapter 4, we have detected two questions where we could have improved the question formulation (e.g. we asked informers of survey [35] if they were members of any community of practice; if they knew what a community of practice was; and if they had belong anytime to a community of practice. We obtained inconsistent data, since there were more users claiming to be part of a community of practice than assuring to know what it was).

In future researches we would have to do a proper review of the questionnaire for establishing the convenient clarifications).

Another limitation of this research refers to "the Hawthorne effect" (Chandler \& Munday, 2011; Macefield, 2007; Sedgwick \& Greenwood, 2015). This effect suggests that participants' natural behaviour can be modified if they know they are being observed and studied. We cannot control if data has been affected by these 
variations when we performed pilot tests of the Share.TEC portal (since they took place with all users in a same room and we asked them to perform tasks).

In the "Study 2" sample was constrained to 15 portals. We wanted to analyse in depth the items from our evaluation model. We decide that number of portals in order to perform an approachable investigation. This study could be complemented with a more numerous and representative sample from every kind of web space.

Furthermore, in "Study 2" portals were analysed throughout last 3 years. Educational portals continuously evolve and are scaled with new functionalities taking into account their user needs and the evolution of emerging educational tools. For this reason we have tried to update the more relevant data concerning our items' evaluation model (items not updated have been specified in chapter 5).

Once we have established the main constraints we have detected in our research, we proceed determining the future work directions that will be performed trying to overcome previous research limitations.

\section{Future work directions}

The main conclusions of this research have been integrated in this chapter, supplementing particular studies conclusions gathered in "chapter 4" (Share.TEC case study conclusions) and "chapter 5" (portals' comparative analysis conclusions). Main limitations have been also outlined. In this section we gather future work directions related with this research:

\subsection{Building an educational web portal for the Spanish "Information and Communication Technology" teacher educators' community:}

We have previously defined conceptual design recommendations for creating educational portals. One of our main future directions deals with performing a proof of concept of an educational web portal for sharing digital contents and experiences in a concrete community. The chosen community is Spanish teacher educators of Educational Technology. The reason for this selection is this is an active (they tend 
to generate and share more digital content than teachers from other areas) and demarcated community 220 .

To do so, firstly we would perform a mixed questionnaire (integrating qualitative and quantitative questions) that would allow us to evaluate the aspects we defined in the conclusions of this research. We will take into account lessons learnt in this investigation, in order we can get statistically-significant data about needs of the community for using and sharing digital content and experiences.

We would perform a review of existent portals integrating quality open educational resources for teacher educators. Initially we would constraint this research on Spain and Latino-America. We will consider the option of establishing agreements with portal owners for federating their contents with the portal we want to design.

We would perform a mixed method research (Creswell \& Plano Clarck, 2010; Creswell, 2003, 2014). After data from the questionnaire would be analysed there would be created a portal mock-up. To do so, we would take into account usability standards and recommendations. Furthermore, we would integrate functionalities and recommendations we propose in this research.

We will perform iterative design and evaluation cycles. Following user-centred design (e.g. Lowdermilk, 2013; UsabilityNet, 2003), we will select 5 (Nielsen, 2000) "ICT" teachers educators per mock-up evaluation. After the every iteration evaluation we would remodel and re-evaluate the mock-up. First mock-up designs will be very basic visually in order informants focus their attention in the portal functionalities. After restructuring the portal based on informants evidences, there will be presented its first final version.

Furthermore we would modify Share.TEC Teacher Education Ontology (e.g. adding terms for describing contents that teachers generally use: research paper, Webquest, book chapter, educational portal, etc.) as well as the metadata model attending "Study 1" recommendations.

To accomplish this work we would need the collaboration of an interdisciplinary group that would provide the knowledge of every area implied in the portal

220 One of these associations is "RUTE" ("Red Universitaria de Tecnología Educativa") (University network of Educational Technology) that organizes events for disseminating progress and experiences from this field http://www.rute.edu.es/. 
Future work directions - Building an educational web portal for the Spanish "Information and Communication Technology" teacher educators' community:

development. We consider this team would need from the following roles: librarian, computer scientist, sociologist, teacher educators and economist.

We will propose this portal to the Spanish Ministry of Education and Science for funding its release, dissemination and maintenance (initially through a project application; later through providing resources for covering maintenance, updating and management associated costs).

One of the lessons we learnt has to do with designing flexible, scalable and interoperable architectures. This structures ease the integration in the portal of new teacher communities belonging to other areas, the automatic inclusion of metadata based in standards (e.g., LOM, DC), as well as the integration of metadata related to resources through "folksonomies" (thus facilitating content multiculturality).

We consider appropriate federating content from existent portals (bringing together in this way scattered content from the net). There should be included in the portal an easy management tool that would allow completing content metadata (e.g. copying somehow the "Mendeley" library management tool software, that would allow users to tag and modify their metadata). This fact would facilitate to a large extent users content contribution, since this would help saving time (usually teachers complained from their lack of time, as seen in "Study 1"). This app would serve as their content management space as well as would promote enriching contents from the portal favouring other members of its community.

New semantic web opens the door to gathering spread contents. Combining semantic web to the appropriate social collaboration tools empowers the generation of large resource banks contextualized through short descriptions and user's contributions.

Building this portal would ease achieving European institutions outlined objectives associated with improvements of teacher training. Especially by promoting educational content and experiences sharing spaces, as stated in "chapter 1" of this work (European Commission, 2013a, 2013b, 2013d; UNESCO, 2003, 2011, 2013, 2014; Unión Europea, 2007).

We perceive highly relevant activating communities. In this sense, we would start this portal with localized communities. We will include different strategies that would promote users participation and exchange of knowledge and contents.

If this experience succeeds, we would expand the metadata model and educational ontology to host new countries. Initially we would try to engage Spanish 
users (adapting them to the linguistic contextual requirements of every region). Subsequently, we would adapt the portal for integrating Latin-American contexts. Finally, we would scale the portal for hosting other international contexts.

We will include different strategies for activating communities (e.g. badges, gammification approaches, and other strategies promoting participation, reward and user recognition in the community).

Regarding badges, there are already developed solutions such as "Mozilla Backpack" that could be integrated in portals. This is a freeware that allows any institution create, issue and verify "open badges" (Mozilla, 2014). This measure is a goof practice used by Open Learn (from the Open University of United Kingdom), MiriadaX (MOOCs platform) and numerous educational institutions.

Moreover, platform should include technological functionalities that would promote communication among participants in the net, as well as promoting collaboration among teachers from different contexts.

Content types from the portal would focus mainly in integrating OERs. As literature research evidences state and as we believe, they can provide big benefits for education. They promote content reuse and modification and can be used in a global scale. Thus, they favour disadvantaged communities having access to quality contents.

\subsection{Applying lessons learnt for improving the design of other educational spaces}

Another challenge we intend to address in a future is the application of lessons learnt around educational, technological and social issues for improving existent educational environments (for sharing content as well as for learning management). We would like to focus on the following environments:

\subsubsection{Virtual Learning Environments and Multi-User Virtual environments}

We would deep on CSCL theories, incorporating new tools to environments that would promote a connectivist learning in these spaces, as well as the collaborative creation of educational content. 
Future work directions - Applying lessons learnt for improving the design of other educational spaces

We would select the Information and "Communication Technologies in Education" courses for pre-service teachers. We will research needs from this context related to: pedagogy (educational methodologies, activities and evaluation performed in these courses); technology (depending on educational aspects, we will research what technology solutions they use and how they could be improved); and social (allowing collaboration among the different "actors" that participate in the course).

We will restructure these environments (e.g. Moodle) integrating the required tools for achieving the courses' educational outcomes, as well as the necessary tools for promoting collaboration among teachers and students through the platform. This will favour to know others' educational practises, in a way that educational processes could be improved and redefined. Through the Spanish RUTE network we will strengthen the creation of OER from their teachers and students from this teachers. There has to be noticed that OER on themselves do not improve access and quality to higher education resources. For guarantying relevant and meaningful resources (Wong, Wong, \& Pang, 2015) there should be used mechanisms as those defined in this thesis to evaluate their quality (e.g., ranking, other authors' comments, number of people that evaluated the resource, experience of use of the content, etc.)

For training teachers in these directions we will propose a webinar for RUTE teacher educators/teachers willing to collaborate in this project. We will ask them to share their created resources in an OER digital portal (this could be the portal defined in section 4.1 from this chapter). We will also encourage them to motivate their students for creating and sharing OERs.

\subsubsection{Course Management platforms (MOOCs and SPOCs):}

These kind of environments sometimes don't take care of active pedagogies, becoming mere content repositories that provide static content and issue certifications following behaviourist learning principles (e.g. test verifying a student has achieved course main outcomes).

We propose studying good educational practices promoting constructivist and connectivist learning among participants. We will evaluate the role of educational tools in promoting these types of learning experiences. To that end we will create a design proposal for creating MOOCs and SPOCs. For the design there will be taken into account lessons learnt through this thesis, as well as the analysis of educational, technological and social good practices from these environments. 
Finally, it will be designed a tool for analysing MOOC and SPOCs platforms based on literature research combined with the "portal evaluation model" we created (see chapter 5). We will focus on the educational processes having place in these environments. This research could be framed in the context of the RESET project (Delgado Kloos, 2014), where the research team GSIC-EMIC is participating. In order to promote OER best practices in MOOCs and SPOOCs environments there will be analysed the elements (educational, social and technological) that influence in these contexts.

\subsection{Improvement of the "evaluation model of educational portals"}

We would like to improve the portals' evaluation model we proposed in "Study 2" from this thesis. To do so we will integrate our model with the one generated by other library scientists (Santos-Hermosa, Ferran, \& Abadal, 2015). We would like to collaborate with them ${ }^{221}$ providing a portals' multidisciplinary analysis model. Educators and library scientists will validate this model in order to incorporate their suggested improvements. Finally we will propose an analysis of current "teacher education content and experiences" portals. We aim helping teachers to decide whether the portals will be useful for them.

Lastly I would like to conclude this dissertation willing this research ease the path to other investigations. Furthermore, I wish this work constitute the framework reference for my future work.

221 In 2012 I had the chance of doing a research visit to the Open University of United Kingdom. There I met the librarian and researcher Gema Santos-Hermosa. I was able to collaborate with her during three months. Currently we have common research interests and works since she is analysing educational portals from other views and items. We will generate soon the integration of both researches. 


\section{Referencias / References}

Abadal, E. (2012). Acceso abierto a la ciencia. Barcelona: UOC.

Abras, C., Maloney-Krichmar, D., \& Preece, J. (2004). Advantages and disadvantages of User-Centered Design. In Berkshire Encyclopedia of Humancomputer Interaction (p. 767). Thousand Oaks.

AENOR. (2009). Guía para la aplicación del perfil de aplicación LOM-ES V1.0 (NORMA UNE-71361) en la educación. Retrieved from http://www.edu.xunta.es/contidos/ODEs/lex2/guia_anexos_ejemplos_lomes/00_guia_lom-es_v1.0.pdf

Alasuutari, P. (2010). The rise and relevance of qualitative research. International Journal of Social Research Methodology, 13(2), 139-155.

Alemu, G., Stevens, B., \& Ross, P. (2012). Towards a conceptual framework for user-driven semantic metadata interoperability in digital libraries: A social constructivist approach. New Library World, 113(1/2), 38-54.

Alesina, A., \& Giavazzi, F. (2008). The future of Europe: Reform or Decline. Cambridge, Massachusetts: MIT Press.

Alexander, V., Thomas, H., Cronin, A., Fielding, J., \& Moran-Ellis, J. (2008). Mixed Methods. In N. Gilbert (Ed.), Researching Social Life (3rd ed.). London: SAGE Publications.

Álvarez Álvarez, C., \& San Fabian Maroto, J. L. (2012). No Title. Gazeta de Antropología, 28(1). Retrieved from http://hdl.handle.net/10481/20644

Alvino, S. (2008). Computer Supported Collaborative Learning e riusabilità: un approccio all'integrazione di risorse riusabili in processi di apprendimento collaborativo. PhD Thesis in "Languages, Cultures and Information and Communication Technologies" (Universidad de Génova). 
Alvino, S., Bocconi, S., Boytchev, P., Earp, J., \& Sarti, L. (2009). An Ontology-Based Approach for Sharing Digital Resources in Teacher Education. In D. Dicheva, R. Nikolov, \& E. Stefanova (Eds.), AIED 2009. SWEL09: Ontologies and Social Semantic Web for Intelligent Educational Systems (pp. 52-59). Retrieved from http://compsci.wssu.edu/iis/swel/SWEL09/Papers/swel09_submission_3_ALVI NO.pdf

Alvino, S., Bocconi, S., \& Sarti, L. (2008). Teacher Education Ontology ( TEO ): version 1. Development.

Alvino, S., Forcheri, P., lerardi, M. G., \& Sarti, L. (2008). A general and flexible model for the pedagogical description of learning objects. In M. y S. Kandall B. (Ed.), IFIP International Federation for Information Processing (Vol. 281, pp. 55-62).

Alvino, S., Forcheri, P., lerardi, M. G., \& Sarti, L. (2009). The Pedagogical Dimension of Metadata for Learning Resources: The POEM Model. In M. Spaniol, Q. Li, R. Klamma, \& R. W. H. Lau (Eds.), Advances in Web Based Learning - $\{I C W L\}$ 2009, 8th International Conference, Aachen, Germany, August 19-21, 2009. Proceedings (pp. 58-67). Springer. http://doi.org/10.1007/978-3-642-034268_7

Anderson, D., Sweeney, D. J., \& Williams, T. A. (2005). Estadística Para Administración y Economía. México, D.F: International Thomson.

Anderson, T. (2008). Towards a theory of online learning. In T. Anderson (Ed.), The theory and practice of online learning (pp. 45-74). Edmonton, Canada: Athabasca University Press.

Area Moreira, M. (2003). De los Webs educativos al material didáctico Web. Comunicación Y Pedagogía, (188), 32-38. Retrieved from http://manarea.webs.ull.es/articulos/art17_sitiosweb.pdf

Ausubel, D. P. (1960). The use of advance organizers in the learning and retention of meaningful verbal material. Journal of Educational Psychology. http://doi.org/10.1037/h0046669

Ausubel, D. P. (1977). The facilitation of meaningful verbal learning in the classroom. Educational Psychologist, 12, 162-178. http://doi.org/10.1080/00461527709529171

Bartolomé-Pina, A.-R., \& Stefens, K. K. (2015). Are MOOCs Promising Learning Environments? Comunicar, 22(44), 91-99. http://doi.org/10.3916/C44-2015-10 
Bartolomé, M. (1984). La pedagogía experimental. In A. Sanviens (Ed.), Introducción a la pedagogía. (pp. 381-404). Barcelona: Barcanova.

Bates, A. W. (2011). Content Management and e-learning: a Strategic Perspective. In N. Ferran Ferrer \& J. Minguillón Alfonso (Eds.), Content Management for ELearning (pp. 197-211). New York, NY: Springer.

Bates, A. W. (2015). Teaching in the Digital Age: Guidelines for designing teaching and learning for a digital age. Ontario, Canada: Ontario's Distance Education \& Training Network. Retrieved from http://opentextbc.ca/teachinginadigitalage/open/download?filename=Teachingin-a-Digital-Age-1428631923\&type=pdf

Bautista Pérez, G., Escofet Roig, A., Forés Miravalles, A., López Costa, M., \& Marimon Martí, M. (2013). Superando el concepto de nativo digital. Análisis de las prácticas digitales del estudiantado universitario. Digital Education Review, 24(1), 1-22.

Beck, C., \& Kosnik, C. (2006). Innovations in Teacher Education: A Social Constructivist Approach. Albany: State University of New York Press. Retrieved from http://muse.jhu.edu.ezpprod1.hul.harvard.edu/books/9780791481844/

Bedriñana Ascarza, A. (2005). Técnicas e indicadores para la evaluación de portales educativosen Internet. Gestión En El Tercer Milenio, Revista de Investigación de La Facultad de Ciencias Administrativas de La Universional Nacional Mayor de San Marcos, 7(14), 81-87. Retrieved from http://sisbib.unmsm.edu.pe/bibvirtualdata/publicaciones/administracion/n14_20 05/a09.pdf

Beetham, H., \& Sharpe, R. (2013). An introduction to Rethinking Pedagogy. In H. Beetham \& R. Sharpe (Eds.), Rethinking Pedagogy for a Digital Age: Designing for the 21st Century (2nd ed., pp. 1-11). New York, NY: Routledge.

Bell, D. (1974). The coming of post-industrial society. New York, NY: Harper Colophon Books.

Benedek, J., \& Miner, T. (2002). Measuring Desirability: New methods for evaluating desirability in a usability lab setting. In Proc. UPA 2002 (p. 5).

Benito, M. (2009). Desafíos pedagógicos de la escuela virtual. Las TIC y los nuevos paradigmas educativos. Telos. Cuadernos de Comunicación E Innovación, 
(78).

Retrieved from http://telos.fundaciontelefonica.com/telos/cuadernograbar.asp@idarticulo=2\&r $\mathrm{ev}=78 . \mathrm{htm}$

Bessenyei, I. (2008). Learning and Teaching in the Information Society Elearning 2.0 and Connectivism. Nformation Society, 2008(9), 11.

Betancur, D., Moreno, J., \& Ovalle, D. (2009). Modelo para la recomendación y recuperación de objetos de aprendizajes en entornos virtuales de enseñanza aprendizaje. Avances En Sistemas E Informática, 6, 45-56. Retrieved from http://redalyc.uaemex.mx/pdf/1331/133112608005.pdf

Bian, P., Jin, Y., \& Zhang, N. (2010). Research on human-computer interaction design for distance education websites. ICCSE 2010 - 5th International Conference on Computer Science and Education, Final Program and Book of Abstracts, 716-719. http://doi.org/10.1109/ICCSE.2010.5593511

Bienkowski, M., \& Klo, J. (2014). The Learning Registry: Applying Social Metadata for Learning Resource Recommendations. In N. Manouselis, H. Drachsler, K. Verbert, \& O. C. Santos (Eds.), Recommender Systems for Technology Enhanced Learning: Research Trends and Applications (Springer, pp. 77-95). New York, NY: Springer. http://doi.org/978-1-4939-0529-4

Big Dog Little Dog, \& Knowledge Jump. (2010). Defining eLearning. Retrieved September 21, 2015, from http://www.nwlink.com/ donclark/hrd/elearning/define.html

Blanco, L., \& Ramos, E. (2009). El futuro ya no es lo que era. Nuevas plataformas, redes y tecnologías para la educación 2.0. Retrieved January 16, 2016, from https://telos.fundaciontelefonica.com/telos/cuadernograbar.asp@idarticulo=5\& rev $=78 . h t m$

Blas, N. Di, Fiore, A., Mainetti, L., Vergallo, R., \& Paolini, P. (2014). A portal of educational resources: Providing evidence for matching pedagogy with technology. Research in Learning Technology, 22. http://doi.org/10.3402/rlt.v22.22906

Blatter, J. K. (2008). Case Study. In L. M. Given (Ed.), The Sage Encyclopedia of Qualitative Research Methods (pp.68-72). Thousand Oaks, California: SAGE Publications. http://doi.org/http://dx.doi.org/10.4135/9781412963909

BOE. (2007). Ley Orgánica 4/2007, de 12 de abril, por la que se modifica la Ley Orgánica 6/2001, 13 de abri(89), 16241-16260. Retrieved from 
https://www.boe.es/boe/dias/2007/04/13/pdfs/A16241-16260.pdf

Bohl, O., Scheuhase, J., Sengler, R., \& Winand, U. (2002). The sharable content object reference model (SCORM) - a critical review. International Conference on Computers in Education, 2002. Proceedings. http://doi.org/10.1109/CIE.2002.1186122

Bozu, Z., \& Canto Herrera, J. (2009). El profesorado universitario en la sociedad del conocimiento: competencias profesionales docentes . Revista de Formación $E$ Innovación Educativa Universitaria, 2(2), 87-97.

Brannen, J. (2005). Mixed Methods Research: A Discussion Paper. ESRC National Centre for Research Methods. http://doi.org/10.1658/11009233(2004)015[0085:SAAMIP]2.0.CO;2

Brewer, J., \& Hunter, A. (1989). Multimethod research: A synthesis of styles. In Collecting data with multiple methods (pp. 77-97). Newbury Park, California: SAGE Publications. http://doi.org/10.1002/nur.4770140212

Brewer, J., \& Hunter, A. (2006). Foundations of Multimethod Research: a synthesis of styles. Thousand Oaks, California: SAGE Publications. http://doi.org/http://dx.doi.org.ezpprod1.hul.harvard.edu/10.4135/9781412984294

Brown, A. J. G. (2012). Skills development: Rethinking the future - OECD Observer. Retrieved August 24, 2015, from http://oecdobserver.org/news/fullstory.php/aid/3779/Skills_development:_Rethi nking_the_future.html

Brun, M., \& Hinostroza, E. (2014). Learning to become a teacher in the 21st century: ICT integration in Initial Teacher Education in Chile. Educational Technology \& Society, 17(3), 222-238. Retrieved from http://www.ifets.info/journals/17_3/17.pdf

Bruner, J. S. (1977). The process of education. Cambridge, MA: Harvard University Press.

Bryant, S. (2009). Overcoming the "Not Invented Here" Syndrome - Experience with Sourcing Education Multimedia Developed Elsewhere. In Same places, different spaces. Proceedings ascilite Auckland 2009 (Vol. Auckland C, pp. 121-127).

Retrieved

from http://www.ascilite.org.au/conferences/wollongong98/asc98-pdf/bryant0076.pdf 
Bryman, A. (1988). Quantity and Quality in Social Research (2nd ed.). London: Routledge.

Butcher, N. (2002). Best Practice in Education Portals. Braamfontein, South Africa. Retrieved from http://oasis.col.org/bitstream/handle/11599/167/EducationPortals_Report.pdf?s equence $=1$ \&isAllowed $=y$

Butcher, N. (2015). A Basic Guide to Open Educational Resources (OER). (A. Kanwar \& S. Uvalic-Trumbic, Eds.)Technology (2nd ed.). Paris, Francia: UNESCO - COL. $\quad$ Retrieved from http://unesdoc.unesco.org/images/0021/002158/215804e.pdf

Cabra-Torres, F., \& Marciales-Vivas, G. P. (2009). Mitos, realidades y preguntas de investigación sobre los "nativos digitales": Una revisión. Universitas Psychologica, 8(2), 323-338. http://doi.org/10.11144/476

California State University. (2012). Multimedia Educational Resource for Learning and Online Teaching (MERLOT).

Campbell, L. R. . (2014). LRMI Implementation Case Study: ISKME OER Commons | Open World on WordPress.com. Retrieved July 10, 2015, from https://lornamcampbell.wordpress.com/2014/10/03//rmi-implementation-casestudy-iskme-oer-commons/

Carabantes Alarcón, D., García Carrión, C., \& Beneit Montesinos, J. B. (2004). Criterios de valoración y análisis de Sitios Web sobre drogodependencias. Salud $Y$ Drogas, 4(1), 39-66. Retrieved from http://www.haaj.org/sites/default/files/CRITERIOS DE VALORACI\%C3\%93N Y AN\%C3\%81LISIS.pdf

Carramolino Arranz, B., \& Rubia Avi, B. (2009). Share.TEC, un sistema para acceder, reutilizar y compartir contenidos digitales para la formación del profesorado. In I Simposio internacional "Buenas prácticas educativas con TIC" (pp. 509-520). Cáceres: Universidad de Extremadura.

Carramolino Arranz, B., \& Rubia Avi, B. (2013). Share.TEC, un portal para compartir contenidos digitales en el ámbito de la formación del profesorado. Revista Fuentes, 13, 283-308. Retrieved from http://www.revistafuentes.es/

Castells, M. (1996). La era de la información. Economía, Sociedad y Cultura. Vol.1 La Sociedad Red (1st ed.). Allianza Editorial. 
Castells, M. (2005). Prólogo. In I. Tubella i Casadevall \& J. Vilaseca i Requena (Eds.), Sociedad del conocimiento (pp. 11-12). Barcelona, España: Universidad Oberta de Catalunya.

Castells, M. (2010). The Rise of the Network Society. The Information Age: Economy, Society, and Culture. Volume I. (2nd ed.). Chichester, West Sussex; Malden, MA: Wiley-Blackwell.

Cechinel, C., Camargo, S. da S., Sánchez-Alonso, S., \& Sicilia, M.-Á. (2014). Towards Automated Evaluation of Learning Resources Inside Repositories. In N. Manouselis, H. Drachsler, K. Verbert, \& O. C. Santos (Eds.), Recommender Systems for Technology Enhanced Learning: Research Trends and Applications (pp. 25-46). New York, NY: Springer. http://doi.org/10.1007/9781-4939-0530-0

Centre for Educational Research and Innovation. (2008). CERI - ICT and Initial Teacher Training: Research reviews. Retrieved from http://www.oecd.org/edu/research/42421255.pdf

Cervone, H. F. (2012). Digital Learning Object Repositories. OCLC Systems and Services, 28(1), 14-16. http://doi.org/doi:http://dx.doi.org/10.1108/10650751211197031

Chandler, D., \& Munday, R. (2011). Hawthorne effect. In A Dictionary of Media and Communication (2014th ed.). Oxford University Press. Retrieved from //www.oxfordreference.com/10.1093/acref/9780199568758.001.0001/acref9780199568758-e-1170

Charlesworth, A. J., Ferguson, N., Massart, D., Van Assche, F., Mason, J., Radford, A., ... Schmoller, S. (2008a). Development of Guide Practice. Guidelines for repository owners. Bristol University: Becta project. Retrieved from http://kint.com/downloads/repository-guidelines-report.pdf

Charlesworth, A. J., Ferguson, N., Massart, D., Van Assche, F., Mason, J., Radford, A., ... Schmoller, S. (2008b). Good Practice Guidelines for Repository Owners. Retrieved October 23, 2015, from http://researchinformation.bristol.ac.uk/en/publications/good-practice-guidelines-forrepository-owners(ab89f2f2-9dc4-4b31-bef4-d6f8617f2b8e).html

Cheung, C. M. K., Lee, M. K. O., \& Lee, Z. W. Y. (2013). Understanding the continuance intention of knowledge sharing in online communities of practice 
through the post-knowledge-sharing evaluation processes. Journal of the American Society for Information Science and Technology, 64(7), 1357-1374. http://doi.org/10.1002/asi.22854

Chou, S.-W. (2010). Why do members contribute knowledge to online communities? Online Information Review, 34(6), 829-854. http://doi.org/10.1108/14684521011099360

Clements, K. I., \& Pawlowski, J. M. (2012). User-oriented quality for OER: understandingteachers' views on re-use, quality, and trust. Journal of Computer Assisted Learning, 28(1), 4-14. http://doi.org/10.1111/j.13652729.2011.00450.x

Clements, K. I., Pawlowski, J. M., \& Manouselis, N. (2015). Open educational resources repositories literature review - Towards a comprehensive quality approaches framework. Computers in Human Behaviour, 51, 1098-1106. http://doi.org/10.1016/j.chb.2015.03.026

Coba Arango, E. (2011). La formación del profesorado en el Espacio Europeo de Educación Superior. CEE Participación Educativa, 16, 31-38. Retrieved from http://www.mecd.gob.es/revista-cee/pdf/n16-coba-arango.pdf

Cobo Romaní, C., \& Moravec, J. W. (2011). Aprendizaje invisible. Hacia una nueva ecología de la Educación. Book (1st ed.). Barcelona, España: Publicacions i Edicions de la Universitat de Barcelona. Retrieved from www.aprendizajeinvisible.com

Collier, G., \& Robson, R. (2002). What is the Open Knowledge Initiative? White paper.

Retrieved from http://web.mit.edu/oki/learn/whtpapers/OKI_white_paper_120902.pdf

Collis, B., \& Moonen, J. (2011). Flexibility in Higher Education: Revisiting Expectations. Comunicar, 19(37), 15-25. http://doi.org/10.3916/C37-2011-0201

Comisión Europea. (2005). Comunicación de la Comisión al Consejo y al Parlamento Europeo - Acciones comunes para el crecimiento y el empleo : el programa comunitario sobre la estrategia de Lisboa [SEC(2005) 981] $/^{*}$ COM/2005/0330 final */. Bruselas. Retrieved from http://eurlex.europa.eu/legal-content/ES/TXT/?uri=celex:52005DC0330

Comisión Europea. (2013). Apertura de la educación: Docencia y aprendizaje innovadores para todos a través de nuevas tecnologías y recursos educativos 
abiertos. Comunicación de La Comisión Al Parlamento Europeo, Al Consejo, Al Comité Económico Y Social Europeo Y Al Comité de Las Regiones., 654, 1-15. Retrieved from http://eur-lex.europa.eu/legalcontent/ES/TXT/PDF/?uri=CELEX:52013DC0654\&from=EN

Consejo Europeo de Lisboa. (2000). Consejo Europeo Lisboa, 23 y 24 de marzo del 2000: Conclusiones de la presidencia. Retrieved from http://www.europarl.europa.eu/summits/lis1_es.htm

Cook, T. D., \& Reichardt, C. S. (1979). Qualitative and quantitative methods in evaluation research. Qualitative and Quantitative Methods in Evaluation Research. Thousand Oaks, CA: SAGE Publications.

CORDIS. (2009). eContent - European Digital Content Programme (Information Society 2001-2005) - European Commission. Retrieved February 26, 2013, from http://cordis.europa.eu/econtent/

Cormier, D. (2008). The CCK08 MOOC - Connectivism course, 1/4 way » Dave's Educational Blog. Retrieved March 15, 2013, from http://davecormier.com/edblog/2008/10/02/the-cck08-mooc-connectivismcourse-14-way/

Creswell, J. W. (2003). A framework for Design. In J. W. Creswell (Ed.), Research design Qualitative quantitative and mixed methods approaches (2nd ed., pp. 3-26). Thousand Oaks, CA: SAGE Publications. Retrieved from http://isites.harvard.edu/fs/docs/icb.topic1334586.files/2003_Creswell_A Framework for Design.pdf

Creswell, J. W. (2014). Research design: Qualitative, quantitative, and mixed methods approaches (4th ed.). Thousand Oaks, California: SAGE Publications.

Creswell, J. W., \& Plano Clarck, V. L. (2010). Designing \& Conducting Mixed Methods Research (Vol. 2nd). Thousand Oaks, California: Sage Publications.

Davis, S. H. (2007). Bridging the gap between research and practice: What's good, what's bad, and how can one be sure? Phi Delta Kappan, 88(8), 569-578. http://doi.org/10.1177/003172170708800804

De Vries, F. (2009). Share.TEC Portal Dublin Validation Session. Retrieved from Documento interno del proyecto Share.TEC - Open University of Netherlands 
De Vries, I. (2013). Evaluating open educational resources: Lessons learned. In Procedia - Social and Behavioral Sciences. 2nd World Conference on Educational Technology Researches - WCETR2012 (Vol. 83, pp. 56-60). Elsevier.

Delgado Kloos, C. (2014). RESET-UC3M: Reformulando Ecosistemas Escalables Educativos. Memoria Científico Técnica - Proyectos de l+D+l "Retos Investigación.

Denzin, N. K. (1970). The research act in sociology. Chicago: Aldine.

Di Paola, L. (2007). Encyclopedia of Portal Technologies and Application. In A. Tatnall (Ed.), Encyclopedia of Portal Technologies and Application (pp. 11611165). Hershey, PA : Information Siene Referene. http://doi.org/10.4018/978-159140-989-2.ch189

Dimitriadis, Y., McAndrew, P., Conole, G., \& Makriyannis, E. (2009). New design approaches to repurposing open educational resources for collaborative learning using mediating artefacts. In R. J. Atkinson \& C. McBeath (Eds.), Same places, different spaces. Proceedings ascilite Auckland 2009 (pp. 200207). Auckland: The University of Auckland, Auckland University of Technology, and Australasian Society for Computers in Learning in Tertiary Education (ascilite). $\quad$ Retrieved from http://www.ascilite.org/conferences/auckland09/procs/dimitriadis.pdf

Dos Reis, A. (2011). From "Connectivism" to "Ethicism." In G. J. Morais da Costa (Ed.), Ethical Issues and Social Dilemmas in Knowledge Management: Organizational Innovation (pp. 113-130). Hersey, PA, USA: Information Science Publisher.

Doulamis, N., Psaltis, C., Georgopoulos, A., Sotiriou, M., Sotiriou, S., \& Doxaras, I. (2008). The COSMOS Approach for Teaching Sicnece: An Architecture That Combines IEEE LM Compatible Content With Multi-Lingual Science Educational Vocabularies and Rights. In D. Remenyi (Ed.), Proceedings of the 7th European Conference on e-Learning, ECEL 2008 (pp. 316-325). Agia Napa, Cyprus.

Downes, S. (2007). Models for Sustainable Open Educational Resources. Interdisciplinary Journal of Knowledge and Learning Objects, 3(January), 2944. http://doi.org/10.1.1.119.6019

Downes, S. (2009). Access2OER: The CCK08 Solution. Retrieved March 15, 2013, 
from solution.html

http://halfanhour.blogspot.com.au/2009/02/access2oer-cck08-

Duart, J. M., \& Sangrá, A. (2000). Formación universitaria por medio de la Web: un modelo integrador para el aprendizaje superior. (J. M. Duart \& A. Sangrá, Eds.) Apreder en la Virtualidad. Madrid, España: Editorial Gedisa SA.

Dublin Core Metadata Initiative. (2010). Dublin Core Metadata Initiative (DCMI). Retrieved from http://dublincore.org/

Earp, J. (2008). Selected ontologies and ontology tools. [Documento interno del proyecto].

Earp, J., Sarti, L., \& Bocconi, S. (2011). Share.TEC Final Project Report. (Vol. D1.11.). ITD. Retrieved from http://www.google.co.uk/url?sa=t\&rct=j\&q=\&esrc=s\&source=web\&cd=1\&ved=0 CCcQFjAA\&url=http://puma.isti.cnr.it/download.php?DocFile=2011-TR004. pdf\&langver=it\&idcode $=2011-\mathrm{TR}-$ 004\&authority=cnr.itd.ge\&collection=cnr.itd\&check=\&ei

Echarri, J., \& Iturriaga, J. (1997). Fenómeno y verdad en Heidegger. Filosofía (Vol. 25). Bilbao: Universidad de Deusto.

EdReNe. (2009). State of the art II. Educational Repositories in Europe. (Vol. 2.6). EDRENE. Retrieved from http://edrene.org/results/deliverables/EdReNe D 2.6 SoA - II.pdf

EdReNe. (2010). EdReNe - Current state of educational repositories - national overview.

EdReNe. (2011). EdReNe Thematic Network members.

EdReNe. (2013). EDRENE - About EdReNe. Retrieved October 22, 2015, from http://edrene.org/about.html

European Commission. (2005). Communication from the Commission: Building the ERA of knowledge for growth, 2007-2013. (Vol. 118 final). European Commission.

European Commission. (2007). Mejorar la calidad de la formación del profesorado. Retrieved January 1, 2009, from http://eur-lex.europa.eu/legalcontent/EN/TXT/?uri=URISERV:c11101 
European Commission. (2008a). European Commision Society. The eContentplus Programme.

European Commission. (2008b). The eContent Plus Programme.

European Commission. (2010a). Developing coherent and system-wide induction programmes for beginning teachers: a handbook for policymakers. Retrieved from http://ec.europa.eu/education/policy/school/doc/handbook0410_en.pdf

European Commission. (2010b). Europe 2020. A strategy for smart, sustainable and inclusive growth: Communication from the Commission.

European Commission. (2011a). Competitiveness and innovation framework (CIP). ICT Policy Support Programme. ICT PSP. ec.europa.eu/information_society/activities/econtentplus/docs/ictpsp_wp2011_ approved.pdf (Vol. Work Progr). Retrieved from ec.europa.eu/information_society/activities/econtentplus/docs/ictpsp_wp2011_ approved.pdf

European Commission. (2011b). Projects: SHARE.TEC | Europa - Information Society. $\quad$ Retrieved from http://ec.europa.eu/information_society/apps/projects/factsheet/index.cfm?proj ect_ref=ECP-2007-EDU-427015

European Commission. (2013a). DIGCOMP: A Framework for Developing and Understanding Digital Competence in Europe. Luxembourg: Publications Office of the European Union. http://doi.org/10.2788/52966

European Commission. (2013b). Europe 2020. Retrieved August 25, 2009, from http://ec.europa.eu/europe2020/index_en.htm

European Commission. (2013c). Opening up Education - A proposal for an European initiative to enhance education and skills development through new technologies. European Commission- Directorate General for Education and Culture.

Retrieved from http://ec.europa.eu/governance/impact/planned_ia/docs/2013_eac_003_openi ng_up_education_en.pdf

European Commission. (2013d). Platform for ICT for Learning and Inclusion. INSO6-2014. Retrieved September 11, 2015, from http://ec.europa.eu/research/participants/portal/desktop/en/opportunities/h2020 /topics/2472-inso-6-2014.html 
European Commission. (2013e). Supporting Teacher Competence Development for Better Learning Outcomes. European Commission, Education and Training, 41.

European Commission. (2013f). Supporting Teacher Educators. Education and Training, 59 . $\quad$ Retrieved from http://ec.europa.eu/education/policy/school/doc/support-teachereducators_en.pdf

European Commission. (2014). HORIZON 2020 WORK PROGRAMME 2014 2015: Future and Emerging Technologies. Revised. Retrieved from http://ec.europa.eu/research/participants/data/ref/h2020/wp/2014_2015/main/h 2020-wp1415-fet_en.pdf

European Commission. (2015a). Europe 2020 - EU-wide headline targets for economic growth. Retrieved August 25, 2015, from http://ec.europa.eu/europe2020/europe-2020-in-anutshell/targets/index_en.htm

European Commission. (2015b). Europe 2020 - Europe's growth strategy. http://doi.org/10.1016/j.resconrec.2010.03.010

European Higher Education Area. (2012a). Bologna Process - European Higher Education Area. History. Retrieved August 27, 2015, from http://www.ehea.info/article-details.aspx?Articleld=3

European Higher Education Area. (2012b). Making the most of our potential: Consolidating the European higher education area. In Bucharest Communiqué (pp. 1-5). Bucharest.

European Parliament, \& Council of the European Union. (2006). Recommendation of the European Parliament and of the Council of December 2006 on key competences for lifelong learning (2006/962/EC). Offical Journal of the European Parliament.

Eurostat. (2014). Internet and cloud services - statistics on the use by individuals. Retrieved from http://ec.europa.eu/eurostat/statisticsexplained/index.php/Internet_and_cloud_services__statistics_on_the_use_by_individuals

Ferran Ferrer, N., \& Minguillón Alfonso, J. (Eds.). (2011). Content management for E-learning. Content Management for E-Learning. New York, NY: Springer. 
http://doi.org/10,1007/978-1-4419-6959-0

Ferran, N., \& Minguillón, J. (2011). Preface. In N. Ferran Ferrer \& J. Minguillón Alfonso (Eds.), Content Management for E-Learning (pp. vii-x). New York, NY: Springer.

Fideli, R. (1998). La comparazione. Milán: Agneli.

Fielding, N., \& Fielding, J. (1986). Linking Data. Beberly Hills, California: SAGE Publications.

Flinders, K. (2014). Government replaces Becta education IT procurement framework. Retrieved October 23, 2015, from http://www.computerweekly.com/news/2240233474/Government-replacesBecta-education-IT-procurement-framework

FLN. (2014). Definition of Flipped Learning. Retrieved September 11, 2015, from http://www.flippedlearning.org/definition

Flyvbjerg, B. (2006). Five Misunderstandings About Case-Study Research. Qualitative Inquiry, 12(2), 219-245. http://doi.org/10.1177/1077800405284363

Gadamer, H. G., \& Parada, A. (1998). El giro hermenéutico. Teorema. Serie Mayor. Madrid: Cátedra.

Gage, N. (1989). The Paradigm Wars and Their Aftermath A "Historical" Sketch of Research on Teaching Since 1989. Educational Researcher, 18(7), 4-10. http://doi.org/10.3102/0013189X018007004

Gharibi, S., Danesh, S. yahah seyed, \& Shahrodi, K. (2012). EXPLAIN THE EFFECTIVENESS OF ADVERTISING USING THE AIDA MODEL. INTERDISCIPLINARY JOURNAL OF CONTEMPORARY RESEARCH IN BUSINESS, 4(2), 926-940.

Gharibi, S., Danesh, S. yahah seyed, \& Shahrodi, K. (2015). AIDA sales funnel. INTERDISCIPLINARY JOURNAL OF CONTEMPORARY RESEARCH IN BUSINESS, 4(05/07), 926-940.

Gibson, D., Ostashewski, N., Flintoff, K., Grant, S., \& Knight, E. (2013). Digital badges in education. Education and Information Technologies, 1-8. http://doi.org/10.1007/s10639-013-9291-7

Gobierno de España. (2015). Interoperabilidad. Retrieved November 24, 2015, from http://administracionelectronica.gob.es/pae_Home/pae_Estrategias/pae_Intero 
perabilidad_Inicio.html\#.VITT1N-rTMU

Green, C. (2013). Open Education, MOOCs, Student Debt, Textbooks and other trends. Retrieved September 11, 2015, from http://cohere.ca/conference-2013presentations/

Greene, J. C., \& Caracelli, V. J. (1997). Defining and describing the paradigm issue in mixed-method evaluation. New Directions for Evaluation, Special Is(74), 517. http://doi.org/10.1002/ev.1068

Greene, J. C., Caracelli, V. J., \& Graham, W. F. (1989). Toward a conceptual framework for mixed-method evaluation designs. Educational Evaluation and Policy Analysis, 11, 255-274.

Grosse Kathoefer, D., \& Leker, J. (2012). Knowledge transfer in academia: An exploratory study on the Not-Invented-Here Syndrome. Journal of Technology Transfer, 37(5), 658-675. http://doi.org/10.1007/s10961-010-9204-5

Gruber, T.-R. (1993). A Translation Approach to Portable Ontology Specifications. Knoledge Adquisition, 5(2), 199-220. Retrieved from http://tomgruber.org/writing/ontolingua-kaj-1993.pdf

Guallar, J., \& Leiva-Aguilera, J. (2013). El content curator. Guía básica para el nuevo profesional de internet. Barcelona, España: Editorial UOC.

Guba, E. G., \& Lincoln, Y. S. (1994). Competing Paradigms in Qualitative Research. In N. K. Denzin \& Y. S. Lincoln (Eds.), Handbook of qualitative research (pp. 105-107). Thousand Oaks, California: SAGE Publications.

Guba, E. G., \& Lincoln, Y. S. (2005). Paradigmatic controversies, contradictions, and emerging confluences. In N. K. Denzin \& Y. S. Lincoln (Eds.), Handbook of qualitative research (3rd ed., pp. 191-215). Thousand Oaks, California: SAGE Publications.

Gutiérrez Martín, A., \& Tyner, K. (2012). Educación para los medios alfabetización mediática y competencia digital. Comunicar, 19, 31-39. http://doi.org/10.3916/C38-2012-02-03

Haaranen, L., Ihantola, P., Hakulinen, L., \& Korhonen, A. (2014). How (not) to introduce badges to online exercises. In Proceedings of the 45th ACM technical symposium on Computer science education - SIGCSE '14 (pp. 3338). http://doi.org/10.1145/2538862.2538921 
Hakulinen, L., Auvinen, T., \& Korhonen, A. (2013). Empirical Study on the Effect of Achievement Badges in TRAKLA2 Online Learning Environment. In 2013 Learning and Teaching in Computing and Engineering (pp. 47-54). http://doi.org/10.1109/LaTiCE.2013.34

Hamilton, L., \& Corbet-Whittier, C. (2013). Using Case Study in Research. London, England: SAGE Publications.

Hammersley, M. (1992). The Paradigm Wars: reports from the front. British Journal of Sociology of Education, 13(1), 131-143. http://doi.org/10.1080/0142569920130110

Harasim, L. (2006). A History of E-learning: Shift Happened. The International Handbook of Virtual Learning Environments. http://doi.org/10.1007/978-14020-3803-7_2

Hathaway, N. E., \& Jaquith, D. B. (2014). Where's the revolution? Phi Delta Kappan, 95(6), 25-29. Retrieved from http://ezpprod1.hul.harvard.edu/login?url=http://search.ebscohost.com/login.aspx?direct $=$ true $\& \mathrm{db}=a p h \& A N=95098552 \&$ site=ehost-live \&scope $=$ site

Hayes, G. (2006). Virtual Worlds, Web 3.0 and Portable Profiles.

Hearn, S., \& White, N. (2009). Communities of practice: linking knowledge, policy and practice. London, England. Retrieved from http://www.odi.org/sites/odi.org.uk/files/odi-assets/publications-opinionfiles/1732.pdf

Heery, R., \& Anderson, S. (2005). Digital Repositories Review. Retrieved from http://www.jisc.ac.uk/uploaded_documents/digital-repositories-review-2005.pdf

Hernández Sampieri, R., Fernández-Collado, C., \& Baptista Lucio, P. (2006). Metodología de la investigación. México Trillas (Vol. 18).

Hernández Sampieri, R., Fernández-Collado, C., \& Baptista Lucio, P. (2010). Metodología de la Investigación (5th ed.). México, D.F: McGraw-Hill.

Hersberg, J. A., Murray, A. L., \& Rioux, K. S. (2007). Examining information exchange and virtual communities: an emergent framework. Online Information Review, 31(2), 135-147. http://doi.org/10.118/14684520710747194

Hew, K. F., \& Hara, N. (2007). Empirical study of motivators and barriers of teacher online knowledge sharing. Educational Technology Research and 
Development, 55(6), 573-595. http://doi.org/10.1007/s11423-007-9049-2

Hewlett, S. A., Sherbin, L., \& Sumberg, K. (2009). How Gen Y \& Boomers Will Reshape Your Agenda. Retrieved August 31, 2015, from https://hbr.org/2009/07/how-gen-y-boomers-will-reshape-your-agenda

Hine, C. (2004). Etnografía Virtual. Colección Nuevas Tecnologías y Sociedad. Barcelona: UOC.

Hodgins, H. W. (2002). The future of learning objects. E-technologies in Engineering Education. In J. R. Lohmann \& M. L. Corradini (Eds.), E-Technologies in Engineering Education. Learning Outcomes Providing Future Possibilities. Proceedings of the 2002 eTEE Conference (pp. 76-82). Davos, Suiza. Retrieved from http://dc.engconfintl.org/cgi/viewcontent.cgi?article=1012\&context=etechnologi es

House, E. R. (1994). Integrating the Quantitative and Qualitative. In C. S. Reichardt \& S. F. Rallis (Eds.), The Qualitative-Quantitative Debate: New Perspectives (pp. 13-22). San Francisco, California: Jossey-Bass. http://doi.org/10.1002/ev.1664

Howe, N., \& Strauss, W. (2000). Millennials Rising The Next Great Generation (Vol. 19). Vintage. Retrieved from http://www.amazon.com/dp/0375707190

Hunter, A., \& Brewer, J. (2003). Multimethod research in sociology. In Handbook of Mixed Methods in Social \& Behavioral Research (pp. 577-595). Thousand Oaks, California: SAGE Publications.

Hylén, J. (2006). Open Educational Resources: Opportunities and Challenges. Open Education. Retrieved from http://66.102.1.104/scholar?hl=en\&lr=\&q=cache:reEWz9kzZt8J:www.knowledg eall.com/files/Additional_ReadingsConsolidated.pdf+quality+of+open+educational+resources

Hylén, J., Damme, Dirk, V., Mulder, F., \& D’Antoni, S. (2012). Open Educational Resources. Analysis of responses to the OECD country questionnaire. OECD Education Working Papers. Retrieved from http://www.oecdilibrary.org/docserver/download/5k990rjhvtlv.pdf?expires=1442506914\&id=id\& accname=guest \&checksum=0394F0A13A48E575939DE265D2947022

IEEE. (2002a). 1484.12.1 - 2002 Learning Object Metadata (LOM). New York: IEEE 
Learning Technology Standards Committee. Retrieved from http://lsc.ieee.org/wg12/20020612-Final-LOM-Draft.html

IEEE. (2002b). IEEE Standard for Learning Object Metadata. New York, NY.

Inclusive Design Research Center - OCAD. (2015). FLOE. Retrieved January 1, 2015, from http://www.floeproject.org/index.html

INE. (2008). Indicadores del Sector TIC. Metodología. Retrieved from http://www.ine.es/daco/daco42/inditic/metoinditic07.pdf

International Council for Open and Distance Education. (2011). ICDE» News archive » 2011 » UNESCO announces launch of new online OER Community. Retrieved September 9, 2015, from http://www.icde.org/UNESCO+announces+launch+of+new+online+OER+Com munity.b7C_wtbIXJ.ips

Isaías, P., Spector, J. M., Ifenthaler, D., \& Sampson, D. G. (2015). E-Learning Systems, Environments and Approaches: Theory and Implementation. In P. Isaías, J. M. Spector, D. Ifenthaler, \& D. G. Sampson (Eds.), E-Learning Systems, Environments and Approaches: Theory and Implementation (pp. 17). New York: Springer. http://doi.org/10.1007/978-3-319-05825-2

ISO. (2002). ISO/TR 16982:2002 - Ergonomics of human-system interaction -Usability methods supporting human-centred design. Retrieved November 30 , 2015, from http://www.iso.org/iso/iso_catalogue/catalogue_tc/catalogue_detail.htm?csnum ber=31176

ISO. (2015). ISO 9241. Retrieved November 30, 2015, from http://www.iso.org/iso/home/search.htm?qt=iso+9241\&sort=rel\&type=simple\&p ublished $=$ on

ITD/CNR. (2004). Istituto Tecnologie Didattiche. Retrieved August 5, 2014, from http://www.itd.cnr.it/

Jick, T. D. (1983). Mixing Qualitative and Quantitative Methods: Triangulation in Action. In J. Van Maanen (Ed.), Qualitative Methodology (pp. 135-148). Beberly Hills, California: SAGE Publications.

Jimoyiannis, A. A., \& Komis, V. (2007). Examining teachers' beliefs about ICT in education: implications of a teacher preparation programme. Teacher Development:

An

International,

11(2),

149-173. 
http://doi.org/10.1080/13664530701414779

JISC. (2014). Open Educational Resources programme - Jisc infoNet. Retrieved September 11, 2015, from http://www.jiscinfonet.ac.uk/projects/ukoer/

JISC. (2015). Open educational resources (OERs) | Full Guide. Retrieved September 17, 2015, from https://jisc.ac.uk/full-guide/open-educationalresources

Johnson, R. B., \& Christensen, L. (2004). Educational Research: Quantitative, Qualitative, and Mixed Approaches (2nd ed.). Boston, Massachusetts: Pearsons Education.

Johnson, R. B., Onwuegbuzie, A. J., \& Turner, L. S. (2007). Toward a Definition of Mixed Methods Research. Journal of Mixed Methods Research, 1(2), 112133.

Jorrín Abellán, I. M. (2006). Perfil formativo generado en los entornos CSCL: Un estudio de caso. Tesis Doctoral. Universidad de Valladolid.

Karampiperis, P., Koukourikos, A., \& Stoitsis, G. (2014). Collaborative Filtering Recommendation of Educational Content in Social Environments Utilizing Sentiment Analysis Techniques. In N. Manouselis, H. Drachsler, K. Verbert, \& O. C. Santos (Eds.), Recommender Systems for Technology Enhanced Learning: Research Trends and Applications (pp. 3-23). New York, NY: Springer.

Kaur, S., \& Baba, M. S. (2006). Development of a networking education portal for secondary education communities in Malaysia. In 2006 International Conference on Computing and Informatics, $\mathrm{ICOCl}$ '06 (pp. 1-6). Kuala Lumpur: IEEE. http://doi.org/10.1109/ICOCI.2006.5276576

Knowledge Management Institute. (2015). About - CORE: Connecting Repositories. Retrieved September 8, 2015, from http://core.ac.uk/about

Kreijns, K., Van Acker, F., Vermeulen, M., \& Van Buuren, H. (2013). What stimulates teachers to integrate ICT in their pedagogical practices? The use of digital learning materials in education. Computers in Human Behavior, 29(1), 217225. http://doi.org/10.1016/j.chb.2012.08.008

Kurilovas, E., \& Dagiene, V. (2009). Multiple Criteria Comparative Evaluation of ELearning Systems and Components. Informatica, 20(4), 499-518. Retrieved 
from http://www.mii.lt/informatica/pdf/INF0770.pdf

Lavagnino, E., Bocconi, S., Earp, J., \& Sarti, L. (2010). SHARE.TEC: a terminological approach to Teacher Education. In Actes du colloque GLAT LISBOA 2010: le multiculturalisme et le role de langues specialises (pp. 75 84). http://doi.org/2-908849-22-4

Lee, Y. J., \& Greene, J. C. (2007). The predictive validity of an ESL placement test: A mixed methods approach. Journal of Mixed Methods Research, 1, 366-389. http://doi.org/10.1177/1558689807306148

Lesley University. (2007). Evaluating Web Sites. Criteria for the Classroom. Trying to sort out the gems from the junk on the Internet? Retrieved May 8, 2011, from http://www.lesley.edu/library/guides/research/evaluating_web

Lichtenthaler, U., \& Ernst, H. (2006). Attitudes to externally organising knowledge management tasks: A review, reconsideration and extension of the $\mathrm{NIH}$ syndrome. $R$ and $D$ Management, 36(4), 367-386. http://doi.org/10.1111/j.1467-9310.2006.00443.x

Lijphart, A. (1971). Comparative Politics and the Comparative Method. The American Political Science Review, 65(3 (Septiembre)), 682-693.

Liu, S. (2008). Engaging users: the future of academic library Web sites. College \& Research Libraries, 69(1), 6-27. http://doi.org/VL - 69

Loveless, A. (2011). Technology, Pedagogy and Education: Reflections on the accomplishment of what teachers know, do and believe in a digital age. Technology, Pedagogy and Education, 20(3), 301-316. http://doi.org/10.1080/1475939X.2011.610931

Lowdermilk, T. (2013). User-centered design (1st ed.). Sebastopol, CA: O'Reilly Media.

Luna, P., Aguaded, J. I., Martínez Méndez, F. J., García, M., Martínez, A. M., \& Pardo, A. (2004). Hacia una metodología de análisis de sitios webs universitarios. In Educar con Tecnología, de lo excepcional a lo cotidiano (pp. 1-15). Barcelona, España: Edutec.

Lund, T. B., \& Hojsholt-Poulsen, L. (2010). Building successfu educational repositories. Consolidated recommendations report. Retrieved from https://files.itslearning.com/data/826/open/co6/790.pdf

Macefield, R. (2007). Usability Studies and the Hawthorne Effect. J. Usability 
Studies, 2(3), 145-154. $\quad$ Retrieved from http://dl.acm.org/citation.cfm?id=2835547.2835551

Mahdizadeh, H., Biemans, H., \& Mulder, M. (2008). Determining factors of the use of e-learning environments by university teachers. Computers \& Education, 51(1), 142-154. http://doi.org/10.1016/j.compedu.2007.04.004

Manouselis, N., Drachsler, H., Verbert, K., \& Santos, O. C. (2014). Recommender Systems for Technology Enhanced Learning. Research trends and applications. New York, NY: Springer. http://doi.org/10.1007/978-1-4939-05300

Margaryan, A., Currier, S., Littlejohn, A., \& Nicol, D. (2006). Learning communities and repositories. CDLOR project desk research report.

Margaryan, A., \& Littlejohn, A. (2008). Repositories and communities at crosspurposes: Issues in sharing and reuse of digital learning resources: Original article. Journal of Computer Assisted Learning, 24(4), 333-347. http://doi.org/10.1111/j.1365-2729.2007.00267.x

Margaryan, A., Littlejohn, A., \& Vojt, G. (2011). Are digital natives a myth or reality? University students' use of digital technologies. Computers \& Education. http://doi.org/10.1016/j.compedu.2010.09.004

Martínez Méndez, F. J., Martínez Méndez, J., \& López Carreño, R. (2012). Portales educativos españoles: revisión y análisis del uso de servicios Web 2.0. Investigación Bibliotecológica, 26(58), 47-69.

Mason, R., \& Rennie, F. (2006). Elearning: The Key Concepts. New York: Routledge. Retrieved from http://lib.myilibrary.com?ID=54298

Masson, P., \& Udas, K. (2009). An agile approach to managing open educational resources. On the Horizon, 17(3), 256-266. http://doi.org/doi:http://dx.doi.org/10.1108/10748120910993286

Matzat, U. (2013). Do blended virtual learning communities enhance teachers' professional development more than purely virtual ones? A large scale empirical comparison. Computers and Education, 60(1), 40-51. http://doi.org/10.1016/j.compedu.2012.08.006

Maxwell, J. A., \& Loomis, D. M. (2003). Mixed Methods Design: an Alternative Approach. In A. Tashakkori \& C. Teddlie (Eds.), Handbook of mixed methods 
in social and behavioral research (pp. 241-271). Thousand Oaks, California: SAGE Publications.

Mayes, T., \& de Freitas, S. (2013). Technology-enhanced learning. In H. Beetham \& R. Sharpe (Eds.), Rethinking Pedagogy for a Digital Age: Designing for the 21st Century (pp. 17-30). New York, NY: Taylor \& Francis.

McAuley, A., Stewart, B., Siemens, G., Cormier, D., \& Creative Commons. (2010). The MOOC model for digital practice. Massive Open Online Courses: Digital Ways of Knowing and Learning, 1-64. http://doi.org/10.1016/j.im.2011.09.007

McGreal, R. (2010). Open Educational Resource Repositories:An Analysis. In The 3rd Annual Forum on e-Learning Excellence in the Middle East 2010, February 1-3, Dubai. Dubai: Hamdan Bin Mohammed e-University. Retrieved from http://elexforum.hbmeu.ac.ae/Proceeding/PDF/Open Educational Resource.pdf

McHaney, R. (2011). New Digital Shoreline: How Web 2.0 and Millennials Are Revolutionizing Higher Education. Sterling, VA, USA: Stylus Publishing. Retrieved from http://www.ebrary.com

MECD. (2016). Formación en red - educaLAB. Retrieved February 1, 2016, from http://educalab.es/intef/formacion/formacion-en-red

Medina, J., \& Delgado, M. A. (1999). Metodología de entrenamiento de observadores para investigadores sobre E. F. y Deporte en las que se utilice como método la observación. Revista Motricidad, 5, 69-86.

Meier, A. (2012). Knowledge Society. In eDemocracy \& eGovernment (pp. 191-204). http://doi.org/10.1080/0305792022000007463

Mello, J., \& Caine, A. (2012). Open Educational Resources | ICT in Education UNESCO Multimedia Archives. World Open Educational Resources Congress. UNESCO HQ: UNESCO. Retrieved from http://www.unesco.org/archives/multimedia/index.php?s=films_details\&id_pag e=33\&id_film $=2573$

Melucci, A. (1997). The Rise of the Network Society by Manuel Castells. American Journal of Sociology, 103(2), 521-523. Retrieved from http://www.jstor.org/stable/10.1086/231245

Merriam, S. B. (1998). Qualitative Research and Case Study Applications in Education. San Francisco, California: Jossey-Bass. 
Mertens, D. M. (2010). Research and evaluation in education and psychology: Integrating diversity with quantitative, qualitative, and mixed methods (3rd ed.). Thousand Oaks, California: SAGE Publications.

Miles, M. B., \& Huberman, A. M. (1984). Drawing valid meaning from qualitative data: Toward a shared craft. Educational Researcher, 13, 20-30.

Miles, M. B., Huberman, A. M., \& Saldaña, J. (2014). Qualitative Data Analyses. A methods sourcebook (Vol. 3rd). Thousand Oaks, California: SAGE Publications.

Milligan, C. (2007). Final Report. http://www.academy.gcal.ac.uk/cd-lor/CDLOR_Final_Report_v1p0.pdf (Vol. 1.0). Glasgow: Centre for Academic Practice and Learning Enhancement. University of Strathclyde. Retrieved from http://www.academy.gcal.ac.uk/cd-lor/documents/CD-

LOR_Final_Report_v1p0.pdf

Minguillón, J., Sicilia, M. Á., \& Lamb, B. (2011). From content management to Elearning content repositories. In N. Ferran Ferrer \& J. Minguillón Alfonso (Eds.), Content Management for E-Learning (pp. 27-41). New York, NY: Springer. http://doi.org/10.1007/978-1-4419-6959-0_2

Miniwatts Marketing Group. (2015). Internet Usage Statistics. The Internet Big Picture: World Internet Users and 2015 Population Stats. Retrieved from http://www.internetworldstats.com/stats.htm

Molinaro, C. A., \& Wolfgang Sarlet, I. (2014). Sociedade em rede, internet e estado de vigilância: algumas aproximações. Revista de AJURIS, 40(132). Retrieved from

http://www.ajuris.org.br/OJS2/index.php/REVAJURIS/article/viewFile/249/184

Morais, C., Miranda, L., \& Alves, P. (2014). Digital educational resources supporting higher education students' learning. Information Systems and Technologies (CISTI), 2014 9th Iberian Conference on. http://doi.org/10.1109/CISTI.2014.6877045

Moravec, J. W. (2008a). A new paradigm of knowledge production in higher education. On the Horizon, 16(3), 123-136. http://doi.org/10.1108/10748120810901422

Moravec, J. W. (2008b). Knowmads in society 3.0. Retrieved August 25, 2015, from http://www.educationfutures.com/2008/11/20/knowmads-in-society-30/ 
Moravec, J. W. (2013). Knowmad Society. (J. W. Moravec, Ed.). Mineapolis: Education Futures. from http://www.knowmadsociety.com/download/KnowmadSociety.pdf

Morse, J. M. (2003). Principles of mixed methods and multimethod research design. In A. Tashakkori \& C. Teddlie (Eds.), Handbook of Mixed Methods in Social \& Behavioral Research (pp. 189-208). Thousand Oaks, California: SAGE Publications.

Mozilla. (2014). Badges - MozillaWiki. Retrieved January 16, 2016, from https://wiki.mozilla.org/Badges

Mullan, E. (2011). What is Digital Content? Retrieved September 1, 2015, from http://www.econtentmag.com/Articles/Resources/Defining-EContent/What-isDigital-Content-79501.htm

Nelson, C., Treichler, P. A., \& Grossberg, L. (1992). Cultural Studies: an Introduction. In L. Grossberg, C. Nelson, \& P. Treichler (Eds.), Cultural studies (pp. 1-16). New York, NY: Routledge.

Newman, I., \& Benz, C. R. (1998). Qualitative-quantitative research methodology: Exploring the interactive continuum. Carbondale, Illinois: Southern Illinois University Press.

Nielsen, J. (2000). Why you only need to test with 5 users? Retrieved February 28, 2015, from https://www.nngroup.com/articles/why-you-only-need-to-test-with5-users/

O'Reilly, T. (2005). What is Web 2.0?

Ochoa, X., \& Duval, E. (2009). Quantitative Analysis of Learning Object Repositories. IEEE Transactions on Learning Technologies, 2(3), 226-238. http://doi.org/10.1109/TLT.2009.28

OECD. (2012). Connected Minds: Technology and Today's Learners, Educational Research and Innovation. OECD Publishing, Paris. http://doi.org/http://dx.doi.org/10.1787/9789264111011-en

OLCOS. (2007). Open Educational Practices and Resources. OLCOS Roadmap 2012. (G. Geser, Salzburg Research, \& Edumedia Group, Eds.). Salzbourg. Retrieved from http://www.olcos.org/english/roadmap/download/index.htm

Onwuegbuzie, A. J., \& Dickinson, W. B. (2008). Mixed methods analysis and information visualization: Graphical display for effective communication of 
research results. The Qualitative Report, 13, 204-255. Retrieved from http://www.nova.edu/ssss/QR/QR13-2/onwuegbuzie.pdf

Onwuegbuzie, A. J., \& Teddlie, C. (2003). A framework for analyzing data in mixed methods research. In A. Tashakkori \& C. Teddlie (Eds.), Handbook of Mixed Methods in Social \& Behavioral Research (pp. 351-383). Thousand Oaks, California: SAGE Publications.

OPAL. (2011). OEP Guide: Guidelines for Open Educational Practices in Organizations (Vs. 2011). Retrieved from http://oerworkshop.pbworks.com/w/file/fetch/44605120/OPAL-OEPguidelines.pdf

Open Access. (2015). Open Access Directory. Retrieved September 8, 2015, from http://oad.simmons.edu/oadwiki/Main_Page

Papert, S. (1990). A Critique of Technocentrism in Thinking About the School of the Future. Retrieved September 28, 2015, from http://www.papert.org/articles/ACritiqueofTechnocentrism.html

Papert, S., \& Harel, I. (1991). Situating Constructionism. Constructionism, 36, 1-11. http://doi.org/10.1111/1467-9752.00269

Parlamento Europeo. (2009). Resolución del Parlamento Europeo, de 11 de marzo de 2009, sobre la contribución al Consejo Europeo de primavera de 2009 en relación con la Estrategia de Lisboa. P6_TA(2009)0120. Retrieved September 22, 2015, from http://www.europarl.europa.eu/sides/getDoc.do?pubRef=//EP//TEXT+TA+P6-TA-2009-0120+0+DOC+XML+V0//ES

Patton, M. Q. (2002). Qualitative research and evaluation methods (Vol. 3rd). Thousand Oaks, California: SAGE Publications.

Patton, M. Q. (2008). Utilization-focused evaluation (4th ed.). Thousand Oaks, California: SAGE Publications.

Pavlov, I. (1927). Conditioned reflexes: An investigation of the physiological activity of the cerebral cortex. Annals of Neurosciences, 17. Retrieved from http://annalsofneurosciences.org/journal/index.php/annal/article/view/246/601

Pérez Gómez, A. I. (1992). Comprender la enseñanza en la escuela. Modelos metodológicos de investigación educativa. In J. Gimeno Sacristán \& A. Pérez Gómez (Eds.), Comprender y transformar la enseñanza (1st ed., pp. 115- 
136). Madrid: Morata.

Pérez Montoro, M. (2011). Theoretical Perspectives on Content Management. In N. Ferran Ferrer \& J. Minguillón Alfonso (Eds.), Content Management for ELearning (pp. 3-26). New York, NY: Springer.

Perez Tejada, H.-E.-. (2008). Estadistica para ciencias sociales, del comportamiento y de la salud (Vol. 3). Santa Fe, Mexico: Cengage Learning Editores S.A.

Pérez-Hernández, M. C. (2002). Explotación de los córpora textuales informatizados para la creación de bases de datos terminológicas basadas en el conocimiento. Estudios de Lingüística Del Español (ELiEs), 18. Retrieved from http://elies.rediris.es/elies18/

Piaget, J. (1964). Part I: Cognitive development in children: Piaget. Development and learning. Journal of Research in Science Teaching, 2(3), 176-186. http://doi.org/10.1002/tea.3660020306

Pirnay-Dummer, P. N. (2012). Ontology and Semantic Web. In N. Seel (Ed.), Encyclopedia of the Sciences of Learning (pp. 2507-2510). Springer US. http://doi.org/10.1007/978-1-4419-1428-6_527

Prensky, M. (2001). Digital Natives, Digital Immigrants Part 1. On the Horizon. http://doi.org/http://dx.doi.org/10.1108/10748120110424816

Pynoo, B., Tondeur, J., Van Braak, J., Duyck, W., Sijnave, B., \& Duyck, P. (2012). Teachers' acceptance and use of an educational portal. Computers and Education, 58(4), 1308-1317. http://doi.org/10.1016/j.compedu.2011.12.026

Red.es. (2012). Agrega.

Reynolds, R. (2015). The Promise of Connected Learning | NextThought. Retrieved October 1, 2015, from https://nextthought.com/thoughts/2015/04/the-promiseof-connected-learning\#fn4

Robinson, K. (2011). Out of Our Minds: Learning to be Creative (2nd ed.). Westford, MA: Capstone Publishing Ltd.

Rocco, T. S., Bliss, L. A., Gallagher, S., Pérez-Prado, A., Acalaci, C., Dwyer, E. S., ... Pappamihiel, N. E. (2003). The pragmatic and dialectical lenses: two views of mixed methods use in education. In A. Tashakkori \& C. Teddlie (Eds.), Handbook of Mixed Methods in Social \& Behavioral Research (pp. 595-615). Thousand Oaks, California: SAGE Publications. 
Rodrígues, R. (2014). Búsqueda, selección y gestión de información académica de los nativos digitales: pocas sorpresas y grandes retos educativos. Digital Education Review, 26(December), 39-60. Retrieved from http://revistes.ub.edu/index.php/der/article/view/11580/14440

Rodríguez Gómez, G., Gil Flores, J., \& García Jiménez, E. (1999). Observación. In Metodología de la investigación cualitativa (2nd ed., pp. 149-166.). Málaga: Aljibe.

Rodríguez Illera, J. L., Escofet Roig, A., \& Azzato, M. (2005). Un sistema abierto para la creación de contenidos educativos digitales. http://www.um.es/ead/red/M4/rodriguez41.pdf.

Rodríguez Rosell, M. D. M., Berlanga Fernández, I., \& Sedeño Valdellós, A. (2013). Análisis crítico de dimensiones de la competencia audiovisual en la etapa de Bachillerato. Historia Y Comunicacion Social, 18(SPEC. ISSUE NOV), 703712. http://doi.org/10.5209/rev-HICS.2013.v18.44273

Rodríguez-Triana, M. J., Vega-Gorgojo, G., Asensio-Pérez, J. I., Martínez-Monés, A., \& Dimitriadis, Y. (2009). MATTER: Metadata Migration and Annotation. Tool of Teacher Education Resources. In Proceedings of International Conference on SOFTWARE, SERVICES \& SEMANTIC TECHNOLOGIES (pp. 76-84). Sofia, Bulgaria: Demetra EOOD. Retrieved from http://hdl.handle.net/10506/659

Rossman, G. B., \& Wilson, B. L. (1994). Numbers and words revisited: Being "shamelessly eclectic." Quality \& Quantity, 28(3), 315-327. http://doi.org/10.1007/BF01098947

Rouse, M. (2015). What is data analytics (DA)? - Definition from Whatls.com. Retrieved November 29, 2015, from http://searchdatamanagement.techtarget.com/definition/data-analytics

Ruíz Bolivar, C. (2008). El enfoque multimétodo en la investigación social y educativa: una mirada desde el paradigma de la complejidad. Revista de Filosofía Y Sociopolítica de La Educación, 4(8), 2008.

Ruíz Requies, I. (2009). El desarrollo de competencias en la Formación Inicial del Profesorado en Tecnología Educativa: Análisis de los diseños educaivos CSCL a partir de un Estudio de Caso Múltiple. Universidad de Valladolid.

Rustici Software. (2012). SCORMRustici Software. (2012). SCORM - SCORM 
Explained. Retrieved May 21, 2015, from http://scorm.com/scorm-explained/ SCORM Explained. Retrieved May 21, 2015, from http://scorm.com/scormexplained/

San Martín, J. (2008). La fenomenología de Husserl como utopía de la razón: introducción a la fenomenología. Razón y sociedad (Vol. 71). Madrid: Biblioteca Nueva.

Santos-Hermosa, G. (2014). ORIOLE, in the Search for Evidence of OER in Teaching. Experiences in the Use, Re-use and the Sharing and Influence of Repositories. Qualitative Research in Education, 3(1), 232-268. http://doi.org/10.4771/qre.2014.46

Santos-Hermosa, G., Ferran, N., \& Abadal, E. (2015). Evaluación de Repositorios Educativos. In XIV Workshop Rebiun de Poyectos Digitales. VI Jornadas OSRepositorios. 11-13 de marzo de 2015. Córdoba: Universidad de Córdoba. Retrieved from http://hdl.handle.net/10396/12635

Sarti, L. (2011). SHAring digital REsources in the Teaching Education Community. Final Report User Guide. Retrieved from http://luigint.itd.cnr.it/Share.TEC/ShareTEC_Final_Report_User.pdf

Sartori, G. (1984). La política, lógica y método en las ciencias sociales. México, D.F: Fondo de Cultura Económico.

Schneider, D. K. (2011). Learning objects repositories - EduTech Wiki. Retrieved September $8, \quad 2015, \quad$ from http://edutechwiki.unige.ch/en/Learning_objects_repositories

Schwandt, A. (2000). Three Epistemological Stances for Qualitative Inquiry: Interpretivism, Hermeneutics and Social Constructionism. In N. K. Denzin \& Y. S. Lincoln (Eds.), Handbook of Qualitative Research (2nd ed., pp. 189-213). Thousand Oaks, California: SAGE Publications. http://doi.org/10.1037/00223514.90.4.644

Schwandt, A. (2006). Opposition redefined. International Journal of Qualitative Studies in Education, 19, 803-810.

Sedgwick, P., \& Greenwood, N. (2015). Understanding the Hawthorne effect. Bmj, 4672(September), h4672. Retrieved from http://www.bmj.com/lookup/doi/10.1136/bmj.h4672

Seel, N. M. (Ed.). (2012). Social Tagging / Folksonomy. In Encyclopedia of the 
Sciences of Learning (p. 3124). Springer US. http://doi.org/10.1007/978-14419-1428-6_2419

Selwyn, N. (2014). Internet y Educación. In Cambio. 19 ensayos clave acerca de cómo internet está cambiando nuestras vidas (pp. 191-214). Open Mind. Fundación BBVA. Retrieved from https://www.bbvaopenmind.com/wpcontent/uploads/2014/04/BBVA-OpenMind-libro-Cambio-19-ensayosfundamentales-sobre-cómo-internet-está-cambiando-nuestras-vidasTecnolog\%C3\%ADa-Interent-Innovación.pdf

Share.TEC Consortium. (2008a). About Share.TEC | Share.TEC teacher education resources. Retrieved July 13, 2015, from http://portal.share-tec.eu/about

Share.TEC Consortium. (2008b). Description of Work. ECP 2007 EDU 427015 Share.TEC. Share.TEC - SHAring digital REsources in the Teaching Education Community (Vol. 1).

Share.TEC Consortium. (2011). Share.TEC Final Project Report. ECP-2007-EDU427015/Share.TEC (Vol. D1.11). ITD. Retrieved from http://www.sharetec.eu/sites/default/files/deliverables/D1.11.pdf

Siemens, G. (2006). Connectivism: A Learning Theory for the Digital Age. Retrieved September 4, 2015, from http://www.elearnspace.org/Articles/connectivism_self-amused.htm

Siemens, G. (2010). Conectivismo: una teoría de aprendizaje para la era digital. In R. Aparici Marino (Ed.), Conectados en el ciberespacio (pp. 77-89). Madrid, España: Editorial UNED.

Siemens, G. (2013). Massive Open Onlice Courses: Innovation in Education? In R. McGreal, W. Kinuthia, \& S. Marshall (Eds.), Open Educational Resources: Innovation, Research and Practice (pp. 1-15). Athabasca University: Commonwealth of Learning. Retrieved from https://oerknowledgecloud.org/sites/oerknowledgecloud.org/files/pub_PS_OER -IRP_CH1.pdf

Siemens, G., \& Conole, G. (2011). Editorial. The International Review of Research in Open and Distance Learning, 12(3), i-iv. Retrieved from http://www.irrodl.org/index.php/irrodl/article/view/994/1820

Simons, H. (2011). El estudio de caso: Teoría y práctica. Madrid: Morata. 
Skinner, B. F. (1963). Operant behavior. American Psychologist. http://doi.org/10.1037/h0045185

Skinner, B. F. (2003). Verbal behavior. In The history of psychology: Fundamental questions (pp. 399-407).

Social Science Open Access Repository. (n.d.). Types of repositories: SSOAR. Retrieved September 8, 2015, from http://www.ssoar.info/en/home/aboutopen-access/types-of-repositories.html

Solomon, P. (1995). The think aloud method: A practical guide to modelling cognitive processes. Information Processing \& Management. http://doi.org/10.1016/0306-4573(95)90031-4

Sosisky, G., Perazzo, M., Bardi, V., \& Ruíz, M. (2007). Cómo evaluar sitios y recursos educativos de Internet.

Southampton, U. of. (2011). Registry of Open Access Repositories.

Stake, R. E. (1994). Case Studies. In N. K. Denzin \& Y. S. Lincoln (Eds.), Handbook of qualitative research (pp. 236-247). London, England: SAGE Publications.

Stake, R. E. (1995). The art of case study research. The art of case study research. http://doi.org/10.1108/eb024859

Stake, R. E. (1998). Case Studies. In N. K. Denzin \& Y. S. Lincoln (Eds.), Strategies of Qualitative Inquiry (pp. 86-109). Thousand Oaks, California: SAGE Publications.

Stake, R. E. (2005). Qualitative case studies. In N. K. Denzin \& Y. S. Lincoln (Eds.), The SAGE Handbook of Qualitative Research (3rd ed., pp. 443-466). SAGE Publications. http://doi.org/10.1016/b978-0-08-044894-7.01532-3

Stake, R. E. (2006). Multiple Case Study Analysis. New York: Guilford Press.

Stake, R. E. (2007). La investigación con estudio de casos (Cuarta Edi). MadridE: Ediciones Morata.

Stake, R. E. (2010). Qualitative Research: Studying How Things Work. New York: Guilford Press.

Stone, D., Jarrett, C., Woodroffe, M., \& Minocha, S. (2005). User Interface Design and Evaluation. German Research (Vol. 21). http://doi.org/10.1057/palgrave.ivs.9500112 
Swanborn, P. (2010). Case Study Research What, Why and How? London: SAGE Publications.

Switch. (2007). Evaluation of an Open-Source Repository System. Switch: Serving Swiss Universities.

Tapscott, D. (1998). Growing Up Digital: The Rise of the Net Generation. Toronto: McGraw-Hill.

Tashakkori, A., \& Teddlie, C. (1998). Mixed Methodology: Combining qualitative and quantitative approaches. Thousand Oaks, California: SAGE Publications.

Taylor, C. (2004). Free Open Source OAI-PMH 2.0 compliant Software. Criteria for choosing repository software. Queensland: Australian Partnership for Sustainable Repositories. Retrieved from http://www.apsr.edu.au/documents/taylor_software.pdf

Technical Committee ISO/TC. (2010). ISO 9241-210:2010 - Ergonomics of humansystem interaction -- Part 210: Human-centred design for interactive systems. Retrieved January 11, 2016, from http://www.iso.org/iso/home/store/catalogue_ics/catalogue_detail_ics.htm?csn umber $=52075$

Teddlie, C., \& Tashakkori, A. (2003). Major Issues and Controversies in the Use of Mixed Methods in the Social and Behavioral Sciences. In A. Tashakkori \& C. Teddlie (Eds.), Handbook of Mixed Methods in Social \& Behavioral Research (pp. 3-50). Thousand Oaks, California.

The Boston Consulting Group. (2013). The Open Education Resources ecosystem An evaluation of the OER movement's current state and its progress toward mainstream adoption. Retrieved from http://www.hewlett.org/sites/default/files/The Open Educational Resources Ecosystem_1.pdf

The Open University. (2014). Frequently asked questions on OpenLearn OpenLearn - Open University. Retrieved July 7, 2015, from http://www.open.edu/openlearn/about-openlearn/frequently-asked-questionson-openlearn

The William and Flora Hewlett Foundation. (2013). Open Educational Resources: Breaking the Lockbox in Education. Retrieved from http://www.hewlett.org/sites/default/files/OER White Paper Nov 222013 
Final_0.pdf

Thomas, G. (2011). A Typology for the Case Study in Social Science Following a Review of Definition, Discourse, and Structure. Qualitative Inquiry, 17(6), 511521. http://doi.org/10.1177/1077800411409884

Thomas, H., \& Arnedillo, I. (2010). CMM End User Guide. ECP-2007-EDU427015/Share.TEC. Retrieved December 2, 2015, from http://portal.sharetec.eu/sites/default/files/CMM End User Guide.pdf

Thompson, R. (2010). School IT quango Becta closed to save £80m. Retrieved October 23, 2015, from http://www.computerweekly.com/news/1280092860/School-IT-quango-Bectaclosed-to-save-80m

Timmons, V., \& Cairns, E. (2010). Case Study Research in Education. In A. Mills, G. Durepos, \& E. Wiebe (Eds.), Encyclopedia of case study research (pp. 100104). Thousand Oaks, CA: SAGE Publications. http://doi.org/10.4135/9781412957397

Toikkanen, T., Purma, J., \& Leinonen, T. (2010). LeMill. In B. Czerkawski (Ed.), Free and Open Source Software for E-Learning (pp. 147-167). Hersey, PA, USA: ICI Global. http://doi.org/10.4018/978-1-61520-917-0.ch010

Tosato, P., Carramolino Arranz, B., \& Rubia Avi, B. (2014). Sharing Resources in Open Educational Communities. Qualitative Research in Education, 3(2). http://doi.org/10.4471/qre.2014.45

Trillo Miravalles, M. P. (2011). Evolución e impacto de los recursos abiertos en la educación para todos. Revista Iberoamericana de Educación, 55(5). Retrieved from http://www.rieoei.org/deloslectores/3995Trillo.pdf

Tuch, A. N., Presslaber, E. E., Stöcklin, M., Opwis, K., \& Bargas-Avila, J. (2012). The role of visual complexity and prototypicality regarding first impression of websites: Working towards understanding aesthetic judgments. International Journal of Human-Computer Studies, 70(11), 794-811. http://doi.org/http://dx.doi.org/10.1016/j.jhcs.2012.06.003

Tuomi, I. (2004). Innovation, Growth and Competitiveness in the Knowledge Society. In Foro de la Innovación y Modernización en Andalucía (Vol. Málaga). Retrieved from http://www.meaningprocessing.com/personalPages/tuomi/articles/InnovationA ndGrowthlnTheKnowledgeSociety.pdf 
UNESCO. (2002a). Experts to Assess impact of Open Courseware for Higher Education. Retrieved September 9, 2015, from http://portal.unesco.org/ci/en/ev.php-

URL_ID=2492\&URL_DO=DO_TOPIC\&URL_SECTION=201.html

UNESCO. (2002b). Final Report. In Forum on the Impact of Open Courseware for Higher Education in Developing Countries, París, 1-3 July 2002. Paris, Francia.

UNESCO. (2003). A Framework. Retrieved September 2, 2015, from http://portal.unesco.org/education/en/ev.phpURL_ID=18614\&URL_DO=DO_TOPIC\&URL_SECTION=201.html

UNESCO. (2005). Hacia las sociedades del conocimiento. Informe mundial de la UNESCO. Ediciones UNESCO. Retrieved from http://unesdoc.unesco.org/images/0014/001419/141908s.pdf

UNESCO. (2011). ICT Competency Framework for Teachers. (P. Hine, Ed.). Paris, Francia: UNESCO. Retrieved from http://unesdoc.unesco.org/images/0021/002134/213475e.pdf

UNESCO. (2012). Paris OER Declaration (p. World OER Congress, Paris, June 2012). Paris, Francia. Retrieved from http://www.unesco.org/new/fileadmin/MULTIMEDIA/HQ/Cl/Cl/pdf/Events/Engli sh_Paris_OER_Declaration.pdf

UNESCO. (2013). Building Knowledge Societies | UNESCO. Retrieved September 5, 2015, from http://en.unesco.org/themes/building-knowledge-societies

UNESCO. (2014a). Education Strategy 2014-2021. France. Retrieved from http://unesdoc.unesco.org/images/0023/002312/231288e.pdf

UNESCO. (2014b). Recursos educativos abiertos | Organización de las Naciones Unidas para la Educación, la Ciencia y la Cultura. Retrieved September 9, 2015, from http://www.unesco.org/new/es/communication-andinformation/access-to-knowledge/open-educational-resources/

Unión Europea. (2007). Europa. Síntesis de la legislación de la UE. Apoyo a la producción de contenidos digitales y al fomento de la diversidad lingüística: programa eContent (2001-2004).

Universidad de Jyväskylän Koppa. (2011a). Constructivism. Retrieved October 10, 
2015 , from

https://koppa.jyu.fi/avoimet/hum/menetelmapolkuja/en/methodmap/philosophyof-science/constructivism

Universidad de Jyväskylän Koppa. (2011b). Hermeneutics - Jyväskylän yliopiston Koppa. Retrieved October 10, 2015, from https://koppa.jyu.fi/avoimet/hum/menetelmapolkuja/en/methodmap/philosophyof-science/hermeneutics

University of Nottingham. (2014). OpenDOAR - About OpenDOAR - Directory of Open Access Repositories. Retrieved September 7, 2015, from http://www.opendoar.org/about.html

UsabilityNet. (2003). UsabilityNet: usability resources for practitioners and managers. Retrieved October 23, 2015, from http://www.usabilitynet.org/home.htm

UsabilityNet. (2006). International standards for $\mathrm{HCl}$ and usability.

Valverde Berrocoso, J., Fernández Sánchez, M. R., \& Garrido Arroyo, M. del C. (2015). El pensamiento computacional y las nuevas ecologías del aprendizaje. RED, Revista de Educación a Distancia. Número Monográfico Sobre Pensamiento Computacional, 46(Septiembre). Retrieved from https://www.academia.edu/15769989/El_pensamiento_computacional_y_las_n uevas_ecologías_del_aprendizaje

Van Dijk, J. (2012). The Network Society (3rd ed.). Thousand Oaks, California: SAGE Publications.

Verd, J. M., \& López, P. (2008). La eficiencia teórica y metodológica de los diseños multimétodo. EMPIRIA. Revista de Metodología de Ciencias Sociales, 16(Julio-Diciembre), 13-42.

Vilaseca i Requena, J., \& Torrent i Sellens, J. (2005). Nueva economía y e-business: hacia la economía global del conocimiento y el trabajo en red. In I. Tubella i Casadevall \& J. Vilaseca i Requena (Eds.), Sociedad del conocimiento (pp. 31-68). Barcelona, España: Universidad Oberta de Catalunya.

Vygotsky, L. S. (1962). The Development of Scientific Concepts in Childhood. http://doi.org/10.1037/11193-006

Vygotsky, L. S. (1978). Mind in society: The development of higher psychological processes. (M. Cole, V. John-Steiner, S. Scribner, \& E. Souberman, Eds.). 
Cambridge, Massachusetts: Harvard University Press.

Warwick, C. (2012). Studyng users in digital humanities. In C. Warwick, M. Terras, \& J. Nyhan (Eds.), . London, England: Facet Publishing. Retrieved from http://citeseerx.ist.psu.edu/viewdoc/download?doi=10.1.1.305.6694\&rep=rep1 \&type=pdf

Watson, J. B. (1913). Psychology as the behaviourist views it. Psychological Review, 20(2), 158-177. http://doi.org/10.1037/h0074428

Weigand, H. (1997). A multilingual ontology-based lexicon for news filtering - the TREVI project. In K. Mahesh (Ed.), Ontologies and Multilingual NLP. Proceedings from the 15th International Joint Conference of Artificial Intelligence (IJCAI), August 23-29, 1997. (pp. 138-159). Nagoya, Japón.

Wenger, E. (1998). Communities of Practice: Learning, Meaning and Identitiy. Cambridge, England: Cambridge University Press. Retrieved from http://scholar.google.com/scholar?start=20\&q="communities+of+practice"\&hl= en\&as_sdt $=0,5 \& a s \_y l o=2010 \# 5$

Wiley, C. (2014). Metadata use in research data management. Bulletin of the American Society for Information Science and Technology, 40(6), 38-40. http://doi.org/10.1002/bult.2014.1720400612

Wiley, D. A. (2002). Connecting Learning Objects to Instructional Design Theory: A Definition, a Metaphor, and a Taxonomy. In D. A. Willey (Ed.), The Instructional Use of Learning Objects (pp. 1-35). Bloomington: Asociation for Educational Communications and Technology.

Wiley, D. A. (2006). The Current State of Open Educational Resources. In Expert Meeting on Open Educational Resources (p. 3). Malmo, Sweden: OECD CERI. Retrieved from http://www.hewlett.org/uploads/files/OECD_ExpertMeetingonOER.pdf

Wiley, D. A. (2008). The Learning Objects Literature. In D. Jonassen, M. J. Spector, M. Driscoll, M. D. Merril, \& J. V. Merrienober (Eds.), Handbook of Research for Educational Communications and Technology: A Project of the Association for Educational Communications and Technology (3rd ed., pp. 345-353). New York, NY: Routledge. Retrieved from http://www.opencontent.org/docs/wileylo-review-final.pdf

Wong, B. Y.-Y., Wong, B. T.-M., \& Pang, S. (2015). Technology in Education. 
Transforming Educational Practices with Technology. In K. C. Li, T.-L. Wong, S. K. S. Cheung, J. Lam, \& K. K. Ng (Eds.), First International Conference, ICTE 2014, Hong Kong, China, July 2-4, 2014. Revised Selected Papers (pp. 175-186). Berlin, Heidelberg: Springer Berlin Heidelberg. http://doi.org/10.1007/978-3-662-46158-7_18

Yalcinalp, S., \& Emiroglu, B. (2012). Through efficient use of LORs: Prospective teachers' views on operational aspects of learning object repositories. British Journal of Educational Technology, 43(3), 474-488. http://doi.org/10.1111/j.1467-8535.2011.01212.x

Yin, R. K. (2009). Case Study Research: Design and Methods. Applied Social Research Methods Series (4th ed., Vol. 5). Thousand Oaks, California: SAGE Publications. http://doi.org/10.1097/FCH.0b013e31822dda9e

Young, J. R. (2012). Badges Earned Online Pose Challenge to Traditional College Diplomas. The Chronicle of Higher Education, pp. 1-7. Retrieved from http://chronicle.com/article/Badges-Earned-Online-Pose/130241/

Yuan, L., MacNeill, S., \& Kraan, W. (2008). Open Educational Resources opportunities and challenges for higher education. Educational Cybernetics. Reports. Bolton, England. Retrieved from http://ubir.bolton.ac.uk/290/1/iec_reports-1.pdf

Zervas, P., \& Sampson, D. G. (2014). The effect of users' tagging motivation on the enlargement of digital educational resources metadata. Computers in Human Behavior, 32, 295-300. http://doi.org/10.1016/j.chb.2013.06.026

Zhang, W., \& Watts, S. (2008). Online communities as communities of practice: a case study. Journal of Knowledge Management. http://doi.org/10.1108/13673270810884255 